\title{
Tobias Fuchs
}

\section{DIE KUNST \\ DES BÜCHERMACHENS}

Autorschaft und Materialität der Literatur zwischen 1765 und 1815

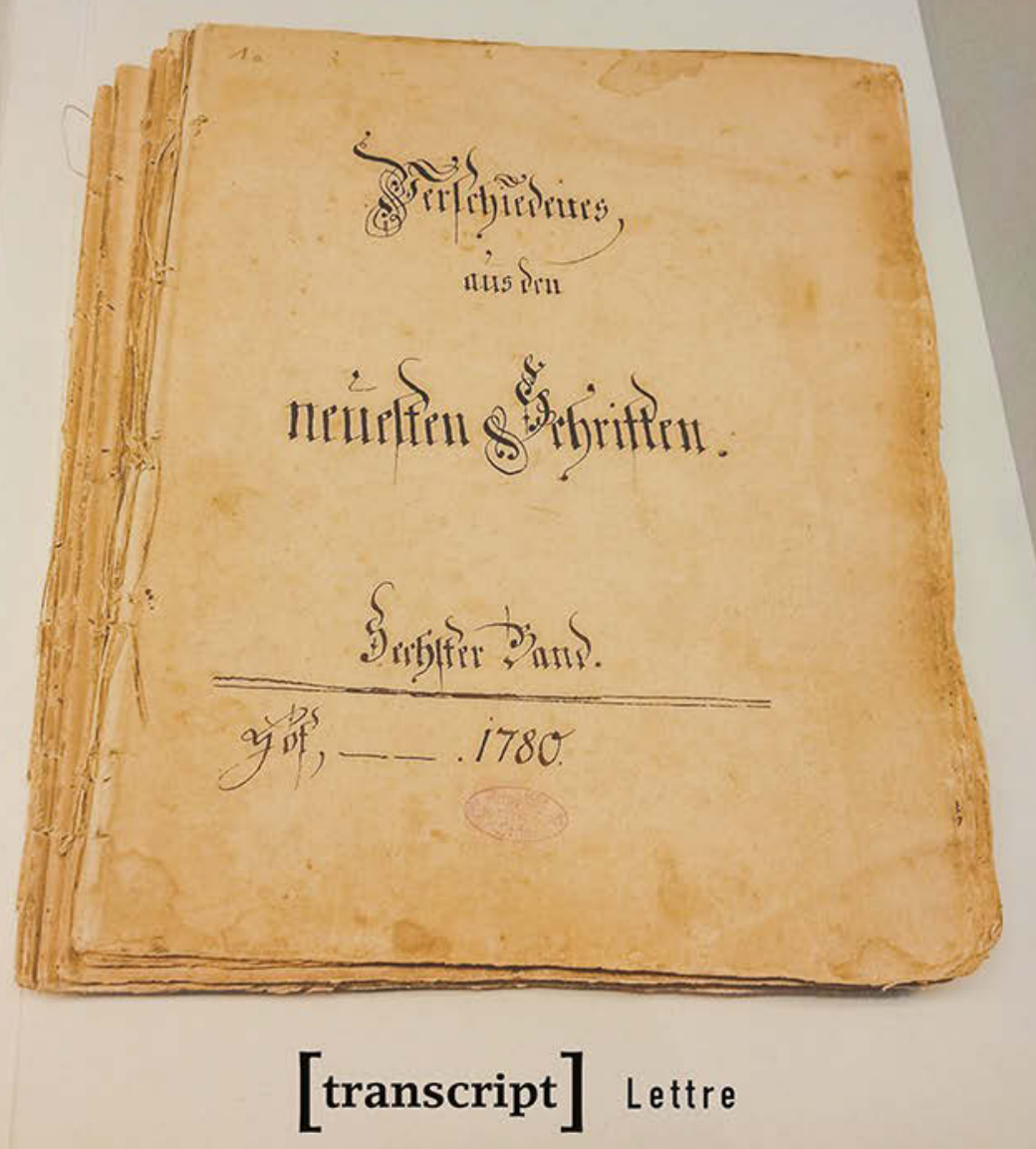


Tobias Fuchs

Die Kunst des Büchermachens:

Autorschaft und Materialität der Literatur zwischen 1765 und 1815 
Tobias Fuchs, geb. 1981, ist Literaturwissenschaftler und arbeitet als Redakteur bei einer Tageszeitung. Er promovierte in Neuerer deutscher Literatur an der Freien Universität Berlin und war wissenschaftlicher Mitarbeiter an den Universitäten München und Erlangen-Nürnberg. 
Tobias Fuchs

Die Kunst des Büchermachens:

Autorschaft und Materialität der Literatur zwischen 1765 und 1815

[transcript] 
Freie Universität Berlin, Dissertation, 2020.

Unterstützt durch die Fritz Thyssen Stiftung für Wissenschaftsförderung im Rahmen des Forschungsprojektes »Manuskript, Buch, Makulatur - Zur Materialität des Schreibens und Publizierens um 1800« (2013-2016) an der LMU München und der FAU Erlangen-Nürnberg.

Die Publikation wurde ermöglicht durch eine Ko-Finanzierung für Open-AccessMonografien und -Sammelbände der Freien Universität Berlin.

\section{Bibliografische Information der Deutschen Nationalbibliothek}

Die Deutsche Nationalbibliothek verzeichnet diese Publikation in der Deutschen Nationalbibliografie; detaillierte bibliografische Daten sind im Internet über http://dnb.d-nb.de abrufbar.

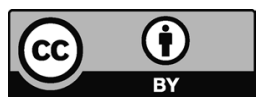

Dieses Werk ist lizenziert unter der Creative Commons Attribution 4.o Lizenz (BY). Diese Lizenz erlaubt unter Voraussetzung der Namensnennung des Urhebers die Bearbeitung, Vervielfältigung und Verbreitung des Materials in jedem Format oder Medium für beliebige Zwecke, auch kommerziell. (Lizenztext: https://creativecommons.org/licenses/ by/4.o/deed.de)

Die Bedingungen der Creative-Commons-Lizenz gelten nur für Originalmaterial. Die Wiederverwendung von Material aus anderen Quellen (gekennzeichnet mit Quellenangabe) wie z.B. Schaubilder, Abbildungen, Fotos und Textauszüge erfordert ggf. weitere Nutzungsgenehmigungen durch den jeweiligen Rechteinhaber.

\section{Erschienen 2021 im transcript Verlag, Bielefeld}

(C) Tobias Fuchs

Umschlaggestaltung: Maria Arndt, Bielefeld

Umschlagabbildung: Handgeschriebenes Titelblatt eines Exzerptbandes aus dem Nachlass Jean Pauls, Stiftung Preußischer Kulturbesitz, Staatsbibliothek zu Berlin, Nachlass Jean Paul.

Druck: Majuskel Medienproduktion GmbH, Wetzlar

Print-ISBN 978-3-8376-5530-8

PDF-ISBN 978-3-8394-5530-2

https://doi.org/10.14361/9783839455302

Gedruckt auf alterungsbeständigem Papier mit chlorfrei gebleichtem Zellstoff. Besuchen Sie uns im Internet: https://www.transcript-verlag.de Unsere aktuelle Vorschau finden Sie unter www.transcript-verlag.de/vorschau-download 


\section{Inhalt}

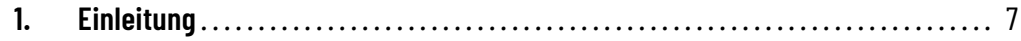

2. Handgeschriebene Bücher ................................... 37

2.1. Aus der »Taschendruckerei «: Zur Mimesis buchspezifischer Materialität ...... 37

2.2. Die blaue Reihe in Jean Pauls Privatbibliothek ......................... 41

2.3. Bücher-nach-machen: Schreiben als Akt der Nachahmung............... 60

2.4. Handgeschriebene Bücher in der Fiktion: Maria Wutz und Quintus Fixlein ...... 80

3. Im Druck erscheinen....................................... 85

3.1. Papierne Existenzen: Typographie und Gelehrsamkeit ................. 85

3.2. Entgrenzung der Gelehrtenrepublik durch Autorschaft ................... 87

3.3. »Schriftstellersucht « und Büchermarkt um 1800 ...................... 93

3.4. Autorschaft als Koppelung von Biographie und Bibliographie............. 106

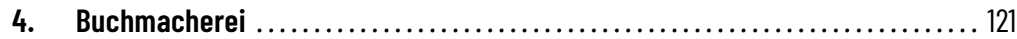

4.1. Lichtenberg als Büchermacher des Königs ......................... 121

4.2. Bücherwissen und $»$ Materialbewusstsein«.......................... 130

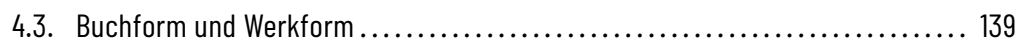

4.4. Im »schönsten Gewande«: Zur Ästhetik des Büchermachens................ 158

4.5. »Setzer $=$ Zersetzer $«:$ Autorschaft und Druckfehler $\ldots \ldots \ldots \ldots \ldots \ldots \ldots . . \ldots 169$

4.6. Wem gehört das Buch? Geistiges Eigentum und Buchmaterialität ........... 181

5. Makulatur .................................................. 203

5.1. Makulatur als Medium zwischen Gelehrsamkeit und Genie ................. 203

5.2. Makulatur publizieren, schreiben, erzählen .......................... 211

5.3. Makulatur publizieren: Vom Ende der Autorschaft........................214

5.4. Makulatur schreiben: Lichtenbergs Autorsatiren und ihre Vorbilder.......... 240

5.5. Makulatur erzählen: Poetologie der Pfeffertüte bei Jean Paul ............ 251 


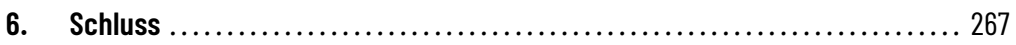

7. Literatur ............................................... 285

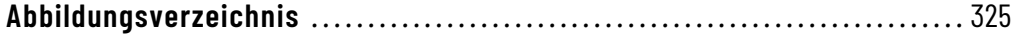

Danksagung ....................................................... 327

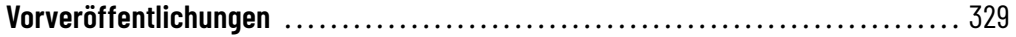




\section{Einleitung}

Jean Paul muss lange warten. Erst 1786 erscheint sein Name im »Gelehrten Teutschland «, dem berühmten Autorenlexikon ${ }^{1}$ - drei Jahre nach der Veröffentlichung seines ersten Buches. Man findet Jean Paul im Nachtragsband der vierten Ausgabe, Seite 526, Buchstabe R, unter seinem bürgerlichen Namen: »RICHTER (Johann Paul Friedrich)«, ergänzt um knappe Angaben zur Person. Im Geburtsjahr fehlt - womöglich ein Druckfehler - die letzte Zahl. Darauf folgt der bibliographische Nachweis des Erstlingswerks: »Grönländische Processe oder satirische Skizzen. Berlin, $1783 . \aleph^{2}$ Der Lexikoneintrag umfasst vier Zeilen. Damit zählt Jean Paul endlich zu den Schriftstellern des 18. Jahrhunderts - als einer von Tausenden.

Herausgegeben wird »Das gelehrte Teutschland« vom Erlanger Geschichtsprofessor Johann Georg Meusel. Man könnte in seinem Nachschlagewerk die abseitige Vergnügung eines späten Polyhistors sehen, eine im historischen Maßstab unbedeutende Fleißarbeit. Tatsächlich entwickelt sich »Das gelehrte Teutschland«, gegründet 1767, im letzten Drittel des 18 . Jahrhunderts zu einem unerreichten Referenzmedium, zunächst der Gelehrtenrepublik, später der deutschsprachigen Literatur. Wer von »Meusels gelehrtem Teutschland « spricht, tut das bis weit ins 19. Jahrhundert mit einer anerkennenden Selbstverständlichkeit, die später Meyers Konversationslexikon oder den Brockhaus auszeichnen wird.

Das Besondere an Meusel: Mit einer enormen Akribie und Beharrlichkeit verbindet er Namen mit bibliographischen und biographischen Daten. So verhilft er Konsistorialräten wie bettelarmen Poeten zu einer zweiten, einer pa-

$1 \quad$ Mit Nennung der männlichen Funktionsbezeichnung ist in diesem Buch, sofern nicht anders gekennzeichnet, immer auch die weibliche Form mitgemeint.

2 Johann Georg Meusel, Georg Christoph Hamberger, Das gelehrte Teutschland oder Lexikon der jetzt lebenden teutschen Schriftsteller, Lemgo 1767-1834, 4. Ausg., 1. Nachtragsband (1786), S. 526. 
piernen Existenz als eingetragene Schriftsteller. Sein Lexikon ist um 1800 das unbestrittene Leitmedium der Autorschaft. Als solches dokumentiert »Das gelehrte Teutschland«, wie Autorschaft sich zwischen 1765 und $1815 \mathrm{zu}$ einem sozialen Phänomen auswächst. Umfasst das Werk in der Gründungszeit nur 2.000 bis 3.000 Schriftsteller, so schätzt Meusel deren Zahl im Jahr 1808 auf 12.000. ${ }^{3}$ Zugleich erhellen die Auswahlkriterien des Lexikons, wo Autorschaft im »druckpapiernen Weltalter (SW I.5, 25) ihren Ursprung hat - im typographischen Artefakt. Auf eine Formel gebracht, bedeutet dies: Bücher machen Autoren.

Wer einen Druck größeren Umfangs vorweisen kann, den würdigt Meusel mit einem Eintrag in seinem Nachschlagewerk. Publizierende sind für ihn »Büchermacher ${ }^{4}$. Daran hält er unerschütterlich fest. Auch wenn der Professor selbst über »Vielschreiberey ${ }^{5}$ klagt oder in Friedrich Nicolais »Allgemeiner Deutscher Bibliothek« (ADB) davon die Rede ist, dass manch »ein angehender Gelehrter es darauf angelegt zu haben scheint, in Meusels Lexicon ganze Seiten füllen zu wollen $\aleph^{6}$. »Das gelehrte Teutschland « findet seinen Niederschlag in solchen Rezensionsorganen, aber auch in der zeitgenössischen Literatur.

Jean Paul offenbart in seinen Erzählungen eine ausgesprochene Vorliebe für das literarhistorische opus magnum aus Erlangen. In den »Flegeljahren« präsentiert er »Das gelehrte Haßlau«, ein fiktives Lexikon, für das ein »Einlaßzettel« genügt, nämlich ein "gedrucktes Blatt«. Während Meusel, wie es heißt, eine große Menge an Autoren »aus seinem gelehrten Deutschland verstößt«, weil »er nicht einmal Leute einläßt, die nur ein Büchlein geschrieben« (SW I.2, 1010) haben. Im »Hesperus« von 1795 wird erwogen, den Posthund Spitzius Hoffmann, der als »fleißiger Handlanger und Kompilator und Spediteur der Gelehrsamkeit« vorgestellt wird, für einen »Sitz im gelehrten Deutschland « (SW I.1, 1233) zu empfehlen. Und im »Siebenkäs« sinniert Heinrich Leibgeber über die Frage, ob er »Meusels gelehrtes Deutschland und Jöchers Gelehrten-Lexikon vollständig« verinnerlicht habe (SW I.2, 122f.).

3

Meusel, Hamberger, Das gelehrte Teutschland, 5. Ausg., XII (1806), S. VI, sowie XIII (1808), S. VIII.

Siehe z.B. Meusel, Hamberger, Das gelehrte Teutschland, 5. Ausg., XII (1806), S. LXIX, zur Wortbedeutung Art. »Büchermacher«, in: Jacob und Wilhelm Crimm, Deutsches Wörterbuch, Leipzig 1854ff., II (1860), Sp. 473.

5 Meusel, Hamberger, Das gelehrte Teutschland, 5. Ausg., XII (1806), S. XLV.

6 [Anonymus], Rez. »Handbuch für Gesandte«, in: Allgemeine Deutsche Bibliothek (1792), 106, S. 89-90, hier: S. 89. 


\section{Autorschaft als soziales Phänomen um 1800}

Autorschaft gilt lange als Domäne akademischer Gelehrsamkeit. Im letzten Drittel des 18. Jahrhunderts löst sich »die alte Wechselbeziehung zwischen Buchmarkt und Bildungswesen «, durch ein Phänomen, das Heinrich Bosse als »unmäßige Autorschaft « bezeichnet. ${ }^{7}$ Man könnte, aus der Sicht vieler Zeitgenossen, auch von übermäßiger Autorschaft sprechen. Sich gedruckt einen Namen zu machen, Ruhm und gesellschaftliche Anerkennung zu verschaffen, erscheint nun reizvoll für jene »Aufsteigerschicht «, die Hans-Ulrich Wehler als die »Bürgerlichen « charakterisiert. ${ }^{8}$ Durch sie erfährt die Gelehrtenrepublik eine Entgrenzung, die sich anhand von Meusels Lexikon nachvollziehen lässt (Kapitel 3). So ereifert sich 1795 ein Rezensent des »Gelehrten Teutschlands« über die Einträge mehrerer Bauern und eines Buchbinders in dem Nachschlagewerk. Süffisant schließt er an: »Unter der hier stehenden Gesellschaft findet man dieß Mahl auch einen Kaminfeger, mehrere Schulmeister, einen Tabacksfabrikanten, einen Küster, und einen Gärtner. « Solche Autorenfiguren finden sich bei Jean Paul reihenweise: Das Schulmeisterlein Wutz oder der Armenadvokat Siebenkäs erfüllen als Halbgelehrte nicht die höchsten Bildungsansprüche, andere Protagonisten wie Gotthelf Fibel zählen gar zu den Autodidakten.

Heinrich Bosse, »Die gelehrte Republik«, in: Hans-Wolf Jäger (Hg.), »Öffentlichkeit«im 18. Jahrhundert, Göttingen 1997, S. 51-76, hier: S. 66.

8 Hans-Ulrich Wehler, Deutsche Cesellschaftsgeschichte. Erster Band: Vom Feudalismus des Alten Reichs bis zur Defensiven Modernisierung der Reformära, 1700-1815. München 2008, S. 204. Wehler beschreibt die »Bürgerlichen«als »Aufsteigerschicht, die außerhalb der altständischen Ordnung emporkam«, die »von Verwaltungsbeamten und Theologen, Professoren und Hauslehrern, Gelehrten und Hofmeistern, Syndici und Magistratsjuristen, Richtern und Landschaftskonsulenten, Anwälten und Notaren, Ärzten und Apothekern, Ingenieuren und Domänenpächtern, Schriftstellern und Journalisten, Offizieren und Leitern staatlicher Betriebe, nicht zuletzt aber auch von jenen Unternehmern gebildet [werde], die Verlage und Manufakturen, Protofabriken und Banken betrieben« (Ebd.). Um 1800 dürfte Autorschaft für diese »Bürgerlichen« nicht zuletzt deshalb reizvoll gewesen sein, weil sich der Autor zu jenen »vielfältig neuen Sozialfiguren ohne festen Ort in der Cesellschaft« rechnen lässt, die Manfred Hettling auf die im 18. Jahrhundert »erodierende Ständegesellschaft« zurückführt (Manfred Hettling, »Bürger/Bürgerlichkeit«, in: Heinz Thoma (Hg.), Handbuch Europäische Aufklärung. BegriffeKonzepte - Wirkung, Stuttgart 2015, S. 123-131, hier: S. 129).

9 [Kmr.], Rez.»Fünften Nachtrags zweyte Abtheilung zu der vierten Ausgabe des gelehrten Teutschlandes«, in: Oberdeutsche allgemeine Litteraturzeitung 8 (1795), 2, St. CXXIV (19. Oktober 1795), Sp. 777-784, hier: Sp. 783. 
Niemals zuvor dürfte Autorschaft als soziales Phänomen so virulent gewesen sein wie in dieser Epoche. Das zeigt sich auch in der deutschsprachigen Literatur: Die Gelehrtensatire entwirft mit der Schriftstellersucht ein eigenes Krankheitsbild. ${ }^{10}$ Die Ratgeberliteratur für Autoren erstreckt sich über Regalmeter. Neben ernstgemeinten Titeln wie Daniel Gotthold Joseph Hüblers »Beyträgen zur Bibliopöie in praktischen Anmerkungen für Schriftsteller und Verleger« (1803) stehen Satiren wie Johann Gabriel Bernhard Büschels »Versuch über die Kunst gut und viel zu schreiben« (1796) oder Heinrich Zschokkes »Schriftstellerteufel« (1791), ein - so der vielsagende Untertitel - »klassisches Original-Lesebuch für unglückliche Autoren «. ${ }^{11}$ Darüber hinaus existieren viele literarische Figuren, die sich zum Schriftsteller berufen fühlen.

Mit Autorschaft wird um 1800 weitaus mehr verbunden als die Frage, wer einen Text verfasst hat. Was sich unter anderem daran zeigt, dass die »Schreib- und Autorsucht « allgemein zu den »Modekrankheiten des achzehendten Jahrhunderts ${ }^{12}$ gerechnet wird. Das unterstreicht die gesellschaftliche Bedeutung des Publizierens. Es trägt bei zum »Konglomerat« der »Bürgerlichen«, das sich Karl Eibl zufolge dadurch auszeichnet, dass es »Individualität durch Exklusion, durch Rollendistanz und -bewußtsein « erlangt ${ }^{13}$ -

10 Günter Theodor Wellmanns, Studien zur deutschen Satire im Zeitalter der Aufklärung. Theorie, Stoffe, Form und Stil, München 1969, S. 68-71; Gunter E. Grimm, »Nachwort«, in: ders. (Hg.), Satiren der Aufklärung, Stuttgart 1975, S. 325-398, hier: S. 382; Alexander Košenina, Dergelehrte Narr. Gelehrtensatire seit der Aufklärung, Göttingen 2003. Den kulturhistorischen Hintergrund der Gelehrtensatire bildet auch ein Strukturwandel innerhalb der Gelehrtenkultur, der sich im frühen 18. Jahrhundert vollzieht und von Marian Füssel wie folgt beschrieben wird: »Gelehrsamkeit spielte sich nicht mehr nur in den Hörsälen ab, sondern trat in das Blickfeld einer breiten, frühaufgeklärten Öffentlichkeit. Der Anspruch auf Ehrbarkeit speiste sich nicht mehr allein aus der höfischen Conduite, sondern auch aus öffentlichem `Ansehen«. (Marian Füssel, »Charlataneria Eruditorum «. Zur sozialen Semantik des gelehrten Betrugs im 17. und 18. Jahrhundert«, in: Berichte zur Wissenschaftsgeschichte 27 (2004), S. 119-135.)

11 Daniel Gotthold Joseph Hübler, Beyträge zur Bibliopöie in praktischen Anmerkungen für Schriftsteller und Verleger, Leipzig 1803; Johann Gabriel Bernhard Büschel, Versuch über die Kunst gut und viel zu schreiben, in vertrauten Briefen eines Vaters an seinen Sohn aufder Universität zum Besten angehender Schriftsteller, Recensenten und Buchhändler herausgegeben, Jena 1796; [Heinrich Zschokke], Der Schriftstellerteufel. Ein klassisches OriginalLesebuch für unglückliche Autoren, Berlin 1791.

12 [Friedrich Justus Riedel], „Skribleriana«, in: ders., Sieben Satyren, nebst drei Anhängen, gesammlet von N.N., []ena] 1765, S. 277-308, hier: S. 298.

13 Karl Eibl, Die Entstehung der Poesie, Frankfurt a.M. 1995, S. 44. Eibl argumentiert in Anlehnung an Niklas Luhmann, dass im 18. Jahrhundert eine funktionale Differenzierung 
und den Rollenwechsel beherrscht. Ohne Eibls systemtheoretischen Ansatz adaptieren zu wollen, soll sein Argument bekräftigt werden. Denn Autorschaft wird in der vorliegenden Arbeit praxistheoretisch als Subjektform betrachtet, die sich Individuen in sozialen Praktiken aneignen. ${ }^{14}$ Damit geht keine Festschreibung einer sozialen Rolle einher, sondern Autorschaft stellt eine Subjektform neben anderen dar, ein Rollenangebot. Die angesprochenen Praktiken beziehen sich im weitesten Sinn auf die Produktion des Buches als Artefakt, weshalb sie im Folgenden als Praktiken des Publizierens beschrieben werden. Als solche treten sie ein in "Praxis-/Diskursformationen «" ${ }^{15}$, etwa dann, wenn um das Artefakt ein Netz bio-bibliographischen Wissens geknüpft wird, das der Repräsentation von Autorschaft dient - wie in Meusels "Gelehrtem Teutschland«. Autorschaft erscheint in dieser Konstellation als eine Kunst des Büchermachens.

immer mehr Individuen aus den ständischen Ordnungen herauslöse und ihr Handeln in den neuen Zusammenhang von Subsystemen mit je eigenem Funktionsprimat stelle. Zugleich verlängerten sich die Handlungsketten aus dem Bereich der persönlichen Beziehungen zunehmend in einen viel weiteren Bereich, in dem nur noch mittelbar über abstrahierte Regeln kommuniziert werden könne, so Eibl. »Immer mehr Menschen leben nicht mehr nur in der >Cemeinschaftı, sondern auch in der `Cesellschaft «", führt er aus. Eibl wirft die Frage auf, welches Problem das »Konglomerat« der »Bürgerlichen«, veranschaulicht durch eine von Wehler (s.o.) übernommene Aufzählung von Berufsgruppen, wie sie auch anhand von Meusels Lexikon spielend leicht zu erstellen wäre, gemeinsam habe. »In Kurzform gesagt eben dies: Konglomerat zu sein, ohne gemeinsame Herkunft, ohne gemeinsame Traditionen, ohne gemeinsame ökonomische Stellung.« (Eibl, Die Entstehung der Poesie, S. 43)

Vgl. Andreas Reckwitz, »Doing subjects. Die praxeologische Analyse von Subjektivierungsformen«, in: ders., Kreativität und soziale Praxis. Studien zur Sozial- und Cesellschaftstheorie, Bielefeld 2016, S. 67-82, Thomas Alkemeyer, »Subjektivierung in sozialen Praktiken. Umrisse einer praxeologischen Analytik«, in: ders., Gunilla Budde, Dagmar Freist (Hg.), Selbst-Bildungen. Soziale und kulturelle Praktiken der Subjektivierung, Bielefeld 2013, S. 33-68.

Andreas Reckwitz, »Praktiken und Diskurse. Zur Logik von Praxis-/Diskursformationen«, in: ders., Kreativität und soziale Praxis. Studien zur Sozial- und Cesellschaftstheorie, Bielefeld 2016, S. 49-66, hier: S. 61. Reckwitz plädiert dafür, »Praktiken und Diskurse nicht als zwei unabhängige Gegenstände zu separieren - von denen dann jeweils einem je nach theoretischem Hintergrund lediglich eine sekundäre Bedeutung zukommt -, sondern als zwei aneinander gekoppelte Aggregatzustände der materialen Existenz von kulturellen Wissensordnungen.« (Ebd.) 


\section{Mehr Aufmerksamkeit für Bücher als Artefakte}

Der Umfang von Meusels Schriftstellerlexikon wächst mit dem Buchmarkt. Im Jahr 1800 werden anlässlich der Leipziger Messe über 4.000 Neuerscheinungen angezeigt, 1765 waren es nur $1.517 .{ }^{16}$ Zwischen 1765 und 1790 entstehen über 2.000 Zeitschriftentitel. ${ }^{17}$ Auch der Buchmarkt überschreitet die Grenzen der Gelehrtenrepublik, es bildet sich ein bürgerliches Lesepublikum heraus, das andere Ansprüche hat als der gemeine Akademiker in der Abgeschiedenheit seiner Studierstube. Das Segment der »Schönen Künste und Wissenschaften « umfasst 1800 mehr als ein Fünftel des gesamten Angebots. Mitte des 18. Jahrhunderts lag sein Anteil noch deutlich unter zehn Prozent. ${ }^{18}$ Die Praktiken des Publizierens unterliegen unter diesen Marktbedingungen einer zunehmend auf das Buch als Artefakt bezogenen Aufmerksamkeitsökono$\mathrm{mie}^{19}$ sowie einer Professionalisierung des Schreibens. Durch die gesteigerte Verbreitung und somit Mediatisierung schöner Literatur erhalten Papier, Format, Typographie oder Kupfer zunehmend die Funktion einer Repräsentation von Autorschaft, die Materialität fungiert als Medium der »Werkpolitik « ${ }^{20}$ (Kapitel 4). Dies lässt sich anhand der Übertragung eines rhetorischen Prinzips auf die Materialität von Büchern nachvollziehen. Dabei geht es um das Prinzip der Angemessenheit (lat. aptum, decorum), das in der Redekunst, aber auch in Kleiderordnungen der Neuzeit wirksam ist, und um eine Metaphorik des Einkleidens, die auf Bücher angewandt wird. Durch die Metaphorik des Einkleidens werden diese Artefakte an die Verhaltensideale und sozialen Praktiken der bürgerlichen Welt angebunden, auch an die zeitgenössischen

16 Paul Raabe, »Der Buchhändler im achtzehnten Jahrhundert in Deutschland«, in: Giles Barber, Bernhard Fabian (Hg.), Buch und Buchhandel in Europa im 18. Jahrhundert, Hamburg 1981, S. 271-291, hier: S. 275, 282. Zur Aussagekraft der Messkataloge siehe Martin Fontius, »Zur literarhistorischen Bedeutung der Messkataloge im 18. Jahrhundert«, in: Weimarer Beiträge 7 (1961), S. 607-616.

17 Um 1700 existieren im deutschsprachigen Raum rund 70 Zeitschriften, im Laufe des 18. Jahrhunderts erscheinen etwa 4.000 Titel, wobei zwischen 1766 und 1790 insgesamt 2.191 Neugründungen gezählt werden (Hans Erich Bödeker, »Die bürgerliche Literaturund Mediengesellschaft«, in: Notker Hammerstein, Ulrich Herrmann (Hg.), Handbuch der deutschen Bildungsgeschichte, München 1996ff., II (2005), S. 499-520, hier: S. 503.)

18 Ebd., $502 \mathrm{f}$.

19 Siehe Georg Franck, Ökonomie der Aufmerksamkeit. Ein Entwurf, München 1998, S. 55-62.

20 Steffen Martus, Werkpolitik. Zur Literaturgeschichte kritischer Kommunikation vom 17. bis ins 20. Jahrhundert, Berlin 2007, zum Begriff der »Werkpolitik« siehe S. 47-51, 202-301 (Klopstock) u.a. 
Diskurse zu Mode und Luxus. ${ }^{21}$ So rät z.B. der Rhetorikprofessor Carl Denina angehenden Autoren beim Druck ihrer Werke von »einer nicht nur überflüßigen, sondern schädlichen Pracht« $a b^{22}$, während der Weimarer Verleger Friedrich Justin Bertuch im Rückblick beklagt:

»]eder neugebohrne Dichterling, Romanschreiber und Kalendermacher wollte nun auf geglättet Schweizer-Papier, mit Didotschen Lettern, Kupfern und Vignetten gedruckt, und in Marroquin gebunden seyn; und so paradirten oft die schaalsten Producte im schönsten Cewande. ${ }^{23}$

Wolfgang von Ungern-Sternberg beobachtet in der zweiten Hälfte des 18. Jahrhunderts unter Publizierenden ein wachsendes Engagement in Ausstattungsfragen, das er einer »schriftstellerischen Emanzipationsbewegung" zuordnet. ${ }^{24}$ Daraus ergeben sich eine Ästhetisierung und eine Popularisierung des handwerklichen Wissens von Papiermachern, Schriftschneidern oder Druckern. Hierfür ein gutes Beispiel ist die von einem umtriebigen Mediziner herausgegebene Abhandlung über die "Kunst des Buchbindens« $(1785) .^{25}$

Siehe Matt Erlin, Necessary Luxuries. Books, Literature, and the Culture of Consumption in Cermany, 1770-1815, Ithaca, NY 2014.

22 Carl Denina, Bibliopoeie, oder Anweisung für Schriftsteller, Berlin, Stralsund 1783, S. 404.

23 Friedrich Justin Bertuch, »Ueber den typographischen Luxus mit Hinsicht auf die Ausgabe von Wielands sämmtlichen Werken«, in: Journal des Luxus und der Moden 8 (1793), 11, S. 599-608, hier: S. 605.

24 Wolfgang von Ungern-Sternberg, »Schriftstelleremanzipation und Buchkultur im 18. Jahrhundert«, in: Jahrbuch für Internationale Cermanistik 8 (1976), 1, S. 72-98, hier: S. 75. Johann Jacob Heinrich Bücking (Hg.), Die Kunst des Buchbindens, Stendal 1785, siehe auch Publikationen wie Joseph Jérôme Le François de LaLande, Die Kunst, Papier zu machen, Berlin 1762; Georg Friedrich Wehrs, Vom Papier und von den Schreibmassen, derer man sich vor der Erfindung desselben bediente, Hannover 1779; Christian Cottlob Täubel, Orthotypographisches Handbuch, Halle, Leipzig 1785, ders., Praktisches Handbuch der Buchdruckerkunst für Anfänger, Leipzig 1791; Daniel Eberhard Beyschlag, Beyträge zur Kunstgeschichte der Reichsstadt Nördlingen: Von der Buchbinderey, dem Papier und dem Münzwesen, Nördlingen 1800; Giambattista Bodoni, Manuale tipographico/Handbuch der Typographie, Parma 1818; Benjamin Krebs, Handbuch der Buchdruckerkunst, Frankfurt a.M. 1827. Dieses Wissen wird im 19. Jahrhundert bereits als historisch begriffen, vgl. Joseph Heller, Leben Ceorg Erlingers, Buchdrucker und Formschneider zu Bamberg, Bamberg 1837; Heinrich Lempertz, Beiträge zur ältern Geschichte der Buchdruck-und Holzschneidekunst, Köln 1839; Johann Martin Lappenberg, Zur Geschichte der Buchdruckerkunst in Hamburg, Hamburg 1840. 


\section{Autoren und gedruckte Artefakte}

Autoren müssen einerseits die Erfahrung machen, dass sie schon bei der Herstellung eines Buches die Souveränität über ihre Texte verlieren, dass diese zunehmend unkontrollierbar werden, sobald sie ihre Manuskripte aus der Hand geben. Das gilt nicht zuletzt in ökonomischer wie juridischer Hinsicht, wie der um 1800 grassierende Raubdruck zeigt, dem auch mit der Theorie eines geistigen Eigentums kaum beizukommen ist (Kapitel 4). Andererseits produzieren Bücher einen Überschuss an Bedeutung, den Autoren des späten 18. Jahrhunderts gerne und vielfältig für sich in Anspruch nehmen, anders noch als Shaftesbury, der erklärt hatte, er sei auf keine Weise mehr Autor, weil er gedruckt sei. ${ }^{26}$ Damit stellt sich umso dringlicher die Frage, in welches Verhältnis sich Schriftsteller gegenüber Verlegern, Druckern oder Korrektoren setzen und zugleich, welche Position sie gegenüber dem Buch als Artefakt einnehmen - beispielsweise bei Druckfehlern. Schließlich wird dieses Artefakt im Subjektivierungsprozess der Autorschaft geradezu ein Teil ihrer selbst.

\section{Was Autoren über Bücher wissen}

Begünstigt wird die Teilhabe an den Praktiken des Publizierens zum einen durch das Bildungsprogramm der Historia literaria, einem Unterrichtsfach höherer Schulen und Universitäten, das die Materialität des Schreibens und Publizierens historisch beleuchtet (Kapitel 3). Die sogenannte »Litterargeschichte« umfasst etwa in der »Encyclopädischen Tafel«, die Johann Samuel Ersch für das »Allgemeine Repertorium der Literatur für die Jahre 1785-1790« anfertigt, neben der »Geschichte der Wissenschaften « und der »Geschichte der Gelehrten« als eine dritte Säule die »Geschichte des Bücherwesens« und darunter die »Geschichte der sich darauf beziehenden Künste und Gewerbe «. ${ }^{27}$

26 Anthony Ashley Cooper of Shaftesbury, Selbstgespräch oder Ratschlag an einen Autor, Standard Edition, hg. v. Gerd Hemmerich, Wolfram Benda, Stuttgart 1981ff., I/I (1981), S. 35-301, hier: S. 230.

27 Rudolf Blum, »Bibliographie. Eine wort- und begriffsgeschichtliche Untersuchung «, in: Archiv für Ceschichte des Buchwesens 10 (1970), Sp. 1009-1246, hier: Sp. 1149f. Zur Historia literaria siehe z.B. Helmut Zedelmaier, »Historia literaria<. Über den epistemologischen Ort des gelehrten Wissens in der ersten Hälfte des 18. Jahrhunderts«, in: Das achtzehnte Jahrhundert 22 (1998), 1, S. 11-21; Martin Gierl, »Bestandsaufnahme im gelehrten Bereich: Zur Entwicklung der >Historia literaria<im 18. Jahrhundert«, in: Klaus A. Vogel (Hg.), Denkhorizonte und Handlungsspielräume. Historische Studien für Rudolf 
Zum anderen wird um 1800 die Praktik des Schreibens als graphisches Verfahren mit strukturellen Ähnlichkeiten zum Buchdruck vermittelt. Das zeigen die frühen Exzerpte im Nachlass Jean Pauls, die sich als handgeschriebene Bücher beschreiben lassen, unikale Artefakte, die in einem mimetischen Verhältnis zu gedruckten Publikationen stehen (Kapitel 2). Jean Paul bildet in seinen Aufzeichnungen die Materialität jener Medien nach, aus denen er sein Wissen bezieht, er versieht sie z.B. mit Titelblättern in Frakturschrift. Dadurch imaginiert er sich als Jugendlicher in die Gelehrtenrepublik - ohne die ironische Brechung, welche literarische Figuren wie Maria Wutz oder Quintus Fixlein kennzeichnet, die ähnlich verfahren. Bedingung der Möglichkeit ist jeweils ein Schreiben, das in zweierlei Hinsicht auf Nachahmung ausgerichtet ist: Es fungiert als Notationsverfahren, das in den Dienst gelehrter Praktiken der Reproduktion wie dem Abschreiben oder Exzerpieren gestellt wird. ${ }^{28}$ Ferner knüpft sich an das Schreiben ein implizites Wissen um dessen graphische Dimension und die ästhetisch-handwerkliche Nähe zu technischen Verfahren des Buchdruckes.

\section{Makulatur als mögliches Ende von Autorschaft}

Die Praktiken des Publizierens lassen sich schließlich auch dann noch beobachten, wenn Bücher vermeintlich an ihr Ende gelangt sind: als Makulatur (Kapitel 5). Aus dem Verkehr gezogene Bücher verdeutlichen die grundlegende Bindung von Autorschaft an gedruckte Artefakte, sie beleuchten die Dynamisierung des Buchhandels im späten 18. Jahrhunderts, der die Nachfrage im Zyklus der Messen durch Novitäten ankurbelt und aussondert, was

Vierhaus zum 70. Geburtstag, Göttingen 1992, S. 53-80, Frank Grunert, Friedrich Vollhardt (Hg.), Historia literaria. Neuordnungen des Wissens im 17. und 18. Jahrhundert, Berlin 2007. Siehe zum Exzerpieren im 18. Jahrhundert u.a. Elisabeth Décultot (Hg.), Lesen, Kopieren, Schreiben. Lese- und Exzerpierkunst in der europäischen Literatur des 18. Jahrhunderts, Berlin 2014; Cornelia Ortlieb, »Materielle Wahrheit<. Zur Kritik des Exzerpierens und seiner Wiederentdeckung im späten 18. Jahrhundert«, in: Christoph Hoffmann, Caroline Welsh (Hg.), Umwege des Lesens. Aus dem Labor philologischer Neugierde. Festschrift für Wolf Kittler, Berlin 2006, S. 49-60, sowie zum Exzerpt bei Jean Paul: Götz Müller, Jean Pauls Exzerpte, Würzburg 1988; Michael Will, »Die (Un-)Ordnung der Dinge«, in: Jahrbuch der Jean-Paul-Cesellschaft 41 (2006), S. 71-95; Michael Will, »Lesen, um zu schreiben - Jean Pauls Exzerpte«, in: Markus Bernauer, Angela Steinsiek, Jutta Weber (Hg.), Jean Paul. Dintenuniversum. Schreiben ist Wirklichkeit, Berlin 2013, S. 39-48; Magnus Wieland, »Exzerpte aus Eden. Sekundäre Schöpfung bei Jean Paul«, in: KulturPoetik 13 (2013), H. 1, S. 26-40. 
im Lager liegengeblieben ist. Die Marktmechanismen negieren den »Ewigkeitsanspruch « ${ }^{29}$ (Aleida Assmann) des Buchdrucks und somit den Anspruch der Autorschaft auf eine Verdauerung menschlicher Existenz im papiernen Medium. Deshalb eignet sich Makulatur wie kaum ein anderes Objekt der Literatur dazu, die äußeren Bedingungen des Publizierens zu reflektieren und die sozialen Verheißungen des Gedrucktseins zu hinterfragen.

\section{Was es heißt, ein Autor zu sein}

Dass Autorschaft durch den Druck konstituiert wird, ist um 1800 alles andere als ein neuer Gedanke. Roger Chartier führt Antoine Furetières »Dictionnaire universel (1690) an, in dem nachzulesen ist: »AUTEUR, en fait de Litterature, se dit de tous ceux qui ont mis en lumiere quelque livre. Maintenant on ne le dit que de ceux qui en ont fait imprimer. ${ }^{30}$ Zugleich gibt es im europäischen Kontext auch Schriftsteller, die ausdrücklich eine andere Position beziehen, wie der um 1770 durch mehrere Übersetzungen in den deutschsprachigen Ländern verstärkt wahrgenommene Shaftesbury. In dessen »Selbstgespräch oder Ratschlag an einen Autor« (1710) heißt es apodiktisch: »AND thus am I no-wise more an AUTHOR, for being in Print. ${ }^{31}$ Als Joachim Heinrich Campe

29 »Der Ewigkeitsanspruch und das Ewigkeitsversprechen der Schrift beruhten auf zwei Grundannahmen: daß erstens der materielle Bestand und zweitens die Lesbarkeit der Texte gesichert ist.« (Aleida Assmann, Erinnerungsräume. Formen und Wandlungen des kulturellen Gedächtnisses, München 1999, S. 203)

30 Antoine Furetière, Art. »Auteur«, in: ders., Dictionnaire universel, contenant généralement tous les mots françois tant vieux que modernes, et les termes de toutes les sciences et des arts, La Haye 1690, Bd. I, o.P. Siehe Roger Chartier, The Order of Books. Readers, Authors, and Libraries in Europe Between the Fourteenth and Eighteenth Centuries, Stanford 1994, S. $39 f$. Shaftesbury, Selbstgespräch, S. 230. Shaftesbury bevorzugt als Autor die Handschrift gegenüber dem Druck. Margaret Ezell betont mit Blick auf das England des frühen 18. Jahrhunderts, dass »script was still a competitive, if not the dominant, mode of transmitting and reading what we term >literary and sacademic materials« (Margaret J. M. Ezell, Social Authorship and the Advent of Print, Baltimore Md. u.a. 1999, S. 12). Diese These folgt dem Narrativ einer historischen Abfolge von Handschrift und Buchdruck hinsichtlich der Medialität schriftlicher Kommunikation, einem Narrativ, das wie Christian Benne argumentiert - „den Wechsel der Medien statt ihrer wechselseitigen Beeinflussung und Differenzierung" (Christian Benne, Die Erfindung des Manuskripts. Zur Theorie und Geschichte literarischer Cegenständlichkeit, Berlin 2015, S. 164) hervorhebt. Zudem operiert Ezell mit einer Unterscheidung zwischen literarischem und wissenschaftlichem Schreiben, die sich um 1700 so kaum treffen lässt, wie u.a. Olaf Simons gezeigt hat (Olaf Simons, »Von der Respublica Literaria zum Literaturstaat? 
das Wort zu Beginn des 19. Jahrhunderts im »Wörterbuch zur Erklärung und Verdeutschung der unserer Sprache aufgedrungenen fremden Ausdrücke« erläutert, bezeichnet er als »Autor« einen »Jeden, der ein Buch geschrieben hat, er mag den Inhalt aus sich selbst, oder aus den Werken Anderer genommen haben ${ }^{32}$

\section{Der »Doppelcharakter« des Buches}

Erkennbar wird bei Campe, dass die Semantik der Autorschaft kompliziert wird durch die verwickelte Ambiguität von Buch, ob als Wort oder Begriff. Die Mehrdeutigkeit ergibt sich aus dem »Doppelcharakter «33 des Buches, der durch die »materiell definierte Differenz ${ }^{34}$ zwischen Text und Artefakt zustande kommt. Die Buchwissenschaftlerin Ursula Rautenberg betont die "Aporien des Buches «5, zu denen diese Differenz führt. Das Buch funktioniert in zweierlei Hinsicht durch das Prinzip der Vervielfältigung. Die technische Einrichtung des Buchdrucks ermöglicht die einfache Herstellung einer größeren Anzahl weitgehend identischer Artefakte. Diese sind ein Grund für das Paradox der Singularität des Buches, das Joseph A. Dane beschreibt: "We all know what a book is - it is something we hold in our hands. We also believe, somewhat preposterously, that that book is something someone else can hold in their hands, at the same time and in a different location. $\ll^{36}$

Überlegungen zur Konstitution des Literarischen«, in: Aufklärung 26 (2014), S. 291-330). Benne zeigt auf, dass noch im England des frühen 18. Jahrhunderts ein »Stigma des Drucks« (Benne, Erfindung des Manuskripts, S. 157) existiert, das sich mit Sicherheit auch auf Shaftesbury beziehen lässt. Entscheidend ist jedoch weniger dieses »Stigma«, sondern die selbstbewusste Markierung als Autor, der des Drucks nicht bedarf. Dahinter stehen vermutlich die Verbreitungswege von Texten jenseits des Drucks, die in England vorhanden sind, aber wohl mehr noch eine Rückbindung von Autorschaft an Texte, nicht Artefakte, die eine Verbreitung versprechen. Benne spricht ausdrücklich von einer »Kulturtechnik der kontrollierten Publikation« (Ebd., S. 158), auf die im englischen Kontext nicht zuletzt im Hinblick auf eine gesellschaftliche Distinktion ein großer Wert gelegt worden zu sein scheint. Joachim Heinrich Campe, Wörterbuch zur Erklärung und Verdeutschung der unserer Sprache aufgedrungenen fremden Ausdrücke, Braunschweig 1813, S. 138. Ursula Rautenberg, Dirk Wetzel, Buch, Tübingen 2001, S. 63ff.

34 Ebd., S. 42.

35 Ebd.

36 Joseph A. Dane, The Myth of Print Culture. Essays on Evidence, Textuality, and Bibliographical Method, Toronto u.a. 2003, S. $6 \mathrm{f}$. 
Der Hauptgrund für das Paradox der Singularität ist allerdings die auf ihrem Zeichencharakter basierende Medialität der Schrift. Denn als Zusammenstellung von Zeichen bleibt ein gedruckter Text ungeachtet seiner Materialität immer derselbe, er ist tatsächlich singulär, auch wenn er beispielsweise beim Lesen handschriftlich und somit nicht typographisch reproduziert wird. Die »Selbigkeit des Buchstabierens « ${ }^{37}$ (Goodman) ist gewährleistet. Dane geht zwar davon aus, dass es sich beim Buch um ein "physical object« handelt, doch er verweist zugleich auf die »various levels of abstraction that transform that book slowly into a text or a textlike object. Key to all these levels is the notion of reproducibility «. ${ }^{38}$ Freilich dient das Buch nicht allein der potenziellen Verbreitung eines Textes durch dessen Vervielfältigung, sondern es zeichnet sich als Artefakt durch etliche Merkmale aus, unter anderem hinsichtlich dessen, was Gérard Genette als Paratext bezeichnet, nämlich die »Beziehung, die der eigentliche Text mit dem unterhält, was ihn umgibt « ${ }^{39}$. In den vergangenen Jahren ist die literaturwissenschaftliche Forschung dazu übergegangen, den Paratext auch als Umgebung des Artefakts zu konzeptualisieren. ${ }^{40}$ Damit gerät neben Titelblättern oder Überschriften, die zwar meist den Erfordernissen des Druckhandwerks entsprungen sind, aber philologisch als Texte verhandelt werden, verstärkt die Materialität von Büchern in den Blick. Sie erscheinen nicht mehr in erster Linie als Textmedien, sondern ihrer Materialität wird eine eigenständige Medialität zugesprochen, unter Berücksichtigung dessen, was im angelsächsischen Raum als »bibliographical code« bezeichnet wird. ${ }^{41}$ Das Buch lässt sich vor diesem Hintergrund als mindestens doppeltes Medium beschreiben. Auf dieser Doppelheit basiert sein spe-

37 Nelson Coodman, Sprachen der Kunst. Entwurf einer Symboltheorie, Frankfurt a.M. 1997, S. 115.

38 Dane, The Myth of Print Culture, S. 8.

39 Cérard Genette, Palimpsestes. La littérature au second degré, Paris 1982, S. 10. (Übs. Jasmin Pfeiffer)

40 Siehe dazu Kristin Knebel, Cornelia Ortlieb, „Sammlung und Beiwerk, Parerga und Paratexte. Zur Einführung«, in: dies., Gudrun Püschel (Hg.), Steine rahmen, Tiere taxieren, Dinge inszenieren. Sammlung und Beiwerk, Dresden 2018, S. 7-30.

41 Siehe Jerome J. McGann, The Textual Condition, Princeton 1991. McGann unterscheidet zwischen dem »linguistic code« eines publizierten Textes und dem »bibliographical code«, wobei er anhand von William Blake erläuternd schreibt: »No one can read an original Blake text, or facsimile text, and not be struck by the following fact: that such work has set in motion two large signifying codes, the linguistic code (which we tend to privilege when we study language-based arts like novels and poetry) and the bibliographical code (which interpreters, until recently, have largely ignored.« (S. 56) 
zifischer Publikationscharakter ebenso wie die angedeutete Mehrdeutigkeit, sobald vom Buch die Rede ist.

\section{Was es heißt, ein Buch zu schreiben}

Befördert wird diese Ambiguität von Topoi, in denen unterschiedliche Bedeutungsaspekte verfilzen. Jemand schreibt ein Buch - dieser Topos ist um 1800 ebenso gängig wie heute. Er wird im Hinblick auf Autorschaft durch das Objekt des Satzes dominiert, nicht durch das Prädikat. Schreiben ist ein transitives Verb, das zunächst überaus passend erscheint, weil man es gewohnt ist, angesichts der Ambiguität von Buch mit diesem Substantiv etwas anderes zu verbinden: einen Text. Allerdings steht ein Buch hier für deutlich mehr, und das hat Auswirkungen auf das Verb schreiben. Einerseits verschleiert schreiben, dass ein Buch auf sehr verschiedenen Tätigkeiten basiert, andererseits erlangt das Wort im Kontext eine spezifische Bedeutung. Das zeigt beispielhaft ein Brief von Heinrich Christian Boie an Nicolai, in dem er diesem den Verlag von Lichtenbergs »Timorus« anträgt. Lichtenberg wird von Boie eingeführt als jemand, der »noch nichts geschrieben ${ }^{42}$ habe. Es mag spitzfindig erscheinen festzustellen, dass das, was Boie mitteilt, im buchstäblichen Sinne nicht zutrifft, weil Lichtenberg freilich schon etliche Texte zu Papier gebracht hat - unter anderem den für den Druck bestimmten »Timorus«. Gemeint ist aber freilich, dass Lichtenberg noch nichts veröffentlicht hat. Es geht somit in diesem Kontext nicht um das Hervorbringen eines Textes, sondern um das Schreiben als Praktik des Publizierens. Daraus ergibt sich, dass alles Geschriebene »nichts « ist, solange es nicht gedruckt vorliegt. Eine Metonymie, das »Bücherschreiben ${ }^{43}$, die in einem Kurzschluss vom Text zur Publikation führt, stellt eine Verknüpfung her, die für eine gängige Auffassung von Autorschaft kennzeichnend ist: Schreiben bedarf des Buches, um Autorschaft zu begründen. Zugleich erscheint das Buch in dieser Verknüpfung als unmittelbares Produkt des Schreibens, ungeachtet aller weiteren Arbeiten, die $\mathrm{zu}$ seiner Verfertigung notwendig sind, sowie der Eigenschaften, die es als

42 Zit. n. Georg Christoph Lichtenberg, Briefwechsel, hg. v. Ulrich Joost, Albrecht Schöne u.a., München 1983-2004, I (1983), S. 271.

43 Siehe z.B. Johann Heinrich Cottlob Justi, »Die Schriftstellersucht, eine gefährliche Krankheit der gelehrten Anfänger«, in: ders., Scherzhafte und Satyrische Schriften, Leipzig 1760, I, S. 162-174, hier: S. 163 u.a. 
Artefakt auszeichnen. Prädikat und Objekt semantisieren sich somit wechselseitig, wenn es heißt, ein Autor sei ein >Jeder, der ein Buch geschrieben hat . In dieser Lesart soll die Würdigung der Leistung, einen Text verfasst zu haben, die dem Topos inhärent ist, nicht übergangen werden. Allerdings gilt zu beachten, was Chartier mit Nachdruck formuliert hat, dass nämlich Autoren keine Bücher schreiben, sondern »Texte, die zu gedruckten Objekten werden ${ }^{44}$. Chartier schärft den Blick dafür, dass Autorschaft aus mehreren Praktiken des Publizierens hervorgeht, die aufeinander bezogen sind, wobei in diesem Zusammenhang dem Akt des Druckens eine Schlüsselfunktion zukommt. Freilich »werden« Texte nicht von allein zu "gedruckten Objekten«, vielmehr werden sie zu solchen gemacht, nicht selten unter Anteilnahme derjenigen, zu deren Autorschaft diese Objekte beitragen, aber meist ohne deren direkte Beteiligung.

\section{Die "Druck-Szene» als Urszene gelehrter Autorschaft}

Es gehört zweifellos zu den Stärken der Literatur, die Rhetorizität der sprachlichen Vermittlung sozialer Praktiken so produktiv zu machen, dass ein Schauplatz entsteht, auf dem diese Praktiken verhandelbar werden. So ist in Jean Pauls »Leben Fibels « zu lesen, dass der nach Autorschaft strebende Fibel »einmal vom Reize, einen Folianten geschrieben zu haben, sich so weit verlocken ließ, daß er seinen Namen als Verfasser auf ein Werk setzte, das einige Jahrzehende vor seiner eigenen Geburt geboren worden «(SW I.6, 479). Mit anderen Worten: Fibel erhebt sich zum Urheber eines Buches, indem er seinen Namen auf das Titelblatt eines Exemplars druckt.

Uwe Wirth hat aufgrund solcher Inszenierungen von Autorschaft vorgeschlagen, in »Leben Fibels« die »Schreib-Szene als Druck-Szene «5 aufzufassen. Er spricht in diesem Zusammenhang von einem »Konzept, das Autorschaft konstitutiv an das Gedrucktwerden koppelt « ${ }^{46}$. So wie Lichtenberg »noch nichts geschrieben« hat, solange kein gedrucktes Buch vorliegt, führt umgekehrt der Foliant zwingend zu der Annahme, dass Fibel diesen "geschrieben« habe, obwohl dies chronologisch ausgeschlossen zu sein scheint.

44 Roger Chartier, Lesewelten. Buch und Lektüre in der frühen Neuzeit, Frankfurt a.M. u.a. 1990, S. 12.

45 Uwe Wirth, Die Geburt des Autors aus dem Geist der Herausgeberfiktion. Editoriale Rahmung im Roman um 1800: Wieland, Goethe, Brentano, Jean Paul und E.T.A. Hoffmann, München 2008, S. 354 .

46 Ebd., S. 358. 
Selbstverständlich lassen sich Paratexte manipulieren, und die Historizität von Texten oder Artefakten verliert sich in der diskursiven Verräumlichung bibliographischer Daten wie dem Autornamen. Das Besondere an dieser Fiktion liegt zum einen darin begründet, dass Fibel eigenhändig seinen Namen auf dem »Folianten « anbringt, zum anderen in der Nachträglichkeit der »DruckSzene«, welche die Konstitution von Autorschaft durch die Typographie offenlegt. Die »Druck-Szene« führt im Roman zu einer Genealogie, in der Fibel zum Urheber von Büchern wird, die »einige Jahrzehende vor seiner eigenen Geburt geboren worden « sind. Jean Paul ironisiert eine Bildlichkeit, die sich auch in einer bekannten Gelehrtensatire über die "Schriftstellersucht« von 1765 findet, in der es heißt, dass ein Werk »durch den Weg der Presse in die gelehrte Welt gebohren ${ }^{47}$ werde - wodurch auch dessen Urheber eine papierne Existenz erlangt. Bemerkenswert an dieser Passage aus dem »Leben Fibels« ist zudem der Umstand, dass Fibel ausgerechnet dem »Reize« erliegt, »einen Folianten geschrieben zu haben«. Stehen die »alten vielpfündigen Folianten« (SW I.5, 495) als schwergewichtige Wissensspeicher doch für eine Gelehrsamkeit, die im späten 18. Jahrhundert zunehmend als Papierarbeit verbrämt wird. Autorschaft am Gedrucktwerden festzumachen, das hat als Konzept seinen Ursprung in eben dieser Bildungstradition. Und dieses Konzept bleibt bestehen, auch wenn es durch ein anderes abgelöst zu werden scheint.

\section{Die Abwertung gelehrten Publizierens}

Die von Chartier hervorgehobene und durch Rautenberg unterstrichene Differenz zwischen Text und Artefakt ist um 1800 ein Gegenstand intellektueller Operationen, die mindestens den Nebeneffekt haben, Autorschaft vom gedruckten Artefakt zu entbinden. Im späten 18. Jahrhundert formiert sich ein wirkmächtiges Konzept von Autorschaft, das Subjektivität mit geistiger Produktivität verknüpft. Autorschaft erfährt eine Inversion, sie hat ihren Ursprung im individuellen Geist, der seine Eigentümlichkeit ${ }^{48}$ nach außen trägt - vornehmlich im Medium der Sprache. Es sind nicht zuletzt der Geniegedanke und eine romantisch-idealistische Ästhetik, die eine Immaterialisierung

47 Justi, »Die Schriftstellersucht«, S. 165.

48 Vgl. Gerhard Plumpe, »Eigentum - Eigentümlichkeit. Über den Zusammenhang ästhetischer und juristischer Begriffe im 18. Jahrhundert«, in: Archiv für Begriffsgeschichte 23 (1979), S. 175-196. 
von Autorschaft forcieren - in deutlicher Abgrenzung von der Materialität gelehrten Publizierens.

Jochen Schmidt hat in seiner Geschichte des Geniegedankens hervorgehoben, dass das Genie "programmatisch gegen den Gelehrten «" ${ }^{49}$ stehe. In der Genieästhetik des 18. Jahrhunderts werden Bücher praktisch zum Verschwinden gebracht. Dieses Kunststück führt Edward Young in seinen einflussreichen »Gedanken über die Original-Werke« (1759) vor. Young erkennt zwar »die verewigende Macht der Presse an und bezeichnet sie als »Quelle des Nachruhms «. ${ }^{50}$ Doch das in der Presse hergestellte Buch gehört trotzdem nicht zu den Produkten des Genies, im Gegenteil: Bücher repräsentieren für Young ein statisches, nicht an ein Subjekt, sondern medial gebundenes Wissen. Den »edeln Titul des Autors ${ }^{51}$ darf Young zufolge nur tragen, wer »denket und schreibt « und sich somit nicht als »Räuber der Presse ${ }^{52}$ betätigt. Solche »Räuber« mögen »reich an vielen Bänden und Gelehrsamkeit« sein, ihr Problem aber besteht in der Nutznießung dieses Reichtums, führt dieser doch dazu, dass sie "nur lesen und schreiben ${ }^{53}$ Diese bemerkenswerte Verbindung von Reichtum und Raub bahnt den Weg zu einem Eigentumsbegriff, der das Schreiben ewig an das denkende Subjekt und den Gedanken bindet den des geistigen Eigentums. Originalität entfaltet sich nach Young nur da, wo Gelehrsamkeit ohne Bücher auskommt. Gelehrsamkeit wird nicht zuletzt deshalb so stark an Bücher gebunden, weil Lesen als gelehrte Praktik vor allem eine Papierarbeit ist, die in der Regel auf Reproduktion und somit Nachahmung sowie der Reorganisation überlieferten Wissens basiert, etwa beim Exzerpieren. Auf das Abschreiben folgt die Wiedergabe auf der Grundlage fester Regeln. Lichtenberg hat den so verfahrenden Gelehrten pointiert dargestellt: »Er exzerpierte beständig, und alles, was er las, ging aus einem Buche neben dem Kopf vorbei in ein anderes. ${ }^{54}$ Darin offenbart sich ein um 1800 gängiges Ressentiment gegenüber einer staubigen Buchgelehrsamkeit. Noch Jean

49 Jochen Schmidt, Die Geschichte des Genie-Gedankens in der deutschen Literatur, Philosophie und Politik, 1750-1945, Band 1: Von der Aufklärung bis zum Idealismus, Darmstadt 1985, S. 3.

50 Edward Young, Gedanken über die Original-Werke, hg. v. Gerhard Sauder, Heidelberg 1977, S. 19, 11.

51 Ebd., S. 48.

52 Ebd., S. 49.

53 Ebd.

54 Georg Christoph Lichtenberg, Schriften und Briefe, hg. v. Wolfgang Promies, 6. Aufl., Frankfurt a.M. 1998, II, S. 166 (G 181). 
Paul verortet sich in der »Vorschule der Ästhetik« im »druckpapiernen Weltalter, wo der Schreibtisch so nah' am Bücherschranke steht« (SW I.5, 25).

\section{Die Entmaterialisierung des Publizierens durch Genieästhetik und Philosophie}

Seine volle Durchschlagskraft entfaltet der Geniegedanke nicht in der Gelehrsamkeit, sondern in den Künsten, die im letzten Drittel des 18. Jahrhunderts eine Autonomisierung erfahren. Andreas Reckwitz beschreibt in diesem $\mathrm{Zu}$ sammenhang eine "ästhetische Sozialität «" ${ }^{55}$, für die das Genie durchaus zentral ist. Im »Essay on Genius« (1774) von Alexander Gerard, der für Kants "Kritik der Urteilskraft« (1790) bedeutsam ist, heißt es, »das Genie umfasst im Kern die Fähigkeit zur Erfindung (inventio), welche es einem Menschen ermöglicht, in der Wissenschaft neue Entdeckungen zu machen oder originelle Kunstwerke zu produzieren $« .{ }^{56}$ Reckwitz verweist auf die für das Genie entscheidende Polarisierung zwischen inventio und imitatio, wobei sich die inventio in den Künsten aus der Einbildungskraft speist. ${ }^{57}$ Für Reckwitz ist es demnach konsequent, dass im Rahmen der Genieästhetik die künstlerische Tätigkeit der Tendenz nach entmaterialisiert werde. ${ }^{58}$

In der romantisch-idealistischen Ästhetik erscheint die schöne Literatur auch nicht im Druck. Dichtung und Poesie besitzen im ästhetischen Denken des frühen 19. Jahrhunderts keine Materialität mehr außer der Sprache. ${ }^{59} \mathrm{Da}$ bei gilt: Ob die Gebrüder Schlegel, Schelling oder Hegel, sie alle ordnen, trotz dem, was sie unterscheidet, die Sprache der Sphäre des Geistes zu. August Wilhelm Schlegel erklärt in der Kunstlehre seiner »Vorlesungen über schöne Literatur und Kunst«: »Das Medium der Poesie ist eben dasselbe, wodurch

Andreas Reckwitz, Die Erfindung der Kreativität. Zum Prozess gesellschaftlicher Ästhetisierung, Berlin 2012, S. 57.

56 Vgl. Alexander Cerard, An Essay on Cenius, London 1774, S. 8 (»CENIUS is properly the faculty of invention; by means of which a man is qualified for making new discoveries in science, or for producing original works of art. «) Übersetzung zitiert nach Reckwitz, Die Erfindung der Kreativität, S. 61. Schmidt hebt hervor, dass Kant eine »strikte Trennung von Genie und Wissenschaftler « vornimmt und sich darin von Gerard unterscheidet, wie auch das Zitat zeigt (Schmidt, Die Geschichte des Cenie-Gedankens, I, S. 363).

57 Reckwitz, Die Erfindung der Kreativität, S. 61.

58 Ebd., S. 64.

59 Vgl. zur folgenden Argumentation bereits Tobias Fuchs, Büchermachen. Autorschaft und Materialität des Buches in Jean Pauls » Leben Fibels«, Hannover 2012, S. 27-29. 
der menschliche Geist überhaupt zur Besinnung gelangt, und seine Vorstellungen zu willkührlicher Verknüpfung und Äußerung in die Gewalt bekömmt: die Sprache. ${ }^{60}$ In der »Philosophie der Kunst « bezeichnet Schelling die »Rede oder Stimme als unmittelbaren Leib der inneren Seele ${ }^{61}$, so dass die in einer bemerkenswerten Disjunktion erfasste »Rede oder Stimme« gar nicht - wie bei Schlegel - als »Medium« begriffen wird, sondern in der Dimension des Klangs eine paradoxale Körperlichkeit (»unmittelbaren Leib der inneren Seele«) erlangt, die nicht semiotisch verfasst ist. Für Hegel ist der Ton als Element der Sprache das »letzte äußere Material der Poesie « ${ }^{62}$. Monika Wagner erkennt noch in seiner Ästhetik, die zeitlich die angedeutete Reihe beschließt, eine bis ins 19. Jahrhundert tradierte »Hierarchie der Künste« wieder, die sich aus einer »Abhängigkeit vom Material « ergibt. ${ }^{63}$ Die vom Artefakt unabhängige Dichtung lässt sich somit in den höchsten Sphären menschlicher Produktivität ansiedeln. Das gedruckte Buch erwähnt Hegel nur ein einziges Mal in einem Nebensatz zur Buchdruckerkunst. ${ }^{64}$

Friedrich A. Kittler fasst in »Aufschreibesysteme« die Entmaterialisierung der Dichtung durch die um 1800 maßgeblichen Philosophen der Kunst zusammen: »Beim Begriffsbestimmen der Dichtung können und dürfen sie vergessen, wie grundsätzlich geschrieben und gedruckt sie vor ihnen liegt. « ${ }^{65}$ Näher erläutert Kittler: »Dichtung genießt in den Ästhetiksystemen eine Sonderstellung. Andere Künste definiert jeweils ihr sinnliches Medium (Stein, Farbe, Baustoff, Klang); das Medium der Dichtung dagegen - Sprache oder Ton, Sprache als Ton, selbstredend keine Buchstaben - verschwindet unter ihrem Gehalt, damit [...] der Geist direkt dem Geist erscheinen kann. « ${ }^{66}$ Es gilt bei dieser Lektüre die Konjunktion "geschrieben und gedruckt « ausreichend zu würdigen, deutet sich in ihr doch eine Differenzierung an, welche die Materialität von »Buchstaben« betrifft - und letztlich das Konzept von

60 August Wilhelm Schlegel, Vorlesungen über schöne Literatur und Kunst [Berlin 1801-1804]. Kritische Ausgabe der Vorlesungen, hg. v. Ernst Behler, Paderborn, München, Wien u.a. 1989, I, S. 179-781, hier: S. 387.

61 Friedrich Wilhelm Joseph Schelling, Texte zur Philosophie der Kunst, ausgewählt u. eingeleitet v. Werner Beierwaltes, Stuttgart 2004, S. 278.

62 Georg Wilhelm Friedrich Hegel, Vorlesungen über die Ästhetik, Werke, neu ediert v. Eva Moldenhauer, Karl Markus Michel, Frankfurt a.M. 1986, XIII, I/122.

63 Monika Wagner, »Material«, in: Karlheinz Barck u.a. (Hg.), Ästhetische Grundbegriffe, Stuttgart, Weimar 2000-2005, III (2001), S. 866-882, hier: S. 868.

64 Georg Wilhelm Friedrich Hegel, Ästhetik, hg. v. Friedrich Basenge, Berlin 1955, S. 764.

65 Friedrich A. Kittler, Aufschreibesysteme 1800-1900, 4. Aufl., München 2003, S. 139.

66 Ebd., S. 139f. 
Autorschaft. Anders als das logozentrische Denken nahelegt, markiert der Druck nicht einzig und allein eine Differenz zwischen Schriftlichkeit und einer vom Geist erfüllten Oralität. In einer praxeologischen Perspektive wird Autorschaft durch eine differente Form der Schriftlichkeit ausgezeichnet: die Typographie, und zwar in Abgrenzung von der Handschriftlichkeit. Diese Differenz unterstreicht die Notwendigkeit, sich Autorschaft mit einer besonderen Aufmerksamkeit für die Praktiken des Publizierens zu nähern, weil Autorschaft in vielerlei Hinsicht ebenso, wenn nicht gar mehr durch die von Chartier angeführten "gedruckten Objekte « als durch Texte bestimmt wird. ${ }^{67}$

Ein schlagendes Beispiel ist in diesem Zusammenhang sicherlich Fichte, der als Philosoph gegen eine Buchstäblichkeit vorgeht, die mindestens rhetorisch auf die Materialität von Schriftlichkeit rekurriert, während er zugleich eine beachtliche »Werkpolitik« betreibt und dem Druck wie der Verbreitung seiner Schriften viel Aufmerksamkeit schenkt. ${ }^{68}$ Gerade Fichte zeigt, wie die Praktiken der Gelehrsamkeit in der idealistischen Philosophie dem Primat des Geistes unterworfen werden: durch eine Rhetorik, die der Abwertung der Materialität dieser Praktiken dient. Seine »Wissenschaftslehre« sei, so Fichte, "von der Art, daß sie durch den blossen Buchstaben gar nicht, sondern daß sie lediglich durch den Geist sich mittheilen läßt; weil ihre Grundideen in jedem, der sie studirt, durch die schaffende Einbildungskraft selbst hervorge-

67 Jedoch sollte bei Betrachtung dieser Praktiken die Handschriftlichkeit nicht ausgeschlossen werden. So betreibt etwa Ceorg Christoph Lichtenberg eine publizistische Buchführung, die zeigt, wie strukturiert und zielorientiert seine Lektüren sich gestalten und welche Bedeutung die Ordnung der Notizbücher und Manuskripte in diesem Zusammenhang erlangt. So führt er ab 1781 einen »Calender«, der in der Forschung als das » Rote Buch «bekannt ist. Hierin sammelte Lichtenberg Literaturauszüge ebenso wie Titel und mögliche Themen, »manchmal auch schon kurze Ausarbeitungen«, so Ulrich Joost, der weiter bemerkt: »Was er für den Druck verarbeitet hatte, markierte er durch einfaches diagonales Ausstreichen als erledigt." (Ulrich Joost, Georg Christoph Lichtenberg, 1742-1799. Wagnis der Aufklärung. Ausstellungskatalog, München 1992, S. 47) Dennoch gibt es für Lichtenberg verschiedene Modalitäten des Publizierens, in die Manuskripte selbstverständlich eingebunden sind: »Was mich allein angeht denke ich nur, was meine guten Freunde angeht sage ich ihnen, was nur ein kleines Publikum bekümmern kann schreibe ich, und was die Welt wissen soll wird gedruckt.« (Lichtenberg, Schriften und Briefe, I, S. 117f. (B 272)).

68 Bernhard Fischer, »)ohann Friedrich Cotta und der Deutsche Idealismus (Fichte und Schelling) «, in: Cornelia Ortlieb, Tobias Fuchs (Hg.), Schreibekunst und Buchmacherei. Zur Materialität des Schreibens und Publizierens um 1800, Hannover 2017, S. 117-138, ders., Johann Friedrich Cotta. Verleger - Entrepreneur-Politiker, Cöttingen 2014, S. 167-184. 
bracht werden müssen $«{ }^{69}$ An anderer Stelle polemisiert Fichte gegen "geistlose Buchstäbler ${ }^{70}$ in der Philosophie, die annehmen, was an Wissen und Erkenntnis überliefert ist. ${ }^{71}$ Und in der Charakterisierung des Geistlosen vergleicht Fichte diesen mit einem Schreibschüler: "Der Geistlose ist ein Schüler, der bei jedem Federzuge sich nach der Vorschrift umsieht. «"2 Solcherlei Bilder und Begriffe durchziehen die Schriften von Fichte von Beginn an. Cornelia Ortlieb weist auf eine Note zu Kant in Fichtes »Versuch einer Critik aller Offenbarung « (1792/1793) hin. ${ }^{73}$ "Der verehrt Kanten noch wenig«, heißt es in der betreffenden Anmerkung apodiktisch, »der es nicht am ganzen Umrisse und Vortrage seiner Schriften gemerkt hat, dass er uns nicht seinen Buchstaben, sondern seinen Geist mittheilen wollen; und er verdankt ihm noch

69 Johann Cottlieb Fichte, Grundlage der gesammten Wissenschaftslehre als Handschrift für seine Zuhörer, Cesamtausgabe, Stuttgart-Bad Canstatt 1962-2012, I,2 (1965), S. 173-461, hier: S. 415. Fichtes »Crundlage der gesammten Wissenschaftslehre«, aus der dieses Zitat stammt, trägt in ihren beiden Auflagen, die 1794/95 bzw. 1802 bei Christian Ernst Gabler in Leipzig (und Jena) erscheinen, im Titel den Zusatz »als Handschrift für seine Zuhörer«. Der Philosoph verteilt die Drucke der Erstauflage bogenweise in seinen Privatvorlesungen (Ebd., S. 175), was man einerseits als Sonderform des Vertriebs ansehen kann. Andererseits gelangt die Publikation im Hörsaal in einen intimen Austausch, wie man ihn z.B. von in geschlossenen Kreisen zirkulierenden, in Abschrift vervielfältigten Manuskripten oder Privatdrucken in Kleinstauflagen kennt (siehe Carlos Spoerhase, » Manuscript für Freundes: Die materielle Textualität literarischer Netzwerke, 1760-1830«, in: DVjs 88 (2014), S. 172-205). Dieses Beispiel zeigt, wie differenziert die Sozialität des Publizierens im Einzelfall zu betrachten ist.

70 Johann Cottlieb Fichte, Ueber den Unterschied des Ceistes, u. des Buchstabens in der Philosophie, Cesamtausgabe, Stuttgart-Bad Canstatt 1962-2012, II,3 (1972), S. 313-342, hier: S. 316. Zum Verhältnis von Geist und Buchstaben bei Fichte siehe Liliane Weissberg, Geistersprache. Philosophischer und literarischer Diskurs im späten 18. Jahrhundert, Würzburg 1990, S. 161-204.

71 Wobei er den »Buchstäbler« auch in den Künsten erkennt, nämlich als jemanden, der zu mehr nicht im Stande ist als »den mechanischen Theil eines geistvollen Products nachzubilden " (Johann Cottlieb Fichte, Ueber Ceist und Buchstab in der Philosophie. Cesamtausgabe, Stuttgart-Bad Canstatt 1962-2012, I,6 (1981), S. 313-361, hier: S. 359). Dass Fichte dabei auch oder vor allem die Dichtung im Blick hat, führt zurück zur Entmaterialisierung zeitgenössischer Ästhetik.

72 Fichte, Ueber den Unterschied, S. 316

73 Cornelia Ortlieb, »Anstreichen, Durchstreichen«, in: dies., Mona Körte (Hg.), Verbergen - Überschreiben -Zerreißen. Formen der Bücherzerstörung in Literatur, Kunst und Religion, Berlin 2007, S. 247-270, hier: S. 269. 
weniger. ${ }^{74}$ Ortlieb führt dazu eine Bemerkung aus der »Vorrede« zur ersten Auflage der »Kritik der reinen Vernunft« (1781) an, in welcher Kant erklärt, er verstehe unter dieser Kritik »nicht eine Kritik der Bücher und Systeme, sondern die des Vernunftvermögens überhaupt « ${ }^{75}$.

Für Fichte sind Buchstaben nicht von Geist erfüllt, sie sind »todte Körper«, und es ist die Aufgabe miteinander kommunizierender Subjekte, den Lettern wechselseitig einen »lebendigen Odem einzuhauchen $« .{ }^{76}$ An der Schwelle zum 19. Jahrhundert wird die Rede von den toten Buchstaben eine immer wichtigere Wendung, und zwar in der Entgegensetzung zum vitalen Geist des aufgeklärten Subjekts. Die toten Buchstaben gehören in den Bereich einer mechanisch betriebenen Gelehrsamkeit, die instrumentell aufgefasst wird, als ein »Werkzeug «, wie es bei Young heißt ${ }^{77}$, das der Reproduktion und Wiedergabe von Wissen dient. Und diese technische Bildlichkeit der Gelehrsamkeit, die in der Regel pejorativ ist, wird häufig in Motive gefasst, die auf der Materialität von Schriftlichkeit und darüber hinaus auch von Büchern beruhen. Als Beispiel sei Lessings »Nathan« angeführt, wo die »kalte Buchgelehrsamkeit « thematisch wird, »die sich mit toten Zeichen ins Gehirn nur drückt «. ${ }^{78}$ Um 1800 entwickelt das idealistische Denken einen enormen Einfluss auf die Buchkultur, wie auch die sich formierende Theorie des geistigen Eigentums beweist. Dabei fungiert die Buchkultur nicht nur als Bildspender, sondern sie bildet den realen Kontext der Produktion und Rezeption von Texten, die von Geist zu Geist vermittelt werden sollen. Ungeachtet dessen wird Autorschaft im sozialen Austausch weiterhin durch Bücher definiert, anhand von Artefakten, weil diese die Bedingung der Möglichkeit sind, mit einem Text in einem größeren Radius wahrgenommen zu werden. Das ist wie Fichte auch allen anderen bewusst, die mittels Büchern kommunizieren. Und es sind die im Druck fixierten toten Buchstaben, die Autorschaft konstituieren.

Dass der Druck, wie in der Polemik des Philosophen gegen die »Buchstäbler« angedeutet, eine Bildlichkeit anbietet, mittels derer Autorschaft abwertend als Handwerk dargestellt werden kann, zeigt eine auf die Vielschreibe-

74 Johann Gottlieb Fichte, Versuch einer Critik aller Offenbarung. Gesamtausgabe, StuttgartBad Canstatt 1962-2012, I,1 (1964), S. 15-162, hier: S. 149.

75 Immanuel Kant, Kritik der reinen Vernunft, Werkausgabe, hg. v. Wilhelm Weischedel, Frankfurt a.M. 1968, III.I, S. 13 [A XII].

76 Fichte, Ueber den Unterschied, S. 320.

77 Young, Gedanken über die Original-Werke, S. 27.

78 Gotthold Ephraim Lessing, Nathan der Weise, Werke und Briefe, hg. v. Wilfried Barner u.a., Frankfurt a.M. 1985-2003, Bd. 9 (1993), S. 483-628, hier: S. 615 (V,6). 
rey gerichtete Satire, die das Wort »Schriftsteller« vom Schriftsetzer ableitet: »Der allzeit-fertige Schriftsteller« (1797) reflektiert das »Handwerksmäßige« des »Büchermachens«, aber letztlich auch die Einbindung des Individuums in die Praktiken des Publizierens:

»Schreiben heißt, nach einer, wie uns dünkt, sehr richtigen Definizion, Denken, oder wenigstens gedacht haben. Daher schien es uns immer von übler Vorbedeutung zu seyn, daß die teutsche Sprache das latinische sautor durch sSchriftsteller< übersezt; welches, mit einem Sinn, den der eigensinnigste Wortforscher nicht tadeln dürfte, einen >Sezzer in der Drukkerey bedeutet. So aber scheint unsre werthe Muttersprache durch jene Benennung die teutschen Autoren selbst zu berechtigen, nur Wort und Buchstab' an einander zu reihen, um den Xenophonten, Ciceronen, und Plutarchen des Alterthums beygezählt zu werden, die sie mit keinem würdigern Namen beehrt. «"

\section{Zur Praxeologisierung von Autorschaft}

Dieses Buch gliedert sich in vier Kapitel, die der Anspruch einer Praxeologisierung von Autorschaft in historischer Perspektive verbindet. Dabei liegt der Fokus auf der Materialität von Büchern, papiernen Artefakten, die als integrale Medien der Literatur fungieren. Praxistheoretisch lässt sich Autorschaft als eine Subjektform beschreiben. Individuen eignen sich diese Form in sozialen Praktiken an. ${ }^{80}$ Thomas Alkemeyer definiert Praktiken im Anschluss an Theodore R. Schatzki als »sozial geregelte, kulturell typisierte und organisierte Bündel menschlicher Aktivitäten ${ }^{81}{ }^{11}$ Andreas Reckwitz betont die Materialität dieser Aktivitäten, die sich für ihn aus der Körperlichkeit des Handelns

79 [Daniel ]enisch], Der allezeit-fertige Schriftsteller. Oder kurze, doch gründliche Anweisung, wie man mit dem möglich-kleinsten Aufwande von Genie und Wissenschaft ein großer und fruchtbarer Schriftsteller werden könne, Berlin 1797, S. 27. Zu Jenisch siehe Iwan d'Aprile, Conrad Wiedemann (Hg.), Daniel Jenisch. Kant-Exeget, Popularphilosoph und Literat in Berlin, Laatzen 2003.

80 Siehe dazu auch Sabine Kyora, »Subjektform >Autor«? Einleitende Überlegungen«, in: dies. (Hg.), Subjektform Autor. Autorschaftsinszenierungen als Praktiken der Subjektivierung, Bielefeld 2014, S. 11-20.

81 Alkemeyer, »Subjektivierung in sozialen Praktiken«, S. 44. Siehe auch Schatzki, der soziale Praktiken als »a temporally unfolding und spatially dispersed nexus of doings and sayings« beschreibt (Theodore R. Schatzki, Social Practises. A Wittgensteinian Approach to Human Activity and the Social, Cambridge 1996, S. 89.). 
und dem Umgang mit Artefakten ergibt. ${ }^{82}$ Materialität wird im »Handbuch Materielle Kultur« als ein »Reflexionsbegriff« definiert, der sich auf sinnliche Phänomene bezieht und seine Entgegensetzung im Begriff der Immaterialität findet. ${ }^{83}$ Somit lässt sich Materialität ausgehend vom Subjekt und dessen Perzeption bestimmen. Auf eine Formel gebracht, hieße das: Materialität besitzt, was potenziell mit allen Sinnen erfahrbar ist. Aber ob und wie Materialität erfahren wird, hängt nicht zuletzt von kulturellen Voraussetzungen ab. Kurz gesagt: Materialität ergibt sich für den Menschen aus Wahrnehmung und Wissen. Bücher stellen vor diesem Hintergrund eine besondere Herausforderung dar, weil sie in ihrer Funktion als Textmedien in wirkmächtige Dispositive der Wahrnehmung eingebunden sind, welche die Dimension der Materialität in der Regel ausblenden.

In den folgenden Kapiteln wird es um Praktiken gehen, die sich allesamt auf Bücher als Artefakte beziehen. Es handelt sich um Handlungen, denen gemeinsam ist, dass sie zur Subjektform der Autorschaft beitragen. Daher werden sie als Praktiken des Publizierens konturiert. Jedoch soll dieser Fokus keinen »Dualismus zwischen nichtdiskursiven Praktiken und Diskursen« befördern, das Erkenntnisinteresse gilt vielmehr »Praxis-/Diskursformationen «. ${ }^{84}$ Nehmen wir die unzähligen Namen in Meusels Schriftstellerlexikon: Michel Foucault schreibt dem Autornamen eine »klassifikatorische Funktion« $\mathrm{zu}$, denn »mit einem solchen Namen«, so Foucault, »kann man eine gewisse Zahl von Texten gruppieren, sie abgrenzen, einige ausschließen, sie anderen gegenüberstellen « ${ }^{85}$ Foucault verbindet mit dem Autornamen also keine »Unifizierung von Papierstößen ${ }^{86}$, sondern die Organisation und Distribu-

82 Andreas Reckwitz, „Grundelemente einer Theorie sozialer Praktiken. Eine sozialtheoretische Perspektive«, in: Zeitschrift für Soziologie 32 (2003), 4, S. 282-301, hier: S. $290 f$. Siehe auch den Forschungsansatz einer »materialen Textkulturforschung « bei Markus Hilgert, »Praxeologisch perspektivierte Artefaktanalysen des Geschriebenen. Zum heuristischen Potential der materialen Textkulturforschung«, in: Friederike Elias, Albrecht Franz, Henning Murmann u.a. (Hg.), Praxeologie: Beiträge zur interdisziplinären Reichweite praxistheoretischer Ansätze in den Ceistes-und Sozialwissenschaften, Berlin, Boston 2014, S. 149-164. Jens Soentgen, Art. »Materialität«, in: Stefanie Samida, Manfred K. H. Eggert, Hans Peter Hahn (Hg.), Handbuch Materielle Kultur. Bedeutungen - Konzepte - Disziplinen, Stuttgart 2014, S. 226-229, hier: S. 226.

84 Reckwitz, »Doing subjects«, S. 73.

85 Michel Foucault, »Was ist ein Autor?«, in: ders., Schriften zur Literatur, aus dem Frz. v. Karin von Hofer, Anneliese Botond, Frankfurt a.M. 1991, S. 7-30, hier: S. 17. Kittler, Aufschreibesysteme, S. 127. 
tion von Texten innerhalb der Ordnung des Diskurses. In der Wissenskultur des ausgehenden 18. Jahrhunderts, die Lichtenberg als »registerartige Gelehrsamkeit ${ }^{87}$ charakterisiert, sind es jedoch hauptsächlich Medien wie Bibliographien und Kataloge, die Autornamen auf die beschriebene Weise zum Funktionieren bringen. Sie begründen Diskursivität nicht durch das Wiedergeben oder Paraphrasieren umfangreicher Texte, sondern durch das Registrieren von »Papierstößen« anhand von Paratexten. Sinnfällig macht dies das inkriminierte Phänomen der »Makulatur-Verlage ${ }^{88}$ : Nicht verkaufte Bücher erhalten neue Titelblätter, um sie ansonsten unverändert ein zweites Mal auf den Markt zu bringen - und erneut in den Diskurs einzuspeisen.

Giorgio Agamben beschreibt die Autorfunktion als einen »Prozeß der Subjektivierung, durch den ein Individuum als Autor eines bestimmten corpus von Texten identifiziert und konstituiert wird «, mit dem Effekt, dass das Subjekt - so Agamben weiter - »seinen Platz dem Register überlassen muß, das definiert, unter welchen Bedingungen und in welchen Formen das Subjekt in der Ordnung des Diskurses erscheinen kann «. ${ }^{89}$ Es liegt nahe, in der Wissensakkumulation von Bibliographien und Katalogen ein solches »Register $\mathrm{zu}$ erblicken. Somit wäre die Autorfunktion in erster Linie mit Praktiken in Verbindung zu bringen, die das Publizieren betreffen, nicht das Produzieren von Texten. Was gleichsam bedeutet, dass das einem Autor zugeschriebene »corpus « sich strukturell aus gedruckten und beschrifteten Artefakten zusammensetzt.

\section{Praxistheorie und Materialität des Buches}

Die Praxistheorie stellt einen überzeugenden Ansatz zur Analyse der Materialität gedruckter Artefakte in der deutschsprachigen Literatur dar. In den vergangenen Jahren erlebt der Materialitätsbegriff in den Geistes-, Kulturund Sozialwissenschaften eine ungebrochene Konjunktur. ${ }^{90}$ Materialität

87 Lichtenberg, Schriften und Briefe, I, S. 271 (D 255).

88 Johann Friedrich Korn, »Warnungs-Anzeige an die Herren Skalen-Meister des Wachsthumes der Schriftstellerei, und der Ausbreitung der Celehrsamkeit in jedem Fache derselben«, in: Allgemeiner Litterarischer Anzeiger (1797), No. C, Sp. $1017 f$., hier: Sp. 1017.

89 Giorgio Agamben, Profanierungen, aus dem Italienischen von Marianne Schneider, Frankfurt a.M. 2005, S. 60.

90 Siehe etwa Martin Baisch, »Textualität - Materialität - Materialität - Textualität. Zugänge zum mittelalterlichen Text«, in: Literaturwissenschaftliches Jahrbuch 54 (2013), S. 9-30; Christian Benne, »Aporetik der Materialität und Philosophie der Philologie - 
bezeichnete in den Philologien zunächst die Abstraktion einer "Äußerlichkeit der Schrift «" ${ }^{91}$, welche als Prädikat dieses Zeichensystems herausgestellt wurde, um es dem Logozentrismus zu entziehen. Unter dem Einfluss der französischen "critique génétique« entwickelte sich ein auf Handschriften konzentriertes Interesse am literarischen Schreibprozess, um dessen Erforschung es heute in der Regel geht, wenn die Materialität von Literatur fokussiert wird. Das hat zu einer enormen Aufwertung der Editionsphilologie im Feld hermeneutisch-interpretativer Textwissenschaften geführt. ${ }^{92}$ Parallel bildete sich ausgehend von Rüdiger Campes Überlegungen zur "Schreibsze-

läßt sich mit Handschriften philosophieren?«, in: Text. Kritische Beiträge 14 (2014), S. 321; Thomas Bremer (Hg.), Materialitätsdiskurse der Aufklärung. Bücher-Dinge-Praxen, Halle 2016; Cathy Burnett, Guy Merchant, Kate Phal, Jennifer Roswell, »The (im)materiality of literacy. The significance of subjectivity to new literacies research«, in: Discours. Studies in the cultural politics of education 35 (2014), 1, S. 90-103; Hans Peter Hahn, Materielle Kultur. Eine Einführung, 2. Aufl., Berlin 2014; Jacob Haubenreich, »The materiality of the manuscript. Textual production in Rainer Maria Rilke's Berner Taschenbuch «, in: Hannes Bajohr u.a. (Hg.), The Future of Philology. Proceedings of the 11th Annual Columbia University Cerman Graduate Student Conference, Cambridge 2014, S. 162-182; Markus Hilgert, »Praxeologisch perspektivierte Artefaktanalysen des Ceschriebenen«; Stephan Kammer, »Visualität und Materialität der Literatur «, in: Claudia Benthien, Brigitte Weingart (Hg.), Literatur und visuelle Kultur, Berlin, New York 2014, S. 31-47; Christina Lupton, »Gender and Materiality on the Eigteenth-Century Page«, in: SEL. Studies in English Lierature 1500-1900 54 (2014), 3, S. 770-771; Thomas Meier, Michael R. Ott, Rebecca Sauer (Hg.), Materiale Textkulturen. Konzepte-Materialien-Praktiken, Berlin u.a. 2015; Sabine Reh, Denise Wilde (Hg.), Schreiben- und Lesenlernen in der Schule der Moderne: Praktiken-Medien - Materialitäten, Bad Heilbrunn 2016; Stefanie Samida, Manfred K. H. Eggert, Hans Peter Hahn (Hg.), Handbuch Materielle Kultur. Bedeutungen - Konzepte-Disziplinen, Stuttgart 2014; Spoerhase, »)Manuscript für Freunde«; Ulrike, Gleixner Constanze Baum, Jörn Münkner, Hole Rößler (Hg.), Biographien des Buches, Göttingen 2017; Susanne Scholz, Ulrike Vedder, Handbuch Literatur \& Materielle Kultur, Berlin, Boston 2018; Jutta Müller-Tamm, Caroline Schubert, Klaus Ulrich Werner (Hg.), Schreiben als Ereignis. Künste und Kulturen der Schrift, Paderborn 2018.

91 David E. Wellberry, »Die Äußerlichkeit der Schrift«, in: Hans Ulrich Gumbrecht, Karl L. Pfeiffer (Hg.), Schrift, München 1993, S. 337-348.

92 Vgl. Per Röcke, »Schreibgründe. Die Materialität des Papiers zwischen skripturaler und editorischer Praxis«, in: Variations 17 (2009), S. 143-154; Martin Schubert (Hg.), Materialität in der Editionswissenschaft, Berlin, New York 2010; Rüdiger Nutt-Kofoth, Wolfgang Lukas, Madleen Podewski (Hg.), Text-Material-Medium. Zur Relevanz editorischer Dokumentationen für die literaturwissenschaftliche Interpretation, Berlin u.a. 2014. 
ne ${ }^{93}$ ein im Hinblick auf die materiale Dimension von Autorschaft überaus fruchtbares Forschungsfeld heraus. ${ }^{94}$ Geht es um gedruckte Bücher und Autorschaft, so hat diesem Verhältnis in Deutschland die Sozialgeschichte der Literatur erstmals gesteigerte Aufmerksamkeit geschenkt, im englischsprachigen Raum wären die hierzulande eher unbeachtete »Bibliography« und Historiker wie Richard Darnton, in Frankreich vor allem Roger Chartier zu nennen. ${ }^{95}$

Gegenwärtig untersuchen die Philologien unter dem Begriff der Materialität gleichermaßen Handschriften wie gedruckte Artefakte. ${ }^{96}$ Sie beteiligen sich neben anderen Disziplinen an der von Reckwitz beschriebenen »Materialisierung des Kulturellen«:

»Auf verschiedenen und zunächst scheinbar kaum miteinander zusammenhängenden Ebenen sind die Kulturwissenschaften dabei, Materialitäten zu entdecken und deren notwendige Verquickung und Vernetzung mit jenem Sinnhaften und Symbolischen, das klassischerweise als Sphäre des Kulturellen wahrgenommen wurde. ${ }^{97}$

Erkenntnistheoretisch stellt das die Literaturwissenschaften vor eine besondere Herausforderung. Während andere Fächer bemüht sind, ihre Objekte

93 Rüdiger Campe, »Die Schreibszene, Schreiben« (1991), in: Sandro Zanetti (Hg.), Schreiben als Kulturtechnik. Crundlagentexte, Berlin 2012, S. 269-282.

94 Siehe Martin Stingelin (Hg.), »Mir ekelt vor diesem tintenklecksenden Säkulum«. Schreibszenen im Zeitalter der Manuskripte, München 2004.

95 Die anglo-amerikanische »Bibliography« im deutschsprachigen Raum produktiv gemacht hat u.a. Uwe Jochum, »Textgestalt und Buchgestalt. Überlegungen zu einer Literaturgeschichte des gedruckten Buches«, in: LiLi 26 (1996), H. 103, S. 20-34. Siehe zu den genannten Autoren z.B. Robert Darnton, Literaten im Untergrund. Lesen, Schreiben und Publizieren im vorrevolutionären Frankreich, Frankfurt a.M. 1988; Robert Darnton, Die Wissenschaft des Raubdrucks. Ein zentrales Element im Verlagswesen des 18. Jahrhunderts, München 2003; Roger Chartier, Guglielmo Cavallo (Hg.), Die Welt des Lesens: Von der Schriftrolle zum Bildschirm, Frankfurt 1999; Roger Chartier, The Author's Hand and the Printer's Mind. Transformations of the Written Word in Early Modern Europe, Cambridge 2013.

96 Stellvertretend genannt seien Benne, Die Erfindung des Manuskripts, und Carlos Spoerhase, Das Format der Literatur. Praktiken materieller Textualität zwischen 1740 und 1830, Göttingen 2018.

97 Andreas Reckwitz, »Die Materialisierung der Kultur«, in: Friederike Elias, Albrecht Franz, Henning Murmann u.a. (Hg.), Praxeologie: Beiträge zur interdisziplinären Reichweite praxistheoretischer Ansätze in den Ceistes- und Sozialwissenschaften, Berlin, Boston 2014, S. 13-28, hier: S. 13. 
zum Sprechen zu bringen, müssen Bücher als schriftsprachliche Medien eher zum Schweigen gebracht werden, um sich auf ihre Materialität einlassen zu können. Aufgrund ihrer textbasierten Medialität lassen sie sich schwer als reines Ding (Latour) begreifen oder dem »Nichthermeneutischen ${ }^{98}$ (Gumbrecht) zuschlagen.

Im »Handbuch Materielle Kultur « wird in Zweifel gezogen, dass die Materialität von Büchern und anderen Objekten aus dem Bereich der literarischen Produktion überhaupt in den Gegenstandsbereich der Literaturwissenschaft fällt. ${ }^{99}$ Eine Literaturwissenschaft, die praxeologisch vorgeht, muss klären, wie sie mit den Artefakten umgeht, die ins Feld der Literatur gehören, allen voran Büchern, deren textbasierte Medialität sie von anderen materiellen Gegenständen unterscheidet. Sobald sie in Praktiken eingebunden sind, treten Bücher als Artefakte in eine zweite Sphäre der Bedeutung ein, die unabhängig ist von der Schrift. Somit erfahren sie im Nebeneinander von Materialität und textbasierter Medialität eine doppelte Signifikation, die sich nur mit einem philologisch-kulturwissenschaftlichen Instrumentarium hinreichend analysieren lässt.

Zum anderen gehört es zu den genuinen Kompetenzen der Literaturwissenschaft, durch schriftliche Quellen vermittelte Praktiken in ihrer Textualität wahrzunehmen und zu analysieren. Wenn wir Praktiken historisieren, ist dies zu einem erheblichen Teil ausschließlich anhand von Texten möglich. ${ }^{100}$ Und sei es nur, dass diese uns über den Umgang mit Artefakten aufklären.

98 Hans Ulrich Gumbrecht, Diesseits der Hermeneutik. Die Produktion von Präsenz, Frankfurt a.M. 2004, insbes. S. 17-37.

99 Dorothee Kimmich, Art. »Literaturwissenschaft«, in: Stefanie Samida, Manfred K. H. Eggert, Hans Peter Hahn (Hg.), Handbuch Materielle Kultur. Bedeutungen - Konzepte Disziplinen, Stuttgart 2014, S. 305-308, hier: S. 305.

100 Siehe zur Praxistheorie in der Ceschichtswissenschaft u.a. Marian Füssel, »Die Rückkehr des >Subjekts in der Kulturgeschichte. Beobachtungen aus praxeologischer Perspektive«, in: Stefan Deines, Stephan Jaeger, Ansgar Nünning (Hg.), Historisierte Subjekte - Subjektivierte Historie. Zur Verfügbarkeit und Unverfügbarkeit von Ceschichte, Berlin 2003, S. 141-159, ders., Celehrtenkultur als symbolische Praxis. Rang, Ritual und Konflikt an der Universität der Frühen Neuzeit, Darmstadt 2006, ders., Thomas Weller (Hg.), Ordnung und Distinktion. Praktiken sozialer Repräsentation in der ständischen Cesellschaft, Münster 2005, ders., »Praktiken historisieren. Ceschichtswissenschaft und Praxistheorie im Dialog«, in: Anna Daniel, Frank Hillebrandt, Franka Schäfer (Hg.), Methoden einer Soziologie der Praxis, Bielefeld 2015, S. 267-287; Arndt Brendecke (Hg.), Praktiken der Frühen Neuzeit. Akteure-Handlungen-Artefakte, Köln 2015. 
Wie aber gehen wir in diesem Zusammenhang mit Rhetorik und Gattungspoetik um, wie ordnen wir die metaphorische Beschreibung einer Praktik in einem literarischen Text ein, noch dazu im Vergleich mit einem - nicht ohne rhetorische Mittel operierenden - Aktenprotokoll? Wie gehen wir mit dem literarischen Text als Schauplatz von Praktiken um, als Schauplatz, auf dem diese verhandelt werden? Autorschaft bedeutet die Anerkennung als Subjekt, in einer distinkten Form, die um 1800 aufgrund ihrer Prädikate zum Inbegriff aufgeklärter Individualität avanciert. Vor diesem Hintergrund ist es nicht verwunderlich, dass Autorschaft zwischen 1765 und 1815 häufig in Satiren und Parodien verhandelt wird, weil solche Schreibweisen soziale Relationen offenzulegen und zu hinterfragen imstande sind. ${ }^{101}$ Und es bedarf einer literaturwissenschaftlichen Methodik, um darauf adäquat einzugehen.

Die Praxistheorie verfügt über eine soziologische Provenienz. Sie lässt sich mit literatursoziologischen Ansätzen der jüngeren Vergangenheit verbinden, die - avant la lettre - der Materialität des Publizierens galten. Hier wäre erneut die »Bibliography« hervorzuheben, die sich bereits in den 1980er Jahren dem Buchartefakt und insbesondere der Typographie des 18. Jahrhunderts zuwandte, um eine »history of material objects as symbolic forms $\mathrm{zu}$ rekonstruieren und eine "Sociology of Texts « zu entwerfen. ${ }^{102} \mathrm{Im}$ deutschsprachigen Raum widmete sich zur selben Zeit die Sozialgeschichte der Literatur, um deren Erneuerung sich die Philologien seit geraumer Zeit bemühen, um die Herausbildung eines literarischen Marktes und des freien Schriftstellers. $^{103}$

Autorschaft erfuhr späterhin durch Poststrukturalismus und Diskursanalyse auch hierzulande eine starke Theoretisierung. Sie als eine Form moderner Subjektivität zu betrachten, erschien überholt. Der von Roland Barthes verkündete »Tod des Autors ${ }^{104}$ entwickelte sich zu einem Gemeinplatz der Literaturwissenschaften. Jedoch überdauerte der Autor als ein Untoter der

101 Insbesondere die Satire eröffnet einen Schauplatz, auf dem kulturelle Praktiken verhandelt werden, wie Marian Füssel in Bezug auf die soziale Distinktion innerhalb der Studentenschaft der Frühen Neuzeit herausarbeitet. (Füssel, »Praktiken historisieren«, S. 276f.)

102 Donald F. McKenzie, Bibliography and the Sociology of Texts, Cambridge 1999, S. 22.

103 Jörg Schönert, »Professionalisierung der Schriftsteller? Zu Praxisformen und Reflexionstypen des Schriftstellerberufs zwischen 1850 und 1920«, in: ders., Perspektiven zur Sozialgeschichte der Literatur. Beiträge zu Theorie und Praxis, Berlin u.a. 2007, S. 161-182.

104 Roland Barthes, »Der Tod des Autors«, in: Fotis Jannidis, Gerhard Lauer, Matias Martinez, Simone Winko (Hg.), Texte zur Theorie der Autorschaft, Stuttgart 2000, S. 185-193. 
Theoriebildung. Seine Verabschiedung belebte den Autorschaftsdiskurs ungemein. 1999 riefen Fotis Jannidis u.a. programmatisch die »Rückkehr des Autors « aus. ${ }^{105}$ Die aktuelle Forschung zu literaturbezogenen Materialitäten, die in einem hohen Maße editionsphilologisch orientiert ist, handelt mit großer Selbstverständlichkeit vom Autor als realexistierender Figur der Literaturgeschichte.

Die Praxistheorie ermöglicht es wiederum, in größeren Zusammenhängen und abstrahierend das Verhältnis zwischen gedruckten Artefakten und Autorschaft als Subjektform zu erörtern. ${ }^{106}$ Das soll in den folgenden Kapiteln geschehen. Sie widmen sich der materialen Seite des Schreibens und Publizierens in der deutschsprachigen Literatur zwischen 1765 und 1815 mit Blick auf die "Praxis-/Diskursformationen« der Autorschaft. Dabei konzentriert sich das Erkenntnisinteresse durchgängig auf Jean Paul, punktuell auf die Schriften von Georg Christoph Lichtenberg und Friedrich Nicolai. Die genannten Autoren erscheinen für die Fragestellungen der vorliegenden Arbeit besonders aufschlussreich und exemplarisch, sie bieten eine Orientierung im weiten Feld der Materialität von Literatur. Ihre Schriften fügen sich in ein breites und über fiktionale Texte hinausgehendes Korpus, das die Möglichkeit einer praxeologischen und diskursgeschichtlichen Rekonstruktion der materialen Bedingtheit literarischer Autorschaft eröffnet. Materialität wird dabei in ihren ästhetischen, merkantilen, poetologischen sowie juridischen Dimensionen betrachtet.

105 Fotis Jannidis, Gerhard Lauer, Matias Martinez, Simone Winko (Hg.), Rückkehr des Autors. Zur Erneuerung eines umstrittenen Begriffs, Tübingen 1999.

106 Matthias Schaffrick und Marcus Willand sehen in einem solchen Ansatz das Potenzial einer »praxeologischen Erdung «des theoretischen Nachdenkens über Autorschaft. Sie schreiben: »Die sozialgeschichtliche Perspektive auf Autorschaft, die immer von realen Autorinnen und Autoren ausgeht, erscheint uns gerade angesichts der im letzten Jahrzehnt verstärkt theoretisch geführten Diskussion um den Autor als Konstrukt ein wichtiges Element der praxeologischen Erdung und Rückbindung theoretischer Autorschaftskonzeptionen an und durch die (historische) Wirklichkeit auktorialer Erscheinungsformen zu sein. «(Matthias Schaffrick, Marcus Willand, »Autorschaft im 21. Jahrhundert. Matthias Schaffrick und Marcus Willand«, in: dies. (Hg.), Theorien und Praktiken der Autorschaft, Berlin, Boston 2014, S. 3-150, hier: S. 37). 



\section{Handgeschriebene Bücher}

\subsection{Aus der »Taschendruckerei«: Zur Mimesis buchspezifischer Materialität}

Um ein Buch zu machen, braucht es um 1800 nicht viel: ein wenig Papier, einfache Werkzeuge zum Schneiden und Lochen, einen Faden und geschickte Hände. Denn: »Mehrere zu einem Ganzen verbundene Blätter Papier oder Pergament $\aleph^{1}$ ergeben - nach dem Wörterbuch von Johann Christoph Adelung - ein Buch. Somit eignet sich das Büchermachen zum Kinderspiel, das in Jean Pauls literarischer Autobiographie, der 1826 als Fragment aus dem Nachlass publizierten »Selberlebensbeschreibung«, auch als solches beschrieben wird:

»Den gegenwärtigen Schriftsteller zeigte schon im kleinen eine Schachtel, in welcher er eine Etui-Bibliothek von lauter eignen Sedezwerkchen aufstellte, die er aus bandbreiten Papierabschnitzeln von den Oktavpredigten seines Vaters zusammennähte und zurechtschnitt. Der Inhalt war theologisch und protestantisch und bestand jedesmal aus einer aus Luthers Bibel abgeschriebenen kleinen Erklärnote unter einem Vers [...].«(SW I.6, 1058)

Freilich liegt der Reiz dieses Kinderspiels ${ }^{2}$ in der Bastelarbeit, aber mehr noch in der Nachahmung eines Artefakts, mit dessen kultureller Bedeutung als Objekt und Medium der Pfarrerssohn Jean Paul nicht zuletzt durch »Luthers Bibel« früh vertraut ist: dem gedruckten Buch.

$1 \quad$ Art. »Das Buch «, in: Johann Christoph Adelung (Hg.), Grammatisch-kritisches Wörterbuch der Hochdeutschen Mundart mit beständiger Vergleichung der übrigen Mundarten, besonders aber der oberdeutschen, 2. Aufl., Leipzig 1793-1801, I, Sp. 1235-1237, hier: Sp. 1235. Siehe Monika Schmitz-Emans, »Kinderfiguren, Kindheitsorte, Kinderspiele und Kinderzeit bei Jean Paul«, in: Caroline Roeder (Hg.), Topographien der Kindheit. Literarische, mediale und interdisziplinäre Perspektiven auf Orts- und Raumkonstruktionen, Bielefeld 2014, S. 283-300. 
Auch in der Erzählung vom »Leben des vergnügten Schulmeisterlein Maria Wutz in Auenthal«, die Jean Pauls »Unsichtbarer Loge« (1793) beigegeben war, findet sich unter den Habseligkeiten des Protagonisten »eine Schachtel mit Zwerg-Büchelchen in 128-Format« (SW I.1, 455). Wutz erkennt darin einen »Schriftstellertrieb« (Ebd.), dem er als Erwachsener folgt, wenn er »eine ganze Bibliothek [...] sich eigenhändig [schreibt]«(SW I.1, 425). Als Vorlage dienen ihm die im Messkatalog angezeigten Titel, die für ihn unerschwinglich sind, so dass Wutz sein »Schreibzeug« als »Taschendruckerei« gebrauchen und die begehrten Bücher selbst herstellen muss (Ebd.). Dem Akt des Schreibens kommt in dieser Konstellation eine bemerkenswerte Rolle zu: Nimmt sich Wutz ein Werk vor, das in "Querfolio« erschienen ist, legt er »seinen Bogen in die Quere hin« (SW I.1, 426). Um zu schreiben wie Klopstock, nämlich unverständlich, schneidet Wutz seine Feder so zu, dass seine Handschrift unleserlich wird. Schließlich wird er zum Besitzer einer »ansehnlichen Büchersammlung, die, wie die heidnischen, aus lauter Handschriften bestand« (SW I.1, 426).

In diesem Kapitel geht es um handgeschriebene Bücher im Nachlass Jean Pauls und in zwei seiner literarischen Texte: der fiktiven Biographie von Maria Wutz und dem »Leben des Quintus Fixlein« (1796/1801). Gemeint sind mit handgeschriebenen Büchern weder Manuskripte, die für den Druck bestimmt sind, noch Schreibe-Bücher, die für Notizen und andere Aufzeichnungen angelegt werden. Vielmehr handelt es sich bei diesen handgeschriebenen Büchern um außergewöhnliche Artefakte, die in einem mimetischen Verhältnis zu gedruckten Büchern und auch Periodika stehen.

Der Druck markiert in der angedeuteten Konstellation nicht nur eine Referenz, sondern eine entscheidende Differenz. Die technische Reproduktion von Texten ist grundlegend für das gedruckte Buch als Objekt und zugleich die Voraussetzung seiner Publizität. Darüber hinaus konstituiert der Druck Autorschaft ${ }^{3}$ und fungiert als Repräsentationsform der Gelehrsamkeit, wie das von Johann Georg Meusel um 1800 herausgegebene Nachschlagewerk »Das gelehrte Teutschland« zeigt. ${ }^{4}$ Meusel verspricht, einen jeden »Büchermacher ${ }^{5}$ in sein »Lexikon der jetzt lebenden teutschen Schriftsteller « aufzunehmen. Einziges Kriterium ist der Druck eines umfangreicheren Textes. kommt«, in: Zeitschrift für Ideengeschichte 4 (2010), 4, S. 14-22, hier: S. 15.

4 Vgl. Fuchs, Büchermachen, S. 25-26.

5 Hamberger, Meusel, Das gelehrte Teutschland, 5. Ausg., XII (1806), S. LXIX. 
Aber auch dem Verfasser kleinerer Schriften nimmt der Historiker nicht die Hoffnung, in seinem Autorenlexikon berücksichtigt zu werden: »Er komme herein, indem er nach und nach eben so viel Papier verdrucken lässt, als ein andrer, der gleich mit einem dicken Band auftritt. $\ll^{6}$

Medienhistorisch erfüllen Manuskripte bis zur Durchsetzung des Buchdrucks mit beweglichen Lettern die Funktion des gedruckten Buches, jedoch wird »dem handschriftlich Vervielfältigten [...] schon bald nach der Umstellung auf die Typographie der Anspruch auf Öffentlichkeit abgesprochen: der Begriff des Publizierens impliziert nun Druckschriftlichkeit «. ${ }^{7}$ Zwar gibt es im 18. Jahrhundert noch immer handgeschriebene Zeitungen (mit denen Jean Paul als "Zeitungsmacher in seinem Bekanntenkreis experimentiert) ${ }^{8}$ und auch halböffentlich zirkulierende Manuskripte ${ }^{9}$, doch ist bereits von einem "medialen Denkhorizont « auszugehen, den Carlos Spoerhase als modern charakterisiert und »in dem Handschriftlichkeit primär in Abgrenzung zum Druckwesen konstruiert wird, das [...] wiederum sehr eng an Konzeptionen

6 Hamberger, Meusel, Das gelehrte Teutschland, 5. Ausg., XII (1806), S. LXIX.

7 Rautenberg, Wetzel, Buch, S. 54.

8 Holger Böning, ")Cewiss ist es/dass alle gedruckte Zeitungen erst geschrieben seyn müssen<. Handgeschriebene und gedruckte Zeitungen im Spannungsfeld von Abhängigkeit, Koexistenz und Konkurrenz«, in: Daphnis 37 (2008), S. 202-242, hier: S. 234-237. $\mathrm{Zu}$ Jean Paul handgeschriebenen Zeitungen siehe Magnus Wieland, Vexierzüge. Jean Pauls Digressionspoetik, Hannover 2013, S. 216ff. »]ean Paul«, so Wieland, »startet seine literarische Karriere nicht als Autor, sondern als `Zeitungsmacher zunächst auch kein Werk oder Buch, sondern ein Blatt - genauer und konsequenter sogar: Blätter. In seiner Frühphase kleidet Jean Paul seine satirischen Versuche in die Form von `Zeitungsblättern`, die er nicht drucken, sondern als Briefmanuskripte in seinem Freundeskreis zirkulieren lässt [...] «(Ebd., 216). Unter diesen »Blättern « findet sich u.a. eine »Höfer Festtagszeitung«, zu der sich Jean Paul als »Höfer Zeitungsmacher« in einem Brief vom 26. Dezember 1785 an die Brüder Otto erklärend zu Wort meldet, indem er sich selbst ein Zitat in den Mund legt, das da lautet: »Wie, sagt ich, London hat seine Daily Post, Paris seine Nouvelles à la main und Wien sein Neuigkeitenblat im Manuskript? Mich dünkt, Hof sollte etwas ähnliches haben und man findet glüklicher weise an mir den Man, der sich ganz dazu schikket. « (HKA III.1, 198, 196 [185]) Diese literarischen Spiele mit der Publikationsform der handgeschriebenen Zeitung lassen sich in Verbindung bringen mit den früheren »Übungen im Denken«, die sich wiederum mit Blick auf ihre paratextuelle Ordnung auf Exzerpte der Jahre 1778 bis 1781 zurückführen lassen, wie im Folgenden gezeigt werden soll.

9 Zum intrikaten Verhältnis zwischen Manuskript und Druck im 18. Jahrhundert siehe Benne, Die Erfindung des Manuskripts. 
der Buchförmigkeit und des Publikationscharakters des Drucks gebunden ist «. ${ }^{10}$

Jean Pauls handgeschriebene Bücher sind keine Sonderformen des $\mathrm{Pu}$ blizierens, keine manuellen Vervielfältigungen, sondern Unikate, die den Anschein von Publikationen erwecken sollen. Durch Nachahmung wird eine Annäherung an die Buchform betrieben, so dass Handschriftlichkeit in diesem Fall gerade nicht »in Abgrenzung vom Druckwesen konstruiert wird«. Sowohl bei Jean Paul selbst als auch in seinen literarischen Texten gehören die handgeschriebenen Bücher zum Bestand von Privatbibliotheken, sie repräsentieren als Nachahmungen ein mediengebundenes Wissen und dienen der Selbstinszenierung ihrer Produzenten. Zugleich stellt sich bei der Betrachtung dieser Artefakte stets die Frage, wie sich die Handschrift zur Typographie verhält. Das gilt auch im Hinblick auf die Praxis des Schreibens. Schreiben erweist sich als ein Akt der Nachahmung buchspezifischer Materialität, was zu der Frage führt, wie sich eine solche Praxis kulturhistorisch einordnen lässt.

Der erste Abschnitt dieses Kapitels befasst sich mit dem Nebeneinander von gedruckten Büchern und handschriftlichen Aufzeichnungen in der Privatbibliothek Jean Pauls. Ein besonderes Augenmerk liegt dabei auf der blauen Reihe der frühen Exzerpte aus den Jahren 1778 bis 1781, die sich aufgrund ihrer visuellen Gestaltung als handgeschriebene Bücher in den Blick nehmen lassen. Diese Nachahmungen erfüllen zwei Funktionen:

a) Paratextuelle Ordnung des Wissens: Jean Paul ordnet seine weitläufigen Abschriften aus Büchern und Zeitschriften, indem er seine Exzerpte mit Paratexten ausstattet, die für diese Publikationsformen charakteristisch sind.

b) Teilhabe an einer mediengebundenen Wissenskultur: Die Nachahmung gedruckter Bücher ermöglicht es Jean Paul, ohne nennenswerten Buchbesitz an einer mediengebundenen Wissenskultur teilzuhaben, wenn auch

10 Carlos Spoerhase, »The Manuscript Book in the Age of sEmpfindsamkeit< ( Sentimentalism`). Caroline Flachsland's und Johann Cottfried Herder's >Silver Book«, in: Archiv für Ceschichte des Buchwesens 69 (2014), S. 59-75, hier: S. 60. Dass Handschriftlichkeit auch semantisch in »Abgrenzung « zum Druck bestimmt wird, belegt der Art. »Handschriftlich«, in: Adelung, Grammatisch-kritisches Wörterbuch, II, Sp. 958-959, hier: Sp. 958f. (»Ceschrieben, im Gegensatze des Gedruckten. Ein Buch, welches nur handschriftlich vorhanden ist, in Handschriften«). 
nur symbolisch bzw. in Form einer Imagination, die ich als papierne Fiktion beschreibe.

Daran anknüpfend wird im zweiten Abschnitt das Schreiben als Akt der Nachahmung einer vornehmlich »visuelle[n] Materialität «" ${ }^{11}$ in einem kulturhistorischen Zusammenhang betrachtet. Abschließend stehen die handgeschriebenen Bücher in Jean Pauls fiktiven Biographien des Schulmeisterlein Wutz und des Quintus Fixlein im Fokus.

\subsection{Die blaue Reihe in Jean Pauls Privatbibliothek}

Jean Pauls Privatbibliothek versetzt seine Besucher immer wieder in Erstaunen. Nachdem er den als so belesen geltenden Schriftsteller in seinem Arbeitszimmer besucht hat, notiert sich der Theologe und Philologe Johann Friedrich Abegg im Mai 1798: »Seine Bibliothek ist sehr schwach, diese steht gleich an der Türe und ist nicht gehörig geordnet. ${ }^{12}$ Ein anderer Besucher schreibt: "Jean Paul hat fast kein Buch selbst, er leiht und exzerpiert sie bloß. « ${ }^{13}$ Umso augenfälliger sind die Unmengen an handschriftlichen Aufzeichnungen, mit denen sich Jean Paul umgibt, allen voran: seine Exzerpte. Diese Leseaufzeichnungen führt Jean Paul seinen Besuchern gerne vor, so auch dem Arzt Karl Bursy:

»]ean Pauls Bibliothek ist ebensogut medizinisch als juristisch und theologisch, und er zeigte mir auf seinem Schreibtisch Bücher des heterogensten Inhalts, die er eben jetzt läse. Vor allem machte er mich auf einige Bände auf-

Stephan Kammer hat die »visuelle Materialität« der Literatur in einem sehr erhellenden Aufsatz herausgearbeitet. Laut Kammer bezieht sich das Interesse beim Blick auf die »visuelle Materialität« auf die »Wahrnehmung und Thematisierung des buchstäblich Augenfälligen [...], das Schriftformen und Tintenfarben, Drucktypen und die Hinterlassenschaften unterschiedlichster Schreibwerkzeuge, Layout und Buchgestaltung zur Erscheinung bringen « (Kammer, »Visualität und Materialität der Literatur«, S. 34). »]ohann Friedrich Abegg, Tagebuch [6. Mai 1798] «, in: Eduard Berend (Hg.), Jean Pauls Persönlichkeit in Berichten der Zeitgenossen, Weimar 1956, S. 27-32 [Nr. 44], hier: S. 28.

13 »Martin Hieronymus Hudtwalker an Wolf von Baudissin, Bayreuth, 3. Mai 1809«, in: Berend, Jean Pauls Persönlichkeit, S. 110 [Nr. 174]. 
merksam, die sehr ge- und verbraucht schienen. Sie waren Quart mit Schlußösen, wie man die Taschenbücher macht. ${ }^{14}$

In wörtlicher Rede lässt Bursy den Schriftsteller kommentieren, was es mit diesen Bänden auf sich hat: ")Diese Bücher gebe ich Ihnen nicht für eine Bibliothek von 200.000 Bänden; es sind meine Exzerpte, zu denen noch ein Real- und ein Verbalregister gehört. « ${ }^{15}$ Auch Abegg, der erste Besucher in dieser Reihe, kommt in seinen Erinnerungen auf die Leseaufzeichnungen zu sprechen. »Gegen das eine Fenster ist ein langer Tisch gestellt; zur Rechten hat er ein Gestell mit Brettern, auf welchen von oben bis unten Mappen, als wäre er ein Advocat, liegen«, beschreibt Abegg das »Arbeitszimmer« von Jean Paul in Leipzig, ehe er die »Mappen«, bei denen es sich höchstwahrscheinlich um die Exzerpte handelt, ins Verhältnis setzt zur Büchersammlung, über die er im folgenden Satz erklärt, sie sei »sehr schwach«.

Abegg wird von Jean Paul am 6. Mai 1798 empfangen. Das geht aus seinem Reisetagebuch hervor. ${ }^{16}$ In den Tagen davor ist Abegg unter anderem Fichte begegnet, in Weimar haben ihn Karl August Böttiger, Goethe und Herder in ihren Privaträumen empfangen. Nun ist er in Leipzig angekommen, im bescheidenen Reich von Jean Paul. Obwohl er in Weimar ausnahmslos bei Eigentümern stattlicher Bibliotheken zu Gast gewesen ist, von Bibliotheken, die auch Jean Paul - abgesehen von derjenigen Goethes - später eifrig nutzen wird $^{17}$, finden diese umfangreichen Büchersammlungen bei Abegg keinerlei Erwähnung. Umso bemerkenswerter ist es, dass der Reisende ausgerechnet auf die Bibliothek Jean Pauls zu sprechen kommt. Dass diese »sehr schwach« ist, wie Abegg schreibt, sieht er einem besonderen »Umstande« geschuldet, über den er sich bei einer zweiten Begegnung mit Jean Paul austauschen wird.

Jean Paul hat zu diesem Zeitpunkt schon einige Berühmtheit erlangt, vor allem als Verfasser des »Hesperus« (1795) und als jemand, der seine Leserschaft »eine Reihe von philosophischen, physischen, historischen Diktionnairen an der Hand zu haben nötigt « ${ }^{18}$, wie ein Rezensent kritisch anmerkt.

14 »Karl Bursy, Tagebuch [14./15. Mai 1816]«, in: Berend, Jean Pauls Persönlichkeit, S. 146-155 [Nr. 201], hier: S. 151.

15 Ebd.

16 Johann Friedrich Abegg, Reisetagebuch von 1798, hg. v. Walter Abegg, Jolanda Abegg, Frankfurt a.M. 1987.

17 Günther Soffke, Jean Pauls Verhältnis zum Buch, Bonn 1969, S. 17.

18 [Anonymus], Rezension über »Siebenkäs« und »Biographische Belustigungen« (1797), in: Peter Sprengel (Hg.), Jean Paul im Urteil seiner Kritiker. Dokumente zur Wirkungsgeschichte Jean Pauls in Deutschland, München 1980, S. 10-12, hier: S. 12. 
Damit stellt sich unweigerlich die Frage, worauf sich das ungeheure Wissen dieses Autors stützt. Jean Paul liefert eine beredte Antwort, und zwar in Form des berühmten, im Jahr 1797 im »Taschenkalender zur belehrenden Unterhaltung für die Jugend und ihre Freunde« veröffentlichten Textes »Die Taschenbibliothek«. Darin öffnet der erstaunlich belesene Tanzmeister Aubin seinen »Bücherschrank«, in dem sich keinerlei Bücher befinden, dafür aber Exzerpte. Als Aubin näher erläutert, wie er diese anfertigt, ist es um seinen Zuhörer geschehen: »Ich mußte hier den Mann, dessen Herz für alles Wissen brannte, an das meinige drücken und es ihm gestehen, daß ich beinahe auf demselben Wege seit dem 14ten Jahre gehe.«(SW III.2, 771, 772)

Dass in dieser Dichtung eine biographische Wahrheit steckt, zeigt ein Porträt im »Deutschen Magazin«, erschienen im Februar 1798, also wenige Monate, bevor Abegg das Arbeitszimmer von Jean Paul betritt. Johann Friedrich Schütze, der Verfasser, nimmt »Die Taschenbibliothek « zum Anlass, das Exzerpieren als Praxis des Schriftstellers herauszustellen. Schütze offenbart sich dabei nicht bloß als aufmerksamer Leser, sondern auch als stolzer Besitzer eines der »Richterschen Excerptenbücher ${ }^{19}$

Es ist also davon auszugehen, dass Johann Friedrich Abegg im Mai 1798 in Leipzig seinen Blick nicht ohne Vorwissen durch das Arbeitszimmer schweifen lässt, sondern dass er mit einem bestimmten Fokus die »Mappen« und schließlich die Bibliothek Jean Pauls fixiert. Das unterstreicht seine zweite Begegnung mit Jean Paul im Rudolphischen Garten:

» Sie haben<, sagte ich, da wir über eine Stunde im Garten auf und ab gingen, seinmal etwas von Ihren Ceheimnissen offenbart [...]; nämlich haben Sie irgendwo gesagt, wie Sie studieren, wenn ich es so nennen darf? «->]a, das habe ich<, sagte er, >und es ist gar kein Geheimnis. Es besteht im Exzerpieren. Wohl exzerpieren muß man, und alle Schriften, die man lieset: sonst fällt alles durch und nützt wenig. Aber gute Exzerpte machen große Bibliotheken entbehrlich. $\ll^{20}$

Jean Paul starb 1825, und während wir wissen, was mit seinem handschriftlichen Nachlass geschehen ist, liegt das Schicksal seines Buchbesitzes im Dunkeln. Dass die Privatbibliothek des Schriftstellers im Vergleich mit seinen Auf-

\footnotetext{
19 Johann Friedrich Schütze, »]ean Paul Friedrich Richter«, in: Deutsches Magazin 15 (1798), S. 97-119, hier: S. 116.

20 »ohann Friedrich Abegg, Tagebuch [6. Mai 1798]«, in: Berend (Hg.), Jean Pauls Persönlichkeit, S. 30.
} 
zeichnungen bis heute so wenig Aufmerksamkeit auf sich gezogen hat, passt zu der von Jean Pauls Besuchern geschilderten Nachlässigkeit des Dichters im Umgang mit seinen Büchern und letztlich zur Überlieferung: Jean Paul hat der Nachwelt offenbar keine Bibliothek hinterlassen, jedenfalls verliert sich nach seinem Ableben die Spur seiner Bücher. Ein Bestandskatalog ist nicht bekannt, über eine mögliche Versteigerung seiner Bücher sind Quellen nicht zu finden. Auch sein Nachlass liefert nur wenige Hinweise, ein Nachlass, der so reich ist an Manuskripten aller Art, in dem sich aber kein einziges gedrucktes Buch findet. Obwohl es sich bei Jean Paul um einen Schriftsteller handelt, dessen Belesenheit als legendär gilt, scheint der Autor selbst keinen gesteigerten Wert auf den Aufbau und die Pflege einer eigenen Büchersammlung gelegt zu haben. Zum Vergleich: 1829, vier Jahre nach dem Tod Jean Pauls, steht im Norden Deutschlands die beeindruckende Bibliothek eines anderen verschiedenen Schriftstellers zum Verkauf, die 12.000 Bände umfassende Kollektion von J.G. Müller aus Itzehoe, genauestens erfasst in einem gedruckten Katalog, der auch Hinweise darauf enthält, wie Müller seinen Bestand generell kennzeichnete und mit Annotationen versah. ${ }^{21}$ Freilich erscheint ein direkter Vergleich dieser bestens dokumentierten Bibliothek mit derjenigen Jean Pauls alles andere als zwingend zu sein. Bemerkenswert ist dennoch, dass Müller in die Bände seinen Namen eintrug, um sie als sein Eigentum auszuweisen. Darauf scheint Jean Paul angesichts der Tatsache, dass sich so gut wie keine Bücher aus seinem Besitz finden lassen, verzichtet zu haben. Dies legt auch das heute einzige bekannte Buch aus seinem Privatbesitz nahe, ein Widmungsexemplar des zweiten Bandes der »Lebens-Ansichten des Katers Murr«, das E.T.A. Hoffmann dem »Herrn LegationsRath Jean Paul, Fridrich Richter « [sic!] am 30. Januar 1822 übersandt hatte. ${ }^{22}$

21 Verzeichniß der von dem Herrn Dr. Ph. Joh. Cottw. Müller in Itzehoe hinterlassenen Bibliothek, [...], Itzehoe 1829. Siehe auch Alexander Ritter, »Der freue und gelehrte Schriftsteller Johann Cottwerth Müller und seine enzyklopädische Privatbibliothek«, in: Ulrich Johannes Schneider (Hg.), Kulturen des Wissens im 18. Jahrhundert, Berlin, New York 2008, S. 221-228.

22 E.T.A. Hoffmann, »An Jean Paul Friedrich Richter in Bayreuth« (30. Januar 1822), in: ders., E.T.A. Hoffmanns Briefwechsel, hg. v. Friedrich Schnapp, München 1967-1969, II (1968), S. 361 [1028]. Der Band befindet sich im Bestand der Staatsbibliothek Bamberg, Signatur Sel. 229a/2. Ich danke Herrn Prof. Dr. Markus Bernauer, Leiter der Jean-PaulEdition an der Berlin-Brandenburgischen Akademie der Wissenschaften, der mich auf dieses Buch aus dem Privatbesitz von Jean Paul aufmerksam gemacht hat. 
Wie viele gedruckte Bücher Jean Paul besaß, darüber lässt sich nur spekulieren. Günther Soffke geht aufgrund einer späten Bemerkung des Autors von etwa 200 Bänden aus. Wie sich dieser Bestand zusammensetzte, ist teilweise anhand von Briefen rekonstruierbar. ${ }^{23}$ In der entsprechenden Korrespondenz findet sich auch die ein oder andere Kuriosität, etwa wenn Jean Paul an seinen Freund Johann Adam Lorenz von Oerthel schreibt: »Möchtest du mir nicht Kants Kritik vorstrekken, nicht um sie ganz durchzulesen, sondern nur um durch deinen Kant die Lükke von etlichen Bogen zu ergänzen, die in meinem ist, den ich wieder lesen will?« (HKA III.I, 182)

Jean Paul, dieser Meister literarischer Buchführung, der Listen und Register, hat seinen Buchbesitz offenbar nicht erfasst, nicht verzeichnet. Eine genauere Aufstellung über seine Bibliothek sucht man im Nachlass vergebens. Es existiert lediglich ein Blatt mit einer über Jahre geführten Liste über »Verliehene Bücher«. Diese umfasst gerade einmal zwei Dutzend Einträge, wobei ein Teil eigene Werke betrifft. ${ }^{24}$ Bereits 1810 notiert Jean Paul ironisch, aber mit dem Selbstbewusstsein des etablierten Schriftstellers: »Ich habe so wenig Bücher, daß ich wie der Sophist Gorgias alles selber gemacht, was ich habe.« (HKA II.8, 583 [236/292])

Im Groben setzt sich die Privatbibliothek zusammen aus:

a) Büchern und Periodika, die Jean Paul sich aus eigenem Antrieb angeschafft oder ohne Barzahlung besorgt hatte. Dazu dürften vor allem philosophische Schriften und Nachschlagewerke zählen, aber auch ausgewählte Titel geschätzter Autoren. ${ }^{25}$

b) Buchgeschenken wie das von E.T.A. Hoffmann, die in der Regel mit einem persönlichen Anliegen verbunden waren. Diese Bücher dienen Jean Paul nicht selten als Tauschobjekte, die er an eine Leihbibliothek abtritt. ${ }^{26}$

c) Leihgaben oder Dauerleihgaben aus öffentlichen und privaten Bibliotheken.

d) Eigenen Werken, die er allerdings nicht vollständig besaß. ${ }^{27}$

e) Exzerpten.

23 Soffke, Jean Pauls Verhältnis zum Buch, S. 23, 25.

24 Siehe »Libri legendi«, HKA, II.6,1, S. 892, sowie HKA II.6,2, S. 205-206.

25 Soffke, Jean Pauls Verhältnis zum Buch, S. $24 \mathrm{f}$.

26 Ebd.

27 Vgl. ebd., S. 28. 
Anzunehmen ist, dass die Mehrzahl der Bücher, die der Besucher Bursy der Privatbibliothek Jean Pauls zuordnet, dem Schriftsteller gar nicht gehörten. Abgesehen von der Bibliothek seines Vaters, die »selten offen« (SW I.6, 1056) ist, wie es in der "Selberlebensbeschreibung« heißt, dürfte die Privatbibliothek des Pfarrers Erhard Friedrich Vogel die erste sein, die Jean Paul regelmäßig nutzt. Zwischen ihm und dem Pfarrer entwickelt sich ein reger Leihverkehr. Als er sein Studium in Leipzig aufnimmt, bemüht sich Jean Paul mehr als einmal, sich gegenüber seinem Leihgeber erkenntlich zu zeigen. Er bietet an, für ihn Kataloge und Bücher zu besorgen, wirbt für Neuerscheinungen wie Kants »Kritik der reinen Vernunft«. Jean Paul ist trotz des eigenen Mangels mit dem Sammeln von Büchern bestens vertraut. Am 8. März 1782 formuliert er in einem Brief an Vogel, er wolle Bücher schreiben, um Bücher kaufen zu können (HKA III.1, 38). Doch auch in späteren Jahren, als ihm die finanziellen Mittel eher zur Verfügung stehen, verzichtet Jean Paul weitgehend auf die Anschaffung von gedruckten Büchern. Stattdessen legt er umfangreiche Listen mit Titeln an, die er lesen möchte und von denen er sich viele leihweise besorgt, um aus ihnen zu exzerpieren. Er borgt sich unablässig Bücher und Periodika bei Privatpersonen, Buchhändlern und Bibliotheken. ${ }^{28}$ Und früh beginnt er damit, sich in Form seiner Exzerpte eine »eigene, handgeschriebene Bibliothek ${ }^{29}$ zusammenzustellen, so Markus Bernauer.

Dass Jean Paul die Exzerpte seiner Privatbibliothek zugerechnet hat, legt ein kurzer, vermutlich 1782 verfasster und im handschriftlichen Nachlass überlieferter Text nahe. Dieser enthält die Beschreibung einer Bibliothek, die sich durchaus autobiographisch lesen lässt. Jean Paul platziert die wenigen Sätze in einem blaugrauen Bändchen mit der Aufschrift »Satiren«. Erstmals veröffentlicht wird der Text viele Jahre später, 1837, unter der Überschrift: »Werthvolle Bibliothek«.

»Meine Bibliothek bestehet theils aus gedruckten, theils aus ungedruckten Büchern. Je mehr Manuscripte in einer Bibliothek, desto mehr Ehre ist es bekanntlich derselben; in der meinigen sind deren mehr, als der gedruckten Bücher. Sie sind von mir abgefasset. $\ll^{30}$

\footnotetext{
28 Ebd., S. 15-22.

29 Markus Bernauer, »Katalog: Lektüren«, in: ders., Angela Steinsiek, Jutta Weber (Hg.), Jean Paul. Dintenuniversum. Schreiben ist Wirklichkeit, Berlin 2013, S. 49-55, hier: S. 49 [Kat. 3.1a].

30 Jean Paul, Werthvolle Bibliothek, Jean Paul's sämmtliche Werke, hg. v. Richard Otto Spazier und Ernst Förster, Berlin 1826-38, LXII.II (1837), S. 136.
} 
Mit der »Werthvollen Bibliothek« spielt Jean Paul vermutlich auf die von ihm hoch geschätzte und wiederholt exzerpierte »Bücherkunde« von Michael Denis an. In ihrem ersten Band von 1777 heißt es über die »Bestandtheile einer Bibliothek«: »Diese Bestandtheile sind Manuscripte, und gedruckte Bücher.« Und im nächsten Satz: »Die Manuscripte verdienen unsre ganze Hochschätzung, weil durch sie alle Gelehrsamkeit des Alterthumes auf uns gekommen ist. « $^{31}$

Die Pointe bei Jean Paul liegt darin, dass die Manuskripte, deren Fülle der eigenen Bibliothek zur Ehre gereichen soll, nicht den historischen Index aufweisen, auf den es Denis ankommt. Zwar entwickelt sich, wie Christian Benne gezeigt hat, um 1800 eine moderne »Manuskriptkultur «, in der autographe Handschriften aus bibliothekarischer Sicht bedeutsam werden, auch ohne einer geschichtlichen Überlieferung zu dienen. ${ }^{32}$ Aber als die »Bücherkunde« im Jahr 1777 publiziert wird, erklärt sich das Nebeneinander von Manuskripten und gedruckten Bücher noch hauptsächlich diachron aus der Medienevolution. In dieser Perspektive werden Manuskripte als Wissensträger vom gedruckten Buch abgelöst. Mit der Erfindung des Buchdrucks mit beweglichen Lettern kommt, so Lothar Müller, »nicht nur das Gedruckte in die Welt, sondern auch das Ungedruckte «33. Selbstverständlich dürften mit den »ungedruckten Büchern« nicht bloß Exzerpte gemeint sein. Aber als Jean Paul

Michael Denis, Einleitung in die Bücherkunde, Wien 1777-1778, I (1777), S. 207 [§ XXXVII]. Benne erkennt in der Vorsorge, die Denis für seinen eigenen Nachlass traf, eine Aufwertung der Handschrift, die seit dem 18. Jahrhundert dazu führt, dass neben Bibliotheken auch literarische Archive eingerichtet werden. So erscheint 1801, ein Jahr nach dem Tod des Schriftstellers und Bibliothekars, sein »Literarischer Nachlass « in Buchform, im Anschluss eine autobiographische Schrift, deren Herausgeber unter anderem den Anspruch formuliert, dass »von einem so berühmten Manne « wie Denis, dessen Verdienste um Sprache und Literatur, Literaturgeschichte und Bibliographie danach aufgezählt werden, »keine Zeile verlohren gehen dürfe« (Johann Michael Denis, Jugendgeschichte, von ihm selbst beschrieben. Aus dem Lateinischen übersetzt, Winterthur 1802, S. X). Benne sieht hier »entscheidende Motive verquickt«, er schreibt: »Eines davon ist die Verbindung der Individualität des Autors und der kulturellen Bedeutung für Sprache und Literatur der gesamten Nation. Wenn jede `Zeile< eine Spur ist, die etwas über den Menschen oder den Schriftsteller verrät, so ist in dieser Trennung der Funktion im Begriff des Schriftstellers auch schon die allgemeine, kulturelle und öffentliche Rolle enthalten. Der berühmte Mann ist jener, bei dem individueller und literarischer Charakter identisch werden. «(Benne, Erfindung des Manuskripts, S. 255ff., hier: S. 256) Müller, »Das Ungedruckte autorisieren«, S. 17. 
dies niederschreibt, haben seine Leseaufzeichnungen bereits einen beträchtlichen Umfang erreicht. Sie umfassen vier Jahre, nachdem Jean Paul damit begonnen hat, sich Aufzeichnungen zu seinen Lektüren anzufertigen, bereits mehr als ein Dutzend »Bände«, wie Jean Paul selbst sie nennt. Ihr Gesamtumfang beläuft sich auf etwa 3.000 Seiten.

Zwischen 1778 und 1825 fertigt Jean Paul Exzerpte an. So entstehen Aufzeichnungen im Umfang von etwa 10.000 Manuskriptseiten. ${ }^{34}$ Während er in den ersten Jahren längere Passagen aus Büchern und Periodika abschreibt, stellt Jean Paul seine Praxis des Exzerpierens im Laufe des Jahres 1782 um. An die Stelle seitenlanger Zitate treten nun kurze Notate, in denen Jean Paul festhält, was ihn interessiert oder affiziert. Sein Augenmerk liegt auf Fakten und Merkwürdigkeiten, die er über ausgeklügelte Register erschließt und in seine literarischen Texte einarbeitet. Eben diese Praxis des Exzerpierens wird heute als charakteristisch erachtet, wenn es um Jean Paul als Schriftsteller geht, während die Exzerpte der ersten Jahre dem Pfarrerssohn zugeschrieben werden, der sich Kollektaneen für eine bescheidene Karriere als Geistlicher anlegt. ${ }^{35}$

Seit wenigen Jahren liegen Jean Pauls Exzerpte in einer digitalen Edition vor. ${ }^{36}$ So verdienstvoll und für die Forschung überaus wertvoll diese Edition auch ist, sie vermittelt keinen Eindruck von der Materialität dieser handschriftlichen Aufzeichnungen. Ihre gängige Beschreibung als »Exzerpthefte« erweist sich mit Blick auf die Überlieferung als nicht unproblematisch. Jean Paul teilt seine Exzerpte selbst in »Bände« ein. Insgesamt umfasst der handschriftliche Nachlass in der Staatsbibliothek $\mathrm{zu}$ Berlin heute 112 dieser von Jean Paul festgelegten Einheiten. ${ }^{37}$ Mehr als die Hälfte seiner Exzerpte hat Jean Paul nicht nur geheftet, sondern binden lassen, wobei in der Regel jeweils fünf »Bände« zusammengefasst worden sind. Sie stecken zwischen Pappdeckeln mit schwarz texturiertem Überzug. Diese solide Ausstattung deutet auf einen regen Gebrauch hin.

Aufschlussreich ist, welche Exzerpte mit einem solchen Einband versehen sind: Es handelt sich ausschließlich um »Bände« der beiden Reihen »Ge-

34 Michael Will, »Lesen, um zu schreiben«, S. 39.

35 Siehe allgemein zu den Exzerpten u.a. Müller, Jean Pauls Exzerpte, Will, »Die (Un-)Ordnung der Dinge«.

36 Jean Paul, Exzerpte. Digitale Edition, www.jp-exzerpte.uni-wuerzburg.de (5.9.2019).

37 Will, »Lesen, um zu schreiben«, S. 40. 
schichte $\lll(1782-1825)$ und »Gemeine Exzerpte $(1786-1825) .{ }^{38}$ Die Bedeutung dieser beiden »Hauptreihen ${ }^{39}$ für das literarische Schreiben von Jean Paul ist kaum zu überschätzen. Als Jean Paul im Juni 1812 nach Nürnberg reist, hinterlässt er seiner Frau Karoline einen Zettel mit Anweisungen, der während seiner Abwesenheit »Täglich durchzulesen« ist. An zweiter Stelle steht: »Bei Feuer sind die schwarzeingebundnen Exzerpte zuerst zu retten [...].« (HKA III.6, 267 [646])

Seine frühen Exzerpte lässt Jean Paul dagegen nicht extra stabil einbinden. In der Forschung werden diese Leseaufzeichnungen der Jahre 1778 bis 1781 auch seltener gewürdigt, sind sie doch - so Michael Will - „für das schriftstellerische Werk Jean Pauls von eher geringerer Relevanz « ${ }^{40}$. Trotzdem sind diese Exzerpte ein äußerst aufschlussreicher Bestandteil des Nachlasses, denn sie vermitteln einen Eindruck von Jean Pauls hoher Affinität zu gedruckten Büchern und Periodika. Man könnte von der blauen Reihe sprechen, da die Mehrzahl der betreffenden Bände mit blaugrauem Buntpapier beklebt ist. Auch die »Übungen im Denken« und der nach eigenem Urteil gescheiterte Romanversuch »Abelard und Heloise« lassen sich mit Blick auf das Äußere der blauen Reihe zuordnen..$^{41}$ Außergewöhnlich an der blauen Reihe der Exzerpte ist ihre von Hand geschaffene Ausstattung. Sind die einzelnen Bände doch, wie Engelhard Weigl bemerkt hat, »von Jean Paul bewußt wie richti-

38 Siehe die Angaben zu den einzelnen Bänden in Ralf Goebel und Markus Bernauer, Der handschriftliche Nachlass Jean Pauls und die Jean-Paul-Bestände der Staatsbibliothek zu Berlin - Preußischer Kulturbesitz, Wiesbaden 2002-11, 1: Faszikel I bis XV, Ralf Goebel (2002), S. 12-25, 34-38. Nach 1810 werden diese beiden Exzerptreihen nur noch geheftet (Ebd., S. 22-25 [Fasz. IIc/3-11], 37-38 [Fasz. IVa/5-8]).

39 Will, »Lesen, um zu schreiben«, S. 43.

40 Ebd., S. 44.

41 Anders als Bücher, die auch noch Ende des 18. Jahrhunderts in der Regel ohne Einband ausgeliefert werden, erhalten seit den Siebzigerjahren vor allem periodische Titel provisorische Umschläge, meist aus Buntpapier. Häufig verwendet wurde Löschpapier, ein Buntpapier minderer Qualität. Lühmann erwähnt überlieferte Ausgaben des »Teutschen Merkur « und des »Deutschen Museums«, Periodika, aus denen Jean Paul exzerpierte, mit blauen oder rosa Umschlägen. Auch Volksbücher und Titel, die in mehreren Lieferungen erschienen, werden mit bunten Einbänden versehen, jedoch bestehen diese oftmals aus stärkerem Buntpapier bis hin zu Karton (Frithjof Lühmann, Buchgestaltung in Deutschland 1770 bis 1800, München 1981, S. 62). Blau ist als Einbandfarbe im Deutschland des späten 18. Jahrhunderts vor allem durch die populäre französische »Bibliothèque bleue« geläufig. 
ge Bücher gestaltet « ${ }^{42}$ worden. Interessanterweise verliert sich dieser Aspekt nicht allein mit fortschreitender Adoleszenz, sondern auch im Übergang zum gedruckten Schriftsteller.

Die Exzerptbände der blauen Reihe bestehen jeweils aus mehreren Lagen grobem Postpapier. Die Blätter im Folioformat dürfte Jean Paul eigenhändig zugeschnitten und zusammengelegt gefalzt haben, um Seiten im Quartformat zu erhalten. Warum sich Jean Paul für dieses Format entscheidet, darüber lässt sich nur spekulieren. ${ }^{43}$ Seiten im Quartformat lassen sich aus einem Papierbogen einfach herstellen, es handelt sich daher um ein gängiges und auch handelsübliches Format für handschriftliche Aufzeichnungen, da die Seiten einen großzügigen Raum zum Schreiben mit der Feder bieten und trotzdem leicht zu handhaben sind. Jean Paul beschreibt die einzelnen Lagen durchgehend mit schwarzer Tinte, ehe er sie zu dickleibigen Bänden in Quart zusammennäht.

Im deutschen Verlagswesen des späten 18. Jahrhunderts gibt es mehr als einen Trend zur kleineren Taschenausgabe in Oktav oder Duodez, während das Quartformat eher für Prachtausgaben genutzt wird, um einen lichteren Satz zu ermöglichen und auch Kupferstiche gut einbinden zu können. Hinsichtlich des Formats läge es also nahe, in den frühen Exzerpten Jean Pauls keine nachgeahmten Bücher zu erkennen. Andererseits ist in der »Selberlebensbeschreibung «, der 1826 als Fragment aus dem Nachlass veröffentlichten Autobiographie, von der »mit leeren Folioblättern durchschoßene[n] Quartbibel« des Vaters die Rede, durch die Jean Paul früh mit der Buchkultur in Berührung kommt. Und auch die »Quartbände der Gespräche im Reiche der Todten« (SW I.6/1057) von David Faßmann, die er als Kind liest, könnten dazu beigetragen haben, das Format als passend für die eigenhändige Buchproduktion anzusehen.

42 Engelhard Weigl, Aufklärung und Skeptizismus. Untersuchungen zu Jean Pauls Frühwerk, Hildesheim 1980, S. 34.

43 In der 1638 erstmals veröffentlichten »Aurifodina«, dem »umfangreichsten und umfassendsten Buch über das Exzerpieren im 17. Jahrhundert«, so Florian Neumann, empfiehlt der ]esuit Jeremias Drexel das Anlegen von Heften im Quartformat für eine systematische Sammlung von Lesefrüchten. Ob vergleichbare Vorgaben auch dem viel später geborenen Jean Paul bekannt waren, lässt sich nicht nachvollziehen (Florian Neumann, »]eremias Drexels Aurifodina und die Ars excerpendi bei den Jesuiten«, in: Helmut Zedelmaier, Martin Mulsow (Hg.), Die Praktiken der Celehrsamkeit in der Frühen Neuzeit, Tübingen 2001, S. 51-61, hier: S. 59, 60 (Zitat), siehe außerdem Martin Mulsow, Prekäres Wissen: Eine andere Ideengeschichte der Frühen Neuzeit, Berlin 2012, S. $367 f f$.$) .$ 
In den Vorarbeiten zur »Selberlebensbeschreibung« findet sich im Abschnitt "Schwarzenbach« ein Hinweis auf die visuelle Gestaltung der frühen Exzerpte: »Ein Schreiber (Wolfram) mußte mit Fraktur die Titel schreiben - ich that, als sei es gedruckt.« (HKA II.4, 371 [23]) Jean Paul hat diese Begebenheit nicht in die ausgearbeiteten Passagen der "Selberlebensbeschreibung« aufgenommen. Überhaupt finden die Exzerpte in der Fragment gebliebenen Autobiographie keine Erwähnung. Aber in Jean Pauls handschriftlichem Nachlass sind jene Titelblätter zu bewundern, die ein professioneller Schreiber aus Schwarzenbach an der Saale für den Pfarrerssohn anfertigte. Sie zeigen, welch großen Wert Jean Paul in den Jahren vor seiner ersten Buchveröffentlichung der Gestaltung seiner >ungedruckten Bücher < beimisst, dass es ihm nicht allein um die Sammlung von Lesefrüchten, sondern auch um die Teilhabe an einer durch die Materialität ihrer Medien geprägten Wissenskultur geht. Hauptsächlich die Titelbilder bilden sozusagen Stoff und Form einer besonderen, man könnte sagen: einer materialen, papiernen Fiktion. Auf sie bezieht sich die bereits angeführte Deklaration, die Jean Pauls Umgang mit der Nachahmung bestimmt: »ich that, als sei es gedruckt.«

Es sind vor allem diese in Fraktur geschriebenen Titelblätter, die ins Auge fallen, wenn man die Exzerpte der blauen Reihe als handgeschriebene Bücher betrachtet. ${ }^{44}$ Titelblätter sind eine Erfindung des Druckzeitalters, sie fungieren als herausragender Schauplatz einer jeder Publikation. ${ }^{45}$ Aber um eine solche handelt es sich bei den Exzerpten gerade nicht, sie sind Handschriften für den privaten Gebrauch. Umso bemerkenswerter ist der Umstand, dass Jean Paul seine Exzerpte mit Titelblättern versieht, die deutsche Frakturdrucke der zweiten Hälfte des 18. Jahrhunderts im Hinblick auf Layout und Schriftbild imitieren. ${ }^{46}$

44 In Fraktur geschriebene Titelblätter haben die überlieferten Exzerptbände eins bis elf, dreizehn und vierzehn, siehe Stiftung Preußischer Kulturbesitz, Staatsbibliothek zu Berlin, Nachlass Jean Paul, Fasz. la/1-5, 7, Fasz. Ib/1-4, 6-8. Die unterschiedliche Ausführung der Titelblätter legt nahe, dass diese von verschiedenen Schreibern angefertigt worden sind.

45 Siehe Ursula Rautenberg, »Die Entstehung und Entwicklung des Buchtitelblatts in der Inkunabelzeit in Deutschland, den Niederlanden und Venedig. Quantitative und qualitative Studien«, in: Archiv für Geschichte des Buchwesens 62 (2008), S. 1-105.

46 Die Fraktur ging laut Konrad F. Bauer als Druckschrift aus der »gepflegten Kanzleischrift« des frühen 16. Jahrhunderts hervor (Konrad F. Bauer, »Zur Ceschichte der Unger-Fraktur«, in: Cutenberg-Jahrbuch (1929), S. 287-296, hier: S. 287). Johann Wilhelm Keßler bezeichnet sie in seinem Lehrbuch zum Schreibenlernen von 1787 »als eine vergrösserte Canzleischrift«, über die es weiter heißt: »Sie ist bei verschiedenen Fällen 
Auf dem allerersten Titelblatt der blauen Reihe steht in den oberen drei Zeilen in einer kunstvoll ausgestalteten Fraktur:»Verschiedenes, aus den neuesten Schriften«, der vollständige Reihentitel, den Jean Paul über drei Jahre beibehält. Darunter ist zu lesen: »Erster Band.« Unter einer doppelten Linie finden sich an der Stelle, die bei einem gedruckten Buch für Verlagsangaben vorgesehen ist, die Ortsangabe »Schwarzenbach an der Saal«, wo der Gymnasiast seinerzeit lebt, und das Jahr, in dem er die Aufzeichnungen anfertigt, nämlich »1778«. ${ }^{47}$

Der Band besteht aus 232 Seiten, die jeweils bis zu den Rändern mit Text in Kurrentschrift gefüllt sind. Auf den Seiten finden sich paratextuelle Elemente, die wie das Titelblatt für gedruckte Bücher charakteristisch sind. ${ }^{48}$ Jean Paul versieht den Band mit einer durchgängigen Paginierung am oberen Seitenrand. Die Auszüge aus den von ihm durchgearbeiteten Schriften sind wie in zeitgenössischen Sammelwerken und Periodika durch römische Ziffern gekennzeichnet und durch dieses Gliederungselement deutlich gegeneinander abgesetzt. Unter jeder Ziffer platziert Jean Paul mittig den Titel des exzerpierten Werks mit genauen bibliographischen Angaben. Zusätzlich nutzt er selbst gewählte Zwischenüberschriften, um die übernommenen Stellen inhaltlich zu ordnen. Der Band enthält jeweils mehrseitige Abschriften aus theologischen Zeitschriften wie dem »Journal der Prediger « und der »Allgemeinen theologischen Bibliothek«, aber auch aus Friedrich Nicolais »Allgemeiner Deutscher Bibliothek« und Büchern wie Gellerts »Moralischen Vorlesungen«. Jean Paul übernimmt das Gelesene wortgetreu, das Schriftbild zeugt von großer Sorgfalt beim Schreiben und dem Bemühen um Leserlichkeit. Korrekturen oder sonstige Durchstreichungen sind zwar durchgängig, aber in der Gesamtschau selten zu finden, auch Verunreinigungen wie Flecken oder die beim späteren Jean Paul notorischen Federproben kaum zu beobachten. Im Detail imitiert Jean Paul auch typographische Zeichen, hauptsächlich Anführungszeichen zur deutlichen Hervorhebung von Zitaten. Den

in Canzleien, Registraturen und Aemtern nothwendig, und wird vorzüglich zu gewissen feierlichen Schriften, als zu Diplomen, Geburts- und Lehrbriefen u.s.w. gebraucht." (Johann Wilhelm Keßler, Lehrbuch der Kunst schön und geschwind zu schreiben, Heilbronn 1787, S. 62) Was unterstreicht, dass bei der Verwendung der Schriftart für Jean Paul die gängige Drucktype die Referenz darstellte, nicht die offiziellen Dokumenten vorbehaltene, von Hand gezeichnete Fraktur.

47 Nachlass Jean Paul, Fasz. la/1, fol. 3 r.

48 Siehe Ursula Rautenberg, »Buchmedien«, in: Natalie Binczek u.a. (Hg.), Handbuch Medien der Literatur, Berlin 2013, S. 235-46, hier: S. 239. 
Abbildung 1: "Verschiedenes aus den neuesten Schriften«: Handgeschriebenes Titelblatt von Jean Pauls erstem Band mit Exzerpten.

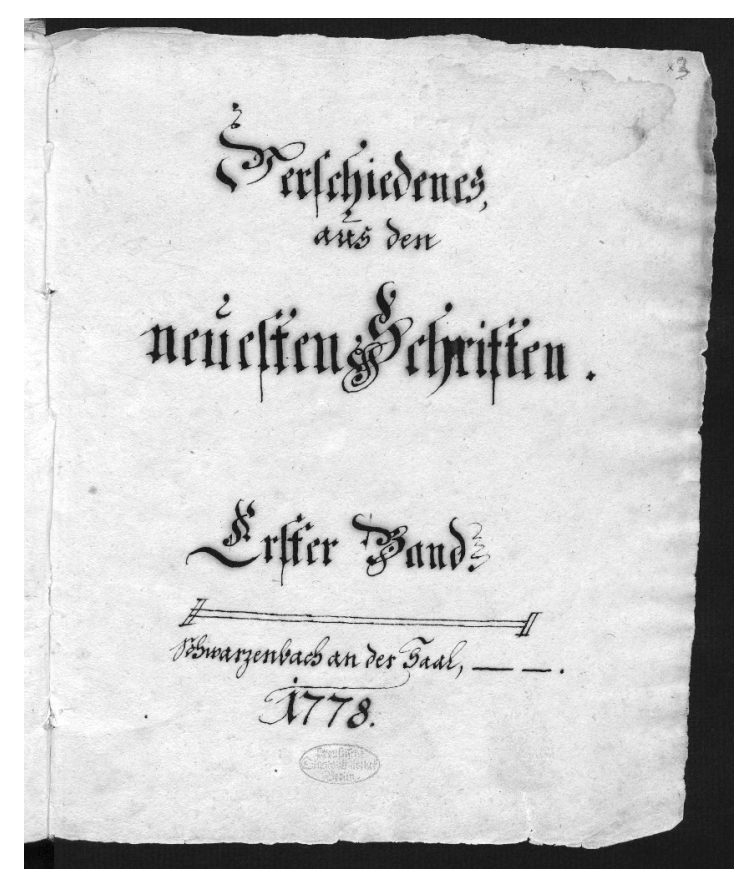

Stiftung Preußischer Kulturbesitz, Staatsbibliothek zu Berlin, Nachlass Jean Paul, Fasz. Ia/1, Bl. 3r.

eigentlichen Textteil beschließen ein »Verzeichnis der Bücher in diesem Bande«, also ein Inhaltsverzeichnis mit genauen Seitenangaben, sowie ein »Register der in diesem ersten Band enthaltenen Sachen«. Darauf folgt auf der letzten Seite die in mehrteiligen oder fortgesetzt erscheinenden Publikationen übliche Formel »Ende des ersten Bandes", die in Fraktur ausgeführt ist. ${ }^{49}$ Sie wird eingefasst von fünf Schnörkeln, wie man sie, wenn auch kunstvoller, von Schreibmeisterblättern kennt. Bei Jean Paul erfüllen die Schnörkel die Funktion der im Druck üblichen Schlussvignetten, indem sie den Weißraum

49 Siehe Nachlass Jean Paul, Fasz. la/1, S. 220-232. 
der angefangenen Seite reduzieren. Ansonsten verzichtet der Büchermacher auf Verzierungen oder gar Illustrationen.

Abbildung 2: »Ende des ersten Bandes«: Auch der Abschluss des ersten Exzerpt-Bandes folgt der typographischen Gestaltung zeitgenössischer Publikationen.

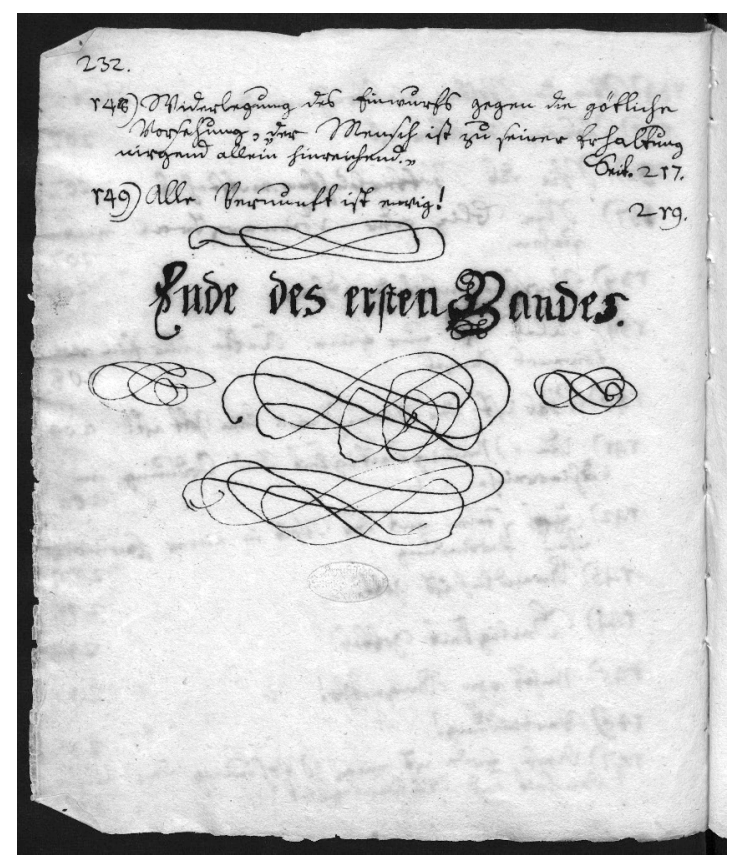

Stiftung Preußischer Kulturbesitz, Staatsbibliothek zu Berlin, Nachlass Jean Paul, Fasz. Ia/1, [S. 232].

Mit eigenen Anmerkungen geht Jean Paul in der blauen Reihe sehr sparsam um. Einen seiner wenigen Kommentare versieht er mit einem Zusatz, der sich in die Logik der Nachahmung einer Druckpublikation fügt. Im vierten Band der Exzerpte stehen Auszüge aus einer Rezension zu der von Hermann Daniel Hermes, einem evangelischen Theologen, verfassten Schrift »Die große Lehre vom Gewissen, in so fern sie die Gesetze der Religion und die Gesetze der 
Staaten verbindet «, erschienen in der "Allgemeinen Deutschen Bibliothek «. ${ }^{50}$ Am Seitenende ergänzt Jean Paul seine Abschrift um eigene Ausführungen über das »moralische Gefühl«, und er endet mit der Formel: »Anm. d. Herausg. " ${ }^{51}$ Damit inszeniert sich der laut Eduard Berend als »Kopist « (HKA II.1, XIX) tätige Jean Paul als Editor einer Publikation, die tatsächlich keine ist.

Für Exzerpte aus französischsprachigen Büchern legt Jean Paul im Jahr 1781 einen eigenen Band an, der zwar kein kalligraphisch gestaltetes Titelblatt, aber einen kompletten französischen Titel hat. Dieser lautet: »Extriats de livres français. Tome 1. MDCCLXXXI./Leipsic « ${ }^{52}$. Auf den 136 Seiten dieses Bandes finden sich Auszüge aus Schriften von Rousseau, Helvétius, Toussaint und Voltaire, und sowohl die Anmerkungen als auch das Inhaltsverzeichnis sind in Französisch abgefasst (»Table des livres contenus dans ce volume«). Offenbar plant Jean Paul eine weitere Ausdifferenzierung seiner Exzerpte. ${ }^{53}$ Letztlich entscheidet er sich jedoch für die Neuanlage einer Reihe zur »Geschichte«, womit die Zeit der »schwarzeingebundnen Exzerpte« beginnt, in denen sich der angehende Schriftsteller nicht nur von seiner bisherigen Praxis des Exzerpierens, sondern auch endgültig von der umfänglichen Nachahmung von Druckpublikationen verabschiedet.

Elisabeth Décultot stellt die Exzerpte der blauen Reihe in die Tradition der "Collectanea«, also umfangreichen Sammlungen von Realien, die nicht zuletzt der eigenen Rhetorik dienlich sein sollen. ${ }^{54}$ Sicher die größte Herausforderung besteht neben dem Abschreiben in der Ordnung der Kollektaneen, für die viele Modelle existieren. Beispielsweise schlägt Friedrich Andreas Hallbauer in seiner 1725 erstmals aufgelegten »Anweisung zur deutschen Oratorie« im Anschluss an Christian Weise eine Sammlung unter alphabetisch geordneten Titeln vor. ${ }^{55}$ Jean Paul überträgt seinerseits die paratextuel-

50 F.G. Resewitz, »Die große Lehre vom Cewissen, in so fern sie die Cesetze der Religion und die Cesetze der Staaten verbindet«, in: Allgemeine Deutsche Bibliothek 13 (1770), 1, S. 214-231.

51 Nachlass ]ean Paul, Fasz. Ia/4, S. 32, in: ]ean Paul,Exzerpte. Digitale Edition, [la-04-17790101], URL: www.jp-exzerpte.uni-wuerzburg.de (5.9.2019). Siehe auch HKA II.1, S. XIX.

52 Coebel, Bernauer, Der handschriftliche Nachlass ]ean Pauls, 1, S. 39 [Fasz. IVb/2].

53 Siehe u.a. den in Faszikel IVb des Nachlasses befindlichen Band mit »Exzerpten aus neuen belletristischen Schriften. Erster Band. 1781/Leipzig«, ebd. [Fasz. IVb/1].

54 Elisabeth Décultot, »Einleitung. Die Kunst des Exzerpierens - Ceschichte, Probleme, Perspektiven«, in: dies. (Hg.), Lesen, Kopieren, Schreiben. Lese- und Exzerpierkunst in der europäischen Literatur des 18. Jahrhunderts, Berlin 2014, S. 7-47, hier: S. 25-26.

55 Friedrich Andreas Hallbauer, Anweisung zur verbesserten teutschen Oratorie, Jena 1725, S. 288-289. 
le Ordnung zeitgenössischer Publikationen auf seine handschriftlichen Aufzeichnungen. Das betrifft die visuelle Gestaltung der einzelnen Eintragungen ebenso wie die Einrichtung von Inhaltsverzeichnissen und Registern, aber auch die grundsätzliche Einteilung in Bände, die durch die Nachahmung von Titelblättern unterstrichen wird.

Der Medientheoretiker Harold Innis hat einen Satz formuliert, der nach Ansicht von Lothar Müller Marshall McLuhans berühmtes Diktum »The medium is the message«»vorgeprägt« hat: »Wir können wohl davon ausgehen«, so Innis in »The Bias of Communication « von 1949, »daß der Gebrauch eines bestimmten Kommunikationsmediums über einen langen Zeitraum hinweg in gewisser Weise die Gestalt des zu übermittelnden Wissens prägt. ${ }^{56}$ Michael Cahn hat deutlich gemacht, in welchem Maße gedruckte Bücher in ihrer spezifischen Materialität und Medialität auf die Formation von Wissen einwirken:»Die Darstellungsformen des Wissens im Druck«, schreibt Cahn, »besitzen eine eigene Logik und eine Widerständigkeit, durch die sie in der Geschichte des Wissens die Rolle eines aktiven, eines strukturierenden Elements übernehmen können. ${ }^{57}$ In diesem Zusammenhang spricht Cahn von einer $»$ Rhetorik des Drucks«, worunter er eine »kohärente Deformation der Kommunikation nach den Strukturen des Mediums « versteht. ${ }^{58}$ Auch wenn die von Jean Paul hergestellten »Bände« nur bedingt auf Kommunikation ausgelegt sind, sie in diesem Sinne nicht als Medien fungieren, so bedient sich Jean Paul in der Nachahmung gedruckter Bücher doch der "Rhetorik des Drucks«, um das Abgeschriebene in eine Form zu bringen, die Wissen durch Paratexte zugänglich und verfügbar macht. Darüber hinaus steht die Buchförmigkeit des Wissens auch für eine gewisse »Autorität «9 $^{59}$ des Gedruckten, auf welche die Gestaltung der Exzerpte offensichtlich Bezug nimmt.

Dass es Jean Paul um die Teilhabe an einer mediengebundenen Wissenskultur geht, dafür spricht der hohe Aufwand, den er bei der Herstellung seiner Exzerpte betreibt. In ihrer Gesamtheit fungiert die »handgeschriebene Bibliothek« zugleich, um mit Pierre Bourdieu zu sprechen, als objektiviertes kulturelles Kapital, das Jean Paul im Umgang mit anderen einsetzt. Denn:

56 Harold A. Innis, »Tendenden der Kommunikation (The Bias of Communication, 1949)«, in: ders., Kreuzwege der Kommunikation. Ausgewählte Texte, hg. v. Karlheinz Barck, Wien, New York 1997, S. 95-119, hier: S. 96.

57 Michael Cahn, Der Druck des Wissens. Ceschichte und Medium der wissenschaftlichen Publikation, Berlin 1991, S. 32.

58 Ebd., S. 50.

59 Müller, »Das Ungedruckte autorisieren«, S. 16. 
Jean Paul hat die frühen Exzerpte nicht allein als privaten Wissensspeicher genutzt, sondern einzelne "Bände« aus der Hand gegeben, sie verliehen oder gar verschenkt. Es ist genau dieser Punkt, der ein Licht auf die spezifische Medialität der sungedruckten Bücher wirft, die sich als Objekte mit Bedeutung aufladen und in soziale Praktiken einbinden lassen.

Ein Beispiel liefert der bis heute verschollene zwölfte Band der Exzerpte, den Jean Paul der von ihm verehrten Sophie Ellrodt zukommen lässt. ${ }^{60}$ Jean Paul tauscht in der Liebeskorrespondenz mit Ellrodt verschiedene Objekte aus, darunter einen Ring, den die Umworbene ihm schickt. Bei der Übersendung eines Schattenrisses kündigt Jean Paul sein erstes Buch an, die 1783 erscheinenden »Grönländischen Prozesse«. Am 14. September 1783 schreibt er an Ellrodt: »In etlichen Wochen schikk' ich Ihnen eine Abbildung, worin ich besser werde getroffen sein - ich meine mein Buch." (HKA III.1, 108) Bevor Jean Pauls erstes gedrucktes Buch vorliegt, behilft er sich jedoch mit einem Band aus seiner handgeschriebenen Bibliothek. In dieser Konstellation zeigt sich ein wesentliches Element des Spiels der Autorschaft: die Repräsentation des Subjekts durch das Buch (»Abbildung«), die nicht unbedingt eines Textes bedarf, sondern in sozialen Praktiken ebenso, wenn nicht gar mehr eines Artefakts. Denn offenbar lässt sich das Werk des Schriftstellers, »mein Buch", wie Jean Paul es stolz nennt, zumindest temporär durch den selbst hergestellten Band substituieren, obgleich dieser ausschließlich Abschriften anderer Autoren enthält. Man könnte diese Substituierung griffig so beschreiben, dass das Eigentum, also das handgeschriebene Buch, hauptsächlich Werk des Fleißes, an die Stelle des Eigentümlichen tritt, des Textes. Damit würde man jedoch vernachlässigen, wie wichtig Artefakte als Medien persönlicher Bindung in der Dingkultur um 1800 sind, welche Bedeutung also ein zugeeignetes Buchexemplar unabhängig von der Lektüre erlangen kann. ${ }^{61}$ Als das Verhältnis zu Ellrodt abkühlt, bittet Jean Paul seine Mutter um die Rückholung des Exzerptbandes: »In Helmbrechts liegt ein blaueingebundnes Schreibbuch von mir mit dem Titel: Verschiedenes aus den neuesten Schriften. Zwölfter

60 Siehe Jörg Paulus, Philologie der Intimität. Liebeskorrespondenz im Jean-Paul-Kreis, Berlin 2013, S. 111-12.

61 Siehe dazu u.a. Christiane Holm, Art. »Andenken/Souveneir«, in: Susanne Scholz, Ulrike Vedder (Hg.), Handbuch Literatur \& materielle Kultur, Berlin, Boston 2018, S. 377-379, dies., »Erinnerungsdinge«, in: Stefanie Samida, Manfred K. H. Eggert, Hans Peter Hahn (Hg.), Handbuch Materielle Kultur. Bedeutungen - Konzepte-Disziplinen, Stuttgart 2014, S. 197-200, dies., Günter Oesterle (Hg.), Schläft ein Lied in allen Dingen? Romantische Dingpoetik, Würzburg 2011. 
Band. - Ich gab es der Ellrodin zu lesen, fordern Sie es zurück, vergessen Sie es ja nicht." (HKA III.1, 113) Aufschlussreich ist die Beschreibung, die der damalige Student in einem Brief aus Leipzig gibt. Nebenbei tarnt er Liebesgaben als Lektüren. Einerseits charakterisiert Jean Paul den vermissten Besitz als »Schreibbuch«, das sich andererseits aber durch seine bibliographischen Daten auszeichnet. Als absehbar ist, dass er den Band nicht zurückerhalten wird, schreibt Jean Paul an die Mutter: »Mein Buch in Helmbrechts ist nur ein geschriebenes aus andern Büchern und ich frage also wenig darnach.« (HKA III.1, 123) In der Schwebe bleibt in dieser Formulierung, ob Jean Paul sein »Buch« nicht einer Nachfrage für würdig erachtet, weil es von Hand geschrieben oder abgeschrieben ist.

Auch im Übergang vom Exzerpieren zur eigenständigen Textproduktion rekurriert Jean Paul auf ihm bekannte Publikationsformen. Das gilt insbesondere für die »Übungen im Denken«, eine Sammlung kürzerer, teilweise schon früher entstandener Abhandlungen, von denen Jean Paul überarbeitete Teile im April 1781 an seinen väterlichen Freund und Buchverleiher, den Pfarrer Vogel, sendet - mit der Bitte, »sie für Schulexerzizien anzusehen, die man korrigiert « (HKA III.1, 3). Anders als bei den Exzerpten ist es bei den »Übungen im Denken« dezidiert das Medium der Zeitschrift, an dem sich Jean Paul orientiert. Zwar platziert er gleich auf der zweiten Seite des ersten Manuskripts eine »Anzeige«, in der es wörtlich heißt: »Diese Versuche sind blos für mich.« (SW II.1, 36) Jedoch formuliert er zum Abschluss dieser Instruktion, die den privaten Übungscharakter unterstreichen soll, den Anspruch einer bestimmten Regelmäßigkeit: »Jedes Monat enthält sechs Bögen und ieder Band drei Monate.«(Ebd.) Daraus ergibt sich die übliche Frequenz eines Periodikums, dessen Umfang zudem genau benannt wird. Norbert Miller spricht von der »Fiktion einer veröffentlichten Monatsschrift« (SW II.4, 100f.). Auch der erste Band der »Übungen im Denken« verfügt über ein in Fraktur geschriebenes Titelblatt mit Bandangabe. ${ }^{62}$ Statt eines Ortes wird ein Datum in der untersten Zeile angegeben (»November 1780«). Zwischen dem Titel und der Bandangabe setzt Jean Paul außerdem ein Motto in Kurrentschrift. Es handelt sich um ein Zitat aus dem zweiten Teil von Johann Jakob Engels »Der Philosoph für die Welt«, das Jean Paul leicht abweichend wiedergibt. ${ }^{63}$ Im Vergleich mit

\footnotetext{
62 Nachlass Jean Pauls, Fasz. XIIla/1, fol. 2 r.

631779 und 1780 hatte er den betreffenden Band zwar exzerpiert, die Passage mit dem nun als Motto verwendeten Zitat jedoch ausgelassen: »Auch schon hienieden ist die Weisheit an himmlischen Freuden reich: und wäre sies nicht: warum sähn wir aus ih-
} 
den frühen Exzerpten erfüllt die Nachahmung einer Druckpublikation in den »Übungen im Denken« eine neue Funktion. Jean Paul verknüpft das Schreiben mit den üblichen Bedingungen eines in einem regelmäßigen Turnus erscheinenden Periodikums. Damit organisiert die ihm vorschwebende Publikationsform der Zeitschrift seine Textproduktion.

Jean Pauls handgeschriebene Bücher zeigen, dass gedruckte Bücher und Periodika keine vom Text transzendierten Artefakte, keine transparenten Medien sind. Sie unterstreichen, in welchem Maße Jean Paul in die Buchkultur des späten 18. Jahrhunderts eingebunden ist. Ihre Betrachtung ermöglicht es, seine Praktiken der Wissensaneignung auf einer anderen Ebene mit gelehrten Praktiken in Beziehung zu setzen als auf der des Textes, und zwar auf der Ebene der Materialität gängiger Druckpublikationen. In der Verbindung von abgeschriebenem Text und nachgeahmter Materialität wird die Buchförmigkeit des Wissens im 18. Jahrhundert sinnfällig. Oder es wird, in einer eher abwertenden Diktion, die in dieser Zeit noch immer präsente »Buchgelehrsamkeit« erkennbar, die nicht wenige von Jean Pauls literarischen Figuren auszeichnet. Deutlich wird in der Weitergabe der Exzerpte zur Befestigung persönlicher Bindungen außerdem, welch vielfältige Rollen gedruckte Bücher als Artefakte in sozialen Praktiken spielen können. Näher einzugehen ist an dieser Stelle noch auf das, was sich im Übergang von den handgeschriebenen Büchern zu den »Übungen im Denken« bloß andeutet: Ausgehend von der Nachahmung buchspezifischer Materialität in seinen Exzerpten entwickelt Jean Paul eine Poetologie der Materialität, die sich durch die Erfindung papierner Objekte auszeichnet, denen in der Fiktion jeweils zugeschrieben wird, die Narration von außen zu konditionieren. In dieser Perspektive zeichnet sich schrittweise eine Transformation nachgeahmter Materialität ab, die vom Artefakt des Exzerpts zum literarischen Text führt, also von der papiernen Fiktion zum fiktiven Papier. Auffällig an dieser Bewegung ist die Auflösung der im Exzerpt noch angestrebten Buchform durch ein scheinbar unerschöpfliches Reservoir an fiktiven Papieren, die - wie die aus Makulatur gefertigten Artefakte in »Leben Fibels« (Kapitel 5.5) - vor allem paratextuell in die Erzählungen eingeführt und vornehmlich für die Digressionen genutzt

rem Schooße so ruhig allen Eitelkeiten der Welt zu?«, »Traum des Galilei«, in: Der Philosoph für die Welt 2 (1777), S. 1-17, hier: S. 14, siehe Nachlass Jean Paul, Fasz. Ib/9, S. 20-26, Ib/10, S. 62-70, Nachlass Jean Paul, Exzerpte. Digitale Edition, URL: www.jp-exzerpte.uniwuerzburg.de (5.9.2019). 
werden, die als charakteristisch für Jean Pauls literarische Texte gelten. ${ }^{64}$ Den handgeschriebenen Büchern kommt im Hinblick auf viele Erzählungen und Romane also eine herausragende Bedeutung $\mathrm{zu}$, die sich nicht aus den Inhalten der Exzerpte ergibt, sondern aus ihrer Materialität.

\subsection{Bücher-nach-machen: Schreiben als Akt der Nachahmung}

Schreiben bedeutet mit Blick auf die blaue Reihe der Exzerpte Jean Pauls nicht bloß Abschreiben, also eine Mobilisierung und Aneignung von Wissen durch die handschriftliche Reproduktion von gedruckten Texten. Schreiben lässt sich zugleich als ein Akt der Nachahmung von gedruckten Büchern und Zeitschriften rekonstruieren, es hat eine graphische Dimension ${ }^{65}$, die unabhängig ist von der Zeichenfunktion der Alphabetschrift. Auch dieses Schreiben kann man durchaus als zeichenhaft begreifen, aber im Hinblick auf das, was Jerome J. McGann den »bibliographical code ${ }^{66}$ nennt. Entscheidend ist jedoch der Akt der Nachahmung selbst, ein Schreiben, durch das das Niedergeschriebene einen Rahmen erhält. Und dieser Rahmen wird gebildet aus den Paratexten zeitgenössischer Druckpublikationen mit ihrer spezifischen, vornehmlich visuellen Materialität. Jean Paul schreibt in dieser Konstellation tatsächlich Bücher, er wird zum Büchermacher oder eher: Bücher-nach-macher, der sich mit Feder und Papier eine Sphäre der Imagination erschließt, die an der kulturellen Bedeutung von Druckpublikationen partizipiert.

Sowohl das Schreiben als auch das Lesen werden um 1800 so vermittelt, dass frühzeitig ein Bezug zur visuellen Materialität von Schrift und den verschiedenen Formen ihrer graphischen Reproduktion hergestellt wird. Lesen

64 Siehe z.B. Magnus Wieland, Vexierzüge, ders., »]ean Pauls Sudelbibliothek. Makulatur als poetologische Chiffre«, in: Jahrbuch der Jean-Paul-Gesellschaft 46 (2011), S. 97119, ders., »Litteratur. Die Lesbarkeit des Mülls«, in: Zeitschrift für deutsche Philologie 133 (2014), Sonderheft: Entsorgungsprobleme: Müll in der Literatur, S. 33-50, Monika Schmitz-Emans, »Vom Leben und Scheinleben der Bücher. Das Buch als Objekt bei Jean Paul«, in: Jahrbuch der Jean-Paul-Gesellschaft 28 (1993), S. 17-46, Bettine Menke, »EinFälle aus Exzerpten. Die inventio des Jean Paul«, in: Renate Lachmann, Riccardo Nicolosi, Susanne Strätling (Hg.), Rhetorik als kulturelle Praxis, München 2008, S. 291-307.

65 Siehe Davide Giuriato, Stephan Kammer, »Die graphische Dimension der Literatur? Zur Einleitung«, in: dies. (Hg.), Bilder der Handschrift. Die graphische Dimension der Literatur, Frankfurt a.M., Basel 2006, S. 7-24.

66 Siehe ]. McGann, The Textual Condition. 
lernen Schüler in der Regel nach der Buchstabiermethode, die aus dem Buchdruck mit beweglichen Lettern hervorgegangen sein soll. ${ }^{67}$ Die Schüler sollen die einzelnen Buchstaben erkennen und benennen können, wobei eine Herausforderung darin besteht, mit verschiedenen Schriftarten wie Fraktur und Antiqua umzugehen. ${ }^{68}$ Laut Heinrich Stephani, der 1803 in Bayern die Lesedidaktik reformiert, sind Buchstaben »für das Auge willkührlich angenommene Zeichen der verschiedenen Sprachlaute ${ }^{69}$, die sich jedoch in der Vermittlung des Lesens nach der Buchstabiermethode verselbständigen, so dass schließlich sogar von Lehrern, wie Stephani bemängelt, »die Nahmen der Buchstaben selbst für die Elemente der Wörter ${ }^{70}$ gehalten werden. Somit wird Leseanfängern nicht beigebracht, die Buchstaben als Zeichen für sprachliche Grundelemente - also Laute - wahrzunehmen, sondern als graphische Elemente, die aufsagbare Namen haben. Heinrich Bosse erkennt in diesem Lesen »eine nennende, keine artikulierende Praxis ${ }^{71}$, die in einem erheblichen Maße durch die visuelle Materialität von Lettern bestimmt wird.

Schreiben - das ist eine kulturelle Praktik, die um 1800 weitgehend vermittelt wird, ohne die Zeichenfunktion der Alphabetschrift zu berücksichtigen. Im Unterricht dominiert die Materialität des Schreibens, so dass Schüler bis ins 19. Jahrhundert vor allem eine Schönschreibekunst erlernen, die technisch überaus anspruchsvoll und ästhetisch in einem hohen Maße selbstre-

67 Ludwig Friedrich Cöbelbecker, Entwicklungsgeschichte des ersten Leseunterrichts von 1477 bis 1932. In quellenmäßiger Darstellung und theoretischer Beleuchtung, Kempten, Leipzig 1933, S. 31. Dass die Buchstabiermethode auf die Erfindung des Buchdrucks mit beweglichen Lettern zurückgeht, ist als These bis heute anerkannt, siehe Bettina Hurrelmann, Susanne Becker, Irmgard Nickel-Bacon, Lesekindheiten. Familie und Lesesozialisation im historischen Wandel, Weinheim, München 2006, S. 118, vgl. Fuchs, Büchermachen, S. 55.

68 Hinzu kommt, »daß wir Deutsche«, wie das »lch« in Friedrich Gedikes Erstlingswerk »Aristoteles und Basedow« (1779) bemängelt, »zweierlei Schrift haben, eine für den Druk, eine andre zum Schreiben«. Und weiter: »Unsre Kinder müssen also einerlei Sache zweimal lernen, und unter dem gemeinen Mann findet man alle Augenblicke Leute, die zwar gedruktes, aber nicht geschriebnes lesen können." (Friedrich Cedike, Aristoteles und Basedow oder Fragmente über Erziehung und Schulwesen bei den Alten und Neuern, Berlin, Leipzig 1779, S. 128)

69 Heinrich Stephani, Ausführliche Beschreibung meiner einfachen Lese-Methode, Erlangen 1814, S. 12.

70 Ebd.

71 Heinrich Bosse, »Die Schüler müßen selbst schreiben lernen< oder: Die Einrichtung der Schiefertafel«, in: ders., Bildungsrevolution 1770-1830, hg. v. Nacim Chanbari, Heidelberg 2012, S. 161-236, hier: S. 172. 
ferentiell ist. Schreiben erscheint in dieser Konstellation als reine "Buchstabenmahlerei«, so Stephani. ${ }^{72}$ Stephani merkt kritisch an, im Schreibunterricht sei das Mittel mit dem Zweck vertauscht worden, auch weil die »bisherige mechanische Schreibmethode ${ }^{73}$ die Schüler in seinen Augen kaum über die Ebene einer handwerklichen Fertigkeit hinausführt. Als eigentlichen, aber verfehlten Zweck dieser Fertigkeit benennt Stephani eine »höhere Schreibekunst ${ }^{74}$, also die Fähigkeit, »die eigenen Gedanken wohlgeordnet in der Gesichtssprache auszudrücken ${ }^{75}$, das heißt: die Schrift als visuelles Medium gesprochener Sprache zu gebrauchen. Stattdessen erkennt er im Schreibunterricht einer zeitlich nicht näher bestimmten Vergangenheit eine andere Zielsetzung: »Man wollte lauter Kalligraphen (Schönschreiber) aus unsern Schülern bilden, als wenn alle Schüler die Bestimmung hätten, durch diese Profession sich einstens zu ernähren«, formuliert der Pädagoge pointiert. ${ }^{76}$

Als Stephani dies 1835 in einem Handbuch niederlegt, hält sich die Kritik am gängigen Schreibunterricht hartnäckig seit mehreren Jahrzehnten. Stephani reagiert auf diese Kritik, indem er 1815 einen eigenen Ansatz präsentiert: die genetische Schreibmethode, die auf wenigen Grundlinien fußt. Auch bei dieser Methode steht die Materialität des Schreibens anfangs im Mittelpunkt, denn selbstverständlich will das Schreiben erst einmal gelernt sein. Allerdings ist die genetische Schreibmethode in der Theorie so angelegt, dass nicht nur eine technische Fertigkeit erworben wird, sondern sich auch ein pädagogisch-didaktischer Anspruch realisiert: Die Schreibschüler sollen sich selbst bilden, indem sie nach bestimmten Prinzipien Buchstaben bilden. Dahinter steht ein Entwicklungsgedanke, der von der »niederen Schreibekunst $^{77}$ - wie Stephani sie 1815 zunächst nennt - zur »höheren Schreibekunst« führt, der bei der Hand ansetzt, um den Kopf zu erreichen und so zu mobilisieren, dass Schreiben am Ende etwas anderes meint als den geschickten Umgang mit Feder oder Bleistift, nämlich im übertragenen Sinn: seine Gedanken zu Papier zu bringen.

72 Heinrich Stephani, Ausführliche Beschreibung der genetischen Schreibmethode für Volksschulen, Erlangen 1815, S. 5.

73 Heinrich Stephani, Handbuch der Unterrichtskunst nach der bildenden Methode für Volksschullehrer, Erlangen 1835, S. 144.

74 Ebd., S. 153.

75 Ebd., S. 144.

76 Ebd.

77 Heinrich Stephani, Ausführliche Beschreibung der genetischen Schreibmethode, S. 5. 
Trotz solcher Reformansätze wird die Materialität des Schreibens um 1800 nie gänzlich überformt durch die reflexive oder kommunikative Funktion dieser Praktik, sondern sie weist eine bemerkenswerte Eigenständigkeit auf, die im Schreibenlernen ihren Ausgang nimmt. Materialität fungiert in diesem Zusammenhang als Oberbegriff für zwei Phänomenbereiche des Schreibens, die untrennbar miteinander verbunden sind: Da wäre zum einen der Bereich der Schreibmaterialien, zum anderen der Graphismus der Schrift in operationaler Hinsicht. Für Anfänger steht der Schriftgebrauch um 1800 im Horizont eines schwer zu erlernenden Umgangs mit Werkzeugen wie der Schreibfeder. Zugleich wird die Handhabung solcher Utensilien durch die graphischen Figurationen der Schrift bestimmt. Bildungsreformern des frühen 19. Jahrhunderts wie Stephani bieten beide Phänomenbereiche immer wieder Ansatzpunkte zur Umsetzung ihrer Konzepte - zumindest theoretisch.

Auch außerhalb des schulischen Bereichs ist die Materialität des Schreibens um 1800 überaus präsent. So zählt Bettine von Arnim in einem Brief an die Mutter Goethes eine Reihe von Gründen auf, die ihr Briefeschreiben komplizieren, darunter, dass sie "gern grade Linien und schöne Buchstaben machen $^{78}$ möchte. Auch Goethes arabische Schreibübungen aus den Jahren, in denen er am »West-östlichen Divan« (1814-1819) arbeitete $^{79}$, erscheinen weniger irritierend, wenn man die Persistenz eines auf materiale Aspekte konzentrierten Schreibens berücksichtigt, die beim Schreibenlernen ihren Ausgang nimmt.

Dass ein Sensorium für die Materialität des Schreibens nicht erst zu Beginn des 19. Jahrhunderts ausgeprägt ist, sondern vielmehr auf einem verbreiteten, älteren Wissen basiert, zeigt der Blick in ein bedeutendes Nachschlagewerk des 18. Jahrhunderts. In der Enzyklopädie von Johann Heinrich Zedler ist im Eintrag »Schreiben« nachzulesen:

»Schreiben, Lat. Scribere, heißt eigentlich nichts anders, als mit Feder und Dinte gewisse Züge auf das Papier machen, oder durch verständliche Worte und Ausdrückungen seine Gedancken darauf entwerffen. Oder: Schreiben

78 Bettine von Arnim, Goethe's Briefwechsel mit einem Kinde, Werke und Briefe, hg. v. Walter Schmitz, Sibylle v. Steinsdorff, Frankfurt a.M. 1986-2004, II (1992), S. 44.

79 Andrea Polaschegg, »)diese geistig technischen Bemühungen...<. Zum Verhältnis von Gestalt und Sinnversprechen der Schrift: Goethes arabische Schreibübungen und E.T.A. Hoffmanns Der goldene Topf«, in: Cernot Crube, Werner Kogge, Sybille Krämer (Hg.), Schrift. Kulturtechnik zwischen Auge, Hand und Maschine, München 2005, S. 279-304. 
heisset dasjenige in diß und das Zeug ritzen und graben, oder mit allerhand Farben oder Säfften verständlich mahlen, was man Buchstaben zu nennen pfleget, und durch welcherley Zeichen Menschen sich unter einander, verglichener oder hergebrachter massen, ihre Gedancken auch in Abwesenheit zu verstehen geben können, auch zu geben pflegen. ${ }^{80}$

In dieser Beschreibung wird die Materialität des Schreibens in besonderer Weise hervorgehoben. Dass es bereits ausreichend ist, "mit Feder und Dinte gewisse Züge auf das Papier [zu] machen«, um eine Tätigkeit als Schreiben bezeichnen zu können, verdeutlicht die Disjunktion, durch welche die zweite Bedeutung, nämlich »durch verständliche Worte und Ausdrückungen seine Gedancken « festzuhalten, angeschlossen wird. Freilich sind es nicht beliebige, sondern "gewisse Züge«, die das Schreiben charakterisieren, und dieser Aspekt wird in den weiteren Ausführungen bemerkenswert differenziert dargestellt. Daneben ist es vor allem der Graphismus, der herausgestellt wird, wenn es als »ritzen und graben« oder ein »verständlich mahlen« dessen bestimmt wird, »was man Buchstaben zu nennen pfleget«. Erst im Nachsatz werden Buchstaben als Zeichen deklariert.

In seinen 2006 erstmals auf Deutsch erschienenen »Variationen über die Schrift« (1973) interessiert sich der französische Kulturtheoretiker Roland Barthes für die »Schreibung« (»scription«), womit der »muskuläre Akt des Schreibens, der Prägung der Buchstaben« gemeint ist, »dieser Gestus, mit dem die Hand ein Werkzeug ergreift (Stichel, Schreibrohr, Feder), es auf eine Oberfläche stützt und darauf, eindrückend oder sanft streichend, fortgleitet und regelmäßige, rhythmische, wiederkehrende Formen einprägt (mehr braucht nicht gesagt $\mathrm{zu}$ werden: es handelt sich nicht zwangsläufig um >Zeichen $\triangleleft) . \ll^{81}$

Der von Barthes beschriebene »Akt des Schreibens « lässt sich mit der von Rüdiger Campe aufgemachten »Schreibszene« in Korrespondenz setzen, allerdings mit einer Einschränkung: Campe definiert die »Schreibszene« als ein "nicht-stabiles Ensemble von Sprache, Instrumentalität und Geste ${ }^{82}$. San-

80 Art. »Schreiben, Lat. Scribere«, in: Johann Heinrich Zedler (Hg.), Grosses vollständiges Universal-Lexicon aller Wissenschaften und Künste, Leipzig, Halle 1731-54, 35 (1743), Sp. 1142-43, hier: Sp. 1142.

81 Roland Barthes, Variations sur l'écriture - Variationen über die Schrift (1973), übers. v. H.-J. Ortheil, Mainz 2006, S. 7.

82 Rüdiger Campe, »Die Schreibszene, Schreiben« (1991), in: Sandro Zanetti (Hg.), Schreiben als Kulturtechnik. Grundlagentexte, Berlin 2012, S. 269-282, hier: S. 271. 
dro Zanetti hat den ersten Punkt dieser Aufzählung diskret auf »Sprachlichkeit/Semiotik « ${ }^{83}$ ausgeweitet, was vor allem deutlich macht, dass Schrift auch anders codiert sein kann als sprachlich. Aber anders als bei Barthes bleibt eine Möglichkeit unberücksichtigt: dass die aus dem Schreibakt hervorgehenden »Formen « nicht zeichenhaft sind. Die »Schreibszene« des Schulunterrichts um 1800 wirft die Frage auf, wie ein Schriftgebrauch einzuordnen ist, der sich weitgehend auf die "graphische Dimension« von Schrift konzentriert, weil er wenig mehr ist als »Buchstabenmahlerei«. Denn diese »Buchstabenmahlerei« meint bis ins 19. Jahrhundert ein Kopieren von Schriftmustern, das sich mitunter über ein halbes Dutzend Jahre hinziehen kann. ${ }^{84}$ Dabei erscheint die übliche Zeichenfunktion der Schrift mindestens nebensächlich, geht es doch weniger um die Repräsentation gesprochener Sprache als um die Reproduktion graphischer Figurationen unter Verwendung vielfältiger Werkzeuge. Am ehesten lassen sich die Grapheme in den Schreibbüchern der Schüler noch als ikonische Zeichen begreifen, die nach der Definition von Peirce »die Ideen der von ihnen dargestellten Dinge einfach dadurch vermitteln, daß sie sie nachahmen $\ll^{85}$.

\section{Kalligraphie und Pädagogik: Schreibunterricht um 1800}

Es gibt um 1800 im deutschsprachigen Raum so viele und noch dazu verschiedene Anleitungen zum Schreiben, dass sich schwerlich ein durchgängiges Konzept beobachten lässt. So beklagt J.C. Hennig in dem von ihm herausgegebenen »Magazin der Schreibkunst« (1821), »daß für das Schreiben keine allgemeinen Grundsätze gelten, und jeder Schreiblehrer seine eigene Art zu schreiben und zu lehren habe ${ }^{86}$. Vor diesem Hintergrund fällt es einigermaßen schwer, von dem Schreibenlernen um $1800 \mathrm{zu}$ sprechen. Dennoch lässt sich von einem Schreibunterricht ausgehen, der lange unverändert bleibt, trotzdem er in der Sattelzeit mit vielen Reformansätzen bedacht wird. Ot-

83 Sandro Zanetti, »Einleitung«, in: ders. (Hg.), Schreiben als Kulturtechnik. Grundlagentexte, Berlin 2012, S. 7-34, hier: S. 21.

84 Stephani, Ausführliche Beschreibung dergenetischen Schreibmethode, S. 5.

85 Charles Sanders Peirce, Semiotische Schriften, hg. v. Christian ]. W. Kloesel, Helmut Pape, Frankfurt a.M. 1986, I, S. 193.

86 J.C. Hennig, Magazin der Schreibkunst, Berlin 1821, S. 2. 
to Ludwig stellt fest, dass die »alten Schreibübungen« des 18. Jahrhunderts »nicht mehr als kalligraphische Übungen ${ }^{87}$ gewesen seien.

Kennzeichnend für diese Übungen ist ein einfaches Prinzip der Nachahmung, das um 1800 in der Regel abwertend als Mechanismus beschrieben wird. Es handelt sich um ein Prinzip, das trotzdem noch immer die Aneignung von Wissen und Fertigkeiten bestimmt. Eindrücklich beschreibt der Erlanger Pfarrer und Pädagoge Johann Paul Pöhlmann, der den Schreibunterricht ausdrücklich als »Verstandesübung« aufgefasst sehen will, gegen welche Praxis er sich richtet. Aufschlussreich sind seine Zeilen auch deshalb, da Pöhlmann materialen Aspekten besondere Beachtung schenkt:

»Ohne alle Vorbereitung setzt man den kleinen Schreibeschüler mit seiner neu geschnittenen Feder, und mit seinem in Octav gebrochnen Bogen Papier an den Schreibetisch, linirt ihm eine Seite, schreibt ihm einen Buchstaben (oft nicht einmal den einfachsten,) vor und sagt: da! das machst du nach. Will man ihm die Sache ja recht erleichtern, so zieht man ihm wohl noch die Buchstaben mit Bleystift vor, und läßt sie ihn mit Dinte überschmieren. ${ }^{88}$

Man kann diese Beschreibung durchaus als exemplarisch ansehen, auch wenn ein solcher Schreibunterricht in vielen Details variiert. Entscheidend ist in jedem Fall das vom Lehrer vorgegebene Schriftbild, die Vorschrift, die um 1800 nicht selten als Kupferstich vorliegt. Schreiblehrbücher konzentrieren sich meist auf diese Vorschriften, von denen einige wenige eine relativ hohe Bekanntheit erlangen, weil sie über Jahrzehnte in Gebrauch sind. Das gilt unter anderem für das 1714 in Preußen erstmals aufgelegte "Schreibevorschriftsbuch« des »alten Hilmar Curas«, das in E.T.A. Hoffmanns »Lebens-Ansichten des Katers Murr« (1819/21) eben diesem Kater als Anleitung für das autodidaktische Schreiben dient. ${ }^{89}$

Das Prinzip der Nachahmung bleibt nach 1800 erhalten, aber buchstäblich unter anderen Vorzeichen: Durch eine Methodisierung des Schreibunter-

87 Otto Ludwig, »Alphabetisierung und Volksschulunterricht im 19. Jahrhundert. Der Beitrag der Schreib- und Stilübungen«, in: Dieter Cherubim, Siegfried Crosse, Klaus ]. Mattheier (Hg.), Sprache und bürgerliche Nation. Beiträge zur deutschen und europäischen Sprachgeschichte des 19. Jahrhunderts, Berlin 1998, S. 148-166, hier: S. 152.

88 Johann Paul Pöhlmann, Meine Schreiblectionen oder praktische Anweisung für Schullehrer, welche den ersten Unterricht im Schönschreiben zugleich als Verstandesübung benützen wollen, Fürth 1803 , S. IV.

89 E.T.A. Hoffmann, Lebens-Ansichten des Katers Murr, Sämtliche Werke, hg. v. Wulf Segebrecht, Hartmut Steinecke, Frankfurt a.M. 1985-2004, V (1992), S. 43. 
richts soll dem häufig bemängelten »Schlendrian« begegnet werden und eine Bewegung »von der Ästhetik zur Pädagogik «" ${ }^{90}$ vollzogen werden. In diesem Sinne stellt Stephani im Jahr 1815 fest, dass »die in kalligraphischer Hinsicht guten Handschriften [...] dieß nicht immer in pädagogischer [Hinsicht sind], weil sie nicht nach Prinzipien geformt sind ${ }^{91}$. Ludwig spricht im Hinblick auf die Vermittlungsansätze des 19. Jahrhunderts dezidiert von einem »anderen Begriff von Schreiben $\ll^{92}$.

\section{Materialität des Schreibens I: Schreibmaterialien}

Die Etymologie von Schreiben verweist auf die Materialität von Schreibutensilien ebenso wie auf die Körperlichkeit dieser kulturellen Praktik. Im Althochdeutschen gibt es das Verb "scrīban«, das laut Bosse auf das lateinische "scrībere« zurückgeht. »Scrībere« hat einen indogermanischen Ursprung, der »kratzen, ritzen « bedeutet. ${ }^{93}$ Ein entsprechendes Verständnis des Schreibens ist in der zweiten Hälfte des 18. Jahrhunderts durchaus präsent. Dies offenbart das Register von Jean Pauls Exzerpten, in dem »Schreiben « gemeinsam mit »Abzeichnen « und »Eingraben « eine Rubrik bildet. ${ }^{94} \mathrm{Um} 1800$ sind die wichtigsten Materialien zum Schreiben sicherlich Feder, Tinte und Papier. Hinzu kommen Utensilien wie Federmesser, Tintenfass und Streusand, ebenso Bleistift und Rötelstift. Im Schreibunterricht sind zudem Tafeln aus verschiedenen Materialien wie Schiefer oder Holz sowie passende Griffel und auch Farben in Gebrauch. Schreiben setzt als kulturelle Praktik ein umfängliches und teilweise sehr detailliertes Wissen sowie praktische Kenntnisse und Fertigkeiten in Bezug auf die Schreibmaterialien voraus. Daher sind die Schreibmaterialien häufig Gegenstand pädagogischer Theorie und Praxis.

»Die Beschaffenheit der Feder, mit welcher man schreibet, hat bekanntlich den ersten und entschiedensten Einfluß auf die größere oder geringere

90 Günther Schorch, Manuela Böhm, Olaf Cätje, »Ceschichte der Didaktik des Handschreibens«, in: OBST 85 (2014), S. 83-110, hier: S. 86.

91 Stephani, Ausführliche Beschreibung der genetischen Schreibmethode, S. 20.

92 Ludwig, »Alphabetisierung und Volksschulunterricht«, S. 153.

93 Heinrich Bosse, »Schreiben «, in: Heiko Christians, Matthias Bickenbach, Nikolaus Wegmann (Hg.), Historisches Wörterbuch des Mediengebrauchs, Köln 2015, I, S. 482-497, hier: S. 483.

94 Cornelia Ortlieb, »Ochsenknochen, Scherben und Papier. Jean Pauls Schreibmaterialien«, in: Markus Bernauer, Angela Steinsiek, Jutta Weber (Hg.), Jean Paul. Dintenuniversum. Schreiben ist Wirklichkeit, Berlin 2013, S. 130-139, hier: S. 131. 
Vollkommenheit der Schrift«, heißt es in Christian Heinrich Moeckels »Vollständiger Anweisung zur Deutschen Schreibekunst « von $1797 .{ }^{95}$ Nicht alle Vogelfedern sind für den Alltag gleichermaßen geeignet. »Die Gänsekiele sind zum Schreiben die tauglichste und bequemste«, so Ferdinand Christian Moser. ${ }^{96}$ Besonders empfohlen werden Federn aus der Flügelspitze, die lebenden Tieren während des Brachmonats, also im Juni, ausfallen. Doch nicht jede dieser Federn lässt sich verwenden. »Die zweite, dritte und vierte sind die besten; doch können auch die nachfolgenden von Anfängern wegen ihrer Weiche mit Nutzen gebraucht werden«, schreibt Johann Friedrich Heynatz, Lehrer am Grauen Kloster in Berlin, in einem Handbuch für fortgeschrittene Schreiber, das dem Grundlagenwissen zur »Calligraphie« trotzdem viel Raum gibt. ${ }^{97}$ Schreibfedern sind in mehreren Güteklassen erhältlich, wie Karl-Heinz Ziessow herausstellt. Außerdem ist der Grad der Konfektionierung entscheidend für den Preis. Als reine Naturprodukte sind die Federn zum Schreiben nämlich nicht zu gebrauchen. Sie müssen u.a. gehärtet werden. ${ }^{98}$ Wichtig ist ferner der Zuschnitt des Gänsekiels mit dem Federmesser. Dieser erfolgt in Rücksicht darauf, für welche Schrift die Feder benutzt werden soll, ob man eine "gewöhnliche Currentfeder «"9 benötigt oder in Fraktur schreiben will. Aufgrund dieses vielfältigen Bearbeitungsbedarfs enthalten viele Schreiblehrbücher des 18. Jahrhunderts genaue Darstellungen der wichtigsten Arbeitsschritte. Über die Präparierung der Feder können die Lehrkräfte mittelbar Einfluss auf die Handschrift ihrer Schüler nehmen. Moser erklärt beispielsweise, wie eine Feder zu schneiden ist, um das zu feste Aufdrücken des Schreibgeräts zu unterbinden. ${ }^{100}$

95 Christian Heinrich Moeckel, Vollständige Anweisung zur Deutschen Schreibekunst, Altenburg 1797, S. 6.

96 Ferdinand Christian Moser, »Zugabe«, in: Taschenbuch für teutsche Schulmeister 3 (1788), S. 480-483, hier: S. 480.

97 Johann Friedrich Heynatz, Handbuch zu richtiger Verfertigung und Beurtheilung aller Arten von schriftlichen Aufsätzen des gemeinen Lebens überhaupt und der Briefe insbesondere, 2. Aufl., Berlin 1775, S. 24.

98 Karl-Heinz Ziessow, »Den Gedanken zu Papier bringen: Feder und Tinte als Schreibmaterial«, in: ders., Utz Maas u.a., Hand.Schrift-Schreib.Werke. Schrift und Schreibkultur im Wandel in regionalen Beispielen des 18. bis 20. Jahrhunderts, Cloppenburg 1991, S. 37-74, hier: S. 41.

99 Moeckel, Vollständige Anweisung zur Deutschen Schreibekunst, S. 7.

100 Ferdinand Christian Moser, »Der Unterricht im Schreiben«, in: Taschenbuch für teutsche Schulmeister 3 (1788), S. 311-378, hier: S. 322. 
Ohne Tinte lässt sich mit der Feder nicht schreiben. Tinte ist um 1800 aber nicht gleich Tinte. So zahlreich sind die Variationen der zum Schreiben notwendigen Flüssigkeit, dass »[d]as wohlbereitete Dinten-Faß« (1731), ein Bändchen des Theologen Tobias Eisler (Fritando), »allein zwanzig Kochrezepte für die schwarze >Dresdner Dinte`, zehn für rote, neun für grüne, drei für blaue und sechs für gelbe Tinten ${ }^{101}$ enthält. Dabei sind die Grundbestandteile einer schwarzen Schreibtinte eigentlich unveränderlich: Galläpfel und Eisenvitriol (Eisensulfat), gebunden mit Gummi arabicum, einer Zutat, die heute u.a. als Verdickungsmittel in der Lebensmittelindustrie zum Einsatz kommt. Daneben werden Flüssigkeiten wie Essig zum Einkochen benötigt und je nach Rezept noch weitere Stoffe zugesetzt. Schreiblehrbücher des ausgehenden 18. Jahrhunderts enthalten in der Regel genaue Tintenrezepte, damit Schreibmeister bzw. Lehrer die Flüssigkeit selbst herstellen können. Tintenfarben repräsentieren bekanntlich bis heute das Hierarchieverhältnis zwischen Schülern und Lehrern. Korrekturen werden mit roter Tinte angebracht, "womit sonst nur die römischen Kaiser schreiben durften«, wie Jean Paul in seinem Roman »Siebenkäs« festhält (SW I.2, 57).

Papier ist - so Johann Wilhelm Keßler - »das erste und nöthigste Stück zum Schreiben ${ }^{102}$. Es wird um 1800 aufwendig aus Lumpen, sprich: aus Textilien und nicht wie in der Gegenwart aus Holz produziert. Wer schreibt, kennt eine Reihe gängiger Papiersorten mit deutlichen Qualitäts- und Preisunterschieden. Der Altenburger Kanzlist Moeckel lenkt die Aufmerksamkeit für den Ankauf von Papier vor allem darauf, »daß es von Unebenheiten und Unreinigkeiten völlig frey, von gehöriger Stärke und Feinheit und in dem erforderlichen Grade geleimt sey « ${ }^{103}$. Die Leimung ist für das Schreiben besonders wichtig, denn von ihr hängt ab, wie das Papier die Tinte aufnimmt. Für den Schreibunterricht wird das Papier in unterschiedliche Formate gebracht. Häufig ist von »Schreibbüchern « zu lesen, die vermutlich eigenhändig aus $\mathrm{Pa}$ pierbögen hergestellt werden, "anfänglich in Octav, nachher in Quart«, wobei die Lehrer meist selbst die nachzuahmenden Buchstaben in die Bücher eintragen. ${ }^{104}$ Die Schreibbücher fungieren als Medien der Beobachtung und Disziplinierung. Nachvollziehen lässt sich dies am Gebot der Reinlichkeit, nicht zuletzt mit Blick auf die Rhetorik der Kinderseele als eines anfänglich

101 Peter O. Büttner, Schreiben lehren um 1800, Hannover 2015, S. 74.

102 Keßler, Lehrbuch der Kunst schön und geschwind zu schreiben, S. 11.

103 Moeckel, Vollständige Anweisung zur Deutschen Schreibekunst, S. $16 \mathrm{f}$.

104 Bernhard Christoph Ludwig Natorp (Hg.), Briefwechsel einiger Schullehrerund Schulfreunde, 2. Aufl., Essen 1823, S. 181. 
reinen, weil unbeschriebenen Blattes. So steht 1805 in einer hamburgischen Zeitschrift über den Auftrag eines Schullehrers: "Er soll das Kind, das ihm anvertrauet, dessen Seele noch größtentheils ein unbeschriebenes Blatt ist, zum Bürger des Staates heranbilden [...]. ${ }^{105}$ Ausgehend von den Städten gilt Reinlichkeit als eine wichtige, in der Schule zu vermittelnde bürgerliche Tugend. ${ }^{106}$ Das dem Schüler überlassene Heft ist dabei permanent einem der größten Risiken der Schriftkultur ausgesetzt: der Sudelei. Und diese wird ins Verhältnis gesetzt $\mathrm{zu}$ anderen Verhaltensnormen:

»Reinlichkeit muß das erste Gesetz beim Schreibenlernen seyn. Denn ein vollgesudeltes Buch, in welchem man überall die Spuren der Nachlässigkeit findet, wo man bald einen Flecken, bald eine Rasur oder etwas Ausgekratztes, bald ein durchstrichenes Wort, und ausgerissene Blätter gewahr wird, ist eben so nachtheilig als ungewaschene Hände und unsaubere Wäsche. ${ }^{107}$

Obgleich das Schreiben mit Feder und Tinte die Norm bildet, gehen die Vorschläge, mit welchen Materialien im Schreibunterricht anfänglich gearbeitet werden soll, durchaus auseinander. Der Philanthrop Peter Villaume schreibt:

»Ich halte nichts davon, daß die Kinder so früh zu schreiben anfangen, und mit der Feder ihre ersten Uebungen vornehmen. Es ist bei der Feder zuviel zu beobachten: Leichtigkeit, Art die Feder zu halten, Schwung, Reinlichkeit; deswegen lasse ich die Kleinen mit Kreide schreiben, und setze die Uebung mit der Feder bis hierher aus. ${ }^{108}$

In einer Fußnote geht Villaume auf alternative Materialien ein, wie sie in dem von Johann Bernhard Basedow gegründeten »Erziehungsinstitut zu Dessau« (Philanthropinum) zum Einsatz kommen. Dort werden geschwärzte Holztafeln mit Bleiweiß beschrieben, was einen Vorzug hat, den Bosse an der um 1800 zunehmend in Mode kommenden Schiefertafel hervorhebt: Geschriebenes kann selbst verbessert werden. Obwohl er das von Villaume angeführte Beispiel aus Dessau bemerkenswert findet und auch andere Materialien eingehend erörtert, kommt Moser zu dem Schluss: »Man bleibe also bei dem,

105 [Anonymus], »Worte eines Mannes in Bremen, über die Schullehrer, auch von und für Hamburg (I) «, in: Hamburg und Altona 4 (1805), H. 12, S. 306-313, hier: S. 306.

106 Michael Maurer, »Alltagsleben«, in: Notker Hammerstein (Hg.), Handbuch der deutschen Bildungsgeschichte, München 2005, II, S. 33-68, hier: S. 53.

107 Keßler, Lehrbuch der Kunst schön und geschwind zu schreiben, S. 28.

108 Peter Villaume, Praktisches Handbuch für Lehrer in Bürger- und Land-Schulen, Wien 1788, S. 105 [§ 208]. 
was auch bisher noch immer das gewöhnlichste war, bei dem Papier, der Feder und schwarzen Dinte. « ${ }^{109}$

Unterschiedlich fallen die Meinungen aus, wenn es darum geht, die Schreibmaterialien für den Unterricht zu manipulieren. Exemplarisch dürften in diesem Zusammenhang die unterschiedlichen Methoden sein, nach denen Kinder "gerade schreiben lernen ${ }^{110}$. Heinrich Gottlieb Zerrenner erzählt in seinem »Volksbuch« vom Schulmeister Liebermann, der Schreibbücher ausgibt, die "gar sehr klein und so breit [waren], wie etwa zwei gute Finger breit sind, daß die Kinder die Weite, wo sie zu schreiben anfangen und aufhören mußten, desto leichter übersehen konnten«. Auf dieser überschaubaren Fläche platziert der Lehrer »etwa drei bis vier ganz kleine Punkte in der Reihe oder Zeile ${ }^{111}$, die beim Schreiben eine Orientierung geben sollen. Johann Wilhelm Keßler, Organist und Schreibmeister am Gymnasium in Heilbronn, nennt als Mittel zum selben Zweck aufgezeichnete Linien, unterlegbare Linienblätter, deren Markierungen durch das Schreibpapier hindurchscheinen, sowie Papiere, bei deren Herstellung die Linien »durch die messingen Spanndrähte der Form ${ }^{112}$ eingearbeitet werden. Alle diese Hilfsmittel werden von ihm freilich unter Hinweis auf seine eigenen Erfahrungen verworfen. Aus einem weniger pragmatischen Grund lehnt Villaume die unterlegbaren Linienblätter $a b$, die nach der Übung entfernt werden. Diese bergen für ihn »die erste Anlage zu Heucheley, Scheinheiligkeit, Betrug, Arglist ${ }^{113}$ in sich. Weitaus weniger verwerflich werden die Hilfslinien von einem Schulmann gefunden, der in Bernhard Christoph Ludwig Natorps »Briefwechsel einiger Schullehrer und Schulfreunde« über seinen Unterricht berichtet. Er schildert die zeitaufwendige Mühe des Linienziehens, derer er sich durch eine ungewöhnliche Maßnahme entledigt: "Die nehmlichen Linien ritzte ich mit einem jedem Schreibschüler mit einem eisernen Griffel in seine Schiefertafel, und hierdurch erreichte ich den Zweck, den ich vorher nicht $\mathrm{zu}$ erreichen wußte ${ }^{114}$, nämlich einen leichteren und schnelleren Lernerfolg.

109 Moser, »Der Unterricht im Schreiben«, S. 318.

110 Heinrich Gottlieb Zerrenner, Volksbuch. Ein faßlicher Unterricht in nüzlichen Erkenntnissen und Sachen mittelst einer zusammenhängenden Erzählung für Landleute. Erster Theil, Magdeburg 1787, S. 93.

111 Ebd.

112 Keßler, Lehrbuch der Kunst schön und geschwind zu schreiben, S. IX.

113 Villaume, Praktisches Handbuch für Lehrer, S. 107 [§ 214].

114 Natorp (Hg.), Briefwechsel einiger Schullehrer und Schulfreunde, S. 181. 
Dass die Schreibmaterialien ein enormes Veränderungspotenzial in sich tragen, hat Heinrich Bosse herausgearbeitet: Mit der bereits erwähnten Schiefertafel hält um 1800 ein neuer Beschreibstoff Einzug in die Schulen, der nicht nur dazu beiträgt, den Papierverbrauch zu reduzieren. Vielmehr wandelt sich mit dieser Innovation der Unterricht grundlegend, wie Bosse argumentiert. Vermittelt die Schiefertafel doch den »Übergang von der Fremdbestimmung zur Selbstbestimmung«, dadurch, dass sie »Selbstkorrektur an die Stelle von Fremdkorrektur setzen lehrt«. Denn die Schüler können sich nun ohne Aufwand selbst verbessern. Folgt man Bosse, so bewirkt die Schiefertafel dadurch »die eigentliche pädagogische Revolution «. ${ }^{115}$ Somit trägt die Schiefertafel in ihrer spezifischen Materialität dazu bei, einen avancierten Bildungsbegriff in die Praxis zu übertragen. Schließlich soll, so heißt es etwa bei Stephani, »die Handschrift eines jeden Schülers das Produkt besonnener Selbstthätigkeit, keineswegs aber des blinden mechanischen Nachbildungstriebes ${ }^{116}$ sein.

Stephani unterstreicht seinen Reformansatz einer genetischen Schreibmethode, indem er für die Unterrichtspraxis andere innovative Utensilien empfiehlt: »Elastische Schreibtafeln, wie sie in bester Güte von den Gebrüdern Scherer aus Dinkelsbühl fabriziert werden. «117 Tatsächlich hatten die besagten Brüder Joseph und Anton Scherer erst 1812, also drei Jahre vor der öffentlichen Bekanntmachung von Stephanis neuer Methode, in Bayern ein Privileg über die Herstellung von »Papiersteintafeln« erhalten. Diese Tafeln bestanden aus Pappen, die mit einer "schieferartigen Masse ${ }^{118}$ überzogen wurden. Sie waren leichter und weniger fest als Schiefertafeln, die sie ersetzen sollten. Stephani führt gleich mehrere Vorteile dieser Tafeln an, wobei der erste seinem Ideal einer in ihrem Aufbau leicht nachvollziehbaren Schrift geschuldet ist: Buchstaben sollen aus Linien gebildet werden. Stephani nennt es einen Fehler, »daß man gewöhnlich den Schülern sogleich die Feder in die Hand gab, das Werkzeug wodurch man Licht und Schatten in den Buchstabenfiguren hervorbringt, ehe sie noch die bloßen Umrisse zu zeichnen gelernt hatten ${ }^{119}$. »Licht und Schatten« stellt darauf $a b$, dass die Buchstaben mit der

\footnotetext{
115 Bosse, »>Die Schüler müßen ...«, S. 161.

116 Stephani, Ausführliche Beschreibung der genetischen Schreibmethode, S. 10.

117 Ebd., S. 51.

118 Johann Carl Leuchs, Allgemeines Waaren-Lexicon oder vollständige Waarenkunde. Zweiter Theil, Nürnberg 1826, S. 234.

119 Stephani, Handbuch der Unterrichtskunst, S. 146.
} 
Schreibfeder aus dünnen Haarstrichen und dickeren Grundstrichen (Schattenstrichen) aufgebaut werden. Dagegen setzt Stephani, wie er formuliert, das »Linearschreiben«, für das sich die mit dem dünnen Griffel zu bearbeitende Tafel aus seiner Sicht besonders gut eignet.

Nur angedeutet wurde bisher die Bedeutung der Physis im Hinblick auf den Gebrauch der Schreibmaterialien. Der »Stellung des Körpers«sind in vielen Schreiblehrbüchern eigene Kapitel mit überaus detaillierten und deshalb seitenlangen Beschreibungen gewidmet. Diese beziehen sich in unterschiedlicher Gewichtung auf die Schreibhand, den führenden Arm und den Torso. Dargestellt werden kleinteilige Bewegungsabläufe der oberen Extremitäten, aber auch die Körperhaltung insgesamt kommt nicht zu kurz. Es geht vor allem darum, den kindlichen Körper auf die materialen und technischen Anforderungen des Schreibens einzustellen. Nicht zuletzt wird der Beginn des Schreibunterrichts davon abhängig gemacht, ab welchem Alter Kinder physisch in der Lage sind, mit Schreibmaterialien wie der Feder umzugehen. ${ }^{120}$ Gesundheitliche und disziplinarische Aspekte spielen im Hinblick auf die Körperlichkeit des Schreibens ebenfalls eine Rolle.

Für Jacob Friedrich Markwordt steht der Körper im Unterricht an erster Stelle, wobei dieser in der Aufzählung des Berliner Schreibmeisters einen Verbund mit dem Schreibgerät einzugehen scheint: »Der Unterricht hebt zuvorderst damit an, dem Schüler die gehörige Richtung des Leibes, der Arme, der Hände und der Feder zu geben. ${ }^{121}$ Roger Chartier spricht im Hinblick auf diesen Verbund von einer »Instrumentalisierung des Körpers und insbesondere der Hand des Schreibenden, denn diese ist - genauso wie die Feder - ein Werkzeug, das nach eisernen Regeln geprägt werden soll. « ${ }^{122}$ Das Schreiben erfordert demnach eine "harte Körper-Disziplinierung « $"$ "23. Parodiert wird dieser Aspekt in E.T.A. Hoffmanns Erzählung vom Kater Murr, der sich das Schreiben selbst beibringt und angesichts der »Unmöglichkeit, die Feder, den Stift so zu halten« wie ein Mensch eine »dem Bau meines rechten Pfötchens angemessene Schreibart ${ }^{124}$ ersinnt.

120 Moser, »Der Unterricht im Schreiben«, S. 313.

121 Jacob Friedrich Markwordt, Darstellung der Lehrart und Einrichtung in der im Monat Oktober dieses Jahrs zu eröffnenden Schreib-und Elementar-Zeichnenschule, Berlin 1817, S. 40.

122 Roger Chartier, »Macht der Schrift, Macht über die Schrift «, in: Hans Ulrich Gumbrecht, Karl L. Pfeiffer (Hg.), Schrift, München 1993, S. 147-156, hier: S. 154.

123 Ebd.

124 Hoffmann, Kater Murr, S. 43. 
Dass das Schreiben eine Gefahr für Leib und Leben darzustellen vermag, wird bei Keßler hervorgehoben: »Wie manche junge Leute sind nicht schon ungestaltet, bucklicht, hypochondrisch, blinzelnd, kurzsichtig oder gar blind geworden, und haben sich dadurch eine schwächliche Gesundheit und einen frühen Tod zugezogen, blos weil sie beim Schreiben eingebogen sasen [...]. «"25 Mit welcher Detailversessenheit die ideale Haltung des Körpers am Schreibtisch in zeitgenössischen Lehrbüchern beschrieben wird, zeigt sich etwa beim Philanthropen und Volksaufklärer Christian Carl André, der unter anderem vorschreibt, darauf zu achten, dass sich der Oberkörper »beständig in einer geraden Richtung befinde, und nicht gegen die Kante des Tisches gelegt, sondern wenigstens 2 bis 3 Finger breit davon abstehe ${ }^{126}$.

Die genauen Vorgaben verlangen von den Unterrichtenden eine unablässige Beobachtung. Moser empfiehlt dem zuständigen Lehrer, »während des Schreibunterrichts auf alles genau aufmerksam ${ }^{127} \mathrm{zu}$ sein. Was in die Beobachtung alles einzubeziehen ist, wenn sich die Kinder im Umgang mit den Schreibmaterialien mühen, unterstreicht Keßler: "Auch auf die Minen und Geberden hat man Acht zu haben, daß man [...] keine Gesichter schneide $[\ldots] . \ll^{128}$

\section{Materialität des Schreibens II: Graphismus}

Die graphische Dimension des Schreibens basiert auf der Materialität von Schreibmaterialien und deren Gebrauch. Zugleich stellt sich die Frage, ob die im Schreibakt entstehenden Grapheme nicht ihrerseits eine ästhetische Qualität aufweisen, die sich ebenfalls als Materialität beschreiben lässt. In diese Richtung weist Stephan Kammer, wenn er differenzierend von einer »visuellen Materialität« der Schrift in ihren verschiedenen Erscheinungsformen spricht. ${ }^{129}$ Sybille Krämer hat in einem vergleichbaren Zusammenhang den Begriff der »Schriftbildlichkeit« eingeführt, »um das phonographische Schriftverständnis zugunsten eines lautsprachenneutralen Schriftkonzeptes

\footnotetext{
125 Keßler, Lehrbuch der Kunst schön und geschwind zu schreiben, S. 45.

126 Christian Carl André, Erstes Lehrbuch des Zeichnens, Schreibens, Lesens, Rechnens, der französischen und Muttersprache. Zum Gebrauch für Lehrer der Kinder aus den gebildeteren Ständen. Erste Lieferung, Halle 1793, S. 63.

127 Moser, »Der Unterricht im Schreiben«, S. 329.

128 Keßler, Lehrbuch der Kunst schön und geschwind zu schreiben, S. 46.

129 Kammer, »Visualität und Materialität der Literatur«, S. 34.
} 
$\mathrm{zu}$ überwinden ${ }^{130}$. Das bedeutet vor allem, die Schrift nicht selbstverständlich als vermittelte Sprache anzusehen, also nicht so, dass die Materialität von Schrift sich in ihrer Medialität aufhebt, sondern eben diese Materialität als graphische Dimension an und für sich wahrzunehmen.

Genau dies ist im Schreibunterricht um 1800 zu beobachten: Der Graphismus überwiegt so sehr, dass teilweise gar nicht mehr gesprochen wird. "So bestanden die Schreibstunden in einem stummen Vormachen und in einem geistlosen Nachahmen; es war kein Unterrichten, sondern ein Abrichten, kein Erlernen, sondern ein Anlernen«, wirft Karl Kehr im späten 19. Jahrhundert einen kritischen Blick zurück. ${ }^{131}$ Tatsächlich ist es aber nicht der Graphismus, der als pädagogisch-didaktisch defizitär betrachtet wird, sondern die Art und Weise, wie über diesen das Schreiben vermittelt werden soll. Solange die Kalligraphie maßgeblich ist, basiert der Schreibunterricht jeweils auf einer »bildnerische[n] Werklehre ${ }^{132}$, die in der Regel weder systematisch noch verbindlich erscheint. Zwar haben sich zwischen dem 16. und 18. Jahrhundert viele Schreibmeister darum bemüht, die Schrift auf ihre »Fundamente« zurückzuführen, also Buchstaben in wenige Striche aufzulösen, damit sie müheloser zu kopieren sind. Allerdings verliert sich der Ansatz, diese Basis aus übergreifenden Regeln der Geometrie abzuleiten. In der Frühen Neuzeit hat sich die Kalligraphie zudem verselbständigt, sie ist in einem Maße artifiziell geworden, dass es im Laufe des 18. Jahrhundert und auch zu Beginn des 19. Jahrhunderts einiger Anstrengung bedarf, gegen die überbordende Gestaltung eine in jeder Hinsicht leicht nachvollziehbare Schrift zu setzen. ${ }^{133}$ Nicht umsonst lässt Jean Paul die Titelblätter seiner frühen Exzerpte von einem professionellen Schreiber anfertigen. 1817 hält Markwordt anlässlich der Eröffnung seiner in Berlin angesiedelten »Schreib- und Elementar-Zeichenschule« fest:

»Wegen unserer deutschen Handschrift ist hier zu bemerken, daß, so viel mir bewußt, solche bis gegenwärtigen Augenblick sich noch keines festen

130 Sybille Krämer, »Zur Sichtbarkeit der Schrift oder: Die Visualisierung des Unsichtbaren in der operativen Schrift. Zehn Thesen«, in: Susanne Strätling, Georg Witte (Hg.), Die Sichtbarkeit der Schrift, München 2006, S. 75-83, hier: S. 76.

131 Carl Hey, »Die Methodik des Schreibunterrichts in ihrer geschichtlichen Entwicklung", in: Karl Kehr (Hg.), Geschichte der Methodik des deutschen Volksschulunterrichts, Gotha 1877-1893, IV (1889, 2. Aufl.), S. 1-157, hier: S. 23.

132 Werner Doede, Bibliographie deutscher Schreibmeisterbücher von Neudörffer bis 1800 , Hamburg 1958, S. 8.

133 Werner Doede, Schön schreiben, eine Kunst. Johann Neudörffer und seine Schule im 16. und 17. Jahrhundert, München 1957, S. 85. 
Cliedbaus (Systems) zu erfreuen gehabt hat; ganz vorzüglich unsere sogenannte Kurrentschrift. Sie ist und war noch immer ein Spiel der Willkühr ihrer Bildner. ${ }^{134}$

Markwordt gehört zwar nicht zu den namhaften Reformpädagogen seiner Zeit, er verfolgt jedoch einen ähnlichen Ansatz wie Stephani und auch Johann Heinrich Pestalozzi, wenn er dem Schreiben das Zeichnen zugrundelegen will. ${ }^{135}$ "Alles Zeichnen besteht in einer durch Kunstübung erlangten Fertigkeit, sämmtliche sinnliche Gegenstände in Linien bildlich darzustellen", so heißt es bei Markwordt. ${ }^{136}$ Während Stephani bemerkt, »daß die gemeine Schreibekunst eine Schwester der Zeichenkunst sey, und sie daher, wie letztere, von der Linearzeichenkunst ausgehen müsse ${ }^{137}$, geht Pestalozzi in der Denkschrift »Die Methode« (1800) gar von mehr als einer Verwandtschaft aus:

»Das Schreiben ist nichts anders als eine auf willkührliche Formen hinlenkende Liniarzeichnung [...]. Der ganze Erfolg ruhet auf dem höchst einfachen Grundsaz, daß, wer Winkel richtig abtheilen und einen Bogen richtig über den Winkel ziehen kann, die Fundamente der Richtigkeit aller Buchstaben in seiner Hand hat. ${ }^{138}$

Das sich aus dem Zeichnen entwickelnde Schreiben erfüllt klar pädagogische Zwecke. Es soll jeweils dazu beitragen, die Bildungskonzepte von Stephani und Pestalozzi zu realisieren. Namentlich bei Stephani geht es nicht allein um eine Vereinfachung des Schrifterwerbs, wie er betont. Bündig formuliert er, was sein Anspruch ist, wenn er die Kinder nicht mehr stumpf kopieren lässt: "[S]ie sollen sich selbst eine gute Handschrift bilden lernen. ${ }^{139}$ Nachahmung bleibt dabei wichtig, nur mechanisch und somit gedankenlos soll sie nicht sein. Entscheidend ist zudem, dass sich der pädagogische Anspruch nicht erfüllt, indem das Schreiben in den Dienst der Sprache gestellt wird, sondern im Bereich seiner graphischen Dimension.

Spielt die kommunikative Funktion der Alphabetschrift im Unterricht doch eine Rolle, werden also Buchstaben als sprachliche Zeichen einge-

\footnotetext{
134 Markwordt, Darstellung der Lehrart und Einrichtung, S. 26.

135 Büttner, Schreiben lehren um 1800, S. 186-189.

136 Markwordt, Darstellung der Lehrart und Einrichtung, S. 26.

137 Stephani, Handbuch der Unterrichtskunst, S. 146.

138 Johann Heinrich Pestalozzi, Die Methode. Eine Denkschrift Pestalozzi's. 27. Juni1800, Sämtliche Werke, Berlin, Leipzig 1932, XIII (Bearb. v. H. Schönebaum, K. Schreinert), S. 101125, hier: S. 113.

139 Stephani, Ausführliche Beschreibung der genetischen Schreibmethode, S. 36.
} 
führt, so ist zu berücksichtigen, wie das Lesenlernen bis ins 19. Jahrhundert vonstattengeht. Verkompliziert wird das Schreibenlernen auch dadurch, dass potenziell mehrere, »wesentlich verschiedene ${ }^{140}$ Schriften $\mathrm{zu}$ beherrschen sind. Die "Zweischriftenherrschaft ${ }^{141}$ der lateinischen und deutschen Schriften differenziert sich im Bereich der Letzteren weiter aus. Neben der alltagstauglichen Kurrentschrift enthalten die in der kalligraphischen Tradition stehenden Schreiblehrbücher selbstverständlich auch Vorschriften zu Kanzlei und Fraktur, also Schriften, die einen repräsentativen Charakter besitzen. Auch an diesem Punkt setzen Reformen an: August Hermann Niemeyer überlässt die Fraktur den professionellen Schreibmeistern ${ }^{142}$, während es Stephani sogar als »Unfug « ${ }^{143}$ bezeichnet, diese Schriften zu lehren.

Doch es sind nicht allein die verschiedenen Schriften, die vermittelt werden, sondern auch verschiedene Techniken der Graphie, die im Unterricht in ein Verhältnis, oft in ein Konkurrenzverhältnis, zueinander treten. Das heißt, dass der Schreibunterricht vielerorts geprägt wird von meisterhaften Vorschriften im Kupferstich, die als Drucke völlig unberührt sind von den üblichen Limitationen der Handschrift. Schreibt jemand eine "schöne Hand «, wie bei Zerrenner der Schulmann Liebermann, gilt entsprechend als ein größtmögliches Lob, »daß man es fast nicht für Geschriebenes gehalten hätte ${ }^{144}$. Somit fungieren professionell hergestellte technische Reproduktionen von Schriften vielerorts als Ideal der Handschriftlichkeit.

Wenn Markwordt bemängelt, dass »selbst in unseren neuesten Deutschen Schreiblehren« noch viele Buchstaben $\mathrm{zu}$ sehen sind, die »auf wahre einfache Schönheit noch gar keinen Anspruch machen dürfen ${ }^{145}$, so stimmt er grundsätzlich überein mit Stephani, der ebenfalls Schönheit mit Einfachheit verbindet. Ästhetik spielt in den Begleittexten der Schreiblehren eine nachgeordnete Rolle, jedenfalls auf einer theoretischen Ebene, obgleich Keßler daran erinnert, dass es zweifellos auf »den richtigen Begriff der Schönheit « ankomme, die er »vornehmlich in dem richtigen Verhältnis aller Theile eines Buchstaben zum Ganzen, in Ebenmaas und Simplicität, nicht aber in Künsteleien

140 Ebd., S. 19.

141 Doede, Bibliographie deutscher Schreibmeisterbücher, S. 23.

142 August Hermann Niemeyer, Grundsätze der Erziehung und des Unterrichts für Eltern, Hauslehrer und Schulmänner, 5. Aufl., Halle 1802, V, S. 366.

143 Stephani, Ausführliche Beschreibung der genetischen Schreibmethode, S. 19.

144 Zerrenner, Volksbuch, S. 94.

145 Markwordt, Darstellung der Lehrart und Einrichtung, S. 27. 
und bunten Zügen besteht ${ }^{146}$. Dieser auch in der typographischen Ästhetik des 18. Jahrhunderts $\mathrm{zu}$ beobachtende und sicherlich durch das gesteigerte Interesse an lateinischen Schriften und ihren regelmäßigen Attributen beeinflusste Schönheitsbegriff hat letztlich eine überaus praktische Dimension. »Denn die Kunst zu schreiben«, so Keßler, "muß mehr noch durch Uebung als durch Regel erlernt werden. ${ }^{147}$

»Einfachheit« eignet sich als zentraler Begriff dieser praktischen Ästhetik, weil dieser im graphischen Vergleich mit den artistischen Schnörkeln der Vergangenheit evident ist und keiner weiteren Erörterung bedarf. Die Vereinfachung der Schrift dient nach 1800 zweifellos einer pädagogischen Fundierung des Schreibens. Man könnte von einer Elementarbildung der Buchstaben aus wenigen Linien sprechen, die offensiv als »schön« beworben wird. Dies führt zu einer Ästhetisierung von Bildung durch die Bildung von Buchstaben. Stephani führt dazu kontrastierend aus: »In unsern Volksschulen wollen wir künftig nur Schönschreiber, nicht aber Zier- und Kunstschreiber bilden, und daher vest bei dem Grundsatze beharren, daß nur das Einfache wahrhaft schön zu nennen sey. « ${ }^{148}$

Den praktischen Nutzen einer auf Reduktion und Einfachheit gegründeten Ästhetik bringt Keßler auf den Punkt, wenn er schreibt: »Kindern fällt nichts leichter nachzuahmen, als was ihnen auf eine einfache Art gezeigt wird, nichts hingegen schwerer, als was schwer zusammengesezt ist.« Aus diesem Grund spricht er sich dagegen aus, die Schreibübungen mit dem Buchstaben »a« - also in alphabetischer Reihenfolge - zu beginnen, denn das sei »ein Buchstabe, der aus andern entspringt, und wegen seiner Zusammengeseztheit wirklich schwer ist«, so dass ohne eingehende Erläuterungen nur bleibt, diesen »mechanisch nach $[\mathrm{zu}]$ mahlen ${ }^{149}$. Daher gibt Stephani etwa drei Jahrzehnte später für seine genetische Schreibmethode ausdrücklich vor: »Alle Buchstaben müssen sich aber, um auf Einfachheit Anspruch machen zu können, erstlich nur von sehr wenigen Elementen oder Grundlinien herleiten lassen. ${ }^{150}$ So werden Kleinbuchstaben bei ihm auf eine sehr überschaubare Zahl von vier Elementen zurückgeführt: »Diese sind der senkrechte Strich, die halbrunde Linie nach der rechten Hand, die halbrunde Linie nach der

146 Keßler, Lehrbuch der Kunst schön und geschwind zu schreiben, S. $50 \mathrm{f}$.

147 Ebd.

148 Stephani, Ausführliche Beschreibung der genetischen Schreibmethode, S. 24.

149 Keßler, Lehrbuch der Kunst schön und geschwind zu schreiben, S. XIII.

150 Stephani, Ausführliche Beschreibung der genetischen Schreibmethode, S. 24. 
linken Hand, und die größere halbovale Linie nach der rechten Hand $\mathrm{zu}$ geöffnet. « ${ }^{151}$

Die Intention dieses Überblicks war es nicht, das Schreiben aus dem funktionalen Kontext der Schriftsprache herauszulösen, sondern vielmehr, anhand des Schreibenlernens den Fokus so zu verschieben, dass die materiale Bedingtheit dieser kulturellen Praktik als etwas erkennbar wird, das außerhalb des dominanten semiotischen Kontextes liegt. Der Schreibunterricht um 1800 ist für die relative Eigenständigkeit der Materialität des Schreibens nicht nur grundlegend, wie die Kritik an der Schönschreibekunst zeigt, sondern er trägt dieser auch auf vielfältige Weise Rechnung. Letzteres unterstreichen Reformansätze wie derjenige Stephanis. Dass diese Ansätze nur mit Mühe den Mechanismus früherer Dekaden überwinden können, belegt ein Zitat aus den 1850 erschienenen »Aphorismen« des katholischen Pädagogen Lorenz Kellner: »Es gibt keinen trostloseren Unterricht in unseren Volksschulen, als der nach dem gewöhnlichen Mechanismus ertheilte Unterricht im Schönschreiben. ${ }^{152}$

Die vielen Beispiele zeigen, dass der Zugang zur Schrift um 1800 über deren graphische Dimension erfolgt und diese als grundlegend für das Schreiben erachtet wird - sowohl in der Tradition, in der die Generation von Jean Paul steht, als auch in den Ansätzen der Bildungsreformer des frühen 19. Jahrhunderts. Die Vermittlung des Schreibens wird in einem hohen Maße durch graphische Nachahmung bestimmt. Dazu tragen auch die Korrespondenzen zwischen der visuellen Materialität von handgeschriebenen und drucktechnisch hervorgebrachten Buchstaben bei. Aufzeigen lässt sich dies anhand der Fraktur in den frühen Exzerpten Jean Pauls, insofern als diese Schrift eine kalligraphische Meisterleistung und im deutschsprachigen Raum zugleich die bevorzugte Druckletter darstellt. Vor diesem Hintergrund wird nachvollziehbar, mit welcher Konsequenz sich Jean Paul der visuellen Gestaltung seiner Exzerpte widmet, die wie Drucke aussehen oder zumindest deren paratextuelle Charakteristika abbilden sollen. Im Hinblick auf die noch zu behandelnden literarischen Texte ist zudem das Nahverhältnis von hoher Bedeutung, das zwischen dem Schreiben als graphischem Verfahren und Reproduktionstechniken wie dem Buchdruck und dem Kupferstich besteht. Sowohl das Schulmeisterlein Maria Wutz als auch Quintus Fixlein gefallen sich nicht nur als gelehrte Autoren, die handgeschriebene Bücher vorweisen können, sie

151 Ebd.

152 Lorenz Kellner, Die Pädagogik der Volksschule in Aphorismen, Essen 1850, S. 68. 
sind zugleich Figuren mit einer ausgeprägten Leidenschaft für graphische Arbeiten.

\subsection{Handgeschriebene Bücher in der Fiktion: Maria Wutz und Quintus Fixlein}

In der Erzählung vom »Leben des vergnügten Schulmeisterlein Maria Wutz in Auenthal« werden die handgeschriebenen Bücher der Hauptfigur besonders exponiert, wenn es auf einer der ersten Seiten heißt:

»Der wichtige Umstand, bei dem uns, wie man behauptet, so viel daran gelegen ist, ihn voraus zu hören, ist nämlich der, daß Wutz eine ganze Bibliothek - wie hätte der Mann sich eine kaufen können? - sich eigenhändig schrieb. Sein Schreibzeug war seine Taschendruckerei [...].«(SW I.1, 425)

Es wurde eingangs bereits angedeutet: Wutz verfasst die Bücher, die er gerne lesen würde, von denen er aber wenig mehr kennt als ihre Titel. Er entnimmt die Titel und weitere bibliographische Angaben aus dem Messkatalog und erfindet den Rest selbst, im Grunde das ganze Buch. Seine Eigenproduktion wirft ein Licht auf die im späten 18. Jahrhundert vielfältigen Formen sekundärer Rezeption, für die der Messkatalog ebenso grundlegend ist wie das Angebot an Rezensionsorganen und Literaturzeitschriften. Nicht wenige Leser kommen mit der Literatur der Epoche ausschließlich über diese Publikationen in Kontakt, also über Sekundärmedien, was dem Diskurs über eine Neuerscheinung keineswegs abträglich ist. Auch Jean Paul greift für seine frühen Exzerpte in einem beträchtlichen Maße auf Rezensionsorgane wie die »Allgemeine Deutsche Bibliothek« (ADB) zurück. Anders als der Messkatalog dienen die Periodika dazu, die Leser, wie Martin Gierl schreibt, »unabhängig vom Buch $\ll^{153}$ zu machen. Dafür birgt der Katalog in Ermangelung der Bücher das Potenzial, die Imagination seiner Leser in Gang zu setzen, wie letztlich auch das Beispiel von Wutz zeigt.

Eindrücklich beschrieben wird die Wirkung des Messkatalogs auch in August Lafontaines »Leben eines armen Landpredigers« von 1801, einem Roman,

153 Martin Gierl, »Kompilation und die Produktion von Wissen im 18. Jahrhundert«, in: Helmut Zedelmaier, Martin Mulsow (Hg.), Die Praktiken der Celehrsamkeit in der Frühen Neuzeit, Tübingen 2001, S. 63-94, hier: S. 80. 
dessen Protagonist einen mit Wutz vergleichbaren sozialen Status hat. Hier heißt es:

»An neuere Lektüre war nicht zu denken: den Meßkatalogus ausgenommen, den mein Schwager, der Papiermüller, mir von Leipzig mitbrachte. Hatte ich den gelesen, und dann noch einen Stoß Recensionen, den ich ebenfalls von ihm bekam, und wodurch ich doch einigermassen mit der litterarischen Welt in Verbindung blieb, so regte sich vier Wochen hindurch meine Schreibbegierde. $\ll^{154}$

Statt einer »Schreibbegierde« empfindet Wutz einen »Schriftstellertrieb « (SW I.1, 457), aus dem heraus im Kindesalter jedoch nicht Texte entstehen, sondern seine Buchbasteleien. Auch später, wenn er seine handgeschriebenen Bücher anfertigt, spielt die Materialität seiner Produktion in Relation zum gedruckten Buch eine besondere Rolle, etwa wenn er, wie eingangs erwähnt, "seinen Bogen in die Quere « legt, sobald er sich einen Titel vornimmt, der im Querformat erschienen ist. Auch seine Handschrift wird in diesem Zusammenhang relevant, eine Handschrift, die - so hofft Wutz - »ebenso leserlich, wenn nicht besser als irgendein Mittel-Fraktur-Druck« (SW I.1, 426) sei. Um das Vorgehen von Wutz zu verdeutlichen, wird ein Vergleich angestrengt, der nicht zuletzt deshalb aufschlussreich ist, da er nicht mit einem Nachschreiber verglichen wird, sondern mit einem »Nachdrucker«: »Er war kein verdammter Nachdrucker, der das Original hinlegt und oft das meiste daraus abdruckt: sondern er nahm gar keines zur Hand.« (SW I.1, 426)

Die Art der Nachahmung, die Wutz praktiziert, erscheint auf den ersten Blick kurios. Angesichts eines literarischen Diskurses, der gut ohne die Bücher auskommt, um die er sich eigentlich dreht, da Sekundärmedien deren mangelnde Verbreitung kompensieren, stellt sich diese Nachahmung jedoch nur bedingt als Kuriosum dar. Die Nachahmung bezieht sich in erster Linie auf die äußere Form der Bücher, während letztlich das, was Wutz aufschreibt, in der Erzählung weitgehend im Dunkeln bleibt. Originell sind die unbekannten Inhalte seiner handgeschriebenen Bücher in dem Sinne, dass sie ohne Lektüre zustande kommen, also frei erfunden sind.

Interessant ist, in welches Verhältnis Wutz seine Artefakte zu den gedruckten Büchern setzt, die ihm die Anlässe zum Schreiben geben. Wutz gelangt zu der Überzeugung, »seine Schreibbücher wären eigentlich die kanonischen Urkunden, und die gedruckten wären bloße Nachstiche seiner ge- 
schriebenen« (SW I.1, 426). Die »Schreibbücher« rücken in dieser Betrachtung an jene Stelle, die im Prozess der Buchproduktion die Manuskripte einnehmen, deren handschriftliche Texte durch den Druck reproduziert werden. Unterstrichen wird diese Reihenfolge dadurch, dass von den Manuskripten des Schulmeisterleins als »kanonischen Urkunden« die Rede ist, womit ihnen also der Status religiöser Urtexte zugemessen wird. Zugleich spielt Jean Paul hier mit der Semantik von »Urkunde«, denn um 1800 haben - so Adelung - »einige Schriftsteller angefangen, dieses Wort [...] für Original zu gebrauchen « ${ }^{155}$. In dieser Bedeutung bildet »Urkunde« den Gegenbegriff zur »Copie«, und als »Nachstiche« werden sie auch in diesem Sinne bezeichnet, wobei der grundsätzliche Reproduktionscharakter der Typographie eine Berücksichtigung findet. Herausgestellt wird durch die Rhetorik dieser Passage die Bildlichkeit von Schrift, ihre Ikonizität.

Dass es im Hinblick auf die visuelle Materialität entscheidend auf das "Schreibzeug« ankommt, das Wutz als »Taschendruckerei« gebraucht, ist eingangs dieses Kapitels bereits angedeutet worden. Das »Schreibzeug« kommt auch ins Spiel, als sich Wutz die »Messiade« von Klopstock vornimmt. In diesem Fall substituiert das durch die Feder beeinflusste Schriftbild den als schwer zugänglich eingestuften Text, so dass erneut deutlich wird, in welchem Maße Wutz über die äußere Form seiner handgeschriebenen Bücher den Bezug zu der von ihm begehrten Literatur herstellt:

»Unter dem Kaffee schnitt er sich, außer den Semmeln, die Federn zur Messiade, die er damals, die drei letzten Cesänge ausgenommen, gar aussang. Seine größte Sorgfalt verwandte er darauf, daß er die epischen Federn falsch schnitt, entweder wie Pfähle oder ohne Spalt oder mit einem zweiten Extraspalt, der hinausniesete; denn da alles in Hexametern, und zwar in solchen, die nicht zu verstehen waren, verfasset sein sollte: so mußte der Dichter, da ers durch keine Bemühung zur geringsten Unverständlichkeit bringen konnte [...], aus Not zum Einfall greifen, daß er die Hexameter ganz unleserlich schrieb, was auch gut war. Durch diese poetische Freiheit bog er dem Verstehen ungezwungen vor.«(SW I.1, 440-441)

Auch im »Leben des Quintus Fixlein« wird den Schreibmaterialien besondere Aufmerksamkeit geschenkt, und zwar in dem Moment, als der Biograph ein handgeschriebenes Buch des Protagonisten entdeckt:

155 Art. »Die Urkunde«, in: Adelung, Grammatisch-kritisches Wörterbuch, IV, Sp. 963-965, hier: Sp. $964 \mathrm{f}$. 
»In der Wohnstube hob ich vom Schreibtisch einen an Rücken und Ecken vergoldeten Band mit dem Rückendekret: >Heilige Reden von Fixlein, erste Sammlung sauf-und da ich nach dem Druckort sehen wollte, war die heilige Sammlung geschrieben. Ich fühlte die Schreibspulen an und tunkte in die Negerschwärze der Dinte ein - und ich befand, daß alles ganz gut war [...].« (SW I.4, 160)

Angesichts der bemerkenswerten Ausstattung hält der Biograph den »vergoldeten Band « zunächst für ein gedrucktes Buch, das sich erst auf den zweiten Blick als mit der Hand geschrieben erweist. Offenbar gelingt es nicht jedem, die Handschrift als solche zu erkennen und damit festzustellen, dass es sich bei Fixleins Büchern nicht um Publikationen handelt, sondern um handschriftliche Artefakte, letztlich Unikate, die durch (materiale) Paratexte gedruckte Bücher nachahmen. So heißt es zu Beginn:

»Fixlein schrieb kleine Werkchen von 1/12 Alphabet, die er im Manuskript, vom Buchbinder in goldne Flügeldecken geschnürt und auf dem Rücken mit gedruckten Lettern betitelt, in die literarische Stufensammlung seines Bücherbrettes mit einstellte. Jedermann dachte, es wären Novitäten, mit Schreiblettern gedruckt.«(SW I.4, 81)

Fixlein wird von Jean Paul als ein subalterner Gelehrter eingeführt, der sich im wörtlichen Sinne als Buchgelehrter charakterisieren lässt. Seine Leidenschaft gilt gedruckten Büchern, er arbeitet »an einer Sammlung der Druckfehler in deutschen Schriften « (SW I.4, 81) und schätzt an seiner Privatbibliothek insbesondere »sein alphabetisches Lexikon von deutschen Bücherpränumeranten « (SW I.4, 82). In diesen Zusammenhang sind auch seine handgeschriebenen Bücher einzuordnen. Zugleich richtet sich Fixleins Interesse auf die konkrete Visualität von Schrift. So erinnert er sich an seine frühe Bildung im kirchlichen Umfeld, daran, wie er die »Polyglotta in Folio«, also eine mehrsprachige Bibel im repräsentativen Großformat barocker Wissensspeicher, "Blatt für Blatt umgeschlagen hatte, um daraus die litteras inversas, majusculas, minusculas etc. mit der größten Mühe zu exzerpieren« (SW I.4, 67-68). Tatsächlich erweist sich dieses Exzerpieren als Nachahmung der gedruckten Lettern. Das wird deutlich markiert durch den nachfolgend beschriebenen Impuls, aufgrund des Schwierigkeitsgrades dieses »Buchstaben-Rauchfutter in einen hebräischen Schriftkasten $[\mathrm{zu}]$ werfen« (SW I.4, 68).

Später offenbart sich dieses Interesse an der Schrift in einer anderen Form. So findet sein Biograph auf Fixleins Schreibtisch nicht nur ein handge- 
schriebenes Buch und Schreibmaterialien, sondern auch eine »Kupferplatte» (SW I.4, 160), deren Bearbeitung sich Fixlein in seiner freien Zeit zuwendet, um das Schreiben in Kanzleien zu verbessern: "Er war so glücklich gewesen, herauszubringen, daß aus einem Zuge, der einem umgekehrten lateinischen S gleichsieht, alle Anfangsbuchstaben der Kanzleischrift so schön und so verschlungen, als sie in Lehr- und Adelsbriefen stehen, herauszuspinnen sind.« (SW I.4, 167) Zum einen lässt sich der virtuose Umgang mit Schriften als eigenständige Kompetenz auffassen, die Gelehrten um 1800 habituell nicht unbedingt eignet, wie das sprichwörtliche »Docti male pingunt« belegt. Zum anderen fungiert das an »Vorschriften« wie der von Fixlein geschulte Schreiben als Bildspender einer Metaphorik, die Verwendung findet, um traditionelle Formen der Gelehrsamkeit abzuwerten, die auf der Reproduktion von Wissen basieren, also insbesondere die auf reinen Papierarbeiten basierende Buchgelehrsamkeit. »Der Geistlose ist ein Schüler, der bei jedem Federzuge sich nach der Vorschrift umsieht ${ }^{156}{ }^{15}$, heißt es in einem Manuskript zu Johann Gottlieb Fichtes »Vorlesungen Ueber den Unterschied des Geistes, u. des Buchstabens in der Philosophie«. Eben diese Rhetorik macht Jean Paul im "Quintus Fixlein« produktiv, indem er sie umkehrt und seinen Protagonisten eine solche »Vorschrift« anfertigen lässt. In der von Fichte eingebrachten Perspektive unterstreichen die graphischen Arbeiten wie bereits die handgeschriebenen Bücher Fixleins Status als Buchgelehrter, im wörtlichen wie im übertragenen Sinn.

Jean Pauls handgeschriebene Bücher lassen sich untereinander nicht einfach vergleichen. Auf der einen Seite stehen die frühen Exzerpte, also real existierende Artefakte, auf der anderen Seite fiktive Produkte, die jeweils in einen diskursiven Zusammenhang des Erzählens eingebettet sind. Aber was diese handgeschriebenen Bücher miteinander verbindet, ist das mimetische Verhältnis, in dem sie auf je unterschiedliche Weise zu gedruckten Büchern stehen, und dieses Verhältnis wird hauptsächlich durch eine Praxis des Schreibens hergestellt, die durch die Nachahmung visueller Materialität gekennzeichnet ist und somit auf der graphischen Dimension von Schrift basiert. Die handgeschriebenen Bücher erhellen den Status und die Bedeutung von gedruckten Büchern und Periodika in der Wissenskultur des späten 18 . Jahrhunderts, die auf vielfältige Weise durch die Materialität ihrer Medien geprägt wird. Sie machen insbesondere deutlich, dass zur Teilhabe an dieser Wissenskultur nicht nur Texte wichtig sind, sondern auch Artefakte.

156 Fichte, Ueber den Unterschied des Geistes, u. des Buchstabens in der Philosophie, S. 320. 


\section{Im Druck erscheinen}

\subsection{Papierne Existenzen: Typographie und Gelehrsamkeit}

Es dauert acht Jahre, bis Johann Georg Meusel das überlange 18. Jahrhundert zu einem Ende bringt. Der Herausgeber des Autorenlexikons »Das gelehrte Teutschland « schickt der fünften Ausgabe seines Nachschlagewerks, das - so der Nebentitel - »alle jetzt lebenden teutschen Schriftsteller« verzeichnet, bis 1808 nicht weniger als vier Nachtragsbände zum 18. Jahrhundert hinterher. Alle Neuerscheinungen des 19. Jahrhunderts lässt der fleißige Historiker und Bibliograph aus Erlangen ${ }^{1}$ währenddessen aus, damit ihm aus dem vorherigen Säkulum bloß niemand entgeht. Doch mit der Zeit muss er die Selbstbeschränkung aufgeben. Denn die Zahl an Publikationen, sie wächst beständig, so dass Meusel auch in seinem berühmten Lexikon die Jahrhundertwende einleiten muss. Der Geschichtsprofessor klagt:

»Ich erlag schier unter dem ungeheuern Anwachs der von mir täglich angemerkten Materialien. Viele Liebhaber dieses unentbehrlich gewordenen litterarischen Hülfsmittels wurden ungeduldig, und harrten der geordneten Anzeige der seit acht Jahren so vieler tausend vorgefallenen Veränderungen in der Teutschen Schriftstellerwelt sehnsüchtig entgegen. «

Tatsächlich ist Meusel wiederholt öffentlich ermahnt worden, endlich ein "gelehrtes Deutschland des neunzehnten Jahrhunderts $\aleph^{3}$ zu liefern. Mit dem

Zur Biographie s. Hans-Otto Keunecke, »Meusel, Johann Ceorg«, in: Neue Deutsche Biographie, Bd. 17, S. $274 \mathrm{f}$.

2 Hamberger, Meusel, Das gelehrte Teutschland, 5. Ausg., XIII (1808), S. VIf.

3 [Anonymus], Rez.»Das gelehrte Teutschland, elfter Band, fünfte Auflage«, in: Allgemeine Literatur-Zeitung 4 (1805), Nr. 297 (13. November 1805), Sp. 301-303, hier: Sp. 303. Das Lexikon gilt im europaweiten Vergleich als einzigartig, siehe dazu Johann Cottfried Eichhorn, Geschichte der Litteratur von ihrem Anfang bis auf die neuesten Zeiten, Cöttin- 
13. Band der fünften Ausgabe beginnt für Meusel eine neue lexikographische Zeitrechnung. Die Masse der Neuzugänge des 19. Jahrhunderts erscheint unüberschaubar. »Nur in den drey ersten Buchstaben allein «, so Meusel, »zähl' ich 328 neue Arbeiter, die zum Theil vielen alten an Geschäftigkeit und an der daher entspringenden Menge der Schriften nichts nachgeben; nämlich im A 60, im B 219 und im C 49. « Insgesamt schätzt Meusel die Zahl der lebenden Autorinnen und Autoren im Jahr 1808 auf 12.000.5 Als 1767 die erste Auflage von »Das gelehrte Teutschland« erschien, verzeichnete Georg Christoph Hamberger, der Begründer und erste Herausgeber, rund ein Viertel dieser Zahl. Die wundersame Vermehrung des »Schriftstellerheers«, wie Meusel zu sagen pflegt, wird von vielen Zeitgenossen aufmerksam registriert, bei Jean Paul finden die Berechnungen von Meusel immer wieder Erwähnung. ${ }^{6}$

Das Schriftstellerlexikon von Meusel zeigt zweierlei: Das Publizieren avanciert um $1800 \mathrm{zu}$ einem sozialen Phänomen, an dem Tausende teilhaben. Und es erhellt, wie Autorschaft sich im »druckpapiernen Weltalter « (SW I.5, 25) konstituiert: mittels Typographie. Nicht nur Texte werden »durch

gen 1805-1812, III.I (1810), S. 557: »Hamberger stiftete 1767 ein gelehrtes Deutschland, das von ihm und nach seinem Tode von Meusel mit solcher Regsamkeit fortgesetzt worden, daß keine Nation sein ganzes Schriftstellerheer sammt dessen Schriften in so vollständigen und genauen Verzeichnissen besitzt."

$4 \quad$ Hamberger, Meusel, Das gelehrte Teutschland, 5. Ausg., XIII (1808), S. VIIf.

5 Hamberger, Meusel, Das gelehrte Teutschland, 5. Ausg., XIII (1808), S. VIII. Mit welcher Aufmerksamkeit diese Zahl verfolgt wird, zeigt exemplarisch eine Rezension im »Ergänzblatt« der »Allgemeinen Literatur-Zeitung«(ALZ) vom 3. Dezember 1812, in der es um den 16. Band der fünften Ausgabe geht. Unter Einbeziehung früherer Angaben Meusels wird der »Bestand des deutschen Schriftstellerheers auf 12,470, oder nach runder Zahl auf 12,500 « summiert, »eine Zahl die sicher nicht übertrieben ist, wenn man bedenkt, wie viele Anonymen [...] unentdeckt und ausgeschlossen bleiben « ([Anonymus], Rez. »Das gelehrte Teutschland, 16. Band, 5. Auflage«, in: Ergänzblätter zur Allgemeinen Literatur-Zeitung (1812), Nr. 133 (3. Dezember 1812), Sp. 1057-1064, hier: Sp. 1058.)

6 In seine Exzerpte übernimmt er beispielsweise aus der Vorrede zum 12. Band (S. VI) der fünften Ausgabe leicht fehlerhaft diese Staffel: »Meusel: im 176oger Jahr war 23000 Aut.; 1788 an 6000; - 1791 an 7000 - 1806 an 10,648« (Fasz. Ilc/41, o.P. [270], Nachlass Jean Paul,Exzerpte. Digitale Edition, [Ilc-41-1810-1811-0270]). Die Zahl 10.648 bezieht Meusel - anders als von Jean Paul wiedergegeben - auf das »Ende des achtzehnten Jahrhunderts «, während er für das Jahr1806 von »ungefähr 11,000 «Schriftstellern ausgeht. Bereits 1796 hatte sich Jean Paul notiert: »In Deutschl[and] nach Meusel 9000 Autor[en].«(Fasz. IVa/13, S. 40 [336], Nachlass ]ean Paul, Exzerpte. Digitale Edition, [IVa-13-1796-1797-0336], URL: www.jp-exzerpte.uni-wuerzburg.de (5.9.2019)). 
den Weg der Presse in die gelehrte Welt gebohren «" ${ }^{7}$, sondern auch menschliche Individuen - als gedruckte Schriftstellerinnen und Schriftsteller. Das typographische Artefakt verhilft zu einer papiernen Existenz, es fungiert in seiner Materialität als Medium der Initiation wie der Repräsentation. Man muss demnach nicht Texte schreiben, sondern welche drucken lassen, um sich im doppelten Sinn einen Namen zu machen (auch als Anonymus). ${ }^{8}$ Kurz gesagt: Autoren erscheinen im Druck.

Zugleich erfordert es Paratexte wie Titelblätter oder -zeilen, um Bücher zu Daten verarbeiten und ihre Urheber in die Ordnung bio-bibliographischen Wissens einfügen zu können. In den Philologien sind wir es gewohnt, solche Paratexte als Rahmung von Texten zu betrachten. Dagegen lehrt uns Meusel, sie als Beschriftungen von Artefakten zu erfassen, deren Materialität die Basis einer autorzentrierten Diskursivität darstellt. Weil die »gelehrte Welt« des 18. Jahrhunderts in der Regel nur das registriert, was im Druck vorliegt mit einem enormen Aufwand an Wissenspraktiken, in der Bildungstradition der um 1800 aus der Mode kommenden Gelehrsamkeitsgeschichte (Historia literaria). Vorgeführt wird die papierne Existenz in Jeans Pauls »Leben Fibels« anhand einer Anekdote, der zufolge ein französischer Lexikograph »das Wort gedruckt als einen Schriftsteller unter dem Titel Mr. Gedruckt an- und fortführt« (SW I.6, 389).

\subsection{Entgrenzung der Gelehrtenrepublik durch Autorschaft}

Trotz des literarhistorischen Hintergrunds bedeutet die Fortsetzung von »Das gelehrte Teutschland« im 19. Jahrhundert keinen Anachronismus, ist sie doch einem grundlegenden Wandel der Buchkultur im komplexen Prozess bürgerlicher Vergesellschaftung um 1800 geschuldet. ${ }^{9}$ Dieser Wandel betrifft auch das Konzept der Autorschaft und mithin die Frage, was es um 1800 heißt, gelehrt zu sein. Laut Heinrich Bosse umfasst die gelehrte Republik lange Zeit die lateinischen Bildungseinrichtungen, den Buchmarkt sowie alle, die lesen, um zu schreiben, wobei eine klassisch fremdsprachliche Lektüre in Latein

7 Justi, »Die Schriftstellersucht«, S. 165.

8 Siehe auch Stephan Pabst, »Anonymität und Autorschaft. Ein Problemaufriss «, in: ders. (Hg.), Anonymität und Autorschaft. Zur Literatur-und Rechtsgeschichte der Namenlosigkeit, Berlin 2011, S. 1-34.

9 Hans-Edwin Friedrich, Fotis Jannidis, Marianne Willems, »Bürgerlichkeit im 18. Jahrhundert«, in: dies. (Hg.), Bürgerlichkeit im 18. Jahrhundert, Tübingen 2006, S. IX-XL. 
vorausgesetzt wird. Daher deckt der Begriff des Gelehrten »eine Reihe von heute ganz getrennten Bedeutungen ${ }^{10}{ }^{\mathrm{ab}}$. Im letzten Drittel des 18. Jahrhunderts »reißt«, so Bosse, »die alte Wechselbeziehung zwischen Buchmarkt und Bildungswesen«, und zwar durch »unmäßige Autorschaft «" ${ }^{11}$ Die »Überdetermination ${ }^{12}$ des Gelehrtenbegriffs führt nun zu einer Öffnung auch des Schriftstellerlexikons, insofern als die notorischen »Halbgelehrten ${ }^{13}$ sich ohne sonstige Weihen durch eine Publikation für dieses empfehlen können. »Gelehrtenrepublik heißt also der ganze Haufe von Schriftstellern, sie mögen nun Bücher oder ein Oktavblatt geschrieben haben, Erfinder einer Wissenschaft oder Gelegenheitsdichterlinge seyn«, ist 1782 bei Johann Melchior Gottlieb Beseke zu lesen, ausgerechnet in einem Band, der anonym in der Dessauer »Buchhandlung der Gelehrten « veröffentlicht wird, die Schreibenden gegen Übernahme der Druckkosten zum Selbstverlag verhilft. ${ }^{14}$

\footnotetext{
10 Bosse, »Die gelehrte Republik«, S. 61.

11 Ebd., S. 66.

12 Ebd., S. 61, Fn. 40.

13 Sie gelten im kulturkritischen Diskurs als Zielgruppe eines als fragwürdig erachteten, unüberschaubaren Publikationswesens, wie eine Polemik aus dem Jahr 1760 zeigt: „Schriftsteller richten sich in unsern Zeiten entweder nach dem Geschmack der großen Anzahl der Halbgelehrten, oder der Buchhändler, und dieser wiederum nach der Mode. Wenn man gleich auf eine kurze Zeit nachgelassen hat, die Buchläden mit verzweifelten Liebes- und jämmerlichen Mordgeschichten zu spicken; so siehet man bald an deren Stelle wie derum eine Menge abentheuerlicher Lebens- und Reisebeschreibungen verirrter Ritter, Bayern, Tyrolerinnen und dergleichen. Man sollte billig in den Bücherverzeichnissen der Buchhändler solche Art Schriften unter einem Haupttitel, z.E. Stultitiensachen bringen, damit die Liebhaber derselben sie beysammen finden und die Gelehrten mit etwas weniger Zeitverlust, die Bücherverzeichnisse durchlesen könnten.« (Johann Carl Conrad Oelrich, Beyträge zur Geschichte und Litteratur, Berlin, Stettin, Leipzig 1760, S. 178, Hervorh. T.F., siehe auch Simons, »Von der Respublica Literaria zum Literaturstaat?«, S. 308f.)
}

14 [Johann Melchior Gottlieb Beseke], Vom Patriotismus in der deutschen Celehrtenrepublik, Dessau, Leipzig 1782, zit.n. der 2. Aufl., Berlin 1794, S. 82. Beseke erörtert an dieser Stelle, ob Schriftsteller ausnahmslos als Gelehrte bezeichnet werden sollten, wobei er zunächst ausführt, wer der »Gelehrtenrepublik« zuzurechnen ist: »In der eingeschränktesten Bedeutung werden nur die Bürger der Gelehrtenrepublik Gelehrte genannt. Um dieses gelehrte Bürgerrecht zu gewinnen, bedarf es nur einer Schrift; daher die Schriftsteller ausschliessungsweise Gelehrte genannt werden. Der Beweis liegt in jedem Kompendium der Gelehrtengeschichte, in jeder Gelehrtenzeitung, in jedem Journal, in jedem Bibliothekensaal. Der gelehrte Prediger, der bey seiner Gemeine den ausgebreitesten Nuzen schaft, sich in den Cirkel seiner Bekannten wegen seiner Gelehrsamkeit, Vertrauen, Liebe, Achtung erworben hat, bleibt der Gelehrtenrepublik, oder 
Was aber macht die Teilhabe an der »Gelehrtenrepublik« qua Autorschaft für Tausende so erstrebenswert? In der sozialen Hierarchie des bürgerlichen Standes rangiert die Bildungselite der Gelehrten nicht allzu hoch, wie Gunter E. Grimm betont. ${ }^{15}$ Johann Jakob Moser erwähnt in seinem Überblickswerk »Von der Teutschen Unterthanen Rechten und Pflichten« (1774) die 1762 im Fürstentum Hessen-Kassel veröffentlichte und als berüchtigt geltende Rangordnung, in welcher »die Doctores denen (vermuthlich Fürstlichen) Cammerdienern, Büchsenspannern und Küchenschreibern, gleich gesezt, und dadurch ernidriget worden ${ }^{16}{ }^{16}$ seien. Außerdem repräsentieren Bücher die im Angesicht der subjektzentrierten Epistemologien der Aufklärungsepoche verbrämte Buchgelehrsamkeit, insbesondere als Wissensform des Polyhistorismus, dem Grimm auch die »Wissenschaftsgeschichte und ausdrücklich Nachschlagewerke wie »Das gelehrte Teutschland « zurechnet $^{17}$. Grimm weist darauf hin, dass sich mit Johann Heinrich Zedler ein Beförderer aufgeklärten Denkens in seinem »Universal-Lexicon« schon vor der Mitte des 18. Jahrhunderts vom Polyhistorismus abgrenzt. ${ }^{18}$ "Die Polyhistorie ist eine Sache, darauf man sich nicht zu legen«, schreibt Zedler. »Denn in allen Theilen der Gelehrsamkeit zeigt sich die Wahrheit in solcher Menge, und die Meditation, so dabey erfordert wird, ist so mühsam, daß das menschliche Leben viel zu kurtz, als daß jemand in vielen Theilen der Gelehrsamkeit zugleich nur mäßige Gelehrsamkeit erlangen sollte. ${ }^{19}$ Zedler markiert aber keineswegs ein Ende des Polyhistorismus, im Gegenteil. 1765 konstatiert

der Gelehrtenwelt ganz unbekannt, so lange er nicht durch irgend eine Schrift den öffentlichen Beweis seiner Gelehrsamkeit gegeben hat. Sein Name und seine Verdienste werden vergessen, ohne daß je in den Annalen der Gelehrsamkeit seiner gedacht würde. Daß die Schriftsteller sich Gelehrte ausschliessungsweise nennen, ist nicht ein Fehler der Selbstsucht, dessen sie leicht von irgend jemanden, der nicht Schriftsteller, aber doch der würdigste Gelehrte seyn kann, beschuldigt werden dürften, sondern ein Sprachgebrauch, der nichts zwischen wahrer Gelehrsamkeit und Unwissenheit entscheidet. «(Ebd., S. 81f.)

15 Gunter E. Grimm, »Vom Schulfuchs zum Menschheitslehrer. Zum Wandel des Gelehrtentums zwischen Barock und Aufklärung«, in: Hans Erich Bödeker, Ulrich Herrmann (Hg.), Über den Prozess der Aufklärung in Deutschland. Personen, Institutionen und Medien, Göttingen 1987, S. 14-38, hier: S. 17. Johann Jacob Moser, Von der Teutschen Unterthanen Rechten und Pflichten, Frankfurt a.M., Leipzig 1774, S. 464.

17 Grimm, »Vom Schulfuchs zum Menschheitslehrer«, S. 25.

18 Ebd., S. 21-23.

19 Johann Heinrich Zedler (Hg.), Grosses vollständiges Universal-Lexicon aller Wissenschaften und Künste, Leipzig, Halle 1731-54, 28 (1741), Sp. 1319. 
Friedrich Justus Riedel: »Die Polyhistors sind so häufig, daß beinahe kein Marktflecken mehr ist, der nicht wenigstens etliche aufweisen könnte und die Schriften, die in jeder Messe zum Vorschein kommen, sind unzählich. « ${ }^{20}$

Der den Vielwissern unterstellte Drang zur Autorschaft ist ein beliebter Gegenstand der Gelehrtensatire der Aufklärung. ${ }^{21}$ Umso erstaunlicher ist der Umstand, dass die als Domäne zweifelhafter Gelehrsamkeit angesehene Autorschaft um 1800 eine offenbar zunehmend reizvolle Subjektform darstellt, so dass mit der bürgerlichen Vergesellschaftung nicht nur eine »unmäßige«, sondern in den Augen vieler Zeitgenossen auch eine übermäßige Autorschaft zu beobachten ist. Friedrich Nicolais Magister Sebaldus Nothanker hatte noch 1773 gefragt: »Wohin soll es mit der deutschen Gelehrsamkeit kommen, wenn der größte Theil der Schriftsteller nicht die Beförderung der Gelehrsamkeit, sondern die Beförderung seines Ruhms und Nutzens sucht. ${ }^{22}$ Doch diese Frage schließt schon nicht mehr mit einem Fragezeichen.

Dass die »alte Wechselbeziehung zwischen Buchmarkt und Bildungswesen« an der Wende zum 19. Jahrhundert noch immer geläufig und durchaus auch prägend ist, zeigen Autorenfiguren wie das Schulmeisterlein Wutz, Quintus Fixlein oder Gotthelf Fibel bei Jean Paul, wenn auch in einer von der Gelehrtensatire vorbereiteten Brechung. Diese Figuren gefallen sich als Gelehrte nach altem Muster. Sie zählen als Schulmeister oder gar Autodidakten jedoch nicht wie der Magister Nothanker zum exklusiveren Kreis der Graduierten. Mit Blick auf ihren sozialen Hintergrund erscheinen diese Figuren vielmehr als Exponenten der von Wehler beschriebenen "Aufsteigerschicht» der »Bürgerlichen ${ }^{23}$ Und es sind eben diese, die um 1800 in $»$ Das gelehrte Teutschland« drängen. So bemerkt ein Rezensent des Lexikons im Jahr 1795 mit einiger Süffisanz die Berücksichtigung mehrerer Bauern und eines Buchbinders aus Altona, um ferner aufzuzählen: »Unter der hier stehenden Gesell-

20 [Friedrich ]ustus Riedel], »Umständlicher Beweiß, daß im heiligen Römischen Reiche viele Narren sind«, in: ders., Sieben Satyren, nebst drei Anhängen, gesammlet von N. N., [Jena] 1765, S. 241-266, hier: S. 253.

21 Wellmanns, Studien zur deutschen Satire im Zeitalter der Aufklärung, S. 68-71; Crimm, »Nachwort«, S. 382f.; Gunter E. Crimm, Letternkultur. Wissenschaftskritik und antigelehrtes Dichten in Deutschland von der Renaissance bis zum Sturm und Drang, Tübingen 1998, S. 202-205; Košenina, Der gelehrte Narr, S. 153-171.

22 Friedrich Nicolai, Sebaldus Nothanker, Sämtliche Werke-Briefe-Dokumente, hg. v. Rainer Falk, István Gombocz, Hans-Cert Roloff, Jutta Weber, Berlin, Stuttgart-Bad Cannstatt u.a. 1991 ff., 1.1 (2015), S. 69.

23 Wehler, Deutsche Gesellschaftsgeschichte, I, S. 204. 
schaft findet man dieß Mahl auch einen Kaminfeger, mehrere Schulmeister, einen Tabacksfabrikanten, einen Küster, und einen Gärtner. « ${ }^{24}$

In dieselbe Zeit fällt eine Ausdifferenzierung des Literaturbegriffs ${ }^{25}$, die sich - wie Andreas B. Kilcher aufgezeigt hat - an einem einfachen Konsonanten festmachen lässt: Aus der Litteratur mit Doppel-t, für Meusel der »Inbegriff der Kenntnisse ${ }^{26}$ der gesamten Menschheit, weil sie eine »Kunst schriftlicher Aufzeichnung von Wissen im allgemeinen Sinn ${ }^{27}$ darstellt, wird um 1800 zunehmend die begrifflich enger gefasste schöne Literatur, reduziert um einen Konsonanten. Sie sorgt nicht allein für eine ungekannte Zunahme der Buchproduktion, sondern etabliert in der zweiten Hälfte des 18. Jahrhunderts auch einen distinkten, höheren Begriff des Schriftstellers, ein neues Ideal der Individualität. Über dem Schriftsteller rangiert im Bereich der schönen Literatur noch der Dichter. ${ }^{28}$ "Das gelehrte Teutschland « entwickelt sich vor diesem Hintergrund vom »litterarischen Hülfsmittel« zu einem Who is who einer sich entgrenzenden Gelehrtenrepublik. Das Schriftstellerlexikon präsentiert ein »Konglomerat « von »Bürgerlichen«, die - so Karl Eibl aus systemtheoretischer Perspektive - »Individualität durch Exklusion, durch Rollendistanz und -bewußtsein« herstellen, was vor allem bedeutet, dass sie verschiedene Rollen anzunehmen im Stande sind. ${ }^{29}$

Eibl beschreibt eine gesellschaftliche Dynamik, die für die vorliegende Arbeit zentral ist. Denn: Autorschaft wird hier als Subjektform betrachtet, die

24 [Kmr.], Rez. »Fünften Nachtrags...«, Sp. 783.

25 Siehe Simons, »Von der Respublica Literaria zum Literaturstaat?«. Simons arbeitet auch heraus, dass die »Öffentlichkeit des Drucks« ein »verwirrendes egalitäres Ethos der Kollegialität durch[setzt], in dem alte Wissensgrenzen und alte Autoritätsgefüge nicht mehr gelten«, wodurch nebenbei das »ubiquitäre Zitieren nun plötzlich zur proliferierenden Praxis wird « (Ebd., S. 300). Johann Georg Meusel, Leitfaden zur Ceschichte der Celehrsamkeit, Leipzig 1799-1800, I (1799), S. 276.

27 Andreas B. Kilcher, »)Litteratur<. Formen und Funktionen der Wissenskonstitution in der Literatur der Frühen Neuzeit«, in: Frank Grunert, Anette Syndikus (Hg.), Wissensspeicher der Frühen Neuzeit. Formen und Funktionen, Berlin, Boston 2015, S. 357-375, hier: S. 360 .

28 Hans Jürgen Haferkorn, »Der freie Schriftsteller. Eine literatur-soziologische Studie über seine Entstehung und Lage in Deutschland zwischen 1750 und 1800«, in: Archiv für Geschichte des Buchwesens 5 (1963), Sp. 523-711, hier: Sp. 527. Haferkorn beleuchtet an derselben Stelle auch die Herkunft des Wortes »Schriftsteller «, das in seinem heutigen Gebrauch erstmals 1723 nachgewiesen und 1748 von Klopstock in seiner »Sprachkunst« aufgegriffen worden sein soll (Ebd.).

29 Eibl, Die Entstehung der Poesie, S. 44. 
sich Individuen in sozialen Praktiken aneignen. Damit ist allerdings keine Festschreibung einer sozialen Rolle verbunden, sondern Autorschaft stellt eine Subjektform neben anderen dar. Gerade in der Pluralität von Rollen liegt, wenn man Eibl folgt, auch die Modernität von Individualität begründet, wobei mit Blick auf den Gegenstand dieser Arbeit festzustellen ist, dass Autorschaft als Subjektform um 1800 besonders geeignet erscheint, das »Bürgerliche« in dieser Hinsicht zu befördern, weil sie sich nicht mehr in die überkommene ständische Ordnung fügt. Genau deshalb stellt Autorschaft, wie Meusel sie begreift, aus der Sicht der katholischen »Oberdeutschen allgemeinen Litteraturzeitung « auch ein Skandalon dar, weil sie zu einer fragwürdigen »Gesellschaft« führt. Es ist bemerkenswert, mit welchen Strategien versucht wird, aus den Tausenden im Lexikon ein Kollektiv zu bilden. Dieses Unterfangen wird in der Rezeption häufig aufgegriffen, etwa durch die verbreitete Rede vom »Schriftstellerheer«. Aber die Leistung von Meusel besteht vor allem darin, in der konsequenten Verbindung von Biographie und Bibliographie die Buchkultur zu einem Schauplatz bürgerlicher Subjektivierung und Individualität $\mathrm{zu}$ machen. Autorschaft bedarf in diesem Zusammenhang nicht allein rezipierbarer Texte, sondern ebenso sozialer Praktiken, die sich auf Bücher und dabei in erster Linie auf Artefakte und Paratexte beziehen. Ein Kennzeichen der besagten »Gesellschaft« ist also, dass für ihre Einheit in der Vielheit nicht entscheidend ist, über was jemand schreibt. Im Lexikon findet so ziemlich alles und jeder Platz, solange etwas Gedrucktes vorliegt.

Möglich wird dies vor allem durch das besondere Auswahlverfahren des Lexikons. Meusel entscheidet nicht unter kritischen Gesichtspunkten, wer in seinem Nachschlagewerk erscheint. In einem anonymen Brief aus Jena, den der Herausgeber eingehend erörtert, muss er sich vorhalten lassen, »von den 10,000 Schriftstellern im gel. Teutschl. wären kaum 50 der Aufnahme in ein solches Werk werth «. ${ }^{30}$ Obwohl auch Meusel die Vielschreiberei beklagt, hält er am Prinzip des Lexikons fest. Im Vorwort zur zweiten Ausgabe hatte bereits Hamberger erklärt, dass eine kritische Auswahl der Absicht des Werks widerstreite. ${ }^{31}$ Das entscheidende Kriterium für die Aufnahme in Das gelehrte Teutschland ist tatsächlich: der Druck eines umfangreicheren Textes. Daher bezeichnet Meusel die von ihm verzeichneten Schriftsteller mit Blick auf

30 Hamberger, Meusel, Das gelehrte Teutschland, 5. Ausg., XIII (1808), S. XV.

31 Hamberger, Meusel, Das gelehrte Teutschland, 2. Ausg., I (1772), [S. II]. 
das Buch als Leitmedium zeitgenössischer Druckkultur auch als »Büchermacher ${ }^{32}$

\section{3. "Schriftstellersucht « und Büchermarkt um 1800}

Die ansteigende Zahl der Schriftsteller korrespondiert mit der rasanten Entwicklung des Buchmarktes im letzten Drittel des 18. Jahrhunderts. Es wird in diesen Jahren in den deutschsprachigen Ländern mehr gedruckt als je zuvor: Zwischen 1765 und 1800 steigt allein die Zahl der zur Leipziger Buchmesse angezeigten Neuerscheinungen von 1.517 auf über 4.000 an. ${ }^{33}$ Daneben werden in beträchtlicher Zahl neue Zeitschriften und Zeitungen aus der Taufe gehoben. ${ }^{34}$ Das Buch dient in diesem Zeitraum immer weniger rein akademischen Zwecken. Es entsteht ein bürgerliches Publikum und mit ihm eine veränderte Nachfrage - hinsichtlich des Inhalts, aber auch der Materialität von Büchern. Vor allem die »Schönen Künste und Wissenschaften« erschließen sich höhere Marktanteile: Von 1740 bis 1800 wächst ihr Anteil am »Gesamtbuchmarkt«, so Hans Erich Bödeker, von sechs auf immerhin 22 Prozent. Insbesondere auf den lange der Historiographie zugerechneten Roman entfallen die größten Zuwachsraten. ${ }^{35}$

»Man lieset selbst da, wo man vor zwanzig Jahren noch an kein Buch dachte. Nicht allein der Gelehrte, nein auch der Bürger und Handwerker beschäftiget sich mit Gegenständen des Nachdenkens, welche sonst ausschließlich dem ersten $\mathrm{zu}$ gehören schienen«, registriert das in Erlangen erscheinende »Neue Archiv für Gelehrte, Buchhändler und Antiquare« im Jahr $1795 .{ }^{36}$ Johann Gottlieb Fichte resümiert in seiner Antrittsvorlesung »Ueber das Wesen des Gelehrten und seine Erscheinungen auf dem Gebiete der Freiheit«, die er als neuer Professorenkollege von Johann Georg Meusel im Sommer 1805 an

32 Meusel beansprucht die Bezeichnung »Büchermacher « für sich (s. Hamberger, Meusel, Das gelehrte Teutschland, 5.XII (1806), S. LXIX), was anhand des Eintrags »Büchermacher« im Deutschen Wörterbuch aber nicht zu belegen ist (Jacob und Wilhelm Grimm, Deutsches Wörterbuch, Leipzig 1854ff., II (1860), Sp. 473.).

Raabe, »Der Buchhändler im achtzehnten Jahrhundert in Deutschland«, S. 275, 282.

Bödeker, »Die bürgerliche Literatur- und Mediengesellschaft«, S. 503.

Ebd. 502f., s.a. zur Einordnung des Romans, Simons, »Von der Respublica Literaria zum Literaturstaat?«.

36 [Anonymus], »Ueber den Begrif und den eigenthümlichen Zweck des Buchhandels«, in: Neues Archiv für Gelehrte, Buchhändler und Antiquare 1 (1795), S. 293-324, hier: S. 295. 
der Universität Erlangen hält: »An die Stelle anderer, aus der Mode gekommener Zeitvertreibe trat in der letzten Hälfte des vorigen Jahrhunderts das Lesen. ${ }^{37}$

Das Lesen findet seine Entsprechung in einem auf Autorschaft abzielenden Schreiben, wie sich an einem kulturpessimistisch gefärbten Begriffspaar aufzeigen lässt: Neben die Lesesucht tritt die Schriftstellersucht, wobei die Phänomene gesellschaftlich andere Proportionen aufweisen. Rudolf Schenda schätzt den Anteil der potenziellen Leser an der Bevölkerung Mitteleuropas an der Wende vom 18. zum 19. Jahrhundert auf ein Viertel. ${ }^{38}$ In diesen Jahren liegt die Bevölkerungszahl im Römischen Reich deutscher Nation zwischen 24 und 30 Millionen Menschen ${ }^{39}$, so dass man hier von mindestens sechs Millionen Lesern ausgehen könnte - mit unterschiedlichsten Fertigkeiten und Möglichkeiten bezüglich der Lektüre, aber auch des Schreibens. ${ }^{40}$ Jean Paul geht mit dem Orientalisten, Philosophen und Schriftstellers Ignaz Aurelius Feßler von einer weitaus geringeren Zahl aus, nämlich 300.000 deutschsprachigen Lesern (SW II.2, 831) ${ }^{41}$, von denen - folgt man Meusel - etwas mehr als drei Prozent selbst als Schriftsteller in Erscheinung treten. Trotzdem suggerieren die zeitgenössischen Klagen über die Schriftstellersucht, dass es sich dabei um ein Massenphänomen handelt.

37 Johann Gottlieb Fichte, Ueber das Wesen des Celehrten, und seine Erscheinungen auf dem Cebiete der Freiheit, Cesamtausgabe, Stuttgart-Bad Canstatt 1962-2012, I,8 (1991), S. 37139, hier: S. 133.

38 Rudolf Schenda, Volk ohne Buch. Studien zur Sozialgeschichte der populären Lesestoffe 17701910, Frankfurt a.M. 1970, S. 444. Zur Kritik an dieservielzitierten Berechnung siehe u.a. Ernst Hinrichs, »Zur Erforschung der Alphabetisierung in Nordwestdeutschland in der Frühen Neuzeit«, in: Anne Conrad, Arno Herzig, Franklin Kopitzsch (Hg.), Das Volk im Visier der Aufklärung. Studien zur Popularisierung der Aufklärung im späten 18. Jahrhundert, Hamburg 1998, S. 35-56, hier: S. $37 f$.

39 Georg Schmidt, Wandel durch Vernunft. Deutschland 1715-1805, München 2009, S. 255.

40 Siehe dazu Reinhard Wittmann, „Cibt es eine Leserevolution am Ende des 18. Jahrhunderts?«, in: Roger Chartier, Guglielmo Cavallo (Hg.), Die Welt des Lesens. Von der Schriftrolle zum Bildschirm, Frankfurt a.M. 1999, S. 419-454

41 Jean Paul bezieht sich auf Berechnungen des Orientalisten, Philosophen und Schriftstellers Ignaz Aurelius Feßler, die im Original leider nicht ausfindig zu machen waren. In Jean Pauls Exzerpten findet sich dazu der Eintrag: »153 Feßler: 300,000 Leser« (Fasz. IIc/33, O.P. [152], Nachlass ]ean Paul, Exzerpte, Digiatle Edition, [IIc-33-1801-18020152], URL: www.jp-exzerpte.uni-wuerzburg.de (6.9.2019)). Da Jean Paul im Jahr 1801 mit Feßler in Berlin persönlich bekannt war (hier traf er Fichte), könnte der Eintrag auf ein Cespräch zurückgehen (HKA III.4, S. 40). 
Bereits Johann Burchard Mencke, der das von Christian Gottlieb Jöcher fortgeführte »Compendiöse Gelehrten Lexicon« begründete, wettert in seinen "Zwey Reden von der Charlatanerie oder Marcktschreyerey der Gelehrten« (1713/15) gegen solche Vertreter dieses Standes, die es »ihre vornehmste Sorge seyn lassen, daß ihre unnütze Arbeit in den Buchläden forne an liegen, und ihr unwürdiger Namen in allen Bücher-Registern fein offte wiederholet werden möge ${ }^{42}$. Mencke führt dies auf die "Schreibsucht « zurück, was begrifflich insofern nicht ganz treffend erscheint, als sich diese Sucht nicht auf ein Schreiben bezieht, das auch in der Abgeschiedenheit der Studierstube stattfinden könnte, sondern eindeutig auf die Publizität der Autorschaft. Dies wird deutlich, wenn Mencke anmerkt, dass »unzeitiger Ehr-Geitz« bei manch Betroffenen soweit führt, dass sie ihre Schriften "auf ihre eigne, und zwar nicht geringe Unkosten drucken lassen $\aleph^{43}$. Als warnendes Beispiel wird der italienische Gelehrte Ulysses Aldrovandus (1522-1605) angeführt, der sein gesamtes Vermögen in den Druck seiner Werke investiert habe.

»Man könte eine schöne medicinische Abhandlung von den Modekrankheiten des achzehendten Jahrhunderts schreiben«, heißt es einige Jahrzehnte später in den »Skribleriana«, die 1765 in dem Band »Sieben Satyren nebst drei Anhängen, gesammlet von N.N. «, erscheinen. ${ }^{44}$ Hinter der ausgestellten Leerstelle des »N.N.«, des »Nomen nominandum«, verbirgt sich Friedrich Justus Riedel, der nach seiner Berufung zum Professor für Ästhetische Wissenschaften im Jahr 1768 in Erfurt zu einer Gruppe aufstrebender Gelehrter um Meusel, Christoph Martin Wieland und Carl Friedrich Bahrdt gehört. ${ }^{45}$ Riedel zählt auf, welche Krankheiten er in die "schöne medicinische Abhandlung« aufnehmen würde: „Die Schreib- und Autorsucht, die Titelseuche, die poetische Wuth, die Demonstrirsucht, das Elektrisirfieber, die galanten Krankheiten, die Vapeurs, die Hypochondrie und andere Pestilenzen würden darinnen ihre Stellen finden. $\ll^{46}$ Unter den Modekrankheiten des achzehendten Jahrhunderts« rangiert die »Schreib- und Autorsucht « bei Riedel also an erster Stelle, wobei er im Vergleich mit Mencke eine auffällige Differenzierung

\footnotetext{
42 Johann Burchard Mencke, Zwey Reden von der Charlatanerie oder Marcktschreyerey der Gelehrten, Leipzig 1716, S. 45.

43 Ebd.

44 [Riedel], »Skribleriana«, S. 298 [16].

45 Michael Zaremba, Christoph Martin Wieland. Aufklärer und Poet. Eine Biografie, Köln, Weimar, Wien 2007, S. 142.

46 [Riedel], »Skribleriana«, S. 298 [16].
} 
vornimmt und in eine Konjunktion fasst, was gemeinhin als begrifflich deckungsgleich angesehen wird. Die »Autorsucht« erscheint bei Riedel jedoch nicht deckungsgleich mit der »Schreibsucht«.

Etwa zur gleichen Zeit wie Riedel behandelt Johann Heinrich Gottlob Justi "Die Schriftstellersucht, eine gefährliche Krankheit der gelehrten Anfänger« (1760). »Alle nützliche Wahrheiten und Entdeckungen erhalten wir durch den Weg des Druckes; und es ist fast das einzige Mittel berühmt zu werden«, ist eingangs zu lesen, ehe die aus dieser Konstellation erwachsende »Begierde, durch das Bücherschreiben berühmt in der Welt zu werden«, in der Satire eingehend pathologisiert wird. Harmlos nimmt es sich noch aus, wenn das Erzähler-Ich schildert, wie es nach einem halben Jahr auf der Universität ein "vortrefflich Buch« verfasst, in dem ausgerechnet dargelegt wird, "wie alle Krankheiten des menschlichen Körpers auf eine leichtere und kürzere Art zu heilen wären«. Dieses Manuskript will der Student gedruckt sehen: »Ich wanderte damit voller Freuden zu einem Buchhändler, und bildete mir nichts gewisser ein, als 24 Ducaten, so viel Bogen war es ongefähr, mit zurück zu nehmen. $\ll^{47}$ Doch der Buchhändler lehnt ab.

Im Anschluss beschreibt Justi »einige Kennzeichen dieser abscheulichen Krankheit«, der Schriftstellersucht, die sich durch "große Beschwerungen im Halse« ankündigt, denen weitere Symptome folgen, bis die »völlige Krankheit « mit "heftigen Convulsionen der Hand und der Finger ${ }^{48}$ ausbricht, besonders stark in räumlicher Nähe zu Schreibmaterialien:

»Ich habe angemerket, daß das weiße Papier dem Patienten sehr schädlich ist. Man kann es ohne Mitleid nicht ansehen, mit was vor Geschwindigkeit die Heftigkeit der Schmerzen Hand und Finger beweget: so bald sie sich denselben nähern. $\ll^{49}$

In der Satire von Justi zeigt sich die »Schriftstellersucht« in einer Abfolge körperlicher Beschwerden, die im Zusammenhang mit Aktivitäten auftreten, die dazu dienen sollen, die Betroffenen als Gelehrte zu exponieren, nämlich Reden und Schreiben, wobei Letzteres auf gedruckte Bücher ausgerichtet ist. Kurieren sollen die Krankheit eine »vortreffliche Mixtur, die Selbsterkenntniß« genannt wird, ein ausgedehntes Studium, aber schließlich auch

\footnotetext{
47 Justi, »Die Schriftstellersucht«, S. 165.

48 Ebd., S. 168, 169, 170.

49 Ebd., S. 170.
} 
die Einsicht in den überschaubaren Statusgewinn, den Bücher einbringen. Das Erzähler-Ich richtet sich direkt an die Betroffenen:

»Ich muss Ihnen demnach sagen, daß das Bücherschreiben bey weiten nicht so viel Ehre zuwege bringet, als sie sich einbilden. Man kann nicht läugen [sic!], daß ein wohlgeschriebenes Buch seinem Urheber Ehre macht. Allein diese Ehre verstehet sich nur von der gelehrten Welt: und auch hier ist diese Ehre sehr geringe. ${ }^{50}$

Andreas Reckwitz hat deutlich gemacht, dass soziale Praktiken immer eine Körperlichkeit besitzen. »Eine Praktik«, so Reckwitz, »besteht aus bestimmten routinisierten Bewegungen und Aktivitäten des Körpers. Dies gilt ebenso für intellektuell anspruchsvollere Tätigkeiten wie die des Lesens, Schreibens oder Sprechens. ${ }^{51}$ Diese Körperlichkeit umfasse die beiden Aspekte einer Inkorporiertheit von Wissen und der Performanz des Handelns. ${ }^{52}$ Durch diese Folie lässt sich das Krankheitsbild der »Schriftstellersucht« lesen, und zwar als ein vermeintliches Gebrechen an Praktiken, deren Körperlichkeit in der Regel nicht als charakteristisch angesehen wird, in der Satire jedoch im Fokus steht. Texte treten bei Justi in den Hintergrund, zumindest werden sie in keiner Zeile als das bestimmt, als was sie in den folgenden Jahrzehnten selbstverständlich angesehen werden: Produkte des menschlichen Geistes. Stattdessen verdeutlicht die durchgängige Körperlichkeit der beschriebenen Praktiken, zu der sich die Materialität der Bücher passend verhält, die soziale Dimension der Autorschaft zur Mitte des 18. Jahrhunderts. Dass es in dieser Dimension auf Anerkennung und durch soziale Rollen hergestellte Relationen ankommt, zeigt der von Justi angestellte Vergleich zwischen der gelehrten Welt und einer anderen Sphäre des gesellschaftlichen Lebens anhand des Ehrbegriffs:

»In der bürgerlichen Welt [...] hat ein Schriftsteller, als ein solcher nicht die geringste Ehre zu gewarten, die Ungelehrten und der Pöbel bekümmern sich um eine Sache wenig, die sie nicht verstehen, und die sie nichts angehet: und selten, daß sie einmal davon Nachricht haben. Bey diesen Leuten macht uns nichts Ehre oder Ansehen, als Ehrenstellen, Titel, Reichthümer, und höchstens eine vernünftige und geschickte Aufführung. Wir werden aber nicht um

\footnotetext{
50 Ebd., S. 170, 171.

51 Reckwitz, »Crundelemente einer Theorie sozialer Praktiken«, S. 290.

52 Ebd.
} 
ein Haar vornehmer, wenn wir gleich hundert vortreffliche und witzige Bücher schreiben. ${ }^{53}$

An das »Bücherschreiben« knüpfen sich somit Erwartungen, die Justi zufolge nicht erfüllt werden, weder im agonal strukturierten Raum der gelehrten noch unter den völlig anderen Bedingungen der bürgerlichen Welt. Trotz der angezeigten Materialität werden Bücher in der Satire relativ abstrakt im Hinblick auf ihre Funktion beschrieben. Unstrittig ist dabei die konstitutive Bedeutung des Drucks für den Status des Schriftstellers, wie die ersten Seiten der Satire belegen, allen voran die Schilderung, wie der Student von einem Buchhändler abgewiesen wird.

Justi untermauert diese Bedeutung des Drucks für die Autorschaft, wenn es bei ihm heißt, dass Werke »durch den Weg der Presse in die gelehrte Welt gebohren werden ${ }^{54}$. An dieser Formulierung sind gleich mehrere Aspekte hervorzuheben, angefangen damit, dass der Druck als Passage vorgestellt wird, als ein vermittelnder »Weg«, der »in die gelehrte Welt« führt, wobei herauszustellen wäre, dass die »Presse« diesen Weg nicht ebnet, sondern ihn selbst darstellt, im Sinne eines Mediums. Doch gelangen Werke »durch den Weg der Presse« nicht einfach »in die gelehrte Welt«, vielmehr wählt Justi für ihren Eintritt das bemerkenswerte Bild, dass sie in die offenbar exklusive Sphäre "gebohren werden«. Damit ist im Grunde nicht gesagt, dass Werke außerhalb dieser Sphäre nicht existieren, aber als Werke nehmen sie ihren Anfang in der gelehrten Welt nach Auffassung von Justi »durch den Weg der Presse«. Nicht unterschlagen werden sollte die Passiv-Konstruktion ("gebohren werden«), die sich so deuten lässt, dass Justi den Druck selbst als generativen Akt ansieht, »durch« den Werke performativ hervorgebracht werden. Seit der Antike wird Autorschaft in sprachliche Bilder der Prokreation gefasst, aber bis heute prägend ist in dieser Beziehung vor allem die Genieästhetik mit ihren in der zweiten Hälfte des 18. Jahrhunderts entwickelten Topoi. ${ }^{55}$ Jedoch verweisen diese Topoi vor allem auf Subjektivität als Prädikat von Autorschaft, deren Ursprung in das Innere des Menschen verlegt wird, das als Schauplatz verschiedener Modi von Schöpfung fungiert. »Ein Original-Scribent «, formuliert Edward Young im Jahr, bevor die »Schriftstellersucht« von Justi erscheint, »ist,

\footnotetext{
53 Justi, »Die Schriftstellersucht«, S. 172

54 Ebd., S. 165.

55 Siehe Christian Begemann, »Der Körper des Autors. Autorschaft als Zeugung und Ceburt im diskursiven Feld der Genieästhetik«, in: Heinrich Detering (Hg.), Autorschaft. Positionen und Revisionen, Stuttgart 2002, S. 44-61.
} 
wie Tacitus von Curtius Rufus sagt, aus sich selbst gebohren; er ist sein eigener Stamm-Vater. $\aleph^{56}$ Nicht nur der »Original-Scribent«, auch die »OriginalWerke«, wie Young sie nennt, gehen im Modus der »Epigenesis « ${ }^{57}$ aus diesem inneren Schauplatz hervor. Vergleicht man die eine Geburtsvorstellung mit der anderen, und zwar in Bezug auf das jeweilige Konzept von Autorschaft, so wird deutlich, dass Autorschaft für Justi nicht durch ein Individuum konstituiert wird, sondern: »durch den Weg der Presse«.

Am Übergang zum 19. Jahrhundert ist die Beteuerung, etwas nicht aus »Autorsucht « veröffentlicht zu haben, ein Gemeinplatz. 1796 erscheint Johann Gabriel Bernhard Büschels satirischer »Versuch über die Kunst gut und viel zu schreiben, in vertrauten Briefen eines Vaters an seinen Sohn auf der Universität«. Der Band trägt den Untertitel: »Zum Besten angehender Schriftsteller, Recensenten und Buchhändler herausgegeben. «War bei Justi die »Schriftstellersucht« noch als ein Problem der "gelehrten Anfänger« ausgewiesen worden, so richtet sich der von Büschel anonym vorgelegte Band dem Titel nach an einen ähnlichen Adressatenkreis, markiert durch den "Sohn auf der Universität«. Allerdings sind es nicht mehr junge Studierende, zu deren »Besten" das Büchlein in erster Linie beitragen soll, sondern ausdrücklich »angehende Schriftsteller«.

Hier deutet sich diskret der im letzten Drittel des 18. Jahrhunderts zu beobachtende Aufstieg der Autorschaft zu einer Subjektform an, die zwar noch immer im Kontext der Gelehrsamkeit stehen kann, gegenüber dieser aber zunehmend eigenständig wird. Dass Büschel die »Schriftsteller « im Titel an die Stelle der Gelehrten setzt, ist nicht zuletzt deshalb bemerkenswert, da er als Autor erkennbar an die große Tradition der Gelehrtenkritik des zu Ende gehenden Jahrhunderts anknüpft. Fünf Jahre vor dem »Versuch« hatte Büschel einen sich als Fortschreibung von Menckes $¥ Z$ wey Reden von der Charlatanerie oder Marcktschreyerey der Gelehrten" präsentierenden Band »Ueber die Charlatanerie der Gelehrten seit Menken ${ }^{58}$ auf den Markt gebracht. In seinem späteren Werk wird die Leserschaft nun im Rahmen einer Herausgeberfiktion "auf der oft unsichern und rauhen Bahn der Schriftstellerey ${ }^{59}$ angeleitet - bzw. mit den "geheimen Schlichen unserer Büchermacher, besonders der Vielschreiber bekannt gemacht«, wie der Rezensent der »Oberdeutschen

56 Young, Gedanken über die Original-Werke, S. 59.

57 Begemann., »Der Körper des Autors«, S. 52-56.

58 Johann Cabriel Bernhard Büschel, Ueber die Charlatanerie der Celehrten seit Menken, Leipzig 1791.

59 Büschel, Versuch über die Kunst, S. 8. 
allgemeinen Litteraturzeitung« ätzt, der sich nicht ganz freiwillig mit Büschel befasst. ${ }^{60}$ Büschel hatte sein Buch dem »Herrn Kmr. « gewidmet, nachdem der unter diesem Kürzel schreibende Rezensent den jüngsten Ausgaben von Meusels »Das gelehrte Teutschland « nicht allzu freundlich begegnet war. »Der Versuch über die Kunst gut und viel zu schreiben« enthält nicht nur ein Kapitel über die »Schriftstellerey und die leichtesten Mittel dazu zu gelangen « (»Zweyter Brief«) oder Ratschläge, wie sich ein Verleger finden lässt, sondern auch ein »Verzeichniß einiger berühmten Polygraphen« (»Siebenter Brief«), also Vielschreiber. Am Inhaltsverzeichnis des satirischen Werks lässt sich ablesen, wie Autorschaft in ihrer sozialen, das Buch als Artefakt stets einschließenden Dimension um 1800 reflektiert wird.

Beständig bleibt in dieser Zeit der Befund einer nicht nur unmäßigen, sondern auch übermäßigen Autorschaft. Quantität wird angesichts einer stark zunehmenden Buchproduktion als Verminderung von Qualität angesehen. Es gehört zur gängigen Rhetorik der Autorschaft, sich gegen eine diffuse Masse abzugrenzen. »Wir leben überhaupt zu einer Zeit, da, so unerträglich auch das Mittelmäsige ist, dennoch fast alle Menschen von der Autorsucht angestecket sind «, bemerkt der publizistisch umtriebige Schauspieler Gottlieb Friedrich Lorenz, auch bekannt als Theophilus Friederikus. ${ }^{61}$ Und der als freier Schriftsteller so erfolgreiche Wieland formuliert: »Jetzt schreibt man um sich gedruckt $z u$ sehen, oder weil es Mode ist, oder weil Einem die Finger jucken, oder weil man sonst nichts zu thun weiß. ${ }^{62}$ Ähnliches ist auch von einem Philosophen zu hören, von Fichte: »Es ist nach der fast allgemein verbreiteten Meinung ein Verdienst und eine Ehre, dass jemand etwas habe drucken lassen, lediglich darum, weil er hat drucken lassen, und ohne alle Rücksicht darauf, was das ist, was er hat drucken lassen, und wie dasselbe ausgefallen. $\aleph^{63}$ Das beklagt Fichte in der letzten seiner Erlanger

$60[\mathrm{Kmr}]$, Rez. »Versuch über die Kunst gut und viel zu schreiben«, in: Oberdeutsche allgemeine Litteraturzeitung 9 (1796), Stk. LXXX (6. Juli 1796), Sp. 38-40, hier: Sp. 38.

61 Cottlieb Friedrich Lorenz (Hg.), Theatralisches Quodlibet für Schauspieler und Schauspielliebhaber, Warschau 1782, I, S. 256.

62 Christoph Martin Wieland, Sympathien, C.M. Wielands sämmtliche Werke, Leipzig $1824 \mathrm{ff}$. , 29 (1857), S. 1-61, hier: S. 55.

63 Fichte, Ueber das Wesen des Gelehrten,S. 133. Fichte variiert diesen Satz an anderer Stelle seiner Vorlesung, wobei er hier auch implizit auf den Beitrag eingeht, den Projekte wie »Das gelehrte Teutschland« zur Konstitution von Autorschaft leisten: »Wie das Schreiben um des Schreibens willen zu ehren vermöge, predigt die Celehrten-Geschichte unserer Tage jedem, der gründlich denkt.« (Ebd., S. 136) 
Vorlesungen »Ueber das Wesen des Gelehrten und seine Erscheinungen auf dem Gebiete der Freiheit«, die er 1806 in den Druck gibt. „Vom Schriftsteller« - so neutral überschreibt Fichte seinen Vortrag, der tatsächlich von Schmähungen durchzogen ist. Es handelt sich, wie der Philosoph gleich zu Beginn feststellt, um eine Vorlesung, die aus der Reihe fällt, da sein Blick auf »die wirkliche Beschaffenheit der Dinge im Zeitalter « ${ }^{64}$ fällt. »Der Begriff des Schriftstellers ist in unserm Zeitalter so gut als unbekannt; und etwas höchst unwürdiges usurpiert seinen Namen«, so Fichte, der einen anderen »Begriff des Schriftstellers« propagiert, der nicht von der Typographie und ihren Implikationen abhängt, sondern vielmehr regulierend auf die zeitgenössische Flut an gedruckten Publikationen wirken soll. Denn der Schriftsteller soll laut Fichte eine Aufgabe erfüllen, die nicht Publizieren heißt: »Er soll die Idee ausdrücken in der Sprache; auf eine allgemein gültige Weise, in einer vollendeten Form. $"{ }^{65}$ Dass die $»$ wirkliche Beschaffenheit der Dinge im Zeitalter« dem entgegensteht, formuliert Fichte drastisch, wobei er sich vor allem gegen die »Betriebsamkeit« einer Ökonomie richtet, die aus seiner Sicht das Verlags- und das Rezensionswesen umfasst:

»Es ist in unserm Zeitalter manches Vortreffliche erschienen, ich will hier nur die Kantische Philosophie nennen; - aber gerade jene Betriebsamkeit des litterarischen Marktes hat es ertödtet, verkehrt und herabgewürdigt, so daß der Geist davon verflogen ist, und statt seiner nur noch ein Cespenst herum geht, dessen niemand achtet. ${ }^{66}$

Es fällt auf, dass Fichte das Buch immer dann als materiales Objekt in den Blick nimmt, wenn es darum geht, die soziale Dimension des »litterarischen Marktes« und mithin der Autorschaft darzustellen. Die sprachlich gefasste Materialität ist jedoch eine Abstraktion, sie wird mal deskriptiv, mal rhetorisch ins Spiel gebracht, und manchmal lässt sich diese Unterscheidung schwer treffen, etwa im Hinblick auf die Charakterisierung des Buchs als Ware. In diesem Zusammenhang firmiert der Schriftsteller als »Fabrikant«, dessen Produkt ihm nur auf zweifelhafte Weise zu »Ehre« gereichen kann, weil er abhängig ist vom »Urtheil des Druckers, welches ja lediglich ein Urtheil über die Verkäuflichkeit oder Nichtverkäuflichkeit der Waare zu seyn vermag ${ }^{67}$.

64 Dieses und die folgenden zwei Zitate. Fichte, Ueber das Wesen des Celehrten, S. 133.

65 Ebd., S. 138.

66 Ebd., S. 135

67 Ebd., S. 134. 
Dafür unterscheidet Fichte streng zwischen einem Buch und dem, was er ein »wahres schriftstellerisches Werk« nennt, das »selbstschöpferisch« zustande kommen muss. ${ }^{68}$ Fichte stellt das Buch in den Dienst einer abwertenden Rhetorik, die in der zweiten Hälfte des 18. Jahrhunderts insbesondere durch die Genieästhetik präfiguriert worden ist, einer Rhetorik, die alles erfasst, was der »wahren Schriftstellerei ${ }^{69}$ als einer im alltäglichen wie im philosophischen Sinne idealistischen Auffassung von Autorschaft nicht entspricht. Jedoch erscheint die Realität von der »wahren Schriftstellerei« weit entfernt.

Die um 1800 immer vielfältiger werdenden Publikationsformen bieten reichlich Gelegenheit, sich als Autor einen Namen zu machen. Lexikograph Meusel registriert das aufmerksam, und er reagiert, indem er unter anderem periodische Schriften und kleinere Veröffentlichungen in "Das gelehrte Teutschland« einbezieht. Der wachsende Umfang des Nachschlagewerks zeugt vom aufklärerisch-egalitären Anspruch seines Machers, aber auch von einem Strukturwandel der Öffentlichkeit, der sich an den Messkatalogen ablesen lässt. Johann Friedrich Ferdinand Ganz stellt sich 1790 beim Durchblättern der Bücherverzeichnisse die Frage:

»[W]ie verhalten sich hierinnen Werke vom Belange zu fliegenden Blättern und Broschüren? Wird man nicht bekennen müßen, daß sich eine zu diesen, gegen ehemalige Zeiten gehalten, wie 1 zu 25 verhalten. Der teutsche Buchhandel wird also immer mehr und mehr zu einem Broschürenhandel. " $^{70}$

Vorbei erscheinen die Zeiten der »alten vielpfündigen Folianten, in Bretter, Leder, Messingbeschläge und Klammern gefaßt, gleichsam lederne, mit Messingnägeln besetzte Großvaterstühle des gelehrten Sitzlebens«, wie Jean Paul pointiert formuliert, um die Schwergewichte des Wissens einem »Taschenbüchlein« gegenüberzustellen (SW I.5, 495). Bereits 1773 hatte Friedrich Nicolai den Buchhändler Hieronymus im »Sebaldus Nothanker« den Zustand seines Berufszweigs beklagen lassen:

»Zur Zeit der schönen dicken Postillen, der centnerschweren Consultationen, der Arzneibücher in Folio, der Opera omnia, der classischen Autoren und Kirchenväter in vielen Folianten, der theologischen Bedenken, der Leichenpredigten in vielen Bänden, der Labyrinthe der Zeit, der Schaubühnen

68 Ebd., S. 134, 136.

69 Ebd., S. 138.

70 Johann Friedrich Ferdinand Ganz, Uebersicht der Gründe wegen des Strafbaren des Büchernachdrucks, Regensburg 1790, S. X. 
der Welt, war die Buchhandlung im Flor. Was gibt man uns jetzt anstatt dieser wichtigen Werke? Kleine Büchelgen von wenig Bogen, die aus Hand in Hand gehen, viel gelesen und wenig gekauft werden, wodurch denn endlich die Leser so klug werden, daß ihnen die alten Kernbücher anstinken. ${ }^{11}$

Für Hieronymus entspricht die Solidität der »alten Kernbücher« ihrem inneren Wert. Die Massivität ihrer Materialität dient in einer überkommenen Logik zugleich der äußeren Repräsentation von Autorschaft. Carlos Spoerhase hat aufgezeigt, dass sich in der Gelehrtenrepublik des 18. Jahrhunderts aus gedruckten Artefakten eine Hierarchie ergibt, eine Rangordnung der Publizierenden. »Die materielle Werthierarchie des Gedruckten«, schreibt er, »die mit der Rangordnung der Schriftsteller kongruiert, berücksichtigt [...] nicht bloß das Format des Bandes, sondern auch den Umfang (Bogenzahl), die Bindung (oder deren Fehlen), die Heftung [...] und die Periodizität des Drucks $[\ldots] \cdot \ll^{72}$

Ungeachtet dessen widmet sich nicht nur Meusel den »Büchelgen von wenig Bogen« und anderen als flüchtig empfundenen Publikationen wie Broschüre, Zeitschrift oder Zeitung. Einer besonderen Popularität erfreuen sich Broschüren in den frühen Achtzigerjahren des 18. Jahrhunderts in Wien, einer Metropole mit über 200.000 Einwohnern, »wo es Schriftsteller zu Hunderten giebt «, wie Meusel feststellt. ${ }^{73}$ Als Reaktion auf die Publikationsflut erscheinen an der Donau etliche Satiren wie die »Bittschrift der 10 Kreuzer Autoren« (1781), so benannt, da Broschüren meist zu diesem Preis zu haben sind, oder »Die Autorsucht - Ursprung, Beschaffenheit, Ausbreitung und Folgen derselben, nebst einem großen Verzeichniß derjenigen, die damit behaftet sind« (1781, Preis: zehn Kreuzer). Der Aufklärer Johann Pezzl fällt zwar, so Kai Kauffmann, ein »differenziertes Urteil« über die Bedeutung der oftmals verschrienen Broschüren für die Aufklärung. ${ }^{74}$ Was die Urheber dieser »Lilliputischen Geschöpfe« angeht, sieht sich Pezzl jedoch 1787 im vierten Heft seiner »Skizze von Wien« gegenüber Meusel zu einer Klarstellung veranlasst:

\footnotetext{
71 Nicolai, Sebaldus Nothanker, S. 73.

72 Spoerhase, Das Format der Literatur, S. $29 f$.

73 Hamberger, Meusel, Das gelehrte Teutschland, 4. Ausgabe. 1. Nachtragsband (1786), S. 775

74 Vgl. Kai Kauffmann, »Es ist nur ein Wien!«. Stadtbeschreibungen von Wien 1700 bis 1873 , Wien, Köln, Weimar 1994, S. 193-198, Zitat: S. 197.
} 
»Hier ist es keinem Menschen eingefallen, die Fabrikanten solcher Waare mit dem Namen der Schriftsteller zu belegen. $"{ }^{75}$

Meusel reagiert mit einer grundsätzlichen Erklärung zu den Auswahlkriterien seines Lexikons. Pezzl mache einen "seltsamen Unterschied zwischen Gelehrten, Schriftstellern und Broschürenschreibern«, befindet er. ${ }^{76}$ Dem hält Meusel zunächst entgegen, dass er selbst »zwischen Gelehrten und Schriftstellern oder Büchermachern, wie ich sie zum erstenmahl nannte, wohl zu unterscheiden ${ }^{77}$ wisse. Hier klingt die von Bosse beschriebene Ausdifferenzierung des Gelehrtenbegriffs noch einmal an, mit einem Akzent auf den »Schriftstellern oder Büchermachern«. »Aber aus Broschürenschreibern eine eigene Klasse von literarischen Wesen $\mathrm{zu}$ formiren, wäre mir nie in den Sinn gekommen«, schließt Meusel an. »Wie? ein Fabrikant kleiner Schriften oder fliegender Blätter soll kein Schriftsteller seyn? ${ }^{78}$

Unerschütterlich stellt Meusel auch dem Verfasser von Broschüren eine Aufnahme in »Das gelehrte Teutschland « in Aussicht, wie er 1806, also etliche Jahre später, erneut betont: »Er komme herein, indem er nach und nach eben so viel Papier verdrucken lässt, als ein andrer, der gleich mit einem dicken Band auftritt. « ${ }^{79}$

Jean Paul greift das Auswahlverfahren des Lexikons in den »Flegeljahren« literarisch auf. Im vierten Bändchen des Fragment gebliebenen Romans erhält Walt »ein Manuskript, aber ein fremdes abgedrucktes«, zur Korrektur. "Das Werk, dessen Titel war: >Das gelehrte Haßlau, alphabetisch geordnet von Schieß<, - nun in aller Händen - war sehr gut in deutscher Sprache mit lateinischen Lettern geschrieben, nur aber ganz schlecht oder unleserlich« (SW I.2, 1031), weshalb sich der durch eine Erbschaft zu solchen Arbeiten verpflichtete Walt der Überarbeitung annehmen soll. In »Das gelehrte Haßlau« findet jeder Bewohner dieser Ortschaft Aufnahme, »der mehr als eine Seite, nämlich zwei, d.h. ein Blatt, für Straße und Welt gemacht« (Ebd.) hat, wie es heißt. Dass dieses Blatt ein "gedrucktes« sein muss und im Vergleich mit anderen Lexika keine übermäßige Anforderung darstellt, wird im Anschluss unter Erwähnung von Georg Wolfgang Augustin Fikenschers »Gelehrtem Fürstentum

75 Johann Pezzl, Skizze von Wien, Viertes Heft, Wien 1787, S. 493 [LXXXVI].

76 Hamberger, Meusel, Das gelehrte Teutschland, 4. Ausgabe. 3. Nachtragsband (1788), S. VIIIf.

77 Ebd., S. IX.

78 Ebd.

79 Hamberger, Meusel, Das gelehrte Teutschland, 5. Ausg., XII (1806), S. LXIX. 
Baireut « (1801-1805) und dem Vorbild, dem alle solche Nachschlagewerke folgen, nämlich Meusel, hervorgehoben:

»Wenn man zählt, welche Menge von Autoren Fikenscher aus seinem gelehrten Baireuth bloß dadurch hinaussperrt, daß er keinen aufnimmt, der nicht mehr als einen Bogen geschrieben - sogar zwei reichen nach der Vorrede nicht hin, wenns bloß Gedichte sind -, und welche noch größere Meusel aus seinem gelehrten Deutschland verstößt, dadurch daß er nicht einmal Leute einläßt, die nur ein Büchlein geschrieben, nicht aber zwei: so sollte wohl jeder wünschen, in Haßlau geboren zu sein, bloß um in das gedruckte gelehrte zu kommen, da Schieß nicht mehr dazu begehrt zum Einlaßzettel als etwas nicht Größeres, als der Zettel ist, nur ein gedrucktes Blatt [...].«(SW I.2,1010)

Tatsächlich findet Meusel etliche Nachahmer, die sich teils um Städte und Regionen im deutschsprachigen Raum kümmern, teils um einzelne Wissenschaften. Mit der relativen Popularisierung der Autorschaft um 1800 wandelt sich jedoch die Funktion des maßgeblichen Schriftstellerlexikons. Es entwickelt sich zu einem Referenzmedium, das Autorschaft allgemein und verbindlich auszeichnet. Wer einen »Einlaßzettel« vorzuweisen hat, darf sich nicht nur sicher sein, in den Kreis der "jetzt lebenden teutschen Schriftsteller « aufgenommen zu werden. Auch für die Nachwelt scheint aus Sicht von Zeitgenossen wie Jean Paul gesorgt. So exzerpiert er 1781 aus dem zweiten Heft der von Johann Karl August Musäus herausgegebenen »Physiognomischen Reisen« (1778) recht unvermittelt eine Passage über einen Dichterbesuch, die das unterstreicht:

»[O]bschon sein Name nicht ganz unbekannt ist in der gelehrten Welt, wenn ihn gleich Meusel in seiner Schmetterlingssammlung noch nicht besitzt. Wird ihn wohl noch fahen und mit seinem unverweßlichen Terpentinöl bestreichen, um ihn der Nachwelt zu conserviren. ${ }^{80}$

Um wen es Musäus an dieser Stelle geht, ist für Jean Paul gleichgültig, er interessiert sich einzig für die mit Meusel verbundene Rhetorik, die dem Le-

80 Johann Karl August Musäus, Physiognomischen Reisen, Altenburg 1788, H. 2, S. 36, der Wortlaut bei Jean Paul: »obschon sein Name (der eines Dichters) nicht ganz unbekant ist in der gelerten Welt, wenn ihn gleich Meusel in seiner Schmetterlingssamlung noch nicht besizt. Wird ihn wol noch fahen und mit seinem unverweslichen Terpentinöl bestreichen, um ihn der Nachwelt zu konserviren.«(Fasz. IVb/1, S. 176 [423], Nachlass ]ean Paul, Exzerpte, Digitale Edition, [IVb-01-bel-1791-0423], URL: www.jp-exzerpte.uni-wuerzburg.de (6.9.2019)) 
xikon als Agentur bio-bibliographischen Wissens eine Funktion zuschreibt, die in der Regel mit der Überlieferung eines Textes an die Nachwelt verbunden wird. Nicht weniger ist es der bibliographische Nachweis, der unsterblich macht. Paradoxerweise bringt der Buchmarkt immer mehr Autorinnen und Autoren hervor, erneuert sich aber in so kurzen Zyklen, dass jemand schnell wieder von der Bildfläche zu verschwinden droht. "Die Dimension, in die Texte hineingeschrieben werden, ist immer weniger die longue durée von fama und memoria und immer mehr der literarische Markt mit seinen Rhythmen kurzlebiger Konjunktur«, beschreibt Aleida Assmann die Konditionen der Autorschaft in einem zunehmend "ökonomisierten und industrialisierten bürgerlichen Zeitalter ${ }^{81}$. Es ist vor diesem Hintergrund die Institution des Schriftstellerlexikons, die Autorschaft mit all ihren Annehmlichkeiten sozialer Anerkennung absichert und auf Dauer stellt - unter der Voraussetzung bedruckten Papiers.

\subsection{Autorschaft als Koppelung von Biographie und Bibliographie}

1779 erscheint Johann Gottlieb Schummels »Spitzbart, eine komi-tragische Geschichte für unser pädagogisches Jahrhundert«, in der sich der Inspektor und Pastor Matthias Theophilus Spitzbart aus dem Städtchen Rübenhausen zur Publikation seines "Ideals einer vollkommenen Schule« verleiten lässt. Groß ist die Begeisterung der gesamten Familie, als vom fertigen Buch schließlich »12 Exemplare, halb auf Holländisch, halb auf gewöhnlich Schreibpapier ${ }^{82}$, bei Spitzbart eintreffen. »Mein liebster Schatz«, ruft die Ehefrau aus, "Dein Buch ist da, gedruckt und alles! $^{83}$ Prompt wird auf Wunsch des Verfassers eine »recht grosse Gesellschaft « ${ }^{84}$ eingeladen, bestehend aus wichtigen Honoratioren des Städtchens, unter ihnen Bürgermeister und Stadtschreiber. Spitzbart ist ergriffen davon, »sich mit Namen und Titel, auf schönem holländischen Papiere gedruckt zu sehen ${ }^{85}$. Die Publikation

\footnotetext{
81 Aleida Assmann, »Texte, Spuren, Abfall. Die wechselnden Medien des kulturellen Gedächtnisses«, in: Hartmut Böhme, Klaus R. Scherpe (Hg.), Literatur und Kulturwissenschaften, Reinbek b. Hamburg 1996, S. 96-111, hier: S. 101.

82 [Johann Gottlieb Schummel], Spitzbart, eine komi-tragische Geschichte für unser pädagogisches Jahrhundert, Leipzig 1779, S. 7.

83 Ebd., S. 2.

84 Ebd., S. 4.

85 Ebd., S. 2.
} 
hat Spitzbart einem geschäftstüchtigen Buchhändler zu verdanken, dem nicht entgangen war, "wie sehr es dem Herrn Inspektor lüstete, in Meusels Gelehrtem Deutschlande einen Platz zu erhalten ${ }^{86}$.

In einer der vielen Rezensionen, die zu jedem neuen Band des Autorenlexikons veröffentlicht werden, wird es ein »fortlaufendes Adressbuch « ${ }^{87}$ genannt. Der Vergleich mit einem solchen Register findet sich auch in Erzählungen von Jean Paul wieder, und er wirft ein Licht auf die soziale Dimen-

Ebd., S. 6. Alexander Košenina liest »Spitz-Bahrdt« als eine »Selbstkritik der Aufklärung«, die Bezug nimmt auf den umstrittenen »Philanthropischen Erziehungsplan« (1776) des Theologen und Pädagogen Carl Friedrich Bahrdt (Košenina, Der gelehrte Narr, S. 163-165). Mit seinem späteren »Kirchen- und Ketzeralmanach« zeigt Bahrdt unfreiwillig, wie ein in Meusels Lexikon verzeichnetes Buch einen Schriftsteller diskursfähig macht, ungeachtet des von ihm verfassten Textes. So wird Bahrdt in einer Rezension vorgeworfen, »daß er Meusels gelehrtes Teutschland zur Hand genommen, das Alphabet durchgegangen, und sobald er nur unter dem Nahmen eines Gelehrten eine Schrift mit einem orthodox klingenden Titel gefunden, den Schriftsteller und sein Buch sogleich verdammt habe« ([Anonymus], Rez. »Freymüthige Anmerkungen über Hrn. D. Bahrdts Kirchen- und Ketzeralmanach auf das Jahr 1781. Von einem Liebhaber der Wahrheit. Frankfurt und Leipzig 1782«, in: Allgemeine Deutsche Bibliothek 54 (1783), 1. Stk., S. 51-54, hier: S. 53). Dieses Beispiel zeigt, weshalb die Litterargeschichte einerseits als »Zerfallserscheinung « gelehrten Wissens, andererseits aber als Wegbereiterin moderner Wissenschaftlichkeit gilt. »Gerade in ihr wurde die Basis für eine Entwicklung der Gelehrsamkeit hin zum explorativen Wissenswachstum einer auf Kontinuität, Überprüfbarkeit und Kontrolle beruhenden kumulativen Wissenschaft gesehen«, führt Gierl aus (Gierl, »Bestandsaufnahme«, S. 66). Mit der Urteilsfähigkeit, die im 18. Jahrhundert als Leistung der Historia literaria betont werde, habe man dem »Praejudicium auctoritatis«, dem blinden Nachfolgen einer Lehre, einen Riegel vorgeschoben und damit ein zentrales Hindernis für den Fortschritt der Wissenschaften beseitigt, argumentiert Gierl (Ebd., S. 67). Auch Zedelmaier erkennt in dieser Hinsicht ein »Prinzip moderner Forschung «, das da lautet: »Die methodische Bearbeitung eines Problems setzt die Problematisierung seiner bereits vorliegenden Bearbeitungen voraus«, wobei Zedelmaier herausstellt, dass diese Problematisierung traditionell anhand eines »engen Kanons« erfolgt sei (Zedelmaier, »Historia literaria«", S. 14). Durch die Abkehr von wenigen Autoritäten und der Hinwendung zu dem von Meusel und anderen verwalteten »Schriftstellerheer « tritt die paradoxe Situation ein, dass die von der Bibliographie zu ordnende Literatur zwar unüberschaubar wird, aber jeder Eintrag im Lexikon als potenziell relevant und mithin zitierfähig angesehen werden kann. Das wertet Autorschaft hinsichtlich ihres sozialen Charakters enorm auf.

87 [Anonymus], Rez.»Das gelehrte Teutschland im neunzehnten Jahrhundert, nebst Supplementen zur fünften Ausgabe desjenigen im achtzehnten, von Joh. Georg Meusel. Zweyter Band«, in: Allgemeine Literatur-Zeitung (1810), Nr. 190 (17. Juni 1810), Sp. 572576, hier: Sp. 572. 
sion von Autorschaft. So liest im »Leben des Quintus Fixlein« der von der Gelehrtengeschichte begeisterte »Fixlein sich und der Gesellschaft den flachsenfingischen Adreßkalender vor; etwas Höheres konnt' er sich außer Meusels gelehrtes Deutschland nicht gedenken«, heißt es im Roman (SW I.4, 75). Im »Leben Fibels« hütet die Mutter der Hauptfigur Gotthelf Fibel ein »ExtraBlatt«, das sie aus einem »alten Kurfürstlichen Sächsischen Hof- und StaatsKalender« gerissen hat, weil das "gedruckte Blatt« (SW I.6, 391) ihren Namen enthält. Darauf wird nach dem Tod von Fibels Vater noch einmal Bezug genommen: Da Siegwart, ein früherer Soldat, der als Vogler arbeitete, auf der Welt keinen »Namen nachgelassen, nämlich im Heiligenguter Adreßkalender keinen«, schwört Fibel »bei Gott, er werde ein Skribent< und schreibe, damit nur durch seine gelehrte Feder sein armer Vater weit und breit bekannt werde, bei Gelegenheit seiner selbst (SW I.6, 409). Indem das Schriftstellerlexikon als »fortlaufendes Adressbuch« charakterisiert wird, werden zwei Sphären miteinander gekoppelt, die 1760 bei Justi noch voneinander geschieden waren: die gelehrte und die bürgerliche Welt. In »Leben Fibels«, einem Roman, der 1811 veröffentlicht wird, erscheint diese Koppelung geradezu selbstverständlich, obwohl Jean Paul seine Figur Fibel ausdrücklich als Polyhistor früheren Datums in Erscheinung treten lässt.

Dass dem bibliographischen Wissen ein erstaunliches Interesse an der Person des Autors innewohnt, lässt sich aus der Vielzahl an Rezensionen und auch prominent platzierten Korrekturanzeigen in Zeitschriften nachlesen. Auch Jean Paul hält Fehler bei Meusel für erwähnenswert, etwa wenn er sich 1796 anlässlich des Todes des fränkischen Kupferstechers Adam Wolfgang Winterschmidt, dem fälschlicherweise eine Publikation seines Vaters zugeordnet worden war, aufschreibt: »Er gehörte nicht ins gelehrte Deutschland.« (HKA II.8.1, 437 [504]) Die dem Lexikon zugrundeliegende Verbindung von Biographie und Bibliographie lässt sich in ihrer Bedeutung auch anhand des ersten Porträts Jean Pauls nachvollziehen, das 1798 im "Deutschen Magazin« veröffentlicht wird und alle seine Schriften enthalten soll. Zwar bescheinigt Johann Friedrich Schütze dem Autor, dass »dessen Werke alle von dem frühesten bis zu dem der lezten Messe den Stempel des Genies tragen ${ }^{88}$. Trotz dieser Markierung bereitet es Schütze einige Schwierigkeiten, die Schriften Jean Pauls vollständig und mit Sicherheit anzugeben. Er bemüht sich um ein Publikationsverzeichnis, »wenigstens vollständiger, als man es in der verdienstvollen Meusel und Ersch Werken 
findet«. An den Anfang setzt er jedoch ungesichertes Wissen: »Darf ich hier mit einer Vermuthung beginnen, die nur Richter, wenn er will, bestätigen oder widerlegen dürfte. Ich vermuthe, daß er der Verfasser jener Aufsäzze sey, die in Archenholz Journal Litteratur und Völkerkunde unter dem Namen Hase $^{*}$ ) vorkommen z.B. ein Aufsaz über die Haut u.a. ${ }^{89}$ Es spricht einiges dafür, dass Schütze besagten »Aufsaz über die Haut«, nämlich Jean Pauls Satire »Von der Verarbeitung der menschlichen Haut ${ }^{90}$, selbst nicht in den Händen gehalten hat, sondern seine Vermutung auf bibliographischen Angaben beruht. Denn: Das einzige Indiz steckt für Schütze im »Namen Hase«, und in einer Fußnote merkt er an, »daß der Verfasser der Auswahl aus des Teufels Papieren einen J. P. F. Hasus unter die Vorrede sezt ${ }^{91}{ }^{11}$. Und tatsächlich steht in der betreffenden Ausgabe des Journals »Litteratur- und Völkerkunde« unter dem Text nicht »Hase«, sondern wie in der "Auswahl aus des Teufels Papieren«: »J. P. F. Hasus«. Eine kleine Anekdote, welche die Wirkmächtigkeit des bibliographischen Diskurses in Fragen der Autorschaft aufzeigt.

Wie sehr es beim bibliographischen Nachweis von Urheberschaft um eine Sichtbarkeit des Subjekts in der bürgerlichen Öffentlichkeit geht, wie sehr dieser Aufmerksamkeit und Anerkennung verspricht, ohne nähere Kenntnis eines Textes, belegt eine Passage aus »Der allzeit-fertige Schriftsteller«:

»Bald werden wir, in der Cesellschaft, auf den Promenaden, auf der Straße, nie anders, als mit Meusels gelehrtem Teutschland in der Hand erscheinen dürfen, um Jeden, der uns aufstößt, wie es die Regeln der Höflichkeit erfodern, auf die angenehmste Art, das heißt, von seinen eigenen schriftstellerischen Denkmälern, unterhalten zu können. ${ }^{92}$

Dass diese Konstellation in der Regel auch Bücher voraussetzt, also Artefakte, die in Praktiken des Publizierens eingebunden sind, in denen Texte keine Priorität genießen, verdeutlicht der anschließende Satz:

»Beynahe kann man keinen Menschen ein Buch einbinden, oder drukken, oder verkaufen, oder auch nur lesen sehen, ohne den Cedanken damit zu

\footnotetext{
89 Ebd., S. 113.

90 Jean Paul []. P. F. Hasus], »Von der Verarbeitung der menschlichen Haut«, in: Litteraturund Völkerkunde 9 (1786), S. 97-113.

91 Schütze, »]ean Paul Friedrich Richter«, S. 113.

92 [Jenisch], Der allezeit-fertige Schriftsteller, S. 18.
} 
verbinden, daß es vielleicht sein eigenes Machwerk ist, was er da einbindet, druckt, verkauft oder liest. «" ${ }^{93}$

Meusel steht mit seinem Autorenlexikon für ein Jahrhundert, zu dessen Beginn die Gelehrsamkeitsgeschichte (Historia literaria) als "ModeWissenschafft « gegolten hatte. ${ }^{94}$ Später firmierte dieser im späten 17. und 18. Jahrhundert stark ausgeprägte und weitgehend eigenständige Wissenschaftszweig vornehmlich als Litterargeschichte. ${ }^{95}$ Sie wurde an Schulen und Universitäten als Lehrfach gepflegt, diente sie doch einer »Bestandsaufnahme im gelehrten Bereich ${ }^{96}$ und somit der Orientierung und Propädeutik im weiten Feld der Wissenschaften. In den Verästelungen der Historia literaria findet sich auch »Das gelehrte Teutschland « - als Kreuzungspunkt von Biographie und Bibliographie. Meusel selbst veröffentlicht 1799 einen aus seiner Lehrtätigkeit an der Universität Erlangen hervorgegangenen »Leitfaden zur Geschichte der Gelehrsamkeit«, ein spätes opus magnum der Litterargeschichte, das auch bei Jean Paul auf größeres Interesse stößt. Hier platziert Meusel das von ihm herausgegebene Schriftstellerlexikon in der Rubrik »biographische Werke, oder solche, worin Nachrichten von Gelehrten und Schriftstellern, wie auch von ihren Büchern und Entdeckungen, enthalten sind « ${ }^{97}$.

Meusel war als Herausgeber der Nachfolger von Georg Christoph Hamberger. Hamberger hatte »Das gelehrte Teutschland« im Jahr 1767 unter deutlich anderen Bedingungen aus der Taufe gehoben. Hamberger fungierte an der 1734 gegründeten Universität Göttingen als »Custos adjunctus« der Hochschulbibliothek, die auf die Anschaffung literarhistorischer Literatur großen Wert legte. 1763 folgte er als Ordinarius für Historia literaria auf Christoph August Heumann ${ }^{98}$, dessen »Conspectus reipublicae literariae« (1718) »die Entwicklung des Faches Historia literaria durch das ganze 18. Jahrhundert « ${ }^{99}$

\section{Ebd.}

94 Johann Burchard Mencke, Compendioses Celehrtenlexikon, Leipzig 1715, [S. 3, Vorrede]. Siehe zur Historia literaria auch Grunert, Vollhardt (Hg.), Historia literaria.

95 Laut Helmut Zedelmaier setzt sich in der zweiten Hälfte des 18. Jahrhunderts die Variante »Litterärgeschichte« als Begriff gegen Eindeutschungen wie »Historie der Celahrheit« oder »Ceschichte der Celehrsamkeit« durch (Zedelmaier, »Historia literaria«", S. 11).

96 Cierl, »Bestandsaufnahme«.

97 Meusel, Leitfaden zur Ceschichte der Celehrsamkeit, I (1799), S. 52.

98 Cierl, »Bestandsaufnahme«, S. 76, 78.

99 Sicco Lehmann-Brauns, »Neukonturierung und methodologische Reflexion der Wissenschaftsgeschichte. Heumanns Conspectus reipublicae literariae als Lehrbuch der 
begleitete. 1789 veröffentlichte Carl Joseph Bouginé, der an der Karlsruher Fürstenschule unter anderem Johann Peter Hebel als Klassenlehrer unterrichtet hatte ${ }^{100}$, den ersten Band seines $»$ Handbuchs der allgemeinen Litterargeschichte nach Heumanns Grundriß «, dem er ein bemerkenswertes Motto voranstellte: »Unser Wissen ist - Stückwerk!«

Heumann hatte in seinem Grundlagenwerk ein umfassendes Schriftstellerverzeichnis geliefert, das jedoch eine »trockene Nomenclatur, bloße Namen der Schriftsteller, ohne Biographie, ohne Verzeichniß der Schriften ${ }^{101}$ anbot, wie Bouginé bemängelte, als »Das gelehrte Teutschland« längst etabliert war. Somit entstammte das Lexikon Hambergers einer weithin sichtbaren Bastion der Gelehrsamkeitsgeschichte, die aber durchaus zu erweitern war. Als Vorbild für »Das gelehrte Teutschland« diente Hamberger das 1752 von François-Joachim Duport du Tertre als »Almanach des Beaux Arts« begonnene »La France littéraire«, das wenige Jahre später Samuel Formey in Berlin adaptierte ${ }^{102}$. Hier erschien es unter einem bündigen Titel, an den sich das Vorhaben aus Göttingen anlehnen sollte: »La France littéraire, ou dictionnaire des auteurs françois vivans«. Sowohl das französische Original als auch dessen preußischer Ableger stellten dem eigentlichen Schriftstellerverzeichnis programmatisch Übersichten des Personals der örtlichen Akademien voran - jeweils auf Dutzenden von Seiten. Auf diese hierarchisch-institutionelle Ebene der Gelehrsamkeit verzichtet Hamberger zugunsten einer egalitären Übersicht komplett.

Neben den französischsprachigen Vorläufern hatte der Herausgeber auch die deutschsprachige Publizistik im Blick. Zwei Jahre vor »Das gelehrte Teutschland« startete Nicolais "Allgemeine Deutsche Bibliothek", die sich mit ihrem Anspruch, eine »allgemeine Nachricht, von der ganzen neuen

aufgeklärten Historia literaria«, in: Frank Grunert, Friedrich Vollhardt (Hg.), Historia literaria. Neuordnungen des Wissens im 17. und 18. Jahrhundert, Berlin 2007, S. 129-160, hier: S. 130.

100 Wilhelm Zentner, Johann Peter Hebel. Eine Biographie, Karlsruhe1965, 19.

101 Carl Joseph Bouginé, Handbuch der allgemeinen Litterargeschichte nach Heumanns Grundriß, Zürich1789-1792, I (1789), S. XI.

102 Martin Fontius, »libertas philosophandi< und `siècle de la philosophie«. Zum geistesgeschichtlichen Standort Formeys«, in: ders., Jens Häseler (Hg.), Franzosen in Berlin: Über Religion und Aufklärung in Preußen. Studien zum Nachlass des Akademiesekretärs Samuel Formey, Berlin 2019, S. 125-252, hier: S. 126, siehe auch Jannis Götze, Martin Meiske (Hg.), Jean Henri Samuel Formey. Wissensmultiplikator der Berliner Aufklärung, Hannover 2016. 
deutschen Litteratur ${ }^{103} \mathrm{zu}$ vermitteln, $\mathrm{zu}$ einem »Integrationsmedium der Gelehrtenrepublik « ${ }^{104}$ entwickelt sollte. Daneben existierte eine größere Zahl gelehrter Journale, die es sich ebenfalls zur Aufgabe machten, jüngste Veröffentlichungen zu vermelden und somit eine Orientierungshilfe zu bieten. Daher wurden auch sie zur Historia literaria gerechnet. ${ }^{105}$ In die Richtung dieser Periodika merkte Hamberger kritisch an: "Man ist verschwenderisch mit Versprechungen, uns in denselben von allem, was im Druck erscheinen würde, Nachricht zu geben. ${ }^{106}$ Tatsächlich führte solcher Tadel auch zu bemerkenswerten Rechtfertigungen. Als Herausgeber der »Freymüthigen Nachrichten von Neuen Büchern« beklagte sich Johann Jakob Bodmer über Leser, die »es vor einen grossen Mangel an[sehen], daß nicht mehrere Artickel und gründliche Nachrichten von verschiedenen Büchern in jedem Stücke vorkommen«. Diesen mochte er »den wohlgemeynten Rath geben, daß sie statt gelehrter Zeitungen und Nachrichten sich die Verlags= und Meß=Catalogos anschaffen und dieselben mit Andacht lesen « sollen. ${ }^{107}$ Entscheidend an diesem Ratschlag ist, dass er vermutlich nur zum Teil als Polemik anzusehen ist. Verlags- und Messkataloge stellen nicht nur heute eine wichtige historische Quelle, sondern zeitgenössisch in vielen Fällen auch in Jean Pauls Erzählung von Quintus Fixlein - den einzigen Zugang zu Büchern dar. Dieses Beispiel macht deutlich, dass die auf dem Buchhandel fußenden Bücherverzeichnisse eine eigenständige Form sekundären Wissens hervorbringen. Gleiches gilt für die Bibliographien der Historia literaria - also auch für »Das gelehrte Teutschland«.

Hamberger hatte sich vor der Herausgabe des Lexikons bereits eingehend und chronologisch mit der »Gelehrten Geschichte« befasst, die Mitte des 18. Jahrhunderts durch Christian Gottlieb Jöchers »Allgemeines

103 [Friedrich Nicolai], »Vorbericht«, in: Allgemeine Deutsche Bibliothek 1 (1765), 1. Stk., S. I-IV, hier: S. I.

104 Ute Schneider, Friedrich Nicolais Allgemeine Deutsche Bibliothek als Integrationsmedium der Gelehrtenrepublik, Wiesbaden 1995.

105 Zedelmaier, »Historia literaria«, S. 14. Siehe auch zum Verhältnis der Historia literaria zu den zwischen 1720 und 1760 besonders wirkungsvollen Moralischen Wochenschriften die Studie von Friedrich Vollhardt, »Die Bildung des Bürgers. Wissensvermittlung im Medium der Moralischen Wochenschriften«, in: Hans-Edwin Friedrich, Fotis Jannidis, Marianne Willems (Hg.), Bürgerlichkeit im 18. Jahrhundert, Tübingen 2006, S. 135147, insbes. S. 138-143.

106 Hamberger, Meusel, Das gelehrte Teutschland, I (1767), [S. 3].

107 [Johann Jakob Bodmer], „Vorrede«, in: Freymüthige Nachrichten von Neuen Büchern, und andern zur Celehrtheit gehörigen Sachen 1 (1744), [S. 3, Vorrede]. 
Gelehrten-Lexikon « profiliert worden war. ${ }^{108}$ Er publizierte "Zuverlässige Nachrichten von den vornehmsten Schriftstellern vom Anfange der Welt bis 1500« (1756-1764), die Johann Matthias Gesner, der erste Bibliothekar der Göttinger Universität, als überaus gelungenes »Handbuch ${ }^{109}$ in vier Bänden lobte. An erster Stelle steht in dieser Gelehrtengeschichte: „Adam, der erste Mensch, und Stammvater des ganzen menschlichen Geschlechts «, den Hamberger als einen »algemeinen Gelehrten« einführt. Hamberger präsentiert sogar ein Werkverzeichnis, denn: »Es ist eine ziemliche Anzahl Bücher, die man dem Adam beigeleget hat. «"10 Die auf den ersten Blick alphabetische Ordnung, die mit Adam beginnt, erweist sich tatsächlich nicht nur als eine chronologische, sondern zudem als eine Ordnung, die selbstverständlich an historischen Autoritäten christlich-abendländischer Kultur festhält. Auch in dieser Hinsicht verzichtet Hamberger im späteren Schriftstellerlexikon auf eine hierarchisierende Bedeutungsperspektive, was seinen bio-bibliographischen Bemühungen einen anderen Status verleiht. Statt auf die Bestätigung werden diese auf die gleichmäßige Herstellung von auctoritas ausgerichtet sein.

Was Gesner in der Vorrede zum ersten Band der »Zuverlässigen Nachrichten « lobend an Hamberger hervorhebt, reflektiert derweil gängige Kritik an der Gelehrsamkeitsgeschichte und ihrem oberflächlichen Wissen: »Er kennet nicht nur die Titel der Bücher, sondern er verstehet ihren Inhalt: er hat Gelegenheit gehabt, die allermeisten selbst zu sehen. ${ }^{111}$ Mit dem später begonnenen Schriftstellerlexikon »Das gelehrte Teutschland « scheinen Hamberger und dessen Nachfolger Meusel eine Gelehrsamkeit zu befördern, die auf einer äußeren Bücherkunde basiert, also auf der reinen Kenntnis von Titeln und sonstigen bibliographischen Daten. ${ }^{112}$ Samuel Ersch, der Meusel zuarbeitete, lässt an einem solchen Wissen kein gutes Haar: »Manche glauben wohl gar,

108 Siehe zu Christian Gottlieb Jöcher den Ausstellungskatalog von Ulrich Johannes Schneider (Hg.), Jöchers 60.000. Ein Mann, eine Mission, ein Lexikon. Katalog zur Ausstellung in der Bibliotheca Albertina, 6. März-28. Juni 2008, Leipzig 2008. Johann Matthias Gesner, »Vorrede«, in: Georg Christoph Hamberger, Zuverlässige Nachrichten von den vornehmsten Schriftstellern vom Anfange der Welt bis 1500, Lemgo 17561764, I/I (1756), [S. 2].

110 Ebd., I/II, S. 1, 2, 3.

111 Cesner, »Vorrede«, [S. 3f.].

112 Siehe Rudolf Blum, Bibliographia. Eine wort- und begriffsgeschichtliche Untersuchung, Frankfurt a.M. 1969, Sp. 1141-1190. 
durch fleissiges Blättern in Meusel's gelehrtem Teutschlande Litteratoren geworden zu sein, wenigstens durch eine starke Sammlung von Büchertiteln $\mathrm{u}$. dgl. einen litterarischen Schatz erworben zu haben [...]. « ${ }^{113}$

Zwar werden damit spezifische Probleme der Historia literaria und insbesondere eines Teilgebiets, der Bücherkunde, angesprochen, jedoch müssen diese auch im größeren Kontext einer sich nach 1750 grundlegend wandelnden Buchkultur betrachtet werden. Die Historia literaria vermittelt einen kursorischen Überblick angesichts der »viel Tausend und Millionen Bücher in der Welt « ${ }^{114}$. Aber gerade am Übergang zu einer bürgerlichen Öffentlichkeit trägt die Litterargeschichte in ihren Ausläufern und mit ihren Mitteln entscheidend dazu bei, die aus den unterschiedlichsten Gründen mangelnde Verfügbarkeit von Büchern bei steigender Nachfrage zu kompensieren.

Lothar Müller hat im Anschluss an den Medientheoretiker Harold A. Innis eine »Koppelung von Papiertechnologie und Raumerschließung «115 beschrieben, die auch für die Buchkultur entscheidend ist. Trotzdem ist von einer Situation auszugehen, die Nicolai in der ersten Ausgabe der ADB beschreibt, dass nämlich die »Lieberhaber der neuesten Litteratur«, die der Verleger mit seinem Periodikum adressiert, »in Deutschland in vielen Städten, zum Theil in kleinen Städten, wo nicht einmal ein Buchladen befindlich ist, zerstreuet« seien. ${ }^{116}$ Ein weiterer Grund sind die enormen Kosten, die mit der Anschaf-

113 [Samuel Ersch], »Über Litteratoren und Rezensenten«, in: Allgemeiner litterarischer Anzeiger 2 (1797), Nr. 1, Sp. 1-4, 9-12, 25-28, hier: Sp. 1.

114 Nicolaus Hieronymus Gundling, Vollständige Historie der Gelahrheit, Frankfurt a.M., Leipzig 1734-1736, I (1734), S. 1.

115 Lothar Müller, Weiße Magie. Die Epoche des Papiers, München 2012, S. 99.

116 [Nicolai], »Vorbericht«, S. II. Pamela E. Selwyn hat herausgearbeitet, dass Friedrich Nicolais Ceschäftserfolg als Buchhändler insbesondere auf einem weiträumigen Vertriebsnetz basierte, das nicht nur größere Städte umfasste. »]ust as they came from many professions, Nicolai's customers were also spread over a wide geographical area, in villages, small towns, and cities from London to Yekaterinenburg. «Selwyn geht von einer Entsprechung zwischen der geographischen Verteilung von Nicolais Kunden und derjenigen der ADB aus (Pamela E. Selwyn, Everyday Life in the German Book Trade. Friedrich Nicolai as Bookseller and Publisher in the Age of Enlightenment, 1750-1810, University Park, Pennsylvania 2000, S. 142). Laut Hermann Kellenbenz lag der Anteil der Einwohner Deutschlands, die auf dem Land oder in Kleinstädten lebten, um 1800 bei 90 Prozent (Hermann Kellenbenz, Deutsche Wirtschaftsgeschichte, München 1977-1981, Bd. 2 (1981), S. 27). Im Hinblick auf die bürgerliche Vergesellschaftung um 1800 und die soziale Dimension, die Autorschaft in deren Kontext erlangt, ist der Schauplatz der Kleinstadt, den ein Buchhändler wie Nicolai bediente, nicht zu unterschätzen. Hier sind Autorenfiguren wie Schummels »Spitzbart« (s.u.) zu Hause, der als »Inspektor 
fung von Büchern verbunden sind, vor allem mit Blick auf die angehenden sowie die »Halbgelehrten«. Aufschlussreich ist in diesem Zusammenhang, dass Jean Paul, der mit einem »Armutszeugnis« ein Theologiestudium in Leipzig aufnimmt und zeitlebens wenige Bücher besitzt, nicht nur fleißig aus geliehenen Büchern, sondern auch aus Rezensionsorganen wie der ADB exzerpiert und zudem das von Hamberger gegründete Lexikon offensichtlich als unverzichtbares Referenzmedium ansieht, auf das er immer wieder zurückkommt.

Die auf die Rezeption von Büchern konzentrierten Medien dienen letztlich dazu, Bücher entbehrlich werden zu lassen, sie ermöglichen, was Heinz Schlaffer als »Paralektüre ${ }^{117}$ bezeichnet. »Kompilation hat diejenigen, die über die Rezensionsorgane verfügten, unabhängig vom Buch gemacht. Das heißt, weder die Leser noch die Rezensenten mussten ein Buch wirklich besitzen und gelesen haben, um ein Urteil darüber abzugeben«, konstatiert Martin Gierl. ${ }^{118}$ Die Periodika fungieren also im Sinne von Derrida als Supplemente, sie ergänzen etwas, indem sie an seine Stelle treten. Dies ist im Hinblick auf das Konzept der Autorschaft stets zu berücksichtigen.

und Pastor des Städtleins Rübenhausen« tätig ist ([Schummel], Spitzbart, S. 1). Manfred Hettling zufolge begünstigte die Kleinstadt gerade Vorstellungen von Individualität, welche eine Integration unterschiedlicher Elemente zu einer umfassenden gesellschaftlichen Ganzheit zum Ziel gehabt hätten. Hettling spricht in diesem Zusammenhang von der Kleinstadt als einem »Modell «, in welchem »Bürgerliche und (Nochnicht-) Bürgerliche zusammenfanden und ihre Unterschiede ausbalancierten « (Manfred Hettling, »Die Kleinstadt und das Geistesleben. Individuum und Gesellschaft um 1800«, in: Hans-Werner Hahn Dieter Hein (Hg.), Bürgerliche Werte um 1800. EntwurfVermittlung - Rezeption, Köln 2005, S. 273-290, hier: S. 275). Dieses Modell weist große Ähnlichkeiten auf mit dem horizontalen und nicht weiter unterteilten Aufbau des Schriftstellerlexikons von Meusel, das zeitgenössisch als »Adresskalender « beschrieben wird, wohl auch in Analogie zu den Adressbüchern, wie es sie ab dem 19. Jahrhundert für Städte in Deutschland gibt.

117 »Lektüre beginnt nicht mit dem ersten Wort des Textes, sondern mit der Lektüre von Begleittexten, die ihm vorausgehen, ihn umgeben und die Lektüre beeinflussen. Eine wirkliche Lektüre kurzer Texte (Titel, Verlagsankündigung, Waschzettel, Vorworte, Rezensionen, Referate) eröffnet die mögliche Lektüre umfangreicher Bücher - und erspart sie in den meisten Fällen. «(Heinz Schlaffer, »Der Umgang mit Literatur. Diesseits und jenseits der Lektüre«, in: Poetica 31 (1999), Nr. 1/2, S. 1-25, hier: S. 5.)

118 Gierl, »Kompilation und die Produktion«, S. 80. Gierl untersucht in seinem Aufsatz »systematisch betriebene Kompilation und ihre Funktion für die Wissensverwaltung der Aufklärung«. Erläuternd heißt es: »Als Kompilation werden hierbei das Arrangement von Textzitaten, Plagiate, aber auch Inhaltsauszüge und das kommentierte Zusammenstellen von Literaturverweisen betrachtet.« (Ebd., 63) 
Rezensenten sind dabei nicht allein als Autoren $\mathrm{zu}$ betrachten, sondern auch als "Autorenmacher«. Besprechungen steigern mit ihren Auszügen und Paraphrasen die Bekanntheit von Büchern. Trotzdem sie die Wirkung der in Büchern enthaltenen Texte durch die Kontingenz der Vermittlung verringern, sorgen sie für ihre Einbindung in Diskurse, als »Knoten in einem Netz«. ${ }^{119}$ Bibliographien sind unter den Gegebenheiten des späten 18. Jahrhunderts nicht bloß ergänzende Hilfsmittel, sondern wirkmächtige Medien eines durch die Historia literaria definierten und legitimierten Wissens, das sich beinahe gar nicht aus Texten speist. Die Bibliographie traktiert anhand von Paratexten das Buch als Buch, sie generiert ein bibliographisches Wissen, für das der Autorname von herausragender Bedeutung ist.

119 Michel Foucault schreibt in die »Archäologie des Wissens«: »Die Grenzen eines Buches sind nie sauber und streng geschnitten: über den Titel, die ersten Zeilen und den Schlußpunkt hinaus, über seine innere Konfiguration und die es autonomisierende Form hinaus ist es in einem System der Verweise auf andere Bücher, andere Texte, andere Sätze verfangen: ein Knoten in einem Netz.« (Michel Foucault, Archäologie des Wissens, Frankfurt a.M. 1981, S. 36) Interessant ist das von Foucault angesprochene »System der Verweise«, da sich dieses auf verschiedene Einheiten bezieht, nämlich Bücher, Texte und Sätze. Man könnte in dieser Reihe eine Zerlegung des Buches in immer kleinere Einheiten erkennen, wobei zu fragen wäre, was die Einheit des Buches auszeichnet, woraus sie sich zusammensetzt. So deutet sich im Hinweis auf den Titel eine Perspektive an, in der Buch nicht synonym für einen größeren Text steht, wie die Reihenbildung durchaus nahelegt. Sondern offenbar erfasst Foucault auch Paratexte als Bestandteile eines Buches, die allerdings nicht dessen »Crenzen« definieren. Man kann mit Foucault zu dem Schluss gelangen, dass dem Buch auch durch die Materialität des Artefakts keine »Crenzen« gesetzt sind, weil es durch ein einfaches Zitat zum »Knoten in einem Netz« werden kann. Dennoch ist die Buchform eine zu berücksichtigende Cröße, unter anderem mit Blick auf die Werkform. Armin Schäfer erkennt in »Dr. Katzenbergers Badereise « einen Versuch Jean Pauls, »das Buch über die Grenzen des Buches hinauszutreiben «. »Dies ist eine Schreibweise, welche die Evidenz des Werkbegriffs verunsichert und die stabile Konfiguration der Texte ins Wanken bringt«, so Schäfer (Armin Schäfer, »]ean Pauls monströses Schreiben«, in: Jahrbuch der Jean-PaulGesellschaft 37 (2002), S. 216-234, hier: S. 221). Zweifellos ist die Buchform um 1800 für die Werkform entscheidend, nicht zuletzt in dem Sinne, dass sich Autoren wie Jean Paul durch die an Parametern des Buchdrucks ausgerichtete Zusammenstellung von Texten für eine Publikation an Praktiken des Publizierens beteiligen, die von der Herstellung zurückführen zum Schreiben, im Sinne einer bewussten Anlage von Texten, welche die Materialität der Produktion in den Text übertragen, aber auch mit Blick auf Rückkoppelungen, die sich z.B. durch Korrekturen ergeben oder den bogenweise erfolgenden Druck (siehe Kap. 4.3). 
Michel Foucault erkennt im Autornamen eine »klassifikatorische Funktion «, denn »mit einem solchen Namen kann man eine gewisse Zahl von Texten gruppieren, sie abgrenzen, einige ausschließen, sie anderen gegenüberstellen«. Darüber hinaus führt der Name, so Foucault, zu einer »Inbezugsetzung der Texte zueinander ${ }^{120}$ Foucault schreibt dem Autornamen also nicht die Funktion einer »Unifizierung von Papierstößen « ${ }^{121}$, sondern einer Organisation und Distribution von Texten innerhalb der Ordnung des Diskurses zu. Es sind Medien wie die in der Wissenskultur um 1800 allgegenwärtigen Bibliographien, die Autornamen in der diskursiven Praxis zuallererst auf die beschriebene Weise zum Funktionieren bringen. Grundlage dieser Medien sind allerdings nicht Texte, sondern durch Paratexte leicht zu erfassende »Papierstöße«. Zweifellos beziehen sich Paratexte auf Texte, aber zugleich auf die Artefakte, deren Teil sie zumeist sind und denen ihre spezifische Materialität einen Publikationscharakter verleiht, der unabhängig davon ist, ob es sich um unikale Privatdrucke oder Exemplare einer hohen Auflage handelt. Titelblätter sind hierfür das beste Beispiel. In Jean Pauls »Leben Fibels« wird die Funktionsweise des Autornamens parodistisch offengelegt. Der Roman präsentiert sich dabei als Schauplatz, auf dem die »Aneignung einer Subjektform ${ }^{122} \mathrm{zu}$ beobachten ist, nämlich die der Autorschaft, für welche die Funktion des Namens als basal anzusehen ist.

In dem Spätwerk Jean Pauls beschreibt der Biograph von Gotthelf Fibel, einem weithin unbekannten Schriftsteller, wie er auf diesen aufmerksam geworden ist: als Besucher einer »Bücher-Versteigerung«. »Sie bestand «, so heißt es über diese Veranstaltung, »anfangs aus 135 Bänden jedes Formats und jeder Wissenschaft, aber sämtlich (zufolge des Titelblattes) von einem Verfasser namens Fibel geschrieben.«(SW I.6, 373) Daran anschließend stellt sich der als »Jean Paul Fr. Richter« eingeführte Biograph in eine Reihe mit den Machern von »Das gelehrte Teutschland«, indem er sich selbst einen Literator nennt: »Vierzigjährige Literatoren wie ich können nicht genug darüber erstaunen über ihre sämtliche Unkenntnis eines solchen vielbändigen Verfassers«, wobei in »sämtliche Unkenntnis« die gängige Titelkonvention »Sämtlicher Werke« anklingt. Was in der Erzählung unmittelbar folgt, ist eine zehn Titel umfassende Liste von Schriften des entdeckten Autors. Diese umfasst neben einem Bibliothekskatalog auch ein keineswegs fiktives Periodi-

120 Foucault, »Was ist ein Autor?«, S. 17.

121 Kittler, Aufschreibesysteme, S. 127.

122 Alkemeyer, »Subjektivierung in sozialen Praktiken«, S. 37. 
kum (»Fibels Erlangische gelehrte Anzeigen, Jahrgang 1749«) sowie eine »Fibelii Biblia. Tondern 1737« (SW I.6, 373) - eine Bibel. Später erfährt die Leserschaft, wie dieses erstaunlich vermischte Werk zustande gekommen ist: Fibel hat seinen Namen auf die Titelblätter ersteigerter Bände gedruckt, um sich einen Autornamen zu machen. Der Roman beginnt freilich mit einer Fiktion, in welcher der Autorname seine Funktion nicht erfüllt, insofern als das erste und bekannteste Buch des Autors, dessen Lebensgeschichte erzählt wird, nämlich die im Selbstverlag erschienene »Bienrodische Fibel«, durch ihre hohe Verbreitung ihren Urheber vergessen lässt, weil das »Wort Fibel « (SW I.6, 372) auf dem Titel nicht mehr als Autorname aufgefasst wird. Vielmehr avanciert Fibel zum Begriff für eine angeblich von Gotthelf Fibel geprägte Gattung von Schulbuch. Erst durch die Bibliographie der von seinem Biographen ersteigerten Bücher wird der Autorname wieder als solcher erkennbar; es fällt ein Licht auf das Leben Fibels, das »Literatoren und Nekrologen« bis dahin entgangen sein soll. Stellvertretend genannt werden »J̈̈her, Jördens, Meusel etc. etc. (SW I.6, 369). ${ }^{123}$

Hamberger setzte als Meusels Vorgänger die Maßstäbe, indem er in »Das gelehrte Teutschland« systematisch Biographie und Bibliographie verband. Er ordnete die Schriften nicht unter fachlichen Gesichtspunkten, sondern allein alphabetisch nach den Namen ihrer Verfasser. Zwar lieferte der Gelehrte aus Göttingen keine Romane wie »Leben Fibels«, sondern hauptsächlich »einzelne Data ${ }^{124}$, aber trotzdem stiftete er in der übersichtlichen Ordnung des Lexikons einen bemerkenswerten Zusammenhang von Autor und Werk, ausgehend von der Person des Publizierenden. »Ich liefere keine Lebensbeschreibungen von Gelehrten, sondern mache sie nur ihren Namen, Vaterland, Alter und Stande nach bekant « ${ }^{125}$, erklärt Hamberger zwar, er trägt aber trotzdem grundlegend dazu bei, die von ihm verzeichneten Namen in einen gelehrten Personenstand zu erheben: den des Autors. Dem bleibt auch sein Nachfolger verpflichtet: Jean Paul erwähnt später die »kurze prosaische Nachricht [...], auf welche in Meusels gelehrtem Deutschland [...] jeder Schriftsteller Anspruch macht« (SW II.3, 632).

123 Jöcher gibt 1750/51 das Allgemeines Gelehrten-Lexicon mit über 60.000 Einträgen heraus, das später unter anderem von Johann Christoph Adelung fortgesetzt wird. Karl Heinrich Jördens, der zwischen 1806 und 1811 das von der Weidmannschen Buchhandlung aus Leipzig verlegte Lexikon deutscher Dichter und Prosaisten besorgt, widmet sich dem Leben ausgewählter Autoren in epischer Länge.

124 [Ersch], »Ueber Litteratoren und Recensenten«, Sp. 4.

125 Hamberger, Meusel, Das gelehrte Teutschland, I (1767), [S. 10]. 
»Das gelehrte Teutschland « macht es möglich, die persönlichen Umstände eines Autors ebenso wie dessen Gesamtwerk als Kontext der Lektüre zu berücksichtigen. Es sind »kurze biographische Notizen«, die dazu dienen sollen, "den Leser in den Stand zu setzen, hie und da selbst zu beurtheilen, in wiefern die Lage des Verfassers im bürgerlichen Leben, der Standpunkt, von dem aus er die Sachen ansah, ihn zu diesem oder jenem Werke qualificierten «, wie Ersch allgemeiner im Hinblick auf die Bücherkunde formuliert. ${ }^{126}$

Dass in dieser Hinsicht um 1800 ein großer Bedarf besteht, zeigen die Nachrichtendienste, um die sich Gelehrte in den deutschsprachigen Ländern regelmäßig bitten. So wendet sich im Dezember 1787 der aus der Schweiz stammende Arzt und Philosoph Johann Georg Zimmermann nach einem publizistischen Angriff durch den angeblich in der alten Heimat lebenden Johann Georg Heinzmann sogleich aus Hannover an seinen Freund Abraham Rengger in Bern und schreibt: »Sagen Sie mir doch, sobald es Ihnen möglich ist, (es würde mich sehr freuen, wenn es mit der ersten Post geschähe): wer ist Herr J.G. Hinzmann [sic!], der Herausgeber von Hallers Tagebuch seiner Beobachtungen über Schriftsteller und über sich selbst, (Bern 1787) und Verfasser der Vorrede zu diesem Buche? « ${ }^{127}$ Schon der fehlerhafte Name - in einem vergleichbaren Fall fahndet Nicolai nach »Harder «, eigentlich Herder ${ }^{128}$ - verdeutlicht den für Zeitgenossen hohen Stellenwert verlässlicher Angaben über die Akteure der Gelehrtenrepublik. Auf die globale Frage, wer Heinzmann sei, folgt bei Zimmermann eine Abfrage von Nationalität, Alter, Studienort, persönlichen Verhältnissen und Verbindungen. Es sind solche Fragen, auf die »Das gelehrte Teutschland« planmäßig Antworten zu geben verspricht.

126 [Ersch], »Ueber Litteratoren und Recensenten«, Sp. 10.

127 Johann Georg Zimmermann, Briefe an einige seiner Freunde in der Schweiz, hg. v. Albrecht Rengger, Aarau 1830, S. 57.

128 Friedrich Nicolai, Verlegerbriefe, hg. v. Bernhard Fabian und Marie-Luise Spieckermann, Berlin 1988, S. 43. 



\section{Buchmacherei}

\subsection{Lichtenberg als Büchermacher des Königs}

Als Georg Christoph Lichtenberg im Oktober 1775 in Birmingham eintrifft, ahnt er nicht, dass er zu spät kommt. Es handelt sich um Lichtenbergs zweiten Aufenthalt in England, nachdem er bereits 1770 einige Wochen auf der Insel verbracht hatte. Gegenüber der Göttinger Universität begründete Lichtenberg die erneute, über 14 Monate andauernde Reise in einem Schreiben vom 28. April 1774 unter anderem mit den »mannichfaltigen Wercke[n] der Kunst «' auf englischem Boden. Dazu zählen auch die Innovationen der Buchdruckerkunst.

Lord Boston hatte Lichtenberg im September 1773 nach London eingeladen. Bis zu seinem Reiseantritt sollte jedoch ein Dreivierteljahr vergehen. Eine größere Arbeit hielt ihn vorerst in Göttingen. An Johann Andreas Schernhagen schrieb Lichtenberg: »Ich würde mich, nach erhaltener Erlaubniß von Königlicher Regierung, gewiß jezt gleich in ein englisches Schiff in Hamburg werfen, und der glücklichen Insul zum zweytenmal zufliegen, wenn mich nicht die Mayerschen Schrifften abhielten. $\aleph^{2}$ Seinen Freund und Verleger Johann Christian Dieterich ließ Lichtenberg wissen: »[D]ie erste Secktion von Mayers Schrifften muß fertig seyn, ohne das darf ich dort nicht erscheinen. $\ll^{3}$

Georg Christoph Lichtenberg, »An das Geheime Rats-Kollegium« (28. April 1774), in: ders., Briefwechsel, hg.v. Ulrich Joost, Albrecht Schöne u.a., München 1983-2004, I (1983), S. 456-457 [247], hier: S. 456. Zu den Englandaufenthalten siehe auch Julia Hoffmann, »)lch laufe und renne den gantzen Tag, mit allen Sinnen sperrweit offen<. Lichtenbergs Reisen nach England «, in: Ulrich Joost (Hg.), Georg Christoph Lichtenberg, 17421799. Wagnis der Aufklärung, München 1992, S. 211-228.

2 Georg Christoph Lichtenberg, »Brief an Johann Andreas Schernhagen« (28. September 1773), in: ders., Briefwechsel, I (1983), S. 391-393 [207], hier: S. 391.

3 Georg Christoph Lichtenberg, »An Johann Christian Dieterich« (28. September 1773), in: ders., Briefwechsel, I (1983), S. 390-391 [206], hier: S. 390. 
Mit »Mayers Schrifften« sind unveröffentlichte Arbeiten des 1762 verstorbenen Astronomen Tobias Mayer gemeint, mit deren Herausgabe Lichtenberg betraut worden war - nachdem er ihre Publikation höchstselbst angeregt hatte. Letztlich zog sich das Erscheinen von Mayers »Opera Inedita« deutlich länger hin als gedacht, so dass Lichtenberg erst im September 1774 den Weg nach England antrat - während der Drucklegung des Buches. Sowohl die Vorrede als auch die Widmung vollendete er auf der Reise. Als er in London den ersten Brief nach Hause verfasste, an Dieterich, kam er auch auf den Band zu sprechen: "Ich hoffe, es ist mit dem Druck alles gut gegangen, ich bin mit dem gantzen jetzt nicht zufrieden, und wünschte alles weg. « ${ }^{4}$

Dass Lichtenberg die Reise so sehr mit der Edition verquickte, hatte nicht nur terminliche Gründe. Er widmete die »Opera Inedita« niemand Geringerem als Georg III., dem König von England und Kurfürsten von Hannover. Georg III. und seine Frau, Königin Sophie Charlotte, hatten sich bereits Wochen vor Lichtenbergs Ankunft bei Lord Boston persönlich nach ihm erkundigt. ${ }^{5}$ Am 22. April 1770 war Lichtenberg dem Monarchen auf der Sternwarte in Richmond als Astronom erstmals begegnet. Er wusste Georg III. mit seinen Kenntnissen derart zu begeistern, dass dieser seine Ernennung zum außerordentlichen Professor der Philosophie in Göttingen empfahl. ${ }^{6}$ An diese Verbindung wollte Lichtenberg als Herausgeber Mayers anknüpfen. Aber nicht nur an diese: Berühmtheit erlangte Georg III. auch als Buchliebhaber und Herrscher über eine eigene Bibliothek, die kurz nach seiner Krönung im Jahr 1760 von ihm initiierte »King's Library«. In den Bestandsaufbau floss ein beträchtlicher Teil seines royalen Einkommens. Zwischen 1768 und 1771 bereiste ein Beauftragter des Königs den europäischen Kontinent, um Bücher für dessen Kollektion anzukaufen. Als Georg III. nach langer Krankheit im Jahr 1820 stirbt, umfasst die »King's Library« zirka 65.000 Bände. ${ }^{7}$ Der bibliophile Regent, dem Lichtenberg seine Stellung an der Göttinger Hochschule zu

Georg Christoph Lichtenberg, »An Johann Christian Dieterich« (30. September 1774), in: ders., Briefwechsel, I (1983), S. 472-473 [261], hier: S. 473.

5 Otto Deneke, Lichtenbergs Leben, München 1944, I, S. 222, vgl. Georg Christoph Lichtenberg, »An Joel Paul Kaltenhofer«, in: ders., Briefwechsel, I (1983), S. 194-197 [103], hier: S. 194.

6 Ulrich Joost, »Lichtenbergs London«, in: Burkhard Moennighoff, Wiebke von Bernstorff, Toni Tholen (Hg.), Literatur und Reise, Hildesheim 2013, S. 97-131, hier: S. $109 f$.

7 Jane Roberts (Hg.), George III \& Queen Charlotte. Patronage, Collecting and Court Taste, London 2004, S. $221 f$. 
Abbildung 3: Titelblatt von Tobias Mayer, „Opera Inedita«, Göttingen 1775, Bd. 1 .

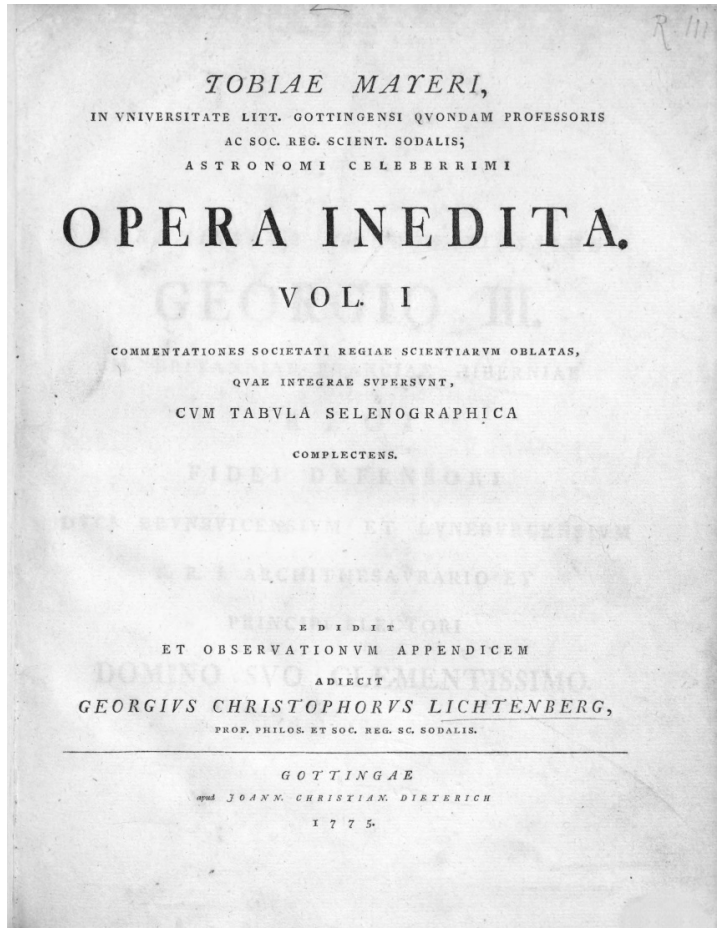

Bayerische Staatsbibliothek, 4 Mapp. 61 h, http://mdz-nbnresolving.de/urn:nbn:de:bvb:12-bsb11164870-6.

verdanken hatte, sollte daher nicht bloß den Inhalt von Mayers Schriften goutieren. Nicht weniger achtete der Englandreisende auf die äußere Form des Buches, von der Georg III. sofort beeindruckt sein sollte, wenn sie einander begegneten.

Anders als beim "Timorus«, seiner ersten eigenen, aber pseudonymen Veröffentlichung, um die er sich parallel zur Edition bemühte ${ }^{8}$, ging es ihm

$8 \quad$ Heinrich Christian Boie setzt sich bei Friedrich Nicolai für eine Veröffentlichung des »Timorus« ein - ohne den Namen des Autors zu nennen. Er teilt dem Verleger am 15. April 1773 mit: »Wollen Sie, so verlangt der Verfaßer nichts als sauberen und richtigen Druck, und eine Anzahl Exemplare, über die wir bald einig werden wollen.« (Brief von 
als Mayers Herausgeber um eine besondere Form sozialer Repräsentation. Lichtenberg inszenierte sich als Büchermacher des Herrschers, und er setzte alles daran, dem »Königs-Astronomen« (»REGIS ASTRONOMI«) ${ }^{9}$, wie er ihn in der Dedikation nannte, die aufwendig gestaltete Edition von Mayers Werken persönlich zu überreichen. Auch der Rezensent der »Allgemeinen Deutschen Bibliothek« erwähnte anerkennend, der Band erscheine in einer dem königlichen Interesse »gemäßen Pracht, die der Sorgfalt des Herausgebers

Boie an Nicolai, 15. April 1773, Staatsbibliothek zu Berlin, Nachlass Friedrich Nicolai, Bd. 7, zit.n. Ulrich Joost, »Über Nicolai, Boie und die Druckgeschichte des >Timorus «, in: Lichtenberg-Jahrbuch 14 (1992), S. 132-137, hier: S. 132) Mit dem »Timorus« schaltet sich Lichtenberg in eine Auseinandersetzung zwischen Johann Caspar Lavater und Moses Mendelssohn ein (Ulrich Joost, »Zweckbündnisse. Ceorg Christoph Lichtenberg und Friedrich Nicolai«, in: Stefanie Stockhorst u.a. (Hg.), Friedrich Nicolai (1733-1811), Berlin 2011, S. 107-124, hier: S. 110), und zwar in einiger Deutlichkeit. Solche »libri famosi« waren, wie Joost ausführt, schwierig mit korrekten Angaben zu veröffentlichen, weshalb Nicolai findig sein musste: Offiziell wird der Band von Johann Friedrich Hartknoch in Riga verlegt, jedoch beim Kanter-Verlag in Königsberg gedruckt, da die ostpreußische Stadt verfassungsrechtlich nicht zum Deutschen Reich gehörte, so Joost. »Durch dieses Spiel mit drei Herrschaftsbereichen und der virtuellen Überquerung ihrer Grenzen (es gibt nicht das mindeste Anzeichen dafür, dass die Bücher selber je im Baltikum gewesen wären) vermied der Autor geradezu perfekt den Konflikt mit irgendwelchen Zensurbehörden - es gab ja nun keine erkennbaren Zuständigkeiten mehr«, erläutert Joost (Ebd., S. 111f.). Schließlich offenbart Boie dem Verleger den Namen des Autors, für den Nicolai diese Strategie entwickelt. Nicolai selbst übernimmt die Rezension in der ADB (Ebd., 112). Das unter dem Autornamen »Conrad Photorin «publizierte Bändchen erregt durchaus Aufsehen, so dass Karl Wilhelm Ramler den »Verfasser des Sebaldus«, also Nicolai, am 12. Juli 1773 darum bittet, das Geheimnis der Autorschaft zu lüften. Diese keineswegs unübliche Anrede unterstreicht, wie selbstverständlich eine durch Autorschaft begründete zweite Existenz im sozialen Umgang anerkannt wird. Zugleich lässt sich anhand der weiteren Rezeption des »Timorus « der sekundäre Diskurs über ein von vielen ungelesenes Buch ebenso anschaulich machen wie die Grenzen der Gelehrtenrepublik, die sich aus der Reichweite eines Verlages und dessen Distribution ergeben. So schreibt nämlich Lavater aus Zürich: »lch habe gestern von Timorus gehört. Es ist aber nur ein Exemplar hier. Ich bin begierig das Buch zu sehen, und mit dem Lacher zu lachen.« (zit.n. ebd., S. 113).

9 Ceorg Christoph Lichtenberg, Observationes. Die lateinischen Schriften, hg. v. Dag Nikolaus Hasse, Göttingen 1997, S. 58f., der Band erschien unter dem lateinischen Titel Tobiae Mayeri, in Vniversitate litt. Cottingensi qvondam Professoris, Ac Soc. Reg. Scient. Sodalis; Astronomi celeberrinim, Opera Inedita. Vol. I, edidit et observationvm appendicem adiecit Ceorgivs Christophorvs Lichtenberg, Prof. Philos. et Soc. Reg. Sc. Sodalis, Cottingae: apud Johann Christian Dieterich, 1775. 
und der Dieterischen Druckerey Ehre machet $\aleph^{10}$. Lichtenberg widmete seine Edition dem König mit den üblichen Floskeln der Ehrerbietung und Ergebenheit, doch die Zueignung endete mit diesen Worten nicht. Lichtenberg fuhr fort, indem er Bezug nahm auf die Begegnung mit Georg III. in Richmond, mit der »Erinnerung an jenen Tag, den glücklichsten meines Lebens, an dem es mir vergönnt war, von Euch, erhabenster König, im Heiligtum Eurer Urania selbst zu hören, wie groß Ihr das Verdienst Mayers einschätzt $^{11}$.

Im Oktober 1774 konnte Lichtenberg sein Geschenk an den Regenten druckfrisch in Empfang nehmen. Von der Übergabe an Georg III. berichtete er Dieterich ausführlich in einem Brief vom 30. Oktober 1774:

»Die Mayerschen Wercke habe ich ihm vor vier Tagen überreicht, er ist gantz davon eingenommen, und nun will ich Dir sagen, was er von Deinem Druck gesagt hat, es sind die Worte des Königs: Das ist ein vortrefflicher Druck, so wie es die Schrifften des Mannes gewiß verdienen, sagte er gleich als er es aufmachte, so gut als Baskerville, hier strich ich, wie Du leicht erachten kanst, Dein Lob heraus und erzählte ihm von Deinen Versuchen, und sagte, ich wünschte daß ich erfahren könnte wie Baskerville sein Papier glättet, hier sagte er, nachdem er sich besonnen, vielleicht kann ich dem Manne dazu verhelfen. Ich glaube, Dieterich, daß Dich der König nun so kennt [...] Schicke ja den Pindar so bald als möglich, der König will ihn sehen [...]. $^{12}$

Der englische König war angetan von den Arbeiten des Göttinger Verlegers, er erbat sich neben einem weiteren Exemplar der »Mayerschen Wercke« sogleich die 1773 bei Dieterich herausgekommenen »Carmina« von Pindar. Lichtenberg lenkte das Zwiegespräch mit Georg III. gezielt auf den Verlegerfreund, auch deshalb, weil er sich für diesen eine finanzielle Hilfe vom Königshaus erhoffte. Daraus entwickelte sich ein intensiver Austausch über die Buchmacherei, so dass Lichtenberg an Dieterich melden konnte: »Ich habe sogar von der Schrifftgießerey heute geredet. ${ }^{13}$

Folgt man den Briefen aus England, so kann Dieterich sich gegenüber einem der berühmtesten europäischen Büchermacher des 18. Jahrhunderts

10 [Sp], Rez. »Tobiae Mayeri in Vniuersitate litt. Göttingensi quondam Professoris - Opera Inedita. Vol. I«, in: Allgemeine Deutsche Bibliothek 33 (1778), S. 362-370, hier: S. 362.

11 Lichtenberg, Observationes, S. 59/61.

12 Ceorg Christoph Lichtenberg, »An Johann Christian Dieterich« (30. Oktober 1774), in: ders., Briefwechsel, I (1983), S. 480-482 [265], hier: S. 480.

13 Ceorg Christoph Lichtenberg, »An Johann Christian Dieterich« (28. Januar 1775, 4./5. Februar 1775), in: ders., Briefwechsel, I (1983), S. 503-509 [272], hier: S. $506 f$. 
behaupten. Der König vergleicht ihn mit John Baskerville. Der Drucker aus Birmingham hatte mit seiner splendiden Vergil-Ausgabe (»Bucolica, Georgica et Aeneis«) in Großquart von 1757 auf dem gesamten Kontinent für Aufsehen gesorgt und neue Maßstäbe in Typographie und Buchausstattung gesetzt. ${ }^{14}$ Das königliche Urteil »so gut als Baskerville« ist für Dietrich ein Achtungserfolg. Aber er lässt auch offenbar werden, dass die als rückständig geltenden Büchermacher aus den deutschsprachigen Ländern nur Anerkennung finden, wenn sie sich an Größen wie dem Engländer, dem Franzosen Pierre Simon Fournier, später Firmin Didot oder Giambattista Bodoni aus Italien orientieren und ihren Sonderweg verlassen. Das erfordert eine nachhaltige Verbesserung der eigenen Buchproduktion, zugleich eine Abkehr von der Schrifttradition der Fraktur. Die »Mayerschen Wercke« sind in einer Antiqua gedruckt, wegen des lateinischen Textes, aber wohl auch mit Blick auf ein internationales Publikum. Denn adressiert ist die Edition ausdrücklich an den "gebildeten Teil Europas« (»meliori Europae parti«), wie der Vorrede zu entnehmen ist. ${ }^{15}$

Um den Anschluss zu halten, bedürfen Büchermacher wie Dieterich einer intimeren Kenntnis des Handwerks und der Techniken des Auslandes, auch deshalb, weil der Import von Ressourcen wie Matrizen kostspielig ist und geschäftlich ein Risiko darstellt. Ein Geheimnis, das Lichtenberg als Freund von Dieterich lüften will, ist die Glättung des Papiers, die Baskerville perfektioniert hatte. Wie die Korrespondenz belegt, bemüht Lichtenberg sich um das entsprechende Wissen beim englischen König höchstpersönlich.

Die außergewöhnliche Beschaffenheit von Baskervilles Papieren ist etwas, auf das Lichtenberg in seinen privaten Aufzeichnungen wiederholt zurückkommt. Sie führt bei ihm zu Assoziationen und Vergleichen, schließlich Metaphern, die lesbar sind als unerwartete Implikationen der Materialität gedruckter Artefakte einerseits, als libidinöse Verdinglichung weiblicher Körperlichkeit andererseits. Im Sudelbuch B, begonnen 1768, heißt es einmal über eine unbekannte Frau: »Ihr Kinn fühlte sich so sanft an daß es auch die feinste Seite in Baskervilles Milton, eines der besten gedruckten Bücher, die man hat, und dieses auf das feinste Papier, nur bloßer Pappdeckel dagegen

14 Offenbar fällt es Baskerville selbst schwer, die Qualität dieser Ausgabe wieder zu erreichen. Philip Gaskell bezeichnet den Vergil in der Erstauflage von 1757 als »Baskerville's first and perhaps his finest book«, an dem er mehr als drei Jahre lang arbeitete (Philip Gaskell, John Baskerville. A Bibliography, Cambridge 1959, S. 19).

15 Lichtenberg, Observationes, S. $62 \mathrm{f}$. 
war. ${ }^{16}$ Bei »Baskervilles Milton« handelt es sich nach Ansicht von Hans Ludwig Gumbert um eine 1759 erschienene Quartausgabe von Miltons »Paradise regained «, von der Lichtenberg ebenso ein Exemplar besitzt wie von einer im Jahr davor von Baskerville gedruckten Ausgabe von »Paradise lost «. ${ }^{17}$ Am 14. August 1771 notiert sich Lichtenberg wahrscheinlich über Marie Sachse, die in seinen Tagebüchern als »Komet« firmiert ${ }^{18}$ :

»Now I have it out at last. I know what is the matter with the white comet. $\mathrm{He}$ is lost for ever. Now there is hope for recovery. Not to know where a thing is, is ten times worse than loosing it quite. Is not it? But he had a tender heart and upon my soul as tender a skin too, when ever I touch Baskerville's Milton I shall think of thee, dearest star [...]. « ${ }^{19}$

Sachse gehört zum Umfeld von Joel Paul Kaltenhofer, dem Zeichenlehrer und Freund Lichtenbergs, der später für Mayers »Opera Inedita« die berühmte Mondkarte stechen wird. Als Lichtenberg drei Jahre nach diesem Eintrag zum zweiten Mal in England ist, greift er die Formulierung aus dem Tagebuch noch einmal auf, diesmal in einem "zweifellos erotische[n] Zusammenhang ${ }^{20}$ als Chiffre für die glatte Haut einer Frau aus dem Covent Garden: »An demselben Abend bezog mich die kleine upon my shoul in Coventgarden. Baskerville und Goldpapier. ${ }^{21}$

Aus den vier Monaten, die er bei seinem zweiten Aufenthalt auf der "glücklichen Insul« verbringen will, werden schließlich sechzehn. Nach einem Jahr begibt sich Lichtenberg auf eine Rundreise »von mehr als 72 deutschen Meilen « ${ }^{22}$ über Oxford, Birmingham und Bath. Sie dient nicht zuletzt der Lösung jenes Rätsels, das selbst der König für ihn nicht hatte aufklären können: Wie glättet Baskerville sein Papier? »Birmingham ist ein sehr groser und volkreicher Ort, wo fast alles hämmert, klopft, reibt und meißelt«, berichtet Lichtenberg in einem Brief an Schernhagen. In dem Fabrikort

\footnotetext{
16 Lichtenberg, Schriften und Briefe, I, S. 106 (B 222).

17 Hans Ludwig Cumbert, Bibliotheca Lichtenbergiana. Katalog der Bibliothek Ceorg Christoph Lichtenbergs, Wiesbaden 1982, S. 262f. [Nr. 1658, 1657].

18 Lichtenberg, Schriften und Briefe, II, S. 606 (Tagebuch 1771, 7), siehe dazu den Kommentarband, S. 906.

19 Lichtenberg, Schriften und Briefe, II, S. 612.

20 Ceorg Christoph Lichtenberg, Lichtenberg in England, hg.v. Hans Ludwig Cumbert, Wiesbaden 1977, II, S. 56.

21 Lichtenberg, Lichtenberg in England, I, S. 68 (T II 26).

22 Ceorg Christoph Lichtenberg, »An Johann Andreas Schernhagen«, in: ders., Lichtenberg in England, I, S. 316-320 [XXII], hier: S. 320.
} 
besichtigt er die Manufakturen von Bolton und Clay. In »Clays Manufacktur von lackirter Arbeit« bekommt er nicht nur Eisenwaren zu Gesicht, sondern auch "papierne Dosen, Theekästchen, Blätter zu Kutschen und Portchaisen, denn in London fährt man jetzt in papiernen Kutschen ${ }^{23}$. Aufschlussreich sind diese Beschreibungen deshalb, weil sie deutlich machen, dass Papier um 1800 als vielseitiger und innovativer Werkstoff in Gebrauch ist. Schließlich gelangt Lichtenberg zu seinem eigentlichen Ziel, wie er seinem Freund Dieterich kurz darauf mitteilt: der Druckerei von Baskerville. Doch: Er ist zu spät.

In einem Brief vom 13. Oktober 1775 berichtet Lichtenberg:

»Ich bin, gröstentheils Dir zu gefallen, nach Birmingham gereißt, welches über 24 deutsche Meilen von hier ist, um Herrn Baskerville zu sprechen, der, wie ich erst dort erfuhr, schon vor einem halben Jahr und drüber begraben worden ist. Ich machte meine Aufwartung seiner Wittwe, einer vortrefflichen Frau, die die Schrifftgießerey fortsetzt, allein die Druckerey fast völlig aufgegeben hat. [...] Ob sie gleich sehr nett und in schwartze Seide gekleidet war, so hat sie mich dennoch selbst in die schmutzigsten Winckel der Schrifftgießerey begleitet. Ich habe die Puntzen und Matricen zu allen den schönen Buchstaben gesehen, die wir so offt bewundert haben. Allein aus der Art, wie sie das Papier glättet, macht sie ein Geheimniß, ich bin aber nun der Sache doch viel näher gekommen, durch Fragen die ich von der Seite gethan habe. Sie glättet Papier selbst für die Londonschen Buchhändler und die schreiben ihr den Grad der Glätte vor, wofür sie eigne Nahmen haben. Ich habe Papier gesehen, das sich nur eben von gemeinem unterschied, und anderes, das so glatt war als ein Spiegel, von dem letzteren hat sie mir einige Bogen gegeben. Ein Stückgen davon liegt bey. [...] Ein andres Geheimniß, worauf sie eben so stolz ist als auf das Clätten, ist das Recept zu ihres Mannes Drucker Schwärtze, die allein englischen Buchdruckern unbekannt ist. [...] Sie will, da sie selbst kein Vergnügen in diesem Wesen findet und Reich genug ist, ihre gantze Druckerey, mit allen Puntzen, Matricen und allem was zur Schrifftgießerey gehört, ferner die Clättmaschine und das Recept der Drucker Schwärtze für 4000 Pfund Sterling verkaufen [...] Das wäre etwas wenn man Geld hätte. Wie viel Schrifften ließen sich nicht mit den vorhandenen Matricen gießen und wie viel Matricen mit den vorhandenen 
Puntzen schlagen. Es ist eine Affaire entweder reich oder Bankrot zu werden. Für Deutschland ist es aber, glaube ich, kaum etwas [...]. ${ }^{24}$

Lichtenberg stellt mit seinem umfassenden Interesse an den mechanischen Künsten und der Buchmacherei im Besonderen sicherlich eine Ausnahme unter den zeitgenössischen Schriftstellern dar. Er wird sich immer wieder damit beschäftigen, unter anderem in einem kurzen Aufsatz über Buchformate. ${ }^{25}$ Und doch vereint die Mehrzahl der Publizierenden um 1800 ein profundes Wissen über das Buch als Artefakt in all seinen Facetten. Aus diesem erwächst ein bemerkenswertes "Materialbewusstsein «, das nicht losgelöst oder in Ergänzung zur Beschäftigung mit den eigenen Texten zu sehen ist, sondern das in vielerlei Hinsicht das Schreiben grundlegend beeinflusst oder gar konditioniert.

»Materialbewusstsein « ist ein Begriff, den Richard Sennett in seiner kultursoziologischen Arbeit über das Handwerk prägt und überraschend am Beispiel eines Dichters erläutert. ${ }^{26}$ Für Sennett beschränkt sich dieses Bewusstsein im Feld der Autorschaft auf das Material der Sprache, nicht auf die Medien der Literatur und ihre Materialität. Daher übernehme ich den Begriff des »Materialbewusstseins« zwar bewusst, aber deutlich anders akzentuiert, mit dem Ziel, ihn so zu erweitern, dass die Bedeutung gedruckter Artefakte für die Praktiken der Autorschaft erkennbar wird. Dieses erweiterte »Materialbewusstsein « wird in diesem Kapitel in einer weitreichenden Darstellung aufgefächert. Anhand von Jean Paul und Lichtenberg, aber auch Nicolai und Lessing soll außerdem exemplarisch nachvollzogen werden, wie Autoren in kooperativen Arbeitsprozessen als Büchermacher agieren. Autoren fungieren dabei nicht als reine Textlieferanten, sondern im steten Zusammenspiel mit

24 Ceorg Christoph Lichtenberg, „An Johann Christian Dieterich, 13.10.1775«, in: ders., Briefwechsel, I (1983), S. 556-559 [287], hier: S. 556-558. Zum Papierglätten siehe als spätere, im weitesten Sinne zeitgenössische Quelle, in der auch Baskerville berücksichtigt ist: Johann Heinrich M. Poppe, Geschichte der Technologie seit der Wiederherstellung der Wissenschaften bis ans Ende des achtzehnten Jahrhunderts, Cöttingen 1810, II, S. 212-215 (\$327).

25 Ceorg Christoph Lichtenberg, »Ueber Bücher-Formate«, in: Cöttinger Taschen Calender (1796), S. 171-178.

26 Richard Sennett, Handwerk, aus dem Amerikanischen von Michael Bischoff, Berlin 2008, S. $162 f f$. 
Akteuren wie Verlegern und denjenigen, die Bücher handwerklich herstellen, sie gehören selbst zu den »book people « ${ }^{27}$ (Robert Darnton).

\subsection{Bücherwissen und "Materialbewusstsein»}

»Um einem Buche die Existenz $\mathrm{zu}$ geben, (ich sagte lieber: ein Buch $\mathrm{zu}$ machen, wenn der Ausdruck nicht manchem zu niedrig scheinen möchte,) kömmt es nicht auf den Schriftsteller allein an: auch durch Verleger und Drucker kann die Güte desselben viel gewinnen und verlieren ${ }^{28}$, schreibt Daniel Gotthold Hübler in der Vorrede eines 1803 veröffentlichten Bändchens mit "praktischen Anmerkungen für Schriftsteller und Verleger«, wie es kleingedruckt auf dem Titelblatt heißt. Dass es eines solchen Untertitels als Verkaufsargument bedarf, liegt am komplizierten Haupttitel dieser Schrift. Enthält sie doch Hüblers gesammelte »Beyträge zur Bibliopöie«, zur "Bücherschreibekunst «, was in der griechischen Diktion der »Bibliopöie» aber weniger ein Ausweis klassischer Sprachkenntnis sein soll, sondern eine Referenz an ein anderes, älteres Buch, das »wohl vielen Lesern unbekannt sein möchte ${ }^{29}$, wie Hübler in einer erläuternden Fußnote einräumt.

1783 erschien in deutscher Übersetzung die 412 Seiten starke »Bibliopoeie, oder Anweisung für Schriftsteller « von Carl Denina. ${ }^{30}$ Der emeritierte Professor der Beredsamkeit und griechischen Sprache aus Turin, Mitglied der Berliner Akademie und Biograph Friedrichs II., war ein Freund des berühmten Schriftschneiders Bodoni, als dessen Vermittler er in Berlin auftrat. ${ }^{31}$ Seine "Anweisung für Schriftsteller« ist um 1800 so unbekannt nicht. Der Rezension eines anderen Titels aus dem Jahr 1792, in der Denina als Standardwerk Erwähnung findet, ist beispielsweise eine Übersetzung von »Bibliopoeie« zu verdanken, die das Verfassen von Büchern vollends als Handwerk erschei-

27 Robert Darnton, »What is the History of Books?«, in: Daedalus 111 (1982), 3, S. 65-83, ders., ")What is the History of Books? Revisited", in: Modern Intellectual History 4 (2007), 3, S. 495-508.

28 Hübler, Beyträge zur Bibliopöie, S. X.

29 Ebd., S. IV.

30 Carl Denina, Bibliopoeie, oder Anweisung für Schriftsteller, Berlin, Stralsund 1783. Die italienische Erstausgabe kam 1776 in Turin heraus.

31 Nikolaus Weichselbaumer, »Die Druckerfamilie Decker und die klassizistische Typographie in Berlin um 1800«, in: Imprimatur N.F. 25 (2017), S. 249-268, hier: S. 256. 
nen lässt: »vom Buchmachergewerk « ${ }^{32}$. Tatsächlich wird der Band, der ausführliche Erörterungen über Gelehrsamkeit, Philosophie und Ästhetik, Sprache, Rhetorik und Poetik, aber auch zur Formulierung von Paratexten wie Überschriften und Dedikationen sowie ein abschließendes Kapitel zur Typographie beinhaltet, gegen das vom Historiker Johann Georg Meusel im Lexikon »Das gelehrte Teutschland « versammelte »Schriftstellerheer« und mithin gegen Autorschaft als soziales Phänomen ins Feld geführt. »Eine das Ganze der schriftstellerischen Kunst umfassende Anweisung ist in unsern Tagen, wo fast alles, was nur Finger hat, einen Beruf zum Schreiben zu haben glaubt, gewiß nicht überflüßig «33, merkt Deninas Übersetzer in einer vorangestellten »Nachricht« kritisch an. Dies »Ganze« umfasst auch die Buchmaterialität, und nicht anders als Hübler vermittelt Denina die Botschaft, dass Autorschaft über das Verfassen von Texten hinausreicht, weil es schließlich darum geht, »ein Buch zu machen«.

Obwohl Denina in den mit »Vom Druck« überschriebenen Paragraphen eingangs festhält, dass die »mechanische Bekanntmachung eines Buchs mehr zur Buchdruckerkunst, als zur gelehrten Beschäftigung gehört ${ }^{34}$, behandelt er die typographische Gestaltung und materiale Ausstattung von Texten in Buchform mit einiger Ausführlichkeit. Das ist nicht ungewöhnlich, bedenkt man, wie selbstverständlich in zeitgenössischen Briefstellern und sonstigen Anleitungen zur Ausgestaltung von Korrespondenzen und Gebrauchstexten die Kalligraphie und andere Aspekte der Einrichtung von Manuskripten behandelt werden, die mit der »visuellen Materialität« chirographischer Aufzeichnungen verbunden sind (Kapitel 2.3). Erwähnenswert ist das von Johann Friedrich Heynatz verfasste »Handbuch zu richtiger Verfertigung und Beurtheilung aller Arten von schriftlichen Aufsätzen des gemeinen Lebens überhaupt, und der Briefe insbesondere«, das sich ausdrücklich an die im Schreiben noch »Ungelehrte[n] $^{35}$ richtete und um 1800 mindestens fünf Auflagen erlebte. Die »Anweisung zur Calligraphie oder zum zierlichen Schreiben « steht bei Heynatz an erster Stelle und erstreckt sich auf knapp 30 Seiten. ${ }^{36}$ Körperhaltung und passendes Mobiliar werden ebenso thematisiert wie Tigurinum Epistolae de ratione edendorum librorum«, in: Allgemeine Literatur-Zeitung 1 (1792), Nr. 20 (18. Januar 1792), Sp. 160, hier: Sp. 160.

33 Denina, Bibliopoeie, Nachricht (unpaginiert).

34 Denina, Bibliopoeie, S. 401.

35 Heynatz, Handbuch zu richtiger Verfertigung, S. VIII.

36 Ebd., S. 7-35. 
die gängigen Schriften und Schreibmaterialien, einschließlich des Beschreibstoffes.

Zwar basieren handschriftlicher Aufsatz und gedrucktes Buch auf unterschiedlichen visuellen Codes, sie stehen auch für unterschiedliche Kommunikationsanlässe, aber hinsichtlich der sozialen Relevanz, die dem Layout zugemessen wird, stimmen Handschriftlichkeit und Druckschriftlichkeit grundsätzlich überein. Somit ist es für Schriftsteller des 18. Jahrhunderts mehr als naheliegend, sich mit der materialen Seite ihrer Publikationen zu befassen. Dabei ist medienhistorisch $\mathrm{zu}$ berücksichtigen, was Albrecht Koschorke in »Körperströme und Schriftverkehr« als These über die Literatur um 1800 formuliert hat: »In dem Maß«, so Koschorke, »in dem Dichtung sich in gedruckten Texten materialisiert, die über den expandierenden Buchmarkt des 18. Jahrhunderts den Weg zu lesenden Einzelpersonen fanden, büßt sie ihren konkreten Geselligkeitsbezug und infolgedessen ihren Platz im Rahmen der rhetorischen Organisationsformen ein. « $^{37}$

Durch die gesteigerte Mediatisierung von Literatur wächst die Bedeutung von Typographie und materialer Ausstattung als Medien einer paratextuellen Repräsentation von Autorschaft. Allerdings geschieht dies, wie noch gezeigt werden wird, sehr wohl in Anlehnung an die Rhetorik. Dabei geht es vor allem um das übergreifende Prinzip der Angemessenheit und eine Metaphorik des Einkleidens, die, in ihrer Anwendung auf Bücher, diese Artefakte an soziale Praktiken anbindet, die sich durch die Formen bürgerlichen Konsums im späten 18. Jahrhundert stark wandeln. Zum Beispiel rät Denina beim Druck von »einer nicht nur überflüßigen, sondern schädlichen Pracht« ab oder lobt Ausgaben »mit dem blosen Text ${ }^{38}$, also ohne Buchschmuck und aufwendige Illustrationen. In diesen Ratschlägen steckt eine Kernbotschaft der Abschnitte »Vom Druck«, schließlich lautet die Überschrift von $\$ 2$ einigermaßen apodiktisch: »Unnütze und schädliche typographische Pracht ${ }^{39}$.

Aus kulturhistorischer Perspektive ist bemerkenswert, wie umfassend $\mathrm{Pu}$ blizierende im späten 18. Jahrhundert über das Buch als Artefakt informiert sind. Dazu trägt eine Reihe von Faktoren bei, die in diesem Kapitel an Beispielen erörtert werden. Angesichts eines expandierenden Marktes, der es zunehmend erlaubt, durch Schreiben seinen Lebensunterhalt zu bestreiten,

37 Albrecht Koschorke, Körperströme und Schriftverkehr. Mediologie des 18. Jahrhunderts, 2. Aufl., München 2003, S. 293.

38 Denina, Bibliopoeie, S. 404.

39 Denina, Bibliopoeie, S. 402. 
gewinnt Buchkunde aus der Sicht vieler Autoren den Charakter einer grundlegend wichtigen und mannigfaltigen Warenkunde. Wolfgang von UngernSternberg betrachtet das gesteigerte Interesse an der Ausstattung im Zuge einer »schriftstellerischen Emanzipationsbewegung ${ }^{40}$, die bei ihm vor allem zum Berufsbild des freien Schriftstellers und somit zu einer Professionalisierung von Autorschaft führt.

Nicht zu vernachlässigen ist in diesem Kontext, dass zur Mitte des 18. Jahrhunderts das schöne Buch entscheidend zum Aufstieg der schönen Literatur, der Dichtung, aus den verstaubten Bibliotheken der Gelehrtenrepublik beiträgt. Der in seinen »Nebenstunden« als Dichter tätige Friedrich von Hagedorn, dessen wohlgestaltete Bücher für Klopstock und viele andere den Maßstab für das eigene Publizieren bildeten, ist hierfür ein herausragendes Beispiel. Ungern-Sternberg spricht von einem sich entwickelnden »Ensemble von Ausstattungspostulaten, das vor allem korrekten Druck, saubere Lettern, gute typographische Gestaltung, Formatwahl, Papierqualität, Buchschmuck und Illustrationen zum Gegenstand hatte ${ }^{41}$. Diesen Postulaten folgen namhafte Autoren wie Klopstock mit ihren Selbstverlags-Projekten. ${ }^{42}$ Ein häufiges Argument für den Selbstverlag, das auch in der Vermarktung entsprechender Titel angeführt wird, ist die vom Urheber garantierte Korrektheit des Abdrucks, wobei die Verfasser in dieser Hinsicht zugleich als Selbstherausgeber fungieren. Bei der Ausstattung weitgehend freie Hand haben Publikationswillige bei der »Gelehrtenbuchhandlung« aus Dessau mit ihrem gewollt niedrigschwelligen Angebot zur eigenen Veröffentlichung. ${ }^{43}$ Denn auch für Schriftsteller, die weniger nach Einkommen als nach Prestige streben, denen es um persönliche Repräsentation und soziale Reputation geht, ist die Ausstattung von hoher Relevanz: Johann Gottlieb Schummel präsentiert in seinem Roman »Spitzbart « (1779) einen Dorfprediger, der sich, ehe er sein erstes Buch den versammelten Honoratioren seiner Ortschaft präsentiert, daran

40 Ungern-Sternberg, »Schriftstelleremanzipation«, S. 75.

41 Ebd., S. 77.

42 Siehe u.a. Gunter Berg, »Die Selbstverlagsidee bei deutschen Autoren im 18. Jahrhundert«, in: Börsenblatt für den deutschen Buchhandel 43 (1965), S. 448-460.

43 Stephanie Rahmede, Die Buchhandlung der Gelehrten zu Dessau. Ein Beitrag zur Schriftstelleremanzipation um 1800, Wiesbaden 2008; Christine Haug, »Das größte Ereignis in der Geschichte des deutschen Selbstverlags . Die >Allgemeine Buchhandlung der Gelehrten < und die >Verlagskasse für Gelehrte und Künstler i im Fürstentum Dessau um 1800«, in: Hanno Schmitt, Holger Böning (Hg.), Dessau-Wörlitz und Reckahn. Treffpunkte für Aufklärung, Volksaufklärung und Philanthropismus, Bremen 2014, S. 85-110. 
ergötzt, »sich mit Namen und Titel, auf schönem holländischen Papiere gedruckt zu sehen ${ }^{44}$.

Sicherlich ist das Wissen über Bücher bei gebildeten Autoren auch deshalb so profund, weil es einen eigenen Bereich im Curriculum der an höheren Schulen und in der akademischen Ausbildung vermittelten Historia literaria bildet. Hinzu kommt eine in der zweiten Hälfte des 18. Jahrhunderts zu beobachtende Ästhetisierung und eine damit verbundene Aufwertung des Wissens wie der handwerklichen Fähigkeiten von Papiermachern, Formschneidern, Druckern und Buchbindern. Eben dieses Wissen wird durch eine Vielzahl von Publikationen einem größeren Publikum vermittelt, auch durch Fachfremde wie den Wolfenbütteler Arzt Johann Jacob Heinrich Bücking, der 1785 eine »Kunst des Buchbindens « herausgibt. ${ }^{45}$ Vor diesem Hintergrund entwickelt sich auf der Arbeitsebene ein reger Austausch zwischen Autoren und Verlegern, von denen nicht wenige noch immer versierte Drucker und einige überaus ambitioniert sind. So bringt sich der Berliner Verleger Johann Friedrich Unger, der sein Handwerk beim preußischen Hofbuchdrucker Georg Jacob Decker gelernt hat, neben dem Holzschnitt, den er beherrscht, selbst das Stahlschneiden bei, um die Fraktur zu reformieren. ${ }^{46}$ Ungern-Sternberg merkt daher an:

»Die kurze Blüte typographischer Kultur gegen Ende des 18. Jahrhunderts, die in mancher Hinsicht bis ins Detail hinein als späte Erfüllung der Ausstattungswünsche der Autoren der fünfziger Jahre erscheint, entsprach oft mehr der ehrgeizigen Druckkunst und typographischen Meisterschaft eines

44 [Schummel], Spitzbart, S. 2

45 Bücking (Hg.), Die Kunst des Buchbindens. Die Vorrede beginnt Bücking mit einer Erklärung in eigener Sache, da er »dem Publiko hier eine Arbeit [liefere], die mit meiner eigentlichen Bestimmung zu wenig Verbindung hat, als daß ich mich nicht darüber, daß ich sie liefere, sollte erklären müssen« (Ebd., S. 2.). Von den 54 Personen oder Institutionen, die als Pränumeranten in dem Band genannt sind, gibt nur die Hälfte an, einen berufspraktischen Bezug zur Buchbinderei zu besitzen. Neben einzelnen Buchbindern und Gesellen sind auch Gruppierungen wie die Augsburger Buchbinderinnung oder die »wohllöbl. Meisterschaft der Buchbinder« aus Zürich als größere Abnehmer genannt. Darüber hinaus finden sich Pränumeranten mit einer ganz anderen Ausbildung oder Profession, z.B. ein Theologiestudent und ein Jura-Professor aus Nürnberg, ein Rostocker Kaufmann sowie der Zolldirektor von der Parenschen Schleuse. Christina Killius, Die Antiqua-Fraktur-Debatte um 1800 und ihre historische Herleitung, Wiesbaden 1999, S. 299, zu Decker siehe Weichselbaumer, »Die Druckerfamilie Decker«. 
I.G.J. Breitkopf, Johann Friedrich Unger und Georg Joachim Cöschen als den Wünschen mancher Schriftsteller. ${ }^{47}$

Neben das merkantile, historische und ästhetische Wissen treten profanere Kenntnisse über die Prozesse der Herstellung von Büchern, vermittelt durch Publikationen wie das »Orthotypographische Handbuch« (1785) Christian Gottlob Täubels. Er reagiert auf eine stets drängende Frage, die wohl ausnahmslos alle Autoren umtreibt: Wie lassen sich Texte ohne Fehler typographisch reproduzieren? Errata bergen ein enormes Konfliktpotenzial, sie belasten das Verhältnis der Schreibenden zu den Buchproduzenten und gelten überdies als Indikator verlegerischer Qualität. Täubel, selbst Drucker und Verleger, verfolgt daher den »Hauptzweck«, »Anweisung zu geben, wie man Bücher, während sie gedruckt werden, gut und regelmäßig corrigiren solle«, er adressiert mit seinem »Handbuch « also nicht seine Handwerkskollegen, das »typographische Publikum ${ }^{48}$, sondern ausdrücklich Schriftsteller, Buchhändler und Korrekturleser. Angesichts der Zunahme an Schriftstellern, die Meusel registriert, während andere sie beklagen, scheint Täubel einen Markt für solch spezielle Fachliteratur ausgemacht $\mathrm{zu}$ haben. Fruchten mochten seine Bemühungen indes nicht allzu sehr, wie 1827 von Benjamin Krebs aus Sicht eines Druckers festgestellt wird:

»Die Erfahrung hat mich gelehrt, daß unter 10 Schriftstellern, die eine Revision von ihren Werken erhalten, es sicherlich acht giebt, die gar nichts von Buchdruckerei und Corrigiren verstehen; und die nach ihrer Lust in der Revision ausstreichen und hineinschreiben, ohne daran zu denken, daß er mit einer solchen Revision einen Beweis von seiner Unordentlichkeit in die Buchdruckerei gesendet hat. Und so ist es unmöglich, auch dem besten Setzer, wenn er nicht die ganzen Columnen umbrechen und das Ganze als einen neuen Satz betrachten will, eine Gleichförmigkeit im Ausschließen zu erreichen; und so wird die Schönheit des Satzes vernichtet, mögen noch so schöne Schriften, noch so weißes Papier genommen worden sein. ${ }^{49}$

All dies erinnert daran, was im 18. Jahrhundert als Allgemeinwissen gelten darf: dass Autoren nicht in der Abgeschiedenheit ihrer Schreibstube ein Manuskript nach dem anderen verfertigen, an dessen weiterer Verarbeitung sie kein gesteigertes Interesse zeigen. Vielmehr sind sie in das Büchermachen

47 Ungern-Sternberg, »Schriftstelleremanzipation«, S. 78.

48 Täubel, Orthotypographische Handbuch, S. 23, 381.

49 Krebs, Handbuch der Buchdruckerkunst, S. 300. 
involviert, an etlichen Arbeitsschritten aktiv, wenn auch mittelbar und nicht federführend, beteiligt, wie das Lemma »Buch« im »Allgemeinen Oeconomischen Lexicon« Georg Heinrich Zinckes unterstreicht:

»Buch, ist ein [...] aus gedruckten Bogen und auf mancherley Weise in Pappe, Pappier, Pergament, Leder cs. eingebundenes höchst nützliches und bequemes Werckzeug, die Wahrheit dem andern auf eine bequeme Weise zum Lesen und Erkennen vorzulegen. An dieser Waare arbeiten viele Leute, ehe sie zu Stande kommt, und zu einem eigentlichen Buche in diesem Verstande wird. Der Gelehrte und Schrifftsteller, der Pappiermacher, der Schrifftgiesser, Setzer und Buchdrucker, der Corrector, der Verleger, der Buchbinder, bisweilen auch der Goldschlager und Gürtler cs. Von dieser Manufactur ernehren sich also viele Leute. $\ll^{50}$

Nicht weniger als neun Professionen rechnet Zincke zu »dieser Manufactur«, und beinahe allen Beteiligten lässt sich das zuschreiben, was Richard Sennett als »Bewusstsein des Handwerkers« bezeichnet. »Sein ganzes Bemühen um qualitativ hochwertige Arbeit«, so Sennett, »hängt letztlich ab von der Neugier auf das bearbeitete Material. $\aleph^{51}$ Deshalb gebraucht Sennett in The Craftsman« (dt. »Handwerk«) auch den Begriff des »Materialbewusstseins« (»material consciousness «). Um diesen Begriff näher zu erläutern, erzählt Sennett erstaunlicherweise von einem Dichter, von Stéphane Mallarmé, der, als ihm der Maler Edgar Degas von der Idee zu einem Gedicht berichtet, entgegnet: "Gedichte macht man nicht aus Ideen, man macht sie aus Worten. "In dieser Anekdote ist es die Sprache, die als Material fungiert (wobei nach der Differenz zwischen Sprache und Schrift zu fragen wäre) und auf das Handwerkliche der Literatur verweist, das jedoch handwerklich nur im übertragenen Sinne ist. Dass Sennett ausgerechnet Mallarmé anführt, der sich - übrigens nicht anders als Degas - in einem besonderen Maße für das buchstäbliche Handwerk seiner Kunst interessierte ${ }^{52}$, der sich beim Schreiben einer Vielzahl unterschiedlicher Beschreibstoffe und papierner Artefakte bediente, offenbart mindestens einen blinden Fleck dieses Exempels. Autoren verfügen über ein

50 Georg Heinrich Zincke, Art. »Buch«, in: ders., Allgemeines Oeconomisches Lexicon, 2. Aufl., Leipzig 1744, I, Sp. 442.

51 Sennett, Handwerk, S. 162.

52 Siehe Cornelia Ortlieb, »Schachtel, Blume, Uhr. Mallarmés Buch-Basteleien«, in: dies., Fuchs (Hg.), Schreibekunst und Buchmacherei. Zur Materialität des Schreibens und Publizierens um 1800, Hannover 2017, S. 69-90. 
Materialbewusstsein, eine Neugier, die bei Sennett unbeachtet bleibt. Es ist ein Bewusstsein, das sich in verschiedenen Praktiken des Publizierens zeigt.

Sennett zufolge interessieren sich Menschen besonders für Dinge, die sie verändern können. ${ }^{53}$ Das trifft auf einen Papierbogen, der mit Tinte beschrieben wird, um ein Gedicht zu entwerfen, zweifellos zu, wie die poetologische Aufladung und Metaphorisierung des unbeschriebenen Blattes zeigt. Wenn jedoch ein Dichter beim Bearbeiten eines Manuskripts dessen Druckausgabe zumindest mit dem inneren Auge voraussieht, wenn die Parameter einer Publikation auf ihn einwirken, so ist auch in diesem Fall von einem Materialbewusstsein zu sprechen, obgleich gedruckte Artefakte zum konkreten Akt des Schreibens stets in einem temporalen Verhältnis der Nachträglichkeit stehen. Aus der »Bibliopöie«, der Kunst, ein Buch zu schreiben, gehen nicht unmittelbar Bücher hervor. Daher soll der Begriff des Materialbewusstseins im Folgenden vor allem dazu gebraucht werden, die Relation zwischen Autoren und ihren Büchern näher zu beschreiben. Und vor dem Hintergrund, dass Schriftsteller aus verschiedenen Motiven genau im Blick haben, wie die Artefakte gestaltet sind, die ihre Arbeit an ein Publikum vermitteln.

Materialbewusstsein bedeutet auch, sich die äußeren Bedingungen von Autorschaft bewusst zu machen: Schreibende müssen einerseits die Erfahrung machen, dass sie schon bei der Herstellung eines Buches die Souveränität über ihre Texte verlieren, dass diese zunehmend unkontrollierbar werden, sobald sie ihre Manuskripte aus der Hand geben. Andererseits wird mit einem Buch ein Überschuss an Bedeutung produziert, den Autoren des späten 18. Jahrhunderts gerne und vielfältig für sich in Anspruch nehmen, anders noch als Shaftesbury, der erklärt hatte, er sei auf keine Weise mehr Autor, weil er gedruckt sei. ${ }^{54}$ Wenn Autorschaft durch das Buch und dessen spezifische Medialität und Materialität konstituiert wird, stellt sich somit umso dringlicher nicht nur die Frage, in welches Verhältnis sich Schreibende gegenüber den übrigen Büchermachern setzen oder setzen lassen, sondern zugleich, welche Position sie gegenüber dem Buch als Artefakt einnehmen. Schließlich wird dieses im Subjektivierungsprozess der Autorschaft geradezu ein Teil ihrer selbst.

Jean Paul identifiziert literarische Werke vielfach mit den Artefakten, durch welche sie zum Publikum gelangen. Er bezeichnet Autoren wiederholt als »Buchmacher « und spielt mit diesem Begriff, etwa wenn er für sich das

53 Sennett, Handwerk, S. 162.

54 Shaftesbury, Selbstgespräch, S. 230. 
kritische Urteil notiert: "Göthe in den Wanderjahren mehr ein Buchbinder als ein Buchmacher.« (HKA II.6/1, 299) In der »Vorrede zum satirischen Appendix « der »Biographischen Belustigungen« führt er im Namen »sämtlicher Leser und Leserinnen« (SW I.4, 347) eine Anklage gegen »Jean Paul«, »Büchermacher und Biograph in Hof (SW I.4, 347f.). Vorgeworfen wird dem Alter Ego, dass »er unter seine Historien die längsten Satiren und Untersuchungen eingeschwärzt« habe; es geht somit um die Digressionen, für die Jean Paul so berühmt wie berüchtigt ist, die er - so die Anklage weiter - »unter dem böslichen Namen eines Extrablattes etc.« (SW I.4, 348) in seinen Texten platziert. Gegenstand des Streits ist damit eine Schreibweise, die auf die Störung einer linear verlaufenden Rezeption abzielt, zu der die Seitenzählung ebenso anhält oder erzieht wie die übliche Abfolge textueller Einheiten wie Kapitel. »In seinem [sic!] Rahmen läßt die Buchform literarischer Kommunikation ein linear organisiertes Sinnkontinuum erscheinen«, so Gerhard Plumpe, der jedoch betont, dass in diesem Rahmen seit dem 18. Jahrhundert eine durch Individualität begründete »Unberechen- und Unerwartbarkeit« ausgestellt wird. ${ }^{55}$ Nichts anderes geschieht in den scheinbar permanent unterbrochenen Texten Jean Pauls, in denen die Materialität verschiedenster Papiermedien aufgegriffen und produktiv gemacht wird, um einen "nichtlinearen Zusammenhang« zu konstruieren. Till Dembeck beschreibt eine solche Faktur mit dem Begriff der »Paratextualität ${ }^{56}$, während Magnus Wieland in produktionsästhetischer Perspektive von einer Digressionspoetik ${ }^{57}$ spricht, die auf der Ebene des literarischen Textes von einer sekundären, da sprachlich verfassten Materialität getragen wird, wenn wieder mal ein Papierfetzen oder Blättchen eine durchgängige Erzählung zwischen zwei Buchdeckeln unterbindet. Jean Paul macht in jeder dieser Konstellationen deutlich, dass für ihn das Buch das integrale Medium der Literatur ist, nicht der Text als ein um 1800 zunehmend vergeistigtes Abstraktum. Er offenbart ein besonderes Materialbewusstsein. Das hat Auswirkungen auf die Art und Weise, wie Jean Paul sein eigenes Schaffen im größeren Rahmen der menschlichen Existenz betrachtet: »Mich tröstet nichts über das Leben und

55 Gerhard Plumpe, »Der Autor im Netz. Urheberrechtsprobleme neuer Medien in historischer Sicht«, in: Klaus Städtke, Ralph Kray (Hg.), Spielräume des auktorialen Diskurses, Berlin 2003, S. 177-194, hier: S. 182.

56 Till Dembeck, Texte rahmen. Grenzregionen literarischer Werke im 18. Jahrhundert (Gottsched, Wieland, Moritz, Jean Paul), Berlin 2007, S. 20.

57 Wieland, Vexierzüge. 
Sterben als daß ich etwas gethan oder gemacht, meine Bücher.« (HKA II.8, 393 [126])

\subsection{Buchform und Werkform}

Jean Pauls zweites Buch, die »Auswahl aus des Teufels Papieren« (1789), entsteht aus einer Satirensammlung, die lange unter einem anderen Titel erscheinen soll: "Scherze in Quart ${ }^{58}$ (SW II.4, 352). Es wird nicht das letzte Mal sein, dass der Schriftsteller in Erwägung zieht, ein Buchformat in den Titel eines Textes aufzunehmen. Mehr als zehn Jahre später erhält Cotta von Jean Paul das Manuskript der »Flegeljahre«, die in den Planungen des Verlegers, wie Bernhard Fischer vermerkt, nur als »komischer Roman« in einem Umfang von "2 Alphabeten « geführt worden sind..$^{59}$ In einem Brief an Christian Otto reiht Jean Paul für diesen Text einen möglichen Titel an den nächsten. Zwischen »Konduitenlisten« und »Der Paradiesvogel« findet sich auch: »Taschenbuch in Oktav«. »Für jeden dieser Titel«, so der Autor am 25. Dezember 1802, »lässet sich im Werke die volständigste Beziehung auftreiben.« (HKA III.4, 195) Nicht nur das: Oktav war auch das zwischen Jean Paul und Cotta vereinbarte Format, anhand dessen ein, so Fischer, »horrendes Bogenhonorar« von sieben Louisd'or errechnet wurde, dem der Verleger im Februar 1803 nur unter der Bedingung des Stillschweigens zustimmte. ${ }^{60}$

Nach etlichen Absagen in den Achtzigerjahren wollen nach dem Erfolg des »Hesperus« (1795) immer mehr Verleger mit Jean Paul ins Geschäft kommen. Interessant sind die Verhandlungen, die der Autor führt, aufgrund der

58 Jean Paul begann nach Abschluss des zweiten Bandes seiner »Crönländischen Prozesse« (1783) mit neuen Arbeiten, wobei er sich in den nächsten Jahren vergeblich um die Publikation dieses »starken Packs Satiren« macht (SW II.4, 351f.). Am 9. April 1785 berichtet Jean Paul in einem Brief an Oerthel von einem Cespräch mit dem Verleger Carl Johann Albrecht Meyer (»Kommerzienrath Maier«), das den ausgewählten Titel erklären könnte: »lch that ihm den Antrag, mein Buch zu verlegen; und er nahm ihn mit vieler Bereitwilligkeit an [...] «, freut sich ]ean Paul: »lch lasse die Satiren in Quart drukken; er lässet mir überhaupt in allem (in der Bogenzahl) freie Hand. Er hoft sogar sie vielleicht mit einer neuen Presse drukken zu können.« (HKA III.1, S. 159, Hervorh. T.F.)

59 Fischer, Johann Friedrich Cotta, S. 234.

60 Ebd. 
unterschiedlichen Einigungen, die er erzielt, obwohl er hinsichtlich des Honorars eine immer klarere Linie vertritt. ${ }^{61}$ Bezahlen lässt er sich nach Druckbögen. Allerdings erfolgt die Berechnung des Bogenhonorars nicht auf der Grundlage einer Norm (wie der heutigen Normseite), sondern die mannigfaltigen Möglichkeiten der Gestaltung eröffnen sowohl dem Schriftsteller als auch seinen potenziellen Geschäftspartnern einigen Spielraum. So lässt Jean Paul dem Verleger August Hennings aus Gera im Dezember 1796 übermitteln, dass er ihm »ein Wergen von sechs bis acht Drukbogen (den Bogen zu 4 Louisd'or, worüber ich wie Herrnhuter und Londner nicht erst handle und abdingen lasse)« (HKA III.2, 282) anzubieten habe. Hennings reagiert mit einem niedrigeren Angebot in Höhe von drei Louisd'or, er legt seinem Brief aber ein Papier bei, das Jean Paul überzeugen soll. Denn der Verleger möchte »den gedrukten Bogen so wie innliegendes Blättchen« honorieren. »Ich bin so frey Sie zuersuchen eins Ihrer geistes Werke zuhanden zunehmen und nur die Zeilen und die Buchstaben zuberechnen, dann werden Sie sehen, das 3 solcher Bogen kaum, oder nicht einmal soviel als 2 so wie Ihre schätzbare Schriften gedrukt sind, enthalten.« (HKA IV.2, 271f.) Der Nutzen für Hennings, der letztlich den Zuschlag für das »Kampanertal« erhalten wird, liegt auf der Hand: Ein großzügiger Satz bedeutet einen größeren Umfang und damit die Chance auf einen höheren Umsatz pro Exemplar.

Im Folgenden soll es zwar auch um die finanziellen Aspekte der Formatwahl gehen, jedoch hauptsächlich um die »volständigste Beziehung« zwischen Buchform und Werkform, die Jean Paul behauptet, wenn er »Taschenbuch in Oktav« als möglichen Titel für einen literarischen Text präsentiert. Nicht immer fungiert der Titel explizit als prominenter Schauplatz dieser »Beziehung«, und wie diese sich im Einzelfall gestaltet, hängt von etlichen Faktoren ab. Doch sie besteht zweifelsohne, wie Gerhard Plumpe herausstreicht: Ontisch transzendiere das Werk die Kontingenz seiner materiellen Anwesenheit zwar, trotzdem erscheine es von der Buchform entscheidend geprägt. »Ein Buch«, führt Plumpe mit Blick auf den literarischen Diskurs der zweiten Hälfte des 18. Jahrhunderts aus, »ist zunächst sinnfällig grenzorientiert, d.h. es markiert eine Innen/Außen-Differenz, die auf der endlichen, eingegrenzten Fläche der Seiten zwischen den Deckeln

61 Einen Überblick zu den wechselnden Verhältnissen zwischen Jean Paul und seinen Verlegern gibt Ludwig Fertig, »)Ein Kaufladen voll Manuskripte<. Jean Paul und seine Verleger«, in: Archiv für Ceschichte des Buchwesens 32 (1989), S. 273-395. 
auf der Basis ubiquitären Drucks riskanten, innovationsorientierten, traditionskritischen Sinn entstehen läßt. « ${ }^{62}$ Freilich gilt es, die von Plumpe mit der Buchform verbundene »Innen/Außen-Differenz « als eine Relation $\mathrm{zu}$ betrachten, mit Blick auf das, was sich mit Genette als Paratext beschreiben lässt, als »Beiwerk des Buches«. Welche Aufmerksamkeit der Relation von Innen und Außen um 1800 geschenkt wird, zeigt der zeitgenössische Diskurs über die Angemessenheit gewählter Buchausstattung. Ob die Typographie oder der bis ins 19. Jahrhundert vom Käufer gewählte Einband einem Werk entsprechen, wird erörtert, indem eine aus der Beredsamkeitslehre entlehnte Metaphorik auf Bücher als Artefakte übertragen wird.

Seit der Antike wird der sprachliche Ausdruck, die elocutio, in Bilder des Einkleidens gefasst. Man denke an die Metapher des »Sprachkleids« oder des Einhüllens in Worte. Um 1800 kommt diese Metaphorik in Diskursen über Buchgestaltung verstärkt zum Einsatz - nicht um das »Sprachkleid« zu diskutieren, sondern sozusagen das »Buchkleid«. Die Bildlichkeit bei der Betrachtung der »äußern Buchmacherkunst ${ }^{63}$ steht nicht nur unter dem Einfluss der Rhetorik, sondern reflektiert zugleich eine neue, bürgerlich zu nennende Modeästhetik ${ }^{64}$ - etwa Jean Paul in »Des Luftschiffers Giannozzo Seebuch «, wo die sich auflösende "Kleiderordnung für sämtliche einwohnende Bücher unsers Landes« (SW I.3, 989-991) problematisiert wird.

Die bürgerliche Mode erfüllt die Funktion sozialer Distinktion, subtiler und individueller, als offizielle »Kleiderordnungen « dies bis weit ins 18. Jahrhundert taten. ${ }^{65}$ Unverändert bleibt jedoch der Anspruch der Angemessen-

62 Plumpe, »Der Autor im Netz«, S. 182.

63 Karl Friedrich Buschendorf, »Zwei Arten Papierglättmaschinen«, in: Journal für Fabrik, Manufaktur, Handlung, Kunst und Mode 23 (1802), S. 335-350, hier: S. 336.

64 Siehe zur »Rhetorik der Kleidung « den Aufsatz von Heiner Weidmann, »Rhetorik der Kleidung um 1800«, in: Andreas Härter (Hg.), Dazwischen. Zum transitorischen Denken in Literatur- und Kulturwissenschaft, Göttingen 2003, S. 215-234. Weidmann schreibt zur Mode im letzten Drittel des 18. Jahrhunderts: »In den Siebzigerjahren des 18. Jahrhunderts greift [...] die englische Mode auf den Kontinent über und löst, indem sie mit der klassizistischen Welle zusammentrifft, eine Revolution im Kleidungsverhalten aus, die nicht nur einer der vielen ununterbrochen einander folgenden Modewechsel zu sein scheint, sondern so etwas wie die Einsetzung eines neuen Mode-Systems: Die sogenannte >bürgerliche`Mode setzt sich jetzt mit ihrem eigenen Pathos durch.« (Ebd., S. 218)

65 Siehe u.a. Volker Sinemus, »Stilordnung, Kleiderordnung und Gesellschaftsordnung im 17. Jahrhundert«, in: Albrecht Schöne (Hg.), Stadt, Schule, Universität, Buchwesen und die deutsche Literatur im 17. Jahrhundert, München 1976, S. 22-43. Angemessenheit (de- 
heit. Angemessenheit (lat. aptum, decorum) bezeichnet ein Prinzip der elocutio, das im Dreieck von Inhalt, Form und Kontext wirksam wird, aber auch ein gesellschaftliches Normativ äußerer Repräsentation.

In den Lehren der Rhetorik fällt unter Angemessenheit die feststehende Metapher des Redeschmucks (ornatus), die ein Innen-Außen-Verhältnis zwischen Inhalt und Form eines Textes begründet, das meist in Bilder des Einkleidens (»Sprachkleid«) gefasst wird. Bezüglich der Materialität von Büchern kommt es zu einer Adaption dieser erprobten Bildlichkeit, im Grunde zu einer konzentrisch verlaufenden Verdoppelung: Die Äußerlichkeit des Buchartefakts verhält sich demnach zum Text wie das »Sprachkleid« als Form zum

corum) ist ein geläufiger Wertungsbegriff, wenn es um eine standesgemäße Kleidung geht. »Was die Kleidung anlanget, so bestehet das Decorum darinnen, daß man sich reinlich, nach der Mode und seinem Stande gemäß halte«, erläutert Christoph August Heumann (Der politische Philosophus, das ist vernunftmässige Anweisung zur Klugheit im gemeinen Leben, 3. Aufl., Leipzig 1724, S. 54, Faksimiledruck: Frankfurt a.M. 1972). Im 40. Band der »Oeconomischen Encyklopädie« von Johann Georg Krünitz, erschienen 1790, wird noch einmal erläutert, was unter einer Kleiderordnung zu verstehen ist um im Anschluss deren Erosion unter Hinweis auf die bürgerliche Vergesellschaftung zu erklären: »Eine obrigkeitliche Verordnung in Ansehung der Kleider, worin besonders der Kleiderpracht Gränzen gesetzet werden, und, in dieser Absicht, jedem Stande und jeder Classe der Einwohner eines Staates vorgeschrieben wird, was für Kleider sie tragen sollen, wird die Kleiderordnung [...] genannt. Ehedem waren diese Kleiderordnungen sehr gebräuchlich.« (Johann Georg Krünitz, Art. »Kleid«, in: ders., Oeconomische Encyklopädie, Berlin 1773-1858, 40 (1787), S. 1-312, hier: S. 224) Die Frage ist: Führt die Auflösung der »Kleiderordnung " geradewegs ins Chaos, zu einer sozialen Unordnung? »Nachdem im Verlauf des 18. Jahrhunderts die frühneuzeitlichen Kleiderordnungen überall im deutschsprachigen Raum ihre Cültigkeit verloren hatten, war der Gebrauch von erkennbar kostspieligen Materialien wie Pelz, Spitze, Gold und Silber nicht länger ständisch reglementiert«, erklärt Julia A. Schmidt-Funke. Sie verweist auf Zedlers Universal-Lexicon, das bereits 1751 »für einen angemessenen Konsum von vornehmen und reichen Leuten nach Maßgabe von Stand und Vermögen«plädiere (Julia A. Schmidt-Funke, »Kommerz, Kultur und die sgebildeten Ständes. Konsum um 1800« (15.01.2012), in: Goethezeitportal, URL: www.goethezeitportal.de/db/wiss/epoche/Schmidt-Funke_Konsum.pdf (2.9.2019), S. 4-5). Patricia Ober schreibt, dass an die Stelle der ständegesellschaftlichen Verordnungen im 19. Jahrhundert ein ausgeklügeltes System feiner Distinktionen trete, deren Einhaltung nicht mehr gesetzlich, sondern gesellschaftlich kontrolliert worden sei. Angemessenheit bleibt hierbei von entscheidender Bedeutung, wenn auch in einem informelleren Sinn. (Patricia Ober, Der Frauen neue Kleider. Das Reformkleid und die Konstruktion des modernen Frauenkörpers, Berlin 2005, S. 123) 
Inhalt desselben. Angemessenheit steht zugleich für ein soziales Ordnungssystem, das über die Metaphorik des Einkleidens eine Anwendung auf die Buchform findet. So empfiehlt Johann Adam Bergk bezüglich der Gestaltung von Bucheinbänden ausdrücklich »Alltagskleidung« statt »Festtagskleider«:

»Bücher sind zum Lesen, und nicht zur Ausschmückung von Zimmern bestimmt. Glänzende Einbände sind Vorlegeschlösser, die wir nicht abzureißen wagen, denn wie leicht könnte der schöne Einband beschmuzt werden! Wer daher seine Bücher zum Lesen bestimmt, muß sie nicht in prächtige Gewänder kleiden. Ihr Inhalt bleibt ihm sonst ewig verschlossen. Sie müssen in einer Alltagskleidung auftreten, um zum täglichen Gebrauche zu dienen: prächtige Einbände sind Festtagskleider, die nur zum Glanze, und nicht zur täglichen Benuzzung bestimmt sind. Es ist ein Glück für die Kultur des menschlichen Geistes, daß wenige Bücher in Prachtausgaben erscheinen: denn diese machen ein Buch zu einem Zauberschloß, in welchem niemand wohnen, und das niemand zu öfnen wagt. ${ }^{66}$

Bergk problematisiert mit Hilfe der einschlägigen Bildlichkeit die Wirkung der Ausstattung auf den Rezipienten, wobei zu berücksichtigen ist, dass um 1800 in der Regel der Käufer eines Buches dessen Einband anfertigen lässt. Gerade im Versuch, sich durch »Alltagskleidung « auf die Lektüre zu konzentrieren, offenbart sich freilich das Artefakt als gängiges Medium sozialer Repräsentation. Der italienische Schriftschneider Giambattista Bodoni erkennt den Vorzug eines Buches im großzügigen Folio-Format wiederum darin, dass »die höhere Schätzung, die es genießt, sich auch auf seinen Besitzer überträgt « ${ }^{67}$. Bergk sieht die Gefahr, dass das Artefakt für eine potenzielle Leserschaft wichtiger wird als der Inhalt eines Buches.

Gleiches gilt, jedenfalls aus Sicht eines Kritikers zeitgenössischen Publizierens wie Johann Georg Heinzmann, für die Urheber. In seinem »Appel an meine Nation« (1795) polemisiert Heinzmann als erfahrener Verleger gegen angebliche »Geldautoren«:

»Sonst war es eine Hauptsorge des Schriftstellers, daß sein Werk correkt, und um einen ehrlichen Preis, nicht mit übertriebenem Luxus, aber doch anständig, gedruckt erscheine, damit der Preis dem Inhalt angemessen sey. Jetzt

66 Johann Adam Bergk, Die Kunst, Bücher zu lesen. Nebst Bemerkungen über Schriften und Schriftsteller, Jena 1799, S. 33.

67 Ciambattista Bodoni, Über Schrift und Typographie. Vorrede zur Ausgabe des Manuale Typografico (1818). Privatdruck der Bauerschen Cießerei, Frankfurt a.M. 1927, S. 13. 
wissen unsre Autoren und Buchhändler so wenig mehr von dieser deutschen Ehrlichkeit, daß man keine Bücher auf besser Papier und splenditer gedruckt siehet, als gerade die Schriften der Geldautoren, die mit Prangen und Scheinen ihre Leerheit deken. ${ }^{68}$

Autoren und Verleger bedienen sich Metaphern des Einkleidens, sobald es im weiteren Sinne um die Äußerlichkeit von Publikationen geht. Meist bringen sie den Anspruch zum Ausdruck, die Materialität eines Buches möge in einem Verhältnis der Angemessenheit zum Inhalt stehen. So erklärt der Theologe Johann Jacob Griesbach in einem Brief an Göschen, dass sein Freund Karl Ludwig von Knebel, trotz der Fürsprache Goethes, eine Lukrez-Übersetzung (»De rerum natura «) nicht von Cotta verlegt sehen will, »weil die Ausstattung, die er seinen Verlagswerken mit zu geben pflegt, gar zu ärmlich ist: schlechtes $\mathrm{Pa}$ pier, und unreinlicher knauseriger Druck«. Griesbach fährt fort: »Aber Knebel ist des Glaubens, ein alter herrlicher Klassiker dürfe nicht in einem schmutzigen Kittel vor dem Publikum producirt werden, sondern so gekleidet, daß er sich selbst, wenn er wieder erstünde, mit Wohlgefallen beschauen könne. ${ }^{69}$ Wobei das Innen-Außen-Verhältnis auch unter umgekehrten Vorzeichen als Missverhältnis wahrgenommen wird. Der berühmte Schriftschneider Johann Gottlob Immanuel Breitkopf formuliert 1791 im Tonfall eines Alarmierten: »Hoffentlich kömmt man wieder in den verfehlten Weg, und erkennt, dass Bücher ihren Werth innerlich, nicht bloss äusserlich, haben müssen. $\ll^{70}$

Es entbehrt nicht einer gewissen Ironie, dass ausgerechnet die Antiqua als Schrift der Klassizisten, die den Zierrat des Fraktur-Drucks verschwinden lässt, häufig mit einer übermäßigen Pracht assoziiert wird. Wobei der »typographische Luxus« laut Susanne Wehde »konnotativ zweifach, sowohl positiv als auch negativ, bewertet wird «11. Sie führt Bertuch an, der 1793 schreibt:

68 Johann Georg Heinzmann, Appel an meine Nation. Über die Pest der deutschen Literatur (1795), Hildesheim 1977, S. 167.

69 Brief vom 27. Oktober 1808, zit.n. Johann Goldfriedrich (Hg.), Aus den Briefen der Göschensammlung des Börsenvereins der Deutschen Buchhändler in Leipzig, Leipzig 1918, S. 70, siehe auch Stephan Füssel, Studien zur Verlagsgeschichte und zur Verlegertypologie der Goethe-Zeit, Berlin, New York 1999, S. 252.

70 Johann Gottlob Immanuel Breitkopf, »Antwort auf Herrn Unger in Berlin: Etwas über Didotsche Letter«, in: Intelligenzblatt der Allgemeinen Literatur-Zeitung (1791), Nr. 95 (3. August 1791), Sp. 783-786, hier: Sp. 786.

71 Susanne Wehde, Typographische Kultur. Eine zeichentheoretische und kulturgeschichtliche Studie zur Typographie und ihrer Entwicklung, Tübingen 2000, S. 234. 
»Ich halte es für eine glückliche Erscheinung bey einer Nation, wenn sie den Druck ihrer Bücher verschönert, ja selbst, wenn sie in gewissen Stücken, und bey gewissen Werken, die als Beweise und ehrende Denkmale ihrer höheren Cultur in Künsten und Wissenschaft auftreten sollen, in einen typographischen Luxus übergeht. ${ }^{72}$

Im Anschluss zitiert Wehde einen anderen, nicht bekannten Autor, bei dem es heißt:

»Ich habe auch nichts dawider, daß classische Werke, für den begüterten Theil der Nation mit diesem Aufwande gedruckt werden, aber junge Schriftsteller, deren erste Versuche freylich allemal vortrefflich sind, sollten sich doch erinnern, daß die Bestechung vermittels eines hübschen Kleides nicht lange dauert. ${ }^{73}$

Es geht also, wenn der »typographische Luxus« problematisiert wird, nicht immer um eine Entsprechung von Form und Inhalt, sondern in mehrfacher Hinsicht um soziale Repräsentation und Distinktion, wobei sich unterschiedliche Aspekte miteinander vermischen: Wehde erkennt im Urteil über die Antiqua einen Gegensatz zwischen Ästhetik und Ökonomie, der gesellschaftlich differenziert zu betrachten ist. Mögen herausragende Werke sich durch die Antiqua auszeichnen lassen, so wird ein erheblicher Teil des Publikums sich diese doch nur in einer wohlfeilen Ausgabe in Fraktur anschaffen können, wenn er nicht gleich zum Nachdruck greift. Hinsichtlich der Autorenschaft wird eine Hierarchisierung betrieben, die auf einem ökonomischen Kalkül aufbaut, aber nicht nur. Dieses Kalkül besteht darin, dass unbekannte Schriftsteller kaum bekannter werden, wenn ihre Bücher keinen Absatz finden. Aber sowohl der Vorwurf einer »Bestechung vermittels eines hübschen Kleides«, der ausdrücklich auf »junge Schriftsteller« bezogen wird, als auch der bei Heinzmann nachzulesende Angriff auf »Geldautoren«, die ihre Leerheit $\mathrm{zu}$ kaschieren suchen, verweist auf einen anderen Kontext, und zwar den der Rhetorik, die sich bereits in der Frühaufklärung weitgehend vom Anspruch der Überwältigung verabschiedet. Weidmann zeichnet nach, wie sich um 1800 in der Rhetorik ein »Paradigmenwechsel« vollzieht. Die Rhetorik des 17. Jahrhunderts sei auf einen demonstrativen Luxus, auf die maßlose

72 Bertuch, »Ueber den typographischen Luxus«, S. 599.

73 [Anonymus], »Leipzig, d. 17. März...«, in: Intelligenzblatt der Allgemeinen Literatur-Zeitung (1791), Nr. 40 (23. März 1791), Sp. 324-326, hier: Sp. 326. 
Entfaltung von Pracht und Prunk angelegt, so Weidmann, weshalb das Interesse noch mehr dem Redeschmuck (ornatus) gelte. Die Forderung der Renaissance, der ornatus müsse der Sache angemessen sein, scheine überholt. Dagegen propagiere der Klassizismus des 18. Jahrhunderts Ökonomie statt Luxus, Sparsamkeit statt Verschwendung. Weidmann konstatiert, dass der von ihm beschriebene Wechsel in der rhetorischen Theorie schwer zu fassen sei und führt zur Begründung an, dass dieser nicht mehr als eine neue Phase der Rhetorik erscheine, sondern als ihr Verschwinden. ${ }^{74}$ Gleichzeitig werden die tradierten Maßstäbe der Rhetorik an die Materialität von Büchern angelegt.

Eben diese Rhetorik speist sich aus einem impliziten Wissen über die Materialität der Medien von Literatur, über das auch Jean Paul offenkundig verfügt, wenn er ein Format wie Quart oder Oktav im Hinblick auf die Verfasstheit eines Textes für aussagekräftig oder gar repräsentativ ansieht. Anders ausgedrückt: Leserinnen und Leser verbinden mit der Buchform gewisse Erwartungen an ihre Lektüre. Das wäre die im Grunde rezeptionsästhetische Dimension im Verhältnis zwischen Buchform und Werkform. Daneben existiert eine produktionsästhetische Größe, die weitaus mehr berücksichtigt als einen Einzelaspekt wie das Druckformat. Es liegt auf der Hand, dass es zwischen diesen Dimensionen zu Überschneidungen kommt, zumal die auf die Buchform bezogenen Überlegungen in der Werkgenese recht unterschiedlich sein können - auch in Abhängigkeit von der literarischen Gattung. Zum Beispiel erbittet sich Klopstock wie später auch Schiller ein großzügigeres Format, um einen Zeilenumbruch innerhalb von Versen zu vermeiden. ${ }^{75}$

Solche produktionsästhetischen Sonderwünsche stoßen angesichts einer sich wandelnden Lesekultur nicht immer auf Gegenliebe bei den Rezipienten. Wobei in dieser Hinsicht eine doppelte Perspektive vonnöten ist. Die eine Sicht konzentriert sich auf Textgattung und Genre: Haferkorn begründet die Ablösung von Großformaten wie Folio damit, dass Mitte des 18. Jahrhunderts »das Interesse der Konsumenten überwiegend auf Teilhabe an leicht lesbaren nützlichen Gehalten abzielte«. Der noch »ständische Dichter« bevorzuge daher »kürzere literarische Formen, wie Fabel, Satire, Lehrgedicht,

74 Vgl Weidmann, »Rhetorik der Kleidung um 1800«, S. 219-220.

75 Lühmann, Buchgestaltung, S. 103, zu Schiller siehe Rüdiger Nutt-Kofoth, »Schillers Medienpolitik«, in: Cornelia Ortlieb, Tobias Fuchs (Hg.), Schreibekunst und Buchmacherei. Zur Materialität des Schreibens und Publizierens um 1800, Hannover 2017, S. 93-115, hier: S. $112 f$. 
Brief, Abhandlung u.ä.«, was in seiner Argumentation zum "griffigen Duodez und Quart « führt. ${ }^{76}$ Das heißt: Für Haferkorn bewirkt die Reduzierung der Textumfänge eine Verkleinerung des Buchblocks.

In der Rede vom "griffigen« Format deutet sich die andere Perspektive an, die Lektüre in den Kontext der Handhabung von Artefakten rückt. So regt 1765 in der »Allgemeinen Deutschen Bibliothek« der Rezensent einer Ausgabe von Gottlieb Wilhelm Rabeners Satiren in Großoktav gegenüber den Verlegern solcher Schriften an, »auf bequeme Tascheneditionen zu denken«. Im selben Beitrag heißt es, nun weniger freundlich:

»Ist es aber nicht ärgerlich, daß ein Frauenzimmer, das einen Gellert und Klopstock, ja auch einen Rabener (denn die gegenwärtige Ausgabe wird wohl nie auf die Nachttische der Damen kommen) gern mit aufs Land oder in einen Garten nehmen wollte, sie zu Hause lassen muß, weil der unförmliche Band in groß Octav nicht in ihrem Nähebeutel Raum findet. «"77

Ungewöhnlich an dieser Buchbesprechung ist, dass sie sich ausschließlich dem angeblich unglücklichen Format der Edition widmet. Gegen Ende heißt es elliptisch, wieder mit Blick auf das Taschenbuch: »Liebhaber pflegen zu solchen Ausgaben das kleinste Octav zu lieben. « ${ }^{78}$

Mit dem von ihm erwogenem Buchtitel »Taschenbuch in Oktav« betreibt Jean Paul eine Semiotisierung medienspezifischer Materialität, die mit Rücksicht auf das Buch als Artefakt und dessen Einbindung in soziale Praktiken erfolgt. Täubel gibt in seinem »Orthotypographischen Handbuch«, das sich ausdrücklich auch an Autoren richtet, ausführliche Hinweise zur »Wahl des Formates«, bei der »man sich hauptsächlich nach dem Inhalt und der Bestimmung eines Buches « ${ }^{79} \mathrm{zu}$ richten habe. Konkret heißt dies nach Auffassung von Täubel beispielsweise:

»Witzige Schriften, Romane, Gedichte, Comödien, und andere schöngeisterische Bücher werden meistentheils im kleinsten Octav-Formate gedruckt, weil man solche manchmal beym Spatzierengehn, in Cärten, auf Reisen,

76 Haferkorn, »Der freie Schriftsteller«, Sp. 654.

77 [Anonymus], »Gottlieb Wilhelm Rabners Satyren. Achte Auflage, 4 Theile. Leipzig, im Verlag der Dyckischen Buchhandlung, 1764. 66 und ein halber Bogen, 8«, in: Allgemeine Deutsche Bibliothek 1 (1766), S. 296-297, hier: S. 296, 297.

78 Ebd., S. 297.

79 Täubel, Orthotypographisches Handbuch, S. 257. 
u.s.w. bey sich zu führen pflegt, und die daher bequemer und leichter zu transportieren seyn müssen. $\ll^{80}$

Angesichts solcher Empfehlungen erscheint naheliegend, dass sowohl die Produzenten als auch die Rezipienten literarischer Texte das Äußere eines Druckes mit gewissen Ansprüchen oder Erwartungen an die Lektüre verbinden, da die Erfahrung sie gelehrt hat, dass der »Inhalt und die Bestimmung eines Buches« miteinander in Beziehung stehen. Was bedeutet, dass die Räume des Sozialen (»beym Spatzierengehn, in Gärten, auf Reisen«), die sich durch das gewählte Buchformat öffnen, auf das Gelesene zurückwirken. Als These formuliert: Die Diskursivität des Publizierten steht unter dem Einfluss der Materialität der Publikation. Ein Umstand, den Jean Paul zu nutzen versucht, wenn er das Buchformat in seiner Zeichenhaftigkeit aufgreift, um die eigenen Werke zu adressieren.

Neben dem Format ist es auch der schiere Umfang eines Buches, dem in solchen Zusammenhängen einige Relevanz zukommt. Über den Roman bemerkt Jean Paul in $\$ 69$ seiner »Vorschule der Ästhetik«, dieser übertreffe »alle Kunstwerke an Papier-Größe« (SW I.5, 249). Daran knüpft er Überlegungen zur Rezeption, die materiale »Ausdehnung « stets berücksichtigend, also die bei der Lektüre zu bewältigende Seitenzahl. Entsprechend schreibt er im Vergleich des Romans mit anderen Gattungen: »[D]er Kenner studiert und mißt wohl ein Drama von einem halben Alphabet, aber welcher ein Werk von zehn ganzen? «1 (Ebd.) Was sich an der »Papier-Größe« für Jean Paul bemessen lässt, ist in erster Linie und ganz praktisch die erforderliche Lesezeit, unabhängig vom gewählten Format. Aber in der von ihm formulierten Frage, die sich darauf bezieht, was »der Kenner studiert und mißt«, steckt auch die Aussage, dass Werke im Umfang eines Romans selbst für einen Rezipienten mit dem Status eines Experten (»Kenner«) kaum zu überblicken und angemessen $\mathrm{zu}$ würdigen sind.

Geht es um die »Ausdehnung« eines Werkes, so gibt der Text in der Regel zwar grob den Umfang eines Buches vor. Andererseits weist die Buchform in ihrer von etlichen, auch ökonomischen Faktoren abhängigen Materialität dem Werk immer auch Grenzen auf. Im »Siebenkäs« reflektiert Jean Paul dies in

\footnotetext{
80 Ebd., S. 258.

81 Mit dem »Alphabet «wird an dieser Stelle zwar eine drucktechnische Einheit angeführt, jedoch eine, die der zeitgenössischen Leserschaft so geläufig ist wie die Paginierung. Sowohl Annoncen als auch Rezensionen enthalten um 1800 in der Regel die Angabe, wie viele Bögen ein Buch umfasst, nicht aber die Anzahl der Seiten.
} 
einem metapoetischen Kommentar. Behauptet wird eine äußere Begrenzung des Erzählens, die in einem Spannungsverhältnis zur narrativen Entgrenzung steht, die als Markenzeichen des Autors gilt: »Nichts tut mir bei dieser an sich schönen Historie mehr Schaden«, heißt es, »als daß ich mir vorgenommen, sie in vier Alphabete zusammenzudrängen; ich habe mir dadurch selber allen Platz geraubt, auszuschweifen.« (SW I.2, 221)

In der Schnittmenge zwischen rezeptions- und produktionsästhetischer Dimension ist die Buchform immer auch Gegenstand der Werkpolitik. Als Jean Paul für die zweite Auflage seiner »Levana« einen Verleger sucht, wendet er sich am 20. September 1811 an Göschen. In seinem Brief an den »Verleger Klopstocks, Wielands, Göthes, Thümmels« lobt Jean Paul die »Glanzpresse« Viewegs, der die Erstausgabe herausgebracht hatte, um nachfolgend in sieben Paragraphen seine Bedingungen für eine zweite Auflage $\mathrm{zu}$ formulieren. An zweiter Stelle steht: »Das Format wird bequemer und kleiner gewählt, ungefähr wie Ludwig's Reise (bei Gräf 1810$)^{82}$ so wie auch die Lettern derselben (die Ihrigen mir durch Thümmel so lieben); nur müßten die Zeilen einige mehr und diese selber etwas länger werden.« (alles HKA III.6, 223)

Für die von 1783 bis 1788 und somit in der Aufbauzeit seines Verlages von Göschen geleitete »Allgemeine Buchhandlung der Gelehrten« in Dessau hatte es zum Geschäftsmodell gehört, solche Wünsche selbstverständlich zu erfüllen. In diesen offenbarte sich in der Regel ungefiltert der mit dem eigenen Werk verbundene Geltungsanspruch eines Autors. Die Gelehrtenbuchhandlung überließ bei Annahme eines Manuskripts die Entscheidung »über Papierqualität, Typografie und Ausstattung ihres Werks ${ }^{83}$ allein den publikationswilligen Urhebern. Schließlich mussten diese die Druckkosten ihres Buches aus eigener Tasche zahlen. Ansonsten bildet das Einvernehmen über das Äußere eines Buches üblicherweise die Basis eines Verlagsvertrages, wie ein Brief zeigt, in dem Lichtenberg seinem Korrespondenzpartner Franz Ferdinand Wolff im Februar 1787 erläutert, wie man mit seinem Verlegerfreund Dieterich ins Geschäft kommt: "Sie suchen sich ein Buch aus, das Dietrich [sic!] gedruckt hat, auch ein Papier, und sagen Dieses wünsche ich, alsdann wird contrahiert. ${ }^{84}$

82 Carl Friedrich Ernst Ludwig, Phantasien und Reflexionen auf einer Reise durch das südliche Deutschland in die Schweiz, 2 Bde., Leipzig 1810.

83 Haug, ») Das größte Ereignis««, S. 92.

84 Georg Christoph Lichtenberg, »An Franz Ferdinand Wolff« (26.? Februar 1787), in: ders., Briefwechsel, III (1990), S. 331f., hier: S. 332. 
Autoren mit einer größeren Reputation betreiben Werkpolitik, indem sie wie Jean Paul gegenüber namhaften Verlegern die Buchform nach ihren Vorstellungen $\mathrm{zu}$ fixieren versuchen. Im August 1799 tritt, wie in Bernhard Fischers Cotta-Biographie zu lesen ist ${ }^{85}$, völlig unerwartet A.W. Schlegel an den Verleger heran, um ihn für eine »Sammlung meiner Gedichte« zu gewinnen, die in den zurückliegenden zehn Jahren "zerstreut « erschienen sind. Schlegel erläutert, offenbar mit dem Blick eines Büchermachers taxierend, dass »diese Gedichte in einem mäßigen Format geräumig gedruckt nur 15 bis 16 Bogen ausmachen«. Dann wird er, was die Ausstattung des Buches betrifft, konkret: »Ich wünschte einige Eleganz des Papiers, Formats und Drucks, am liebsten französische Lettern, was auch bey solchen Büchern gewiß dem Absatze günstig ist. ${ }^{86}$

Gottlieb Conrad Pfeffel schließt im März und Juni 1802 einen Kontrakt mit Cotta, der, wie Fischer aufzählt, »Bestimmungen über die Termine der Manuskriptablieferung und des Drucks, das Format resp. den Satzspiegel, die Auflagenhöhe, den Verkaufspreis, die Frei- und Autorenrabattexemplare« sowie andere Regelungen enthält, welche die Materialität des Buches betreffen. ${ }^{87}$ Darunter findet sich auch das Versprechen des Verlegers, einen Kupferstich vom Porträt des Autors anfertigen zu lassen und "wenigstens der VerlinAusgabe dieser Ausgabe beizulegen«, sollte Pfeffel ihm eine Zeichnung als Vorlage liefern. ${ }^{88}$

Dass die Buchform eines Werkes relativ ist, weil eine Ausgabe in Teilauflagen mit unterschiedlicher Ausstattung (»VerlinAusgabe«) angeboten wird, ist um 1800 geradezu selbstverständlich - unter anderem als Rezept gegen den Nachdruck. Was die Frage aufwirft, wie stringent sich Werkpolitik anhand von Büchern gestalten lässt. Fischer zeigt am Beispiel von Pfeffel, dessen »Poetische Versuche« von zwei Verlegern auf den Markt gebracht werden, und zwar in Ausgaben, deren Ausstattung sich fundamental unterscheidet (eine wird z.B. in Fraktur gedruckt, die andere in Antiqua), dass mit einer Publikation nicht bloß mehrere Zielgruppen adressiert werden, sondern dass Verleger differente Vorstellungen vom selben Schriftsteller haben. Fischer folgert aus der unterschiedlichen Ausstattung von Pfeffels »Poetischen Versuchen«,

85 Fischer, Johann Friedrich Cotta, S. 163.

86 Zit. n. Fischer, Johann Friedrich Cotta, S. 163f., siehe Online-Edition unter https://augustwilhelm-schlegel.de/version-07-19/briefid/2197 (5.9.2019).

87 Fischer, Johann Friedrich Cotta, S. 242.

88 Zit. n. Fischer, Johann Friedrich Cotta, S. 242. 
dass der Baseler Verleger Wilhelm Haas diesen im Vergleich zu Cotta »eher im repräsentativen Bereich ${ }^{89}$ verortet.

Dass indes die Schreibweise eines Autors durch die Antizipation der Buchform konditioniert, schlimmstenfalls deformiert wird, zeigt sich einige Jahre früher am Ratschlag Friedrich Nicolais an einen anderen Schweizer, Johann von Müller: »Ihre helvetische Geschichte kann ein vortreffliches Werk werden; nur binden Sie Sich ja an keinen Verleger, Bogenanzahl, Format, Zeit u.s.w. « ${ }^{90}$ Einer von Nicolais bekanntesten Kontrahenten, Heinzmann, thematisiert die äußeren Vorgaben, um eine Kritik an der Ökonomie von Autorschaft $\mathrm{zu}$ formulieren:

»Cewöhnlich ist es, daß der Buchhändler dem Schriftsteller die Bogenzahl angiebt, wie stark das Werk werden soll; aber noch schlechter ist es an dem dem Schriftsteller, wenn er durch allerley Hülfsmittelchen sein Buch an Crösse anschwellen macht, nur damit er desto mehr Honorar beziehen könne; wenn er noch dazu klein Format und die Zeilen der Bogen bestimmt, damit ihm ja nichts entgehe, und das Publikum ein theures Buch erhalte! «"1

Mit deutlich mehr Wohlwollen lässt hingegen Jean Paul seinen Siebenkäs, der sich mit Rezensionen über Wasser hält, auf den Druck vorausschauen, »mit dem Setzer-Augenmaß die Handschrift ausrechnen und den Lohn erheben« (SW I.2, 189). Konkret denkt Siebenkäs über den Gegenwert dessen nach, was er sich an Honorar erschreibt - in Form von Geschirr, das es beim Pfandleiher auszulösen gilt:

»Er bemerkte, lobte, tadelte und exzerpierte das Werkchen so lange, bis er glaubte, er habe damit so viel Papier vollgemacht, daß der Ehrensold für das Papier dem Pfandschilling für die Heringschüssel, für die Saladière und Saucière und den Teller beikomme - nämlich einen Bogen lang war seine Meinung über die Rede, und 4 Seiten und 15 Zeilen.« (SW I.2, 184)

Die Buchform birgt in sich auch das Potenzial, eine Werkform zu stiften. Also zusammenzuführen, was nicht unbedingt zusammengehören soll. So hat etwa Jean Paul zeitweise gar nicht vor, sein »Leben Fibels« als eigenständiges

89 Fischer, Johann Friedrich Cotta, S. 242.

90 »Friedrich Nicolai an Johann von Müller« (16. März 1773), in: Johann von Müller, Sämmtliche Werke, Supplement: Briefe an Johann von Müller, Schaffhausen 1810-1840, IV (1840), S. 52-62 [6], hier: S. 57.

91 Heinzmann, Appel an meine Nation, S. $166 \mathrm{f}$. 
Werk zu veröffentlichen. Das geht aus einem Schreiben an den Verleger Johann Georg Zimmer hervor, welches unterstreicht, wie relativ die Einheit des Werks für ihn als Autor ist: Am 12. Juni 1810 teilt er Zimmer mit, dass er keine Möglichkeit sehe, den Fibel als dritten Teil des Katzenbergers zu publizieren. Deshalb will er den Roman als ein »eignes einziges Buch in I Bändchen« (HKA III.6, 282) veröffentlichen. Doch hat diese Überlegung keinen Bestand, bald schon plant Jean Paul das »Leben Fibels« für die Fortsetzung seines Freiheitsbüchleins mit ein. Deutlich wird in diesem Zusammenhang, wie sehr die Buchform von Jean Paul bedacht wird, wenn es darum geht, seine Texte zu gruppieren. Jedoch ist diese Relativität des Werks nicht nur charakteristisch für Jean Paul, dessen Poetik von Brüchen bestimmt wird.

Gängig ist auch, dass Schriftsteller unzusammenhängende Texte in einem Buch zusammenfassen, um einen Umfang zu erreichen, durch den sie der Zensur entgehen können. Ein prominentes Beispiel hierfür ist die Zusammenstellung des zweiten Bandes von Heinrich Heines »Reisebildern« in Folge der Karlsbader Beschlüsse von 1819 und dem zugehörigen »Preßgesetz«, das eine Vorzensur aller Titel vorschreibt, »die nicht über 20 Bogen im Druck stark sind «. ${ }^{92}$ Daher bemüht sich Heine, diese Marke zu überschreiten, um einer staatlichen Kontrolle zu entgehen. Und so beschließt er den Band nicht mit den »Ideen - Das Buch Le Grand«, sondern mit älterem Material, darunter leicht überarbeiteten Auszügen seiner »Briefe aus Berlin«. Heine klagt:

»Ein Schriftsteller ist oft übel dran; allerhöchstäußere Bedingnisse können verlangen, daß ein Buch, welches er in die Welt schicken will, über 20 Druckbogen enthalte, während er mit seinen guten `Ideen`nur die Hälfte zu füllen vermag. «3 $^{33}$

Kurios nur, dass Heine seine Klage über solch »allerhöchstäußere Bedingnisse« nicht in einem Privatbrief platziert, sondern in einer »Anmerkung«, die er ans Ende des Buches setzen lässt. Solche Versuche, die Zensur zu umgehen, sind freilich nur eine Variante derselben Herausforderung, beim Publizieren die Buchform in all ihren Facetten zu berücksichtigen.

92 Provisorische Bestimmungen hinsichtlich der Freiheit der Presse (»Bundes-Preßgesetz«, 20. September 1819), §1.

93 Heinrich Heine, »Anmerkung. <zu >Reisebilder. Zweyter Theil, I. Aufl.>«, in: ders., Historisch-kritische Gesamtausgabe der Werke (Düsseldorfer Ausgabe), hg. v. Manfred Windfuhr, Hamburg 1973-1997, VI (1973), S. 347. 
Hinsichtlich der Beziehung zwischen Buchform und Werkform gilt es auch zu berücksichtigen, dass Manuskripte häufig unabgeschlossen in den Druck gehen - was eine Dynamisierung dieser Beziehung zur Folge hat. Sie ergibt sich zum einen daraus, dass Autoren fortlaufend Korrekturen anbringen, aber auch aus der Vorliebe mancher, sozusagen unter Druck zu schreiben. Auch in diesem Zusammenhang lässt sich die Verlagsgeschichte von Jean Pauls »Leben Fibels« heranziehen: "Hier send' ich Ihnen endlich das Ende eines Buchs, an welchem mehrere Jahre mitgearbeitet als man ihm wol ansieht«, schreibt Jean Paul am 28. Juli 1811 an den Verleger Johann Leonhard Schrag in Nürnberg (HKA III.6, 212). Dass er Schrag den Zuschlag für das »Leben Fibels« gegeben hat, erklärt Jean Paul gegenüber dessen Konkurrenten Johann Georg Zimmer, den er über Jahre auf die Fertigstellung des Buches hatte warten lassen, ehe er es dem Verlag Mohr \& Zimmer nach einem Zögern kurzfristig entzog, mit einer besonderen Dringlichkeit, »da ich das Unglück habe, an einem sogar kopierten Werke, so lang' es neben mir liegt, immer wieder von neuem anzufangen und so über eine altes jedes neue zu versäumen « (HKA III.6, 216). Dennoch übersendet Jean Paul die Reinschrift keineswegs in einem Stück an Schrag. Als dem das »Ende« des Buches zugeht, hat der Verleger längst mit dem Druck begonnen. Ein Monat früher ist ihm »der größere Theil des Mspts.« (HKA III.6, 207) zugegangen.

Daher kann Jean Paul mit der Übersendung des restlichen Manuskripts auch gleich Korrekturen zum »Bogen A« übermitteln. Nachdem ihm zunächst nur ein Fehler aufgefallen ist, weist er im Postskriptum auf drei weitere hin. "Ich bitte sehr um genauere Korrektur", lässt Jean Paul den Verleger wissen (HKA III.6, 212), nachdem er im früheren Brief bereits »inständig« (HKA III.6, 207), aber offenbar vergeblich um größte Sorgfalt gebeten hatte. Ferner hält der Autor seinen Verleger dazu an, ihm jeden fertigen Teil zügig zukommen zu lassen: »Schicken Sie mir bei Gelegenheit immer etwas Abgedrucktes, damit ich bequemer die Druckfehler anmerke.« (HKA III.6, 212) Das bedeutet also, dass die Herstellung des Buches nicht auf den vollständigen Abschluss des Manuskripts folgt, sondern Schreiben und Drucken zwar versetzt, aber doch zeitgleich stattfinden.

Diese Parallelität der Produktionsprozesse ist keineswegs eine Vorliebe Jean Pauls, sie kennzeichnet beispielsweise auch die Arbeitsweise Gotthold Ephraim Lessings. Moses Mendelssohn schreibt am 25. Oktober 1757 in einem Brief an ihn: »Ich weiß es schon, daß Sie nicht eher arbeiten, als wenn der Druckerjunge in der Stube sitzt, und darauf wartet; wir wollen Ihnen also 
diesen über den Hals schicken. ${ }^{94}$ Christian Felix Weiße, ein anderer Freund des Schriftstellers, beschreibt Lessings "Gewohnheit, seine theatralischen Arbeiten von Akt zu Akt, und Scene für Scene aufs genaueste zu entwerfen, und dann zu sagen, er daß er sie fertig habe. Erst, wenn er sie in den Druck geben wollte, arbeitete er sie nach seinem Entwurfe langsam und mit vieler Bedachtsamtkeit für die Presse, welches ihm nie leicht wurde, sondern die äußerste Anstrengung kostete.${ }^{95}$ Vor diesem Hintergrund ist genau zu lesen, was Lessing am 24. Dezember 1771 in einem Brief an den Verleger Christian Friedrich Voß über seine »Emilia Galotti« schreibt: »Ich bin wirklich so gut als fertig damit; fertiger, als ich noch mit keinem Stücke gewesen, wenn ich es habe anfangen lassen zu drucken. ${ }^{96}$

Um Lessing und dessen Büchermachen soll es nun in einem Exkurs ausführlicher gehen - unter besonderer Berücksichtigung des engen Verhältnisses zwischen dem Schriftsteller und Friedrich Nicolai. Nicolai hat als Verleger schon vieles gesehen - aber ein Buch ohne Buchstaben? "Das ist etwas unerhörtes«, schreibt er am 9. August 1768 in einem Brief an Lessing, der ihm die ersten vier Druckbögen des ersten Teils seiner "Briefe antiquarischen Inhalts« hatte zukommen lassen. Zwar liest der Verleger, bei dem der Band auf Wunsch des Autors erscheinen soll, »die Briefe alle mit Vergnügen«, wie Nicolai anmerkt. ${ }^{97}$ Schließlich war er es gewesen, der Lessing ermuntert hatte, ein "Litteraturbriefchen « gegen den Altertumsforscher Christian Adolf Klotz und dessen Gewährsleute aufzusetzen. "Aber was hat Ihr Buchdrucker gemacht, daß er die Signaturen (A B C) unter den Bogen weggelassen! « ${ }^{98}$ Die unauffälligen Buchstaben, unterhalb des Textes platziert, dienen als Markierung und somit als Orientierung beim Ordnen der Bögen eines ungebundenen Buches - dem sogenannten Kollationieren. Für den erfahrenen Verleger Nicolai ist das Fehlen der Lettern alles andere als eine Kleinigkeit: »Glauben Sie, daß dies mir große Konfusion und wirklichen Schaden machen wird; denn weil

94 »Von Moses Mendelssohn« (25. Oktober 1757), in: Cotthold Ephraim Lessing, Werke und Briefe, hg. v. Wilfried Barner u.a., Frankfurt a.M. 1984-2003, 11/1 (1987), S. 256-258 [162], hier: S. 257.

95 Karl Lessing (Hg.), Cotthold Ephraim Lessings Leben, nebst seinem noch übrigen litterarischen Nachlasse, Berlin 1793, I, S. 69.

96 »An Christian Friedrich Voß« (24. Dezember 1771), in: Lessing, Werke und Briefe, 11/2 (1988), S. 304-306 [764], hier: S. 304f.

97 »on Friedrich Nicolai« (9. August 1768), in: Lessing, Werke und Briefe, 11/1 (1987), S. 531f. [429], hier: S. 531f.

98 Ebd., S. 531. 
das Buch nicht ordentlich kann collationieret werden; so werde ich beständig Defecte aufzusuchen haben«, erklärt Nicolai. ${ }^{99} \mathrm{Ob}$ nun beim Drucker, Händler oder Buchbinder, überall droht die Gefahr eines heillosen Durcheinanders. Knapp drei Wochen später meldet Lessing sich zurück, mit sechs weiteren Bögen. "Aber alle ohne Signatur!«, warnt er Nicolai in seinem Brief vor. "Ich muß Ihnen nur gestehen, daß sie der Buchdrucker nicht vergessen, sondern auf mein ausdrückliches Verlangen weglassen müssen. Wozu der Bettel, der das Viereck der Columnen so schändlich verstellt? ${ }^{100}$ Noch im selben Schreiben lenkt Lessing zwar ein, doch nur für den zweiten Teil der »Briefe antiquarischen Inhalts«, der 1769 bei Nicolai erscheinen wird.

Tatsächlich enthält der erste Band von 1768 keine einzige Bogensignatur. Dass Lessing einen Drucker beauftragt, dem er ohne Rücksprache mit dem gewünschten Verleger eigenwillige Instruktionen erteilt, um eine »kleine Neuerung $^{101} \mathrm{zu}$ erreichen, wirft ein Licht auf sein Selbstverständnis als Autor und seine, um mit Ungern-Sternberg zu sprechen, semanzipatorische Publikationspraxis $\aleph^{102}$. Sie verführt Lessing auch $\mathrm{zu}$ einer eigenen, unglücklich verlaufenden Geschäftstätigkeit als Teilhaber der Druckerei »Bode \& Comp.«. Johann Joachim Christoph Bode hatte 1767 eine Druckerei gekauft, Lessing war in das Unternehmen eingestiegen. Um sich Kapital zu verschaffen, hatte er den allergrößten Teil seiner 6.000 Bände umfassenden Privatbibliothek veräußert. ${ }^{103}$ Sein früherer Geschäftspartner ist es auch, den Lessing mit der Herstellung der »Briefe« betraut. Ob sein Eingriff in die Einrichtung des Drucks vom Publikum wahrgenommen wurde, ist nicht überliefert. Öffentlich gemacht wird dieser spätestens durch die 1794 von Nicolai publizierten "Briefwechsel« Lessings mit ihm und anderen. Sie umfassen auch die Korrespondenz zu den »Briefen antiquarischen Inhalts«. Im Autorenratgeber von Hübler dient die Anekdote als warnendes Beispiel: »Die Eleganz des Druckes artet auch bisweilen in Mikrologie aus«, so Hübler, und er legt nahe, den Verzicht auf die Bogenmarken als »Kunstgrille« abzutun. ${ }^{104}$

\footnotetext{
99 Ebd., S. 532.

100 Gotthold Ephraim Lessing, »An Friedrich Nicolai« (27. August 1768), in: ders., Werke und Briefe, 11/1 (1987), S. 533f., hier: S. 533 [431].

101 Ebd.

102 Ungern-Sternberg, »Schriftstelleremanzipation«, S. 77.

103 Wisso Weiss, »Zum Papier einiger Lessing-Druckschriften«, in: Gutenberg-Jahrbuch 55 (1980), S. 174-182, hier: S. 175.

104 Hübler, Beyträge zur Bibliopöie, S. 86.
} 
Um Lessings erste »Kunstgrille« handelt es sich freilich nicht, wie der im Jahr 2000 erschienene Faksimiledruck der Reinschrift seiner ersten Gedichtsammlung zeigt, der »Kleinigkeiten ${ }^{105}$ von 1751 . Die Ausgabe präsentiert ein »detailliert ausgefertigtes Manuskript«, wie es im Nachwort heißt, wobei »detailliert « bedeutet, dass die Handschrift eine »ungewöhnliche Simulation der Buch- und Druckgestalt « ${ }^{106}$ darstellt. Man könnte sagen: Das Manuskript schreibt den Druck buchstäblich vor. Dies betrifft das Titelblatt ebenso wie die Anlage aller übrigen Seiten. Der Zuschnitt der Blätter ${ }^{107}$ entspricht mit ca. 19 x 12 Zentimetern knapp dem Oktavformat der Druckfassung. ${ }^{108}$ Das gesamte Konvolut der Handschrift heftete mutmaßlich Lessing selbst mit Fäden zusammen. ${ }^{109}$ Mit Bleistift und teilweise Rötel wurden auf dem Manuskript die später bei Lessing so unbeliebten Signaturen für die Bogenzählung angebracht. ${ }^{110}$ Elke Bauer merkt an, dass der Verleger »Metzler im Druck exakt wiederzugeben versuchte "111, was der Autor Lessing ihm vorgelegt hatte. Jedoch lassen sich Argumente finden, diese Sichtweise zu relativieren: Zunächst

105 Gotthold Ephraim Lessing, Kleinigkeiten. Faksimile des Marbacher Manuskripts, vorgestellt von Jochen Meyer, Göttingen 2000. Siehe zu den materialen Aspekten von Lessings Handschriften auch Christine Vogl, »Zur Materialität des handschriftlichen Nachlasses von Cotthold Ephraim Lessing. Ein Plädoyer für analytische Handschriftenforschung«, in: Editio 32 (2018), S. 137-166.

106 Jochen Meyer, »Nachwort: Einige Bogen Wein und Liebe«, in: Lessing, Kleinigkeiten, S. 195-238, hier: S. 214.

107 Für die Reinschrift der »Kleinigkeiten« verwendete Lessing überwiegend feingeripptes Papier der Firma Cornelis \& Jan Honig (im Wasserzeichen: »C \& I Honig«), das ab 1748 ein Jahrhundert lang im norddeutschen Raum nachweisbar ist, auch in Form von Fälschungen, wie Ulrich Joost ausführt. Lichtenberg griff für seine Briefe »ab 1780 meistens, ab 1790 fast nur noch (und durchaus im Gegensatz zu den meisten seiner Korrespondenten) [auf] feines holländisches Papier « dieser Firma zurück (Ulrich Joost, Lichtenberg - der Briefschreiber, Göttingen 1993, S. 67), auch Hegel, Hölderlin, Brentano oder Beethoven schätzten diese Marke.

108 Lessing, Kleinigkeiten, S. 162. Die „Göttingischen Anzeigen von Gelehrten Sachen« geben das Format, anders als andere Rezensionsorgane, mit »klein Octav« an (Lessing, Werke und Briefe, 2 (1998), S. 970).

109 Lessing, Kleinigkeiten, S. 163.

110 Ebd., S. 165.

111 Elke Bauer, »)Der Buchdruckerjunge aber klopfte und verlangte Manuscript«. Lessings Arbeitsweise und ihre mögliche Konsequenz für eine historisch-kritische Ausgabe«, in: Jochen Golz, Manfred A. Koltes (Hg.), Autoren und Redaktoren als Editoren, Tübingen 2008, S. 130-143, hier: S. 140. 
war es Lessing, der sich bemühte, die Handschrift wie ein gedrucktes Artefakt anzulegen. Er mag dies getan haben, um gewünschte Aufteilungen und Zeilenumbrüche anzuzeigen. Indes bemüht Lessing sich an keiner Stelle um eine Nachahmung zeitgenössischer Typographie, wie dies bei Jean Paul und seinen Exzerpten der Fall ist (Kapitel 2.2). Somit scheint das ungewöhnliche Manuskript in erster Linie die Funktion einer Druckvorlage zu erfüllen. Hinsichtlich des Schriftbildes ist es Metzler also höchstens auf einer abstrakten Ebene möglich, die Papiere »exakt wiederzugeben«.

Allerdings beschließt Lessing das Manuskript mit einem »Bericht an den Buchbinder«, der Hinweise zur Platzierung von "Zuschrifft « und »Vorrede« enthält, sowie einem »Register der wichtigsten Sachen«. Sowohl die Vorrede als auch das Register erscheinen in der Handschrift mehr oder weniger als Leerstelle, sie werden lediglich durch Platzhalter wie ein über vier Manuskriptseiten durchbuchstabiertes Alphabet ausgefüllt. $\mathrm{Zu}$ erwarten wäre, dass diese Leerstellen in der Druckausgabe durch Text ersetzt werden. Doch sind die Platzhalter bei der Erstveröffentlichung von 1751 exakt so abgedruckt wie in der Reinschrift vorgezeichnet. Angesichts dieser Tatsache präsentiert sich das überlieferte Manuskript weniger als gestrenge Druckvorlage, sondern eher als Entwurf einer paratextuellen Ironisierung der Buchform. ${ }^{112}$ In der Rezension der »Jenaischen gelehrten Zeitungen « wird diese Besonderheit aufmerksam registriert und ins Verhältnis zu den literarischen Arbeiten gesetzt:

112 Erstaunlicherweise findet sich nicht nur am Rande mehrerer Gedichte, sondern auch unter dem »Bericht an den Buchbinder« der zunächst dezente, am Ende aber umso deutlichere Vermerk »Vidi Censor«. In der Faksimile-Ausgabe der »Kleinigkeiten« ist die Frage erörtert worden, ob diese Marker von Lessing selbst stammen. Manches spricht dagegen, die Handschrift ebenso wie der Umstand, dass Gedichte, die vom »Zensor gesehen«wurden, im Druck fehlen oder abgeändert erschienen. »Auf der anderen Seite«, so heißt es in den Anmerkungen, »liegt die Versuchung nahe, die Zensorenvermerke und ebenso die im Manuskript fehlenden Blätter jenem Spiel des Autors mit der Phantasie der Leser zuzurechnen, dem wir auch `Zuschrifft, >Vorredes und >Register < verdanken. « (Lessing, Kleinigkeiten, S. 165) Dass man dieser Versuchung nicht erliegen sollte, dafür spricht wohl vor allem, dass »Vidi Censor«- anders als die Überschriften »Vorrede« und »Zuschrifft« - kein einziges Mal abgedruckt wurde. Man könnte höchstens davon ausgehen, dass das Spiel des Autors im Falle von »Vidi Censor « ausgerechnet der Zensur zum Opfer gefallen ist, was mit Blick auf andere, sehr wohl veröffentlichte Inszenierungen von Zensur um 1800 nicht naheliegend erscheint. 
»Das ganze Werk ist von der Zuschrift bis auf das Register scherzhaft. Denn so finden wir ein leeres Blatt mit der Aufschrift: Zuschrift; ein anders, mit der Aufschrift: Vorrede; und noch ein Blatt zulezt, darauf nach dem Worte: Register, nichts als die Buchstaben unsers Alphabets stehen. Doch der Inhalt dieser anakreontischen Lieder ist beträchtlich. ${ }^{113}$

Wiederholt ist darauf hingewiesen worden, dass Lessing diese durchaus provokanten Dichtungen gegenüber Dritten zu Übungen erklärt hat, "Begabungsproben«, wie Jürgen Stenzel sie nennt. ${ }^{114}$ Dem würde auch ein Buch entsprechen, dessen Anordnung ostentativ »scherzhaft« ist. Später wird diese Rahmung verschwinden: Als 1769 bei Metzler die vierte Auflage der »Kleinigkeiten« erscheint - mit dem Namen des Autors (»G.E. Leßing«) sowie der korrekten Verlagsangabe auf dem Titelblatt - fehlen die paratextuellen Spielereien vollständig. Diese Ausgabe fällt mitten in die Auseinandersetzungen mit Christian Adolph Klotz, die sich an die Veröffentlichung des ersten Teils der »Briefe antiquarischen Inhalts« anschließen. Entsprechend wird in einer Rezension der von Klotz herausgegebenen »Deutschen Bibliothek der schönen Wissenschaften« über den »Antiquar« Lessing und die »Spiele seiner Jugend « gespottet. ${ }^{115}$

\subsection{Im »schönsten Gewande«: Zur Ästhetik des Büchermachens}

»Wie kann ein erhabner Gedanke auf Fliespapier leben? Wie ser erbleicht nicht das glänzendste Geisteskind zugleich mit der Druckerschwärze? und steht nicht die Schärfe des Wizes mit der Schärfe der Lettern in einem unläugbaren Verhältnis?« (SW II.1, 681) Was Jean Paul in seiner frühen »Bittschrift der deutschen Satiriker an das Publikum« von 1783 so pointiert formuliert, ist für viele Autoren des späten 18. Jahrhunderts selbstverständlich: Die Materialität von Büchern steht in einem »unläugbaren Verhältnis« zu deren Inhalten.

113 [Anonymus], Rez. »Kleinigkeiten«, in: Jenaische gelehrte Zeitungen (1751), 88. Stk. (6. November 1751), S. 720, wiederabgedruckt in Lessing, Werke und Briefe, 2 (1998), S. 967. In den »Critischen Nachrichten aus dem Reiche der Gelehrsamkeit « steht am Ende der Rezension: »Zuschrift, Vorrede und Register kann sich ein jeder Käufer nach seinem Geschmack einrichten, denn es ist Platz dazu gelassen.«(Ebd., S. 968) Lessing, Werke und Briefe, 2 (1998), S. 964.

115 [Anonymus], Rez. »Kleinigkeiten von G.E. Leßing«, in: Deutsche Bibliothek der schönen Wissenschaften (1769), 14. Stk., S. 346f., hier: S. 347, wiederabgedruckt in Lessing, Werke und Briefe, 2 (1998), S. 971. 
Dies wird allgemein konstatiert, obgleich um 1800 zwischen Teilauflagen ein und derselben Ausgabe mitunter enorme Unterschiede in der Ausstattung bestehen, da angesichts des grassierenden Nachdrucks versucht wird, mit einem Titel verschiedene Käufergruppen zu bedienen. Daher erklärt Jean Paul auch global, es sei »wol unstreitig, daß besseres Papier und besserer Druk der deutschen Poesie den gehörigen Schwung geben würde, und es felet uns weniger an guten Dichtern als an guten Verlegern «(SW II.1, 680f.). Dass ausdrücklich von der »deutschen Poesie« die Rede ist, hat einen einfachen Grund: Was die Heimat von Gutenberg an Gedrucktem zu bieten hat, gilt schon lange und erst recht, seit Baskerville und andere im Ausland neue Maßstäbe in der materialen Ästhetik des Buches gesetzt haben, als altbacken, hoffnungslos rückständig und im europäischen Vergleich nicht wettbewerbsfähig. ${ }^{116}$ Dazu trägt das Festhalten an der Schrifttradition der Fraktur ebenso bei wie die lange Zeit stockende Entwicklung des Verlagswesens und des angeschlossenen Handwerks. Zwar erlebt der deutschsprachige Buchmarkt in der zweiten Hälfte des 18. Jahrhunderts ein ungekanntes Wachstum (das auch eine Ausdifferenzierung des Angebots bewirkt). Jedoch sind die Ausgangswerte relativ bescheiden: Erst in den Vierzigerjahren des 18. Jahrhunderts hat die Buchproduktion das Niveau der Jahre vor dem Dreißigjährigen Krieg erreicht ${ }^{17}$, ehe sie sich zwischen 1765 und 1800 mehr als verdoppelt. Die Masse an Neuerscheinungen wird nicht selten mit immer weniger Klasse in der Herstellung assoziiert.

Hier ausdrücklich von einer Ästhetik zu sprechen, legen kunstphilosophische Begriffe nahe, wie Jean Paul sie auf Gedrucktes anwendet, wenn er die Typographie des Auslandes betrachtet: »Wodurch übertrift der Britte den

116 Vgl. Lühmann, Buchgestaltung, S. 19f. Johann Heinrich Merck beklagt in seinen »Cedanken über die Irrwege der deutschen Schriftsteller« (1780) »die Thorheit, daß wir allein die Mönchsschrift [Fraktur, Anm. T.F.] im Drucken beybehalten haben, die schon längst, seit Jahrhunderten bey allen anderen Völkern abgeschafft ist. Dieser einzige Umstand ist hinlänglich, die Kenntniß unserer Sprache bey den Ausländern hinderlich zu machen, wozu der traurige Bettelanzug unseres gelben Löschpapiers und unsrer stumpfen Lettern das Seynige reichlich beyträgt. Wir überschicken nichts brochirt und so Vieles auf ungeleimtem Papier an den Ausländer, der schlechterdings Nichts von Planiren weiß. Ueberlegt man ferner den ungeheuren Preiß unsrer Bücher, die nach dem inneren und äußeren Werth gerechnet, gerade um 200 pc. höher stehen, als die französischen, so ist die Unmöglichkeit des Vertriebs sehr begreiflich. (Johann Heinrich Merck, Gedanken über die Irrwege der deutschen Schriftsteller, Werke, hg. v. Arthur Henkel, Frankfurt a.M. 1968, S. 490ff., hier: S. 492.)

117 Ungern-Sternberg, »Schriftstelleremanzipation«, S. 73. 
Deutschen? durch das, was wir noch nicht nachgeamet, durch typographischen Wiz und Tiefsin. (SW II.1, 681) Und es sind vor allem Typographen wie Breitkopf, der in seinem Bereich ausdrücklich »Künstler « am Werk sieht. ${ }^{118}$ Bodoni wird in seinem »Handbuch der Typografie«, das 1818 auf Deutsch erscheint, eine grundlegende Frage der Ästhetik aufwerfen: »Worin aber sollen wir sagen, daß das Schöne bestehe? ${ }^{119}$ Andererseits werden, nicht zuletzt in der Literatur, die Grenzen künstlerischer Buchgestaltung thematisiert. »Ein schöner Druck gefällt wohl; aber wer wird ein Buch des Druckes wegen in die Hand nehmen?«, heißt es 1795, als Prachtausgaben in Mode sind, in »Wilhelm Meisters Lehrjahren ${ }^{120}$.

Ein Rückblick auf die Jahre um 1760 offenbart einerseits eine große Unzufriedenheit mit der Buchgestaltung, die geradezu als Topos fortgeschrieben wird, weshalb auf längere Sicht ihre Verhältnismäßigkeit zu hinterfragen ist. Denn andererseits führen die leuchtenden Vorbilder aus England oder Frankreich zu einer "Art Zäsur « ${ }^{121}$ auch in deutschen Landen, und es zeigen sich bemerkenswerte Ansätze einer Ästhetisierung des Buches, die spätestens am Ende des 18. Jahrhunderts einhergehen mit einer deutlich anspruchsvolleren Gestaltung. Zur Jahrhundertmitte sind es vornehmlich Schriftsteller, nicht Verleger oder Drucker, die mit Blick auf die europäischen Nachbarn formulieren, wie ein »schöner Druck« auszusehen habe und wie nicht. Dies geschieht im privaten Austausch, aber ebenso in der Kommunikation mit einem gebildeten und durchaus konsumfreudigen Publikum, das seinen Geschmack in allen Lebensbereichen verfeinert. ${ }^{122}$

Christoph Martin Wieland klagt früh über seine zwei Schweizer Verleger, die »Hrn. Papierbesudler«, und lässt Johann Georg Zimmermann im August 1758 wissen: »Ich kan nichts dafür daß Hr. Zunftmeister Heidegger, und Hr.

118 Siehe den Wortgebrauch in Johann Gottlob Immanuel Breitkopf, Ueber Bibliographie und Bibliophilie, Leipzig 1793.

119 Zit. n. Wulf D. von Lucius, Akka von Lucius, Anmut und Würde. Bücher und Leben um 1800, Stuttgart 2005, S. 32.

Johann Wolfgang von Coethe, Wilhelm Meisters Lehrjahre, Werke (Hamburger Ausgabe), hg. v. Erich Trunz, 8. Aufl., München 1972ff., VII (1973), S. 412.

121 Lühmann, Buchgestaltung, S. 20. Siehe zum Überblick auch Ernst L. Hauswedell, Christian Voigt, Buchkunst und Literatur in Deutschland 1750 bis 1850, Hamburg 1977.

122 Siehe dazu die erhellende, beim Luxusdiskurs ansetzende Studie von Erlin, Necessary Luxuries, insbes. S. 24-77, sowie exemplarisch Boris Gibhardt, Vorgriffe auf das schöne Leben. Weimarer Klassik und Pariser Mode um 1800, Göttingen 2019. 
Orell, Meine Verleger, der eine keinen Geschmak hat und der andere das wohlfeilste für das beste hält. « ${ }^{123}$ Tatsächlich gibt es in diesen Jahren ein erkennbares Bemühen um ästhetisch anspruchsvollere Drucke. In den deutschsprachigen Ländern bilden Mitte des 18. Jahrhunderts die von Johann Carl Bohn in Hamburg besorgten Ausgaben der Schriften Friedrich von Hagedorns den Maßstab in Gestaltung und Ausstattung, weshalb sie für viele Autoren als Referenz fungieren, wenn es um die eigenen Bücher geht. ${ }^{124}$ Eine Werkausgabe Hagedorns erscheint 1757, also im selben Jahr, in dem Baskerville mit seiner Vergil-Ausgabe reüssierte und »Europa aus dem Schlafe weckte « ${ }^{125}$. Klopstock hat bereits 1749, als er seinen »Messias « auf Subskriptions-Basis herausgeben will, die Einzelausgabe von Hagedorns »Die Freundschaft«, im Jahr zuvor als schmales Bändchen bei Bohn veröffentlicht, vor Augen: »Meine Absicht wäre in groß 4 [Quart, Anm. d. Verf.] wie Hagedorns Freundschaft mit solchen Lettern auf solches Papier drucken zu lassen. $\aleph^{126}$

An den Anfang von »Die Freundschaft ${ }^{127}$ lässt Bohn ein aufgeräumtes Titelblatt ohne Vignette setzen. Darauf stehen lediglich der Buchtitel in Fraktur, zentriert, das Wort »Freundschaft«, hervorgehoben durch Fettdruck und die zeittypisch mit Zugwerk verzierte Initiale $\equiv E$ «, sowie - sauber getrennt durch einen haarfeinen Strich - die Verlagsangaben (mit Erscheinungsdatum »Im November, 1748«). Bohn wählt einen lichten Satzspiegel mit einem großzügigen Durchschuss, breiten Seitenrändern und einem sparsamen Schmuck. Abgesehen vom dezenten Ornament, mit dem die Paginierung am oberen Seitenrand eingefasst wird, und einer Schlussvignette enthält der Innenteil keinerlei üblichen Zierrat.

Eine weitere Publikation Hagedorns bei Bohn (»Oden und Lieder in fünf Büchern«, 1747) wird von Klopstock als Referenz benannt, als er mit Carl Hermann Hemmerde über eine neue, von ihm autorisierte Buchausgabe

123 Christoph Martin Wieland, »An M. Künzli in Winterthur « (12. April 1757), in: ders., Wielands Briefwechsel, Berlin 1963-2007, I (1963), S. 299-300 [253], hier: S. 299, sowie »An Zimmermann in Brugg (August 1758), ebd., S. 355-356 [312], hier: S. 356. Ungern-Sternberg, »Schriftstelleremanzipation«, S. 81. Bertuch, »Ueber den typographischen Luxus«, S. 600. Friedrich Gottlieb Klopstock, »An Johann Andreas und Charlotte Cramer, Langensalza, 17. Juni 1749«, in: ders., Werke und Briefe. Historisch-kritische Ausgabe, hg. v. Horst Gronemeyer, Elisabeth Höpker-Herberg, Klaus Hurlebusch u.a., Berlin, New York 1974ff., Abt. Briefe, I (1979), S. 54f. [32], hier: S. 55.

127 Friedrich von Hagedorn, Die Freundschaft, Hamburg 1748. Der Band umfasst 30 Druckseiten im Quartformat. 
Abbildung 4: Titelblatt von Friedrich von Hagedorn, »Die Freundschaft«, Hamburg 1748.

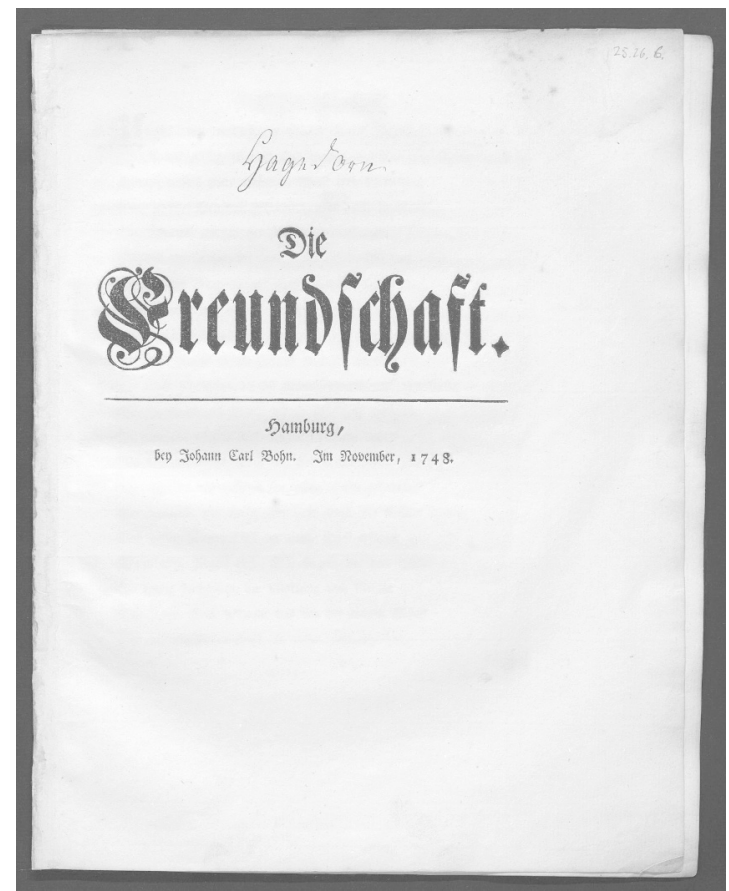

Zentralbibliothek Zürich, 25.26,6, https://doi.org/10.3931/e-rara-72274.

des »Messias« verhandelt. Der Autor war von Hemmerdes erster Publikation seines Werks vom Jahresanfang 1749 überrascht worden ${ }^{128}$, auch wenn er dem Verleger versicherte, darin keinen »unerlaubten Nachdruck « zu sehen. ${ }^{129}$ Umso klarer formuliert er jedoch seine Vorstellungen für einen neuerlichen

128 Nach der Erstveröffentlichung der ersten drei Cesänge in den »Bremer Beyträgen « hatte Carl Hermann Hemmerde den Verleger der Zeitschrift, Nathanael Saurmann, erfolgreich um eine Druckerlaubnis ersucht. Helmut Pape merkt dazu an: »Klopstock hat erst verhältnismäßig spät von diesem Unternehmen erfahren.« (Helmut Pape, Klopstocks Autorenhonorare und Selbstverlagsgewinne, Frankfurt a.M. 1969, Sp. 22.)

129 »An Hemmerde, Langensalza, 30. September 1749«, in: Klopstock, Werke und Briefe, Abt. Briefe, I (1979), S. 61-62, hier: S. 61. 
Druck. In einem Brief vom 30. September 1749 wünscht er sich »merklich weisses Papier, als Langens Oden sind ${ }^{130}$ und »die Lettern, die zu Gellerts Fabeln sind gebraucht worden«, wobei er anmerkt: »Sie werden vielleicht so gut als ich sehen, daß ein richtiger sauberer Druck mehr Ihr eigner Vortheil als der meinige ist. «31 Schließlich kündigt Klopstock an, er werde »auch einige Anmerkungen schreiben, die die Zierde und den Wohlstand des Drucks angehen $«{ }^{132}$ Die nicht genau zu datierenden »Anmerkungen wegen des Drucks«, die Hemmerde am Ende weitgehend ignorieren wird, lassen im Rekurs auf Drucke »der Art « von Hagedorn und Gellert, »ohne Zierrathen«, die Tendenz zu einem entrümpelten und reduzierten Schriftbild erkennen, wie sie wenig später vor allem in den Antiquadrucken (des Klassizismus) verwirklicht werden wird:

»1. Die Anfangsbuchstaben jedes Cesangs ohne Züge, u sonst ohne Zierrathen, mit denen sie gewöhnlich umgeben werden. Von der Art, wie sie auf Hagedorns neuen Oden u L. oder auf der neuen Ausgabe von Gellerts Fabeln ${ }^{133}$ sind

2. Keine Holzstiche zu Ende der Cesänge, wenn auch Raum da ist, oder wenn ja nöthig ist, so klein u simple als möglich ist

$[\ldots]$

4. Die Zeilen weit von einander, u so viel möglich ist, jeden Vers in eine Zeile.

5. Von dem Titel bleibt das gewöhnliche Kupfer weg.

6. Die Benennungen: Erster Gesang, Zweiter Cesang, -- werden auf ein besonderes Blatt gedruckt

130 Ebd., gemeint ist der Band von Samuel Cotthold Lange, Horatzische Oden nebst G.F. Meiers Vorrede vom Werthe der Reime, Halle 1747 (ebd., S. 283).

131 Ebd., S. 62.

132 Ebd.

133 Cemeint ist die zweite Auflage von Gellerts »Fabeln« (1748-1751), auf deren Titelblättern das noch bei der Erstausgabe (1746-1748) zu sehende Zugwerk der Initialen durch eine zurückhaltende Verzierung der Anfangsbuchstaben ersetzt worden war. Entgegen der Annahme von Elisabeth Höpker-Herberg dürfte es an dieser Stelle nicht um die grundsätzliche Frage gehen, ob der Band in Fraktur gesetzt werden soll, sondern um ein typographisches Detail, das jedoch sehr aufschlussreich ist, da der Wunsch, die »Anfangsbuchstaben jedes Cesangs ohne Züge«drucken zu lassen, erkennen lässt, dass sich Klopstock an den zeitgenössischen Versuchen orientierte, den Frakturdruck einfacher, klarer und reduzierter zu gestalten (Friedrich Cottlieb Klopstock, Der Messias, Werke und Briefe. Historisch-kritische Ausgabe, hg. v. Horst Cronemeyer, Elisabeth Höpker-Herberg, Klaus Hurlebusch u.a., Berlin, New York 1974ff., Abt. Werke, IV/6 (1999, hg. v. Elisabeth-Höpker-Herberg), S. 151.) 
7. Der Inhalt eines jeden Cesangs mit kleinen Lettern.

8. Die Buchstaben des Titels auch ohne Züge, wie oben Anmerk. 1). $[\ldots] \ll^{134}$

Als der von Klopstock geschätzte Bohn im Jahr 1757 »Des Herrn Friedrichs von Hagedorn Poetische Werke« in drei Bänden herausgibt, stellt er den Gedichten eine "Nachricht des Verlegers« voran. Immerhin war erwartet worden, dass jeder Band »ein Muster eines Buches $\aleph^{135}$ werden würde. Nicht nur erklärt sich Bohn als Editor, der mit der »äussersten Gewissenhaftigkeit« der Vorlage des Dichters gefolgt sei, was er, so Bohn, »Jedermann mit seiner eigenen Hand beweisen kann « ${ }^{136}$. Bohn hebt auch die Unterstützer und Gönner hervor, die für ein in Kupfer gestochenes Porträt von Hagedorns ebenso gesorgt hätten wie »für die Vignetten und die Richtigkeit des Abdrucks«, wobei er sich in Bezug auf die Korrektheit noch einmal allgemein zu dem Projekt äußert: »Mit welcher Genauigkeit solches geschehen sey, und wie ich selbst keine Kosten gesparet habe, dieser neuen Ausgabe alle äusserliche Zierde zu geben, zeiget der Augenschein. ${ }^{137}$

Bohn benennt in wenigen Zeilen nahezu alle Aspekte, die in den folgenden Jahrzehnten die Diskurse um die materiale Ästhetik des Buches und mithin das Materialbewusstsein von Publizierenden bestimmen werden. Ungern-Sternberg rechnet zu diesen Aspekten, wie erwähnt, »korrekten Druck, saubere Lettern, gute typographische Gestaltung, Formatwahl, Papierqualität, Buchschmuck und Illustrationen « ${ }^{138}$. Die materiale Ästhetik des Buches unterliegt in einem hohen Maße kulturellen und sozialen Einflüssen, da die betreffenden Artefakte in der Regel als Gebrauchsgegenstände betrachtet werden, deren mediale Funktion ihrer Gestaltung immer den Anschein des Sekundären verleiht. So befürchtet etwa Breitkopf, als er zur Präsentation seiner Schriftschnitte bekannte Gedichte abdruckt und veröffentlicht, er könne für einen Nachdrucker gehalten werden. Bücher gelten gemeinhin nicht als eigenständige Kunstwerke, es sei denn, man versteht diesen Begriff im handwerklichen Sinne des mechanischen Kunstwerks oder

134 Klopstock, Der Messias, S. $264 \mathrm{f}$.

135 Johann Peter Uz in einem Brief an Johann Wilhelm Ludwig Gleim vom 12. März 1756, in: Carl Schüddekopf (Hg.), Briefwechsel zwischen Cleim und Uz, Tübingen 1899, S. 263-268 [70], hier: S. 267.

136 »Nachricht des Verlegers«, in: Friedrich von Hagedorn, Des Herrn Friedrichs von Hagedorn Poetische Werke, Hamburg 1757, I, S. V-VI, hier: S. V.

137 Ebd., S. VI.

138 Ungern-Sternberg, »Schriftstelleremanzipation«, S. 77. 
beschränkt sich exklusiv auf die hohe Kunst der Buchillustration. Entsprechend würdigt Hegel Bücher in seiner "Ästhetik« auch nur ein einziges Mal, in einem Nebensatz zur Buchdruckerkunst. ${ }^{139}$ Da Bücher einem gebildeten Publikum so alltäglich sind, geht es in Fragen der materialen Ästhetik häufig auch nicht um die bestmögliche Ausstattung und Ausgaben für Liebhaber, sondern um einen gehobenen Standard. Die Antiqua, für viele der Inbegriff typographischer Schönheit, findet zwar selbst am Höhepunkt ihrer Popularität bei »weniger als $10 \%$ der Bücher eine Verwendung. ${ }^{140}$ Doch es sind nicht nur bis heute bekannte Autoren, die gesteigerten Wert auf die Ausstattung ihrer Veröffentlichungen legen. 1799 wendet sich der Jurist und ostfriesische Chronist Tileman Dothias Wiarda an Friedrich Nicolai in Berlin, weil er in seiner entlegenen Heimat keinen guten Satz oder Druck bekommen könne. ${ }^{141}$ Der Weimarer Verleger Bertuch vertritt zwar die Meinung, dass »typographischer guter Geschmack und Sauberkeit als wesentliche Stücke in allen Druckereyen eingeführt seyn sollten«. Jedoch warnt der Verleger eindringlich davor, diesen Standard »bey Büchern des täglichen Bedürfnisses, und bey jedem fliegenden Blatte in einen unnötigen Luxus ausarten « zu lassen. Die steigenden Ansprüche wird Bertuch im Rückblick mit wenig Wohlwollen beschreiben:

»]eder neugebohrne Dichterling, Romanschreiber und Kalendermacher wollte nun auf geglättet Schweizer-Papier, mit Didotschen Lettern, Kupfern und Vignetten gedruckt, und in Marroquin gebunden seyn; und so paradirten oft die schaalsten Producte im schönsten Cewande. $\aleph^{142}$

Gegen Ende des 18. Jahrhunderts erlebt die materiale Ästhetik des Buches einen neuen Höhepunkt. Es kommt zur "Antiqua-Fraktur-Debatte", die in der buchbezogenen historischen Forschung vielfach aufgearbeitet worden ist, weshalb an dieser Stelle eine kurze Skizze ausreicht: Christina Killius betont, dass es vornehmlich Verleger und Drucker sind, die diese Debatte tragen, ${ }^{143}$ wobei es sich um Stimmen aus einer herstellenden Praxis handelt, die eine

139 Vgl. Hegel, Ästhetik, S. 764.

140 Lucius, Anmut und Würde, S. 32. Siehe auch Wulf D. Lucius, »Anmut und Würde. Zur Typographie des Klassizismus in Deutschland«, in: Monika Estermann, Michael Knoche (Hg.), Von Göschen bis Rowohlt. Beiträge zur Geschichte des deutschen Verlagswesens, Wiesbaden 1990, S. 33-63.

141 Selwyn, »Everyday Life«, S. 318-319.

142 Bertuch, »Ueber den typographischen Luxus«, S. 605.

143 Killius, Die Antiqua-Fraktur-Debatte, S. 352. 
gesteigerte Aufmerksamkeit und Anerkennung erfährt. Neben handwerklich virtuosen Druckern wie Breitkopf oder Unger bemühen sich auch einige der reinen Kaufleute unter den Verlegern um die »Erfüllung der Ausstattungswünsche der Autoren der fünfziger Jahre«, so Ungern-Sternberg. ${ }^{144}$ Georg Joachim Göschen, der einige Jahre die Dessauer "Gelehrtenbuchhandlung« führte, zu deren Geschäftsmodell es gehörte, solche Wünsche zu erfüllen, wirbt am 19. Oktober 1793 in einem Brief um Klopstock. Der berühmte Dichter zählte zu den Selbstverlegern der deutschsprachigen Literatur und ist an Buchgestaltung nachhaltig interessiert, ebenso wie Wieland, als dessen Verleger Göschen zu überzeugen versucht:

»Ich habe eine Druckerey angelegt, welche mit den schönsten Werken der Engländer und Franzosen weteifern soll. In wiefern ich meinen Wunsch erreicht habe, davon sind die Proben von Wielands Werken, welche Dieselben bey dem Herrn von Archenholz sehen können ein Beweiß. Jenes Wielandische Werk ist zu voluminös um es mit der möglichsten Pracht und doch dem Beutel der Deutschen Bücherliebhaber angemeßen heraus geben zu können. Ein Werk von der Stärke Ihrer Oden würde mir Gelegenheit geben ein Monumentum Typograph. dieses Jahrzehends zu liefern, welches durch kein Werk des vergangenen Zeitalters in unserm Vaterlande übertroffen werden solte. ${ }^{145}$

Göschen und der aufstrebende Johann Friedrich Cotta entfalten in einer verlegerischen Konkurrenz einigen »typographischen Wetteifer ${ }^{146}$, wobei Cotta auf Friedrich Schiller vertraut, der es ihm gegenüber als vorteilhaft bezeichnet hatte, "auch im Typographischen etwas bedeutendes zu leisten, und sich auf diese Art in Respect zu bringen $« .{ }^{147}$ Es ist die Zeit der aufwendigen Prachtausgaben, und Schiller stellt fest: »Lateinische Schrift ist $\mathrm{zu}$ einer Pracht-

144 Ungern-Sternberg, »Schriftstelleremanzipation«, S. 78.

145 »Von Göschen, Leipzig, 19. Oktober 1793«, in: Klopstock, Werke und Briefe, Abt. Briefe, 8.1 (1994), S. 301f. [216], hier: S. 301.

146 Zit. n. Fischer, Johann Friedrich Cotta, S. 156.

147 »Brief an Cotta, 13. März 1796«, in: Friedrich Schiller, Schillers Werke. Nationalausgabe [NA], begründet v. Julius Petersen, fortgeführt v. Lieselotte Blumenthal und Benno von Wiese, hg. im Auftrag der Nationalen Forschungs- und Cedenkstätten der klassischen deutschen Literatur in Weimar (Goethe- und Schiller-Archiv) und des SchillerNationalmuseums in Marbach v. Norbert Oellers, Siegfried Seidel, Weimar 1943ff., 28 (1969), 7.1.6, S. 200-201, hier: S. 200. 
ausgabe wohl nothwendig [...].«" ${ }^{148}$ Ein »Monumentum Typograph.«, wie Göschen es gegenüber Klopstock anpreist, soll nach dem Willen von Bertuch für »National-Monumente ${ }^{149}$ reserviert sein.

Antiqua oder Fraktur - diese Grundsatzfrage treibt nicht nur Verleger um, sondern auch etliche Autoren positionieren sich angesichts der lebhaften Debatte um die beiden Schriftgattungen in typographischen Fragen. Prominent tun dies die Exponenten der Weimarer Klassik, sei es Schiller, der auf Cotta einwirkt, oder Wieland, der wegen der Antiqua an der Verbreitung seiner von Göschen verlegten »Sämmtlichen Werke« zweifelt. ${ }^{150}$ Goethe wird von seiner Mutter eindringlich ermahnt, an der Fraktur festzuhalten ${ }^{151}$ - die Breitkopf oder Unger zugleich zu modernisieren versuchen. Unbedingt $\mathrm{zu}$ berücksichtigen ist das Eingehen auf die Bedürfnisse des deutschsprachigen Marktes und dessen Segmente durch die Adaption der Antiqua einerseits, die Anpassung und Erneuerung der gebrochenen Schrift andererseits. Jean Paul, der andere Klassiker, macht die Typographie zum Gegenstand literarischen Schreibens: im »Offenen Brief an Leibgeber anstatt einer Vorrede«, zu finden im ersten Band der »Palingenesien« aus dem Jahr 1798, als - so Frithjof Lühmann - die Diskussion um die Reformversuche der Fraktur bereits wieder im Abebben begriffen gewesen sei. ${ }^{152}$ Hier heißt es: »Ich bin recht froh, daß ich mich bei dieser Gelegenheit recht ärgern kann über unser Übersetzen der deutschen Typen in lateinische und über mehr. " (SW I.4, 725) Gesetzt ist die Ausgabe in neuen gebrochenen Lettern, die nach ihrer Wiederentdeckung im frühen 20. Jahrhunderts fortan als »Jean-Paul-Fraktur« bekannt werden wird. Ungewöhnlich ist, dass dieser Schriftschnitt im Medium der Literatur beworben, die Materialität des Textes ausgestellt und so eingehend kommentiert wird, dass man sich in einer Vorschule der Ästhetik wähnt:

\footnotetext{
148 »Brief an Crusius, 10. März 1803«, in: Schiller, Schillers Werke [NA], 32 (1984), 7.1.10, S. 21.

149 Bertuch, »Ueber den typographischen Luxus«, S. 606.

150 Die Ausgabe wird zwar durchgängig in einer Antiqua gedruckt, aber in vier Ausgaben mit je unterschiedlichem Format, Satzspiegel und anderer Papierqualität auf den Markt gebracht. Hierzu bemerkt Wehde: „Die wirtschaftliche Mischkalkulation, die den formal unterschiedlichen Ausgaben zugrunde liegt, errichtet ein ökonomisches Wertesystem, das dem Käufer bzw. Besitzer als soziokulturelles Unterscheidungsmerkmal zurechenbar wird. Die äußere Gestalt eines Werkes erlangt soziale Distinktionsfunktion und wird zu einem entscheidenden Faktor bei der Vermarktung eines Wekes." (Wehde, Typographische Kultur, S. 233.)

151 Siegfried Unseld, Goethe und seine Verleger, Frankfurt a.M. 1991, S. 202. Lühmann, Buchgestaltung, S. 215.
} 
"Sobald wir der gotischen Schrift die Halskrausen, die Troddeln, das Spitzenwerk, die Knickse und Bruchbänder verbieten: so steht sie ungemein schön mit zwei Bestandteilen da, erstlich mit einer geraden Linie wie die römische, und dann, statt des Zirkels der letztern, mit einer halben Ellipse (zugleich das Sinnbild unsers Geschmacks!). In der Reinigung und Wiederbringung der ersten schönern Form haben nun die Herren Breitkopf und Härtel hier in meinen Palingenesien und in diesem Briefe die ersten glücklichen, obwohl das Auge der Gewohnheit noch schonenden Versuche gemacht, von denen sie zu weitern und ihrem Ideale nähern übergehen wollen, wenn du und das Publikum sie so aufmuntern wie ich.«(SW I.5, 725)

Susanne Wehde sieht den Antiqua-Fraktur-Streit »bedingt durch die funktionale Koppelung von Typographie und Literatursystem in dieser Zeit«, wobei sie sich damit auf die »Formierung der literarischen Klassik in Deutschland $\aleph^{153}$ bezieht. Sie schreibt:

»Dabei werden die Ausdrucksmöglichkeiten von Typographie als doppelt codiertes Zeichensystem sowohl für die poetologisch-ästhetische Differenzierung literarischer Textklassen als auch für die wirtschaftliche und soziokulturelle Strukturbildung des Literatursystems genutzt und soweit ausgearbeitet, daß die Grundlagen für die (literatur-)unabhängige Weiterentwicklung von Typographie als ästhetisches Ausdruckssystem gelegt werden. ${ }^{154}$

Original und Nachahmung entwickeln sich vor diesem Hintergrund auch zu Kategorien in der Beurteilung zeitgenössischer Schriftschnitte. 1791 lässt der Berliner Buchdrucker Johann Friedrich Unger im »Intelligenzblatt « der »Allgemeinen Literatur-Zeitung« (ALZ) eine Anzeige platzieren, in welcher er sich als der einzige rechtmäßige Vertrieb von Didotschen Lettern in Deutschland vorstellt. ${ }^{155}$ Die Veröffentlichung enthält auch ein Urteil des Franzosen Firmin Didot über die Nachschneider seiner Lettern, allen voran Johann Carl Ludwig Prillwitz aus Jena, sowohl auf Französisch als auch in Übersetzung. Aufschlussreich sind die Narrative, derer sich beide - Unger wie Didot - zumindest implizit bedienen. Da wäre zum einen das Narrativ der Fälschung bei Unger, während Didot den eigenen Fortschritt betont, indirekt das Neue

\footnotetext{
153 Wehde, Typographische Kultur, 22of.

154 Ebd., S. 221.

155 Johann Friedrich Unger, »Noch etwas über Didotsche Lettern, als eine Antwort auf das anonyme Schreiben im 40sten Stück des Intelligenzblatts der allgemeinen LiteraturZeitung«, in: Intelligenzblatt der ALZ (1791), Nr. 64 (14. Mai 1791), Sp. 528-530.
} 
als Verbesserung herausstellt, wenn er angibt, dass Prillwitz sich an frühen Schnitten versucht und deren Mängel ebenso imitiert wie durch eigenes $\mathrm{Zu}$ tun bereichert habe.

\section{5. »Setzer = Zersetzer «: Autorschaft und Druckfehler}

Druckfehler sind für Autoren um 1800 mehr als ein beiläufiges Ärgernis. Wie groß der Einfluss der Schriftsetzer auf die Arbeit des Schriftstellers ist, offenbart eine kurze Notiz aus den »Gedanken « Jean Pauls: »Setzer = Zersetzer « (HKA II.8.1, 399 [179]) ist dort zu lesen, wobei der Betroffene an anderer Stelle durchaus Verständnis für den Berufsstand zeigt, bei dem er eine professionelle Deformation erkennt: »Ein Setzer verwandelt philantropisch, empirisch und kategorisch stets in unorthographische Schreibart, weil er die falsche schon so oft gesetzt.« (HKA II.8.1, 394 [137]) Trotzdem hält sich dieses Verständnis in Grenzen, geht es doch letztlich um das eigene Werk und die mit diesem verbundenen Mühen, deren Ergebnis in der typographischen Umsetzung auf dem Spiel steht. Im »Siebenkäs« liest man dazu:»Es ist schwer, ein Buch zu setzen, noch schwerer, zu schreiben« (SW I.2, 181). Daher giftet Jean Paul in seinen privaten Aufzeichnungen: ॥Unter allen möglichen Lesern denk' ich mir den Setzer immer als den dümmsten." (HKA II.8.1, 516 [205/182]) Als er mit dem Nürnberger Verleger Johann Leonhard Schrag über das »Leben Fibels« verhandelt, schreibt er diesem, seine alte Gleichung wieder aufgreifend, am 28. Juni 1811: »Um eines bitt' ich Sie inständig: um einen bessern Setzer und Korrektor, als mir bisher meistens zu Theil geworden; der Setzer wurde immer mein Zersetzer und der Korrektor ein Inkorrektor, und letzterer dieses immer um so mehr, je leichter er mich zu errathen und zu ergänzen glaubte.«(HKA III.6, 207 [502]) Schlechte Erfahrungen hat Jean Paul tatsächlich reichlich gesammelt. Den »Schmelzle« bezeichnet er gegenüber Cotta als sein »am schärffsten durchgearbeitetes Werk im Komischen«. Umso schwerer wiegt daher, dass »so sehr viele Druckfehler « darin zu finden sind. »Wie kann ich da helfen?", fragt Jean Paul in einem Brief vom 12. Februar 1809 an den Verleger (HKA III.6, 11 [81]).

Doch allzu sehr belasten sollte dieser Ärger das Verhältnis zum jeweiligen Verleger nicht, vielmehr berücksichtigt Jean Paul als mildernden Umstand seine durchaus ungewöhnliche Schreibweise. Als ihm der Verleger Johann Georg Zimmer im Februar 1809 nach einem Teilhonorar auch die letzten Aushängebögen des »Dr. Katzenberger« zur Korrektur zukommen lässt, bedankt 
sich der Autor zunächst für die »niedliche Einrichtung des Buchs«. Um in dem Brief vom 27. Februar anzufügen:

»Grämen Sie sich so wenig über die Druckfehler als ich; aus meinem Ergänzungsblatte und der Vorschule sehen Sie, daß es mir bei allen guten Buchhandlungen gleich schlecht geht. Ein Crund dieser Setzer-Interpolazion liegt vielleicht in meinem Stile, der ihnen nicht wie bei vielen andern Autoren das Gewöhnlichste zu errathen verstattet.« (HKA III.6, 14 [37])

Zimmer hatte bei der Übersendung der Bögen geschrieben: »Gebe Gott daß Ihnen weniger Druckfehler begegnen als Sie berichten." (HKA IV.6, 16 [9]) Tatsächlich hatte Jean Paul ausdrücklich um Aushängebögen gebeten mit der Begründung, dass Druckfehler »in meinen Werken so häufig sind als Gleichnisse« (HKA III.6, 5 [16]).

Mit dem in der Korrespondenz angesprochenen »Ergänzblatte« meint Jean Paul sein »Ergänzblatt zur Levana«, ein Bändchen, »dessen Kapitel die verschiedenen Druckfehler so vieler meiner Werke und sonst nichts enthalten« (SW I.5, 1281). Die Vorrede von 1806 liefert die Erzählung eines Traums, in dem Verfasser, Abschreiber, Setzer und Korrektur auftreten, um sich nacheinander zu Druckfehlern zu äußern. Der Abschreiber verteidigt sich damit, dass »er sich nicht, wie einer, der etwas liest, auf Sinn und Verstand einlassen « (SW I.5, 1290) könne. Der Setzer nimmt für sich in Anspruch, ein bildender Künstler zu sein, der das "schwere schwarze Musaik « der Typographie erschafft, »indem ich Stiftchen nach Stiftchen einsetze« (SW I.5, 1291). Die Druckseite erscheint somit als ein Produkt vieler Hände, von Setzern, Buchdruckern und andern, deren Handwerk sich nur durch eine Störung bemerkbar macht, den Druckfehler, der die auctoritas von Autorschaft unterminiert. Die an der Buchproduktion unmittelbar Beteiligten übernehmen stellenweise und meist unwillkürlich die Werkherrschaft, während die Verfasser in eine Ohnmacht verfallen.

Jean Paul bildet in seinem Ärger über Druckfehler keine Ausnahme. »Mit meiner Autorschaft geht mirs so elend, daß ich mich verbeißen möchte, keine Zeile mehr drucken zu lassen«, klagt Herder im Mai 1778 in einem Brief an Johann Friedrich Hartknoch, den Verleger seiner soeben erschienenen »Plastik«. "Was das für Druckfehler in der Plastik sind, einem Buche, das ich Jahre lang, wie Du weißt, am Herzen getragen habe [...]«. ${ }^{156}$ Herder schimpft

156 Johann Gottfried Herder, »An Johann Friedrich Hartknoch, Weimar, Mitte Mai 1778«, in: ders., Briefe. Gesamtausgabe, hg. v. der Klassik-Stiftung Weimar u.a. (Goethe- und 
über »Fratzen«, »Barbarei« und beklagt die »Nachlässigkeit solcher Mietlinge und Schw-!«. Über Breitkopf, in dessen Druckerei das Buch entstanden ist, schreibt Herder fassungslos: »Und der Mann will der erste Buchdrucker sein in Deutschland!!! ${ }^{157}$ Ein wenig mehr Verständnis bringt dem Handwerk der lange als Mitglied der Akademie der Wissenschaften in Berlin tätige Carl Denina entgegen:

»Wer weis, was Drucken heist, muß sich gar nicht über die Druckfehler wundern; aber vielmehr wird er sich wundern müssen, wie es so korrekt gedrukte Schriften geben könne. Eine jede Seite ist aus mehrern tausenden unzusammenhangenden Stücken zusammengesezt, die man auf tausenderley Art verwechseln kann [...]. $\ll^{158}$

Druckfehler berühren die entscheidenden und nicht selten heiklen Punkte der Debatten um Autorenrechte im 18. Jahrhundert. Das betrifft insbesondere den Nachdruck, und zwar nicht erst gegen Ende des Säkulums. In einer gelehrten Korrespondenz übersendet Thomasius eine Sammlung von Thesen, ergänzt um eine tabellarische Übersicht. Als er plötzlich »hiervon ein gedruckt Exemplar aus L. zugesendet [erhält]/in welchen mein Nahme vorgesetzet « ${ }^{159}$ ist, sieht sich der Gelehrte im Jahr 1701 zu einer Erklärung gezwungen. Thomasius erklärt nicht nur "öffentlich", dass dieser Druck ohne seine Zustimmung erfolgt sei, sondern zusätzlich, dass er »diese Schrifft wegen der vielen Druck-Fehler für die meinige nicht erkenne $\ll^{160}$.

Obwohl die Theoretiker der Autorschaft um 1800 den Geist über den Buchstaben stellen, erscheinen Errata nicht als zu vernachlässigende Akzidenzien des Buchdrucks. Sie weisen darauf hin, so Bernhard J. Dotzler, »daß auch Werke Des Geistes ihre Buchstäblichkeiten haben ${ }^{161}$. Johann Gottlieb Fichte knüpft das geistige Eigentum an die »eigenen Worte eines Schriftstellers ${ }^{162}$.

Schiller-Archiv), Weimar 1977-2016, IV (1979), S. 65-66 [49], hier: S. 65. Diese Angabe gilt auch für die nächsten beiden Zitate.

Ebd., S. 66.

Denina, Bibliopoeie, S. 407.

Christian Thomasius, „Christian Thomasens/Erinnerung/Wegen einer gedruckten Schrifft/Deren Titul: Christiani Thomasii Confessio Doctrinae Suae«, in: ders. (Hg.), Allerhand bißher publicirte Kleine Teutsche Schrifften, Halle 1701, S. 435-451, hier: S. 440.

Ebd., S. 441 [Setzfehler: S. 641].

Bernhard ]. Dotzler, Diskurs und Medium III: Philologische Untersuchungen. Medien und Wissen in literaturgeschichtlichen Beispielen, München 2011, S. 29.

Johann Gottlieb Fichte, Beweis der Unrechtmäßigkeit des Büchernachdrucks, Sämmtliche Werke, hg. v. J. H. Fichte, Berlin 1845ff., VIII (1846), S. 223-244, hier: S. 229. 
Bei einem von Schnitzern durchsetzten Text handelt es sich streng genommen nicht mehr um die »eigenen Worte« des Verfassers, aber auch nicht um solche, die ein anderer für sich beanspruchen würde. Daraus ergibt sich eine Reihe von Fragen: Wie ist es um die Werkherrschaft bestellt, solange die »eigenen Worte« dem Handwerk des Setzers unterworfen und fortgesetzt dem Risiko von Entstellungen unterworfen sind? Wem gehören Druckfehler? Welchen Status haben sie als Text, wenn niemand je beabsichtigt hat, den betreffenden Wortlaut so $\mathrm{zu}$ formulieren?

Solchen Fragen hat sich die Literatur häufiger gewidmet, in der Regel en passant und mit einer Neigung zur komischen Entstellung, etwa bei Riedel:

»Ich versichere nämlich auf das heiligste und schwöre, so wahr ich ein Autor bin, daß ich mir durchaus keinen Fehler werde vorwerfen lassen, er mag so gering sein, als er will und daß, wenn es aufs äusserste kommt und ich mir weiter nicht zu helfen weis, ich alle Schnitzer, die man in meinen Schriften finden wird, vor Druckfehler erklären und auf die Rechnung des Setzers schreiben werde. ${ }^{163}$

Über seine »Teufelspapiere«, die angeblich eine "Salve von Drukfehlern « ${ }^{164}$ (HKA III.1, 262) enthalten, schreibt Jean Paul am 27. Mai 1789 an Otto Richter: »Der einzige Mitarbeiter ist der Drukker, der seine Gedanken durch Drukfehler von sich gab. «(HKA III.1, 261) Bekannt ist der Kommentar des fiktiven Herausgebers in E.T.A. Hoffmanns »Kater Murr«, der erklärt: »Wahr ist endlich, daß Autoren ihre kühnsten Gedanken, die außerordentlichsten Wendungen, oft ihren gütigen Setzern verdanken, die dem Aufschwunge der Ideen nachhelfen durch sogenannte Druckfehler. ${ }^{165}$ Goethe hebt dagegen - anders als Hoffmann, bei dem die Fehler ins Werk übergehen, so dass nur »sogenannte Druckfehler « übrig bleiben - eine produktive Differenz hervor: »Ich denke immer, wenn ich einen Druckfehler sehe, es sei etwas Neues erfunden. « ${ }^{166}$

163 [Friedrich ]ustus Riedel], »Lies Ochse oder Anzeige der vornehmsten Druckfehler«, in: ders., Sieben Satyren, nebst drei Anhängen, gesammlet von N.N., [Jena] 1765, S. 337-351, hier: S. 341.

164 Das schreibt Jean Paul am 7. Juni 1789 an seinen Ceraer Verleger Christoph Friedrich Beckmann, der die »Auswahl aus des Teufels Papieren «nach einer langen Verzögerung in einer Auflage von 750 Exemplaren gedruckt hatte. Nach wenigen Jahren werden die unverkäuflichen Bücher zu Makulatur. (Fertig, »]ean Paul und seine Verleger«, S. 284)

165 Hoffmann, Lebens-Ansichten des Katers Murr, S. 13.

166 Johann Wolfgang von Goethe, Maximen und Reflexionen, Werke (Hamburger Ausgabe), hg. v. Erich Trunz, 7. Aufl., München 1964ff, XII (1973), S. 511 [1032]. 
Der Dichter verfasst auch eine Miszelle über »Hör-, Schreib- und Druckfehler« (1820).

Fest steht: Errata sind ein perpetuum mobile des Schreibens und Publizierens, auf einen Fehler folgt mit Sicherheit der nächste, wie die Vorrede zu Jean Pauls »Ergänzblatt« offenbart, in der »Herzeichniß « steht anstelle von »Verzeichniß $\ll^{167}$. Korrektheit erweist sich als ein angestrebtes, aber kaum zu verwirklichendes Ideal, da ein jeder Eingriff das Risiko in sich birgt, neue Fehler zu produzieren. Lichtenberg schlägt daher in seinen "Sudelbüchern« ein »Verzeichnis der Druckfehler in dem Druckfehler-Verzeichnis ${ }^{168}$ vor. Selten werden die Patzer freilich als das bezeichnet, was sie ursächlich sind, nämlich - so Friedrich Karl Gottlob Hirsching - »uebersehene Setzfehler « ${ }^{169}$. Jean Paul bezeichnet sie als »Setzfehler, Greif- oder Sehfehler« (SW I.5, 1286).

Goethe nennt als einen Grund für die Häufung von Errata die übliche »Entfernung des Verfassers vom Druckort « ${ }^{170}$. Cotta geht dazu über, die Bücher nicht am Verlagsort, sondern in der Nähe seiner Autoren herstellen zu lassen, damit der Korrekturprozess sich vereinfacht. ${ }^{171}$ Mit der räumlichen Distanz zwischen Schreibtisch und Setzkasten wächst die Bedeutung des Korrektors. Nicht wenige Autoren legen gesteigerten Wert darauf, in der Nähe der Druckerei lebende Kollegen für eine solche Aufgabe zu gewinnen oder gar die gesamte Herstellung überwachen zu lassen. Karl Wilhelm Ramler, der sich den »Ruf eines gnadenlosen Redaktors ${ }^{172}$ erworben hatte, wird häufig beauftragt, als »Aufseher und Corrector ${ }^{173}$ zu wirken, wenn in Berlin gedruckt wird. Johann Gottfried Seume, der für Göschen die Klopstock-Ausgaben korrigierte, formuliert im Anschluss ein bescheidenes Selbstlob:

167 Jean Paul, Ergänzblatt zur Levana. Sämmtliche Werke, Berlin 1826-1838, 38 (1827), S. 139178, hier: S. 152.

168 Lichtenberg, Schriften und Briefe, I, S. 317 (D 580).

169 Friedrich Karl Cottlob Hirsching (Hg.), Versuch einer Beschreibung sehenswürdiger Bibliotheken Teutschlands, Erlangen 1786-1791, IV (1791), S. 215.

170 Johann Wolfgang von Goethe, Hör-, Schreib-und Druckfehler. Sämtliche Werke (Frankfurter Ausgabe), hg. v. Friedmar Apel, Hendrik Birus, Anne Bohnenkamp u.a., Frankfurt a.M., Berlin 1987-2013, I.20 (1999), S. 450-454.

171 Fischer, Johann Friedrich Cotta, S. 90.

172 Alexander Košenina, »Ein deutscher Horaz? Karl Wilhelm Ramler in der zeitgenössischen Rezeption«, in: Laurenz Lütteken, Ute Pott, Carsten Zelle (Hg.), Urbanität als Aufklärung. Karl Wilhelm Ramler und die Kultur des 18. Jahrhunderts, Göttingen 2003, S. 129152, hier: S. 129.

173 »Cleim an Ramler« (8. Februar 1749), in: Carl Schüddekopf (Hg.), Briefwechsel zwischen Gleim und Ramler, Tübingen 1906-1907, I (1906), S. 154-157 [80], hier: S. 156. 
»Ich halte es für eine meiner herkulischen Arbeiten, daß ich Klopstocks Oden noch so gemacht habe, wie sie gemacht worden sind; denn sie sind in jeder Rücksicht das schwerste Werk der Typographie in Hinblick auf Korrektheit, ausgenommen mathematisches Zahlenwerk. ${ }^{174}$ (Seume an Cöschen, 10. März 1799)

Um einen möglichst fehlerfreien Druck zu erreichen, greifen Verleger und Herausgeber bisweilen zu ungewöhnlichen Mitteln. Als Lichtenberg mit seinem Freund Dieterich die Edition der unveröffentlichten Schriften des Astronomen Mayer vorbereitet, bieten sie einem »in solchen Arbeiten sehr geübten Manne«, so Lichtenberg in seiner Vorrede, »nicht geringe Prämie für jeden Fehler, den er entdecken würde « ${ }^{175}$. Häufiger begegnet einem jedoch der Vorwurf organisierter Nachlässigkeit. Cotta hat den zweifelhaften Ruf, eine »ungeheure Menge an Druckfehlern« (in der Ausgabe von Herders Werken) $\mathrm{zu}$ produzieren und einen beachtlichen Wohlstand durch »seine miserabelen Ausgaben unserer guten Werke« erzielt zu haben. ${ }^{176}$

Einerseits scheint die Perfektion des Drucks das Ziel eines jeden Autors zu sein - ungeachtet der um 1800 uneinheitlichen Orthographie. Andererseits relativiert sich dieser Anspruch in der schriftstellerischen Praxis. Mangelt es doch nicht an Fehlerquellen handwerklicher Natur, die sich durch den unkontrollierbaren Markt der Nachdrucke vervielfachen. So lässt Goethe sich zur Überarbeitung seines »Werthers« für eine erste Werkausgabe eine Abschrift anfertigen. Als Vorlage dient ein unautorisierter Raubdruck des Berliner Verlegers Christian Friedrich Himburg. ${ }^{177}$ Hierbei handelt es sich, wie Bernhard Seuffert in der "Weimarer Ausgabe« beklagt, um den »nachlässigste[n] aller Nachdrucke ${ }^{178}$. Freilich betrifft dieses Urteil nicht nur die Druckfehler, sondern auch Texteingriffe - die bei Raubdrucken üblich sind. Darnton stellt in seiner »Wissenschaft des Raubdrucks« fest: »Bücher waren im 18. Jahrhundert

174 Zit. n. Friedrich Gottlieb Klopstock, Werke und Briefe. Historisch-kritische Ausgabe, hg. v. Horst Gronemeyer u.a., Berlin 1974ff., Abt. B, 10,2 (2003), S. 329. Siehe auch UngernSternberg, »Schriftstelleremanzipation«, S. 87.

175 Lichtenberg, Observationes, S. 65.

176 [Anonymus], »Ueber Cotta's erste Lieferung der v. Herder'schen Schriften«, in: Revisionsblatt zur Ceorgia (1806), 4, o.P.; [Ignaz Ferdinand Kajetan Arnold], Meine Wanderungen aus Schwaben durch die Maingegenden nach Thüringen und Sachsen im Frühjahr1810 und Sommer 1811, Erfurt 1811, S. 12, Hinweise bei Fischer, Johann Friedrich Cotta, S. 680 f.

177 Jochum, »Textgestalt und Buchgestalt«, S. 3of.

178 Johann Wolfgang Goethe, Goethes Werke (Weimarer Ausgabe), hg. im Auftrag der Großherzogin Sophie von Sachsen, Weimar 1887-1919, I.19 (1899), S. 327. 
ein fließendes Medium. Je größer ihre Popularität desto weniger sicher der Text. « ${ }^{179}$ Wie kann sich unter solchen Umständen die Idee eines feststehenden Textes durchsetzen? Christian Benne verweist auf Alvin Kernan, der eine "Drucklogik« ins Feld führt, aus der sich die "Vorstellung eines korrekten, idealen Texts, der auf ewig in eine permanente Form gebracht worden « ist, überhaupt erst ergibt. ${ }^{180}$ Wobei sich argumentieren lässt, dass es des Druckfehlers bedarf, der feststellbaren, unautorisierten Differenz, um eben diese Vorstellung zu etablieren.

Wie lassen sich indes die Fehlerquellen minimieren? Aus der Sicht etlicher Autoren des späteren 18. Jahrhunderts ist der Selbstverlag eine Antwort auf diese Frage. Ungern-Sternberg führt aus, worum es den meisten Schriftstellern geht, die über den Weg in die publizistische Eigenständigkeit nachdenken: Neben dem wirtschaftlichen Interesse ist es vor allem der Wunsch nach korrekteren Ausgaben ihrer Texte, der sie umtreibt. ${ }^{181}$ Somit erscheint der Selbstverlag angetrieben zu sein von einer Autorenschaft, die editorische Ziele verfolgt, die in der Herausgabe der eigenen Texte die einzige Möglichkeit sieht, eine ungestörte Werkherrschaft zu erlangen. Doch sollte man Errata nicht nur als Angriff auf die Werkherrschaft ansehen, im Gegenteil. Ihr Nachweis ist lesbar als Supplement, das Autorschaft bekräftigt. Bei gravierenden Schnitzern nutzen Drucker, wie Martin Boghardt ausführt, den Dienst der Buchbinder, um "Doppel- oder Einzelblätter, die sogenannten Cancellanda«, gegen korrigierte Druckseiten auszutauschen, die in der Fachsprache Cancels (Englisch) oder Cartons (Französisch) heißen und »den einzelnen Exemplaren beigelegt oder beigebunden « werden. ${ }^{182}$ Dass in Nach- oder Raubdrucken keine Kartons zu finden sind, dürfte, wie Boghardt vorsichtig anmerkt, »wohl doch charakteristisch sein für eine Gruppe von Drucken, die sozusagen per definitionem ohne die Mitwirkung des Autors entstehen ${ }^{183}$. Demnach wäre der verbesserte Druckfehler nicht nur ein lästiges Übel, sondern durchaus ein Baustein souveräner Autorschaft.

So verlangt Herder von seinem Verleger Hartknoch angesichts der erwähnten Schnitzer in der von Breitkopf gedruckten »Plastik«: »Besorge um

179 Darnton, Die Wissenschaft des Raubdrucks, S. 66.

180 Benne, Erfindung des Manuskripts, S. 162.

181 Ungern-Sternberg, »Schriftstelleremanzipation«, S. 90.

182 Martin Boghardt, Archäologie des gedruckten Buches, hg. v. Paul Needham, Wiesbaden 2008, S. 178.

183 Ebd., S. 179. 
Gotteswillen diese Druckfehlerliste $u$. treibe, dränge, stoße, daß ich wo möglich die übrigen Bogen bekomme, um wenigstens die Scandale draus zu ziehen $u$. hinten zu setzen. ${ }^{184}$ Mit »hinten zu setzen« dürfte Herder die Anlage eines Druckfehler-Verzeichnisses meinen. Es bietet eine der wenigen Möglichkeiten, nachträglich Korrekturen anzubringen. Magnus Wieland sieht im Druckfehler-Verzeichnis die Definition des Paratextes "nachgerade exemplarisch« erfüllt, bestimmt Genette dessen Formen doch als »Anhängsel, die ja einen auktorialen oder vom Autor mehr oder weniger legitimierten Kommentar enthalten « und im »Dienst einer besseren Rezeption des Textes « stehen. ${ }^{185}$ Nicht wenige Bücher enthalten eine »Nachricht an den Buchbinder mit teilweise komplizierten Anweisungen, die sich z.B. auf die Platzierung von Kupfern beziehen, und weiteren Mitteilungen. Sowohl die DruckfehlerVerzeichnisse als auch die »Nachrichten« haben einen unklaren Status. Sie werden oftmals gesondert geliefert oder diskret im Anschluss an den Text platziert, in den meisten Fällen aber nicht im Inhaltsverzeichnis erfasst oder durch eine Seitenzahl auffindbar gemacht. Auf diese Exterritorialität spielt auch Riedel an, wenn in seinem Satirenband von 1765 der Text »Lies Ochse oder Anzeige der vornehmsten Druckfehler. Nebst einer Einleitung zur Sphalmatologie« als »Dritter Anhang « am Ende des Buches steht, als Einleitung zur tatsächlichen Auflistung der Errata, die zwar keine Seitenzahl mehr erhält, dafür aber auf Seite 350 durch einen Kustos klar platziert wird. ${ }^{186}$

Druckfehler-Verzeichnisse weisen dem Rezipienten eine aktive Rolle $\mathrm{zu}$. Nicht selten werden die Leserinnen und Leser aufgefordert, vor der Lektüre den Drucktext handschriftlich zu verbessern. Die Leser von Georg Andreas Gablers »System der theoretischen Philosophie« sollen nicht nur selbst Hand an den Text anlegen, sondern sie werden ferner darum gebeten, »kleine Versehen und Ungleichheiten der Orthographie [...] zu übersehen ${ }^{187}$. Somit bleibt es dem Rezipienten überlassen, darüber zu befinden, ob und in welchem Umfang er tätig werden muss. Hilfestellung bietet das Druckfehler-Verzeichnis durch eine Differenzierung der Errata, denn getilgt werden sollen bei Gabler

\footnotetext{
184 Herder, »An Johann Friedrich Hartknoch, Weimar, Mitte Mai 1778«, S. 66.

185 Magnus Wieland, »Der Satz der Sätze. Praxis und Poesis des Schriftsetzers«, in: Cornelia Ortlieb, Tobias Fuchs (Hg.), Schreibekunst und Buchmacherei. Zur Materialität des Schreibens und Publizierens um 1800, Hannover 2017, S. 171-195, hier: S. 181; Gérard Genette, Paratexte. Das Buch vom Beiwerk des Buchs, Frankfurt a.M. 1989, S. 10.

186 [Riedel], »Lies Ochse oder Anzeige der vornehmsten Druckfehler«, S. 350.

187 Georg Andreas Gabler, System der theoretischen Philosophie, Erlangen 1827, I, S. 447.
} 
»insbesondere die mit einem Sternchen bezeichneten sinnentstellenden oder sinnerschwerenden Druckfehler ${ }^{188}$, während andere lässlich sind.

Mitunter wird auch in Rezensionen auf angeblich gravierende Druckfehler hingewiesen, so im "Leipziger Jahrbuch der neuesten Literatur vom Jahre 1801 « gegen Ende einer ausführlichen Besprechung von Johann Gottlieb Fichtes "Sonnenklarem Bericht an das grössere Publikum über das eigentliche Wesen der neuesten Philosophie ${ }^{189}$. Hier wird ein Fehler angezeigt, »welcher den populären Leser irre und ungewiss machen könnte «, da nämlich auf Seite 73 , letzte Zeile, »statt unmittelbare, mittelbare zu lesen sey«. Abschließend heißt es: »Die übrigen Druckfehler verbessern sich beym Lesen mit gewöhnlicher Aufmerksamkeit, von selbst. ${ }^{190}$ Kurioserweise wird diese Schrift Fichtes im Nebentitel ausgewiesen als »Versuch, die Leser zum Verstehen zu zwingen«. Dass sich die Errata keineswegs »von selbst « verbessern müssen, ist in der Rezension nur angedeutet, wenn als Voraussetzung eine Lektüre »mit gewöhnlicher Aufmerksamkeit « genannt wird, wobei ferner zu berücksichtigen ist, dass Fichte seine Publikation »an das grössere Publikum « richtet, weshalb die in der Rezension angezeigte Korrektur auch vor allem dem »populären Leser« helfen soll.

Anders als die Philosophie verfügt die Literatur buchstäblich über mehr Spielraum im Umgang mit Druckfehlern. Jean Pauls »Ergänzblatt zur Levana« hat bereits Erwähnung gefunden. Barbara Hunfeld befasst sich mit der Übersicht der Druckfehler in der Erstausgabe des »Hesperus«, welche Jean Paul mit folgendem Hinweis versieht: »Da ich selber die Unart habe, daß ich mich um das Verzeichniß fremder Errata nicht im Geringsten bekümmere: so hoff' ich vom Leser auch nichts besseres: und dann werden folgende Druckfehler ganzen halben Seiten den Sinn nehmen.«Hunfeld betont, dass die angezeigten »Fehler gewichtig« seien. ${ }^{191}$ Sie sieht den »lässigen Habitus des Autors«

188 Ebd.

189 Johann Gottlieb Fichte, Sonnenklarer Bericht an das grössere Publikum über das eigentliche Wesen der neuesten Philosophie, Berlin 1801.

190 [Anonymus], Rez.»Berlin, in der Realschulbuchhandlung: Sonnenklarer Bericht an das grössere Publikum über das eigentliche Wesen der neuesten Philosophie«, in: Leipziger Jahrbuch der neuesten Literatur vom Jahre 18014 (1802), Sp. 237-255, hier: Sp. 255.

191 Barbara Hunfeld, »Die Autographen sind schuld. Jean Pauls (un)absichtliche Errata", in: Jochen Golz, Manfred A. Koltes (Hg.), Autoren und Redaktoren als Editoren, Tübingen 2008, S. 204-214, hier: S. 206. Das Zitat von Jean Paul ist zu finden in: Hesperus, oder 45 Hundsposttage. Eine Biographie. Erstes Heftlein, Berlin 1795, unpaginiert, laut Hunfeld »an Seite 392, der letzten Textseite des Bandes, angeklebt« (Ebd., Fn. 6). 
Abbildung 5: Druckfehler-Verzeichnis aus Jean Paul, »Hesperus, oder 45 Hundsposttage. Erstes Heftlein«, Berlin 1795.

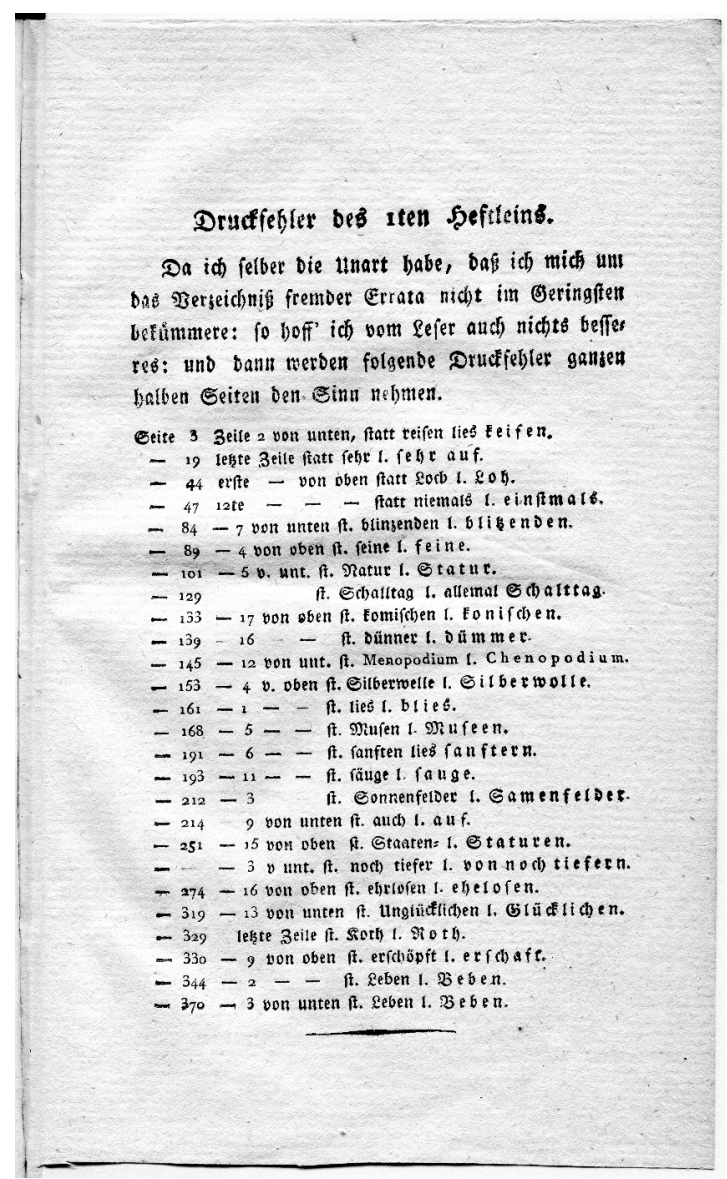

BBAW, 2007 B 209.

relativiert durch eine Anweisung, die sich im Fettdruck unterhalb der Errata findet und sich, so Hunfeld, an den »Leser oder vielmehr dessen Buchbinder« 
richte. ${ }^{192}$ Diese lautet: "Druckfehler müssen vorn vor jeden Band kommen.« Also möglichst prominent platziert werden. Tatsächlich seien die Korrekturen, wie Hunfeld beobachtet, aber »unpaginiert, ganz hinten angefügt « worden. In ihrem Aufsatz dokumentiert Hunfeld, wie Jean Paul die Druckfehler in den folgenden Ausgaben kommentiert, wobei er jeweils darauf reagieren muss, dass in der zweiten Auflage längst bekannte Errata versehentlich stehenbleiben - und bis zur dritten neue hinzukommen. In eben dieser dritten Auflage, erschienen 1819, leitet Jean Paul die Korrekturen mit den Worten ein:

»Da mir die Druckfehler der ersten Auflage Anlaß zur Aufstellung der kleinen Thesis gaben, daß sogar ich selber, der Autor möge bitten wie er wolle, nie seine Druckfehler vor dem Lesen änderte, und daß ich mir daher von meinen Lesern gleichfalls nichts Besseres verspräche: so hab' ich, damit die Thesis nicht umkäme, statt der vorigen Druckfehler in der ersten und in der zweiten Auflage, einige leichte neue in der dritten absichtlich setzen lassen. ${ }^{193}$

Hunfeld beschreibt dies als »Ironisierung des Dilemmas ${ }^{194}$. Sie argumentiert:

»Was die Hoheit des Verfassers über seinen Text durchkreuzt, wird fiktional entkräftet. Mit ihren eigenen Mitteln sucht die Literatur sich anzueignen, was sie überformt. Erschriebene Selbstermächtigung hebt die Ohnmacht gegenüber der Kontingenz der Rahmenbedingungen auf. Indem selbst Setzerfehler Anlaß zum literarischen Spiel geben können, treibt die Kontingenz das Schreiben weiter an. ${ }^{195}$

Mit aktiven Lesern rechnet auch Jean Pauls Quintus Fixlein, der sich der von Lichtenberg bemerkten »registerartige[n] Gelehrsamkeit « ${ }^{196}$ mehr als verdächtig macht, weil es sich bei einem seiner »Hauptwerke« um eine »Sammlung der Druckfehler in deutschen Schriften« (SW I.4, 81) handelt. Dabei werden die Fehler zwar registriert, aber darüber hinaus keinen gelehrten Operationen unterzogen oder gar hermeneutisch ausgedeutet, »er verglich die Errata untereinander, zeigte, welche am meisten vorkämen,

192 Hunfeld, »Die Autographen sind schuld«, S. 206. Die Angabe gilt auch für die folgenden Zitate.

193 Zit. n. Hunfeld, »Die Autographen sind schuld«, S. 207.

194 Ebd.

195 Ebd., S. $207 f$.

196 Lichtenberg, Schriften und Briefe, I, S. 271 (D 255). 
bemerkte, daß daraus wichtige Resultate zu ziehen wären, und riet dem Leser, sie zu ziehen « (Ebd.). Dennoch scheint die Romanfigur umzusetzen, wofür Riedel bereits 1765 scherzhaft geworben hat: eine »Sphalmatologie«, abgeleitet - so Magnus Wieland - von »sphalmata typographica«, also der griechischen Bezeichnung für Druckfehler. ${ }^{197}$

Um 1800 erlebt nicht nur der Buchmarkt eine Expansion, auch die Anzahl an Titeln, die sich der Herstellung von Büchern in allen ihren Facetten widmen, nimmt zu. Mit den »Formatbüchern« der Drucker existiert bereits eine Fachliteratur, die nun in Lehr- und Handbücher integriert und einem größeren Publikum zugänglich gemacht wird. Hinzu kommt der Ansatz, mit solchen Publikationen potenziell alle Büchermacher anzusprechen. Das zeigt das Beispiel des Leipziger Verlegers Christian Gottlob Täubel, dem die Aufgabe zufällt, das 1743 von Christian Friedrich Gessner herausgegebene Einführungswerk »Der in der Buchdruckerei wohl unterrichtete Lehrjunge« $\mathrm{zu}$ erneuern. Täubel tut dies mit seinem »Praktischen Handbuch der Buchdruckerkunst für Anfänger « (1791). Im Jahr 1785 hat er bereits ein »Orthotypographisches Handbuch« verfasst, das, so die ALZ, eher »für Buchhändler, Correctoren und Schriftsteller ${ }^{198}$ gedacht ist. 1810 veröffentlicht er schließlich ein »Neues theoretisch-practisches Lehrbuch der Buchdruckerkunst für angehende Schriftsetzer und Drucker in den Buchdruckereyen«, in dem er aber die Autoren nicht unerwähnt lässt. »Es ist freylich eines jeden Schriftstellers Schuldigkeit, seine zum Drucke bestimmte Manuscripte nicht allein leserlich und deutlich, sondern auch grammatisch richtig, oder nach den Regeln der Rechtschreibekunst, zu schreiben - allein die tägliche Erfahrung lehrt, daß dieses nur sehr selten geschieht ${ }^{199}$, tadelt Täubel vor dem Hintergrund der eigenen verlegerischen Praxis.

Gleich in drei Auflagen (1792/94/99) erscheint Ernst Wilhelm Gottlieb Kirchers Handreichung zum »Gebrauch der Zeichen welche in den Buchdruckereien zum Korrigiren gewöhnlich sind«, eine »Kleinigkeit«, so Kircher, die sich an »angehende Schriftsteller und Korrektoren ${ }^{200}$ richtet. Bemerkens-

197 Wieland, »Der Satz der Sätze«, S. 182.

198 [Anonymus], Rez. »Leipzig in der Müllersch. Buchh.: Praktisches Handbuch der Buchdruckerkunst«, in: Allgemeine Literatur-Zeitung 2 (1792), Nr. 161 (22. Juni 1792), Sp. 605606, hier: Sp. 605.

199 Christian Gottlob Täubel, Neues theoretisch-practisches Lehrbuch der Buchdruckerkunst für angehende Schriftsetzer und Drucker in den Buchdruckereyen, Leipzig 1810, S. 156.

200 Ernst Wilhelm Gottlieb Kircher, Gebrauch der Zeichen welche in den Buchdruckereien zum Korrigiren gewöhnlich sind, Braunschweig 1792, S. [7]. 
wert an dem Bändchen ist vor allem der Abdruck gängiger Drucktypen zur »Erlangung einiger Schriftkenntnis ${ }^{201}$. Kircher ist selbst vom Fach, ein Geschäftspartner von Johann Heinrich Campe, für dessen Schulbuchhandlung in Braunschweig er eine Druckerei einrichtet und auch betreibt. Die Schulbuchhandlung gehört auch zu den wenigen Abnehmern der in Deutschland von Friedrich Unger im Alleinvertrieb gehandelten Lettern von Didot. ${ }^{202} 1793$ gibt Kircher außerdem eine vielfach gelobte »Anweisung in der Buchdruckerkunst, zum Unterricht für Drucker und Lehrlinge« heraus, er hat also alle im Blick, die an der Herstellung eines Buches beteiligt sind. Diesen Anspruch überträgt Kircher durch seine Korrekturanleitung auf die Autoren. Sie sollen vertraut sein mit den Abläufen in der Produktion, vor allem aber in der Lage, sich an diesen zu beteiligen - und nicht nur über Fehler zu klagen. Weshalb Kircher für sie eine »Kenntnis der Korrekturzeichen ebenso nöthig« erachtet wie für den Setzer. ${ }^{203}$

\subsection{Wem gehört das Buch? Geistiges Eigentum und Buchmaterialität}

Jean Paul gilt als erster freier Autor der deutschsprachigen Literatur. Er lebt von seinen Büchern und gehört somit zum "schriftstellerischen Stand, der bei uns der mittlere und also der ärmere ist« (SW II.3, 498), wie der Betroffene selbst anmerkt. Umso erstaunlicher ist es, dass ausgerechnet er die jahrzehntelangen Auseinandersetzungen um den unautorisierten Büchernachdruck lange aus der Halbdistanz verfolgt. Schließlich rührt das, was häufig als »Raubdruck" gebrandmarkt wird, auch an seinen Einkünften. Erst 1815 veröffentlicht Jean Paul »Sieben letzte oder Nachworte gegen den Nachdruck« im »Morgenblatt für gebildete Stände«. Darin bezeichnet er die Nachdrucker als "Spitzbuben" (SW II.3, 493) und bedient sich auch ansonsten einer Rhetorik, welche ex negativo eine Denkfigur verfestigt, die um 1800 grundlegend ist für die Rechtsform der Autorschaft. Es handelt sich um die Figur des geistigen Eigentums, die stets die Frage aufwirft, in welchem Verhältnis diese Spielart der Proprietät zum gedruckten Buch steht. In den »Nachworten« bemerkt Jean Paul in einem historisierenden Gestus, gerade das Eigentumsrecht

201 Ebd.

202 Killius, Die Antiqua-Fraktur-Debatte, S. 267.

203 Kircher, Cebrauch der Zeichen, S. [7]. 
schwanke unter Völkern und Zeiten am meisten, wenn es nicht »umschränkende Gesetze« befestigten. (SW II.3, 514) Weiter fährt der Schriftsteller fort:

»Wo müssen aber solche magnetische Abweichungen der Cewissenzeignadel am stärksten und dauerhaftesten sich zeigen als über den Bücherdruck, da dessen Erfindung so spät hinter alle alte römische und deutsche Cesetzgebungen fiel, daß diese für ihn nur in gezwungen Anwendungen zu nützen sind, wie etwa Luftschiffe und Flugmaschinen - wenn sie vollendet in den Gang kommen - sich anfangs über alle bisherigen Gesetze erheben werden!« (SW II.3, 514)

Jean Paul begründet die »Abweichungen der Gewissenzeignadel« in der Nachdruckdebatte mit der Ungleichzeitigkeit von Rechts- und technologischer Entwicklung. In seiner Argumentation kommt die »Erfindung« des Buchdrucks »so spät«, dass die bestehenden Gesetze zum einen keine ethische Orientierung bieten, zum anderen "nur in gezwungenen Anwendungen« eine Wirksamkeit erlangen. Um die historische Lücke zu markieren, stellt Jean Paul den Buchdruck vergleichsweise in eine Reihe mit »Luftschiffe[n] und Flugmaschinen«, technischen Zukunftsphantasien, die um 1800 greifbar erscheinen. Diese Innovationen sieht Jean Paul metaphorisch sich »über alle bisherigen Gesetze erheben«, jedenfalls »anfangs« - was im Grunde nicht anders klingt als ein Kommentar zur »disruptiven« Kraft der Digitalisierung im 21. Jahrhundert. Trotz dieser eingehenden Erörterung formuliert der Berufsschriftsteller eine klare Forderung: »Wir brauchen also neue und allgemeine Sicherheitsgesetze für das Büchereigenthum.«(SW II.3, 514)

Eine Praxeologie der Autorschaft darf die von Jean Paul bemühte Rechtsgeschichte nicht unbeachtet lassen. ${ }^{204}$ Gerhard Lauer würdigt das 18. Jahrhundert als »Jahrhundert des Urheberrechts ${ }^{205}$. Eingeläutet wird diese Epoche durch das 1710 vom britischen Parlament verabschiedete "Statute of Anne«. Das Gesetz gewährt Autoren für einen begrenzten Zeitraum die Freiheit und das alleinige Recht zum Druck ihrer Bücher. Auf diese Kodifikation lässt sich die angloamerikanische Rechtstradition des »Copyright« zurückführen.

204 Zum Folgenden vgl. Tobias Fuchs, Art. »Urheberrecht«, in: Joseph Vogl, Burkhardt Wolf (Hg.), Handbuch Literatur und Ökonomie, Berlin 2020, S. 305-308.

205 Gerhard Lauer, »Offene und geschlossene Autorschaft. Medien, Recht und Topos von der Cenese des Autors im 18. Jahrhundert«, in: Heinrich Detering (Hg.), Autorschaft. Positionen und Revisionen, Stuttgart, Weimar 2004, S. 461-478, hier: S. 461. 
Aber sie verweist auch auf die historische Konstellation, die im deutschsprachigen Raum zur diskursiven Formation von Autorenrechten führt. Im Mittelpunkt dieser Konstellation stehen Bücher als Artefakte statt als Medien geistiger Produktivität. Die Rechtsentwicklung konzentriert sich auf das Eigentum an Objekten aus Papier und Druckerschwärze, selbst dann, wenn der Geist des Urhebers beschworen wird.

In diesem Unterkapitel soll es um die Frage gehen, welche Bedeutung das Buchartefakt im Hinblick auf das »juristische Autorenmodell ${ }^{206}$ hat, welches sich im 18. Jahrhundert entwickelt und in der Moderne durchsetzt. Die Propertisierung von Autorschaft bildet die Grundlage dieses Modells. Sie erfolgt über die Denkfigur des geistigen Eigentums. Hannes Siegrist begreift geistiges Eigentum »als ein Bündel sozialer, kultureller und rechtlicher Handlungsregeln und Handlungsrechte, wodurch Rollen, Beziehungen und Praxisformen des kulturellen und wissenschaftlichen Feldes bestimmt sind «. ${ }^{207}$ Diese »Handlungsregeln und Handlungsrechte« beziehen sich auf den Umgang mit der Materialität von gedruckten Texten, mit einem normativen Anspruch. Daraus folgt, dass die sozialen Praktiken der Autorschaft in einem erheblichen Maße durch das Recht geformt werden.

1726 spricht Nicolaus Hieronymus Gundling zeitgenössischen Autoren »in Ansehung ihrer eigenen Gedanken« zwar ein »Eigentum« zu. Trotzdem steht für den Rechtsgelehrten außer Frage, dass "Dominus des Buches« der Verleger ist. Er habe den "Schaden, wann ihme die Chartequen übrig bleiben und zu Makulatur, oder Pfeffer-Teuten werden ${ }^{208}$. Anlass zu dieser Erörterung gibt ein älteres Phänomen, das ab der zweiten Hälfte des 18. Jahrhunderts als Katalysator auf dem Weg zum modernen Urheberrecht wirkt: der unautorisierte Büchernachdruck.

Bis weit ins 19. Jahrhundert existiert mit dem Druckprivileg nur ein einziger, allgemein als unzureichend angesehener Schutz gegen diese Praxis, die

206 Fotis Jannidis, Gerhard Lauer, Matias Martinez, Simone Winko, »Rede über den Autor an die Gebildeten unter seinen Verächtern. Historische Modelle und systematische Perspektiven«, in: dies (Hg.), Rückkehr des Autors. Zur Erneuerung eines umstrittenen Begriffs, Tübingen 1999, S. 3-35, hier: S. 7.

207 Hannes Siegrist, »Geschichte des geistigen Eigentums und der Urheberrechte. Kulturelle Handlungsrechte in der Moderne«, in: Jeanette Hofmann (Hg.), Wissen und Eigentum. Geschichte, Recht und Ökonomie stoffloser Güter, Bonn 2006, S. 64-80, hier: S. 64.

208 Nicolaus Hieronymus Gundling, Rechtliches und vernunfftmäßiges Bedencken eines ICTI, der unpartheyisch ist, von dem schändlichen Nachdruck andern gehöriger Bücher, [Halle] 1726, S. $5,6$. 
ihre Gegner häufig als »Raubdruck «brandmarken. ${ }^{209}$ Reproduziert werden in der Regel nicht die Artefakte in ihrer konkreten Gestalt, nicht Papier, Format, Satz oder Typographie, sondern allein die Inhalte der betroffenen Titel. Weitgehend identisch sind die Nachdrucke ausschließlich in Bezug auf das, was Nelson Goodman die »Selbigkeit des Buchstabierens « ${ }^{210}$ nennt. Somit offenbart die inkriminierte Praxis die Besonderheit des Buches im Vergleich mit anderen Objekten: Es lässt sich nachmachen, ohne dem »Original« hinsichtlich seiner Materialität zu ähneln. Der Regelungsgehalt eines Druckprivilegs betrifft somit die technische Vervielfältigung eines Textes. Die Nachteile eines solchen Privilegs: Es handelt sich nicht um einen juristisch klaren und einklagbaren Anspruch, sondern um einen hoheitlichen Gnadenakt. ${ }^{211}$ Die Unwägbarkeiten der Gewährung und die territoriale Begrenzung des Druckprivilegs lassen es als fragwürdiges Instrument gegen den Nachdruck erscheinen.

Unter diesen Umständen entwickeln sich in Deutschland erste Ansätze eines Urheberrechts, und zwar in den Formulierungen eines geistigen Eigentums, die rechtliche, ökonomische, philosophische und produktionsästhetische Überlegungen aufgreifen. Geistiges Eigentum wird in dieser Vielschichtigkeit zum integralen Bestandteil eines Konzepts von Autorschaft, in dem die eigenen Gedanken zum exklusiven Produkt eines Individuums erhoben werden, um unabhängig zu sein von der Materialität genutzter Medien. Dieses Konzept beinhaltet in seinen Anfängen hauptsächlich eine vermögensrechtliche Zuordnung, die im 19. Jahrhundert um eine persönlichkeitsrechtliche Dimension erweitert werden wird. ${ }^{212}$ Für die frühe Akzentuierung steht in den Auseinandersetzungen um 1800 der Begriff des Eigentums, ungeachtet seiner recht variablen Herleitung. Heinrich Bosse hat den Kern besagten Konzeptes auf eine Formel gebracht, die in den Literaturwissenschaften allgemein anerkannt ist: "Autorschaft ist Werkherrschaft«. Neben die von Bosse in urheberrechtlichen Entwürfen des späten 18. Jahrhunderts beobachtete »Analyse

209 Vgl. Elmar Wadle, »Der langsame Abschied vom Privileg: Das Beispiel des Urheberrechts«, in: ders., Geistiges Eigentum. Bausteine zur Rechtsgeschichte, München 1996ff., II (2003), S. 101-116.

210 Goodman, Sprachen der Kunst, S. 115.

211 Volker]änich, Geistiges Eigentum-eine Komplementärerscheinung zum Sacheigentum?, Tübingen 2002, S. 32.

212 Elmar Wadle, »Entwicklungsschritte des Geistigen Eigentums in Frankreich und Deutschland«, in: Hannes Siegrist, David Sugarman (Hg.), Eigentum im internationalen Vergleich. 18.-20. Jahrhundert, Göttingen 1999, S. 245-263, hier: S. 258. 
der Mitteilung ${ }^{213}$ ist eine Analyse des Buches zu setzen, die dessen Materialität auch deshalb nicht ausschließt, weil die Frage des geistigen Eigentums immer auch vom Artefakt abhängt.

Aufschlussreich sind viele Ansätze zu einer Theorie geistigen Eigentums deshalb, weil sie jeweils als Theorie des Buches lesbar sind. So zieht sich wie ein roter Faden eine Frage durch die Nachdruckdebatte: Was ist das Wesentliche eines Buches? Ist es bedrucktes Papier, also das Medium in seiner Materialität, sind es die Gedanken, die ein Buch enthält, oder doch eher die Formulierungen, in denen sie fixiert werden?

Mit der »Werkherrschaft« (Bosse) erlangen Autoren eine ungekannte Rechtsposition. Ihr lange ungelöstes Problem: Bücher sind im Grunde keine Texte, sondern handwerklich hergestellte Produkte, an deren Finanzierung, Herstellung und Vermarktung die Verfasser der abgedruckten Texte nur mittelbar beteiligt sind. 1773 verschreibt sich Klopstock vor diesem Hintergrund dem Modell des Selbstverlags, durch das Autoren »Eigenthümer ihrer Schriften« werden sollen. "Denn jetzt sind sie dies nur dem Scheine nach", wie Klopstock beklagt. ${ }^{214}$ Die gewählte Formulierung erinnert nicht bloß an den »Dominus des Buches«, wie Gundling ihn ein halbes Jahrhundert früher definiert. Sie entspricht ihm vollumfänglich.

Tatsächlich sieht die Realität bis zum Ende des 18. Jahrhunderts in der Regel so aus: Autoren veräußern mit ihren Manuskripten das Verlagsrecht. In einem Vertrag von 1737 ist davon die Rede, dass dem Verleger und dessen Erben die »freye Macht und Gewalt bleibet mit dem $\mathrm{Ms}^{\text {cto }}$ als ihren [sic!] erworbenen Erbe und Eigenthume zu verfahren wie Sie belieben ${ }^{215}$ An diesem Beispiel lässt sich eine begriffliche Unschärfe beobachten, die bis in Rechtstexte des 19. Jahrhunderts zu verfolgen ist. Sie führt zu der Frage: Ergibt sich das Verlagsrecht aus dem Sacheigentum der Handschrift oder aus einer weiteren Übereinkunft zwischen Autor und Verleger ${ }^{216}$ Für den ersten Ansatz

213 Heinrich Bosse, Autorschaft ist Werkherrschaft. Über die Entstehung des Urheberrechts aus dem Ceist der Goethezeit (1981), Paderborn 2014, S. 45.

214 Zit. n. Pape, Klopstocks Autorenhonorare, Sp. 103.

215 [A. Kirchhoff], »Ein Verlags-Contract vom Jahre 1737«, in: Archiv für Ceschichte des Deutschen Buchhandels 1 (1878), S. 195-197, hier: S. 196. Siehe auch Harald Steiner, Das Autorenhonorar-seine Entwicklungsgeschichte vom 17. bis 19. Jahrhundert, Wiesbaden 1998, S. $63 \mathrm{ff}$.

216 Vgl. Walter Bappert, Wege zum Urheberrecht. Die geschichtliche Entwicklung des Urheberrechtsgedankens, Frankfurt a.M. 1962, S. $225 f$. 
spricht ein im Dezember 1771 von Lessing formuliertes Angebot an den Verleger Christian Friedrich Voß, in dem ausdrücklich nicht von Proprietät die Rede ist. Allerdings leitet der Schriftsteller geradezu selbstverständlich ein Recht zur Publikation aus der Verfügung über fremde Papiere ab. Der verschuldete Lessing bewirbt ein Manuskript, »wovon ich, zwar nicht selbst Verfasser, aber der einzige Besitzer bin ${ }^{217}$. Immanuel Kant stellt Mitte der Achtzigerjahre des 18. Jahrhunderts fest:

»Das Exemplar, wornach der Verleger drucken läßt, ist ein Werk des Autors (opus) und gehört dem Verleger, nachdem er es im Manuscript oder gedruckt erhandelt hat, gänzlich zu, um alles damit zu thun, was er will, und was in seinem eigenen Namen gethan werden kann; denn das ist ein Erforderniß des vollständigen Rechtes an einer Sache, d.i. des Eigenthums. « ${ }^{218}$

Aus dem Jahr 1773 stammt der vom berüchtigten Verleger Philipp Erasmus Reich mittels einer anonymen Publikation geführte Angriff auf Klopstocks »Gelehrtenrepublik«. Der Kopf der »Weidmannschen Buchhandlung« bestreitet, was der Dichter als Problem benennt: dass Autoren den Buchhändlern überlassen müssen, was ihnen zugehört:

»Ihr Eigentum? Dieß wird Ihnen kein Mensch streitig machen. Sie sind, wie jeder Kaufmann über seine Waare, so Herren über Ihre Handschriften, und will der Käufer nicht ihre Bedingungen eingehen, so wird kein Buchhändler Ihnen dieselben mit Gewalt zu entreissen wagen. ${ }^{219}$

217 Gotthold Ephraim Lessing, »Brief an Christian Friedrich Voß« (6. Dezember 1771), in: Werke und Briefe, hg. v. Wilfried Barner u.a., Frankfurt a.M. 1984-2003, 11/2 (1988), S. 278f. [744], hier: S. 279. Lessing soll Voß die Handschrift bereits im September 1771 offeriert haben, eine Veröffentlichung jedoch an der Zensur gescheitert sein (Wolfgang Albrecht, Lessing. Cespräche, Begegnungen, Lebenszeugnisse, Kamenz 2005, S. 268f., ders., Lessing. Chronik zu Leben und Werk, Kamenz 2008, S. 79). Es handelt sich um das Manuskript, das im Druck später unter dem Titel »Von Duldung der Deisten. Fragment eines Ungenannten erscheinen und Gegenstand des sogenannten Fragmentenstreits wird, siehe dazu die Anmerkungen in Gotthold Ephraim Lessing, Werke und Briefe, hg. v. Wilfried Barner u.a., Frankfurt a.M. 1984-2003, 8 (1989), S. 841-856, sowie Monika Fick, Lessing-Handbuch. Leben-Werk-Wirkung, Stuttgart, Weimar 2000, S. 344-346.

218 Immanuel Kant, Von der Unrechtmäßigkeit des Büchernachdrucks, Gesammelte Schriften, hg.v. der Königlich Preußischen Akademie der Wissenschaften, Berlin 1902ff., VIII (1912), S. 77-87, hier: S. 84.

219 [Philipp Erasmus Reich], Zufällige Gedanken eines Buchhändlers über Herrn Klopstocks Anzeige einer gelehrten Republik, O.o. 1773, S. 11. 
Reich verschleiert an dieser Stelle, worum es unter Verwendung des Eigentumsbegriffs eigentlich geht: die dauerhafte Übertragung des Verlagsrechts. ${ }^{220}$ Klopstock erkennt im Selbstverlag die einzige Möglichkeit, Schriftstellern dieses Recht langfristig zu sichern. Wobei Reich als mögliche Reaktion auf die »Gelehrtenrepublik« eine »Republik der Buchhändler« ankündigt, welche als Kampfgemeinschaft »die brauchbaren Artikel sofort und noch correcter und schöner, als die Originale wären, nachdruckte, und sie dem Publico um die Hälfte des Preißes anböte «. ${ }^{221}$ Im Klartext: Im Schutze der Anonymität droht der berühmte Verlagsleiter den Selbstverlegern mit strategischem Nachdruck, einer Entfesselung von Marktkräften, die das in Frage stehende Autoreneigentum ökonomisch wertlos machen sollen.

Das Verhältnis zwischen dem Verlagsrecht als Gegenstand von Proprietät und der Materialität zu publizierender Manuskripte bleibt indes unklar. Noch im Badischen Landrecht (1809), das mit dem »Schrifteigenthum« einen eigenen Begriff für das einführt, was um 1800 als geistiges Eigentum diskutiert wird, bedarf es einer genauen Differenzierung: »Das Schrifteigenthum erstreckt sich nicht nur auf die Handschrift, sondern auch auf deren Inhalt; es enthält daher das Recht über die Vervielfältigung durch Abschrift oder Abdruck nach Gutfinden zu verfügen.« Entsprechend heißt es: »Wer eine Handschrift zum Abdruck für eigenen Verlag hingibt, begibt sich damit des Eigenthums in keinem Stück. ${ }^{222}$ Johann Nikolas Friedrich Brauer, der das Landrecht nach Vorbild des »Code civil« entworfen hat, merkt im Kommentar die Notwendigkeit einer »Rechtsdichtung« an:

»Indem das Schrifteigenthum nicht bei dem Eigenthum des Stoffes, worauf die Gedanken abgedruckt sind, stehen bleiben darf, weil damit allein dem Verfasser nicht gedient wäre [...], sondern hauptsächlich das Eigenthum der Gedanken in sich aufnehmen muß, kann es nur durch eine Rechtsdichtung zu Stande kommen, welche diesen innern und geistigen Gegenstand wie einen äußeren und sinnlichen behandelt $[. ..] . \ll^{223}$

Deutlich werden an allen genannten Stellen die Tücken des Eigentumsbegriffes. Geht es um die Geschichte des geistigen Eigentums, wird zu selten be-

220 Siehe Wittmann, Geschichte des deutschen Buchhandels, S. 153.

221 [Reich], Zufällige Gedanken eines Buchhändlers, S. 15.

222 Code Napoléon mit Zusäzen und Handelsgesezen als Land-Recht für das Großherzogthum Baden, Karlsruhe 1809, S. 161 ( 5777 db, § 577 dd).

223 Johann Nikolas Friedrich Brauer, Erläuterungen über den Code Napoleon und die Großherzoglich Badische bürgerliche Gesezgebung, Karlsruhe 1809f., I (1809), $469 f$. 
rücksichtigt, dass dessen Bestimmungen im 18. Jahrhundert keineswegs auf rechtlichen Standards aufbauen können. Sicherlich existiert eine vornehmlich durch das Römische Recht bestimmte Tradition, die Definition von Eigentum (dominium, proprietas) auf die absolute Verfügungsgewalt über Dingliches zu gründen. ${ }^{224}$ Bis weit in die Moderne wirkt die Formulierung des Rechtsgelehrten Bartolus aus dem 14. Jahrhundert nach, der zufolge dominium als »ius de re corporali perfecte disponendi nisi lege prohibeatur « aufzufassen ist, zu Deutsch: als Recht, über eine körperliche Sache vollkommen zu bestimmen, solange ein Gesetz dies nicht untersagt. ${ }^{225}$ Doch: Daneben entwickelt sich über Jahrhunderte ein schwer zu überschauendes Dickicht an handlungsbezogenen Übereinkünften, die ebenfalls Eigentum und Besitz betreffen. Entscheidend ist an dieser Stelle: Einen privatrechtlichen Rahmen erhält Eigentum im deutschsprachigen Raum erst 1756 durch die gesetzlichen Regelungen des »Codex Maximilianeus Bavaricus Civilis« und spätere Kodifikationen wie das "Allgemeine Preußische Landrecht « (1794). ${ }^{226}$ Damit lassen sich die differenten Ansätze zum geistigen Eigentum erklären. Jedoch ergeben sich die weitaus größeren Irritationen in der Begriffsgeschichte buchstäblich aus der Sache selbst, aus dem, was Ursula Rautenberg als »materiell definierte Differenz zwischen Text und Buch - oder zwischen geistigem Erzeugnis und gehandeltem Artefakt - « beschreibt, aus welcher sich die »Aporien des Buches « ergeben. ${ }^{227}$

Rekapitulieren wir die kulturgeschichtliche Konstellation: In der zweiten Hälfte des 18. Jahrhunderts entwickeln und verfestigen sich privatrechtliche Vorstellungen, zu denen ein Eigentumsbegriff gehört, der insbesondere die Ausschließlichkeit von Proprietät hervorhebt, mittels einer staatstragenden Rhetorik, die den Eigentümer zum Souverän erhebt. ${ }^{228}$ Selbstverständlich betrifft das auch Bücher. Für diese nun das zu reklamieren, was Bosse als »Werkherrschaft « bezeichnet, und zwar in Begriffen eines geistigen Eigentums, gestaltet sich nachvollziehbar schwierig. Nicht allein, dass in der römischen Rechtstradition ein Eigentum nur an körperlichen Gegenständen bestehen

224 Dieter Schwab, »Eigentum«, in: Otto Brunner, Werner Conze, Reinhard Koselleck (Hg.), Geschichtliche Grundbegriffe. Historisches Lexikon der politisch-sozialen Sprache in Deutschland, Stuttgart 1972-1997, II (1975), S. 65-115, hier: S. 70.

225 Vgl. Hendrikje Carius, Recht durch Eigentum. Frauen vor dem Jenaer Hofgericht (16481806), München 2012, S. 59.

226 Ebd., S. 57.

227 Rautenberg, Wetzel, Buch, S. 42.

228 Schwab, »Eigentum«, S. 76-79. Siehe auch Jänich, Geistiges Eigentum, S. 37. 
konnte. Vielmehr existierte mit dem im Auflagendruck hergestellten Buchartefakt ein eigentumsfähiges Objekt, womit ein intrikates Rechtsproblem zu lösen war: Ein geistiges Eigentum am Buch zu behaupten, das bedeutete nichts anderes, als dem Käufer eines Exemplars sein Eigentum zumindest im Ansatz streitig zu machen. ${ }^{229}$ Kant fasst die Problemlage prägnant zusammen, wenn er schreibt: »Der Autor und der Eigenthümer des Exemplars können beide mit gleichem Rechte von demselben sagen: es ist mein Buch! aber in verschiedenem Sinne. $\aleph^{230}$

Hinzu kommt mindestens ein weiterer Akteur: Um 1800 werden Bücher nicht bloß als Medien angesehen, deren Materialität transzendiert wird durch das geistige Werk eines Schriftstellers, sondern auch, wenn nicht gleichermaßen als Artefakte, aufwendig hergestellt aus kostbaren Ressourcen wie Papier, durch vieler Hände Arbeit. Und finanziert durch Verleger, die sich jeweils »Dominus des Buches« nennen dürfen - so die Formulierung bei Gundling. Autoren haben an der Produktion und Vermarktung ihrer Bücher einen überschaubaren Anteil. Zwar handeln sie im ausgehenden 18. Jahrhundert nicht selten die Auflagenhöhe und Ausstattung eines Titels aus, sie mahnen Korrekturen an, aber letztlich sind und bleiben sie mittelbar Beteiligte. Vor diesem Hintergrund besteht also die Herausforderung an den Ursprüngen des Urheberrechts darin, dem Autor eine Verfügung über etwas zuzuschreiben, das als Artefakt juristisch betrachtet niemals sein, sondern stets und uneingeschränkt Eigentum eines andern ist. Somit erweist sich das Buchartefakt als größtes Hindernis in der Begründung eines geistigen Eigentums.

Wie kompliziert die Gemengelage ist, zeigt sich unter anderem daran, dass sich in der Debatte um diese Sonderform des Eigentums ununterbrochen Deklarationen finden, die alle Beteiligten unterschreiben würden - zur jeweiligen Untermauerung ihrer widerstreitenden Meinungen. Den

229 Siehe dazu Ludwig Gieseke, Vom Privileg zum Urheberrecht. Die Entwicklung des Urheberrechts in Deutschland bis 1845, Baden-Baden 1995, S. 122. Eckhard Höffner schreibt dazu: »Die Möglichkeit, andere in ihrer Freiheit einzuschränken, war und ist der zentrale Cegenstand des geistigen Eigentums. « Vor diesem Hintergrund ist seine Lesart Kants zu verstehen, der sich auch zum Nachdruck einlässt und über den es bei Höffner heißt: »Das Recht, das Rechtsverhältnis und damit auch das Eigentum betrifft für Kant die Beziehung der Personen untereinander, nicht das einer Person zu einer Sache.« (Eckhard Höffner, Geschichte und Wesen des Urheberrechts, München 2010-2011, I (2010), S. 188, 187)

230 Kant, »Von der Unrechtmäßigkeit des Büchernachdrucks«, S. 86. 
Gegenstand der Auseinandersetzung bildet der um 1800 grassierende Nachdruck. Aufschlussreich ist, welche Rechtsposition von Befürwortern wie Gegnern exklusiver Autorenrechte beansprucht wird: die des Staatsbürgers. So formuliert z.B. Rudolph Zacharias Becker, der sich mit seinem »Nothund Hilfsbüchlein« als Volksaufklärer einen Namen gemacht hat und von dessen »Nachdruck, Verstümmelung und Verfälschung« betroffen ist: »Das Eigenthumsrecht ist eins der heiligsten Rechte, die der Staat dem Bürger gewähret. ${ }^{231}$ Becker verbindet mit dieser emphatischen Formulierung die Forderung nach einem entschiedenen Vorgehen des Staates gegen die umstrittene Verlagspraxis. Johann Gottlieb Fichte spricht sich im Briefwechsel mit Cotta pragmatischer für Druckprivilegien aus, »bis die Fürsten gelernt [haben], daß es ohne besondere Bitte ihre Pflicht ist, das Eigenthum des Bürgers zu schützen ${ }^{232}$. Dagegen mahnt der Hamburger Arzt und Ökonom Johann Albert Heinrich Reimarus: »Eigenthum - laßt uns doch dies wichtige Wort welches Obrigkeiten so wohl als Privatpersonen heilig sein sollte, nicht misbrauchen! « ${ }^{233}$ Er fügt hinzu: »Eigenthum, denke ich, gilt uneingeschränkt der Besizzer mag damit verfahren, wie er will, von einem Ende der Erde bis zum andern und von Zeit zu Zeit. $\aleph^{234}$ Nicht weniger emphatisch als Becker oder Fichte verteidigt Reimarus das Rechtsgut des Eigentums - das er durch die Einräumung von Autorenrechten theoretisch wie praktisch gefährdet sieht.

Einen tieferen Einblick in die zeitlich über Jahrzehnte gedehnte Nachdruckdebatte des späten 18. Jahrhunderts eröffnet eine Auseinandersetzung zwischen Fichte und Reimarus. Aus dem Nachlass seines Vaters Hermann Samuel Reimarus stammte jene Handschrift, die Lessing 1771 zur Begleichung seiner Schulden zum Verlag angeboten hatte (ehe er mit ihrer fingierten Veröffentlichung den »Fragmentenstreit« auslöste). Was bedeutet, dass der Hamburger mit komplizierteren Fragen der Autorschaft längst vertraut ist,

231 Rudolph Zacharias Becker, Das Eigenthumsrecht an Geisteswerken mit einer dreyfachen Beschwerde über das Bischöflich-Augsburgische Vikariat wegen Nachdruck, Verstümmelung und Verfälschung des Noth- und Hülfsbüchleins, Frankfurt a.M., Leipzig 1789, S. 39.

232 »Fichte an Johann Friedrich Cotta in Tübingen « (15. November 1795), in: Johann Gottlieb Fichte, Gesamtausgabe, Stuttgart-Bad Canstatt 1962-2012, III.2 (1970), S. 433-435 [328], hier: S. 435.

233 Johann Albert Heinrich Reimarus, »Der Bücherverlag in Betrachtung der Schriftsteller, der Buchhändler und des Publikums abermals erwogen«, in: Deutsches Magazin 1 (1791), S. 383-414, hier: S. 385.

234 Ebd., S. $385 f$. 
als er Fichte mit einer Verteidigung des Nachdrucks zum Widerspruch provoziert. 1793 veröffentlicht der Philosoph seinen »Beweis der Unrechtmäßigkeit des Büchernachdrucks«, ausdrücklich adressiert an Reimarus. ${ }^{235}$ Dieser hat zwei Jahre zuvor geschrieben: »Rechtsgelehrte und Philosophen haben sich um die Wette bemühet, [...] ein ausserordentliches, mit dem Verkauffe nicht veräussertes Eigenthumsrecht zu erkünsteln.« Und weiter: »Die Rechtsgelehrten nehmen ihre Zuflucht zu einer metaphysischen Spizfündigkeit, wenn sie sagen, das Geistes-Eigenthum (literary property) werde nicht mit der Materie des Buches dem Käuffer übertragen.« ${ }^{236}$

Der im »Deutschen Magazin« abgedruckte Aufsatz von Reimarus ist nicht dessen erster Debattenbeitrag. Der hanseatische Gelehrte, der seine wirtschaftliche Liberalität betont und sich selbst als »unpartheiisch ${ }^{237}$ ansieht, formuliert den Anspruch, jedes Einzelinteresse zu berücksichtigen, nicht zuletzt das des »Publikums «. Daher trägt sein Text auch den umfassenden Titel: »Der Bücherverlag, in Betrachtung der Schriftsteller, der Buchhändler und des Publikums abermals erwogen «. Aus der Sicht von Reimarus gibt es Konstellationen, in welchen der Nachdruck zu missbilligen ist, aber mit Blick auf die Eigentumsverhältnisse keinen Grund, diesen rechtlich zu verbieten. Bereits 1773 hatte Reimarus sich empört: "Man hat die Klagen über die Nachdrucker so weit getrieben, daß man sie öffentlich Diebe nennet, die andern Leuten ihr Eigenthum rauben. Ihr Eigenthum, meine Herren! $\aleph^{238}$ Schon damals hinterfragte er den zugunsten der Autoren eingeführten Eigentumsbegriff: »Bleibt das Buch, was Sie verkauft und dem Publikum überlassen haben, ihr Eigenthum? Kann ich es nicht, zu welchem Nutzen ich will, anwenden, es übersetzen, abschreiben oder abdrucken lassen? « «39 Im gewählten Singular (»das Buch«) deutet sich das von Joseph A. Dane beschriebene »Paradox der Singularität « an. ${ }^{240}$ In dieser Paradoxie verbinden sich zwei Seiten eines, mit Reimarus gesprochen: des Buches. Da wäre zum einen der an das jeweilige Artefakt gebundene Warencharakter (»verkauft»), zum anderen ein alle Exemplare miteinander verschmelzender Inhalt, der - so eine gängige Argumentation - durch die Veröffentlichung zum Gemeingut (»publici juris«)

235 Siehe auch Cieseke, Vom Privileg zum Urheberrecht, S. $176 f$.

236 Reimarus, »Der Bücherverlag ... abermals erwogen«, S. 384.

237 Ebd., S. 414.

238 [Johann Albert Heinrich Reimarus], Der Bücherverlag in Betrachtung der Schriftsteller, der Buchhändler und des Publikums, Hamburg 1773, S. $18 \mathrm{f}$. 
wird. Darauf deutet die Formulierung »dem Publikum überlassen« hin. Jedoch: Veräußert wird das Buch nicht an ein kollektives »Publikum«, sondern Exemplar für Exemplar an einzelne Interessenten. Wenn Reimarus die Konjunktion »verkauft und dem Publikum überlassen« gebraucht, verbinden sich zwei tendenziell gegenläufige Konzepte: Privateigentum und Öffentlichkeit.

Eigentumsfähig sind Bücher aufgrund der Materialität eines jeden Exemplars, und zwar in einem exklusiven Sinn. Dagegen erwächst Publizität aus der freien Verfügung über Inhalte und deren Weitergabe - durch die Verbreitung möglichst vieler Abdrucke (in Privateigentum), aber auch vermittels reproduzierender Wissenspraktiken. Sowohl »anwenden«, »übersetzen« als auch »abschreiben« lassen sich solchen Praktiken zurechnen, denen gemeinsam ist, dass sie eine Distribution von Wissen bezwecken. Unter den Befürwortern des Büchernachdrucks finden sich nicht wenige, die in dieser Verlagspraxis denselben Zweck und daher einen Akt der Aufklärung erkennen. Reimarus argumentiert in eine ähnliche Richtung, jedoch so, dass er den Nachdruck (»abdrucken«) in eine Reihe mit anderen Wissenspraktiken stellt und durch den Kauf eines Exemplars als legitimiert ansieht. Dieser Linie folgt Reimarus auch zwanzig Jahre später, wenn er sich - konkret bezogen auf den Popularphilosophen Johann Georg Heinrich Feder, der sich für ein buchspezifisches Eigentum und dessen einschränkbare Übertragung ausgesprochen hatte - gegen ein »philosophisches Handelsgesez« wendet. »Wir müssen also wohl gestehen«, so Reimarus, »daß eine solche reservatio, welche ipso facto der Handlung des öffentlichen Verkaufs, und besonders der Bekanntmachung eines litterarischen Werks widerspricht, wenn sie auch ausdrücklich beigefügt wäre, keine Statt findet. «241 Zusammenfassend kommt Reimarus zum Schluss,

»1) daß weder Verfasser noch Verleger ein Recht des bleibenden Eigenthums oder des einzuschränkenden Cebrauchs, über ein herausgegebenes und verkauftes Werk behaupten können.

2) Daß der Unterschied eines Geistesprodukts von gemeiner Handelswaare eben desto weniger die Verwehrung des freien und ausgebreitesten Cebrauchs derselben zulasse.

3.) daß es in keiner Hinsicht zum Vortheil des Cemeinwesens gereiche, von Obrigkeitswegen ein allgemeines und beständiges ausschliessendes

241 Reimarus, »Der Bücherverlag ... abermals erwogen«, S. 388. 
Verlagsrecht zu ertheilen; und dieses ist es doch, das man ietzt mit so vielem Eifer verlangt $[. ..] \ll^{242}$

Wie argumentiert nun Fichte in seinem »Beweis der Unrechtmäßigkeit des Büchernachdrucks«? Der Philosoph beginnt mit einer allgemeinen Betrachtung des Buches, er unterscheidet dessen Körperliches, »das bedruckte Pa-

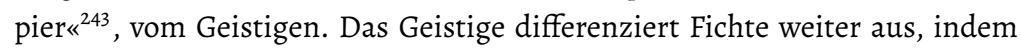
er das Materielle, den Inhalt, gegen dessen Form abgrenzt. Unter der Form versteht Fichte die »eigenen Worte eines Schriftstellers « ${ }^{244}$. Keinen Zweifel lässt Fichte daran, dass das Eigentum am Körperlichen des Buches uneingeschränkt gilt, mit Absolutheit, und er verdeutlicht dies durch ein drastisches Bild der Zerstörung, auf das einige Jahre zuvor auch Kant zurückgegriffen hatte. Der Käufer eines Buches dürfe dieses »zerreissen, verbrennen: wer könnte darüber mit ihm streiten? «, fragt Fichte. ${ }^{245}$ Aber ist ein Buch dafür gemacht, es so zu gebrauchen? In Friedrich Nicolais »Sebaldus Nothanker«, dem erfolgreichsten deutschsprachigen Roman im letzten Drittel des 18. Jahrhunderts, muss sich die Hauptfigur vom Buchhändler Hieronymus darüber aufklären lassen, was so alles mit Gedrucktem angestellt wird. Ernüchtert erklärt Sebaldus:

»So ist dies das Schicksal der Bücher, der Früchte des Fleißes so vieler verdienstvollen würdigen Gelehrten? Zerrissen, zu Düten verbraucht, oder vergessen, oder verbrannt zu werden? Darüber möchte man Blut weinen. ${ }^{246}$

Obwohl Fichte in seinem Nachdenken über die zeitgenössische Buchkultur durchaus zur Polemik neigt, wie 1805 seine Erlanger Vorlesungen über die Gelehrsamkeit zeigen werden, enthält er sich in der Beweisführung gegen den Nachdruck der Kulturkritik. Vielmehr bewegt sich der Philosoph auf Höhe zeitgenössischer Darstellungen von Proprietät. Etwas unsachgemäß zu gebrauchen, bis hin zur Vernichtung, das ist der höchste Begriff von Eigentum. In $\$ 362$ des österreichischen »Allgemeinen Bürgerlichen Gesetzbuches« (1811) wird dem Eigentümer ausdrücklich das Recht zugesprochen, eine Sache auch $\mathrm{zu} »$ vertilgen ${ }^{247}$ Doch will Fichte dem absoluten Sacheigentum etwas entge-

242 Ebd., S. 407.

243 Fichte, Beweis der Unrechtmäßigkeit, S. 225.

244 Ebd., S. 229.

245 Ebd., S. 225.

246 Nicolai, Sebaldus Nothanker, S. 74.

247 Schwab, »Eigentum«, S. 75. 
gensetzen, er verfolgt in seiner Argumentation nur ein Ziel: ein »forthdauerndes Eigenthum des Verfassers an seine [sic!] Schrift « zu begründen. Dies versucht er unter einer bemerkenswerten Prämisse: Man behalte »nothwendig das Eigenthum eines Dinges«, so Fichte, wenn es für andere "physisch unmöglich « sei, sich dieses zuzueignen. ${ }^{248}$

Obgleich die auf Papier gedruckten Lettern in seinen Augen »todte Buchstaben « sind, die in der Kommunikation zwischen Autor und Leser wechselseitig mit Geist erfüllt werden müssen, erkennt er in diesen eine individuelle Form. Und es ist eben diese Form, es sind die »eigenen Worte «, die nach Ansicht von Fichte das geistige Eigentum ausmachen, weil sich diese niemand anderes zu eigen machen kann. Im selben Jahr publiziert Fichte an anderer Stelle naturrechtliche Überlegungen zum Eigentum, die seinen Ansatz zu den Autorenrechten erhellen: »Wir sind unser Eigenthum: sage ich, und nehme dadurch etwas Zweifaches in uns an: einen Eigenthümer und ein Eigenthum«, erklärt Fichte, ganz im Sinne des von ihm angenommenen Grundverhältnisses zwischen Ich und Nicht-Ich, als Relation zwischen Subjekt und Objekt. "Das reine Ich in uns, die Vernunft, ist Herr unserer Sinnlichkeit, aller unserer geistigen und körperlichen Kräfte«, fährt er fort, um der Ratio die Autorität zuzuweisen, die genannten Kräfte »als Mittel zu jedem beliebigen Zwecke $\mathrm{zu}$ gebrauchen $\aleph^{249}$.

In dieser Logik gelangt Fichte zum Begriff der Form, dessen Gehalt sich so paraphrasieren ließe: Das menschliche Subjekt wendet seine vernunftgeleiteten Kräfte auf, um wahrgenommene Dinge in die »Form eines Mittels« für individuell bestimmte Zwecke zu bringen. Damit begründet Fichte den Eigentumsbegriff, er schreibt: »Diese Bildung der Dinge durch eigene Kraft (Formation) ist der wahre Rechtsgrund des Eigenthums; aber auch der einzige naturrechtliche. ${ }^{250}$ Es klingt schließlich ganz ähnlich wie im »Beweis« von 1793, wenn es heißt: »Wir haben also das Recht, jeden anderen von dem Gebrauche der Sache auszuschließen, die wir durch unsere Kräfte gebildet haben, der wir unsere Form gaben. Und dieses Recht heisst bei Sachen das Eigenthum. $\ll^{251}$

\footnotetext{
248 Fichte, Beweis der Unrechtmäßigkeit, S. 224, 225.

249 Johann Gottlieb Fichte, Beiträge zur Berichtigung der Urtheile des Publicums über die französische Revolution, Sämmtliche Werke, hg. v. J. H. Fichte, Berlin 1845ff., III.I (1845), S. 39288, hier: S. 117.

250 Ebd., S. 118.

251 Ebd.
} 
Fichte übernimmt als grundlegendes Prädikat des Eigentums dessen Ausschließlichkeit, aber nicht nur das: Seine Rhetorik (»Sache«) erscheint gesättigt von der Materialität der physischen, im Licht der um 1800 gängigen Rechtsauffassung einzig eigentumsfähigen Welt. Auch deshalb lesen sich seine Ausführungen wie die idealistische Fassung des arbeitstheoretisch begründeten, mit Blick auf Autorschaft häufig herangezogenen Eigentumsbegriffs von John Locke: »The Labour of his Body, and the Work of his Hands, we may say, are properly his«, erklärt Locke in der zweiten seiner »Zwei Abhandlungen über die Regierung (1689): »Whatsoever then he removes out of the State that Nature hath provided, and left it in, he hath mixed his Labour with, and joyned to it something that is his own, and thereby makes it his Property. « ${ }^{252}$ Zweifellos drehen sich diese Gedanken um körperliche, nicht geistige Arbeit. Gerade in der Überführung der auf die materielle Welt bezogenen Begriffe von Arbeit und Eigentum in die Sphäre des Geistes wird die im deutschen Idealismus projektierte Vergeistigung des Kulturellen um 1800 augenfällig. Wobei die Leistung eines Autors von Fichte als das betrachtet wird, was Gerhard Plumpe in seiner Rekonstruktion des semantischen Zusammenhangs von Eigentum und Eigentümlichkeit als »Investition von Individualität « ${ }^{253}$ bezeichnet.

Allein: Die von Fichte im Buch ausgemachte Form lässt sich problemlos reproduzieren, sie hat notwendig etwas Körperliches, die »Äußerlichkeit der Schrift« (Wellbery), die sich ebenso problemlos wie identisch wieder in bedrucktes Papier umsetzen und somit physisch übertragen lässt. Deshalb warnt Fichte davor, »Bücher mit mechanischen Kunstwerken« zu verwechseln, »als ob zu ihrer Verfertigung nichts weiter gehöre, als etwa ein Recept, ein Buch zu machen im Kopfe, und übrigens gelenke Finger, Papier und Dinte ${ }^{254}$. Tatsächlich gewinnt die Form der Gedanken aber nur im gedruckten Artefakt eine wahrnehmbare Gestalt.

Aus heutiger Sicht gelangt Fichte $\mathrm{zu}$ wegweisenden Unterscheidungen, auf die in der weiteren Geschichte des Urheberrechts immer wieder Bezug genommen wird. Er ebnet den Weg zu Vorstellungen wie derjenigen Wilhelm August Kramers, der die Exemplare eines Buches als »äußere Darstellungen

252 John Locke, Two treatises of government, hg. v. Peter Laslett, 2. Aufl., Cambridge 1967, 304f. (II/§ 27).

253 Plumpe, »Eigentum - Eigentümlichkeit«, S. 183.

254 Fichte, Beweis der Unrechtmässigkeit, S. 236. 
eines einzigen, ideellen Buches« betrachtet. Dieses ideelle Buch bleibe im Eigentum des Autors. ${ }^{255}$ Gleichzeitig stößt Fichte auf die von Rautenberg so genannten »Aporien des Buches ${ }^{256}$, die sich daraus ergeben, dass es Körperliches wie Geistiges permanent einschließt.

»Was macht also das Wesentliche eines Buchs aus? ${ }^{257}$ Diese Frage stellt auch Johann Jakob Cella in seinem 1784 publizierten Aufsatz »Vom Büchernachdruck«. Seine Antwort lautet:

»Daß gerade die Anzahl einzelner Wahrheiten und Begebenheiten, daß sie in dieser und keiner andern Ordnung, in dieser Beweisart, in dieser Deutlichkeit und Undeutlichkeit, in dieser Sprache vorgetragen sind: dies macht das Wesentliche des Buches aus, wodurch sich das Buch des einen Verfaßers von dem Buch eines andern unterscheidet. ${ }^{258}$

Cella hebt auf einen Begriff der Eigentümlichkeit ab, ohne sich mit dem Buch als Artefakt eingehender zu beschäftigen. Weil für ihn gilt: »Papier und Farbe [...], wenn sie gleich das Allgemeine aller gedruckten Exemplarien und Manuskripten von Büchern sind, gehören doch nicht zum Wesentlichen des Buchs selbst. ${ }^{259}$ Der Jurist schreibt: »Ich mag daher Feders Logik in Quart, Oktav oder Duodez drucken, so masse ich mir immer ein Recht über das unveränderte individuelle Ganze zu, auf dem Feders Eigenthum beruht. ${ }^{260}$

Dass Cella als Beispiel ausgerechnet Feder wählt, dürfte als Anspielung auf den Beitrag aufzufassen sein, mit dem sich der Göttinger Philosophieprofessor unter großer Beachtung an der Nachdruckdebatte beteiligt hatte. Auch Reimarus setzt sich 1791 noch mit Feders »Neuem Versuch einer einleuchtenden Darstellung der Gründe für das Eigenthum des Bücherverlags, nach Grundsätzen des natürlichen Rechts und der Staatsklugheit« auseinander, mit dem 1780 die erste Ausgabe des von Lichtenberg und Georg Forster herausgegebenen »Göttingischen Magazins der Wissenschaften und Litteratur« eröffnet worden war. Im Geschäftsverhältnis mit dem Verleger bleibt der

\footnotetext{
255 Wilhelm August Kramer, Die Rechte der Schriftsteller und Verleger, Heidelberg 1827, S. 29.

256 Rautenberg, Wetzel, Buch, S. 42.

257 Johann Jacob Cella, »Vom Büchernachdruck«, in: ders., Freymüthige Aufsätze, Anspach 1784, I, S. 75-166, hier: S. 104.

258 Ebd.

259 Ebd., S. 118.

260 Ebd., S. 105.
} 
Autor für Feder weiterhin »Eigenthümer des geistischen Grundstofs $\aleph^{261}$. Geht es um das Wirken des Nachdruckers, heißt es: "Der Nachdrucker verkauft wirklich das Product, die Arbeit, den Grundstof eines andern, das Gedicht, das philosophische Werk des andern; der Titel selbst sagt es aus, Gellerts Schriften, Klopstocks Messiade. «"62

Im direkten Anschluss stellt Feder einen in der Nachdruckdebatte gängigen Vergleich mit der graphischen Nachahmung von Bildwerken an: »Der Nachahmer eines Gemähldes, eines Kupferstiches, einer Uhr verkauft nichts, was eben so fremde Arbeit heissen könnte. ${ }^{263}$ Es ist bereits hervorgehoben worden, dass sich der Nachdruck eines Buches in der Regel nicht auf die äußere Gestalt einer Publikation bezieht. Das mimetische Verhältnis zur Vorlage stellt sich einzig durch die Reproduktion eines Textes her - anders als beim Holzschnitt oder Kupferstich; so dass sich eine unüberbrückbare Differenz einstellt, weil der Nachdruck unter Berücksichtigung der Arbeitsteiligkeit des Büchermachens keine vergleichbare Leistung darstellt. Denn dieser bezieht sich auf »fremde Arbeit« auch im Hinblick auf die Tätigkeit des Autors: das Verfassen eines Textes. Angesichts von Wissenspraktiken, die größtenteils auf Nachvollzug durch Reproduktion setzen, ist die erkennbar genaue Würdigung des jeweiligen Aufwands nicht unbedeutend. Mit anderen Worten: Der Kupferstecher wird in der Regel nicht mit dem Nachdrucker gleichgesetzt, weil die von ihm erbrachte Leistung als gleichermaßen eigenständig und ähnlich umfangreich anerkannt wird.

Auch bei Jean Paul findet sich der von Feder angestellte Vergleich wieder: »Unbegreiflich erscheint es mir«, so schreibt dieser 1815 in »Sieben letzte oder Nachworte gegen den Nachdruck«, »wie man aus der Erlaubnis, fremde Gemälde, Kupferstiche etc. zu vervielfältigen, sich den Übergang zu einer Erlaubnis, fremde Bücher nachzudrucken, bahnen wollte.« (SW II.3, 501) Der Schriftsteller erkennt die bildliche Reproduktion deshalb an, weil der Nachmaler oder Kopist körperliche Arbeit auf sich nehmen und neben dem ersten ein zweiter Meister werden müsse. Anders fällt sein Urteil hinsichtlich des Druckgewerbes aus: Jean Paul wirft die Frage auf, was »Drucker und Nachdrucker mit dem Schöpfer eines geistigen Werks« gemeinsam hätten. Denn:

261 Johann Georg Heinrich Feder, »Neuer Versuch einer einleuchtenden Darstellung der Gründe für das Eigenthum des Bücherverlags, nach Grundsätzen des Rechts und der Staatsklugheit«, in: Göttingisches Magazin der Wissenschaften und Literatur 1 (1780), S. 137, 220-242, hier: S. 17. 
»Das Manuskript ist hier nicht das Gemälde, sondern nur die Leinwand, worauf ein geistiges steht.« (Ebd.)

In dieser Argumentation pocht Jean Paul auf die angesprochene Differenz zwischen der Hervorbringung eines handwerklichen und eines "geistigen Werks«. Zugleich offenbart sich, wie untrennbar das eine mit dem anderen in der Materialität von Literatur verbunden ist. Wenn das »Manuskript« laut Jean Paul »nicht das Gemälde, sondern nur die Leinwand « darstellt, erscheint dieses ausschließlich als Träger des Geistigen. Anders als die »Leinwand « handelt es sich bei der Handschrift jedoch nicht um eine ungestaltete Fläche, vielmehr umfasst sie auch die zum Text sich formierenden Buchstaben. Jean Paul trägt diesem Umstand durchaus Rechnung, indem er eine Formulierung wählt, in welcher "geistiges« als räumliche Figuration (»steht«) erfassbar wird. ${ }^{264}$ Somit stellt sich ein Widerspruch ein zwischen der Materialität und der Medialität der Schrift. Als Frage formuliert, eng am Sprachbild von Jean Paul: Gehört das Geschriebene nun zur Leinwand oder zum Gemälde? Weiter wäre zu erörtern, wie der Autor sich den Zugriff der »Drucker und Nachdrucker« auf die etwaige Manifestation des "geistigen Werks« vorstellt.

Vermutlich gelangt Jean Paul zu dieser Bildlichkeit durch die 1814 von August Kotzebue zwar anonym, dafür jedoch »im Namen deutscher Buchhändler« verfasste »Denkschrift über den Büchernachdruck«, die den Wiener Kongress dazu bewegen sollte, ein Gesetz gegen den Nachdruck auf den Weg $\mathrm{zu}$ bringen. Kotzebue hatte in seiner weitgehend als Kompilation erprobter Argumentationsmuster lesbaren »Denkschrift « folgende These zu entkräften versucht: »Der Nachdrucker thue nichts weiter, als was der Nachahmer einer Fabrikwaare, eines Zeuges oder eines Kunstwerks thue ${ }^{265}$. Sein Gegenargument lautet:

»Ein Gemählde ist das Kunstwerk selbst, ein Buch hingegen nur das Mittel, es dem Geiste darzustellen. Wer dem Mahler die Pinselstriche nachahmt, der liefert darum sein Kunstwerk nicht; wer aber dem Schriftsteller die Zeichen nachmacht, durch die er sich verständigt hat, der eignet dessen Werk sich ganz so zu, wie es aus dem Ceiste des Verfassers entsprang. Nachah-

264 Vgl. Fuchs, Büchermachen, S. 35.

265 [August Kotzebue], Denkschrift über den Büchernachdruck, zugleich Bittschrift um Bewürkung eines deutschen Reichsgesetzes gegen denselben. Den Erlauchten, bei dem Congress zu Wien versammleten [sic!] Gesandten deutscher Staaten ehrerbietigst überreicht im Namen der deutschen Buchhändler, Leipzig 1814. 
mungen von Kunstwerken liefern nicht das Original, welches von Kennern doch immer vorgezogen wird; wohl aber thut es der Nachdruck. ${ }^{266}$

Kotzebue führt an dieser Stelle die Medialität der Schrift ins Feld, der »Zeichen«, um das aus seiner Sicht so Fatale der Nachdrucke herauszustellen: Auch in einer differenten Materialität »liefern « diese »Nachahmungen « nichts anderes als das »Original«, solange die - wieder mit Goodman gesprochen - »Selbigkeit des Buchstabierens« als gewährleistet gelten darf. Die zweckgerichtete Begrifflichkeit Kotzebues erscheint etwa im Vergleich zu derjenigen Fichtes deutlich weniger konsistent. Sie vermeidet auch einen Grad an Differenzierung, wie ihn beispielsweise Matthias Ehlers anstrebt, wenn er zwischen Plagiator ("gelehrter Dieb«), »Nachahmer« und Nachdrucker unterscheidet. ${ }^{267}$ Dafür spiegelt Kotzebue in seiner Auftragsarbeit den über Jahrzehnte andauernden Diskurs stellenweise Wort für Wort wider - im angesprochenen Rückgriff auf gängige Begriffe und Argumente. So dass es nicht verwundert, wenn die "Denkschrift « ex negativo ebenfalls das »Wesentliche eines Buches« $\mathrm{zu}$ bestimmen sucht:

»Wer ein Zeug nachmacht, der kann ihm doch nur die Form des nachgeahmten geben, die Materie aber darf er dem Erfinder nicht entwenden, er muß sie selbst herbey schaffen und eben so mühsam verarbeiten als Jener. Wer aber ein Buch nachdruckt, der kümmert sich wenig um die Form; dieselbe Materie, der selbe Grundstoff ist es, dessen er sich bedient; denn Papier und Druck machen nicht das Wesentliche eines Buches. ${ }^{268}$

In der Beantwortung der Frage, was als Kern des Gedruckten anzusehen ist, worin dessen »Grundstoff « besteht, offenbart sich die jeweilige Position in der Nachdruckdebatte. Weil diejenigen, die sich an das Artefakt halten, an Papier und Druckerschwärze, in der Regel die unautorisierte Reproduktion zu legitimieren versuchen. Und das tun sie ebenso häufig, indem sie das Recht zum Nachdrucken aus der absoluten Verfügungsgewalt des Eigentümers über ein papiernes Exemplar ableiten. 1783 erscheint im »Deutschen Museum« ein

266 Ebd., S. $16 f$.

267 »Der Nachahmer liefert doch in der Hauptsache ein Werk seiner Kräfte. Das thut der gelehrte Dieb nicht. Dieser schreibt aus. Der Nachdrucker ist auch keineswegs ein Nachahmer, sondern ein Copist. (Matthias Ehlers, Über die Unzulässigkeit des Büchernachdrucks nach dem natürlichen Zwangsrecht, Dessau, Leipzig 1784, S. 175) [Kotzebue], Denkschrift über den Büchernachdruck, S. 23. 
Beitrag, in dem diese Argumentation nicht unparteiisch, aber luzide dargelegt und überdies differenziert wird zwischen den Objekten der Literatur, um welche die Frage nach der Proprietät auf intrikate Weise kreist:

»Was thun die Herren Nachdrucker, wenn sie ein Buch nachdrucken wollen? Sie kaufen sich ein Exemplar für ihr Geld. Völlig recht und gesezmässig! Allein wozu denn? Um es zu vervielfältigen, wie sie sagen, und dadurch - den Verleger um das Seinige bringen. Würde ihnen wohl der Verleger ein Exemplar gegeben haben, wenn sie gesagt hätten, daß sie es nachdrucken wollten? Hätte er das gewollt, so würde er ihnen gleich die ganze Auflage und das Manuskript dazu gegeben haben. $\ll^{269}$

Da wäre also das Exemplar, das sich veräußern lässt, wobei es das Potenzial in sich birgt, als Vorlage für den Nachdrucker zu fungieren und somit den ursprünglichen Verleger dessen zu berauben, was Ludwig Gieseke abstrakt als "Verlagseigentum ${ }^{270}$ beschreibt: ein Bündel exklusiver Verfügungsrechte, die aus dem Abdruck einer Handschrift erwachsen. Zugleich bleibt mit dem »Manuskript« das Objekt nicht unerwähnt, welches dem Autor qua Eigentum eine, wenn auch schwache Rechtsposition eröffnet. Auch im »Deutschen Museum« wird der Vergleich des Nachdruckers mit dem Nachahmer von Kunst bzw. Handwerk erörtert. An dieser Stelle geht es ebenfalls um das »Wesentliche eines Buches«:

»Das gewöhnliche Gleichniß mit andern Künstlern paßt gar nicht hierher. Der Künstler produzirt selbst etwas neues, er nimt Materie, die auf seinem Grund und Boden gewachsen ist, und ahmt mehr nach; so wie jeder Handwerksmann die Materie eben so bearbeiten kann, wie sein ehemaliger Lehrmeister, ohne darum einen Diebstahl an ihm zu begehen. Papier und Farbe ist nicht das Wesentliche eines Buchs, es ist das Allgemeine aller Bücher; der Nachdrucker würde etwas neues und eigenes hervorbringen, wenn er die Buchstaben nach seiner Einsicht und aus sich selbst zusammen sezte: allein, wenn er ein Buch nachdruckt, so nimt er das wesentliche selbst, das, was ein Buch zum Individuum macht. [...] Wo die Güte eines Buchs blos im schönen Papiere und Chodowieckischen Kupfern besteht, da drucken die Herren

269 [Anonymus], »Reliquien von Fr. A.«, in: Deutsches Museum I (1783), S. 195-207, hier: S. 198. (Dieser Beitrag enthält die angeblich postum veröffentlichte Abhandlung »Ueber Bücherverlag und Nachdruck«, datiert auf Mai 1781, aus der hier zitiert wird.)

270 Ludwig Gieseke, Die geschichtliche Entwicklung des deutschen Urheberrechts, Göttingen 1957, S. $51 \mathrm{ff}$. 
nicht nach, denn sie suchen Geist; oder wenn das Buch dennoch verlangt wird, so verliert man bei dem Nachdruck vollends alles. « $^{271}$

Diebstahl ist in der Nachdruckdebatte der schwerwiegendste Vorwurf, der sich unmittelbar aus der Logik der Proprietät ergibt. Der prominente Verleger Reich brandmarkt 1776 kursierende Raubdrucke als "gestohlene Waaren«. Allerdings richtet aus seiner Sicht die inkriminierte Verlagspraxis weitaus größeren Schaden an als ein übliches Eigentumsdelikt:

»Der Diebstahl aller Art ist dem leidenden Theil nicht so empfindlich, als der Büchernachdruck dem rechtmäßigen Verleger! Jener verlieret nur einen Theil seines Vermögens; dieser verliehret es gantz, und wer ersetzt ihm dann den Verlust seiner mißlungenen Unternehmung? $^{272}$

An diese Frage fügt Reich an, was für ihn das Buch im Innersten zusammenhält. Und er bemüht an dieser Stelle den von Heinrich Bosse so bezeichneten "Schutzgeist, der jedes Exemplar vor dem Zugriff des Konkurrenten « ${ }^{273}$ abschirmt: "Das wesentliche bey einem Buche«, so Reich, »ist nicht Druck und Papier, sondern es ist der Geist des Verfaßers. ${ }^{274}$ Somit bedarf es der Konstruktion eines geistigen Eigentums, um die Nachdrucker als Langfinger zur Rechenschaft ziehen zu können. Jedoch muss der Verleger einstweilen eingestehen, dass der Vorwurf des Diebstahls nicht hinreichend erscheint, »weil der Nachdruck nicht das corporelle, d.i. das bedruckte Pappier, sondern, wenn man so sagen mag, nur das Spirituelle, i.e. den eben so gut bezahlten Innhalt [...] raubet $\ll^{275}$.

Der Vorwurf des Diebstahls verfängt in der Nachdruckdebatte, weil er griffig ist. Das weiß auch Johann Gottwerth Müller, der die Debatte auf den Schauplatz der Literatur verlegt. Im fünften Teil von »Emmerich«, erschienen 1788 beim Lichtenberg-Freund Dieterich in Göttingen, heißt es:

»Wer zum Druck eines Buches aus einer Druckerey etliche Unzen Buchdruckerfarbe, oder einem Papierhändler einige Rieß Papier entwendet, den hält

271 [Anonymus], »Reliquien«, S. 204.

272 Zit. n. Hermann Meyer, »Reformbestrebungen im achtzehnten Jahrhundert«, in: Archiv für Ceschichte des deutschen Buchhandels 13 (1890), S. 213-244, hier: S. 217.

273 Bosse, Autorschaft ist Werkherrschaft, S. 35.

274 Zit. n. Meyer, »Reformbestrebungen« (1890), S. 217.

275 Zit. n. Hermann Meyer, »Reformbestrebungen im achtzehnten Jahrhundert «, in: Archiv für Ceschichte des deutschen Buchhandels 12 (1889), S. 201-300, hier: S. 213. 
ganz Europa einstimmig für einen Dieb: und wer zum Druck eines Buches den ganzen buchstäblichen Innhalt entwendet, der sollte kein Dieb seyn? « ${ }^{276}$

Ausgehend von diesem Vergleich konzentriert sich auch Müller auf das »Wesentliche eines Buches «, und er operiert dabei mit einem Begriff, der bis heute maßgeblich für das Urheberrecht ist - dem des Werks:

»Druck und Papier sind Nebendinge, und nicht das Wesentliche eines Buchs; denn es giebt Bücher die auf Pergament, und andre die auf Blätter geschrieben sind; noch andre, wie z.B. der Pineische Horaz, sind ganz in Kupfer gestochen. Die Hauptsache, das Wesen des Buches, das wodurch Papier zum Werke wird, ist der Innhalt, oder die Gedanken die durch Buchdruckerschriften, Grabstichel oder Feder etc. sichtbar gemacht sind. Sie sind das Cold in der Börse. - Wer mein Gold stiehlt sollte kein Dieb seyn? Wie? ${ }^{277}$

Auch in den »Nachworten« von Jean Paul erscheinen diejenigen, die den Nachdruck verantworten, als "Spitzbuben« (SW II.3, 493). Was erkennen lässt, wie eingefahren die Bahnen des Streits um Autorenrechte nach Jahrzehnten sind. Das wiederum macht nachvollziehbar, weshalb die »Nachworte« des Schriftstellers noch lange keinen Endpunkt auf dem Weg zu einem modernen Urheberrecht markieren.

276 Johann Cottwerth Müller, Emmerich, eine komische Ceschichte vom Verfasser des Siegfried von Lindenberg, Fünfter Theil, Göttingen 1788, S. 67. Siehe zu Müller auch Paul Münch, »Nachdruck und literarischer Markt im späten 18. Jahrhundert. J.G. Müller, J.A.H. Reimarus, A. von Knigge und die sSchmiederey«, in: Alexander Ritter (Hg.), J. G. Müller von Itzehoe und die deutsche Spätaufklärung. Studien zur Literatur und Cesellschaft im 18. Jahrhundert, Heide 1978, S. 228-247.

277 Ebd., S. 68. 


\section{Makulatur}

\subsection{Makulatur als Medium zwischen Gelehrsamkeit und Genie}

"Die Seele des Dichters scheint eine Menschenseele zu sein wie andre, und ist's doch nicht. Von der Flamme des Himmels durchglüht, scheint er auf Erden zu leben, und lebt im Äther. ${ }^{1}$ Mit diesen Worten beginnt ein mehrseitiger Auszug aus dem ersten Teil von Carl Friedrich Cramers »Klopstock« (1777), den Jean Paul im Jahr 1780 für den siebten Band seiner Exzerpte anfertigt. Er stellt die Abschrift unter die selbstgewählte Überschrift »Gemählde - wie der Poët wird - und ist « ${ }^{2}$. Cramer beschreibt Klopstock in der exzerpierten Passage an einem biographischen »Scheidewege«, zwischen der Laufbahn eines Dichters und der eines Gelehrten. »Tausend Bücher zu lesen, sie mit der schärffsten Aufmerksamkeit zu prüfen, zu excerpieren, zu sceletiren «, das sind für Cramer die üblichen Praktiken des Gelehrten. ${ }^{3}$ Es geht in dieser Konstellation mit Blick auf den Dichter auch um die Kennzeichnung einer Autorschaft, die sich deutlich abhebt von dem bis ins letzte Drittel des 18. Jahrhunderts dominanten Paradigma gelehrten Schreibens und Publizierens.

Es ist eben dieses Paradigma der Gelehrsamkeit, das Jean Paul ab den Neunzigerjahren des 18. Jahrhunderts für Autorenfiguren wie Quintus Fixlein und Gotthelf Fibel produktiv machen wird. Die genannten Figuren sind Halbgelehrte, beide sammeln Wissen, indem sie Makulatur horten, um schließlich durch eigenwillige Papierarbeiten zur Autorschaft zu gelangen. Die Materialität gelehrter Praktiken, die von Jean Paul in seinen Erzählungen aus-

Nachlass ]ean Paul, Fasz. Ib/7, S. 16, in: Jean Paul, Exzerpte. Digitale Edition, [lb-07-17800053], URL: www.jp-exzerpte.uni-wuerzburg.de (14.9.2019).

2 Nachlass ]ean Paul, Fasz. Ib/7, S. 16, in: Jean Paul, Exzerpte. Digitale Edition, [lb-07-17800052], URL: www.jp-exzerpte.uni-wuerzburg.de (14.9.2019).

3 Karl Friedrich Cramer, Klopstock (In Fragmenten aus Briefen von Tellow an Elisa), Hamburg 1777 , I, S. $38,40$. 
gestellt wird, ist bereits ihren Begriffen inhärent. Anke te Heesen hat z.B. darauf hingewiesen, dass »Exzerpieren « etymologisch auf das lateinische excerpo zurückgeht, das »herausklauben« oder »auslesen« bedeuten kann, auBerdem »weglassen«, "streichen « oder »ausschneiden " $^{4}$. Die Datenverarbeitung in solchen Praktiken funktioniert epistemologisch auf der Grundlage einer planmäßigen Kontingenz, für die sich Makulatur als Metapher wie als tatsächliches Medium anbietet.

Jean Paul legt in der Modellierung seiner gelehrten Autorenfiguren großen Wert auf das Wissen der Makulatur und dessen Implikationen. Quintus Fixlein hat eine solch hohe "Achtung für alle Makulatur«, »daß er sich, wie Morhof rät, die einzelnen Hefte von Makulaturbögen, wie sie der Kramladen ausgab, fleißig sammelte«, und in seinen Augen ist »der Krämer ein Fortius (der Gelehrte) oder ein Friedrich (der König), weil beide letztere sich aus kompletten Büchern nur die Blätter schnitten, an denen etwas war« (SW I.4, 88). In »Leben Fibels« ist es ein ebenfalls polyhistorisches Wissen, das die Hauptfigur in Form von Makulatur erwirbt. Gotthelf Fibel, genannt Helf, verbringt die meiste Zeit mit »Büchern von Makulatur« (SW I.6, 388). »Helf las«, heißt es hier, und zwar alles, »was er poetisches, juristisches, chemisches Gedrucktes aus dem Gewürzladen, seiner Lese-Bibliothek, vorbekam« (SW I.6, 388). Der Gewürzhändler beschert ihm »Düten aus allen Fächern«, die ihn später - so der Erzählerkommentar - als »Vielwisser« (ebd.) in Erscheinung treten lassen, als Polyhistor, der schließlich nach dem Ruhm gelehrter Autorschaft strebt.

In dem bei Jean Paul vorgeführten Umgang mit Makulatur deuten sich einige Motive an, die auch für die Gelehrtenkritik des ausgehenden 18. Jahrhunderts kennzeichnend sind: Im Makulaturbogen figuriert ein aus Gedrucktem geschöpftes, sich selbst vermehrendes, weil endlos repetitives, aber angeblich nutzloses Wissen. Makulatur fungiert in diesem Kontext zudem als Trope fragwürdigen Publizierens, wenn Gelehrten unterstellt wird, längst Bekanntes ohne Sinn und Verstand oder in plagiatorischer Absicht reproduziert zu haben. Sie findet außerdem Verwendung, wenn der mögliche oder tatsächliche Vorwurf verhandelt wird, jemand habe eine Veröffentlichung einzig aus Gründen sozialer Anerkennung angestrebt. 
Diese Negativbilder, mit denen Jean Paul operiert, werden in der zweiten Hälfte des 18. Jahrhunderts in Beziehung gesetzt zu neuen Formen souveräner Autorschaft. Edward Young gewinnt in seinen einschlägigen »Gedanken über die Original-Werke« (1759, dt. 1760) die Konturen des Genies aus einer grundlegenden Kritik an der Gelehrsamkeit, wobei sich das Genie aus seiner Sicht dadurch auszeichnet, dass es nicht »wie andre« ist, die sich im Rahmen überkommener Praktiken bewegen, indem sie bloß »lesen und schreiben«. Young über das Genie:

»Seine Werke werden stets ein unterscheidendes Merkmal an sich tragen! Ihm allein wird das Eigenthum darüber zugehören; und nur dieses Eigenthum kann allein den edeln Titul des Autors uns geben; das heißt, um genau $z u$ reden, den Titul desjenigen, welcher denket und schreibt, indessen daß die andern Räuber der Presse, wenn sie auch noch so reich an vielen Bänden und Celehrsamkeit waren, [...] nur lesen und schreiben. $\aleph^{5}$

Der »Original-Schriftsteller « schöpft aus sich selbst heraus, indem er »denket und schreibt«, statt sich als »Räuber der Presse« angreifbar zu machen. Ähnlich wie Young polarisiert Cramer zwischen dem Dichter und dem Gelehrten, wenn er über Klopstock schreibt. Der Dichter trägt bei ihm Züge des Genies, das ab den Sechzigerjahren des 18. Jahrhunderts in der Dialektik der Säkularisierung seinen Aufstieg aus der Gelehrtenrepublik feiert und sein Refugium ebenfalls »im Äther $z u$ haben scheint statt »auf Erden«, in einer profanen Welt, wo Bücher als Makulatur enden.

Angesichts der Autorenfiguren, die er mit Fixlein und Fibel erfinden wird, eindrücklichen Figuren, welche der »alten« Gelehrtenkultur so stark verhaftet sind, ist es bemerkenswert, dass Jean Paul in seinem frühen Exzerpt zu Klopstock alles, was Cramer dem Gelehrten abwertend andichtet, auslässt, um sich in der Abschrift voll auf das zu konzentrieren, was Cramer über dessen Widerpart schreibt. Der Dichter, »er schaft « ${ }^{6}$, so Cramer, und selbst wenn er sich nicht in ätherischen Sphären, sondern in weltlicher »Gesellschaft« bewegt, »so ist er nicht minder wunderbar«. Denn: »Er sondert das Gewöhnliche von dem Seltnen, prägt dieses sich tief ein, faßt's und verwandelt's in sein Eigenthum.«Dies betrifft alles Menschliche, auch Allzumenschliches. Sogar

5 Young, Gedanken über die Original-Werke, S. 48f.

6 Cramer, Klopstock, I, S. 42. 
dem abgelauschten »Witz der Toilette«, des aufgeputzt Körperlichen, verleiht der Dichter sein Gepräge, so Cramer. ${ }^{7}$

An dieser Stelle der Klopstock-Biographie, auf Seite 45, bricht der Auszug in Jean Pauls Exzerpten ab. Somit entgeht ihm ein besonderer »Witz der Toilette«: Nur fünf Seiten weiter findet sich bei Cramer nämlich eine Anekdote, ganz nach dem Geschmack des späteren Jean Paul, dessen Aufzeichnungen und literarische Texte durchzogen sein werden von Papieren aller Art, nicht zuletzt: von Makulatur. Cramer schildert eindrücklich, wie Meta Moller, spätere Klopstock, erstmals auf ihren zukünftigen Ehemann aufmerksam wird:

»Sie hatte den Messias zuerst aus einer Papiliotte kennen lernen. [...] Sie kömmt zu einer Bekanntinn, sieht geschnittene Haarwickel liegen, nimmt eine in die Hand, liest ein paar Zeilen - ey! was ist das? ruft sie aus. - Oh! dumm Zeug, sagt die Andre, es kanns kein Mensch verstehen! - So? Sagte sie; sie verstehts gleichwohl, erkundigt sich näher nach dem Buche und dem Manne, läßts holen, verschlingts, von dem Augenblicke an kömmts ihr nicht von der Seite, Tag und Nacht liest sies, weidet ihre ganze Seele daran, denkt, spricht, schreibt von nichts als von Klopstock, und besonders will sie durch Giseken viel von ihm wissen. ${ }^{8}$

Es erscheint kongenial, wie Meta Moller sich den Inhalt der Makulatur, dies »dumm Zeug«, das sich angeblich »kein Mensch « zugänglich zu machen vermag, als verständige Leserin aneignet; so dass sie endlich, beseelt und völlig eingenommen vom Genie des Dichters, nicht mehr nur rezipiert, sondern »denkt, spricht, schreibt «. Jedoch dürfte es nicht - anders als von Cramer behauptet - die erste Buchausgabe des »Messias« bei Hemmerde in Halle gewesen sein, die Moller in Überresten bei ihrer Freundin fand. Sondern die Verse entstammten höchstwahrscheinlich einer Veröffentlichung in den »Neuen Beyträgen zum Vergnügen des Verstandes und Witzes« (1749, 2. Aufl. 1751), den sogenannten »Bremer Beyträgen«. Möglicherweise hat Cramer sich für dieses Detail nicht interessiert, obgleich sein Vater Johann Andreas die Literaturzeitschrift mitbegründet hatte. Die Publikation in einer Zeitschrift zu berücksichtigen, hätte ihm womöglich auch seiner Pointe beraubt. Denn die Verarbeitung des bedruckten Papiers zu Lockenwicklern war wohl eher einer medialen Taxonomie geschuldet, in welcher Periodika als weniger bewahrenswert eingestuft wurden, als der Einschätzung, es handele sich beim Werk des

\footnotetext{
7 Ebd., S. 45.
}

8 Ebd., S. 50. 
Dichters um »dumm Zeug«. Cramer benennt als seine Quelle die Schwester von Meta Moller, Elisabeth Schmidt, die ebenfalls aufschrieb, wie die Liebe zum Dichter durch Lockenwickler gestiftet worden war:

»Meta hat den Messias dadurch zuerst kennen lernen daß sie etwas von den 3 ersten Gesängen, in Papliotten zerschnitten auf der Toilette einer ihrer Freundinnen gefunden, welches sie zusammen geklebt, und mit großem Beyfall gelesen; Gieseke mit vielem Feuer gefragt: Ist mehr von diesen [sic!] göttlichen Gedicht zuhaben, u wo? und wer ist der Verfasser. « 9

Die Verräumlichung des Textes im Medium der Makulatur führt in diesem Fall nicht zum »Tod des Autors« (Barthes). Angesichts der Dissemination bedruckten Papiers stellt sich für Meta Moller umso dringlicher die Frage: »wer ist der Verfasser «? ${ }^{10}$ Zwar ist die Akzeptanz von Kontingenz um 1800 durchaus wesentlich für viele Formen des Lesens (und Schreibens), die Integrität eines Textes also nicht abhängig von einer vollständigen Kenntnisnahme. Pars pro toto lautet vielmehr das Prinzip zeitgenössischer Lektüre. Gebildete Leser des späten 18. Jahrhunderts sind bestens vertraut mit dem Anfertigen von Exzerpten einerseits, der Kompilation und dem sekundären Diskurs von Zeitschriften, die Auszüge und Rezensionen drucken, andererseits. Auch das Lesen von Makulatur ist so ungewöhnlich nicht, wie der um 1800 vielgelesene August Lafontaine schön an der Romanfigur des armen Landpredigers zeigt,

9 »Elisabeth Schmidt geb. Moller über die erste Begegnung Klopstoks mit Meta, am 4.4.1751 «, in: Meta Klopstock, Briefwechsel mit Klopstock, ihren Verwandten und Freunden, hg. v. Hermann Tiemann, Hamburg 1956, I, S. 16-19, hier: S. 16.

10 Marianne Schuller schreibt zum gesteigerten Interesse am Autor des »Messias«: »Auf ihn, auf dieses emphatische Subjekt als Autor, führt das Leseinteresse hin. Es ist, wie wir sehen, erotisch aufgeladen: hinter den Schriftzeichen, gleichsam in ihnen verborgen, steckt der Autor, der sich in ihnen selbst zum Ausdruck bringt. Er also ist zu lesen, wenn man den Text liest. Und diese Funktion haben vor allem die Frauen: indem sie den Text lesen und damit nach dem Urheber verlangen, konstituieren sie die neuzeitlich-bürgerliche Position und Funktion Autorschaft mit. « (Marianne Schuller, »)Es sind wunderliche Dinger, meine Briefe $\triangleleft$. Randbemerkungen zur Schreibweise Meta Klopstocks«, in: Inge Stephan, Hans-Gerd Winter (Hg.), Hamburg im Zeitalter der Aufklärung, Berlin, Hamburg 1989, S. 269-283, hier: S. 275.) Siehe auch Tanja Reinlein, Der Brief als Medium der Empfindsamkeit. Erschriebene Identitäten und Inszenierungspotentiale, Würzburg 2003, S. 206-216. 
der sich von einem Buchbinder mit Papierabfällen versorgen lässt. ${ }^{11}$ Trotzdem geschieht mit den Lockenwicklern etwas nicht Alltägliches. Sie werden von Meta Moller von ihrem »rezeptionsästhetischen Mangel ${ }^{12}$ befreit, nur noch Makulatur zu sein. Wenn die geneigte Leserin mit ihrer Bastelarbeit beginnt, wenn »zusammen geklebt « wird, was einmal zusammengehörte, geht es im exklusiven Zugriff auf ein zerstörtes Artefakt zum einen um die Lesbarmachung eines im Auflagendruck vervielfältigten und ansonsten unbeschadet zirkulierenden Textes. Zum andern dient die Rekonstruktion des Druckexemplars der Wiederherstellung der Autorfunktion. Denn nur anhand eines halbwegs intakten Textes lässt sich die Frage klären, wer der Verfasser ist, um schließlich weitere Gedichte damit in Verbindung bringen zu können.

Die Bastelarbeit dokumentiert zudem ein ästhetisches Urteilsvermögen, sie lässt Meta Moller als Rezipientin in einem günstigen Licht erscheinen. Als sie mit Klopstock längst eine empfindsame Korrespondenz unterhält, erwähnt Moller gegenüber dem Dichter in Abgrenzung zu sich jene Freundin, die »Eure Beyträge zu Papillotten verschneiden kann « ${ }^{13}$. Über das Medium des Buches im Allgemeinen hat Monika Schmitz-Emans geschrieben, dass seine Präsentation »als primär sinnlich-materielles Objekt [...] eine komplementäre Einbuße an Lesbarkeit, harmlosestenfalls eine Ablenkung vom Inhalt « mit sich bringt. Pointiert zusammengefasst: »Materialität und Sinnhaltigkeit stehen zumindest in latenter Konkurrenz. ${ }^{14}$ Dies bestätigt sich bei Meta Moller, jedoch ist hier, im Sinne der »Ablenkung«, auch eine Bewegung in umgekehrter Richtung zu beobachten: Indem die »Papillotten« nicht mehr als solche wahrgenommen werden, indem sie gelesen werden, scheinen sie sich $\mathrm{zu}$ entmaterialisieren, denn sie verwandeln sich aus Sicht von Meta Moller von profanen Lockenwicklern in ein »göttliche[s] Gedicht«.

11 »Makulatur bekam ich von dem Buchbinder, [...] und sie war mir ein Fest; aber ich sah daraus doch nur, wie viel ich an dem verlor, was nicht Makulatur war.« (Lafontaine, Leben eines armen Landpredigers, I, S. 122)

12 Uwe Wirth, »(Papier-)Müll und Literatur: Makulatur als Ressource«, in: Zeitschrift für deutsche Philologie 133 (2014), Sonderheft: Entsorgungsprobleme: Müll in der Literatur, S. 19-32, hier: S. 19.

13 »Von Margarete Moller, Borgesch, 16. August 1752«(An Klopstock und Giseke), in: Friedrich Gottlieb Klopstock, Werke und Briefe. Historisch-kritische Ausgabe, hg. v. Horst Gronemeyer u.a., Berlin 1974-, Abt. B, 2 (1985, hg. v. Rainer Schmidt), S. 212-213 [167], hier: S. 213.

14 Schmitz-Emans, »Vom Leben und Scheinleben der Bücher«, S. 21. 
Makulatur führt deutlich vor Augen, wie unterschiedlich die Materialität von Literatur in soziale Praktiken eingeflochten sein kann. Sie verdeutlicht zugleich die Bindung von Autorschaft an gedruckte Artefakte. Nicht zu vernachlässigen ist in diesem Zusammenhang die Historizität sozialer Praktiken: Anders als heute gilt es im 18. Jahrhundert nicht als Tabu, Gedrucktes zu zerstören und als materielle Ressource zu gebrauchen. ${ }^{15}$ Makulatur verfügt daher über eine enorme Präsenz im Alltag wie auch in unterschiedlichen Diskursen. Das Nachleben der Bücher geht einher mit einem Perspektivwechsel. Unter dem Primat des Nutzens werden aus Texten: Papiere.

Vor diesem Hintergrund konzentriert sich das Standardnarrativ der Makulatur auf eine Irritation, die sich einstellt, wenn die aus ihr hergestellten Gegenstände wieder wie Texte gebraucht werden. Seien es die »Düten aus allen Fächern« (SW I.6, 388) in Jean Pauls »Leben Fibels«, Karl Immermanns »Papierfenster eines Eremiten ${ }^{16}$ oder eben die Lockenwickler in der Anekdote aus dem Leben der Meta Moller. Gemeinsam ist allen diesen Beispielen, dass Lesen in den Praktiken, in welche die makulierten Papiere überführt werden, nicht vorgesehen ist. In den betreffenden Erzählungen wird die (Re-)Lektüre als große Ausnahme dargestellt; vermittelt wird, dass Makulatur in der Regel weder zurück zum Text noch zur Frage nach dem Autor führt.

\section{Was heißt Makulatur?}

Makulatur geht zurück auf das lateinische Verb maculare, was »beflecken« heißt oder »beschmutzen«. Im deutschen Sprachraum ist das Wort seit dem ersten Viertel des 16. Jahrhunderts in Gebrauch. ${ }^{17}$ Die Etymologie von Makulatur erscheint irreführend, mitunter paradox. Zwar lässt sich makuliertes Papier nur noch als Verpackungsmaterial gebrauchen, weil es durch Farbe »befleckt« ist. Dass es aber anders benutzt wird als ursprünglich gedacht, hat

Siehe Caspar Hirschi, Carlos Spoerhase, »Kommerzielle Bücherzerstörung als ökonomische Praxis und literarisches Motiv. Ein vergleichender Blick auf das vorindustrielle und digitale Zeitalter«, in: Kodex 3 (2013), S. 1-23.

16 Karl Immermann, Die Papierfenster eines Eremiten, Hamm 1822.

17 Laut dem »Deutschen Wörterbuch « lässt sich »Makulatur« seit dem ersten Viertel des 16. Jahrhunderts nachweisen, »wo es auch bereits seine verwendung auszerhalb der druckereien, im sinne von pack- und einwickelpapier, findet «. Spekuliert wird, dass das Wort »in den kreisen der gelehrten drucker des 15. jh. aufgekommen« sei (Art. »Makulatur«, in: Jacob und Wilhelm Grimm, Deutsches Wörterbuch, Leipzig 1854ff., VI (1885), Sp. 1492f.). 
oftmals andere Gründe. Fehldrucke, Korrekturabzüge (wie die »Makulaturblätter« in E.T.A. Hoffmanns »Kater Murr«) oder beim Transport besudelte Papiere sind zweifellos alltägliche Erscheinungen. Doch speist sich aus diesem Vorkommen nicht das bemerkenswerte Interesse von schöner Literatur und Publizistik an Makulatur.

Es gibt miteinander zusammenhängende, aber doch differente Semantiken der Makulatur, eine überwiegend technisch-sachliche sowie eine soziale Semantik. Adelung macht dies nachvollziehbar, wenn er betont, »Maculatur« heiße »eigentlich, beschmutztes Papier, am häufigsten aber solches Papier, welches nur noch zum Einwickeln oder Einpacken anderer Körper dienet«. Er setzt hinzu: »Ein Buch wird Maculatur oder zu Maculatur, wenn es keine Leser findet, und daher zum Einwickeln verbraucht wird. ${ }^{18}$

Neben der in Produktion und Distribution anfallenden Makulatur existieren einwandfreie Druckerzeugnisse, die zu Makulatur erklärt werden, weil sie auf dem Markt nicht gefragt sind. Darin besteht ihr eigentlicher Makel, lat. macula, Fleck, Schandfleck, Unehre. Und es gibt solche Bücher, die nicht nachgefragt werden sollten. In diesem Sinne fungiert Makulatur zur Mitte des 18. Jahrhundert als ein Kampfbegriff kritischer Kommunikation, als eine griffige Metapher, mittels derer Texte anhand ihrer Materialität von der Lektüre ausgeschlossen werden sollen. Johann Jakob Breitinger gibt Ratschläge, wie ein Buch »von dem Gerichte der Makulatur noch zu erretten wäre « ${ }^{19}$, in Wielands »Teutschem Merkur« heißt es mit Blick auf einen Roman, der als »[t]ief unter aller Kritik« stehend bezeichnet wird, grundsätzlicher: »Dieser Waare ist aber kein Name zu geben, es wäre denn die große Rubrik Makulatur darauf zu prägen. ¿ $^{20}$ Makulatur verheißt in beiden, die Nachfrage auf dem

18 Art. »Maculatur«, in: Adelung (Hg.), Grammatisch-kritisches Wörterbuch, III, Sp. 11-12, hier: Sp. 11.

19 [Johann Jakob Breitinger], »Wohlgemeinter Vorschlag, wie Hrn. Christoph Schwartzens deutsche Aeneis von dem Gerichte der Makulatur noch zu erretten wäre«, in: Sammlung Critischer, Poetischer, und andrer geistvollen Schriften (1744), Stk. 8, S. 33-53, Nachweis bei Wolfgang Bender, Johann Jakob Bodmer und Johann Jakob Breitlinger, Stuttgart 1973, S. 50.

20 Es lohnt sich hier, die gesamte Kritik wiederzugeben, enthält diese in wenigen Zeilen doch eine ganze Reihe abwertender Formulierungen wie die »Rubrik Makulatur «: »Tief unter aller Kritik ist das Büchlein Martin Dickius Leben und Meynungen, sodann noch tiefer als jenes, Martin Flachs eine Geschichte des 18ten Jahrhunderts. Es ist wohl kein Land wie Teutschland, wo sich so elende Köpfe wie diese zum Beruf aufwerfen, das Publikum zu unterhalten. Bey den Ausländern hat das Schlechteste dieser Art doch wenigstens ein zunftgerechtes Ansehen, und den Manufaktur-Zuschnitt, daß man weiß, 
Buchmarkt betreffenden Konstellationen das Gegenteil dessen, was Autorschaft in seiner sozialen Dimension gemeinhin verspricht, kurz: Ehre, Ruhm, Unsterblichkeit. ${ }^{21}$

Soziale Praktiken lassen sich in historischer Perspektive überwiegend anhand von Texten rekonstruieren. Sie verfügen aufgrund dieser sprachlichen Vermittlung über eine Rhetorizität, die es stets zu beachten gilt, wobei sich die Literatur in besonderem Maße als ihr Schauplatz anbietet. Umgekehrt finden Praktiken aber auch Eingang in die Rhetorik von unterschiedlichsten Texten: Wenn in der Literaturkritik eine »Rubrik Makulatur « eingeführt wird, so rekurriert diese vernichtende Formulierung auf kulturelle Übereinkünfte und konkrete Selektionsprozesse im Umgang mit bedrucktem Papier. Die »Rubrik Makulatur « partizipiert überdies an Wertvorstellungen, die sich daraus ergeben, dass im Alltag überhaupt Gedrucktes ausgesondert und mit Makulatur weitaus prosaischer verfahren wird als mit gepflegten Bibliotheksbeständen, obgleich die allgemeine Erfahrung lehrt, dass die inhaltliche Qualität, um der es Kritik ja eigentlich geht, nicht entscheidend für das jeweilige "Schicksal der Bücher ${ }^{22}$ ist.

\subsection{Makulatur publizieren, schreiben, erzählen}

Dieses Kapitel gliedert sich in die Abschnitte Makulatur publizieren (5.3), schreiben (5.4), erzählen (5.5.). Die »Kultur der Makulatur « ${ }^{23}$, um die es im ersten Teilkapitel gehen wird, folgt Entwicklungen, die auch für den Diskurs der Autorschaft in der zweiten Hälfte des 18. Jahrhunderts entscheidend sind, wobei von einem wechselseitigen Einfluss auszugehen ist. So bringt ein immer stärker Marktgesetzen folgendes Verlagswesen immer mehr Makulatur

was es ist. Dieser Waare ist aber kein Name zu geben, es wäre denn die große Rubrik Makulatur darauf zu prägen. «(Der teutsche Merkur 3 (1776), S. 261f.) den Topos in der Literatur: »Dem literarischen Topos der kommerziellen Bücherzerstörung lag damit meist ein denunziatorisches Motiv zugrunde, dessen Logik ebenso simpel wie drastisch war: In jedem Fetzchen Buch steckte der ganze Autor, und je unrühmlicher die Anwendung war, die man von ihm machte, desto stärker wurde er erniedrigt. Das zerfetzte Buch symbolisierte die besudelte Ehre des Autors. Und jeder Bericht über den Schmutz, der auf seinen Seiten landete, diente dazu, ihn durch den Dreck zu ziehen.«(S. 7).

22 Nicolai, Sebaldus Nothanker, S. 74.

23 Fuchs, Büchermachen, S. 20. 
in immer kürzerer Zeit hervor. Makulatur verweist somit auf eine gesteigerte Ökonomisierung der Buchkultur, die in immer schnelleren Zyklen nach »Novitäten« verlangt und letztlich dem »Ewigkeitsanspruch « ${ }^{24}$ (Aleida Assmann) des Buchdrucks entgegensteht. Sie negiert damit das zentrale Versprechen der Dauerhaftigkeit von Autorschaft, das gleichermaßen an die Materialität wie die Medialität des Buches gebunden ist. Makulatur steht zugleich für eine überkommene Wissenskultur der Reproduktion und der Papierarbeiten in Abgrenzung zu einem Wissen, das sich auf subjektive Erkenntnis und Empirie konzentriert. Zugleich erfährt dieses Wissen eine starke Dynamisierung, es wird, nicht zuletzt unter dem Einfluss der prokreativen Ideen der Genieästhetik, einem Primat des Neuen unterworfen. Angesichts einer zunehmenden Polarität zwischen Neuem und Altem entwickelt sich Makulatur zu einer wirkmächtigen Trope des Überholten und Entwerteten. Darauf reagieren Gelehrte wie Justus Claproth mit seinem Versuch, »neues Papier« aus Makulatur $\mathrm{zu}$ fertigen. ${ }^{25}$ In dieser Erfindung offenbaren sich unter anderem die weitreichenden Implikationen der Genieästhetik, nur geht es Claproth nicht um Dichter oder Gelehrte, nicht um »Original-Schriftsteller«, die immer wieder einen neuen Anfang setzen. Sondern bei ihm soll auch das gedruckte Buch wieder zum unbeschriebenen Blatt werden, nicht zu Makulatur.

Die Schreibweisen der Makulatur in der Literatur um 1800 erfüllen vor allem eine metapoetische Funktion: Sie reflektieren Autorschaft in ihrer sozialen Dimension. Eine Autorschaft, die ihre Ursprünge in der Gelehrtenkultur des 18. Jahrhunderts hat. Dabei sind es hauptsächlich Schreibweisen des Komischen, allen voran des Satirischen, die ab den Sechzigerjahren des 18. Jahrhunderts geradezu selbstverständlich mit der Bildlichkeit der Makulatur verknüpft werden. Makulatur steht als eine so zugerichtete Reflexionsfigur im Kontext einer zeitgenössischen Buchkultur, die einen tiefgreifenden und vielfach kritisch hinterfragten Wandel vollzieht. Im zweiten Teilkapitel wird anhand von Lichtenbergs "Sudelbüchern« exemplarisch eine auf Autorschaft konzentrierte Schreibweise der Makulatur verhandelt. Dabei soll aufgezeigt werden, wie unter dem Einfluss von Zeitschriften, die »Fidibus« und »Tapeten« heißen, sprachliche Bilder ausgesonderten Papiers in einer satirischen Konturierung zu Reflexionsfiguren des eigenen Schreibens und Publizierens werden.

\footnotetext{
24 Assmann, Erinnerungsräume, S. 203.

25 Justus Claproth, Eine Erfindung aus gedrucktem Papier wiederum neues Papier zu machen, Cöttingen 1774.
} 
Makulatur ist um 1800 an prominenter Stelle in Buchtiteln und Überschriften präsent, sie begegnet in Literaturkritiken und Polemiken oder als Topos in den Vorreden von Texten unterschiedlichster Provenienz. Darüber hinaus hält sie Einzug in literarische Texte: Makulatur erscheint in der Literatur meist als »Materie am falschen Ort $\aleph^{26}$ (Mary Douglas), und gerade das macht sie zum geeigneten Gegenstand komischen Schreibens. Beispielsweise eröffnet Makulatur durch das satirische »Prinzip der transparenten Entstellung ${ }^{27}$ als rhetorische Figur wie als Gegenstand der Narration irritierende Zwischenräume, aus der Sicht der Schreibenden vor allem Spielräume, die als Schauplätze inszenierter Autorschaft oder Herausgeberschaft ebenso genutzt werden wie als Denkräume poetologischer Reflexion oder Freiräume zum literarischen Experiment. Magnus Wieland betrachtet Makulatur bei Jean Paul als "poetologische Chiffre ${ }^{28}$ eines literarischen Schreibens, das gelehrte Praktiken wie das Exzerpieren umfunktioniert, um sie für die schöne Literatur nutzbar zu machen. Auch diese Lesart der Makulatur steht im Kontext des Komischen, bei Jean Paul: des Witzes.

Makulatur offenbart die Veränderungen, die sich um 1800 in der Bestimmung von Autorschaft im Bereich der schönen Literatur ergeben, den Aufstieg des Dichters und die wirtschaftliche Emanzipation des Schriftstellers, wobei diese Veränderungen eine künstlerische Dimension aufweisen, die anhand der Makulatur verhandelt wird. So betont Mona Körte, dass sich »programmatische Szenen der Schriftvernichtung in Phasen einer Re- und Neuformulierung der Modalitäten des Ästhetischen ${ }^{29}$ häufen. Jürgen Nelles formuliert eine ähnliche These, nämlich »dass sowohl die Materialität wie die Medialität des Buches bereits am Übergang vom 18. zum 19. Jahrhundert zum Thema wird; und zwar vor allem in erzählerischen Texten solcher Autoren, die nach neuen Darstellungs- und Schreibformen suchen $\aleph^{30}$. Makulatur steht somit für eine künstlerische Souveränität, die im Medium der Fiktion nicht selten dementiert wird.

26 Vgl. Mary Douglas, Purity is Danger. An Analysis oft he Concepts of Pollution and Taboo (1966), London 2000, S. 36

27 Wolfgang Preisendanz, »Zur Korrelation zwischen Satirischem und Komischem«, in: ders., Rainer Warning (Hg.), Das Komische, München 1976, S. 411-413.

28 Wieland, »]ean Pauls Sudelbibliothek«.

29 Mona Körte, Essbare Lettern, brennendes Buch. Schriftvernichtung in der Literatur der Neuzeit, München 2012, S. 14.

30 Jürgen Nelles, Bücher über Bücher. Das Medium Buch in Romanen des 18. und 19. Jahrhunderts, Würzburg 2002, S. 58. 
Die Materialität des Buches fungiert in der Literatur, wie Monika Schmitz-Emans über Jean Paul, aber im Grunde allgemeingültig formuliert hat, als »metaphorische Chiffre für Bedingtheit in mehr als einer Hinsicht « ${ }^{31}$. Das gilt für Makulatur in einem gesteigerten Maße. Makulatur lässt den "Doppelcharakter « ${ }^{32}$ des Buches deutlich werden, indem sie dessen oftmals marginalisierte Materialität gegenüber dem Text in einer meist prekären Weise hervorhebt. Die von Schmitz-Emans markierte "Bedingtheit« ist in Jean Pauls »Leben Fibels« (1811), einem Roman, der Gegenstand des letzten Teilkapitels sein wird, zugleich die Bedingung der Möglichkeit eines weitgehend ungebundenen Erzählens. Hier muss sich ein fiktiver Biograph auf das beschränken, was ihm in Form von Makulatur an Quellen zugetragen wird. "Bedingtheit« wird bei Jean Paul aufwendig inszeniert, der Begriff der inventio erscheint mehrdeutig, geradezu paradox, ist es doch die literarische Fiktion von Quellen, die aufgefunden werden müssen, die einen weiten literarischen Spielraum eröffnet, losgelöst von den Konventionen des zeitgenössischen Erzählens. Auch die textuelle Faktur von »Leben Fibels« wird bestimmt von Makulatur: Die Kapitel sind nach papiernen Fundstücken wie »Kaffee-Düten« benannt, nach Überresten gedruckter Bücher, so dass durch diese Paratextualität die Buchform im Medium der Literatur destruiert wird, jene Form, die für den Leser eigentlich die Kohärenz des gelesenen Werks garantiert. Es ist die so herbeigeführte Spannung zwischen vorgeblicher Kontingenz und einem in Wirklichkeit intakten Buch, durch welche Fiktionalität als Übereinkunft hergestellt wird, unter Beteiligung des Rezipienten.

\subsection{Makulatur publizieren: Vom Ende der Autorschaft}

Es klingt nicht allzu verheißungsvoll, was auf dem Buchmarkt des späten 18. Jahrhunderts mitunter feilgeboten wird: "Makulatur zum bewußten Gebrauch« (1762), »Gedichte, welche das Makulatur vermehren« (1771) oder schlicht »Makulaturen. Erstes Bändchen« (1790) - so lauten Titel von Neuerscheinungen aus drei Jahrzehnten, beliebig ausgewählt, denn diese Reihe ließe sich mühelos fortsetzen. Auch in Nebentiteln wird fündig, wer nach

31 Schmitz-Emans, »Vom Leben und Scheinleben der Bücher«, S. 22.

32 Rautenberg, Wetzel, Buch, S. 63. 
Büchern sucht, die ihr Ende antizipieren: Mal verspricht ein Buch »satyrisch-moralische Makulatur«, mal ein anderes, ein »demüthiger Beitrag zur Makulatur des achtzehnten Jahrhunderts « zu sein. 1804 erscheint der Band "Leben, Thaten und Meinungen des Vetter Hans Dampfs«, eine - so der Nebentitel - »komische Geschichte«, die sich unter anderem an »Buch- und Tauschhändler, Gewürz- und Makulatur-Krämer « richtet. ${ }^{33}$

Auch die Herausgeber von Periodika legen Wert auf die paratextuelle Abwertung ihrer Unternehmungen: In Leipzig, dem seinerzeit unumstrittenen Zentrum des Buchhandels, werden Ende der Sechzigerjahre die "Pragmatische Makulatur « und der jeweils im »Bündel« angebotene »Fidibus« aus der Taufe gehoben. Fidibus - das sind schmale Papierstreifen, mit denen Pfeifen angezündet werden. Von ihnen bleibt nichts als Asche. In Fortsetzung dieser Traditionslinie wagt sich 1811 der Jean-Paul-Verleger Joseph Max in Breslau mit der »Makulatur oder Zeitung für Narren und ihre Freunde« auf den Markt. »Triumph Deutschland! bald ist die Literatur verschwunden. Mit Makulatur bist $d u$ angefüllt bis zu Makulatur « ${ }^{34}$, so beschreiben die Macher der kurzlebigen Zeitschrift eine Gegenwart, die im Rückblick als »Zeitalter der Makulatur « ${ }^{35}$ betrachtet werden wird.

Makulatur zu sein - das behaupten um 1800 also nicht wenige Publikationen vermittels ihrer Paratexte, aber wieso? Auf dem Titelblatt markiert »Makulatur « Schreibweisen des Komischen und weckt damit gewisse Rezeptionserwartungen. Deuten lässt sich die Selbstzuschreibung von Makulatur aber auch als publizistische Selbstbehauptung. Die vorauseilenden Titel erfüllen die kommunikative Funktion einer Deklaration, die als ein Akt der Souveränität gegenüber Publikum und Kritik zu verstehen ist, also gegenüber solchen

33 Die vollständigen Titel der angeführten Publikationen lauten: Johann Friedrich Hinz, Makulatur zum bewussten Gebrauch, Königsberg 1762; Gedichte, welche das Makulatur vermehren, Gernrode 1771; Makulaturen. Erstes Bändchen, Pilsen, Klattau 1790; Diogenes in ***, oder satyrisch-moralische Makulatur, Berlin 1774; Johann Friedrich Brömel, Nichts oder Etwas, nachdem es der geneigte Leser beliebt. Ein demüthiger Beitrag zur Makulatur des achtzehnten Jahrhunderts, Leipzig, Schleiz 1780; Hans Dampf, Leben, Thaten und Meinungen des Vetter Hans Dampfs. Eine komische Geschichte wider das Todtschiessen und Todtärgern, auch zugleich Hochzeit-, Braut-und Neujahrs-Ceschenk für lustige Leute, Spaßvögel, Buchund Tauschhändler, Gewürz-und Makulatur-Krämer, o.O. 1804. [Anonymus], »Makulatur«, in: Hesperus 2 (1812), Nr. 51, S. 408. Zitiert wird nach dem Wiederabdruck in einer anderen Zeitschrift.

35 Ludwig Friedrich Otto Baumgarten-Crusius, Festrede bei der akademischen Secularfeier von der Erfindung der Buchdruckerkunst, Jena 1840, S. 19. 
Adressaten, die gemeinhin darüber entscheiden, was unter die »Rubrik Makulatur« fällt. Das im späten 18. Jahrhundert vielfach beschworene »Schicksal der Bücher ${ }^{36}$, es liegt in der Logik dieser Selbstzuschreibung wieder in den Händen von Schriftstellern und Verlegern, aus der angeblichen Ohnmacht gegenüber der Macht der Märkte erwächst eine rhetorisch gewonnene Autorität. Und für manche Autoren gehört es geradezu zum Selbstverständnis, hauptsächlich Makulatur zu publizieren. So bezeichnet sich Georg Christoph Lichtenberg in einem Brief selbstironisch und nicht weniger selbstbewusst als »Makulaturisten ${ }^{37}$.

Solche Berufungen auf Makulatur erhellen die soziale Dimension von Autorschaft, die Gebundenheit an Bücher-Spiele, in denen mehrere Praktiken miteinander verflochten sind, die sich auf je unterschiedliche Weise auf die Materialität von Büchern beziehen. Solche Bücher-Spiele sind »soziale Spiele«, da sie Individuen die Möglichkeit eröffnen, sich gegenüber anderen in Position $\mathrm{zu}$ bringen und eine Subjektform anzunehmen ${ }^{38}$ - die der Autorschaft.

36 Nicolai, Sebaldus Nothanker, S. 74.

37 »An Wilhelm Gottlieb Becker« (19. April 1795), in: Lichtenberg, Briefwechsel, IV (1992), S. 435f. [2512], hier: S. 436.

38 Siehe zum praxeologischen Ansatz, der mit dem Begriff der »sozialen Spiele« verbunden ist, insbesondere Alkemeyer, »Subjektivierung in sozialen Praktiken«, S. 34: »Im Unterschied zu einer philosophischen Tradition, in der das Subjekt als ein überdauerndes, autonomes Canzes transzendent vor, hinter oder außerhalb der gesellschaftlichen Praxis angesetzt wird, richtet sich die praxeologische Perspektive auf SubjektBildungen und damit auf jene in Zeit und Raum ausgedehnten Prozesse, in denen sich die Ordnung des Subjekts herstellt, organisiert und verändert. Sie hebt den transitorischen Status, die Unabgeschlossenheit und Unvollständigkeit jeder Subjekthaftigkeit hervor. Der Begriff der Subjektivierung bringt das Subjekt nicht als Substanz, sondern als eine sin Formierung begriffene Struktur in den Blick: Es wird in einer ProzessPerspektive unter dem Gesichtspunkt seiner Entstehung, Entwicklung, Erhaltung und Veränderung betrachtet und in einer Praxis-Perspektive mit Wie-Fragen konfrontiert: Wie erlangt ein Individuum durch seine Teilnahme an sozialen Praktiken den Status eines intelligiblen, als >mitspielfähig anerkannten Subjekts? Wie bildet, organisiert und transformiert es sich dabei selbst? Und wie beeinflusst es in dieser >Arbeit< der Selbstgestaltung seinerseits die Verlaufsmuster der sozialen Spiele, in denen es seine gesellschaftliche Existenz gewinnt? Zusammengenommen begründen beide Perspektiven ein performatives Verständnis des Subjekts, das sich für die Schritte von SubjektBildungen ebenso interessiert wie für ihre Regelmäßigkeiten und die jeweils beteiligten Entitäten.« Ferner die Anmerkung ebenda: »Mit der Spiel-Metapher hebt Pierre Bourdieu hervor, dass Felder keine statischen Cerüste fixierter Positionen sind, sondern sich in kollektiver Praxis zusammen mit den Spielern herstellen und verändern. 
Texte zu verfassen, das ist in diesen Spielen der Autorschaft nicht entscheidend. Es gilt weiterhin, was Chartier mit Nachdruck formuliert hat: dass Autoren keine Bücher schreiben, sondern »Texte, die zu gedruckten Objekten werden ${ }^{39}$. Damit Autorschaft gelingt, muss man um 1800 nichts schreiben, sondern etwas drucken lassen. Makulatur lässt Autorschaft gerade deshalb in einem hohen Maße prekär erscheinen, weil sie die Versprechungen sozialer Anerkennung negiert, die mit Büchern verbunden werden. Weil sie, kurz gesagt, anhand der buchspezifischen Materialität die Grenzen von Autorschaft aufzeigt. Pointiert formuliert dies Lichtenberg:

»Was dem Ruhm und der Unsterblichkeit manches Schriftstellers ein größeres Hindernis in den Weg legt, als der Neid und die Bosheit aller kritischen Journale und Zeitungen zusammengenommen, ist der fatale Umstand, daß sie ihre Werke auf einen Stoff müssen drucken lassen, der zugleich auch zu Cewürzduten gebraucht werden kann. ${ }^{40}$

Makulatur erweist sich an dieser Stelle als Reflexionsfigur, mit der die Grenzen von Autorschaft ausgelotet werden, nicht zuletzt im Spiel mit der besonderen Zusammensetzung dessen, was wir Buch heißen. Denn Bücher-Spiele sind auch deshalb komplizierte Spiele, weil Bücher keine einfachen Dinge sind. Sie besitzen einen "Doppelcharakter ${ }^{41}$, so Ursula Rautenberg, weil sie Artefakt und Text zugleich sind; sie weisen eine "Doppelcodierung « ${ }^{42}$ auf, so Georg Jäger, da sie einen wirtschaftlichen und einen kulturellen Wert besitzen. Aus diesen Doppelheiten ergibt sich eine verwickelte Ambiguität, die für Makulatur ebenso kennzeichnend ist wie für Bücher.

\section{Buchverlag und Makulatur}

Die Korrespondenz eines Verlegers wie Friedrich Nicolai macht nachvollziehbar, wie sehr der Buchverlag im 18. Jahrhundert vom Material abhängt, insbe-

Soziale Spiele sind insofern ernste Spiele, als es ihnen um Existenz, Macht und Einfluss geht. Empirisch lassen sich Spiele als Praktiken-Geflechte analysieren.« (S. 34, Fn. 7)

42 Georg Jäger, »Keine Kulturtheorie ohne Geldtheorie. Grundlegung einer Theorie des Buchverlags«, in: Monika Estermann, Ernst Fischer, Ute Schneider (Hg.), Buchkulturen. Beiträge zur Geschichte der Literaturvermittlung. Festschrift für Reinhard Wittmann, Wiesbaden 2005, S. 59-78, hier: S. 69. 
sondere von der Verfügbarkeit des Papiers und dessen Marktpreisen. Das gilt ungeachtet regionaler Besonderheiten und der im letzten Drittel des 18. Jahrhunderts immer tieferen Konfliktlinie zwischen Sachsen und den norddeutschen Verlegern auf der einen, dem »Reichsbuchhandel« im Süden auf der anderen Seite. ${ }^{43}$ Der im Norden beheimatete Nicolai benennt in seinen Verlegerbriefen die mit der Materialität des Publizierens verbundenen Faktoren sehr genau. Während des Siebenjährigen Krieges (1756-1763) mutmaßt er gegenüber Johann Peter Uz, die Verzögerung der - nicht von ihm in Verlag genommenen - »Auserlesenen Gedichte« (1764) von Anna Louisa Karsch liege unter anderem daran, dass »itzt die Druckmaterialien entsetzlich theuer « ${ }^{44}$ seien. Und als er in Friedenszeiten seinen Freund Lessing über das Verlagsgeschäft aufklärt, formuliert Nicolai knapp: »Das Drucken macht große Kosten. ${ }^{45}$ Im Vergleich mit diesen Kosten sind die Autorenhonorare lange Zeit überschaubar, wenn überhaupt Geld fließt. Eine Entlohnung in Büchern ist vor der Professionalisierung des Publizierens keine Ausnahme, sondern eher die Regel - auch wegen des verlegerischen Risikos, dass ein vielversprechendes Buch als Makulatur endet. ${ }^{46}$

Bei den Herstellungskosten entfällt der größte Anteil auf die Beschaffung des nötigen Papiers. Wobei es angesichts der Kleinstaaterei des deutschsprachigen Raumes merkliche Unterschiede gibt. Nicolai hat es in Preußen schwerer als die Verleger in Sachsen, wo sich mit Leipzig die Hauptstadt des Buchhandels befindet. Marcus Conrad hat die Kostenentwicklung beim Papier anhand der "Allgemeinen Welthistorie « nachgezeichnet, die von 1744 bis 1814 bei Gebauer in Halle/Saale hergestellt wurde. Dabei ergibt sich ein Bild, das sich mit dem bei Nicolai deckt: Nach dem Siebenjährigen Krieg fallen die Papierpreise zwar wieder, sie klettern jedoch während der Ausweitung des Buch-

\footnotetext{
43 Siehe Wittmann, Ceschichte des deutschen Buchhandels, S. 121-150.

44 »An Johann Peter Uz, 5. Oktober 1762«, in: Nicolai, Verlegerbriefe, S. 19-24, hier: S. 20.

45 »An Gotthold Ephraim Lessing, 8. November 1769«, in: Nicolai, Verlegerbriefe, S. 65-70, hier: S. 68.

46 Lichtenberg wirbt im Februar 1787 in einem Brief an Franz Ferdinand Wolff für seinen Freund Dieterich als Verleger, wobei er dessen Ceschäftspolitik näher erläutert: »Freylich anfangs ist er [Dieterich] zurückhaltend, er giebt alsdann gewöhnlich halb Bücher und halb Geld u.s.w. Man kann ihm dieses nicht verdencken. Die vortrefflichsten Werke werden leider nur zu offt Makulatur, und aus manchem Bogen Packpapier ist mehr zu lernen, als aus dem offt mehr glücklich als verständigen Buch, das sich froh über den unverdienten Triumph darin einpacken läßt. « (Ceorg Christoph Lichtenberg, »An Franz Ferdinand Wolff (26.? Februar 1787), in: ders., Briefwechsel, III (1990), S. 331f., hier: S. 331.)
} 
marktes im letzten Jahrzehnt des 18. Jahrhunderts auf ein beständig hohes Niveau. ${ }^{47}$ Daniel Bellingradt beziffert den Anteil des Papiers an den Herstellungskosten im frühmodernen Europa auf 40 bis 75 Prozent. ${ }^{48}$

$\mathrm{Zu}$ beachten ist auch, dass es - so Bernhard Fischer ${ }^{49}$ - seit den Zeiten des machtvollen Leipziger Großverlegers und umstrittenen Reformers Philipp Erasmus Reich üblich ist, einen Titel in mehreren Papierqualitäten anzubieten. Dazu findet sich eine knappe, aber dennoch erhellende Erörterung verlegerischen Kalküls bei Johann Christian Gaedicke, mehrere Jahre Miteigentümer von Bertuchs Industrie-Comptoir in Weimar, der bei einer Verteuerung durch ein aufwendiges Material »zweyerley Ausgaben« anrät, um das Aufkommen an Makulatur zu minimieren:

»Die Bücher können durch das Papier auch sehr bedeutend vertheuert werden, zumal wenn ein Verleger etwas auf Schweitzer- oder sehr feinen englischen Papieren gedruckt liefert. Ein so gedrucktes Buch nimmt sich freylich recht gut aus, und wenn auch das Format, die Lettern und der Druck schön sind, so kann man sagen: es sey typographisch schön; aber ist diese Vertheuerung auch immer dem Inhalte des Werks angemessen? Ein noch so schön gedruckter Roman vom gewöhnlichen Schlage wird doch Maculatur, und nicht als typographische Seltenheit aufbewahrt. Classische Werke allein verdienen einen ausgezeichnet schönen Druck; jedoch immer müssen solche Werke in zweyerley Ausgaben geliefert werden; denn nicht alle Menschen können den schönen Druck bezahlen. $\ll^{50}$

Umso dringlicher und wirtschaftlich bedeutsamer wird vor diesem Hintergrund die Frage, was mit Büchern anzufangen ist, die niemand kauft. Gerne verweisen Verleger in Verhandlungen mit Schriftstellern auf das Risiko der

47 Marcus Conrad, »Kostenfaktoren beim Publikationsprojekt der Allgemeinen Welthistorie im Verlag Gebauer in Halle (1744-1814)«, in: Archiv für Geschichte des Buchwesens 68 (2013), S. 105-118, hier: S. 112. Siehe auch Manuel Schulz, »Zur Rezeption der Papierkrise 1788-1793 im Halleschen Verlag Gebauer«, in: Leipziger Jahrbuch zur Buchgeschichte 20 (2011/12), S. 143-154, zu Nicolai und der Situation in Preußen ferner Selwyn, Everyday Life, S. 59-62.

48 Daniel Bellingradt, »Trading Paper in Early Modern Europe. On distribution logistics, traders, and trade volumes between Amsterdam and Hamburg in the mid-late eighteenth century«, in: Jaarboek vorr Nederlandse boekgeschiedenis 21 (2014), S. 117-131, hier: S. 117.

49 Fischer, Johann Friedrich Cotta, S. 205.

50 Johann Christian Gaedicke, Der Buchhandel von mehreven Seiten betrachtet, Weimar 1803, S. 72-73. 
Makulatur. In der Kalkulation darf die Wahrscheinlichkeit, dass nicht alle Exemplare einer Auflage abzusetzen sind, nicht unberücksichtigt bleiben. ${ }^{51}$ Mit Makulatur ist also stets zu rechnen. Dabei gilt die Nachfrage als große Unbekannte und die Klage, »daß manches selbst gute Buch dem Buchhändler zu Maculatur wird«, als notorisch. ${ }^{52}$ Nicht nur deshalb ist Unverkäufliches selbstverständlich Gegenstand des Geschäfts. Verlagshandel ist um 1800 immer auch Handel mit Makulatur, aus betriebswirtschaftlicher Sicht ist sie nicht randständig, sondern bildet ein eigenes Sortiment mit unterschiedlichen Formaten und Papierqualitäten, wenn auch mit deutlich geringeren Erträgen als der Verkauf von Büchern und Zeitschriften. Das lässt sich anhand der Geschäftskorrespondenz im Verlagsarchiv Gebauer-Schwetschke in Halle nachvollziehen. So will der Kasseler Hofbuchhändler Johann Friedrich Hemmerde seiner verwitweten Tante Johanna Hemmerde im September 1783 die restlichen Exemplare des bei ihm erschienenen dritten Teils von Urban Gottlob Thorschmids »Freydenker-Bibliothek« (1766) »vom Halse schaffen« und bittet daher um aktuelle Preise für Makulatur. ${ }^{53}$

Regelmäßig informieren die Verlagsleitungen in kurzen Mitteilungen über ihr Angebot an Makulatur. Dann heißt es etwa bei Johann Jacob Gebauer: "Es ist gegenwärtig Makulatur vorräthig. " ${ }^{54}$ Abnehmer gibt es eine ganze Reihe: Tatsächlich handeln Verlage untereinander mit ausgesondertem Papier. Wiederholt wendet sich z.B. der in Leipzig ansässige Johann Philipp Haug an den Verleger Gebauer. Ende August 1782 schreibt er: »Ich habe gehört, daß Sie eine Parthie Maculatur gemacht haben und vermuthe, daß vielleicht noch nicht alles verkauft sein wird. $"$ "Gebauer steht 1788 in Sachen Makulatur auch in Verbindung mit dem umtriebigen Hamburger Papierlieferanten Haupt \& Grisson, der im selben Jahr mit eingesandten Proben französischen und holländischen Papiers bei Friedrich Nicolai für sich wirbt

51 Siehe Hirschi, Spoerhase, »Kommerzielle Bücherzerstörung«, S. 14f., die u.a. die Subskription als verlegerisches Instrument des 17. und 18. Jahrhunderts ansehen, um Makulatur in größerem Umfang zu vermeiden (S. 15).

52 [Reich], Zufällige Gedanken eines Buchhändlers, S. 11.

53 Brief von Johann Friedrich Hemmerde aus Kassel an seine Tante Johanna Hemmerde, 18.9.1783, Verlagsarchiv Gebauer-Schwetschke, Stadtarchiv Halle, A 6.2.6 Nr. 21153 (Kartonnr. 75), Bl. 2.

54 Nachricht von Johann Jacob Gebauer aus Halle, 22.12.1787, Verlagsarchiv GebauerSchwetschke, Stadtarchiv Halle, A 6.2.6 Nr. 23206 (Kartonnr. 79).

55 Brief von Johann Philipp Haug aus Leipzig, 31.8.1782, Verlagsarchiv GebauerSchwetschke, Stadtarchiv Halle, A 6.2.6 Nr. 20596 (Kartonnr. 73). 
und im beiliegenden Brief auf seine Geschäftskontakte zu einer Reihe Berliner Verleger verweist. ${ }^{56}$ Hoch ist die Nachfrage auch seitens des Handels, vor allem der Krämer, die Waren nicht en gros, sondern in kleineren Einheiten verkaufen und daher einen größeren Bedarf an Verpackungsmaterial haben.

Für die in Dessau ansässige »Verlagskasse für Gelehrte und Künstler«, einen der »Buchhandlung der Gelehrten« assoziierten Fonds, der wenig begüterten Autoren den Selbstverlag durch die Übernahme der Herstellungskosten ermöglicht, ${ }^{57}$ ist Makulatur ein gewichtiger ökonomischer Faktor. Über Wielands »Teutschen Merkur « macht sie 1781 ihre Konditionen bekannt: »Die Gesellschaft behält sich das Recht vor, eine auf Kosten der Verlagskasse gedruckte Schrift für Makulatur zu erklären, wenn in drei aufeinanderfolgenden Jahren in jedem derselben nicht mehr als 5 Exemplare abgesetzt werden. ${ }^{58}$ Autoren erhalten vom Verkaufserlös ihrer makulierten Bücher immerhin 88 1/3 Prozent. ${ }^{59}$ Heikel erscheinen diese Regelungen nicht zuletzt deshalb, weil der Selbstverlag im Ruch steht, dem Geltungsdrang Einzelner mehr Rechnung zu tragen als dem Markt. Das ausgesonderte Papier fungiert als Indikator für gutes verlegerisches Handeln. Dass Bücher zu Makulatur werden, gehört zwar zum Alltag von Verlegern um 1800. Trotz aller Routine des Verlagsbuchhandels steht Makulatur immer auch für wirtschaftliches Risiko und geschäftlichen Misserfolg.

Seit den Sechzigerjahren des 18. Jahrhunderts erhöht sich das Aufkommen an Makulatur merklich. Dafür gibt es eine Reihe von Gründen. Die ungekannte Expansion des Buchmarktes geht einher mit einer stark veränderten Nachfrage. Zugleich kommt es zu tiefgreifenden Umwälzungen in den Strukturen des Buchhandels. ${ }^{60}$ Nicht wenige Unternehmen fallen diesen zum Opfer. $\mathrm{Zu}$ den Veränderungen gehört auch der von Reich, dem einflussreichen Geschäftsführer der Weidmannschen Buchhandlung aus Leipzig, angeschobene Nettohandel.

56 Schreiben v. 7.11.1788, 18.11.1788, Verlagsarchiv Gebauer-Schwetschke, Stadtarchiv Halle, A 6.2.6 Nr. 23757 (Kartonnr. 82), A 6.2.6 Nr. 23758 (Kartonnr. 82); Selwyn, Everyday Life, S. 71.

57 Zur Verlagskasse siehe Rahmede, Die Buchhandlung der Gelehrten, S. 88-97.

58 [Anonymus], »Nachricht von der in Dessau errichteten Verlagskasse für Celehrte und Künstler« (1781), in: Evi Rietzschel (Hg.), Gelehrsamkeit ein Handwerk? Bücherschreiben ein Gewerbe? Dokumente zum Verhältnis von Schriftsteller und Verleger im 18. Jahrhundert in Deutschland, Leipzig 1982, S. 148-153, hier: S. 152.

59 Ebd.

60 Vgl. Ungern-Sternberg, »Schriftstelleremanzipation«, S. $75 f$. 
Bis zur Mitte des 18. Jahrhunderts bestimmt der Tauschhandel den Warenverkehr zwischen den Händlern. Auf den Buchmessen in Frankfurt a.M. und vor allem Leipzig wechseln, in Fässern ${ }^{61}$ angekarrt, Bögen bedruckten Papiers ohne Bezahlung den Besitzer. Lühmann betont, »daß der Handel allein auf dem Materialwert und der Quantität basierte « ${ }^{62}$. Das führt zu einem Überangebot, denn wer handeln will, muss selbst Titel im Angebot haben. Wittmann beschreibt die überquellenden Büchergewölbe der Buchhändler als Investitionsgräber: "Die allgemeine Lagerentwertung am Ende der Tauschhandelszeit war groß, nachdem sich langsam, aber stetig überall der neue Lesegeschmack durchgesetzt hatte und die alten Ladenhüter hoffnungslos unzeitgemäß wurden. $\ll^{63}$ An die Stelle des Stechens, wie die Praxis des Tauschens genannt wird, die vor allem süddeutsche Produzenten bevorzugen, deren Sortimente im aufgeklärteren Norden als schwer vermittelbar gelten, treten Barzahlung und harte Konditionen, während Reich die Preisspirale immer weiter ankurbelt. ${ }^{64}$

Für die mächtigen Buchhändler aus Norddeutschland bedeutet diese Konstellation einen enormen Vorteil, denn verkaufen sie ihre nachgefragten Titel direkt, "so bringen sie kein Makulatur sondern klingende Münze mit nach Hause ${ }^{65}$. Es kommt zu einer Trennung von Verlegern und Sortimentern, wobei Letzteren teilweise nicht einmal ein Remissionsrecht eingeräumt wird. »Wo will das hinaus?«, fragt ein Buchhändler im Jahr 1784. »Mit Schrecken sehen wir die fürchterlichen Ballen bedruckten Papiers ankommen; wir wissen, daß der größte Theil darunter Makulatur ist, doch müssen wirs

61 Hazel Rosenstrauch, »Buchhandelsmanufaktur und Aufklärung. Die Reformen des Buchhändlers und Verlegers Ph. E. Reich (1717-1787). Sozialgeschichtliche Studie zur Entwicklung des literarischen Marktes«, in: Archiv für Geschichte des Buchwesens 26 (1986), S. 1-128, hier: S. 34.

62 Lühmann, Buchgestaltung in Deutschland, S. 114. Reinhard Wittmann relativiert die Feststellung von Lühmann, indem er Tauschverhältnisse von 1:2, 1:3 oder 1:4 damit erklärt, dass »Ausstattung und innerer Wert allzusehr differierten « (Wittmann, Geschichte des deutschen Buchhandels, S. 90).

63 Wittmann, Ceschichte des deutschen Buchhandels, S. 114.

64 Siehe zur Preispolitik und mit Blick auf den Nachdruck die Darstellung bei Reinhard Wittmann, Buchmarkt und Lektüre im 18. und 19. Jahrhundert: Beiträge zum literarischen Leben 1750-1880, Tübingen 1982, S. 74-77, sowie Rosenstrauch, »Buchhandelsmanufaktur«, S. 55-57.

65 Ludwig Christian Kehr, »Vertheidigung des Bücher-Nachdrucks« (1799), in: Reinhard Wittmann (Hg.), Der Nachdruck in der publizistischen Diskussion. Pro und Contra, München 1981, S. 241-257, hier: S. 247. 
nehmen. ${ }^{66}$ Die für viele ungünstigen Geschäftskonditionen befördern den Nachdruck, forciert durch Unternehmer wie Thomas von Trattner aus Wien, denen gerne unterstellt wird, ansonsten nur »christkatholische Makulatur « ${ }^{67}$ im Verlag zu haben. All diese Umstände sorgen für reichlich Makulatur.

Vor diesem Hintergrund werden Buchauktionen wie in Jean Pauls »Leben Fibels « und Lotterien zunehmend wichtiger. ${ }^{68}$ Außerdem bildet sich der Antiquariatsbuchhandel heraus. Beide Entwicklungen sind nicht zuletzt deshalb aufschlussreich, weil sie offenbaren, welch beschränkte Möglichkeiten der Buchhandel bis dahin hatte, wenn Titel nicht abgingen: Ladenhüter vorzuhalten oder sie komplett dem Buchmarkt zu entziehen. Zugleich bilden die Vertriebsformen des "Sekundärmarktes « ${ }^{69}$ den beschleunigten Rhythmus eines Buchhandels $\mathrm{ab}$, in dem weniger gehortet, sondern immer schneller zwischen Neuem und Altem unterschieden wird.

Manche Verlage gehen ungewöhnliche Wege, damit ihre Produktion nicht zu Altpapier gerät. So ist 1795 einer Annonce in der Erlanger Zeitschrift »Neues Archiv für Gelehrte, Buchhändler und Antiquare« zu entnehmen:

»Wir machen hiermit dem Publikum die Anzeige, daß wir einige unsrer Verlagsartikel mit neuen Titeln versehen haben, um solche wieder in dessen Gedächtniß zu bringen, und noch einmal anzufragen, bevor wir solche wirklich dem Makulatur überliefern, ob diese Schriften kein besseres Schicksal verdienen. ${ }^{70}$

Andere widmen sich weniger transparent dem »Makulatur-Verlage«. Mit der fragwürdigen Praxis der Umwidmung von Büchern, die neue »Modetitel« er-

66 Zit. n. Wittmann, Geschichte des deutschen Buchhandels, S. 125.

67 Cottfried August Bürger, »Vorschlag, den Büchernachdruck zu steuern« (1777), in: Evi Rietzschel (Hg.), Gelehrsamkeit ein Handwerk? Bücherschreiben ein Cewerbe? Dokumente zum Verhältnis von Schriftsteller und Verleger im 18. Jahrhundert in Deutschland, Leipzig 1982, S. 58-75, hier: S. 72.

68 Zu den Lotterien siehe exemplarisch Daniel Bellingradt, »Book lotteries as sale events for slow-sellers: The case of Amsterdam in late eighteenth century«, in: Shanti Graheli (Hg.), Buying and Selling. The Business of Books in Early Modern Europe, Leiden, Boston 2019, S. 154-177.

69 Siehe Manfred Tietzel, Literaturökonomik, Tübingen 1995, S. 77, zu den Sekundärmärkten ebd., S. 74-77.

70 [Anonymus], »Literarische Anzeige über neue Büchertitel «, in: Neues Archiv für Celehrte, Buchhändler und Antiquare 1 (1795), S. 523-527, hier: S. 523, zit.n. Marie-Kristin Hauke, »In allen guten Buchhandlungen ist zu haben... «. Buchwerbung in Deutschland im 17. und 18. Jahrhundert, Dissertation, Erlangen-Nürnberg 1999, S. 167. 
halten, beschäftigt sich 1797 der Breslauer Buchhändler Johann Friedrich Korn in einer »Warnungs-Anzeige an die Herren Skalen-Meister des Wachsthumes der Schriftstellerei, und der Ausbreitung der Gelehrsamkeit in jedem Fache derselben«. Korn bezeichnet sie schlicht als »Betrug«, weil bis auf den Titel stets dasselbe Buch angeboten wird..$^{71}$

Auch Johann Theodor Benjamin Helfrecht, Rektor des Gymnasiums in Hof, greift solch fragwürdige Praktiken auf, in »Shakal, der schöne Geist«, einem Pasquill auf Jean Paul, erschienen in "Dintenstadt« - so behauptet das Titelblatt. ${ }^{72}$ Die Schmähschrift, verschlüsselt als Übersetzung einer aus dem Mittelalter stammenden Biographie Shakals, verfasst »von dem Araber Albezor«, liest sich nebenbei wie eine Satire auf den Buchmarkt des späten 18. Jahrhunderts. Im Rahmen einer »Digression von dem Nutzen der Polygraphie«, der Vielschreiberei, verunglimpft Albezor die Verleger einer angeblichen Vorzeit als »Bücherverkäufer«, »da doch wirklich das Verkaufen das Wichtigste ist «. ${ }^{73}$ Und diesen erscheint selbstverständlich, was bei ihren Nachfolgern um 1800 noch immer üblich sein soll:

»Wollte irgend eine Waare nicht abgehen: man wußte sich zu helfen. Man gab dem Buche einen neuen Titel und rief: >Siehe, es ist alles ganz neu! Der weise O.K. hat seine Wahrheiten aufs neue bearbeitet! «Um den Verkauf noch gemeinnütziger für Bücherverkäufer zu machen, hatte man auch oft zween Titel in Vorrath und verkaufte das Buch unter beiden. ${ }^{74}$

\section{»Maculatur-Exspectanz«: Ein Topos der Autorschaft um 1800}

Trotz alledem haben Schriftsteller um 1800 stets ein »Schicksal der Bücher « ${ }^{75}$ vor Augen, welches nichts anderes verheißt als Makulatur. Es gehört zur allgemeinen Rhetorik zeitgenössischer Vorreden, das eigene Buch in den Händen des geneigten Kleinhandels zu imaginieren, die »Maculatur-Exspectanz « ${ }^{76}$ ist ein vertrauter Topos. So heißt es zu Beginn von »Das Leben und Meinungen

$71 \quad$ Korn, »Warnungs-Anzeige«, Sp. 1017.

72 Johann Theodor Benjamin Helfrecht, Shakal, der schöne Ceist. Ein zeitgenössisches Pasquill aufJean Paul, hg. v. Dorothea Böck, Hannover 2013. Das Titelblatt der zweiten Auflage von 1801 findet sich auf S. $18 f$.

73 Helfrecht, Shakal, der schöne Geist, S. 93, Fn. 42.

74 Helfrecht, Shakal, der schöne Geist, S. 95f.

75 Nicolai, Sebaldus Nothanker, S. 74

76 Friedrich Lindheimer, Die Leihbibliothek. Ein Lustspiel in zwey Akten, Grätz 1799, o.P. 
des Herrn Magister Sebaldus Nothanker«, dem erfolgreichsten deutschsprachigen Roman des späten 18. Jahrhunderts, verfasst vom Buchhändler Friedrich Nicolai, der seine Figuren besagtes Schicksal eingehend erörtern lässt:

»Vielleicht lieset niemand dieses Buch, niemand findet etwas besonders darin, und es erregt vielleicht bloß die vorübergehende Aufmerksamkeit eines Cewürzkrämers, der schon bey sich überdenkt, welche dauerhafte Caffedüten aus dem haltbaren Papiere könnten gemacht werden. $\ll^{77}$

Die »vorübergehende Aufmerksamkeit «, von der an dieser Stelle die Rede ist, markiert nicht ein Verfallsdatum des Buches als Lektüre, sondern es geht um die Möglichkeit, dass allein der denkbare Nutzen des Artefakts eine zeitlich beschränkte Aufmerksamkeit generiert. Dass diese sich daraus speist, dass »dauerhafte Caffedüten aus dem haltbaren Papiere könnten gemacht werden«, sorgt für eine besondere Spannung: Als dauerhaft erachtet wird die Materialität des Buches, während sein Inhalt prekär und bestenfalls als etwas Ephemeres erscheint. Denn das vorangestellte und mit Blick auf den Krämer wiederholte Adverb (»Vielleicht«) schließt nicht aus, dass der Inhalt keinerlei Bestand hat, weil »niemand« das Buch liest oder ihm größere Bedeutung beimisst.

Ähnlich wie bei Lichtenberg werden die zwei Seiten eines Buches, die seinen »Doppelcharakter « ausmachen, so in ein Verhältnis zueinander gesetzt, dass sie sich gegeneinander ausspielen lassen, meist zu Lasten dessen, der für den Inhalt verantwortlich zeichnet. Dem entzieht sich der Satiriker Franz Xaver Huber scheinbar dadurch, dass er eines seiner Werke umstandslos als »Makulatur, mit welcher ich fürs erstemal die Heringsweiber, und die Käsekrämer zu versorgen gedenke ${ }^{78}$, vorstellt. Wer solche Sätze liest, hält allerdings in der Regel ein intaktes Druckerzeugnis in Händen. Darin liegt die Ironie einer solchen, meist polarisierenden Rede über Makulatur, die Autorschaft bekräftigt, sobald ein Buchexemplar in der Realität tatsächlich zur Lektüre genutzt wird. Trotz ironischer Volten dieser Art gilt: »Makulatur! - Fürchterlicher Gedanke für einen Autor, dem's mehr zu thun ist um den unbeschnittenen Beyfall seiner Leser, als um die beschnittenen Dukaten seines Verlegers. « ${ }^{79} 1820$ kommt Jean Paul im »Komet« auf das »Schicksal« sei-

77 Nicolai, Sebaldus Nothanker, S. 12.

78 Franz Xaver Huber, Lebensbeschreibung des weiland hochgelehrten, ehrengeachteten und kunstreichen Herrn Jodocus Rusch, Wien 1788, S. 5.

79 Lindheimer, Die Leihbibliothek, o.P. 
ner »Auswahl aus den Teufels Papieren« (1789) zu sprechen, die ihn berühmt machen sollten, während der Verleger Christoph Friedrich Beckmann nach wenigen Jahren nicht mehr viel mit den Büchern anzufangen wusste: »Der Verleger«, so heißt es, »brauchte schon damals kein Geheimnis aus meinem Namen zu machen, weil mein Buch selber eines blieb und zu Makulatur wurde $[$...].«(SW I.6, 833)

Wenn Autorschaft mit dem Druck ihren Anfang nimmt, dann markiert die Makulatur ihr scheinbares Ende. Doch die Grenzen der Autorschaft wirken durch die Rhetorik klarer als sie sind. Die Rede von der Makulatur spielt mit einem worst case, der als nahezu ausgeschlossen anzusehen ist. Denn ganze Auflagen von Büchern werden in der Regel nicht aus dem Verkehr gezogen. Vorstellbar sind Akte der Zensur, aber gerade dann ist die »diskursive Materialität « ${ }^{80}$ der verbreiteten Texte meist so ausgeprägt, dass zwar Bücher, aber nicht Inhalte spurlos verschwinden. Letztlich gilt das Heraufbeschwören der Makulatur seitens der Schriftsteller einer Ökonomie, auf die Nicolai anspielt, indem er die »vorübergehende Aufmerksamkeit« des Krämers anspricht: der von Georg Franck für das überreizte Informationszeitalter reklamierten »Ökonomie der Aufmerksamkeit ${ }^{81}$.

Makulatur lässt offenbar werden, dass es sich bei Büchern nicht um gewöhnliche Waren handelt. Georg Jäger beschreibt in diesem Zusammenhang eine »Doppelcodierung« des gedruckten Buches, »das auf der einen Seite seinen kulturellen (oder im engeren Sinne literarischen, wissenschaftlichen etc.) Wert und auf der anderen Seite seinen wirtschaftlichen Wert hat ${ }^{82}$. Diese zwei Seiten existieren nicht einfach nebeneinander, sondern stehen in einem Spannungsverhältnis zueinander, denn: »Die Tatsache, dass der Zerfall und die Zerstörung von Büchern ebenso zwingend zum Buchmarkt gehören wie ihr Verfassen und Verlegen, steht dem Glauben an die Beständigkeit des Buches diametral entgegen. ${ }^{83}$ In der "Doppelcodierung « liegt auch ein Potenzial für Paradoxien, und zwar dergestalt, dass Bücher ihrem Verleger einen hohen Verlust einbringen und zugleich ihren Wert steigern können.

80 Anne-Kathrin Reulecke, »Hinter dem Rücken der Bücher. Zerstörte Enzyklopädien in Jorge Luis Borges' Tlön, Uqbar, Orbis Tertius«, in: Mona Körte, Cornelia Ortlieb (Hg.), Verbergen - Überschreiben-Zerreißen. Formen der Bücherzerstörung in Literatur, Kunst und Religion, Berlin 2007, S. 227-243, hier: S. 228.

81 Siehe Franck, Ökonomie der Aufmerksamkeit, S. 55-62

82 Jäger, »Keine Kulturtheorie«, S. 69.

83 Hirschi, Spoerhase, »Kommerzielle Bücherzerstörung«, S. 2. 
In der Zeitschrift »Neue Litteratur und Völkerkunde« wird im Hinblick auf die wirtschaftlichen Risiken des Buchhandels betont, »daß der Kaufmann nie das ganze Geld, welches er in seine Waaren gesteckt hat verliehren, daß aber der Buchhändler beynahe die ganze Auflage eines Buches zu Maculatur machen kann $\ll^{84}$. Der Verleger Reich formuliert in Frageform, wie sich dieses Verlustgeschäft darstellt: »Muß ich nicht oft ganze Auflagen als Maculatur hingeben, wobey ich nicht einmal Auslagen, welche mich Pappier und Druckerlohn gekostet haben, wieder erhalte? ${ }^{85}$

\section{Taxonomien des »Lumpenpapiers"}

Dagegen verbucht Johann Gottlob Immanuel Breitkopf den kulturellen Wert eines Buches bereitwillig auf der ökonomischen Habenseite, und zwar auf eine bemerkenswerte Weise, da sich in seinen Ausführungen das von Joseph A. Dane beschriebene »Paradox der Singularität ${ }^{86}$ wiederfindet:

»Es ist [...] ein besonderer Umstand, welcher die Bücher-Fabrike vor andern Fabriken einen Vorzug gibt; dieser ist, daß die Fabrikate der mehresten Fabriken, nach Gebrauch von einigen Jahren, vernichtet und nicht weiter geachtet: hingegen für die wichtigsten und nützlichsten Fabrikate der Buchdruckerei Paläste erbaut und Hüter besoldet werden, solche für die Nachkommen zu erhalten; und wenn jene durch ihr Alter den größten Teil ihres Werts verlieren: das Alter den Wert vieler Produkte der Buchdruckerei mit jedem Jahre vermehret. ${ }^{87}$

Das Paradoxon besteht darin, dass auch die »wichtigsten und nützlichsten Fabrikate« nur als einzelne Exemplare den Weg in »Paläste« finden, während die restliche Auflage eines hochgelobten Buches durchaus »vernichtet und nicht weiter geachtet « werden kann. Breitkopf, dem als Verleger auch eine kaufmännischere Betrachtung der »Bücher-Fabrike« zuzutrauen wäre, be-

84 [Anonymus], »Gedanken über Buchhandlung und Nachdruck«, in: Neue Litteratur und Völkerkunde 1.2 (1787), S. 189-216, hier: S. 193.

85 Philipp Erasmus Reich, Der Bücher-Verlag in allen Absichten genauer betrachtet, 0.0. 1773, S. 18.

86 Dane, The Myth of Print Culture, S. $6 \mathrm{f}$.

87 Johann Cottlob Immanuel Breitkopf, „Über Buchdruckerei und Buchhandel in Leipzig« (1793), in: Evi Rietzschel (Hg.), Celehrsamkeit ein Handwerk? Bücherschreiben ein Cewerbe? Dokumente zum Verhältnis von Schriftsteller und Verleger im 18. Jahrhundert in Deutschland, Leipzig 1982, S. 7-13, hier: S. 9. 
dient zugleich ein Denken, das seine negative Entsprechung in der kritischen Rede von der »Rubrik Makulatur « findet. Die »Beständigkeit des Buches ${ }^{88}$ ist für Breitkopf nicht selbstverständlich, sie ergibt sich nicht aus seiner schieren Materialität; vielmehr ist es die Taxierung seiner Inhalte, die Anlass gibt, ein Buch »für die Nachkommen zu erhalten« oder nicht, wobei sich sein kultureller Wert aus dem Aufwand ableiten lässt, der seinetwegen betrieben wird. Makulatur kann in diesem Sinne als Metapher für die geringe Wertschätzung von Büchern fungieren, während sie als konkrete Erscheinung den Verfall verlegerischer Investitionen anzeigt.

Es ist eine durchaus zwiespältige Würdigung, wenn Johann Gottfried Herder ausruft: »Heil dem Erfinder des Lumpenpapiers; wo er begraben liege, Heil ihm! Mehr als alle Monarchen der Erde hat er für unsre Literatur gethan, deren ganzer Betrieb von Lumpen ausgeht und so oft in Makulatur endet! « ${ }^{89}$ Herder liefert im 95. Brief zur »Beförderung der Humanität«, der von »Schrift und Buchdruckerei« handelt, eine kleine Literaturtheorie des »Lumpenpapiers« in historischer Perspektive. Denn er ist sich sicher: »Setzet ihn, setzet Horaz und wen ihr wollet, in unsre bücherreichen Zeiten; schwerlich hätten sie mit so viel Zuversicht, mit so umfassendem, tiefdringendem Fleiße gedichtet. ${ }^{90}$ Jedoch sind es nicht die »bücherreichen Zeiten« an sich, die einen Horaz derart konsterniert hätten, sondern Herder geht es vielmehr um ihre Ursachen. Er schreibt: »Der mühsamere Weg, wie man damals zu Büchern kommen konnte, machte Bücher auch werther; bei einem höheren Begriff von dem, was sie enthielten, wandte man auch mehr Fleiß auf das, was sie enthalten sollten. "11 Herder führt also die Qualität und letztlich Beständigkeit von Texten produktionsästhetisch auf die Materialität ihrer Medien zurück.

So eigenwillig diese Theorie erscheinen mag, sie weist in die Richtung einer um 1800 gängigen Betrachtung der Materialität von Publikationsformen, die eine gewisse Leichtfertigkeit des Schreibens zwar nicht generell mit den Eigenschaften des »Lumpenpapiers« verbindet. Dafür existiert eine Taxonomie papierner Medien, in der gewisse Formen und Formate in der Regel abwertend mit Inhalten assoziiert werden. In solche Betrachtungen zeit-

88 Hirschi, Spoerhase, »Kommerzielle Bücherzerstörung«, S. 2.

89 Johann Gottfried Herder, Briefe zur Beförderung der Humanität, Sämtliche Werke, hg. v. Bernd Suphan, Berlin 1877-1913, XVIII (1883), S. 86-92 (Achte Sammlung, Nr. 95, Siebentes Fragment, Schrift und Buchdruckerei), hier: S. 89.

90 Ebd., S. 88.

91 Ebd. 
genössischer Druckkultur wird meist auch eine sich verändernde Nachfrage auf dem Buchmarkt einbezogen. Tatsächlich schlägt sich diese auch in der Gestalt von Publikationen nieder. Anstelle der »vielpfündigen Folianten« (SW I.5, 495), welche die Gelehrtenkultur prägten, halten nun »Büchelgen von wenig Bogen, die aus Hand in Hand gehen, viel gelesen und wenig gekauft werden ${ }^{92}$, Einzug in die Sortimente vieler Händler. In Friedrich Nicolais »Sebaldus Nothanker« beschreibt der Buchhändler Hieronymus die Vorlieben seiner »besten Kunden«, wobei ein wirtschaftlich motiviertes Bedauern über das Ende des gelehrten Umgangs mit dem Buch mitschwingt: »Itzt hat die leidige Sucht, Gedichte und kleine Modebücher zu lesen, die großen Bibliotheken und die schwerfällige Art zu studiren wozu große Bibliotheken nöthig waren, ganz aus der Mode gebracht, und seitdem ist eine sehr ergiebige Quelle des Reichthums der Buchhändler verstopft. ${ }^{93}$ Eine solche Taxonomie gedruckter Medien wird auch an anderer Stelle in der Literatur entfaltet, etwa in August Lafontaines »Leben eines armen Landpredigers«, einem Roman, in dem die männliche Hauptfigur Frau und Tochter davon überzeugen will, ihre Habseligkeiten in passende Makulatur einzuwickeln, unter anderem "neue Moden in Bogen von Zeitschriften, die eben so hinfällig sind, als das, was hineingewickelt wird «. ${ }^{94}$ In einer Zeit, in der Publikationsformate wie das Taschenbuch oder die Zeitschrift maßgeblich werden für die Lesekultur, gilt dies sogar zunehmend.

Es gehört zur gängigen Rhetorik des späten 18. Jahrhunderts, den Warencharakter des Buches mit dessen Materialität zu identifizieren. Nie erscheinen die Werke der schönen Literatur papierner als im ökonomischen Diskurs dieser Zeit. Die Makulatur verweist auf den faktischen Gegenstand des Buchgeschäfts, an dem Schreibende vor dem Urheberrecht kaum Anteil haben: das gedruckte Artefakt, das als Ware gehandelt und im ungünstigen Fall zu Makulatur wird. Wenn Schriftsteller an der Schwelle zum 19. Jahrhundert von Fichte als »Fabrikanten ${ }^{95}$ bezeichnet werden, so ist dies zwar als Polemik zu verstehen, die Schreiben als berechnend ausgeübtes Handwerk abwertet, aber auch als Hinweis darauf aufzufassen, dass Autoren nun zu Marktteilnehmern geworden sind, weil sie einen Anteil am Buch als Ware beanspruchen.

92 Nicolai, Sebaldus Nothanker, S. 73.

93 Ebd., S. 74.

94 Lafontaine, Leben eines armen Landpredigers, I, S. 7.

95 Fichte, Ueber das Wesen des Celehrten, S. 134. 
Bedeutete eine Publikation bis ins letzte Drittel des 18. Jahrhunderts vor allem die Aufnahme in den Gelehrtenstand, soziales Prestige, so wird Autorschaft zunehmend wirtschaftlichen Prinzipien unterworfen. Ruhm und Ehre erfahren als Werte gesellschaftlicher Anerkennung innerhalb der Ständegesellschaft mit der bürgerlichen Vergesellschaftung eine auf Arbeit und Leistung ausgerichtete Neucodierung. Friedrich Schiller spricht von einem »oekonomischen Ruhm « ${ }^{96}$, der sich aus Auflagenhöhen und Verkäufen ableiten lässt. Für einen solchen Ruhm steht Makulatur faktisch wie symbolisch, wenn auch: ex negativo. Somit vollzieht sich in der Rhetorik der Makulatur um 1800 unmerklich ein Paradigmenwechsel hin zum Kalkül des Marktes, das nun selbstverständlich auch Autorschaft betrifft, weil Makulatur für Schriftsteller unmittelbar einen wirtschaftlichen Schaden bedeutet. Dieser Schaden besteht freilich nicht materialiter in der Zerstörung von Büchern, sondern ist finanzieller Art, wenn Ware zu Makulatur wird. »Das unternehmerische Risiko wie der Erfolg werden«, so Bernhard Fischer, »zu gemeinsamen Geschäftsprinzipien des Verlegers und des Autors, der Autor wird zum Interessenten an der von ihm produzierten Ware, die er nicht mehr nach dem einmaligen Verkauf von sich abstößt, sondern der er über die Absatztermine verbunden bleibt - sein Werk wird selbst zu einem Kapitel.« ${ }^{97}$

Jenseits der Ökonomie führt Makulatur vor Augen, dass nicht zutrifft, was Jakob Ayrer im Jahr 1618 behauptet hatte, dass es nämlich »nichts Tauerhaffters und unsterblichers ist/als eben die Bücher/die lassen sich nimmermehr außrotten/noch das jenige in vergessenheit kommen/was drinnen lob und denckwürdiges der posteritet zu guten beschrieben und gleichsam $\mathrm{zu}$

96 Nachdem der»Teutsche Merkur «zu Jahresbeginn einen Auszug seiner »Ceschichte des Abfalls der vereinigten Niederlande von der spanischen Regierung « veröffentlicht hat, schreibt Schiller am 17. März 1788 in einem Brief an Gottfried Körner: »Bedenke dieses, so wirst Du mir zugeben müssen, daß kein Fach (Geschichte, Anm. d. Verf.) so gut dazu taugt, meine Oekonomische Schriftstellerei darauf zu gründen sowie auch eine gewisse Reputation; denn es gibt auch einen oekonomischen Ruhm.« (»An Körner, 17. 3. 1788«, in: Friedrich Schiller, Schillers Werke. Nationalausgabe [NA], begründet v. Julius Petersen, fortgeführt v. Lieselotte Blumenthal und Benno von Wiese, hg. im Auftrag der Nationalen Forschungs- und Gedenkstätten der klassischen deutschen Literatur in Weimar (Goethe- und Schiller-Archiv) und des Schiller-Nationalmuseums in Marbach v. Norbert Oellers, Siegfried Seidel, Weimar 1943ff., 25 (1979), 7.1.3, S. 28-31 [20], hier: S. 30 .

97 Fischer, Johann Friedrich Cotta, S. 43. 
einem Schatz eingewickelt ist ${ }^{98}$. Ayrer betont die Speicherfunktion, die Michael Giesecke als Charakteristikum der Buchkultur betrachtet, eine Funktion, die auch auf Autorschaft zu beziehen ist, im Gestus eines Versprechens: »Während noch im Mittelalter der memoria ganz selbstverständlich die Funktion sowohl des Behaltens als auch des Vergessens zugeschrieben wurde, sieht die Buchkultur nur noch die Speicherfunktion. "Die Buchkultur habe das Vergessen für einen Mangel gehalten und diesem durch die Verbreitung von Informationen im Druck abhelfen wollen, so Giesecke. ${ }^{99}$ Deshalb gilt das Buch bis heute als »Garant eines epochenübergreifenden kulturellen Gedächtnisses ${ }^{100}$.

In Bezug auf die Subjektform der Autorschaft ist die Konzentration auf die Speicherfunktion der Bücher von hoher Bedeutung, wie die Historia literaria (als eine Vorläuferin der Literaturgeschichte) und angrenzende Wissensgebiete im 18. Jahrhundert zeigen. Hier wird ein enormer Aufwand betrieben, die zu sichernden Informationen in ein dichtes Netz aus bibliographischen und biographischen Daten zu fassen, wobei Letztere den Bestand von Autorschaft absichern. Michael Maurer erkennt in der "gelehrten Memoria" eine Wurzel der Biographie, der um 1800 im Prozess bürgerlicher Vergesellschaftung eine grundlegende Funktion zukommt. ${ }^{101}$ Daher bedeutet Makulatur in jedem Einzelfall einen empfindlichen Schlag gegen das bürgerliche Subjekt in der Form von Autorschaft, weil letztlich mit dem Buch immer auch eine Biographie auf dem Spiel steht.

Sowohl Aleida Assmann als auch Mona Körte befassen sich mit der Speicherfunktion von Büchern, auch wenn sie diese abstrakter der Schrift als Medium zuschreiben. Assmann verbindet mit der Speicherfunktion sowohl einen Anspruch als auch ein Versprechen im Hinblick darauf, die »Textspuren vergangenen Lebens zu bewahren ${ }^{102}$ und somit auch Autorschaft langfris-

98 Jacob Ayrer (Hg.), Opus Theatricum. Dreißig Außbündtige Comedien und Tragedien von allerhand Denckwürdigen alten Römischen Historien und andern Politischen geschichten und gedichten [...], Nürnberg 1618, [Vorrede].

99 Michael Giesecke, Von den Mythen der Buchkultur zu den Visionen der Informationsgesellschaft, Frankfurt a.M. 2003, S. 244.

100 Hirschi, Spoerhase, »Kommerzielle Bücherzerstörung«, S. 1.

101 Michael Maurer, »Kultur und bürgerliche Vergesellschaftung«, in: Hans-Edwin Friedrich, Fotis Jannidis, Marianne Willems (Hg.), Bürgerlichkeit im 18. Jahrhundert, Tübingen 2006, S. 31-44, hier: S. 38. Siehe weiterführend Michael Maurer, Die Biographie des Bürgers. Lebensformen und Denkweisen in der formativen Phase des deutschen Bürgertums (1680-1815), Göttingen 1996.

102 Assmann, »Texte, Spuren, Abfall«, S. 101. 
tig zu sichern: »Der Ewigkeitsanspruch und das Ewigkeitsversprechen der Schrift beruhten auf zwei Grundannahmen: daß erstens der materielle Bestand und zweitens die Lesbarkeit der Texte gesichert ist. « ${ }^{103}$ Körte ergänzt in Bezug auf den »Ewigkeitsanspruch«, dass Texte trotz ihrer »rhetorischen und poetologischen Qualitäten« nicht über eine »inhärente Widerstandskraft gegen Verfall und Gewalt « ${ }^{104}$ verfügten. »Vielmehr ist die Überlebensdauer der Texte von sozialen Verabredungen ebenso wie von der Ausbildung eines philologischen Instrumentariums abhängig«, führt sie aus. ${ }^{105}$ Pointiert erläutert wiederum Assmann, wie sich solche »sozialen Verabredungen« darstellen und wie wandelbar sie sind. Nicht ohne Grund formuliert sie im Präteritum, welche Grundannahmen bis zur Mitte des 18. Jahrhunderts dem Verhältnis von Schrift und Ewigkeit zugrunde lagen. Diese Annahmen waren bis dahin ebenfalls bedeutsam für die Vorstellungen von Autorschaft, und sie bleiben es, wenn auch unter deutlich anderen Vorzeichen. Das heißt, dass um 1800 zwar noch immer erwartet wird, durch Autorschaft zeitlos zu wirken. Doch die Rahmenbedingungen sind längst andere, wie Assmann schreibt:

»Die Nachwelt verwandelt sich [...] vom Garanten der Ewigkeit zur schärfsten Bedrohung von Dauer. In einem ökonomisierten und industrialisierten bürgerlichen Zeitalter veränderten sich nicht nur die Bedingungen literarischen Schreibens und Lesens, sondern auch die des Ruhms. Die Dimension, in die Texte hineingeschrieben werden, ist immer weniger die longue durée von fama und memoria und immer mehr der literarische Markt mit seinen Rhythmen kurzlebiger Konjunktur. ${ }^{106}$

Zeitlichkeit wird an der Schwelle zum 19. Jahrhundert in allen Bereichen des Publizierens an die Ökonomie gekoppelt, mit dem Ergebnis einer Konditionierung des Temporalen durch den Buchmarkt mit seinen jährlichen Messen, die im Rhythmus nicht nur immer Neues hervorbringen, sondern auch Altes, nämlich Bücher, die angesichts der Neuerscheinungen nur noch zu Makulatur taugen. Daher wird in der Zeitschrift »Der neue deutsche Zuschauer« beispielsweise vorgeschlagen, nur noch »eine jährliche Messe«stattfinden zu

103 Ebd., S. 103.

104 Körte, Essbare Lettern, S. 16.

105 Ebd.

106 Assmann, »Texte, Spuren, Abfall«, S. 101. 
lassen. ${ }^{107}$ Nebenbei offenbart sich die Kehrseite des im späten 18. Jahrhundert für das Konzept der Autorschaft maßgeblichen Geniegedankens. Der Schöpfer des Neuen fällt sich gewissermaßen selbst zum Opfer, weil ein ewig auf das Neue ausgerichteter Markt sich zyklisch von jedem Werk abwendet. ${ }^{108}$ Was von den »Novitäten« der letzten Messe bleibt, ist in nicht wenigen Fällen: Altpapier.

\section{»Bücherschatz« im Kramladen}

Mit der Konjunktur des Buchmarktes erhöht sich um 1800 das Angebot an Makulatur. Eine Nachfrage besteht vor allem auf Seiten anderer Händler. »Der Buchhandel«, so ist in Jean Pauls »Leben Fibels« von $1811 \mathrm{zu}$ lesen, »hat sich vielleicht nie so stark als jetzt fast mit allen anderen Handelszweigen verflochten, indem er überall die Tara [das Verpackungsgewicht, Anm. d. Verf.] festsetzt und der gemeinen Material-Materie erst ein Kleid geben muß.« (SW I.6, 371) Entsprechend bereist in dieser Erzählung der Biograph von Gotthelf Fibel auf der Suche nach den »Hand- und Druckschriften« (SW I.6, 372) des vergessenen Autors nicht Universitäts-, sondern mehrere Handelsstädte. Seine "gelehrten Reisen « führen ihn dort auch nicht zu Buchhändlern, sondern in die "Materialhandlungen « (SW I.6, 372) der übrigen Kaufleute. Materialhandlungen - dieses Wort lässt sich in abgewandelter Bedeutung auf die sozialen Praktiken beziehen, die sich gegenseitig aufzuheben scheinen, wenn Bücher in der Literatur als Makulatur im Kleinhandel auftreten. Das Ergebnis sind intrikate Spiele mit der Materialität von Büchern, die sich um die von Assmann und Körte angeführten Aspekte drehen, also um die materiale Beständigkeit und Lesbarkeit von Texten, aber auch um die gemeinschaftlichen Verabredungen, die für ihre Überlieferung entscheidend sind.

In diesen Spielen ist es vor allem die soziale Figur des Krämers, die aufgrund ihrer Materialhandlungen zu einem Exponenten der Buchkultur avanciert $^{109}$, und zwar in einer Doppelrolle als Zerstörer und Bewahrer. Johann

107 [Anonymus], »Einige Bemerkungen über den, in dem neunten Heft des neuen deutschen Zuschauers abgedrukten, Artikel: Ueber den deutschen Buchhandel«, in: Der neue deutsche Zuschauer 4 (1790), S. 181-190, hier: S. 189.

108 Vgl. Assmann, »Texte, Spuren, Abfall«, S. 103.

109 Siehe zur Unterscheidung zwischen Kaufmann und Krämer den Eintrag »Kaufmann «in Adelung, Grammatisch-kritisches Wörterbuch, II, Sp. 1524-1525, hier: Sp. 1524: »In engerm Verstande ist ein Kaufmann nur derjenige, welcher im Ganzen oder im Großen handelt, 
Heinrich Voß erwähnt in einem Brief einen Kaufmann, der ganze Büchersammlungen ausschließlich deshalb aufkauft, um Tüten aus dem Papier drehen zu lassen. ${ }^{110}$ Dagegen bezieht die Romanfigur Fibel bei Jean Paul »vom Würzhändler Düten aus allen Fächern«, nicht als Verpackungsmaterial, sondern zur Lektüre, so dass der Gewürzladen zu einer »Lese-Bibliothek« (SW I.6, 388) wird. In den Vorarbeiten zu »Leben Fibels« wird diese Art der Literaturbeschaffung noch anders akzentuiert: »Er las bei den Krämern die besten Werke und neuerer Zeit konnte er noch bessere da lesen. " rer Zeit« bei den Krämern »noch bessere« als die »besten Werke« zu finden sind, liest sich wie eine ironische Spitze gegen die üblichen Anpreisungen des Buchmarktes. Im noch früheren »Komischen Anhang zum Titan« (1800) findet sich unerwartet ein »Bücherschatz«, der ebenfalls auf die Konditionen des Marktes anspielt: »Der Landkrämer Seirich überraschte uns mit dem größten Bücherschatz, zumal an Novitäten, wovon schon ein Teil geleimt um den Ofen hing, Kaffeesäcke in Quart und Pfefferdüten in Oktav.« (SW I.3, 863)

Der Kramladen eignet sich deshalb als literarischer Schauplatz der Buchkultur, weil er deren ökonomische Seite stets präsent hält und überdies als Umschlagplatz sozialer Praktiken zwischen Makulatur und Literatur genutzt werden kann. In der kurzen Passage des »Komischen Anhangs zum Titan« kommt es unmerklich $\mathrm{zu}$ einer Umwandlung und auch Umwertung von Makulatur, im Grunde einer enormen Aufwertung, und zwar zum »Bücherschatz«. Dass es sich bei diesem »Bücherschatz« um Makulatur handelt, wird jedoch erst klar, wenn es heißt, dass der Landkrämer »Kaffeesäcke in Quart und Pfefferdüten in Oktav« zum Trocknen aufgehängt habe. Die Formatangaben deuten an, dass es die Maßstäbe des Buches sind, die an das anderweitig nutzbar gemachte Papier angelegt werden. Entscheidend ist jedoch, dass die Makulatur offenbar gelesen wird, denn die Einschätzung, dass es sich hier um einen "Bücherschatz« handelt, setzt mindestens eine flüchtig-taxierende Lektüre voraus. Dass es nicht zuletzt »Novitäten« sind, die der Landkrämer unwissentlich im Angebot hat, legt en passant die Kategorisierungen eines Marktes offen, die überhaupt erst Makulatur in größerem Umfang hervorbringen, indem Neuerscheinungen andere Titel alt aussehen

d. i. einkauft und verkauft, zum Unterschiede von einem Krämer, welcher die Waaren nach Ellen, Pfunden u. s.f. verkauft."

110 Vgl. Joachim Wachtel, Vom Ballenbinder zur Selbstbedienung. Verpackung-anno dazumal und heute, Cütersloh 1965, S. 65.

111 Ferdinand Josef Schneider, Jean Pauls Altersdichtung Fibel und Komet. Ein Beitrag zur litterarhistorischen Würdigung des Dichters, Berlin 1901, S. 101. 
lassen. Zugleich lässt sich diese kurze Passage als ironisch angelegte Überlieferungsphantasie begreifen. Zwar wird die Speicherfunktion der Schrift technisch durch die papierne Materialität gewährleistet, es bedarf allerdings einer Lektüre am falschen Ort, damit diese Funktion ihren Zweck erfüllt.

In »Der Schriftstellerteufel« (1791), einem Bändchen, das im Nebentitel als »klassisches Original-Lesebuch für unglückliche Autoren« ausgewiesen wird, spielt Heinrich Zschokke eine ähnliche Konstellation der Überlieferung durch. Zschokke geht es dabei um die Auswirkungen, die eine Makulierung auf Autorschaft hat:

»Cesetzt auch, unser unsterbliches Werk ginge den Weg alles verdorbenen Papiers - verlöre sich in die Makulaturkammer, was schadet das? über zwei, drei, vier Jahrhunderte verkauft vielleicht ein unwissender Krämer einem Celehrten für drei Pfennig Käse in unsre unsterbliche Schrift gewikkelt; dieser liest das Blatt, entdeckt unser Ich, und supplirt stante pede seinen Jöcher damit; hält wohl gar eine erstaunlich gelahrte Disputazion über das Käseblatt - ein Fall, der sehr möglich ist, weil wir izt schon täglich derlei Käseblattdisputationen anzuhören haben! « $^{112}$

Allzu tröstlich erscheint dieses gute Ende freilich nicht, denn offensichtlich ist der Gestus des Komischen. Außerdem wird das Überlieferte seinen »rezeptionsästhetischen Mangel «113 ${ }^{11}$ der es zu Makulatur hat werden lassen, kaum los, da sich dieser darin bestätigt findet, dass es als »Käseblatt « deklariert wird, das diskursiv zu wenig mehr führt als zu »Käseblattdisputationen«. Unabhängig davon erscheint bedrucktes Papier als beständiger, wenn auch nicht als alleiniger Träger von Autorschaft. Als zweite Säule erweist sich eine Wissenskultur, an der ein »unwissender Krämer« für gewöhnlich keinen Anteil hat. Aufschlussreich ist die Formulierung, die Zschokke wählt, sobald diese Wissenskultur zum Tragen kommt, denn »entdeckt« wird nicht weniger als »unser Ich«, das trotz der Großschreibung nicht als Begriff einer avancierten Subjektphilosophie eingeführt wird, sondern im Sinne einer Subjektivierung durch die Zuschreibung von Autorschaft. Dabei wird das Subjekt der Autorschaft nachträglich in gelehrten Praktiken hervorgebracht, die sich auf eine »unsterbliche Schrift« beziehen, allen voran: das Bibliographieren. Diese Praktiken führen keineswegs »stante pede«, aber doch zielgenau über den »J̈̈cher«, das von Christian Gottlieb Jöcher herausgegebene und am Ende

112 [Zschokke], Der Schriftstellerteufel, S. 7.

113 Wirth, (Papier-)Müll und Literatur«, S. 19. 
des 18. Jahrhunderts durch Johann Christoph Adelung ergänzte »GelehrtenLexicon«, einem Konkurrenzprodukt zu Meusels »Das gelehrte Teutschland«.

Die von Jean Paul und Zschokke präsentierten Überlieferungsphantasien erweisen sich an anderer Stelle als eine ernsthafte Methode: In seiner einflussreichen Abhandlung »Von Archiven« (1777) widmet sich Philipp Ernst Spieß eingehend der Einrichtung solcher Institutionen und somit dem Bestandsaufbau. Der $\$ 4$ betrifft die »Untersuchung des Maculaturs in KramLäden«, die staatlich angeordnet werden soll, wie Spieß ausführt:

»Ferner würde es eine sehr nüzliche Verordnung seyn, wenn nemlich allen Handels-Leuten, besonders Specerey-Krämern, durch ein allgemeines Ausschreiben ernstlich verbotten werden moegte, ihre als Maculatur erkauffte Papiere nicht eher zu verbrauchen, als bis solche einer gewissen iedes Orts hiezu aufgestellten obrigkeitlichen oder andern Person vorgezeiget und von solcher untersucht worden wäre. Man wird sich wundern, was für ein seltenes Manuscript oder gedrucktes Stuck manchmal hie und da zum Vorschein kommen wird. Besonders wird man viele alte Leichen-Predigte, Schul-Programmata, gedruckte Landes-Verordnungen und Ausschreiben etc. finden, woraus, was die erstern betrifft, der Lebenslauf manches an Stand und Wissenschafften berühmten und grossen Mannes entnommen [...] werden kann. "114 $^{114}$

Interessant ist die Bedeutung, die Spieß dem Biographischen beimisst, wenn er anmerkt, dass der Makulatur »der Lebenslauf manches an Stand und Wissenschafften berühmten und grossen Mannes entnommen« werden könne. Dies weist in dieselbe Richtung wie die Passage aus dem "Schriftstellerteufel«, wobei es in beiden Beispielen um "gedruckte Repräsentationen «" ${ }^{115}$ des Individuums geht. Nicht zu vernachlässigen ist in diesem Zusammenhang die Aufzählung möglicher Funde, wird diese doch angeführt durch »viele alte Leichen-Predigte«. Maurer sieht neben der gelehrten Memoria in den »biographischen Anhängen der protestantischen Leichenpredigten « ${ }^{116}$ einen zweiten Ursprung der zeitgenössischen Biographik, ohne die Autorschaft als Subjektform undenkbar wäre.

Bemerkenswert ist schließlich die Kompensation, die Spieß für das Archivgut vorschlägt, denn obwohl er die Makulatur als wertvolle Quelle ansieht,

114 Philipp Ernst Spieß, Von Archiven, Halle 1777, S. 26f. (§ 4).

115 Maurer, »Kultur und bürgerliche Vergesellschaftung«, S. 37.

116 Ebd., S. 38. 
will er für diese keinen höheren Wert ansetzen. Vielmehr schlägt Spieß einen einfachen Tausch vor, der scheinbar dem Gebrauch gerecht wird, den Krämer von der Makulatur machen: »Gegen solche aus dem Maculatur herausgesuchte Stücke könnten dem Besizer eben so viel Bögen anderes Maculatur-Papier auf herrschafftliche Kosten abgereichet werden, womit derselbe auch wohl zufrieden seyn wird und kan.«"17

Christian Siegmund Krause erörtert in einem ironischen Ton, welche wirtschaftlichen Folgen es haben könnte, wenn ausschließlich aus dem Inhalt eines Buches ein Nutzen gezogen werden dürfte: »[D]ie Pfefferkrämer und Heringsweiber kämen in Verlegenheit, und durch diese das ganze jezige Fabrikwesen. Jene würden ihre Waare vielleicht in Lumpen, diese in Stroh packen, und dadurch litten die Strohteller und der Papierhandel, und durch diesen am Ende gar die Schriftsteller selbst. ${ }^{118}$ Krause ist nicht der Einzige, der darüber nachdenkt, was geschehen würde, wenn jemand die »Concurrenz der Krämer « ${ }^{119}$ suchen würde und diese über weniger Makulatur verfügten. Eine Probe aufs Exempel möchte kein übereifriger Archivar machen, sondern Justus Claproth, ein Jurist aus Göttingen. Er veröffentlicht 1774 ein schmales Bändchen über »Eine Erfindung aus gedrucktem Papier wiederum neues Papier zu machen«. Innovativ ist Claproth vor allem deshalb, weil er ausdrücklich eine $» V e r w a n d l u n g ~ «{ }^{120}$ der Makulatur in »neues Papier anstrebt.

Was sich im Ansatz als Versuch präsentiert, ein kostbares Gut sinnvoller zu nutzen als bisher, rekurriert in mehrfacher Hinsicht auf die Ideenwelt der zeitgenössischen Buchkultur. Die Überlegungen von Claproth erhalten eine tiefere Dimension, wenn man sie im Lichte einer Buchkultur betrachtet, die ökonomisch wie ästhetisch zunehmend bestimmt wird von der steten Suche nach Neuem. Die in Angriff genommene Makulatur repräsentiert potenziell all das, von dem sich dies Neue jeweils abhebt. Nicht weit sind hier die prokreativen Ideen der Genieästhetik. Es ist die Denkfigur der Originalität, durch die das Primat des Neuen in die gelehrte Welt gelangt und damit auch dessen Kehrseite, das Alte. Das Genie beginnt dagegen stets von Neuem, mit einem weißen Blatt. Daneben steht die Erfindung des Göttinger Juristen im

117 Spieß, Von Archiven, S. 27.

118 R.A.F.N. [d.i. Christian Siegmund Krause], »Ueber den Büchernachdruck«, in: Deutsches Museum 1 (1783), S. 400-430, 487-514, hier: S. 499.

119 Johann Georg Krünitz, Art. »Maculatur«, in: ders., Oeconomische Encyklopädie, Berlin 1773-1858, 82 (1801), S. 154-181, hier: S. 171.

120 Claproth, Eine Erfindung aus gedrucktem Papier..., [S. 2]. 
Kontext einer Experimentalkultur, welche gesichertes Wissen schneller denn je veralten lässt. Wissensgeschichtlich ist dies die Zeit, in der auf Dauer angelegte Nachschlagewerke sukzessive durch Periodika ersetzt werden. »Zeitschriften werden gegründet, um mit dem Tempo der Entdeckungen Schritt zu halten «, argumentiert Wolf Lepenies in »Das Ende der Naturgeschichte «. ${ }^{121}$ Der Übergang zu periodischen Publikationen bilde, so Lepenies, einen wichtigen Aspekt der Verzeitlichung in der Umbruchphase der Wissenschaften zwischen 1775 und $1825 .{ }^{122}$ Für die Naturgeschichte beschreibt Lepenies die Zunahme an Zeitschriften als Erleichterung. Als Beispiel führt er Peter Collinson an, der 1757 seinem Forscherkollegen Carl von Linné dazu geraten habe, aufgrund täglich neuer Entdeckungen in der Botanik mit einer neuen Ausgabe seines Werks »Systema naturae « zu warten. ${ }^{123}$ Allerdings führt die durch die Publikationsform bewerkstelligte Dynamisierung des Wissens auch zu Paradoxien, wird den Periodika doch mitunter eine Funktion zugeschrieben, die ihrer Beschleunigung entgegenzustehen scheint. Das geschieht in Form von Zeitschriftentiteln wie »Archiv« oder »Bibliothek«. So zählt Lepenies im Zeitraum um 1800 »allein neunzig deutsche medizinische Fachblätter, die mit dem Wort >Archiv beginnen « ${ }^{124}$ und somit eine Dauerhaftigkeit suggerieren, die sie aufgrund ihrer iterativen Periodizität im Grunde negieren.

\section{Dauerhaftigkeit und Handschriftlichkeit}

Obwohl gedruckte Bücher schnell zu Makulatur werden können, gelten sie gegenüber Handschriften als relativ dauerhafte Medien. So veröffentlicht Johann J. von Füldener im Jahr 1731 für Schlesien eine »Bio- \& Bibliographica Silesiaca«, angelegt als ein »Catalogum dererjenigen Autorum, welche von Schlesischen Sachen etwas geschrieben, und in den Druck befördert haben ${ }^{125}$. Mehr als aufschlussreich ist es, wenn Füldener anmerkt, »daß viele gelehrte Leute eine fast eben so grosse Anzahl ungedruckter Schrifften [...] hinterlassen haben, welche nicht anderst als eine Speise derer Motten « ${ }^{126}$

Wolf Lepenies, Das Ende der Naturgeschichte. Wandel kultureller Selbstverständlichkeiten in den Wissenschaften des 18. und 19. Jahrhunderts, München 1976, S. 104.

122 Vgl. ebd., S. 103.

123 Ebd., S. 105.

124 Ebd., S. 103.

125 Johann J. von Füldener, Bio- \& Bibliographica Silesiaca. Das ist: Schlesische Bibliothec und Bücher-Historie, Breslau 1731, I, S. 11 (§ 4).

126 Ebd., S. 7 (§ 3). 
und auch anderweitig vom endgültigen Verlust bedroht sind. Bei Füldener geht ein solcher Verlust vom Tode aus, er betrifft Hinterlassenschaften, die »hilflosen Papiermassen ${ }^{127}$, von denen eineinhalb Jahrhunderte später auch noch Wilhelm Dilthey sprechen wird, in einer Zeit, in welcher der Stellenwert von Handschriften längst ein anderer ist. Das Versprechen der Autorschaft auf Unsterblichkeit scheint für Füldener bei Manuskripten keine Erfüllung $\mathrm{zu}$ finden. Ohne eine typographische Manifestation steht Autorschaft bei ihm mehr als in Frage. Manuskripte lassen ihre Verfasser in dieser Perspektive schutzlos erscheinen, den Zeitläufen ebenso ausgeliefert wie dem Zugriff Dritter. Makulatur ist also nicht gleich Makulatur. Es ist nicht unwesentlich, ob Pfeffertüten aus Manuskripten oder Druckschriften bestehen, jedenfalls nicht dann, wenn die Makulatur wieder eingespeist werden soll in die Kreisläufe gelehrten Wissens.

Jean Paul hält in seinen Exzerpten gleich zwei Stellen aus Morhofs »Polyhistor « fest, die einen fragwürdigen Umgang mit hinterlassenen Manuskripten betreffen und sich miteinander in Beziehung setzen lassen. »Morhof wünscht «, so notiert sich Jean Paul im Jahr 1788, »da so viele herliche Werke nach dem Tode des Verf. in ungelehrte od. plagiarische Hände komm., daß der Magistrat sich ihrer annehmen und das Leben der Schriftst. lesen möchte weil darin oft der unedirt. Werke gedacht wird « ${ }^{128}$. Auf einen prominenten Fall aus dem 17. Jahrhundert, in dem eine Schrift in "plagiarische Hände« gelangt ist, kommt Morhof in einem anderen Band seines »Polyhistors « zu sprechen. Es ist eine Anekdote, die nicht nur das Interesse von Jean Paul findet, sondern bis ins 19. Jahrhundert wiederholt nacherzählt wird. Noch 1808 wird in Cottas »Morgenblatt für gebildete Stände« unter der Überschrift »Trost für Schriftsteller, deren Manuscripte Makulatur werden «, ein kurzer Text eingerückt, in dem Johann Karl Höck zusammenfasst, was über den Gelehrten Barbosa berichtet wird. ${ }^{129}$ In den Exzerpten Jean Pauls klingt die Begebenheit so: »Erythräus: der Bediente des Barbosa bekam um falsa muriatica Papier von

127 Wilhelm Dilthey, »Archive für Literatur«, in: ders., Zur Ceistesgeschichte des 19. Jahrhunderts. Portraits und biographische Skizzen, Quellenstudien und Literaturberichte zur Theologie und Philosophie im 19. Jahrhundert, hg. v. Ulrich Herrmann, 3. Aufl., Göttingen 1991, S. 1-16, hier: S. 9. Nachlass Jean Paul, Fasz. Ila/13, S. 40, in: ]ean Paul,Exzerpte. Digitale Edition, [lla-131788-0402], URL: www.jp-exzerpte.uni-wuerzburg.de (15.9.2019).

129 Karl Höck, »Trost für Schriftsteller, deren Manuscripte Makulatur werden«, in: Morgenblatt für gebildete Stände 2 (1808), Nr. 195, S. 779. 
einem berühmt. Manuskript üb. das Kirchenrecht - Barbosa kauft's dem Krämer ab und lässets für seines drukken. ${ }^{130}$

Das ist die Kürzestfassung einer Geschichte, die sich unter Einbeziehung des lateinischen Textes so wiedergeben lässt: Morhof berichtet im Anschluss an die "Pynacoteca« des Janus Nicius Erythraeus davon, dass der Famulus des Rechtsgelehrten Agostino Barbosa mittags gesalzenen Fisch eingekauft habe, der vom Krämer in Papiere (»chartis«) eingewickelt worden sei, damit die Hände des Bediensteten nicht schmutzig werden und riechen. Als der Famulus das Papier abnimmt und zu Boden wirft, weil er die Fische einwässern will, hebt Barbosa es auf, das Papier neugierig betrachtend, um zu sehen, was darauf geschrieben steht. Er erkennt, dass es sich um den Anfang eines überaus eleganten und gelehrten Werks handelt, und er stellt sich sogleich vor, dass der Autor gestorben sei, ehe es in Typen gedruckt herausgegeben wurde. Und da die Erben nicht gewusst hätten, wie gut es ist, sei das Werk als unnützes Papier an den Fischhändler verkauft worden. Barbosa macht sich Hoffnungen, den Fund als seine Arbeit auszugeben, die ihm zu Ehre gereichen soll. Schließlich findet er beim Krämer das gesuchte Buch, aus dem nur wenige Blätter herausgerissen sind, und er ersteht es für wenig Geld. Barbosa ergänzt, was fehlt, setzt noch mehr dazu und lässt das Werk unter dem Titel »De Jure Ecclesiastico universo« drucken. ${ }^{131}$

\subsection{Makulatur schreiben: Lichtenbergs Autorsatiren und ihre Vorbilder}

In einem Brief an den Schriftsteller und Pädagogen Wilhelm Gottlieb Becker berichtet Georg Christoph Lichtenberg von seinen Überlegungen zu einem »comisch=didactischen Gedicht: die Bibliogenie oder die Entstehung der Bücherwelt «. ${ }^{132}$ Die »Satyre« soll mehrere Gesänge umfassen, aufgeteilt an die »Dichter Deutschlands«. Lichtenberg selbst möchte, so schreibt er an Becker, das Ende der »Bücherwelt« besingen: »das Makulatur und dessen Ent-

130 Nachlass ]ean Paul, Fasz. Ila/13, S. 41, in: ]ean Paul, Exzerpte. Digitale Edition, [Ila-13-17880410], URL: www.jp-exzerpte.uni-wuerzburg.de (15.9.2019).

131 Die Paraphrase hält sich weitgehend an den lateinischen Text von Morhof, insbesondere in Bezug auf die Beschreibung der gefundenen Papiere (»chartis«), Daniel Georg Morhof, Polyhistor Literarius, Philosophicus et Practicus, 4. Aufl., Lübeck 1747, S. 82.

132 »An Wilhelm Cottlieb Becker« (19. April 1795), in: Lichtenberg, Briefwechsel, IV (1992), S. 435f. [2512], hier: S. 435. 
stehung«. »Ich beweise«, so Lichtenberg, »daß niemand dazu fähiger sey als ich, weil ich nun bereits 19 Jahre zwischen Maculatur wohnte und lehrte. (bey Herrn Dietrich). «Aber nicht nur das: »Der stärckste Beweiß aber von meiner Vocation dazu ist, daß ich mir seit jeher eine große Fertigkeit erworben habe welches zu schreiben. " 133 In diesem Zusammenhang bezeichnet sich Lichtenberg als "Makulaturisten ${ }^{134}$. Der Gelehrte liefert an dieser und weiteren Stellen eindrückliche Beispiele für eine spezifische Schreibweise der Makulatur, die so heißen soll, da sich in dieser der komische Gestus des Satirischen mit einer einschlägigen Bildlichkeit verbindet, einer Bildlichkeit der Makulatur, die vornehmlich dann zum Einsatz kommt, wenn es um die Reflexion der eigenen Autorschaft geht. Schauplatz seiner mit Makulatur verbundenen Autorsatiren sind vor allem die zu Lebzeiten unveröffentlichten »Sudelbücher«, so dass sich gleichermaßen die Frage nach der genaueren Funktion sowie der Adressierung des Satirischen stellt. Der Fokus dieses Teilkapitels liegt allerdings mehr auf den möglichen Vorbildern von Lichtenbergs Schreibweise der Makulatur.

Aufgrund seiner persönlichen und auch räumlichen Nähe zum Göttinger Verleger Johann Christian Dieterich, der sein Freund und Vermieter war, hatte Lichtenberg offenbar dessen »Bücher Kirchhof $^{135}$ und somit ausgesonderte Papiere permanent im Blick. Mal notiert sich Lichtenberg: »Dieterich läßt eine Makulaturei in seinem Garten anlegen. « ${ }^{136}$ Ein anderes Mal sinniert er: »Dieterich sollte auf sein Makulatur-Magazin die Aufschrift setzen lassen: Piperariis et Apollini, oder auch Musis et Piperi, Mercurio Piperario « ${ }^{137}$, was sich ins Deutsche wörtlich übersetzen lässt mit: den Pfefferhändlern und dem Apollo, den Musen und dem Pfeffer, dem Pfefferhändler Merkur.

Spannend sind die von Lichtenberg ersonnenen Konjunktionen vor allem, weil das, was Eingang findet ins »Makulatur-Magazin«, jeweils gleichermaßen dem einen und den anderen gewidmet ist, den Pfefferhändlern und Apollo, nicht: oder. Spannend ist dies auch deshalb, weil die ungleichen Paare jeweils einen starken Kontrast bilden. In diesem Kontrast offenbart sich auch der mediale Charakter des Buches, das zugleich Papier und Text liefert, wobei die Pointe lautet: alles Makulatur.

133 Ebd.

134 Ebd., S. 436.

135 »An Georg August Ebell« (19. Januar 1789), in: Lichtenberg, Briefwechsel, III (1990), S. 644-646 [1654], hier: S. 644.

136 Lichtenberg, Schriften und Briefe, I, S. 673 (] 130).

137 Lichtenberg, Schriften und Briefe, I, S. 697 (] 293). 
Apollo, den Lichtenberg in sein erstes Paar aufnimmt, ist eine mythologische Figur mit vielen Facetten; er gilt unter anderem als Erfinder von Poesie, Musik, Medizin sowie der »Kunst wahrzusagen«. So ist es in Benjamin Hederichs »Gründlichem mythologischen Lexikon« nachzulesen, das für Lichtenberg nachweislich eine Referenz darstellte. ${ }^{138}$ Andere sehen in Apollo den Erfinder aller Wissenschaften. Und als Sonnengott eignet sich diese Figur ebenso zur Repräsentation absolutistischer Herrschaft wie als Allegorie aufklärerischen Denkens. In Bibliotheksbauten ist Apollo in bildlichen Darstellungen und als Skulptur häufig anzutreffen. 1742 widmet Friedrich der Große mittels einer weithin sichtbaren Inschrift über dem Eingang das Opernhaus in Berlin »Apollini et musis«, wohl auch deshalb, da Apollo als »Vorsteher« der neun Musen gilt, die sich bei Lichtenberg in der Widmung an »Musis et Piperi« ebenfalls wiederfinden.

In den »Sudelbüchern« wird die nicht seltene Verbindung »Apollini et musis« jedoch aufgelöst, Lichtenberg ersinnt andere Paare, die das Profane einschließen, um es in seiner Gegensätzlichkeit zum Göttlichen auszuspielen. Ähnlich verhält es sich mit dem »Pfefferhändler Merkur«, der jedoch im Vergleich mit den vorherigen Paaren eine Sonderstellung einnimmt. Die römische Tradition konzentriert sich auf Merkur als Boten und Handelsgott. Im 18. Jahrhundert wechselt er vom Frontispiz von Handelslexika auf den Titel allgemeiner Nachschlagewerke, laut Ulrich Johannes Schneider befindet sich Merkur auf dem besten Weg, eine "Spitzenstellung« als »Lexikongott« einzunehmen. ${ }^{139}$ Zum einen repräsentiert der »Pfefferhändler« einen Buchhandel, der unwillkürlich immer mehr Makulatur im Angebot hat. Zum anderen steht die Gottheit für eine zweifelhafte Gelehrtheit. Die von Lichtenberg erdachte »Aufschrift« erinnert somit an den Status des Ephemeren, durchaus Prekären dessen, was Eingang findet ins »Makulatur-Magazin«, und sie erinnert an die merkantilen Hintergründe dieser zweifelhaften Sammlung.

All die angedeuteten Niederungen lassen die parallele Bezugnahme auf Götter und Musen ebenso fragwürdig erscheinen wie die beflissen auf Latein verfasste »Aufschrift « für das »Makulatur-Magazin« als solches, wäre da nicht der komische Effekt, auf den es Lichtenberg ganz offenbar ankommt. Das

138 Benjamin Hederich, Art. »Apollo«, in: ders., Gründliches mythologisches Lexikon, Leipzig 1770, Sp. 327-347, hier: Sp. 333, vgl. Lichtenberg, Schriften und Briefe, K I+II, S. 410.

139 Ulrich Johannes Schneider, »Merkur und andere enzyklopädische Götter«, in: Zeitschrift für Ideengeschichte (2007), I,2, S. 89-100, hier: S. 91. 
»Makulatur-Magazin« führt assoziativ zu einem Spiel mit Kontrasten, dessen Niederschlag lesbar ist als eine kleine Etüde in der Schreibweise der Makulatur. Eine weitere Übung in dieser Schreibweise findet sich an anderer Stelle, im Sudelbuch E. Hier thematisiert Lichtenberg seine eigene Autorschaft in mehrfacher Hinsicht. Und er präsentiert sich auf diesem Schauplatz erneut in der Rolle des begnadeten »Makulaturisten«, wenn auch nicht, wie noch im Brief an Becker, eindeutig adressiert an eine andere Person:

»Einer schrieb Fidibus und Tapeten, oder vielmehr nannte zuerst sein Buch so, denn im Vorbeigehn muß ich dem guten Mann sagen, daß er nicht der erste ist der Fidibus geschrieben hat, denn vieler vortrefflichen Männer aus allen vier Fakultäten jetzt nicht zu gedenken, so kann ich von meiner Wenigkeit versichern, daß ich Fidibus, Pfefferdutten, Papier zum Unterlegen und anderm Cebrauch in der Haushaltung geschrieben habe vielleicht ehe man an ihn dachte. $\ll^{140}$

Mit diesem Absatz beginnt einer der längeren Texte aus dem Sudelbuch der Jahre 1775 und 1776. Die Zeilen stehen unvermittelt da, unvermittelt, aber nicht unverbunden mit den folgenden Absätzen, die als Einleitung zu einer »Bittschrift der Narren! ${ }^{141}$ fungieren, die Lichtenberg eigens mit einer Überschrift ausstattet. Die »Bittschrift« hat eine längere Vorgeschichte, die lediglich angedeutet wird, wenn gegen Ende der Einleitung ein »Büchelgen von mir ${ }^{142}$ kurz Erwähnung findet. Bei der »Bittschrift« handelt es sich um eine Reaktion auf die Rezeption des »Timorus«, der ersten Buchveröffentlichung Lichtenbergs, erschienen 1773.

Bereits der vollständige Titel dieser Publikation hat es in sich: »Timorus, das ist Vertheidigung zweyer Israeliten, die durch die Kräftigkeit der Lavaterischen Beweisgründe und der Göttingischen Mettwürste bewogen, den wahren Glauben angenommen haben «, so steht es, verteilt über 12 Zeilen, auf dem Titelblatt des Bändchens. Gunter E. Grimm bezeichnet den »Timorus« als "Gipfelpunkt der aufklärerischen Satire ${ }^{143}$. Hintergrund war die Aufforderung von Johann Casper Lavater an Moses Mendelssohn, vom Judentum zum »wahren Glauben« überzugehen, zum Christentum zu konvertieren. Lichtenberg schaltet sich mit dem »Timorus« als eigentlich Unbeteiligter in den

\footnotetext{
140 Lichtenberg, Schriften und Briefe, I, S. 399 (E 245).

141 Ebd., S. 400.

142 Ebd.

143 Grimm (Hg.), Satiren der Aufklärung, S. 279 (Kommentar).
} 
heraufziehenden Konflikt ein, allerdings unter dem Schutz des Pseudonyms »Conrad Photorin«. Seine Autorschaft hält Lichtenberg lange Zeit geheim, sogar gegenüber seinem Freund Dieterich. ${ }^{144}$ Umso bedeutsamer werden die "Sudelbücher« als nicht-öffentlicher Resonanzraum der am »Timorus« geübten Kritik. Lichtenberg bereitet sich auf diese erstaunlich gewissenhaft vor: In Sudelbuch C finden sich unter Überschriften wie »Wenn der Timorus angegriffen werden sollte« oder »Zur Verteidigung des Timorus« gleich mehrere Antworten nicht auf erschienene, sondern mögliche Angriffe. ${ }^{145}$

Tatsächlich wird der Rezensent der »Frankfurter gelehrten Anzeigen« dann auch wenig zimperlich mit dem »Timorus« umgehen. »Kein vernünftiger Mensch«, so richtet sich dieser an den unbekannten Verfasser, »wird in die Versuchung gerathen, in einer Gesellschaft leben zu wollen, wo einem jeden Narren, laut zu denken, verstattet ist. ${ }^{146}$ Außerdem wirft er dem in der Anonymität verharrenden Lichtenberg vor, »daß er auch einer von denen ist, die der Religion und ihren Dienern gerne einen Schandflecken anhängen möchten $\aleph^{147}$. Mit dieser Formulierung (»Schandflecken anhängen«) erfolgt eine Einstufung des »Timorus« als Pasquill, denn diese Benennung für Schmähschriften wird im 18. Jahrhundert zurückgeführt auf Pasquino, eine in Rom zu findende Statue, die angeblich aus dem Volksmund den Namen eines bekannten Handwerkers erhalten hat. »An selbige werden offt bey der Nacht satyrische Schrifften gehänget, wider solche Personen, die man nicht auf andere Weise anzugreiffen sich unterstehen darf«, ist im Lexikon von Johann Heinrich Zedler nachzulesen. ${ }^{148}$ Im 19. Jahrhundert werden diese »Schandschriften« im Brockhaus mit Rücksicht auf ihre Materialität auch als "Zettel ${ }^{149}$ charakterisiert.

Lichtenberg bemüht sich in der Folge um eine passende Reaktion: Über einen längeren Zeitraum hinweg entwirft er eine »Bittschrift der Wahnsinnigen«, wohl ausgehend von realen Ereignissen im Zuchthaus von Celle, die

144 Deneke, Lichtenbergs Leben, I, S. 186.

145 Lichtenberg, Schriften und Briefe, I, S. 205 (C 254), S. 208 (C 260).

146 [Anonymus], Rez. »Timorus«, in: Frankfurter gelehrte Anzeigen (1773), S. 474f., hier: S. 475.

147 Ebd., S. 474.

148 Art. »Pasquino«, in: Zedler (Hg.), Grosses vollständiges Universal-Lexicon, 26 (1740), Sp. 1148, hier: Sp. 1148.

149 Art. »Das Pasquill«, in: Conversations-Lexikon oder kurzgefaßtes Handwörterbuch, Amsterdam 1809, III, S. 374f., hier: S. 375; Art. »Pasquill«, in: Allgemeine deutsche RealEncyclopädie für die gebildeten Stände (Conversations-Lexicon), 5. Aufl., Leipzig 1819, VII, S. $289 f$., hier: S. 290. 
»eine gute Satyre abgeben ${ }^{150}$ würden, wie Lichtenberg notiert, und zwar als eine »Allegorie auf die Rezensenten in Deutschland « ${ }^{151}$, wie er kurze Zeit später ausführt. Unter den Figuren, die er unter dieser Prämisse ersinnt, befindet sich »Einer der ganz nackend da saß und von seinem geistlichen Ornat nichts am Leibe hatte, als einen alten Kragen«, und der »bei dem Wort Timorus nach seinem Nachttopf [griff] um ihn über das Buch auszuleeren ${ }^{152}$. Unschwer ist ein Bezug zur Rezension zu erkennen, in der Lichtenberg vorgehalten worden war, »der Religion und ihren Dienern gerne einen Schandflecken anhängen« zu wollen.

Dieser Bezug auf die »Frankfurter gelehrten Anzeigen« wird in der Einleitung zur späteren »Bittschrift der Narren!« explizit hergestellt. Eingangs ist von umtriebigen »Patienten« die Rede, die sich für die Einrichtung einer »öffentlichen Bibliothek im Narrenhause ${ }^{153}$ einsetzen, indem sie eine Petition verfassen, ergänzt um Anschaffungsvorschläge in Form eines umfänglichen Bücherverzeichnisses. In diesem Verzeichnis steht auch jenes »Büchelgen von mir«, wobei der »Titul des Buches «, wie hervorgehoben wird, »ausgestrichen« ist. ${ }^{154}$ Lichtenbergs »Bittschrift der Narren! « und die ihr vorgelagerten $A b-$ schnitte erweisen sich in der Gesamtschau als eine Satire zur Verteidigung der Autorschaft des »Timorus«. Die Satire hat einen klaren Adressaten, es ist »der Frankfurter Rezensent«, eingeführt als Rezipient, der - wie die Narren - von einem »ironice und im Hof-stilo« verfassten Werk annimmt, »es wäre Ernst ${ }^{155}$. Nur: Lichtenberg wird diesen Text niemals selbst drucken lassen.

Geht man zurück zum Anfang, zu der Erklärung, »daß ich Fidibus, Pfefferdutten, Papier zum Unterlegen und andern Gebrauch in der Haushaltung geschrieben habe«, so bleibt zunächst der Eindruck bestehen, dass zwischen dieser Selbstzuschreibung und der »Bittschrift der Narren!« kein Zusammenhang besteht. Eine Verbindung ergibt sich jedoch aus dem ersten Satz, durch eine Referenz, die wie eine Weichenstellung für alles Übrige erscheint: Lichtenberg weist an dieser Stelle in die Richtung bestimmter Schreibweisen des Komischen, des Satirischen. Und er nimmt dabei durchaus Bezug auf die historische Semantik des Pasquills, die sich - man denke an den Frankfurter »Schandflecken« - mit derjenigen des Wortes Makulatur (lat. macula, Fleck,

150 Lichtenberg, Schriften und Briefe, I, S. 353 (E 53).

151 Lichtenberg, Schriften und Briefe, I, S. 353 (E 58).

152 Ebd.

153 Lichtenberg, Schriften und Briefe, I, S. 399 (E 245).

154 Lichtenberg, Schriften und Briefe, I, S. 400. (E 245).

155 Lichtenberg, Schriften und Briefe, I, S. 400 (E 245). 
Schandfleck, Unehre) leicht in Beziehung setzen lässt, so dass Abfälliges im zettelhaften Abfall figuriert. Lichtenberg schreibt: »Einer schrieb Fidibus und Tapeten $\ll^{156}$.

"Fidibus und Tapeten« - so lauten die Titel zweier Zeitschriften, die für die Schreibweisen der Makulatur um 1800 als prägend angesehen werden können, wobei es sich bei dem einen Periodikum, den »Tapeten«, um den Nachfolger des anderen handelt: Zwischen 1771 und 1776 gibt Johann Jacob Ebert, ein Magister der Mathematik und Philosophie, der »in den Humanioribus sehr geübt « ${ }^{157}$ ist, wie sein Lehrer Gellert in einem Empfehlungsschreiben lobt, in Wittenberg die Wochenschrift »Tapeten« heraus. Zuvor hat er gemeinsam mit dem Theologen Karl Gottfried Küttner in Leipzig von 1768 bis 1770 den »Fidibus« publiziert.

Die Rezeption beider Periodika überdauert die wenigen Jahre ihres Erscheinens. Laut Eduard Berend dienen sie Jean Paul, geboren 1763, als Vorlagen für seine frühen Satiren (HKA II.2, XVII, Anm. 1). Die »Göttingischen Anzeigen von Gelehrten Sachen « widmen sich den »Tapeten « mehrfach und beschreiben sie als "unterhaltend, und so weit sich Menschen durch gutartige Satiren bessern lassen, bessernd ${ }^{158}$. Vermutlich lernt Lichtenberg die Zeitschriften durch diese Rezensionen kennen. Lesbar sind sowohl die Bezugnahme auf »Fidibus und Tapeten« als auch die folgende Selbstzuschreibung als eine Programmierung der eigenen Textproduktion, als ein Umschalten auf eine durch Ebert und seinen Mitstreiter geprägte Schreibweise. ${ }^{159}$

156 Lichtenberg, Schriften und Briefe, I, S. 399 (E 245).

157 Christian Fürchtegott Gellert, »An Peter Hohmann, Graf von Hohenthal « (15. Februar 1769), in: ders., C.F. Gellerts Briefwechsel, hg. v. John F. Reynolds, Berlin u.a. 1983-2013, 5 (2013), S. 191f. [1212], hier: S. 191.

158 [Anonymus], Rez. »Tapeten«, in: Göttingische Anzeigen von Gelehrten Sachen 1 (1772), 13. Stk. (30. Januar 1772), S. 104, hier: S. 104.

159 Man kann diese Programmierung auch auf einer anderen Ebene des Textes beobachten: auf der Ebene des Manuskripts. Jens Loescher hat mit Blick auf die überlieferte Handschrift zur »Bittschrift der Narren« auf deren Auffälligkeiten hingewiesen. Im Vergleich mit anderen Manuskripten Lichtenbergs betont Loescher »das stark veränderte Schriftbild «, das sich dadurch auszeichnet, dass »das ansonsten so kontrollierte Autographenbild Lichtenbergs [...] sich hier zu einem Jean-Paulschen schöpferischen Chaos « wandele (Jens Loescher, Schreiben. Literarische und wissenschaftliche Innovation bei Lichtenberg, Jean Paul, Goethe, Berlin u.a. 2014, S. 73). Der Schluss liegt nahe, dass sich das Umschalten im Schriftbild niederschlägt, in einem erkennbaren Bemühen um treffende Formulierungen, das mutmaßlich angetrieben wird durch die Entscheidung 
In der ersten Ausgabe des »Fidibus« von 1768 schreibt Ebert unter dem Pseudonym Zachäus Fidibusifer, Hunger und Schulden hätten ihn veranlasst, zum Schriftsteller zu werden und »Wochenblätter « herauszugeben, die es ihm ermöglichen, »seinen ansehnlichen Vorrath an Gelehrsamkeit aus allen Fakultäten, und an witzigen Einfällen, ohne große Mühe auszukramen « ${ }^{160}$. Als er ein Kaffeehaus aufsucht, um über die Namensgebung nachzudenken - der »Philosoph « ist bereits vergeben -, muss er mitansehen, wie »ein süsses Stutzerchen meine sehr gründlich geschriebene Inaugural-Disputation unbarmherziger Weise zerriß, und Fidibus daraus machte ${ }^{161}$. Fidibus sind schmale Papierstreifen, die zum Anzünden von Pfeifen gebraucht werden, also mit einem Mal verschwinden. Zachäus unterbindet jedoch nicht, dass seine akademische Schrift zerstört wird. Vielmehr wird diese Szene zum Schauplatz einer Selbstbehauptung des Autors: »Hier dachte ich, voll Ahndungen, an das Schicksal meiner künftigen Blätter, und entschloß mich, sie gleich zu diesem Gebrauche zu bestimmen [...]. $\ll^{162}$ Mehr noch: Zachäus beansprucht Exklusivität in der Produktion von Fidibus. Nicht anders als später Lichtenberg erklärt er sich somit zum »Makulaturisten«.

Während die Titelblätter des »Fidibus« schmucklos gestaltet sind, erscheint ab dem Jahr 1771 der Nachfolger »Tapeten« mit einem eigens angefertigten Kupferstich: Der Titelkupfer ${ }^{163}$ zeigt einen am Boden sitzenden Satyr, mit Pinsel und Farbpalette in den Händen, um eine zwischen Kanthölzern aufgespannte Leinwand mit einem Selbstbildnis zu versehen. Das Porträt präsentiert den Satyr mit einem Hut, tief ins Gesicht gezogen, so dass man sein Antlitz kaum sieht. Während des Malens trägt die illustre Gestalt ihre Kopfbedeckung nicht. Sie hängt zwar in Blickrichtung des Satyrs, aber doch ein wenig abseits auf einem Holzpflock. Aufgrund der Bildperspektive ist für Betrachter des Stichs nicht nur der zerbeulte Hut sehr gut zu erkennen, sondern auch eine Schelle, die an dessen Rückseite angebracht ist und ihn

für eine Schreibweise, die Lichtenberg als angemessen erscheint, um sich mit seinen Kritikern auseinanderzusetzen: die Schreibweise der Makulatur.

[Zachäus Fidibusifer], »Der Autor erzählt seine schlechten Umstände, die ihn bewogen haben, Fidibus zu machen, und wünscht der Stadt Leipzig, seinen Lesern, den Schönen und Häßlichen, den vier Facultäten, den Studirenden, den Kaufleuten und schlechten Schriftstellern in wäßrigen Versen ein glückseliges neues Jahr«, in: Fidibus 1 (1768), Nr. 1 (8. Januar 1768), S. 1-9, hier: S. 2. 
Abbildung 6: Titelkupfer der Zeitschrift »Tapeten« I (1771).

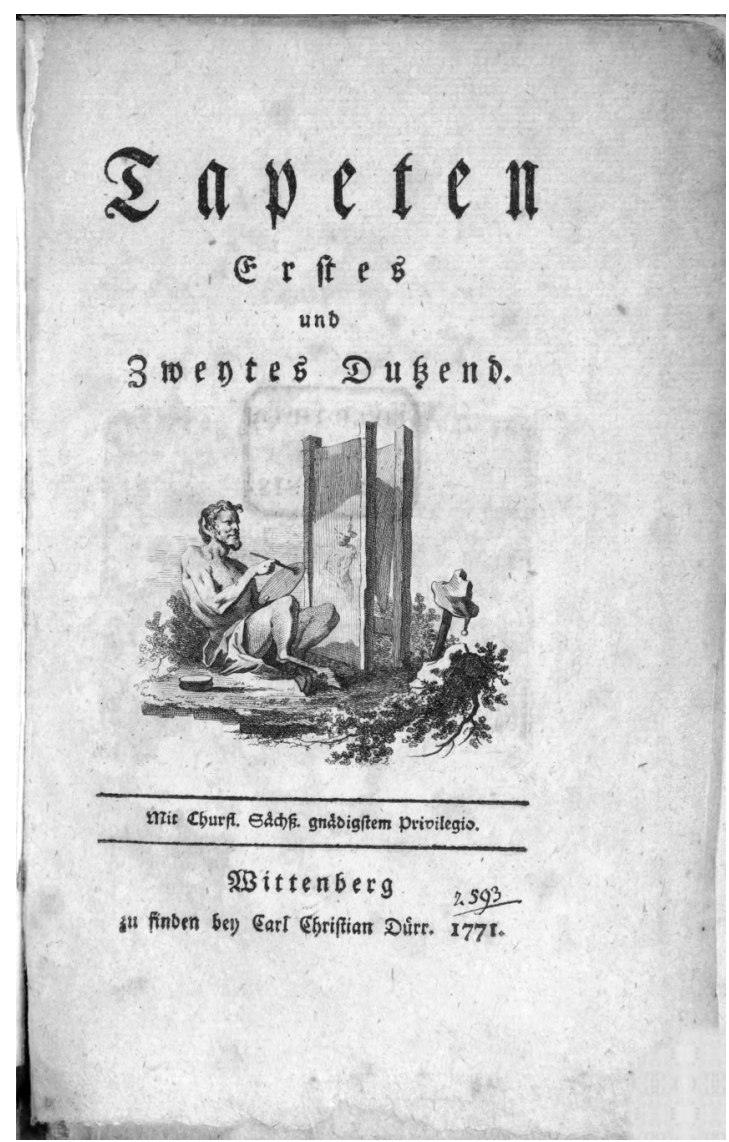

Bayerische Staatsbibliothek, Per. 189-1/2, http://mdz-nbnresolving.de/urn:nbn:de:bvb:12-bsb10616777-3.

zur Narrenkappe macht. Auf dem Selbstbildnis, dessen Konturen sich auf der Tapetenbahn abzeichnen, fehlt dieses entscheidende Detail jedoch. Ein Satyr als Tapetenmaler - der Kupferstich verbindet programmatisch die Ikonographie des Satirischen mit dem für die Zeitschrift namensgebenden Motiv. 
Die Bildlichkeit der »Tapeten« durchzieht die Wochenschrift, ohne - wie beim Titelkupfer - auf die Tapete als teure und hochwertige Wanddekoration aus Leinwand zu rekurrieren. Mitte des 18. Jahrhunderts kommt in Europa die Papiertapete in Mode, ausgehend von England. 1746 entstehen auf der Insel die ersten Tapetenfabriken. ${ }^{164}$ Anfang der Siebzigerjahre sind Papiertapeten auch im deutschsprachigen Raum längst geläufig. Sie werden in der Regel von Hand bedruckt, mit Stempeln, im Verfahren des Modeldrucks, das aus der Bearbeitung von Kattun geläufig ist. ${ }^{165}$ Aufgrund des Werkstoffs und der Fabrikation ergibt sich eine Nähe zwischen Papiertapeten und gedruckten Artefakten wie Zeitschriften oder Büchern. Hinzu kommt der Umstand, dass Makulatur benutzt wird, um Papiertapeten zu grundieren. ${ }^{166}$ Es liegt also nahe, dass durch die Namenswahl der »Tapeten« das vom »Fidibus« noch stärker evozierte Bildfeld der Makulatur beibehalten werden soll. Jedenfalls werden »Fidibus und Tapeten« von Lichtenberg in einem Atemzug genannt, ehe er seine eigene Befähigung zur Makulatur hervorhebt.

Im »I. Stück« der »Tapeten« erklärt Zachäus, aus der »Sphäre eines tiefsinnigen und gelehrten Schriftstellers [...] wieder auf die niedrige Stufe eines Fabricanten herab zu steigen ${ }^{167}$. Statt weiterhin »Fidibus« zu produzieren, habe er sich für eine »Tapeten-Fabrik« entschieden, »da es doch heut zu Tage unter Gelehrten und Ungelehrten eine herrschende Mode geworden ist, sein Zimmer mit gedruckten Sachen zu tapeziren ${ }^{168}$. Eine solche Tapete aus Büchern und Zeitschriften wird um 1800 geradezu sprichwörtlich. Als die hehre Hauptfigur in Friedrich Nicolais "Sebaldus Nothanker« ihren Freund, den Buchhändler Hieronymus, fragt, was seine gewinnsüchtigen Kollegen denn

164 Heinz Schmidt-Bachem, Aus Papier. Eine Kultur- und Wirtschaftsgeschichte der Papier verarbeitenden Industrie in Deutschland, Berlin, Boston 2011, S. 699.

165 Carl Philipp Funke, Naturgeschichte und Technologie für Lehrer in Schulen und für Liebhaber dieser Wissenschaften, 4. Aufl., Braunschweig 1802, II (1802), S. 728. Gotthelf Fibel, der allerlei Drucksachen sammelt, blickt in Jean Pauls »Leben Fibels« in seinem Wohnort »lange einem durchs Dorf gehenden Drucker durstend nach, der in einer - Kattunmanufaktur arbeitete« (SW I.6, 389).

[Anonymus], Ueber den Nutzen der Papier-Tapeten nebst kurzer Anleitung zum Tapezieren, Augsburg 1829, S. 23.

167 [Zachäus], »Der Fabricant Zachäus entschuldigt sich bey dem Publico, daß er, statt der versprochnen gelehrten Werke, andre geringe papierne Waare verfertigen müsse, und erzählt hernach, was für ein Gemälde seine Kunden auf diesen Tapeten zu erwarten haben«, in: Tapeten 1 (1771), 1. Stk. (3. April 1771), S. 1-8, hier: S. 3. 
als Gebrauch vorschwebe, wenn ihnen an der Lektüre von Büchern nichts gelegen sei, erhält sie zur Antwort: »Man soll sie zerreißen oder Wände damit tapezieren. ${ }^{169}$ Mehrdeutig ist die Wendung, weil sie zum einen meint, dass Bücher allein zur Dekoration dienen. Zum anderen schließt das semantische Spektrum ein, dass Wände kostengünstig mit Makulatur beklebt werden. In beiden Bedeutungen erscheinen Bücher zwar nützlich, in ihrer eigentlichen Funktion allerdings: nutzlos.

Autorschaft ist eines der prägenden Themen beider Zeitschriften, genauer: Autorschaft in ihrer Sozialität, einer Dimension, die satirisch erschlossen wird. Gleich die ersten »Stücke« der »Tapeten« widmen sich Autorschaft geradezu programmatisch, wobei zu beachten ist, dass Autorschaft um 1770 noch hauptsächlich im Kontext der Gelehrtenkultur verhandelt wird. Anknüpfen kann die Zeitschrift somit an die Gelehrtensatire der Sechzigerjahre, für die Namen wie Rabener und Riedel stehen, aber auch Justi, der sich unter anderem der »Schriftstellersucht« widmete. Ein Beispiel für eine solche Anknüpfung ist das im elften »Stück « der »Tapeten« zu findende »Schreiben des Herrn Alexander Gernegroß, der berühmt zu werden wünschet«, und zwar in der Gelehrsamkeitsgeschichte, der Historia literaria. Nachdem Gernegroß sein Anliegen wortreich vorgetragen hat, wird das Motiv der »Tapete« paratextuell in den Text eingeführt, um eine Fortsetzung anzukündigen: »Die Antwort«, so ist zu lesen, "soll auf der künftigen Tapete folgen. « ${ }^{170}$ Tatsächlich erhält Gernegroß gleich zwei Rückmeldungen: Zachäus teilt Gernegroß mit, dass »unter allen Mitteln zur gelehrten Unsterblichkeit, die Autorschaft oben an zu stehen verdiene ${ }^{171}$, allerdings nicht aus Gründen der Wertschätzung. Vielmehr wird

169 Nicolai, Sebaldus Nothanker, S. 73. Siehe dazu u.a. auch Helfrecht, der in »Shakal, der schöne Geist« (1799, 2. Aufl. 1801), jener weiter oben bereits erwähnten Schmähschrift wider Jean Paul, verallgemeinert die Käuferschaft eines Buches betrachtet und grob einteilt: »Wir nehmen ein Buch von einer gewissen Materie an: wie wenige können es, wie wenige wollen es benutzen! Wir wollen 1.000 Exemplare von diesem Buche denken. Drey bis vier Hundert werden wirklich abgesetzt, die übrigen liegen oder cirkuliren in den Buchläden. Von diesen Käufern des Buchs rechne ich 150, die das Buch hinstellen und nicht lesen, weil vielleicht der Verfasser ihre Begierde nicht genug zu fesseln und sie angenehm zu unterhalten wußte; oder auch solche, die eine Wand mit Büchern tapezieren, weil es andre auch thun; [...].« (Helfrecht, Shakal, der schöne Geist, S. 72)

170 [Anonymus], „Schreiben des Herrn Alexander Gernegroß, der berühmt zu werden wünschet«, in: Tapeten 1 (1771), 11. Stk. (12. Juni 1771), S. 81-87, hier: S. 87.

171 [Zachäus], »Noch etwas an Herrn Alexander Gernegroß«, in: Tapeten 1 (1771), 13. Stk. (26. Juni 1771), S. 97-104, hier: S. 98. 
Autorschaft von Zachäus als der leichteste Weg zum avisierten Ziel ins Spiel gebracht. Dass es keiner größeren Anstrengung bedarf, jedenfalls nicht derjenigen des Verfassens eines Textes, ist für Zachäus selbstverständlich. Unter anderem schlägt er vor, »einige arme Studenten oder Schüler« anzuwerben, um »aus etlichen Büchern Aufsätze von einerley oder von verschiedenen Materien « abschreiben zu lassen, um diese Manuskripte »unter einem beliebigen Titel mit Ihrem Namen und mit einer Vorrede drucken zu lassen $\ll^{172}$. Schließlich wird Gernegroß noch eine »Theorie der Autorschaft ${ }^{173}$ in Aussicht gestellt, die tatsächlich veröffentlicht werden wird und vor allem eines ist: ein Lehrstück in Satire, in der Schreibweise der Makulatur.

\subsection{Makulatur erzählen: Poetologie der Pfeffertüte bei Jean Paul ${ }^{174}$}

Ein Buch, das auf jeder Ebene von Makulatur handelt, ist Jean Pauls »Leben Fibels«. In der Rahmenfiktion des Romans von 1811 verdankt sich Autorschaft dem Zusammentragen von »biographischen Papierschnitzeln« (SW I,6, 375), einer Rekonstruktion der zu Gegenständen des täglichen Gebrauchs verarbeiteten Lebensbeschreibung des vergessenen Autors Gotthelf Fibel, die ursprünglich aus vierzig mächtigen Bänden bestand. Nur durch diese Vorlage wird der Schriftsteller »Johann Paul Fr. Richter« (SW I,6, 377, im Folgenden: ১Jean Pauk) »vermögend, gegenwärtiges Leben oder Buch anzufangen« (SW I,6, 376). In »Leben Fibels« liefern »Kaffee-Düten«, »Stuhlkappen« oder »Papier-Drachen« (ebd.), gefertigt aus Makulatur, die Quellen für das Vorhaben einer Autoren- bzw. Gelehrtenbiographie.

Nimmt man sich »Leben Fibels« vor, so hat man es mit einer Fiktion materialer Determination zu tun, die sich in der Buchform nur schwer darstellen lässt. Dies ist nur möglich auf der Ebene des literarischen Textes selbst, in dem behauptet wird, sein Aufbau hänge von äußeren Faktoren ab, der Verfügbarkeit zweckentfremdeter Druckseiten, auf welche der fiktive Autor kei-

172 [Zachäus], »Antwort auf das Schreiben des Herrn Alexander Gernegroß«, in: Tapeten 1 (1771), 12. Stk. (19. Juni 1771), S. 89-96, hier: S. 94.

173 Ebd., siehe [Anonymus], »Betrachtungen über die Autorschaft, nebst zwey Sinngedichten über Meils Gedächtniß-Münzel auf Gellerten, und auf einen stark erleuchteten Tanzsaal«, in: Tapeten 7 (1773), 77. Stk. (2. Juni 1773), S. 609-615.

174 Dieses Unterkapitel basiert teilweise auf Überlegungen in Fuchs, Büchermachen, S. 4953. 
nen Einfluss zu nehmen imstande ist. Auch die paratextuelle Ordnung von »Leben Fibels« spiegelt die prekäre Materialität des Materials wider, tragen die einzelnen Abschnitte des Romans doch Überschriften wie »HaubenmuserKapitel« (SW I.6, 381) oder »Vogelscheuche« (SW I.6, 441), je nach der Zurichtung der Papiere, die als Medien der Überlieferung wahrgenommen werden. Es ist somit die Makulatur, der im Rahmen einer Poetologie der Pfeffertüte zugeschrieben wird, den Text inhaltlich wie strukturell zu bestimmen, während sie tatsächlich einen literarischen Schauplatz der Fiktion eröffnet, der sich vor allem als Spielraum des Erzählens erweist.

Autorschaft ist auf der Ebene des Erzählten wie der des Erzählens das bestimmende Thema im »Leben Fibels«, wobei die Narration einem `Jean Pauk obliegt, der »in subversiver Umkehr des Genie-Paradigmas«, so Magnus Wieland, »als sekundärer Bearbeiter bereits vorhandener Materialien in Szene ${ }^{175}$ gesetzt wird. Dieser Autor präsentiert sich »eher als ein Bastler denn als ein souveräner Schöpfer « ${ }^{176}$, von einer um 1800 in der Dialektik der Säkularisierung auf seinesgleichen übergegangenen »Allmacht « ${ }^{177}$ erscheint 〉Jean Pauk weit entfernt, vielmehr erfährt er die »schmerzliche Säkularisation des Zufalls « ${ }^{178}$. Denn das, was `Jean Pauk über Fibel zu erzählen weiß, erschöpft sich ja weitgehend in dem, was beigebrachte Papiere ihm mitteilen. Dass in dieser Figuration wirkmächtige, im späten 18. Jahrhundert entwickelte Vorstellungen von Autorschaft in Subversion begriffen sind, ist zweifellos zutreffend, jedoch präsentiert der Roman kein reines Gegenbild zum genialen Schöpfer. Aktualisiert werden zugleich ältere Praktiken gelehrter Autorschaft, auch solche, die höchst fragwürdig anmuten. So ist zum Schluss der mit »Vor-Geschichte oder Vor-Kapitel« überschriebenen Seiten, die zur eigentlichen Biographie hinführen, zu erfahren, dass der fiktive `Jean Pauk mit dem Gedanken gespielt hat, »das Ganze für mein eigenes Gemächt auszugeben«, da er als »Plagiarius« (SW I.6, 377) nach eigener Ansicht wahrscheinlich unentdeckt bleiben würde. Hier verbinden sich in einem einzigen Wort, nämlich »Gemächt«, die für das Genie verbindliche Rhetorik der Prokreation und die herabsetzende Kon-

\footnotetext{
175 Wieland, »Sudelbibliothek«, S. 105.

176 Schmitz-Emans, »Vom Leben und Scheinleben der Bücher«, S. 27.

177 Daniel Weidner, »Himmelskarten und Erdkarten. Gott und der Romanerzähler bei Fielding und Jean Paul«, in: Christel Meier, Martina Wagner-Egelhaaf (Hg.), Autorschaft. Ikonen-Stile-Institutionen, Berlin 2011, S. 231-251, hier: S. 248.

178 Erich Köhler, Der literarische Zufall, das Mögliche und die Notwendigkeit, München 1973 , S. 31.
} 
notation des Machers, die auch im Büchermacher mitschwingt ${ }^{179}$. Der Macher kann als Figur der auf Reproduktion gegründeten Gelehrtenkultur des 17. und 18. Jahrhunderts angesehen werden, in der Erfindung (inventio) das gekonnte Suchen und Finden gesammelten Wissens bedeutete ${ }^{180}$. Darüber hinaus erinnern die Anfechtungen, denen sich >Jean Pauk ausgesetzt sieht, an die von Jean Paul in seinen Exzerpten festgehaltenen Stellen zur Aneignung fremder Arbeiten aus Morhofs »Polyhistor«, allen voran der Episode, in welcher der Rechtsgelehrte Agostino Barbosa ein im Kramladen gefundenes Manuskript als eigenes Werk drucken lässt. ${ }^{181}$

Über diese Passage hinausgehend spricht einiges dafür, die Reflexion von Autorschaft in der Rahmenfiktion nicht nur mit der Literaturästhetik der Goethezeit, sondern ebenso mit der vom 18. bis ins frühe 19. Jahrhundert virulenten Kritik an der Gelehrsamkeit in Verbindung zu bringen, sowohl inhaltlich als auch in anderer Hinsicht. Autorschaft wird um 1800 von der Gelehrsamkeit her gedacht und weniger von der Dichtung, was in den Philologien aus nachvollziehbaren Gründen häufig übersehen wird. Am Beispiel von Lichtenberg wurde oben außerdem gezeigt, dass die Bildlichkeit der Makulatur ab dem letzten Drittel des 18. Jahrhunderts mit Schreibweisen des Komischen verknüpft wird, wobei es zunächst die Gelehrtensatire ist, in der diese Verbindung zu beobachten ist. Daher liegt die Annahme nahe, dass die so prominent eingeführte Makulatur in einer Autoren- bzw. Gelehrtenbiographie wie »Leben Fibels«, mit welcher Jean Paul eine »Vereinigung der Parodie mit dem Roman ${ }^{182}$ anstrebt, auch die Funktion erfüllt, den Text als einen komischen auszuweisen.

Was >Jean Pauk auf seiner Suche nach »Fibels Hand- und Druckschriften« (SW I.6, 372) erlebt, dass ihm nämlich Teile einer zu Makulatur gewordenen Biographie in die Hände fallen, die schließlich zur Grundlage eines ei-

179 Stephan Kammer, »Buchmacherei, Bücher, Buchstäblichkeit bei Kant«, in: Cornelia Ortlieb, Tobias Fuchs (Hg.), Schreibekunst und Buchmacherei. Zur Materialität des Schreibens und Publizierens um 1800, Hannover 2017, S. 199-215, hier: S. 199.

Vgl. Hans-Walter Schmidt-Hannisa, »Lesarten. Autorschaft und Leserschaft bei Jean Paul«, in: Jahrbuch der Jean-Paul-Gesellschaft 37 (2002), S. 35-52, hier: 39f., sowie Menke, »Ein-Fälle aus Exzerpten«.

181 Im Vergleich besteht der feine Unterschied auf den ersten Blick darin, dass `Jean Pauk nicht mit einer unbekannten Handschrift, sondern einer gedruckten Biographie konfrontiert ist. Allerdings entsteht bei der Lektüre von »Leben Fibels« der Eindruck, dass die vierzig Bände der Lebensbeschreibung allesamt einen unikalen Charakter besitzen.

182 Zit. n. Schneider, Jean Pauls Altersdichtung, S. 94. 
genen Buches werden, erinnert nicht nur an Morhof, sondern auch an eines der berühmtesten Werke der Weltliteratur: Miguel Cervantes' „Don Quixote« (1605-15). Auch dort basiert die Erzählung weitgehend auf dem Fund von Quellenmaterial. Schon Ferdinand Josef Schneider hat in seiner Dissertation über »Jean Pauls Altersdichtung (1901) auf die intensive Lektüre des Buches von Cervantes hingewiesen, das der Schriftsteller offenbar in verschiedenen Übersetzungen kannte. ${ }^{183}$ In der Exposition von »Leben Fibels « erkennt Schneider einen deutlichen Hinweis auf den "Don Quixote ${ }^{184}$ Anhand von edierten Manuskripten aus dem Nachlass Jean Pauls belegt er außerdem, dass in den sogenannten »Fibliana«, einer Sammlung von 93 Blättern mit Notizen zu dem Romanprojekt ${ }^{185}$, konkret darüber nachgedacht wird, den ersten Biographen, der dem fiktiven गJean Pauk seine Vorlage liefert, »wie Cervantes [...] nur beiläufig « zu nennen, freilich mit dem Ergebnis: "so macht's aber keine Wirkung ${ }^{186}{ }^{18}$ Aufgrund dieser Rezeption lohnt sich eine eingehendere Betrachtung des »Don Quixote« mit einem Fokus auf der Makulatur.

Der »Don Quixote« erschien um 1800 in mehreren Übersetzungen in deutscher Sprache, angefangen bei Friedrich Justin Bertuchs drei Bände umfassenden Opus »Leben und Thaten des weisen Junkers Don Quixote von Mancha« (1775-1777). Es folgten zur Jahrhundertwende die Arbeiten von Ludwig Tieck (»Leben und Thaten des scharfsinnigen Edlen Don Quixote von la Mancha«, 1799-1801) und Dietrich Wilhelm Soltau (»Der sinnreiche Junker Don Quixote von la Mancha«, 1800-1801). Anders als im spanischen Original und auch in der ersten deutschsprachigen Übersetzung (»Don Kichote de la Mantzscha, Das ist: Juncker Harnisch auß Fleckenland«) von 1621 bzw. 1648 ist in den Übertragungen des späten 18. Jahrhunderts in Bezug auf das Quellenmaterial selbstverständlich die Rede von »Makulatur«. Obwohl der Begriff im Deutschen seinerzeit bereits verwendet wurde, war er Joachim Caesar, dem ersten, unter Pseudonym tätigen Übersetzer von Cervantes, anscheinend nicht geläufig oder erschien ihm nicht adäquat. Cervantes führt die unverhofften Quellen als »vnos cartapacios, y papeles viejos ${ }^{187}$ ein, was im 17. Jahrhundert ins Deutsche übertragen wird mit »alte beschriebene

\footnotetext{
183 Ebd., S. 203.

184 Ebd., S. 79.

185 Goebel, Bernauer, Der handschriftliche Nachlass Jean Pauls, 1, S. 215.

186 Zit. n. Schneider, Jean Pauls Altersdichtung, S. 94.

187 Miguel de Cervantes Saavedra, El ingenioso hidalgo don Quixote de la Mancha, Madrid 1605, S. 32.
} 
Papier vnd Brieffe ${ }^{188}$. Unter den »cartapacios « findet sich schließlich »el libro«, das Buch mit der Geschichte von Don Quixote, bei dem es sich um ein noch ungedrucktes Manuskript handelt. ${ }^{189}$ Dagegen entscheidet sich Bertuch geradezu selbstverständlich für die Formulierung: »verschiedenes Maculatur und andere alte Papiere ${ }^{190}$.

$\mathrm{Ob}$ mit Graphemen versehene Papiere unter die Bezeichnung Makulatur fielen, darüber entschied bis weit ins 18. Jahrhundert offenbar ihr Gebrauch, wie Füldener in seiner Verwendung des Wortes nahelegt. Ihm zufolge konnten auch »ausgearbeitete Msta« (Manuskripte) unter ungünstigen Umständen "als Maculatur « benutzt werden. ${ }^{191}$ Einige Jahre später ist dem »UniversalLexicon« Zedlers eine andere, auf den Buchdruck konzentrierte Bedeutung von Makulatur (»Mackeltur«) zu entnehmen: »In der Druckerey bedrucktes Papier, so entweder verdorben, oder keinen Abgang findet, und anders nicht, als zum einwickeln, oder einpacken dienet. ${ }^{192}$ Das deckt sich mit dem Bedeutungsspektrum in Adelungs »Grammatisch-kritischen Wörterbuch«, also dem Nachschlagewerk, das den bekannten Übersetzungen des »Don Quixote« zeitlich am nächsten kommt. ${ }^{193}$

Semantisch ist Makulatur um 1800 in einem hohen Maße an eine von der Typographie bestimmte Buchkultur und deren Implikationen gebunden. Und diesem Kontext werden die Papiere im »Don Quixote« durch die Übertragungen von Bertuch bis Soltau mindestens angenähert, wenn Makulatur für etwas anderes als Gedrucktes, nämlich für handschriftliche Aufzeichnungen eingesetzt wird. Makulatur erweckt im medialen Kontext des 18. Jahrhunderts zwar den Eindruck einer missglückten Veröffentlichung, sie repräsentiert aber dennoch die Publizität des Auflagendrucks und die mit der Vervielfältigung verbundene Beständigkeit von Texten. Aus dieser Publizität wird

188 [Miguel de Cervantes Saavedra], Don Kichote de la Mantzscha, Das ist: Juncker Harnisch auß Fleckenland, Frankfurt a.M. 1648, S. 138.

189 Cervantes, El ingenioso hidalgo don Quixote, S. 32.

190 Friedrich Justin Bertuch, Leben und Thaten des weisen Junkers Don Quixote von Mancha. Neue Ausgabe, aus der Urschrifft des Cervantes, nebst der Fortsetzung des Avellaneda, Weimar, Leipzig 1775-1777, I (1775), S. 126.

191 Füldener, Bio- \& Bibliographica Silesiaca, S. 7.

192 Art. »Mackeltur«, in: Zedler (Hg.), Grosses vollständiges Universal-Lexicon, 19 (1739), Sp. 95, hier: Sp. 95.

193 Vgl. Art. »Maculatur«, in: Adelung (Hg.), Grammatisch-kritisches Wörterbuch, III, Sp. 1112. 
gemeinhin Autorschaft abgeleitet, auch als soziale Figur, weshalb es alles andere als unerheblich ist, ob ein Text im Druck oder als Manuskript vorliegt. ${ }^{194}$ Das zeigt schon Morhof in seinem »Polyhistor«, wenn er dem Missbrauch von Manuskripten durch Plagiatoren entgegenzuwirken versucht. Das Problem der Handschriften besteht im Vergleich darin, dass ihr Status als Medium der Überlieferung in kaum einer Hinsicht gesichert ist, wie auch im »Don Quixote« unterstrichen wird. Es existiert eine mediale Differenz zwischen handschriftlich Verfasstem und Gedrucktem, die allerdings mehr als unklar erscheint, wenn das Wort »Makulatur« gebraucht wird, um ein Manuskript $\mathrm{zu}$ bezeichnen.

Jean Paul zeigt sich in "Leben Fibels« durchaus sensibel für die Differenz zwischen Handschrift und Druck: Nachdem sich der Biograph selbst die Aufgabe gestellt hat, die »Hand- und Druckschriften« (SW I.6, 372) des unbekannten Autors Fibel zu recherchieren, wird die Suche nach den Manuskripten stillschweigend eingestellt. Dadurch ist schnell zu übersehen, dass es ausschließlich gedruckte Artefakte (angesichts der fiktiven Überlieferung wäre man versucht zu sagen: bedruckte) sind, die vom »Leben Fibels« zeugen. Das trifft auf die (angeblichen) Werke des Autors zu, aber auch die erste Lebensbeschreibung liegt in einer Druckfassung vor. Das erscheint konsequent für ein derart durch Autorschaft definiertes Leben und verweist darauf, auf was Autorschaft um 1800 gegründet ist: Typographie. Autorschaft, so lehrt das »Leben Fibels«, bedarf der Medialität des Drucks als einer grundlegenden Voraussetzung, aber auch im Hinblick auf eine abgesicherte und möglichst lückenlose Überlieferung. Da gerät leicht aus dem Blick, um welch ungewöhnliches Artefakt es sich bei der biographischen Vorlage in »Leben Fibels« handelt: um einen Einzeldruck, der für Verluste nicht weniger anfällig zu sein scheint als eine ungedruckte Handschrift. Deshalb besteht die Gefahr, dass jemand die Lebensbeschreibung unwiederbringlich zerstört oder den Inhalt dieses Unikats als eigenes »Gemächt« ausgibt - wie `Jean Pauk es erwägt.

194 Siehe Elisabeth Eisenstein, The Printing Press as an Agent of Change. Communications and Cultural Transformations in early-modern Europe, Cambridge 1980, S. 121: »The wish to see one's work in print (fixed forever with one's name in card files and anthologies) is different from the desire to pen lines that could never get fixed in a permanent form, might be lost forever, altered by copying, or - if truly memorable - be carried by oral transmission and assigned ultimately to sanon.« 
Umso bemerkenswerter erscheint es, wie sich bei Cervantes die Autorfigur zu ihren ungedruckten Quellen verhält: Auch sie eignet sich diese nicht an, sondern deklariert sich als »der zweite Autor« (»el segundo autor«), und zwar in einer Passage, in der sie zunächst in der dritten, schließlich aber in der ersten Person Singular von sich spricht, aus Anlass einer jähen Zäsur: Im achten und letzten Kapitel des ersten Buchs des »Don Quixote« bricht die Erzählung vom Leben des Ritters inmitten eines spannenden Zweikampfs ab. ${ }^{195}$ Dadurch eröffnet sich ein narrativer Zwischenraum, genutzt als Schauplatz nachgeordneter Autorschaft. Der »zweite Autor« tritt in Erscheinung und denkt sogleich darüber nach, ob nicht in la Mancha - so Tieck - »in den Archiven oder in einigen Schreibepulten Papiere ${ }^{196} \mathrm{zu}$ finden sein könnten, die eine Fortsetzung der Geschichte ermöglichen würden. Im Folgekapitel spekuliert er darüber, dass die Geschichte, »wenn sie auch nicht geschrieben existire, sie doch in dem Gedächtnisse der Leute seines Dorfes und seiner Nachbarschaft leben müsse ${ }^{197}$, dass die Überlieferung also durch das kommunikative Gedächtnis gewährleistet sein könnte. Dieser Gedanke scheint für 'Jean Pauk alles andere als naheliegend zu sein. Erst als ihm die papiernen Quellen ausgehen, bemüht er sich in »Leben Fibels« um den Kontakt zu einem greisen »Männchen von mehr als 125 Jahren« (SW I.6, 527), das sich letztlich als Fibel höchstselbst offenbart.

Bei Cervantes bedarf es, wie Tieck übersetzt, einer Trinität von »Himmel, Zufall und Glück « ${ }^{198}$, damit der »segundo autor« an sein Ziel gelangt: Auf dem Marktplatz von Toledo begegnet ihm nämlich »ein Junge mit alten Schreibebüchern und Papieren, die er einem Seidenhändler verkaufen wollte ${ }^{199}$. Entscheidend wird in dieser Konstellation eine unwillkürliche Lektüre: "Da es nun meine Leidenschaft ist, alles zu lesen, wenn es auch zerrissene Papiere von der Straße wären, so folgte ich meiner natürlichen Neigung, nahm einige Blätter von denen, die der Junge verkaufte, sah sie an und erkannte die arabischen Lettern. ${ }^{200}$ Es braucht einen Dolmetscher, um »die ganze Makulatur zu übersetzen ${ }^{201}$. Dieser liest aus den Blättern vor, die sich als

195 Cervantes, El ingenioso hidalgo don Quixote, S. 30.

196 Miguel de Cervantes Saavedra, Leben und Taten des scharfsinnigen Edlen Don Quixote von la Mancha, übers. v. Ludwig Tieck, Berlin 1799-1801, I (1799), S. 93.

197 Ebd., S. 99.

198 Ebd., S. 100.

199 Ebd.

200 Ebd.

201 Ebd., S. 102. 
die »Historia des Don Quixote von la Mancha, geschrieben vom Cide Hamete Benengeli, [einem] Arabische[n] Historienschreiber ${ }^{202}$, entpuppen. Angesichts dieser fremden Herkunft des Autors entwickelt sich ein abwertender Diskurs über Fiktionalität, ausgehend von dem Vorwurf, dass es der arabischen »Nation eigenthümlich sei, zu lügen ${ }^{203}$, obwohl der Anspruch an den »Geschichtschreiber« doch lautet, er solle »genau sein, wahrhaft ${ }^{204}$.

Der fiktive >Jean Pauk sieht sich dagegen mit einem zwar deutschsprachigen, aber offenbar in der Tradition barocker Gelehrsamkeit ausladend formulierten Titel konfrontiert, der da lautet: „Curieuse und sonderbare LebensHistorie des berühmten Herrn Gotthelf Fibel, Verfassern des neuen Markgrafluster, Fränkischen, Voigtländischen und Kur-Sächsischen Abc-Buchs, mit sonderbarem Fleiße zusammengetragen und ans Licht gestellt von Joachim Pelz, der heil. Gottesgelahrtheit Beflissenen « (SW I.6, 374). Basal für die Verarbeitung dieser in Makulatur aufgelösten Vorlage durch >Jean Pauk ist, dass es sich bei ihm - dem eigenen Verständnis nach - um einen »fibelschen Lebensbeschreiber $($ SW I.6, 375) handelt, der sich an keiner Stelle mit »Dichtungen« (SW I.6, 446) behilft. Vielmehr macht er sich, wie Adam von Bergk allgemein über den Leser geschrieben hat, der nicht durch selbständiges Denken über seine Lektüre hinausgeht, vollkommen zum »Sklav seiner Materialien ${ }^{205}$. In der Rahmenfiktion deutet sich somit eine strikte Trennung von Fakt und Fiktion an, die 'Jean Pauk zum Nachteil gereicht. Sie kann auch gattungspoetisch aufgefasst werden: als Polarität zwischen historischer Biographie und Roman.

Christian Friedrich Blanckenburg grenzt in seinem einflussreichen »Versuch über den Roman« (1774) den Biographen gegen den Dichter ab. Er aktualisiert damit die von Aristoteles in seiner Poetik getroffene Unterscheidung zwischen Geschichtsschreiber und Dichter, die sich daraus ergibt, »daß der eine das wirklich Geschehene mitteilt, der andere, was geschehen könnte ${ }^{206}$. Mit einer ähnlichen Begründung kommt Blanckenburg zu dem Schluss, dass der Biograph nicht auf der Stelle des Dichters stehe, weil er aufzeichne, was er sehe und wisse. ${ }^{207}$ Dagegen solle und wolle der Dichter mehr, als Biograph

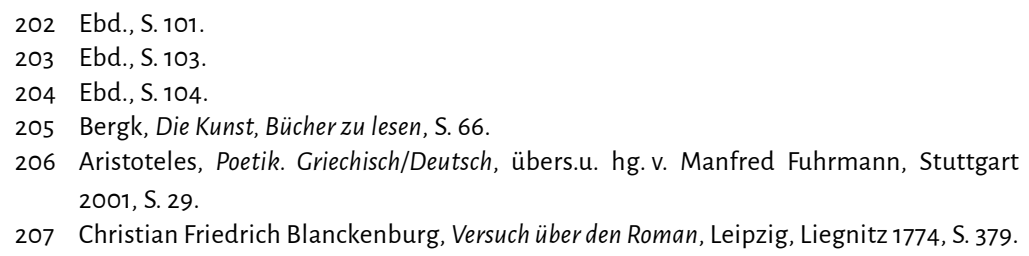


seiner Personen zu sein. »Er ist Schöpfer und Geschichtschreiber seiner Personen zugleich ${ }^{208}$, führt Blanckenburg aus. Es ist genau diese Konjunktion, die in »Leben Fibels« negiert wird.

Tatsächlich vermitteln sich Fakt und Fiktion im 18. Jahrhundert im Wahrscheinlichen. Britta Herrmann argumentiert, dass Historiographie und Fiktion seit dem 17. Jahrhundert als komplementäre, nicht kontradiktorische Formen des Erzählens erschienen. ${ }^{209}$ Das entspricht der Einordnung des Romans als Gattung: Er wird um 1800 meist der Historiographie zugerechnet ${ }^{210}$, Johann Heinrich Faber bezeichnet Romane als »unächte Brüder der Geschichte ${ }^{211}$. Die Biographie gilt in dieser Konstellation als ein »Seitenstück « ${ }^{212}$ der Geschichtsschreibung. Georg Jäger weist darauf hin, dass im 18. Jahrhundert das Erzählen im Wesentlichen im Kontext derselben erörtert wird. ${ }^{213}$ Romane erleben im letzten Drittel des Jahrhunderts eine Konjunktur, als das historiographische Erzählen neu konfiguriert wird. Den »Versuch« Blanckenburgs, eines Autodidakten, den Jean Paul eingehend studiert, bezeichnet Ralf Berhorst als »Adaption der pragmatischen Geschichtsschreibung für die erzählende Literatur ${ }^{214}$. Der historiographische Pragmatismus bemüht sich, so Johann Christoph Gatterer, um die »Entwicklung des Systems der Begebenheiten $\aleph^{215}$, wobei der Systemzusammenhang auf der Kausalität von Ursache und Wirkung beruht. ${ }^{216}$

Als seine Quellen versiegen, entwirft der fiktive >Jean Pauk in »Leben Fibels« eine poetologische Allegorie, deren zentrales Bild das des Flusses ist:

\section{Ebd.}

209 Vgl. Britta Herrmann, »Wir leben in einem colossalen [...] Roman<. Fiktivität und Faktizität um 1800«, in: dies., Barbara Thums (Hg.), Ästhetische Erfindung der Moderne? Perspektiven und Modell 1750-1850, Würzburg 2003, S. 115-137, hier: S. 116.

Vgl. Ralf Berhorst, Anamorphosen der Zeit. Jean Pauls Romanästhetik und Geschichtsphilosophie, Tübingen 2002, S. 170-182.

211 Johann Heinrich Faber, Anfangsgründe der Schönen Wissenschaften zu dem Cebrauche seiner akademischen Vorlesungen, Mainz 1767, S. 871.

212 Daniel Jenisch, Theorie der Lebens-Beschreibung. Nebst einer Lebens-Beschreibung Karls des Croßen: einer Preisschrift, Berlin 1802, S. X.

213 Ceorg Jäger, Empfindsamkeit und Roman. Wortgeschichte, Theorie und Kritik im 18. und frühen 19. Jahrhundert, Stuttgart, Berlin u.a. 1969, S. 114.

214 Berhorst, Anamorphosen der Zeit, S. 174.

215 Johann Christoph Gatterer, Rez. »Pragmatische Ceschichte des Hauses Geroldseck «, in: Allgemeine historische Bibliothek 2 (1767), S. 269-294, hier: S. 274.

216 Siehe dazu Johannes Süssmann, Geschichtsschreibung oder Roman? Zur Konstruktionslogik von Geschichtserzählungen zwischen Schiller und Ranke (1780-1824), Stuttgart 2000, S. $35 \mathrm{ff}$. 
»Die Sache war nämlich so: nachdem der bisherige Fluß der Fibelschen Geschichte gleichsam als eine perte du Rhône nur unter die Erde hin verschwunden war: so mußt' ich nachsuchen, wo die Ceschichte oder der Fluß wieder hervorbräche, und befragte deshalb alle Welt.«(SW I.6, 527)

Diese Bildlichkeit erinnert an Albrecht Haller, der Samuel Richardsons berühmten Briefroman »Clarissa« als eine »eigentümliche Historie« lobt, »wo eine Begebenheit aus der andern fließt, und der Zusammenhang der Thaten mit ihren Ursachen niemals unterbrochen wird « ${ }^{217}$. Damit setzt er Richardson gegenüber Pierre de Marivaux $a b$, dem er bescheinigt, mit seiner Erzählung vom »Vie de Marianne« (1731-1745) »eine blosse Chronick, wo man nichts als einige merckwürdige und wohlbeschriebene Vorfallenheiten antrift $\ll^{218}$, geliefert zu haben. Was Haller metaphorisch als ein Fließen beschreibt, ist ein Verhältnis von Ursache und Wirkung, ein Kausalitätsverhältnis, in dem »eine Begebenheit aus der andern« folgt. Mit Hilfe des Verbs »fließen« wird diese Relation als eine Bewegung dargestellt, die "niemals unterbrochen wird «, so dass die »Historie« als ein Kontinuum aufzufassen ist: als ein steter Fluss.

In »Leben Fibels« spielt die Bildlichkeit des Flusses nicht auf eine »innere Kausal-Kette« (SW I.4, 412) an, wie sie im »Jubelsenior« thematisch ist, sondern auf eine Bewegung im Verborgenen, deren Dynamik eine Verräumlichung bewirkt, da unklar ist, »wo die Geschichte oder der Fluß wieder hervorbräche« (SW I.6, 527). Anhand von Blanckenburg beschreibt Britta Herrmann den Roman als einen narrativen Verstehensentwurf, der aufgrund seiner fiktiven Konsistenz und Kohärenz der Zusammenhanglosigkeit und dem Zufälligen des Faktischen überlegen sei. ${ }^{219}$ Es sind gerade diese Prädikate des Faktischen, die kennzeichnend sind für das Dilemma des fiktiven Autors in »Leben Fibels« und sein Erzählen.

Mit der Reflexion von Autorschaft verbindet sich in der Rahmenfiktion von »Leben Fibels« eine poetologische Reflexion. Jedoch handelt es sich dabei um ein Nachdenken, das sich als integraler Bestandteil der Fiktion erweist, weil es die reale Konstruktion des Textes paradoxerweise transparent verschleiert. Fiktion und Wirklichkeit stehen somit in einem besonderen Verhältnis zueinander. Denn die Behauptung, die Zusammensetzung des Textes sei abhängig von äußeren Bedingungen, dient in erster Linie dazu, sich im

217 Albrecht von Haller, »Beurtheilung der berühmten Ceschichte der Clarissa«, in: ders., Sammlung kleiner Hallerischer Schriften, 2. Aufl., Bern 1772, I, S. 293-315, hier: S. 297.

218 Ebd.

219 Herrmann, »Fiktivität und Faktizität um 1800«, S. 121. 
Verborgenen von allen denkbaren Vorgaben der zeitgenössischen Romanpoetik zu befreien, wobei das Wissen um dieses Verborgene ein Wissen des Rezipienten um die Fiktionalität des Textes ist. Der »Fiktionalitätskontrakt « ${ }^{220}$ basiert somit auf Makulatur, und er schließt die Konstruktion des Romans ein. Der Makulatur wird die Ordnung des gesamten Textes zugeschrieben, aber freilich handelt es sich bei dieser Ordnung um eine Setzung des Autors. Die Illusion eines äußeren Zufalls, vermittelt als Einbruch der Materialität in die Konstruktion des Textes, weist demnach über sich hinaus: als ein gesteuertes, gewissermaßen "göttliches« Chaos. In der aufwendig dargestellten Konditionierung des Schreibens durch die Unwägbarkeiten einer »materielle[n] Welt«, diesem angeblichen »Reich des Zufalls« (SW I.4, 411), wie es in Jean Pauls »Jubelsenior« heißt, offenbart sich in produktionsästhetischer Hinsicht eine Entbindung von jeder Regelhaftigkeit literarischer Narration. Ausgehend davon lässt sich die Fiktion materialer Bedingtheit auch lesen als eine Inszenierung poetologischer Selbstermächtigung. Die Makulatur bildet in ihrer sekundären Materialität zugleich den Stoff, aus dem die Digressionen gemacht werden, für die der reale Jean Paul als Schriftsteller berühmt ist. $^{221}$

\section{Makulatur und narrative Struktur in "Leben Fibels"}

In »Leben Fibels« beschäftigt ১Jean Pauk im Örtchen Heiligengut eine Reihe analphabeter Dorfjungen, die als »Kompilatoren der im Dorfe zerstreueten Quellen« (SW I.6, 376) fungieren. Seine »trefflichen barfüßigen Sammler« (SW I.6, 376) bringen bald umgenutzte Papiere wie die genannten »KaffeeDüten«, aber auch allerlei »andere fliegende Blätter fiblischen Lebens« (SW I.6, 376) ein. Mit dieser Hilfestellung wird es ihm möglich, als »treue[n] Auszug aus den 40 bruchstücklichen Bänden« der ersten Biographie ein neues Buch zu schreiben: »Leben Fibels, des Verfassers der Bienrodischen Fibel«. Eine vergleichbare Konstellation findet sich im »Hesperus«, also jenem Roman von 1795, der Jean Paul als Autor zum Durchbruch verhalf. Hier muss sich ein Biograph an das halten, was ihm postalisch zugetragen wird - durch einen Hund namens Spitzius Hoffmann, der sich dadurch für einen »Sitz im

\footnotetext{
220 Siehe Rainer Warning, »Der inszenierte Diskurs. Bemerkungen zur pragmatischen Relation der Fiktion«, in: Dieter Heinrich, Wolfgang Iser (Hg.), Funktionen des Fiktiven, München 1983, S. 183-206.

221 Siehe Wieland, Vexierzüge.
} 
gelehrten Deutschland« (SW I.1, 1233) empfiehlt. »Ich meines Orts lese nichts, sondern schreibe nur das ab, was mir der Hund gebracht«, erklärt der vorgebliche Autor, welcher auf der Ebene der Fiktion an ein Material gebunden wird, das ihm vorschreibt, was er schreibt, ein Autor, dessen Namen bekannt ist: »Jean Paul«. Andreas Erb betont und erörtert in Bezug auf den »Hesperus« die Funktion des fiktiven Autors als eines Kopisten ${ }^{222}$, während sich die dortige Vorgehensweise anhand des Textes näher als »exzerpieren« oder »aus den Briefen extrahieren « (SW I.1, 508) bestimmen lässt. Die Nähe zum »Leben Fibels« ist unverkennbar: »Kompilatoren«, »fliegende Blätter«, »Auszug« - wie im »Hesperus« stellt Jean Paul das Narrativ der Autorschaft in den Kontext einer bei Erscheinen seines Spätwerks überkommenen Wissenskultur. Eine Besonderheit dieser ironischen Metaphorik liegt darin, dass durch sie ein Licht auf die gelehrten Praktiken fällt, die zunächst nur als Bildspender fungieren. Erhellt wird indirekt die selten beachtete Materialität dieser Praktiken, die in der Regel als intelligible Verfahrenstechniken aufgefasst werden, ebenso ihre Körperlichkeit. Das geschieht beispielsweise dann, wenn die »Kompilatoren« in »Leben Fibels« die gefundenen "Quellen« nicht schriftlich, sondern ganz buchstäblich zusammentragen. Hinzu kommen Anspielungen, die sich denselben Praktiken zuordnen lassen, etwa wenn die Aufgabe formuliert wird, die Biographie »zusammenzuleimen« (SW I.6, 375). In der dezidiert auf Autorschaft bezogenen Gelehrtensatire der Sechzigerjahre des 18. Jahrhunderts ist mitunter die Rede davon, jemand habe etwas aus anderen Schriften »Zusammen gestoppelt ${ }^{223}$, um sich Anerkennung als Autor zu verschaffen. Das solcherart beschriebene Handwerk des Autors schlägt sich in der zeitgenössischen Wahrnehmung auch in der Subjektbildung nieder: Beim Gelehrten, so ist es 1781 beim frühen Jean Paul nachzulesen, handele es sich um ein »Wesen, das aus dem Staub der Folianten zusammengekleistert (SW II.1, 244) sei.

Metaphorisch wird die in der Fiktion auftauchende Makulatur zudem mit einer textuellen Kontingenz in Verbindung gebracht, die um 1800 für die Publikationsform der Zeitschrift als charakteristisch erachtet wird ${ }^{224}$, wobei

222 Andreas Erb, Schreib-Arbeit. Jean Pauls Erzählen als Inszenierung»freier «Autorschaft, Wiesbaden 1996, S. 44-49.

223 [Zachäus], »Antwort«, S. 94.

224 Bettine Menke, »Alphabetisierung. Kombinatorik und Kontingenz Jean Pauls >Leben Fibels, des Verfassers der Bienrodischen Fibel««, in: Zeitschrift für Medien-und Kulturforschung 1 (2010), H. 2, S. 43-60, hier: S. 57. 
in »Leben Fibels « als Referenzorgan die »Allgemeine Deutsche Bibliothek « ${ }^{25}$ fungiert. Rhetorisch verweist der Roman anhand der Makulatur, in welcher die Biographeme des Gelehrten Fibel überliefert sind, noch auf eine andere Referenz: Trotz seiner späten Geburt war Jean Paul mit der in Leipzig erscheinenden satirischen Zeitschrift »Fidibus« (1768-1770) bestens vertraut, und in diesem Periodikum kam es zu einer rhetorischen Koppelung von Makulatur und Struktur, bestanden die einzelnen Ausgaben doch jeweils aus einem »Bündel« unnützen Papiers, und zwar ausgehend von dem Anspruch des fiktiven Herausgebers, »fliegende Blätter« zu publizieren, um in diesen sein reichhaltiges Wissen »auszukramen «. ${ }^{226}$

Die Autorschaft von >Jean Pauk wird in »Leben Fibels« durch die Struktur des Textes und die Bildlichkeit, durch welche diese eingehegt wird, eher abgewertet. \Jean Pauk erscheint als Autor in einem zweifelhaften Licht, er schreibt auch praktisch nicht. Er liefert einen "Auszug« aus aufgefundenen Quellen, ohne dass eine einzige Schreibszene den Roman im Entstehen zeigen würde. Dieser »treue Auszug aus den 40 bruchstücklichen Bänden « (SW I.6, 376) weist eine bemerkenswerte Ordnung auf. Zwar werden dem fiktiven Autor seine Quellen »vom Zufall zugetragen « ${ }^{227}$. Aber das bringt die Lebensbeschreibung erstaunlicherweise kaum durcheinander. In der Forschung ist diese Fiktion der Textproduktion sicher zu Recht mit Jean Pauls eigener Praktik des Exzerpierens und seinem literarischen Schreiben in Verbindung gebracht worden ${ }^{228}$. Magnus Wieland hat aufgezeigt, dass bei Jean Paul die Organisation seiner Exzerpte einer "Abfall-Logik« folgt, und zwar in dem Sinne, dass es sich bei Abfall, so Mary Douglas, um »Materie am falschen Ort« (»dirt is matter out of place«) handelt ${ }^{229}$. Wieland argumentiert ähnlich wie Schmidt-Hanissa, demzufolge die Praktik des Exzerpierens bei Jean Paul »in der radikalen Dekontextualisierung von Daten und in der Auflösung aller hierarchischer Strukturen des Wissens $«^{230}$ besteht. Dadurch entwickelt

225 »Hingegen floß die Makulatur so schön auf Fibels Leben ein wie eine zweite allgemeine deutsche Bibliothek und vertrat deren Stelle.«(SW I.6, 388)

226 [Zachäus Fidibusifer], »Der Autor erzählt...«, S. 2.

227 Menke, »Alphabetisierung«, S. 43

228 Wieland, »Sudelbibliothek«, Menke, »Aphabetisierung«, S. 57.

229 Wieland, »Litteratur«, S. 38f., unter Verweis auf Douglas, die u.a. schreibt: »If we can abstract pathogenecity and hygiene from our notion of dirt, we are left with the old definition of dirt as matter out of place.«(Douglas, Purity is Danger, S. 36) 
die »Abfall-Logik « einige Sprengkraft, insbesondere vor dem Hintergrund einer ordnungsliebenden Wissenskultur, wie sie in einer rhetorisch verfassten Litteratur zum Ausdruck kommt. Litteratur bezeichnet bis ins späte 18. Jahrhundert nicht nur den eingegrenzten Bereich der belles lettres, sondern - mit Andreas B. Kilcher gesprochen - die »Kunst schriftlicher Aufzeichnung von Wissen im allgemeinen Sinn ${ }^{231}$. Wieland macht auf die Doppeldeutigkeit von Litteratur aufmerksam, die sich ergibt, wenn man das englische Wort für Abfall, also »litter«, darin mit anklingen lässt. Ein Buchstabe wird schließlich gegen Ende des 18. Jahrhunderts aus der Litteratur entsorgt, übrig bleibt eine schöne Literatur, die nicht mehr selbstverständlich topischen Regeln folgt. Schmidt-Hanissa führt dazu aus:

»Hatte die Literatur im Aufschreibesystem des 17. Jahrhunderts die Funktion, unter Einsatz unterhaltsamer Mittel die kulturelle Zirkulation des Wissens in Gang zu halten, so instrumentalisiert Jean Paul die Elemente des Wissens und stellt sie in den Dienst einer Logik des poetischen Effekts. « ${ }^{232}$

In Bezug auf die von ihm beobachtete »Abfall-Logik« stellt Wieland weniger darauf $a b$, wie Jean Paul das »als Spielmaterial verfügbar« gemachte Wissen einsetzt, vielmehr betont er allgemeiner dessen Potenzial: »Im Abfall steckt somit ein Kreativitätspotential, das offen ist für neue Kombinationen und Arrangements. ${ }^{233}$ Menke leitet aus diesem Potenzial wiederum ein für Jean Paul geltendes "Prinzip kombinatorischer Produktion ${ }^{234} \mathrm{ab}$, das für sie in der Fiktion von »Leben Fibels« exemplarisch zum Tragen kommt. Allerdings ist die Konstellation in »Leben Fibels « doch eine andere als im »Zufallsverfahren der Aleatorik des Kombinierens ${ }^{235}$, dem sich Jean Paul als Autor selbst verschreibt. Schließlich folgt die Kombinatorik im Roman zwar nicht en detail, aber im Großen und Ganzen dem Plan einer Gelehrtenbiographie. Eine vorgängige Dekontextualisierung »durch Stuhlklappen, Papier-Drachen und andere fliegende Blätter« (SW I.6, 376) wird mit einer Rekontextualisierung beantwortet. Mit der Geburt ist nicht nur ein bestimmtes Ende höchstwahrscheinlich, nämlich der Tod (auch wenn dieser im Roman schließlich umgangen wird). Sondern in der Spanne zwischen diesen beiden existentiellen

231 Kilcher, »Litteratur «, S. 360.

232 Schmidt-Hannisa, »Lesarten«, S. 40.

233 Wieland, »Litteratur«, S. 39.

234 Menke, »Alphabetisierung«, S. 44.

235 Ebd., S. 49, Fn. 23. 
Daten unterliegt alles der Linearität eines Lebenslaufes, der Zufall eines jeden Fundes hebt sich auf in einer biographischen Kausalität.

Die Narration müsste dabei dem Zufall der Funde oder einer nachträglichen Ordnung folgen. Stattdessen zeichnet sich eine Progression des Erzählten ab, durch die - wie an anderer Stelle bemerkt - auf der Ebene des Erzählens der »Eindruck eines geordneten Zufalls « ${ }^{236}$ erweckt wird. ${ }^{237}$ So entwickelt sich ein weitgehend der Chronologie von Fibels Lebenslauf folgender Fortschritt, dem es inhaltlich jedoch an Vollständigkeit und letztlich an Kontinuität mangelt. Fehlt es an passenden Quellen, gerät das Erzählen ins Stocken. Es tun sich Lücken auf, ablesbar an Überschriften von einzelnen Kapiteln. So ist eines der fortlaufend nummerierten und somit abstrakt eine Abfolge suggerierenden Kapitel überschrieben mit: »Nicht das 16., sondern das 17. Kriminal-Kapitel« (SW I.6, 445). Es beginnt mit einer Erklärung: »Ich stelle das ganze Dorf zum Zeugen auf, daß ich das 16te Kapitel vermittelst aller Jungen desselben nicht aufzujagen vermocht.« (Ebd.) Angesichts dessen fällt ein Licht auf die Poetologie des fiktiven Autors, auf sein Selbstverständnis, das dem von Schmitz-Emans angeführten »Bastler« verpflichtet bleibt: »Wollt' ich«, erklärt er selbstbewusst, »[...] die Lücke bloß mit Dichtungen zufüllen: so könnt' ichs wohl; oder ich müßte in meinem Leben nicht gelebt oder gelesen haben.«(SW I.6, 446) »Dichtungen« eignen sich dazu, handwerklich betrachtet, eine »Lücke« zu füllen, doch wird dies wortreich unterlassen. Und so kommt es noch schlimmer, in einem Abschnitt, dem keine Ziffer mehr vorangestellt ist, sondern das nur noch einen Titel trägt, nämlich: »Nicht Judas-, sondern Jean Pauls-Kapitel «, wobei erklärend anzufügen ist, dass Judas der Name des "getauften Juden « (SW I.6, 373) ist, von dem >Jean Pauk die Makulatur zur Grundlegung seiner Biographie erhalten hat. In diesem Kapitel gelangt nun das Erzählen scheinbar an ein Ende, denn es zeichnet sich durch einen »Mangel an umlaufendem Papier« (SW I.6, 523) kein »Ausweg« aus dem $\mathrm{zu}$ rekonstruierenden Lebensweg ab:

236 Fuchs, Büchermachen, S. 44.

237 »Zu den treuesten Begleiterinnen der Überlieferung zählen ihre Materialität und die vielfältigen Formen der Kontingenz, denen sie sich durch jene ausgesetzt sieht. Autorschaft ist unter diesen Vorzeichen zunächst das Phantasma, immer schon Herr über die Zufälle und Bedingtheiten der Überlieferung gewesen zu sein oder sich wenigstens über diese aufschwingen zu können, sei es als >Autor< selbst, sei es als dessen Stellvertreter, Editor.« (Martin Stingelin, »>Dämmerpunkteく der Überlieferung. Autor, Text und Kontingenz«, in: MLN 117 (2002), Nr. 3, S. 650-660, hier: S. 650) 
»Verdrüßlich und fast grimmig hab' ich das Kapitel ohne eine Zahl überschrieben; denn seit Wochen lauft nichts mehr von den Dorfungen ein, und ich sehe mich mitten im Buche und im Dorfe mit leeren Händen festsitzen, ohne einen Ausweg zu einem ordentlichen Ausgang.«(SW I.6, 522)

Schließlich führt auch diese missliche Lage nicht dazu, dass der Autor auf seine eigene Kreativität und Imagination setzen würde, so dass Dichtung und Wahrheit in einer Kontinuität des Erzählten stillschweigend miteinander verbunden werden würden. Sondern `Jean Pauk begibt sich zur Suche nach weiteren Quellen an einen Ort, welcher der Sphäre geistiger Produktion in all seiner Körperlichkeit diametral entgegengesetzt zu sein scheint: den Abort. Dort, wo in der Schermesser-Episode von Grimmelshausens »Simplicissimus« die Makulatur das Wort ergreift, um zur eigenen Rettung eine Lebensgeschichte zu erzählen, die der Lichtenberg vorschwebenden »Bibliogenie« zur Ehre gereicht hätte, findet der Biograph in »Leben Fibels« nichts dergleichen, auch keine dem Äther entsprungenen Verse von Klopstock, sondern nur »karge Zeilen« (SW I.6, 524), aus denen sich nicht viel mehr machen lässt als fünf »Kapitelchen«, die mit Sätzen enden wie: »Hier fehlt alles.« (SW I.6, 525) 


\section{Schluss}

Um 1800 wird Autorschaft durch das gedruckte Buch definiert. Johann Georg Meusel, der Herausgeber des Schriftstellerlexikons »Das gelehrte Teutschland«, bezeichnet Publizierende mit großer Selbstverständlichkeit als »Büchermacher ${ }^{1}$. Denn das typographische Artefakt konstituiert für ihn Autorschaft (Kapitel 3.1). Meusels Nachschlagewerk ist ein deutschsprachiges Leitmedium der Autorschaft im »druckpapiernen Weltalter« (SW I.5, 25). Jeder Eintrag ermöglicht eine papierne Existenz als eingetragener Schriftsteller und dokumentiert, wie sich das Publizieren zwischen 1765 und 1815 zu einem sozialen Phänomen entwickelt. Gedruckt zu Ruhm und Ehre zu gelangen, das ist nicht mehr nur der Anspruch einer Bildungselite innerhalb der ständischen Gesellschaft, sondern plötzlich eine Option für die »Aufsteigerschicht« der Bürgerlichen, wie Hans-Ulrich Wehler sie beschreibt. ${ }^{2}$ Dadurch erlebt die Gelehrtenrepublik eine ungekannte Entgrenzung, die »unmäßige Autorschaft ${ }^{3}$ bricht sich Bahn (Kapitel 3.2). 1782 heißt es bei Johann Melchior Gottlieb Beseke: »Gelehrtenrepublik heißt also der ganze Haufe von Schriftstellern, sie mögen nun Bücher oder ein Oktavblatt geschrieben haben, Erfinder einer Wissenschaft oder Gelegenheitsdichterlinge seyn. $\ll^{4}$

Niemals zuvor dürfte Autorschaft in einem solchen Maße populär gewesen sein wie in dieser Hochphase bürgerlicher Vergesellschaftung, die »alte Wechselbeziehung zwischen Buchmarkt und Bildungswesen ${ }^{5}$ ist in Auflösung begriffen. Es entsteht eine breite Ratgeberliteratur für Publizierende, doch die in der Tradition der Gelehrtensatire stehenden Klagen über eine

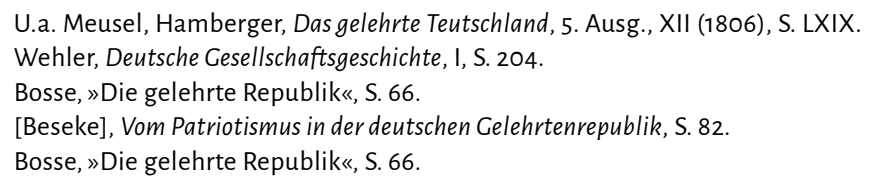


»Schriftstellersucht" gehören ebenso zur Epoche (Kapitel 3.3). Bei Friedrich Justus Riedel rangiert die "Schreib- und Autorsucht" sogar an erster Stelle der »Modekrankheiten des achzehendten Jahrhunderts « ${ }^{6}$. Autorschaft erscheint als ein attraktives gesellschaftliches Rollenangebot, das die Überwindung ständischer Grenzen ermöglicht. So klagt ein Rezensent von Meusels Lexikon über die in dem Nachschlagewerk sich abzeichnende »Gesellschaft«, die auch »einen Kaminfeger, mehrere Schulmeister, einen Tabacksfabrikanten, einen Küster, und einen Gärtner « ${ }^{7}$ umfasst.

Praxistheoretisch lässt Autorschaft sich als eine Subjektform neben anderen beschreiben, die sich Individuen in sozialen Praktiken aneignen. Konkret geht es um Praktiken des Publizierens, die sich um Bücher als gedruckte Artefakte gruppieren und in "Praxis-/Diskursformationen « eingebunden sind. ${ }^{8}$ Eine dieser Praktiken ist das Schreiben, das vom Publizieren nicht geschieden ist, sondern empfänglich macht für die Anforderungen des Büchermachens. Denn: Bis weit ins 19. Jahrhundert wird die Praktik des Schreibens grundständig als graphisches Verfahren vermittelt, das wie die meisten Wissenspraktiken dieser Zeit auf Reproduktion basiert (Kapitel 2.3). Der ausgeprägte Graphismus der Schrift entbindet diese in operationaler Hinsicht von der Funktion, die gesprochene Sprache zu vermitteln. Die »Schönschreibekunst« erscheint selbstzweckhaft, sie erlangt über die Elementarbildung eine relative Eigenständigkeit, verbunden mit dem Anspruch einer möglichst genauen Nachahmung. Somit folgt das Schreibenlernen einem übergreifenden Prinzip zeitgenössischer Bildung. Als Notationsverfahren steht das Schreiben im Dienst iterativer Praktiken der Gelehrsamkeit wie dem Abschreiben oder dem Exzerpieren. Daher polemisiert der Philosoph Johann Gottlieb Fichte gegen den unselbständig Denkenden als jemanden, der sich wie ein Schüler bei »jedem Federzuge [...] nach der Vorschrift « umsehe. ${ }^{9}$

Hinsichtlich des Büchermachens garantiert die ästhetisch-handwerkliche Konvergenz zwischen »Schreibekunst« und Typographie die Aufmerksam-

$6 \quad$ [Riedel], »Skribleriana«, S. 298 [16].

$7 \quad$ [Kmr.], Rez. »Fünften Nachtrags...«, Sp. 783.

8 Reckwitz, »Doing subjects«, S. 73. Man könnte mit Michel Foucault von einem Dispositiv der Autorschaft sprechen. Im Anschluss an Foucault bestimmt Giorgio Agamben ein Dispositiv als »heterogene Gesamtheit, die potentiell alles Erdenkliche, sei es sprachlich oder nichtsprachlich, einschließt: Diskurse, Institutionen, Gebäude, Gesetze, polizeiliche Maßnahmen, philosophische Lehrsätze usw.« (Giorgio Agamben, Was ist ein Dispositiv?, Zürich u.a. 2008, S. 9).

9 Fichte, Ueber den Unterschied, S. 316. 
keit der Publizierenden für die in ihren Büchern gebrauchten Druckschriften. Das gilt nicht weniger für den Buchschmuck, bedenkt man den Stellenwert, den meisterhaft in Kupfer gestochene »Vorschriften« mit allerlei Zierrat im Schreibunterricht dieser Zeit besitzen. Eine »schöne Hand«, geschult an solchen Vorbildern, zeichnet sich dadurch aus, dass man die Lettern "fast nicht für Geschriebenes $\aleph^{10}$ hält. Auch Jean Pauls frühe Exzerpte basieren hinsichtlich ihrer Materialität auf der graphischen Konvergenz zwischen Handschriftlichkeit und Druckschriftlichkeit (Kapitel 2.1, 2.2). Gemeint sind die im Nachlass überlieferten Leseaufzeichnungen der Jahre 1778 bis 1781, die nach Auffassung von Michael Will »für das schriftstellerische Werk Jean Pauls von eher geringerer Relevanz ${ }^{11}{ }^{11}$ sind. Ein Urteil, das es nach meinen Recherchen in der Berliner Staatsbibliothek zu revidieren gilt, offenbaren die mit blaugrauem Buntpapier ummantelten Exzerptbände doch die frühe Affinität des späteren Schriftstellers zu gedruckten Medien. Jean Paul ließ für diese Exzerpte eigens Titelblätter in einer repräsentativen Fraktur anfertigen, auch andere Standards des Buchdrucks übertrug er von Hand auf die von ihm zusammengenähten Bände. Es handelt sich bei diesen Aufzeichnungen um ungewöhnliche Artefakte, die in einem mimetischen Verhältnis zu gedruckten Büchern und Zeitschriften stehen, weshalb ich sie als handgeschriebene Bücher beschrieben habe. Als solche stellen sie keine Sonderform des Publizierens dar, für eine Vervielfältigung hat Jean Paul diese Manuskripte nie vorgesehen. Dennoch verleiht er den Unikaten durch Titelblätter und andere Ausstattungselemente den Anschein gedruckter Publikationen. Zum einen nutzt Jean Paul diese Elemente, mit welchen er als Leser bestens vertraut ist, um das in seinen Exzerpten gesammelte Wissen so zu ordnen, wie es in zeitgenössischen Veröffentlichungen üblich ist. Die handgeschriebenen Bücher lassen zum anderen den Willen erkennen, symbolisch an einer Wissenskultur teilzuhaben, für welche die typographische Reproduktion in Buchform prägend ist. Jean Paul entwirft mit diesen Nachahmungen eine papierne Fiktion. Nebenbei nutzt er seine Buchbasteleien in Ermangelung einer eigenen Bibliothek als objektiviertes kulturelles Kapital. In der Liebeskorrespondenz mit Sophie Ellrodt lässt der angehende Schriftsteller seiner Verehrten einen »Band« aus seinem Privatbesitz zukommen.

In der eigenen Textproduktion greift Jean Paul ebenfalls auf geläufige Paratexte zurück. Die frühen »Übungen im Denken« erhalten ein Titelblatt in

10 Zerrenner, Volksbuch, S. 94.

11 Will, »Lesen, um zu schreiben«, S. 44. 
Fraktur mit Bandangabe, obwohl es auf der zweiten Manuskriptseite in einer »Anzeige« ausdrücklich heißt: »Diese Versuche sind blos für mich.« (SW II.1, 36) Hier erfüllt die Nachahmung eines Periodikums offenbar die Funktion, das eigene Schreiben zu disziplinieren und im Turnus einer Zeitschrift zu verstetigen. Tatsächlich verliert sich die Mimesis des gedruckten Buches im handschriftlichen Nachlass Jean Pauls am Übergang zur eigenen Autorschaft. Fortan entfaltet das Werk dieses Autors eine Poetologie der Materialität, die papierne Fiktion der handgeschriebenen Bücher wird abgelöst durch die fiktiven Papiere, die seine Erzählungen durchziehen. Nicht selten bilden sie die Grundlage der Digressionen, also jener Ausschweifungen, für die Jean Paul als Erzähler ebenso berühmt wie berüchtigt ist. So wird im Medium der Fiktion die Buchform nicht nachgebildet, sondern regelmäßig destruiert. Daneben erfindet Jean Paul mit dem Schulmeisterlein Maria Wutz oder Quintus Fixlein auch Autorenfiguren, die es ihm mehr oder weniger gleichtun, die in ihrer »Taschendruckerei« (SW I.1, 425) handgeschriebene Bücher fertigen (Kapitel 2.4). Fixlein zeigt überdies eine besondere Vorliebe für den Kupferstich, und zwar mit dem Anspruch, das Schreiben als graphisches Verfahren $\mathrm{zu}$ verbessern.

Weiter als Wutz und Fixlein bringt es bei Jean Paul die Romanfigur Gotthelf Fibel, die sich eine Druckwerkstatt einrichtet, um buchstäblich als Büchermacher den Ruhm eines Schriftstellers zu erlangen. In der Romanfiktion wird auf die Spitze getrieben, was sich um 1800 in der Realität beobachten lässt: Das Gedrucktsein begründet eine eigenständige, mediatisierte Existenz als Autorsubjekt. Jean Paul legt das in »Leben Fibels« auch anhand einer Anekdote offen, die vom »Irrtum des Franzosen Mr. Martin« handelt, »der in seinem Verzeichnis der Bibliothek des Mr. de Bose das Wort gedruckt als einen Schriftsteller unter dem Titel Mr. Gedruckt an- und fortführt« (SW I.6, 389).

Um das gedruckte Artefakt spinnen Bücherverzeichnisse, Lexika und Rezensionsorgane ein dichtes Netz bio-bibliographischen Wissens. Das geschieht auf der Grundlage der im späten 18. Jahrhundert noch immer wirkmächtigen Literargeschichte, der Historia literaria (Kapitel 3.1, 3.4). Sie verspricht eine Orientierung innerhalb der Gelehrtenrepublik angesichts der "viel Tausend und Millionen Bücher in der Welt « ${ }^{12}$ und kompensiert deren Unverfügbarkeit für das Gros des Publikums. Die mit der Registratur der Literatur befassten Medien machen Bücher entbehrlich, sie funktionieren -

12 Gundling, Vollständige Historie der Celahrheit, I, S. 1. 
mit Derrida gesprochen - als Supplemente. Bibliographien sind nicht nur ergänzende Hilfsmittel, sondern wirkmächtige Medien eines durch die Historia literaria definierten Wissens. Gelehrte wie Meusel koppeln die Bücherkunde planmäßig mit der Biographie, sie liefern zu einem jeden Titel »kurze biographische Notizen «, um »den Leser in den Stand zu setzen, hie und da selbst zu beurtheilen, in wiefern die Lage des Verfassers im bürgerlichen Leben, der Standpunkt, von dem aus er die Sachen ansah, ihn zu diesem oder jenem Werke qualificierten ${ }^{13}$. Wie stark die Wissensakkumulation vom Interesse an der Person des Publizierenden getragen wird, zeigen unter anderem die Bemühungen um öffentliche Korrekturen fehlerhafter Angaben. Aber auch die Nachrichtendienste, um welche sich die Beteiligten des literarischen Diskurses regelmäßig wechselseitig bitten, sind ein Beleg dafür. So erkundigt sich 1787 der Arzt und Philosoph Johann Georg Zimmermann nach einem unerwarteten Anwurf durch Johann Georg Heinzmann in seinem Korrespondenznetz genauestens nach den persönlichen Daten des Verlegers. Tatsächlich wäre die Autorfunktion, wie Foucault sie beschreibt, ohne biobibliographische Sekundärmedien undenkbar. Das bedeutet zugleich, dass die eingehende Beschäftigung mit Texten für die Ordnung des Diskurses nachrangig ist. Agamben betrachtet die Autorfunktion als einen »Prozeß der Subjektivierung, durch den ein Individuum als Autor eines bestimmten corpus von Texten identifiziert und konstituiert wird«, mit dem Ergebnis, dass das Subjekt »seinen Platz dem Register überlassen muß, das definiert, unter welchen Bedingungen und in welchen Formen das Subjekt in der Ordnung des Diskurses erscheinen kann « ${ }^{14}$ Bibliographien und Kataloge bilden um 1800 ein solches "Register", dessen Basis nicht in erster Linie Texte bilden, sondern »bibliographische Titelkopien $\aleph^{15}$ gedruckter Artefakte.

Zugleich widmen sich Rezensionsorgane wie Nicolais »Allgemeine Deutsche Bibliothek « oder die »Allgemeine Literatur-Zeitung « ausführlich Fragen des Formats oder der Typographie besprochener Bücher. Dabei kommt der "Doppelcharakter « des Buches zum Tragen, der sich daraus ergibt, dass das Artefakt durch eine »materiell definierte Differenz $«^{16}$ vom Buch als Textmedium zu unterscheiden ist. Das Buchartefakt fungiert als vielfach codiertes

[Ersch], »Ueber Litteratoren und Recensenten«, Sp. 10.

Agamben, Profanierungen, S. 60.

Markus Krajewski, Zettelwirtschaft. Die Ceburt der Kartei aus dem Geiste der Bibliothek, Berlin 2002, S. 38.

Rautenberg, Wetzel, Buch, S. 63, S. 42. 
Objekt und Bildspender der schönen Literatur wie der ihr gewidmeten kritischen Kommunikation. Das ist auch der Dynamik eines wachsenden Buchmarktes geschuldet, durch welche die Praktiken des Publizierens zunehmend am Marktgeschehen ausgerichtet werden. Das belegt der kulturkritische Diskurs des späten 18. und frühen 19. Jahrhunderts, in dem Schriftstellerinnen und Schriftsteller gerne als »Fabrikanten« abgewertet werden. Prominent verhandelt wird die verschärfte Ökonomisierung des Publizierens auch in Friedrich Nicolais »Sebaldus Nothanker«, einem Roman, der sich in den Siebzigerjahren des 18. Jahrhunderts einer großen Beliebtheit erfreut. In der Regel fällt dabei ein Licht auf das Artefakt, das neben einem kulturellen auch einen wirtschaftlichen Wert besitzt. Die ökonomische Seite des Buches, sein Warencharakter, wird im literarischen Diskurs des späten 18. Jahrhunderts mit der Materialität des Artefakts identifiziert. Der Philosoph Fichte betrachtet Bücher nur dann als materiale Objekte, wenn er die »Betriebsamkeit des litterarischen Marktes« anprangert. Schließlich begeben sich die Publizierenden als »Fabrikanten« laut Fichte in Abhängigkeit vom »Urtheil des Druckers, welches ja lediglich ein Urtheil über die Verkäuflichkeit oder Nichtverkäuflichkeit der Waare zu seyn vermag « ${ }^{17}$.

Das Wachstum des Buchmarktes geht mit einem tiefgreifenden Wandel und einer Ausdifferenzierung des Publikationswesens einher. Exemplarisch lässt sich diese Veränderung anhand einer Auseinandersetzung zwischen dem Lexikon-Herausgeber Meusel und Johann Pezzl aus Wien nachvollziehen. Dort sind zu Beginn der Achtzigerjahre des 18. Jahrhunderts günstige Broschüren groß in Mode. Weshalb Meusel in einem Vorwort zu seinem fortlaufenden Lexikon feststellt, dass es in der Donaumetropole mit mehr als 200.000 Einwohnern »Schriftsteller zu Hunderten giebt $\aleph^{18}$ - die er allesamt in »Das gelehrte Teutschland« aufnehmen will. Pezzl erwidert, in Wien sei es »keinem Menschen eingefallen, die Fabrikanten solcher Waare mit dem Namen der Schriftsteller zu belegen ${ }^{19}$. Worauf wiederum Meusel mit einigem Befremden reagiert: »Wie? ein Fabrikant kleiner Schriften oder fliegender Blätter soll kein Schriftsteller seyn? ${ }^{20}$ In dieser Kontroverse deutet sich

\footnotetext{
17 Fichte, Ueber das Wesen des Gelehrten, S. 134.

18 Hamberger, Meusel, Das gelehrte Teutschland, 4. Ausgabe. 1. Nachtragsband (1786), S. 775 .

19 Pezzl, Skizze von Wien, Viertes Heft, S. 493 [LXXXVI].

20 Hamberger, Meusel, Das gelehrte Teutschland, 4. Ausgabe. 3. Nachtragsband (1788), S. VIIIf.
} 
eine Taxonomie gedruckter Medien an, die durch den Strukturwandel öffentlicher Kommunikation in Bewegung gerät. Vorbei erscheinen die Zeiten der »alten vielpfündigen Folianten« (SW I.5, 495), mit denen Gelehrte ihren Ruf untermauerten.

Vor diesem Hintergrund formulieren in der zweiten Hälfte des 18. Jahrhunderts vorrangig Dichter selbstbewusst Ausstattungswünsche für ihre $\mathrm{Pu}$ blikationen (Kapitel 4.4). Das Jahr 1757 markiert in diesem Zusammenhang eine Zäsur, weil damals der englische Drucker John Baskerville mit seiner Vergil-Ausgabe die Buchästhetik in Europa revolutioniert. Etwa zur selben Zeit erscheint in Hamburg bei Johann Carl Bohn eine mit hohem Aufwand produzierte Werkausgabe des in seinen »Nebenstunden « zu poetischer Meisterschaft gelangten Friedrich von Hagedorn. Zeitgenössische Schriftsteller erwarten von Bohn, dass der Verleger mit jedem Band das "Muster eines Buches ${ }^{21}$ abliefert. Für Friedrich Gottlieb Klopstock bilden die HagedornAusgaben über Jahre den gestalterischen Maßstab für die Publikation seiner eigenen Schriften. Als Klopstock seinen »Messias« auf Subskriptions-Basis herausgeben will, greift er auf Hagedorns »Freundschaft« von 1748 zurück. Er schreibt: »Meine Absicht wäre in groß 4 [Quart, Anm. d. Verf.] wie Hagedorns Freundschaft mit solchen Lettern auf solches Papier drucken zu lassen. ${ }^{22}$

Für Ungern-Sternberg offenbart sich in solchen Wünschen eine »emanzipatorische Publikationspraxis « ${ }^{23}$, die nicht nur bei Klopstock zum Selbstverlag führt. Gleichzeitig bilden Drucker und Verleger im letzten Drittel des 18. Jahrhunderts ein neues Selbstverständnis aus. Einerseits legt der bekannte Schriftschneider Johann Gottlieb Immanuel Breitkopf gesteigerten Wert auf die Feststellung, »dass Bücher ihren Werth innerlich, nicht bloss äusserlich, haben müssen ${ }^{24}$. Andererseits ist es derselbe Breitkopf, der eine Aufwertung des eigenen Schaffens betreibt, indem er Typographen ausdrücklich als »Künstler« bezeichnet. In der »Antiqua-Fraktur-Debatte« gelingt es Buchgestaltern wie ihm, die Aufmerksamkeit eines konsumfreudigen Lesepublikums auf die Materialität der Literatur zu lenken. Engagiert diskutieren Autoren und Verleger um 1800 über »typographischen Luxus« und die grundsätzliche (Hg.), Briefwechsel zwischen Cleim und Uz, S. 267. 
Frage, in welchem Verhältnis das Buchartefakt zum Werk stehen sollte. Georg Joachim Göschen wirbt 1793 um Klopstocks Oden, indem er dem Dichter ein »Monumentum Typograph. dieses Jahrzehends ${ }^{25}$ in Aussicht stellt. Zur selben Zeit beklagt der Verleger Friedrich Justin Bertuch, der in Weimar das berühmte »Journal des Luxus und der Moden« herausgibt: »Jeder neugebohrne Dichterling, Romanschreiber und Kalendermacher wollte nun auf geglättet Schweizer-Papier, mit Didotschen Lettern, Kupfern und Vignetten gedruckt, und in Marroquin gebunden seyn; und so paradirten oft die schaalsten Producte im schönsten Gewande. ${ }^{26}$ Mit dem »schönsten Gewande« bedient sich Bertuch einer Metaphorik der Bekleidung, die im ausgehenden 18. Jahrhundert in Ausstattungsfragen eine permanente Verwendung findet. Die Bildlichkeit partizipiert an der Konjunktur einer bürgerlichen Mode, welche die Funktion sozialer Distinktion zwar subtiler und individueller erfüllt als die »Kleiderordnungen« der ständischen Gesellschaft. Dennoch folgt die Kleidermode weiterhin dem Anspruch der Angemessenheit (lat. aptum, decorum), einem gesellschaftlichen Normativ äußerer Repräsentation.

Eben dieses Normativ der Angemessenheit begegnet einem in Verbindung mit der Metaphorik der Bekleidung im zeitgenössischen Diskurs über das schöne Buch allenthalben (Kapitel 4.3). Das liegt am Status des Buches als Konsumgut, es ist ein Gegenstand der Warenwelt neben anderen. Deshalb muss ein Verleger wie Göschen in seiner Kalkulation darauf achten, wie sich eine aufwendige Buchausgabe »mit der möglichsten Pracht und doch dem Beutel der Deutschen Bücherliebhaber angemeßen heraus geben ${ }^{27}$ lässt. Zugleich manifestiert sich in der Reflexion über die Angemessenheit von Lettern und Papiersorten immer auch ein Urteil über den jeweiligen Autor, die Materialität dient der Distinktion und mithin einer sozialen Ordnung der Bücherwelt. Dabei sind freilich die Abstufungen nicht zu vergessen, die Verleger in der Ausstattung von Teilauflagen vornehmen, um dasselbe Werk für verschiedene »Beutel« anbieten zu können. Hinzu kommt die bis ins 19. Jahrhundert bestehende Notwendigkeit, ein gekauftes Buch selbst einbinden zu lassen. Aus der Ausstattung ergibt sich auch auf Seiten der Käufer eine Hierarchisierung, wie der italienische Schriftschneider Giambattista Bodoni betont,

25 »Von Göschen, Leipzig, 19. Oktober 1793«, in: Klopstock, Werke und Briefe, Abt. Briefe, 8.1 (1994), S. 301.

26 Bertuch, »Ueber den typographischen Luxus«, S. 605.

27 »Von Göschen, Leipzig, 19. Oktober 1793«, in: Klopstock, Werke und Briefe, Abt. Briefe, 8.1 (1994), S. 301. 
wenn er zugunsten eines Buches im großen Folio-Format anführt, dass »die höhere Schätzung, die es genießt, sich auch auf seinen Besitzer überträgt « ${ }^{28}$. Gegen solche Überlegungen wendet sich der Aufklärer Johann Adam Bergk, der gegen die Mode prächtiger Einbände ins Feld führt:»Wer [...] seine Bücher zum Lesen bestimmt, muß sie nicht in prächtige Gewänder kleiden. Ihr Inhalt bleibt ihm sonst ewig verschlossen.« Daher schlägt er »Alltagskleidung« anstelle von »Festtagskleider[n] « vor. ${ }^{29}$

Autorschaft erfährt durch die fortschreitende Ökonomisierung des Buchmarktes eine Professionalisierung. Die Schreibenden behaupten sich als Publizierende gegenüber ihren Verlegern. Papier, Format, Typographie oder Buchschmuck sollen nicht nur geneigte Leser ansprechen, sie erhalten als Merkmale des gedruckten Artefakts zunehmend die Funktion der Repräsentation ihrer Autoren und werden somit zu Medien der »Werkpolitik«. Das führt sowohl zu einer Ästhetisierung als auch zu einer Popularisierung des handwerklichen Wissens von Papiermachern, Schriftschneidern oder Druckern. Georg Christoph Lichtenberg (Kapitel 4.1) spürt während seines zweiten Englandaufenthaltes über Monate der Frage nach, wie der berühmte Drucker Baskerville sein Papier glättete. Selbst Georg III., den König von England, für den Lichtenberg mit seinem Verlegerfreund Johann Christian Dieterich ein bibliophiles Buch anfertigt, fragt er nach dem Betriebsgeheimnis von Baskerville. Begünstigt wird das gesteigerte Interesse an einem solchen Wissen durch das Bildungsprogramm der Historia literaria, das den mit dem Buch verbundenen Künsten einen festen Platz im Lehrplan höherer Schulen sichert. Darüber hinaus verfügen Schriftsteller als Büchermacher über ein ausgeprägtes Materialbewusstsein (Kapitel 4.2), das sie unter anderem in Briefen an ihre Verleger offenbaren, die bezüglich der Ausstattung lange Forderungskataloge und immer auch Vergleiche mit anderen Titeln enthalten.

Das Materialbewusstsein umfasst mehr als eine genaue Beobachtung von Konkurrenzprodukten. Angefangen bei dem Umstand, dass Honorare sich nach dem Umfang der Druckbögen richten, also eine jede Entscheidung über die Einrichtung einer Druckseite sich finanziell bemerkbar machen kann. Im "Siebenkäs« von Jean Paul taxiert die publizierende Hauptfigur ihr Manuskript »mit dem Setzer-Augenmaß« (SW I.2, 189), um sich vorab ihr Honorar ausrechnen zu können. Mehrfach erwägt Jean Paul in der Wirklichkeit, das

28 Bodoni, Über Schrift und Typographie, S. 13.

29 Bergk, Die Kunst, Bücher zu lesen, S. 33. 
Format eines Buches im Werktitel zu berücksichtigen, er plant »Scherze in Quart« oder ein »Taschenbuch in Oktav« und behauptet, dafür »im Werke die volständigste Beziehung auftreiben« (HKA III.4, 195) zu können. Damit betreibt der Autor eine Semiotisierung der Buchmaterialität, die auf den Rezeptionserwartungen und dem Leseverhalten des zeitgenössischen Publikums fußt. In der Regel erlaubt der Zuschnitt eines Buchblocks um 1800 bereits eine grobe Aussage über Gattung oder Genre. Auch wie und wo gelesen wird, spielt zunehmend eine Rolle. Der Leipziger Verleger Christian Gottlob Täubel gibt in seinem »Orthotypographischen Handbuch« für Schriftsteller eingehende Hinweise zur »Wahl des Formates«, bei der »man sich hauptsächlich nach dem Inhalt und der Bestimmung eines Buches $\aleph^{30} \mathrm{zu}$ richten habe. Täubel führt aus: »Witzige Schriften, Romane, Gedichte, Comödien, und andere schöngeisterische Bücher werden meistentheils im kleinsten Octav-Formate gedruckt, weil man solche manchmal beym Spatzierengehn, in Gärten, auf Reisen, u.s.w. bey sich zu führen pflegt, und die daher bequemer und leichter $\mathrm{zu}$ transportieren seyn müssen. ${ }^{31}$

In seinen literarischen Texten hält Jean Paul das Materialbewusstsein seiner Leserinnen und Leser gerne wach, etwa wenn er im »Siebenkäs« eine narrative Selbstbeschränkung behauptet, in der sich die übliche Bezahlung nach Druckbögen (»Alphabete«) widerspiegelt. »Nichts tut mir bei dieser an sich schönen Historie mehr Schaden«, ist in dem Roman zu lesen, "als daß ich mir vorgenommen, sie in vier Alphabete zusammenzudrängen; ich habe mir dadurch selber allen Platz geraubt, auszuschweifen.« (SW I.2, 221) Tatsächlich lässt sich auch in der Publikationspraxis des Autors eine bemerkenswerte Korrespondenz zwischen Buchform und Werkform beobachten (Kapitel 4.3). Sie zeigt sich in der enormen Flexibilität, die Jean Paul bei der Gruppierung seiner Texte an den Tag legt. Sein »Leben Fibels «, das schließlich 1811 als eigenständiges Buch erscheinen wird, will der Schriftsteller in der Entstehungszeit wiederholt in andere Publikationen integrieren. Einerseits deutet sich in diesen Erwägungen die Relativität der Werkeinheit an. Andererseits birgt die Buchform offenbar das Potenzial in sich, eine Werkform zu stiften.

Das gilt auch im Hinblick auf die Parallelität des Schreibens und Publizierens um 1800. Dass Schriftsteller ein abgeschlossenes Manuskript in den Druck geben, ist nicht die Regel. Die Reinschrift seines »Leben Fibels« übersendet Jean Paul dem Verleger Johann Leonhard Schrag nicht in einem Stück.

30 Täubel, Orthotypographisches Handbuch, S. 257.

31 Ebd., S. 258. 
Als der Autor im Juli 1811 das »Ende des Buches« (HKA III.6, 212) nach Nürnberg zu Schrag schickt, hat der Druck längst begonnen, so dass Jean Paul nebenbei auch schon Korrekturen übermitteln kann. Dass er sozusagen erst unter dem Druck der Presse zu einem Ende findet, gilt eine Generation früher als Charakteristikum von Gotthold Ephraim Lessing. Bekannt ist der Brief, den Moses Mendelssohn am 25. Oktober 1757 an Lessing richtet. Darin heißt es: »Ich weiß es schon, daß Sie nicht eher arbeiten, als wenn der Druckerjunge in der Stube sitzt, und darauf wartet; wir wollen Ihnen also diesen über den Hals schicken. $\ll^{32}$

Lessing gehört zugleich zu den Schriftstellern, deren Materialbewusstsein sie zu Experimenten mit der Form des gedruckten Buches verleitet (Kapitel 4.3). Die Reinschrift seiner ersten Gedichtsammlung, der »Kleinigkeiten« von 1751, präsentiert sich als eine »ungewöhnliche Simulation der Buch- und Druckgestalt « ${ }^{33}$, wie Jochen Meyer im Nachwort der Faksimile-Ausgabe anmerkt. Tatsächlich stattet Lessing die Handschrift mit den Paratexten eines gedruckten Buches aus, selbst an ein Register ist gedacht - auch wenn dieses nur die Buchstaben des Alphabets enthält, ansonsten ohne Eintrag bleibt. Im Gegensatz zu den handgeschriebenen Büchern Jean Pauls ist Lessings Manuskript publiziert worden, und zwar genau nach der Reinschrift. Das bedeutet, dass in der ersten Druckausgabe der »Kleinigkeiten « auch die Leerstellen des Registers zu bestaunen sind, als ob es dem Autor um eine paratextuelle Ironisierung der Buchform gegangen wäre. Jedenfalls haben zeitgenössische Rezensenten die »Kleinigkeiten« in diesem Sinne interpretiert. "Das ganze Werk ist von der Zuschrift bis auf das Register scherzhaft «, urteilt der Kritiker der »enaischen gelehrten Zeitungen«. ${ }^{34}$

Humor verlangt Lessing auch seinem späteren Verleger Friedrich Nicolai ab. Den ersten Band seiner »Briefe antiquarischen Inhalts« lässt der Schriftsteller im Sommer 1768 bei sich in Hamburg drucken. Den ihm vertrauten Drucker weist Lessing an, auf die Markierungen zu verzichten, mit deren Hilfe sich die Druckbögen ordnen lassen. Dabei handelt es sich um Buchstaben in alphabetischer Reihenfolge, die in Drucken des 18. Jahrhunderts am Fuß einer Seite zu entdecken sind. Lessing sieht durch das ordnende Alphabet »das Viereck der Columnen so schändlich verstellt«, dass er ohne vorherige [162].

33 Meyer, »Nachwort«, S. 214.

34 [Anonymus], Rez. »Kleinigkeiten«, S. 720. 
Absprache mit Nicolai eine »kleine Neuerung « einzuführen versucht. ${ }^{35}$ Ganz zum Leidwesen des erfahrenen Verlegers, der angesichts der unmarkierten Bögen eine "große Konfusion und wirklichen Schaden ${ }^{36}$ befürchtet. Begebenheiten wie diese machen die Praktiken des Publizierens anschaulich.

Gleichzeitig müssen Autoren des späten 18. Jahrhunderts die schmerzhafte Erfahrung machen, dass sie mit dem Druck die Souveränität über das Geschriebene einbüßen. Diese Erfahrung relativer Ohnmacht hat mehrere Dimensionen, sie reicht vom Verlagsrecht über die Unkontrollierbarkeit von Druckfehlern und den »Raubdruck« als Publikationspraxis bis zur Makulatur als dem vermeintlichen Endpunkt der Literatur. In welchem Verhältnis die Publizierenden zum Buch als Artefakt stehen, wird um 1800 immer mehr zur Kardinalfrage der Autorschaft, zumal sich das Feld derer ausweitet, die dieses Artefakt ebenso für sich beanspruchen. Dabei sind Buchkäuferinnen und Buchkäufer und ein sich ausdifferenzierendes Lesepublikum nicht zu vernachlässigende Gruppen.

Der Materialität der Literatur enthoben erscheint der Genius. Der Geniegedanke und eine romantisch-idealistische Ästhetik bewirken in der Theorie eine Immaterialisierung des Schreibens und Publizierens, in deutlicher Abgrenzung zu den Papierarbeiten althergebrachter Gelehrsamkeit. Edward Young zieht »die verewigende Macht der Presse« nicht in Zweifel, sie erscheint ihm als sichere "Quelle des Nachruhms «. ${ }^{37}$ Doch reserviert Young den »edeln Titul des Autors« für das Genie, das souverän »denket und schreibet«, statt bloß »reich an vielen Bänden und Gelehrsamkeit « zu sein. ${ }^{38}$ Aus einem solchen Denken entstehen erste Entwürfe eines Urheberrechts, wobei die Anerkennung des Schreibens als »Investition von Individualität « ${ }^{39}$ als basal anzusehen ist. Die »Eigentümlichkeit« dessen, was zur Veröffentlichung in Druck gegeben wird, begründet um 1800 die Theorie des geistigen Eigentums. Doch eine völlige Entbindung der Autorschaft vom gedruckten Buch findet in dieser Theorie nicht statt (Kapitel 4.6). Im Gegenteil: Das geistige Eigentum konzentriert sich als Sonderform der Proprietät auf Bücher als Artefakte, nicht als Medien geistiger Produktion. Die Rechtsentwicklung kreist auch dann um das papierne Objekt, wenn der Geist des Urhebers mit Emphase beschworen wird. Somit stellt sich die Frage, welche Bedeutung das

35 »An Friedrich Nicolai« (27. August 1768), in: Lessing, Werke und Briefe, 11/1, S. 533 [431].

36 »on Friedrich Nicolai« (9. August 1768), in: Lessing, Werke und Briefe, 11/1, S. 532 [429].

37 Young, Gedanken über die Original-Werke, S. 19, 11

38 Ebd., S. 48, 49.

39 Plumpe, »Eigentum - Eigentümlichkeit«, S. 183. 
Buchartefakt im Hinblick auf das »juristische Autorenmodell ${ }^{40}$ hat, das sich in der Moderne durchsetzt. Neben die von Heinrich Bosse in urheberrechtlichen Entwürfen des späten 18. Jahrhunderts festgestellte »Analyse der Mitteilung ${ }^{41}{ }^{11}$, des gedruckten Wortes, tritt in denselben Texten eine Analyse des Buches. Dabei stellt sich immer wieder eine Frage: Was ist das Wesentliche eines Buches? Ist es das bedruckte Papier, sind es die eigenen Worte oder Gedanken? "Das wesentliche bey einem Buche«, argumentiert der Verleger Philipp Erasmus Reich, »ist nicht Druck und Papier, sondern es ist der Geist des Verfaßers. $\aleph^{42}$ Rechtlich findet eine solche Auffassung lange keinen Niederschlag. Schriftsteller sehen sich nicht erst durch den unautorisierten Nachdruck mit dem Problem konfrontiert, dass die Bücher, auf denen ihr Name steht, handwerkliche Produkte sind, an deren Finanzierung, Herstellung und Verkauf sie als Textlieferanten nur mittelbar einen Anteil haben. Das gilt in einer verschärften Form für das Werk des Nachdruckers. Mit dem im Auflagendruck hergestellten Buchartefakt existiert zudem ein nach Römischem Recht eigentumsfähiges Objekt, auf das die Verfechter eines geistigen Eigentums ebenfalls einen Anspruch anmelden. Der Hamburger Arzt und Ökonom Johann Albert Heinrich Reimarus begegnet ihnen kritisch: »Die Rechtsgelehrten nehmen ihre Zuflucht zu einer metaphysischen Spizfündigkeit, wenn sie sagen, das Geistes-Eigenthum (literary property) werde nicht mit der Materie des Buches dem Käuffer übertragen. ${ }^{43}$ Treffend formuliert Immanuel Kant das intrikate Rechtsproblem: „Der Autor und der Eigenthümer des Exemplars können beide mit gleichem Rechte von demselben sagen: es ist mein Buch! aber in verschiedenem Sinne. $\aleph^{44}$ Somit liegt die Herausforderung an den Ursprüngen des Urheberrechts darin, dem Autor eine Verfügungsgewalt über ein Artefakt zuzusprechen, das im juristischen Sinne immer das uneingeschränkte Eigentum eines anderen ist. Fichte unterscheidet vor diesem Hintergrund das Körperliche eines Buches, »das bedruckte Papier « ${ }^{45}$, vom Geistigen. Unter das Geistige fallen für den Philosophen das Materielle, also der Inhalt, sowie die Form. Die Form definiert Fichte als die »eigenen Worte eines Schriftstellers ${ }^{46}{ }^{6}$, die aus seiner Sicht ein »forthdauerndes Eigenthum

\footnotetext{
40 Jannidis, Lauer, Martinez, Winko, »Rede über den Autor «, S. 7.

41 Bosse, Autorschaft ist Werkherrschaft, S. 45.

42 Zit. n. Meyer, »Reformbestrebungen« (1890), S. 217.

43 Reimarus, »Der Bücherverlag ... abermals erwogen«, S. 384.

44 Kant, »Von der Unrechtmäßigkeit des Büchernachdrucks«, S. 86.

45 Fichte, Beweis der Unrechtmäßigkeit, S. 225.

46 Ebd., S. 229.
} 
des Verfassers « darstellen, weil es "physisch unmöglich « sei, sich diese zuzueignen. ${ }^{47}$ Fichte trägt in der Nachdruckdebatte dazu bei, das Verhältnis der Autoren zu den Artefakten der Literatur neu zu bestimmen. Im Jahr 1827, also zehn Jahre, bevor in Preußen das wegweisende "Gesetz zum Schutze des Eigenthums an Werken der Wissenschaft und Kunst gegen Nachdruck und Nachbildung « in Kraft treten wird, bezeichnet Wilhelm August Kramer die Exemplare eines Buches bereits mit großer Selbstverständlichkeit als »äußere Darstellungen eines einzigen, ideellen Buches« - welches Eigentum des Schriftstellers bleibt. ${ }^{48}$ Mit dem geistigen Eigentum etabliert sich die von Heinrich Bosse beschriebene »Werkherrschaft«, die Publizierenden erlangen rechtlich eine Verfügungsgewalt über ihre gedruckten Texte. Auf dem Weg dahin stellt das Buchartefakt, wie ich gezeigt habe, das größte Hindernis dar.

Die »Werkherrschaft« leidet nicht unerheblich unter Druckfehlern, stehen diese doch für eine Ohnmacht des Publizierenden gegenüber dem produzierenden Handwerk (Kapitel 4.5). Dass Errata aus Autorensicht mehr sind als Akzidenzien des Buchdrucks, zeigt die Gleichung, die der von Druckfehlern gebeutelte Jean Paul in seinen »Gedanken« aufstellt: »Setzer = Zersetzer« (HKA II.8.1, 399 [179]). Die handwerklichen Schnitzer rühren - mit Fichte gesprochen - an den »eigenen Worte[n] eines Schriftstellers«. Darin liegt ein Hauptmotiv für den in der zweiten Hälfte des 18. Jahrhunderts vielfach erwogenen Selbstverlag. Denn vom Publizieren in Eigenregie versprechen sich nicht wenige Schriftsteller mehr Sorgfalt in der Herstellung und ein höheres Maß an Kontrolle. Liegt eine größere Distanz zwischen Schreibtisch und Setzkasten, steigt die Bedeutung zwischengeschalteter Redaktoren und Korrektoren. Dabei handelt es sich um Rollen, die häufig Autorenkollegen übernehmen. Johann Georg Seume zählt es 1799 in der Korrespondenz mit dem Klopstock-Verleger Göschen zu seinen »herkulischen Arbeiten«, dass er "Klopstocks Oden noch so gemacht [hat], wie sie gemacht worden sind, denn sie sind in jeder Rücksicht das schwerste Werk der Typographie in Hinblick auf Korrektheit, ausgenommen mathematisches Zahlenwerk « ${ }^{49}$. Korrektheit erscheint jedoch auch unter idealen Bedingungen ein schwer erreichbares Ziel, da jede Druckseite aus "mehrern tausenden unzusammenhangenden Stücken zusammengesezt [ist], die man auf tausenderley Art ver-

47 Fichte, Beweis der Unrechtmäßigkeit, S. 224, 225.

48 Kramer, Die Rechte der Schriftsteller, S. 29.

49 Zit. n. Klopstock, Werke und Briefe, Abt. B, 10,2, S. 329. 
wechseln kann ${ }^{50}$, wie es bei Carl Denina heißt. Daher hat das DruckfehlerVerzeichnis in der Literatur des ausgehenden 18. Jahrhunderts einen unumstößlichen Platz, allerdings nicht nur als strenge Korrekturanleitung, sondern auch als humoristisches Genre. In der paratextuellen Ordnung von Büchern haben ernstgemeinte Errata-Listen dennoch einen unklaren Status, im Inhaltsverzeichnis tauchen sie in der Regel nicht auf, weil sie meist gesondert geliefert und den Büchern beigebunden werden. Trotz dieser Exterritorialität sollte die Bedeutung des Druckfehler-Verzeichnisses nicht unterschätzt werden. Einerseits markiert es die Stellen im Buch, an denen »Werkherrschaft« in Frage steht. Andererseits beglaubigt es die Autorität des Urhebers als Supplement. Nicht vergessen werden darf, wie viele Ausgaben um 1800 ohne Einverständnis des Autors entstehen. Die Fehlerquellen potenzieren sich durch den unautorisierten Nachdruck, weshalb Robert Darnton vorschlägt, Bücher im 18. Jahrhundert als »fließendes Medium « einzustufen. Er schreibt: »Je größer ihre Popularität desto weniger sicher ist der Text. ${ }^{51}$ Um die Korrektheit in offiziellen Ausgaben zu befördern, gibt der Verleger Täubel für Schriftstellerinnen und Schriftsteller mehrere Handbücher heraus, die unterstreichen, wie groß der Markt der Autorschaft um 1800 ist.

Makulatur offenbart die enge Bindung von Autorschaft an gedruckte Artefakte, sowohl in ihrem konkreten Vorkommen als auch als Motiv der Literatur (Kapitel 5). In etlichen Diskursen fungiert Makulatur als Supertrope missglückter Autorschaft und Kampfbegriff kritischer Kommunikation (»Rubrik Makulatur«). Sie legt die Marktmechanismen offen, die dem »Ewigkeitsanspruch $\ll^{52}$ des Publizierens zuwiderlaufen. Makulatur fällt in Herstellung und Distribution von Büchern an, aber auch im Verlagsgeschäft durch die Bereinigung von Warenbeständen. Als ausgesonderter Verlagsartikel wirft sie ein Licht auf die Risiken und Zyklen des Buchhandels, der um 1800 in immer kürzeren Abständen nach Novitäten verlangt (Kapitel 5.3). Das liegt am enormen Wachstum, aber auch an den Umwälzungen dieses Handelszweigs. Dazu gehört die aggressive Durchsetzung des mit Geldzahlungen verbundenen Nettohandels gegenüber dem üblichen Tauschhandel durch den Verleger Reich. Der Nettohandel bewirkt im letzten Drittel des 18. Jahrhunderts eine Entwertung der Lagerbestände an Büchern, langlebige Tauschobjekte verkommen in Büchergewölben zu Makulatur. Im Verlagshandel bildet diese wiederum ein

50 Denina, Bibliopoeie, S. 407.

51 Darnton, Wissenschaft des Raubdrucks, S. 66.

52 Assmann, Erinnerungsräume, S. 203. 
eigenes Warensortiment, regelmäßig vermelden Buchproduzenten: »Es ist gegenwärtig Makulatur vorräthig. ${ }^{53}$ Abnehmer der Papiermassen sind unter anderem Krämer, die händeringend nach günstigem Verpackungsmaterial suchen. Die Ressourcen des Krämers hat der Göttinger Jurist Julius Claproth im Blick, der mit einer Erfindung aus Bedrucktem wieder »neues Papier« zu machen verspricht. Seine Innovation lässt sich als Reflex einer dem immer Neuen verpflichteten Wissenskultur und Ästhetik deuten. Zugleich erblickt Philipp Ernst Spieß, ein Vordenker des Archivs, in der beim Krämer lagernden Makulatur ein enormes Überlieferungspotenzial.

So verwundert es nicht, dass der Kramladen im 18. Jahrhundert auch ein beliebter Topos der Satire und Schauplatz der Erzählliteratur ist. Bei Jean Paul beziehen Autorenfiguren wie Quintus Fixlein und Gotthelf Fibel ihr Wissen aus Makulatur. Der Gewürzladen wird für Fibel zur »Lese-Bibliothek«, der Krämer bietet ihm »Düten aus allen Fächern« (SW I.6, 388). Auch Fixlein hat eine »hohe Achtung für alle Makulatur« (SW I.4, 88). In beiden Erzählungen streben die Figuren als Exponenten einer überkommenen Gelehrtenkultur zu Publizität. In ihrem Umgang mit Altpapier klingen Motive der Gelehrtenkritik des ausgehenden 18. Jahrhunderts an, in der Makulatur figuriert ein aus Gedrucktem gewonnenes, stets nur reproduziertes und sich selbstzweckhaft bis zur Nutzlosigkeit vermehrendes Wissen (Kapitel 5.1). Zugleich verweisen die »Düten« auf gelehrte Papierarbeiten wie das Exzerpieren, das laut Anke te Heesen auf excerpo im Lateinischen zurückgeht, was herausklauben, auslesen, aber auch ausschneiden bedeuten kann. ${ }^{54}$ Jedoch kann Makulatur ebenfalls als ein Gegenstand besonderer Wertschätzung in Erscheinung treten, wie ich anhand einer Anekdote aus dem Leben Meta Mollers nachgezeichnet habe, die auf papiernen Lockenwicklern erstmals Verse ihres späteren Mannes Klopstock entdeckt. Moller befreit das prosaisch gebrauchte Papier als verständige Leserin von seinem »rezeptionsästhetischen Mangel $\aleph^{55}$, nicht anders als es in Karl Immermanns "Papierfenster eines Eremiten « oder in Jean Pauls »Leben Fibels« geschieht. In dem Spätwerk von Jean Paul handelt die Rahmenfiktion vom Auffinden historischer Quellen, unwillkürlich überliefert als »Kaffee-Düten«, »Stuhlklappen« oder »Papier-Drachen« (SW I.6, 376), anhand de, 18.9.1783, Verlagsarchiv Gebauer-Schwetschke, Stadtarchiv Halle, A 6.2.6 Nr. 21153 (Kartonnr. 75), Bl. 2.

54 Heesen, »Die Schere in der Hand des Wissenschaftlers«, S. 31.

55 Wirth, »(Papier-)Müll und Literatur«, S. 19. 
derer eine biographische Erzählung rekonstruiert wird. Der Roman liefert eine große Fiktion materialer Determination, eine Poetologie der Pfeffertüte, denn behauptet wird, dass aufgefundene Makulatur die Narration inhaltlich wie strukturell bestimme und limitiere (Kapitel 5.5). Tatsächlich erweitert diese fiktive Beschränkung für Jean Paul den Spielraum des Erzählens. Das entspricht dem Befund von Jürgen Nelles, demzufolge »sowohl die Materialität wie die Medialität des Buches [...] am Übergang vom 18. zum 19. Jahrhundert zum Thema wird; und zwar vor allem in erzählerischen Texten solcher Autoren, die nach neuen Darstellungs- und Schreibformen suchen ${ }^{56}$. Makulatur steht somit für eine künstlerische Souveränität, die zumindest bei Jean Paul im Medium der Fiktion dementiert wird. Als ein signalhaftes Motiv und Mittel auktorialer Selbstbehauptung begegnet Makulatur dem zeitgenössischen Publikum prominent auch im Schreibmodus der Satire, wie ich eingehend am Beispiel von Lichtenberg gezeigt habe, der sich selbst als »Makulaturisten ${ }^{57}$ bezeichnete (Kapitel 5.4).

Die Digitalisierung des 21. Jahrhunderts stellt Grundbegriffe literarischer Kommunikation in Frage. Das betrifft Autorschaft in einem besonderen Maße, einen Begriff, der seit dem 18. Jahrhundert durch Theorien geistiger Urheberschaft bestimmt zu werden scheint. Dabei entbehrt es nicht einer gewissen Ironie, dass in der Gegenwart die Entmaterialisierung der Medien das Immaterialgüterrecht erschüttert. Dieser Umstand unterstreicht, wie elementar die Materialität zunächst des Buchartefakts, später anderer Medien wie dem Tonträger ${ }^{58}$ für das Urheberrecht war und ist. Um 1800 knüpft sich ein engmaschiges Netz ästhetischer, poetologischer und rechtlicher Diskurse um das gedruckte Buch als integrales Medium der Literatur. Der »Geist des Verfaßers«, laut Heinrich Bosse ein »Schutzgeist ${ }^{59}$, durchdringt nun scheinbar jede Druckseite. Durch die Konzentration auf die Kreativität und die geistige Produktivität von Schreibenden bleibt weitgehend unbeachtet, als was sich Autorschaft zwischen 1765 und 1815 stärker denn je begreifen lässt: als eine Kunst des Büchermachens. Die materiale Bedingtheit des Publizierens bildet den roten Faden der Literatur vom Manuskript über das gedruckte Artefakt bis hin zur Makulatur.

56 Nelles, Bücher über Bücher, S. 58.

57 »An Wilhelm Gottlieb Becker« (19. April 1795), in: Lichtenberg, Briefwechsel, IV (1992), S. 436.

58 Siehe Monika Dommann, Autoren und Apparate. Die Ceschichte des Copyrights im Medienwandel, Frankfurt a.M. 2014.

59 Bosse, Autorschaft ist Werkherrschaft, S. 35. 



\section{Literatur}

\section{Ungedruckte Quellen}

Stiftung Preußischer Kulturbesitz, Staatsbibliothek zu Berlin, Nachlass Jean Paul, Faszikel Ia, Ib, IIa, IIb, IVa, IVb, XIIIa.

Brief von Johann Friedrich Hemmerde aus Kassel an seine Tante Johanna

Hemmerde, 18.9.1783, Verlagsarchiv Gebauer-Schwetschke, Stadtarchiv Halle, A 6.2.6 Nr. 21153 (Kartonnr. 75), Bl. 2.*

Nachricht von Johann Jacob Gebauer aus Halle, 22.12.1787, Verlagsarchiv Gebauer-Schwetschke, Stadtarchiv Halle, A 6.2.6 Nr. 23206 (Kartonnr. 79).*

Brief von Johann Philipp Haug aus Leipzig, 31.8.1782, Verlagsarchiv GebauerSchwetschke, Stadtarchiv Halle, A 6.2.6 Nr. 20596 (Kartonnr. 73).* Schreiben der Papierlieferanten Haupt \& Grisson aus Hamburg, 7.11.1788, Verlagsarchiv Gebauer-Schwetschke, Stadtarchiv Halle, A 6.2.6 Nr. 23757 (Kartonnr. 82).*

Schreiben von Haupt \& Grisson aus Hamburg, 18.11.1788, Verlagsarchiv Gebauer-Schwetschke, Stadtarchiv Halle, A 6.2.6 Nr. 23758 (Kartonnr. 82).*

* Gearbeitet wurde mit Digitalisaten, abrufbar unter www.gebauer-schwetschke.halle.de.

\section{Siglen}

SW Jean Paul, Sämtliche Werke, hg. v. Norbert Miller, 6. Aufl., Darmstadt 2000.

HKA Jean Paul, Sämtliche Werke. Historisch-Kritische Ausgabe, hg. v. Eduard Berend u.a., Weimar, Berlin 1927-. 
Der Nachweis der Zitate erfolgt unter Angabe von Ausgabe (Kürzel), Band und Seitenzahl im Text.

\section{Weitere Primärliteratur}

Abegg, Johann Friedrich, Reisetagebuch von 1798, hg. v. Walter Abegg, Jolanda Abegg, Frankfurt a.M. 1987.

Adelung, Johann Christoph, Art. »Das Buch«, in: ders. (Hg.), Grammatischkritisches Wörterbuch der Hochdeutschen Mundart mit beständiger Vergleichung der übrigen Mundarten, besonders aber der oberdeutschen, 2. Aufl., Leipzig 17931801, I, Sp. 1235-1237.

Adelung, Johann Christoph, Art. »Handschriftlich«, in: ders. (Hg.), Grammatisch-kritisches Wörterbuch der Hochdeutschen Mundart mit beständiger Vergleichung der übrigen Mundarten, besonders aber der oberdeutschen, 2. Aufl., Leipzig 1793-1801, II, Sp. 958-959.

Adelung, Johann Christoph, Art. »Kaufmann«, in: ders. (Hg.), Grammatischkritisches Wörterbuch der Hochdeutschen Mundart mit beständiger Vergleichung der ̈̈brigen Mundarten, besonders aber der oberdeutschen, 2. Aufl., Leipzig 17931801, II, Sp. 1524-1525.

Adelung, Johann Christoph, Art. »Maculatur«, in: ders. (Hg.), Grammatischkritisches Wörterbuch der Hochdeutschen Mundart mit beständiger Vergleichung der übrigen Mundarten, besonders aber der oberdeutschen, 2. Aufl., Leipzig 17931801, III, Sp. 11-12.

Adelung, Johann Christoph, Art. »Die Urkunde«, in: ders. (Hg.), Grammatischkritisches Wörterbuch der Hochdeutschen Mundart mit beständiger Vergleichung der übrigen Mundarten, besonders aber der oberdeutschen, 2. Aufl., Leipzig 17931801, IV, Sp. 963-965.

André, Christian Carl, Erstes Lehrbuch des Zeichnens, Schreibens, Lesens, Rechnens, der französischen und Muttersprache. Zum Gebrauch für Lehrer der Kinder aus den gebildeteren Ständen. Erste Lieferung, Halle 1793.

[Anonymus], Rez. »Kleinigkeiten«, in: Jenaische gelehrte Zeitungen (1751), 88. Stk. (6. November 1751), S. 720.

[Anonymus], »Gottlieb Wilhelm Rabners Satyren. Achte Auflage, 4 Theile. Leipzig, im Verlag der Dyckischen Buchhandlung, 1764. 66 und ein halber Bogen, 8«, in: Allgemeine Deutsche Bibliothek 1 (1766), S. 296-297.

[Anonymus], Rez. »Kleinigkeiten von G.E. Leßing«, in: Deutsche Bibliothek der schönen Wissenschaften (1769), 14. Stk., S. 346f. 
[Anonymus], Gedichte, welche das Makulatur vermehren, Gernrode 1771.

[Anonymus], "Schreiben des Herrn Alexander Gernegroß, der berühmt zu werden wünschet «, in: Tapeten I (1771), 11. Stk. (12. Juni 1771), S. 81-87.

[Anonymus], Rez. »Tapeten«, in: Göttingische Anzeigen von Gelehrten Sachen 1 (1772), 13. Stk. (30. Januar 1772), S. 104.

[Anonymus], »Betrachtungen über die Autorschaft, nebst zwey Sinngedichten über Meils Gedächtniß-Münzel auf Gellerten, und auf einen stark erleuchteten Tanzsaal«, in: Tapeten 7 (1773), 77. Stk. (2. Juni 1773), S. 609-615. [Anonymus], Rez. »Timorus«, in: Frankfurter gelehrte Anzeigen (1773), S. 474f. [Anonymus], Diogenes in ***, oder satyrisch-moralische Makulatur, Berlin 1774. [Anonymus], »Nachricht von der in Dessau errichteten Verlagskasse für Gelehrte und Künstler (1781), in: Evi Rietzschel (Hg.), Gelehrsamkeit ein Handwerk? Bücherschreiben ein Gewerbe? Dokumente zum Verhältnis von Schriftsteller und Verleger im 18. Jahrhundert in Deutschland, Leipzig 1982, S. 148-153.

[Anonymus], Rez. »Freymüthige Anmerkungen über Hrn. D. Bahrdts Kirchen- und Ketzeralmanach auf das Jahr 1781. Von einem Liebhaber der Wahrheit. Frankfurt und Leipzig 1782«, in: Allgemeine Deutsche Bibliothek 54 (1783), 1. Stk., S. 51-54.

[Anonymus], »Reliquien von Fr. A.«, in: Deutsches Museum I (1783), S. 195-207.

[Anonymus], »Gedanken über Buchhandlung und Nachdruck«, in: Neue Litteratur und Volkerkunde 1.2 (1787), S. 189-216.

[Anonymus], »Einige Bemerkungen über den, in dem neunten Heft des neuen deutschen Zuschauers abgedrukten, Artikel: Ueber den deutschen Buchhandel«, in: Der neue deutsche Zuschauer 4 (1790), S. 181-190.

[Anonymus], »Leipzig, d. 17. März...«, in: Intelligenzblatt der Allgemeinen Literatur-Zeitung (1791), Nr. 40 (23. März 1791), Sp. 324-326.

[Anonymus], »Chemnitz, b. Hofmann: Jacobi Acontii Tridentini ad Joannem Wolfium Tigurinum Epistolae de ratione edendorum librorum «, in: Allgemeine Literatur-Zeitung 1 (1792), Nr. 20 (18. Januar 1792), Sp. 160.

[Anonymus], Rez. »Leipzig in der Müllersch. Buchh.: Praktisches Handbuch der Buchdruckerkunst«, in: Allgemeine Literatur-Zeitung 2 (1792), Nr. 161 (22. Juni 1792), Sp. 605-606.

[Anonymus], Rez. »Handbuch für Gesandte«, in: Allgemeine Deutsche Bibliothek (1792), 106, S. 89-90.

[Anonymus], »Literarische Anzeige über neue Büchertitel«, in: Neues Archiv für Gelehrte, Buchhändler und Antiquare 1 (1795), S. 523-527. 
[Anonymus], »Ueber den Begrif und den eigenthümlichen Zweck des Buchhandels«, in: Neues Archiv für Gelehrte, Buchhändler und Antiquare 1 (1795), S. 293-324.

[Anonymus], Rezension über »Siebenkäs« und »Biographische Belustigungen « (1797), in: Peter Sprengel (Hg.), Jean Paul im Urteil seiner Kritiker. Dokumente zur Wirkungsgeschichte Jean Pauls in Deutschland, München 1980, S. 1012.

[Anonymus], Rez. »Berlin, in der Realschulbuchhandlung: Sonnenklarer Bericht an das grössere Publikum über das eigentliche Wesen der neuesten Philosophie«, in: Leipziger Jahrbuch der neuesten Literatur vom Jahre 1801 4 (1802), Sp. 237-255.

[Anonymus], »Worte eines Mannes in Bremen, über die Schullehrer, auch von und für Hamburg (I)«, in: Hamburg und Altona 4 (1805), H. 12, S. 306-313.

[Anonymus], Rez. »Das gelehrte Teutschland, elfter Band, fünfte Auflage«, in: Allgemeine Literatur-Zeitung 4 (1805), Nr. 297 (13. November 1805), Sp. 301303.

[Anonymus], »Ueber Cotta's erste Lieferung der v. Herder'schen Schriften«, in: Revisionsblatt zur Georgia (1806), 4, o.P.

[Anonymus], Rez. »Das gelehrte Teutschland im neunzehnten Jahrhundert, nebst Supplementen zur fünften Ausgabe desjenigen im achtzehnten, von Joh. Georg Meusel. - Zweyter Band«, in: Allgemeine Literatur-Zeitung (1810), Nr. 190 (17. Juni 1810), Sp. 572-576.

[Anonymus], »Makulatur«, in: Hesperus 2 (1812), Nr. 51.

[Anonymus], Rez. »Das gelehrte Teutschland, 16. Band, 5. Auflage«, in: Ergänzblätter zur Allgemeinen Literatur-Zeitung (1812), Nr. 133 (3. Dezember 1812), Sp. 1057-1064.

[Anonymus], Ueber den Nutzen der Papier-Tapeten nebst kurzer Anleitung zum Tapezieren, Augsburg 1829.

[Anonymus], Verzeichniß der von dem Herrn Dr. Ph. Joh. Gottw. Müller in Itzehoe hinterlassenen Bibliothek, [...], Itzehoe 1829.

Arnim, Bettine von, Goethe's Briefwechsel mit einem Kinde, Werke und Briefe, hg. v. Walter Schmitz, Sibylle v. Steinsdorff, Frankfurt a.M. 1986-2004, II (1992).

[Arnold, Ignaz Ferdinand Kajetan], Meine Wanderungen aus Schwaben durch die Maingegenden nach Thüringen und Sachsen im Frühjahr 1810 und Sommer 1811, Erfurt 1811.

Art. »Das Pasquill«, in: Conversations-Lexikon oder kurzgefaßtes Handwörterbuch, Amsterdam 1809, III, S. 374f. 
Art. »Pasquill«, in: Allgemeine deutsche Real-Encyclopädie für die gebildeten Stände (Conversations-Lexicon), 5. Aufl., Leipzig 1819, VII, S. $289 f$.

Art. »Büchermacher«, in: Jacob und Wilhelm Grimm, Deutsches Wörterbuch, Leipzig 1854ff., II (1860), Sp. 473.

Art. »Makulatur«, in: Jacob und Wilhelm Grimm, Deutsches Wörterbuch, Leipzig 1854ff., VI (1885), Sp. 1492f.

Ayrer, Jacob (Hg.), Opus Theatricum. Dreißig Außbündtige Comedien und Tragedien von allerhand Denckwürdigen alten Römischen Historien und andern Politischen geschichten und gedichten [...], Nürnberg 1618.

Baumgarten-Crusius, Ludwig Friedrich Otto, Festrede bei der akademischen Secularfeier von der Erfindung der Buchdruckerkunst, Jena 1840.

Becker, Rudolph Zacharias, Das Eigenthumsrecht an Geisteswerken mit einer dreyfachen Beschwerde über das Bischöflich-Augsburgische Vikariat wegen Nachdruck, Verstümmelung und Verfälschung des Noth-und Hülfsbüchleins, Frankfurt a.M., Leipzig 1789.

Bergk, Johann Adam, Die Kunst, Bücher zu lesen. Nebst Bemerkungen über Schriften und Schriftsteller, Jena 1799.

Bertuch, Friedrich Justin, Leben und Thaten des weisen Junkers Don Quixote von Mancha. Neue Ausgabe, aus der Urschrifft des Cervantes, nebst der Fortsetzung des Avellaneda, Weimar, Leipzig 1775-1777, I (1775).

Bertuch, Friedrich Justin, »Ueber den typographischen Luxus mit Hinsicht auf die Ausgabe von Wielands sämmtlichen Werken«, in: Journal des Luxus und der Moden 8 (1793), 11, S. 599-608.

[Beseke, Johann Melchior Gottlieb], Vom Patriotismus in der deutschen Gelehrtenrepublik, 2. Aufl., Berlin 1794.

Beyschlag, Daniel Eberhard, Beyträge zur Kunstgeschichte der Reichsstadt Nördlingen: Von der Buchbinderey, dem Papier und dem Münzwesen, Nördlingen 1800. Blanckenburg, Christian Friedrich, Versuch über den Roman, Leipzig, Liegnitz 1774.

[Bodmer, Johann Jakob], »Vorrede«, in: Freymüthige Nachrichten von Neuen Büchern, und andern zur Gelehrtheit gehörigen Sachen I (1744), o.P.

Bodoni, Giambattista, Manuale tipographico/Handbuch der Typographie, Parma 1818.

Bodoni, Giambattista, Über Schrift und Typographie. Vorrede zur Ausgabe des Manuale Typografico (1818). Privatdruck der Bauerschen Gießerei, Frankfurt a.M. 1927.

Bouginé, Carl Joseph, Handbuch der allgemeinen Litterargeschichte nach Heumanns Grundriß, Zürich 1789-1792, I (1789). 
Brauer, Johann Nikolas Friedrich, Erläuterungen über den Code Napoleon und die Großherzoglich Badische bürgerliche Gesezgebung, Karlsruhe 1809f., I (1809).

[Breitinger, Johann Jakob], »Wohlgemeinter Vorschlag, wie Hrn. Christoph Schwartzens deutsche Aeneis von dem Gerichte der Makulatur noch zu erretten wäre«, in: Sammlung Critischer, Poetischer, und andrer geistvollen Schriften (1744), Stk. 8, S. 33-53.

Breitkopf, Johann Gottlob Immanuel, »Antwort auf Herrn Unger in Berlin: Etwas über Didotsche Letter«, in: Intelligenzblatt der Allgemeinen LiteraturZeitung (1791), Nr. 95 (3. August 1791), Sp. 783-786.

Breitkopf, Johann Gottlob Immanuel, »Über Buchdruckerei und Buchhandel in Leipzig« (1793), in: Evi Rietzschel (Hg.), Gelehrsamkeit ein Handwerk? Bücherschreiben ein Gewerbe? Dokumente zum Verhältnis von Schriftsteller und Verleger im 18. Jahrhundert in Deutschland, Leipzig 1982, S. 7-13.

Breitkopf, Johann Gottlob Immanuel, Ueber Bibliographie und Bibliophilie, Leipzig 1793.

Brömel, Johann Friedrich, Nichts oder Etwas, nachdem es der geneigte Leser beliebt. Ein demüthiger Beitrag zur Makulatur des achtzehnten Jahrhunderts, Leipzig, Schleiz 1780.

Bücking, Johann Jacob Heinrich (Hg.), Die Kunst des Buchbindens, Stendal 1785. Bürger, Gottfried August, »Vorschlag, den Büchernachdruck zu steuern« (1777), in: Evi Rietzschel (Hg.), Gelehrsamkeit ein Handwerk? Bücherschreiben ein Gewerbe? Dokumente zum Verhältnis von Schriftsteller und Verleger im 18. Jahrhundert in Deutschland, Leipzig 1982, S. 58-75.

Büschel, Johann Gabriel Bernhard, Ueber die Charlatanerie der Gelehrten seit Menken, Leipzig 1791.

Büschel, Johann Gabriel Bernhard, Versuch über die Kunst gut und viel zu schreiben, in vertrauten Briefen eines Vaters an seinen Sohn aufder Universität zum Besten angehender Schriftsteller, Recensenten und Buchhändler herausgegeben, Jena 1796.

Buschendorf, Karl Friedrich, "Zwei Arten Papierglättmaschinen«, in: Journal für Fabrik, Manufaktur, Handlung, Kunst und Mode 23 (1802), S. 335-350.

Campe, Joachim Heinrich, Wörterbuch zur Erklärung und Verdeutschung der unserer Sprache aufgedrungenen fremden Ausdrücke, Braunschweig 1813.

Cella, Johann Jacob, »Vom Büchernachdruck«, in: ders., Freymüthige Aufsätze, Anspach 1784, I, S. 75-166.

Cervantes Saavedra, Miguel de, El ingenioso hidalgo don Quixote de la Mancha, Madrid 1605. 
[Cervantes Saavedra, Miguel de], Don Kichote de la Mantzscha, Das ist: Juncker Harnisch auß Fleckenland, Frankfurt a.M. 1648.

Cervantes Saavedra, Miguel de, Leben und Taten des scharfsinnigen Edlen Don Quixote von la Mancha, übers. v. Ludwig Tieck, Berlin 1799-1801, I (1799).

Claproth, Justus, Eine Erfindung aus gedrucktem Papier wiederum neues Papier zu machen, Göttingen 1774.

Code Napoléon mit Zusäzen und Handelsgesezen als Land-Recht für das Großherzogthum Baden, Karlsruhe 1809.

Cramer, Karl Friedrich, Klopstock (In Fragmenten aus Briefen von Tellow an Elisa), Hamburg 1777, I.

Dampf, Hans, Leben, Thaten und Meinungen des Vetter Hans Dampfs. Eine komische Geschichte wider das Todtschiessen und Todtärgern, auch zugleich Hochzeit-, Braut- und Neujahrs-Geschenk für lustige Leute, Spaßvögel, Buch- und Tauschhändler, Gewürz- und Makulatur-Krämer, o.O. 1804.

Denina, Carl, Bibliopoeie, oder Anweisung für Schriftsteller, Berlin, Stralsund 1783.

Denis, Johann Michael, Jugendgeschichte, von ihm selbst beschrieben. Aus dem Lateinischen übersetzt, Winterthur 1802.

Denis, Michael, Einleitung in die Bücherkunde, Wien 1777-1778, I (1777).

Ehlers, Matthias, Über die Unzulässigkeit des Büchernachdrucks nach dem natürlichen Zwangsrecht, Dessau, Leipzig 1784.

Eichhorn, Johann Gottfried, Geschichte der Litteratur von ihrem Anfang bis aufdie neuesten Zeiten, Göttingen 1805-1812, III.I (1810).

[Ersch, Samuel], »Über Litteratoren und Rezensenten«, in: Allgemeiner litterarischer Anzeiger 2 (1797), Nr. 1, Sp. 1-4, 9-12, 25-28.

Faber, Johann Heinrich, Anfangsgründe der Schönen Wissenschaften zu dem Gebrauche seiner akademischen Vorlesungen, Mainz 1767.

Feder, Johann Georg Heinrich, »Neuer Versuch einer einleuchtenden Darstellung der Gründe für das Eigenthum des Bücherverlags, nach Grundsätzen des Rechts und der Staatsklugheit «, in: Göttingisches Magazin der Wissenschaften und Literatur 1 (1780), S. 1-37, 220-242.

Fichte, Johann Gottlieb, Sonnenklarer Bericht an das grössere Publikum über das eigentliche Wesen der neuesten Philosophie, Berlin 1801.

Fichte, Johann Gottlieb, Beiträge zur Berichtigung der Urtheile des Publicums über die französische Revolution, Sämmtliche Werke, hg. v. J. H. Fichte, Berlin 1845ff., III.I (1845), S. 39-288.

Fichte, Johann Gottlieb, Beweis der Unrechtmäßigkeit des Büchernachdrucks, Sämmtliche Werke, hg. v. J. H. Fichte, Berlin 1845ff., VIII (1846), S. 223-244. 
Fichte, Johann Gottlieb, Versuch einer Critik aller Offenbarung. Gesamtausgabe, Stuttgart-Bad Canstatt 1962-2012, I,1 (1964), S. 15-162.

Fichte, Johann Gottlieb, Grundlage der gesammten Wissenschaftslehre als Handschrift für seine Zuhörer, Gesamtausgabe, Stuttgart-Bad Canstatt 1962-2012, I,2 (1965), S. 173-461.

Fichte, Johann Gottlieb, Ueber Geist und Buchstab in der Philosophie. Gesamtausgabe, Stuttgart-Bad Canstatt 1962-2012, I,6 (1981), S. 313-361.

Fichte, Johann Gottlieb, Ueber das Wesen des Gelehrten, und seine Erscheinungen auf dem Gebiete der Freiheit, Gesamtausgabe, Stuttgart-Bad Canstatt 1962-2012, I,8 (1991), S. 37-139.

Fichte, Johann Gottlieb, Ueber den Unterschied des Geistes, u. des Buchstabens in der Philosophie, Gesamtausgabe, Stuttgart-Bad Canstatt 1962-2012, II,3 (1972), S. 313-342.

Fichte, Johann Gottlieb, »Fichte an Johann Friedrich Cotta in Tübingen « (15. November 1795), in: ders., Gesamtausgabe, Stuttgart-Bad Canstatt 19622012, III.2 (1970), S. 433-435 [328].

Füldener, Johann J. von, Bio- \& Bibliographica Silesiaca. Das ist: Schlesische Bibliothec und Bücher-Historie, Breslau 1731, I.

Funke, Carl Philipp, Naturgeschichte und Technologie für Lehrer in Schulen und für Liebhaber dieser Wissenschaften, 4. Aufl., Braunschweig 1802, II (1802).

Furetière, Antoine, Art. »Auteur«, in: ders., Dictionnaire universel, contenant généralement tous les mots françois tant vieux que modernes, et les termes de toutes les sciences et des arts, La Haye 1690, Bd. I, o.P.

Gabler, Georg Andreas, System der theoretischen Philosophie, Erlangen 1827, I.

Gaedicke, Johann Christian, Der Buchhandel von mehreren Seiten betrachtet, Weimar 1803.

Ganz, Johann Friedrich Ferdinand, Uebersicht der Gründe wegen des Strafbaren des Büchernachdrucks, Regensburg 1790.

Gatterer, Johann Christoph, Rez. »Pragmatische Geschichte des Hauses Geroldseck«, in: Allgemeine historische Bibliothek 2 (1767), S. 269-294.

Gedike, Friedrich, Aristoteles und Basedow oder Fragmente über Erziehung und Schulwesen bei den Alten und Neuern, Berlin, Leipzig 1779.

Gellert, Christian Fürchtegott, »An Peter Hohmann, Graf von Hohenthal (15. Februar 1769), in: ders., C.F. Gellerts Briefwechsel, hg. v. John F. Reynolds, Berlin u.a. 1983-2013, 5 (2013), S. 191f. [1212].

Gerard, Alexander, An Essay on Genius, London 1774. 
Gesner, Johann Matthias, »Vorrede«, in: Georg Christoph Hamberger, Zuverlässige Nachrichten von den vornehmsten Schriftstellern vom Anfange der Welt bis 1500, Lemgo 1756-1764, I/I (1756), o.P.

Goethe, Johann Wolfgang von, Wilhelm Meisters Lehrjahre, Werke (Hamburger Ausgabe), hg. v. Erich Trunz, 8. Aufl., München 1972ff., VII (1973).

Goethe, Johann Wolfgang von, Maximen und Reflexionen, Werke (Hamburger Ausgabe), hg. v. Erich Trunz, 7. Aufl., München 1964ff, XII (1973).

Goethe, Johann Wolfgang, Hör-, Schreib- und Druckfehler. Sämtliche Werke (Frankfurter Ausgabe), hg.v. Friedmar Apel, Hendrik Birus, Anne Bohnenkamp u.a., Frankfurt a.M., Berlin 1987-2013, I.20 (1999), S. 450-454.

Göschen, Georg Joachim, »Von Göschen, Leipzig, 19. Oktober 1793«, in: Friedrich Gottlieb Klopstock, Werke und Briefe. Historisch-kritische Ausgabe, hg. v. Horst Gronemeyer, Elisabeth Höpker-Herberg, Klaus Hurlebusch u.a., Berlin, New York 1974ff., Abt. Briefe, 8.1 (1994), S. 301f. [216].

Gundling, Nicolaus Hieronymus, Rechtliches und vernunfftmäßiges Bedencken eines ICTI, der unpartheyisch ist, von dem schändlichen Nachdruck andern gehöriger Bücher, [Halle] 1726.

Gundling, Nicolaus Hieronymus, Vollständige Historie der Gelahrheit, Frankfurt a.M., Leipzig 1734-1736, I (1734).

Hagedorn, Friedrich von, Die Freundschaft, Hamburg 1748.

Hagedorn, Friedrich von, Des Herrn Friedrichs von Hagedorn Poetische Werke, Hamburg 1757, I.

Hallbauer, Friedrich Andreas, Anweisung zur verbesserten teutschen Oratorie, Jena 1725.

Haller, Albrecht von, »Beurtheilung der berühmten Geschichte der Clarissa«, in: ders., Sammlung kleiner Hallerischer Schriften, 2. Aufl., Bern 1772, I, S. 293-315.

Hederich, Benjamin, Art. »Apollo«, in: ders., Gründliches mythologisches Lexikon, Leipzig 1770, Sp. 327-347.

Hegel, Georg Wilhelm Friedrich, Ästhetik, hg. v. Friedrich Basenge, Berlin 1955.

Hegel, Georg Wilhelm Friedrich, Vorlesungen über die Ästhetik, Werke, neu ediert v. Eva Moldenhauer, Karl Markus Michel, Frankfurt a.M. 1986, XIII.

Heine, Heinrich, »Anmerkung. <zu >Reisebilder. Zweyter Theil<, I. Aufl.>«, in: ders., Historisch-kritische Gesamtausgabe der Werke (Düsseldorfer Ausgabe), hg. v. Manfred Windfuhr, Hamburg 1973-1997, VI (1973), S. 347.

Heinzmann, Johann Georg, Appel an meine Nation. Über die Pest der deutschen Literatur (1795), Hildesheim 1977. 
Helfrecht, Johann Theodor Benjamin, Shakal, der schöne Geist. Ein zeitgenössisches Pasquill aufJean Paul, hg. v. Dorothea Böck, Hannover 2013.

Heller, Joseph, Leben Georg Erlingers, Buchdrucker und Formschneider zu Bamberg, Bamberg 1837.

Hennig, J.C., Magazin der Schreibkunst, Berlin 1821.

Herder, Johann Gottfried, Briefe zur Beförderung der Humanität, Sämtliche Werke, hg. v. Bernd Suphan, Berlin 1877-1913, XVIII (1883), S. 86-92.

Herder, Johann Gottfried, »An Johann Friedrich Hartknoch, Weimar, Mitte Mai 1778«, in: ders., Briefe. Gesamtausgabe, hg. v. der Klassik-Stiftung Weimar u.a. (Goethe- und Schiller-Archiv), Weimar 1977-2016, IV (1979), S. 6566 [49].

Heumann, Christoph August, Der politische Philosophus, das ist vernunftmässige Anweisung zur Klugheit im gemeinen Leben, 3. Aufl., Leipzig 1724, Faksimiledruck: Frankfurt a.M. 1972.

Heynatz, Johann Friedrich, Handbuch zu richtiger Verfertigung und Beurtheilung aller Arten von schriftlichen Aufsätzen des gemeinen Lebens überhaupt, und der Briefe insbesondere, 2. Aufl., Berlin 1775.

Hinz, Johann Friedrich, Makulatur zum bewussten Gebrauch, Königsberg 1762.

Hirsching, Friedrich Karl Gottlob (Hg.), Versuch einer Beschreibung sehenswürdiger Bibliotheken Teutschlands, Erlangen 1786-1791, IV (1791).

Höck, Karl, »Trost für Schriftsteller, deren Manuscripte Makulatur werden«, in: Morgenblatt für gebildete Stände 2 (1808), Nr. 195, S. 779.

Hoffmann, E.T.A., "An Jean Paul Friedrich Richter in Bayreuth« (30. Januar 1822), in: ders., E.T.A. Hoffmanns Briefwechsel, hg. v. Friedrich Schnapp, München 1967-1969, II (1968), S. 361 [1028].

Hoffmann, E.T.A., Lebens-Ansichten des Katers Murr, Sämtliche Werke, hg. v. Wulf Segebrecht, Hartmut Steinecke, Frankfurt a.M. 1985-2004, V (1992).

Huber, Franz Xaver, Lebensbeschreibung des weiland hochgelehrten, ehrengeachteten und kunstreichen Herrn Jodocus Rusch, Wien 1788.

Hübler, Daniel Gotthold Joseph, Beyträge zur Bibliopöie in praktischen Anmerkungen für Schriftsteller und Verleger, Leipzig 1803.

Immermann, Karl, Die Papierfenster eines Eremiten, Hamm 1822.

Jean Paul [J. P. F. Hasus], »Von der Verarbeitung der menschlichen Haut«, in: Litteratur- und Völkerkunde 9 (1786), S. 97-113.

Jean Paul, Hesperus, oder 45 Hundsposttage. Eine Biographie. Erstes Heftlein, Berlin 1795.

Jean Paul, Ergänzblatt zur Levana. Jean Paul's sämmtliche Werke, hg. v. Richard Otto Spazier und Ernst Förster, XXXVIII (1827), S. 139-178. 
Jean Paul, Werthvolle Bibliothek, Jean Paul's sämmtliche Werke, hg. v. Richard Otto Spazier und Ernst Förster, Berlin 1826-38, LXII.II (1837), S. 136.

Jean Paul, Exzerpte. Digitale Edition, www.jp-exzerpte.uni-wuerzburg.de.

[Jenisch, Daniel], Der allezeit-fertige Schriftsteller. Oder kurze, doch gründliche Anweisung, wie man mit dem möglich-kleinsten Aufwande von Genie und Wissenschaft ein großer und fruchtbarer Schriftsteller werden könne, Berlin 1797.

Jenisch, Daniel, Theorie der Lebens-Beschreibung. Nebst einer Lebens-Beschreibung Karls des Großen: einer Preisschrift, Berlin 1802.

Justi, Johann Heinrich Gottlob, »Die Schriftstellersucht, eine gefährliche Krankheit der gelehrten Anfänger«, in: ders., Scherzhafte und Satyrische Schriften, Leipzig 1760, I, S. 162-174.

Kant, Immanuel, Von der Unrechtmäßigkeit des Büchernachdrucks, Gesammelte Schriften, hg. v. der Königlich Preußischen Akademie der Wissenschaften, Berlin 1902ff., VIII (1912), S. 77-87.

Kant, Immanuel, Kritik der reinen Vernunft, Werkausgabe, hg. v. Wilhelm Weischedel, Frankfurt a.M. 1968, III.I.

Kehr, Ludwig Christian, »Vertheidigung des Bücher-Nachdrucks« (1799), in: Reinhard Wittmann (Hg.), Der Nachdruck in der publizistischen Diskussion. Pro und Contra, München 1981, S. 241-257.

Kellner, Lorenz, Die Pädagogik der Volksschule in Aphorismen, Essen 1850.

Keßler, Johann Wilhelm, Lehrbuch der Kunst schön und geschwind zu schreiben, Heilbronn 1787.

Kircher, Ernst Wilhelm Gottlieb, Gebrauch der Zeichen welche in den Buchdruckereien zum Korrigiren gewöhnlich sind, Braunschweig 1792.

[Kirchhoff, A.], »Ein Verlags-Contract vom Jahre 1737«, in: Archiv für Geschichte des Deutschen Buchhandels I (1878), S. 195-197.

Klopstock, Friedrich Gottlieb, »An Johann Andreas und Charlotte Cramer, Langensalza, 17. Juni 1749«, in: ders., Werke und Briefe. Historisch-kritische Ausgabe, hg. v. Horst Gronemeyer, Elisabeth Höpker-Herberg, Klaus Hurlebusch u.a., Berlin, New York 1974ff., Abt. Briefe, I (1979), S. 54f. [32].

Klopstock, Friedrich Gottlieb, »An Hemmerde, Langensalza, 30. September 1749«, in: ders., Werke und Briefe. Historisch-kritische Ausgabe, hg. v. Horst Gronemeyer, Elisabeth Höpker-Herberg, Klaus Hurlebusch u.a., Berlin, New York 1974ff., Abt. Briefe, I (1979), S. 61-62.

Klopstock, Friedrich Gottlieb, Der Messias, Werke und Briefe. Historisch-kritische Ausgabe, hg. v. Horst Gronemeyer, Elisabeth Höpker-Herberg, Klaus Hurlebusch u.a., Berlin, New York 1974ff., Abt. Werke, IV/6 (1999, hg. v. Elisabeth-Höpker-Herberg). 
Klopstock, Meta, »Von Margarete Moller, Borgesch, 16. August 1752« (An Klopstock und Giseke), in: Friedrich Gottlieb Klopstock, Werke und Briefe. Historisch-kritische Ausgabe, hg. v. Horst Gronemeyer u.a., Berlin 1974ff., Abt. Briefe, II (1985, hg. v. Rainer Schmidt), S. 212-213 [167].

Klopstock, Meta, Briefwechsel mit Klopstock, ihren Verwandten und Freunden, hg. v. Hermann Tiemann, Hamburg 1956, I.

[Kmr.], Rez. »Fünften Nachtrags zweyte Abtheilung zu der vierten Ausgabe des gelehrten Teutschlandes«, in: Oberdeutsche allgemeine Litteraturzeitung 8 (1795), 2, St. CXXIV (19.10.1795), Sp. 777-784.

[Kmr.], Rez. »Versuch über die Kunst gut und viel zu schreiben«, in: Oberdeutsche allgemeine Litteraturzeitung 9 (1796), Stk. LXXX (6. Juli 1796), Sp. 38-40.

Korn, Johann Friedrich, »Warnungs-Anzeige an die Herren Skalen-Meister des Wachsthumes der Schriftstellerei, und der Ausbreitung der Gelehrsamkeit in jedem Fache derselben«, in: Allgemeiner Litterarischer Anzeiger (1797), No. C, Sp. 1017f.

[Kotzebue, August], Denkschrift über den Büchernachdruck, zugleich Bittschrift um Bewürkung eines deutschen Reichsgesetzes gegen denselben. Den Erlauchten, bei dem Congress zu Wien versammleten [sic!] Gesandten deutscher Staaten ehrerbietigst überreicht im Namen der deutschen Buchhändler, Leipzig 1814.

Kramer, Wilhelm August, Die Rechte der Schriftsteller und Verleger, Heidelberg 1827.

Krebs, Benjamin, Handbuch der Buchdruckerkunst, Frankfurt a.M. 1827.

Krünitz, Johann Georg, Art. »Kleid «, in: ders., Oeconomische Encyklopädie, Berlin 1773-1858, 40 (1787), S. 1-312.

Krünitz, Johann Georg, Art. »Maculatur«, in: ders., Oeconomische Encyklopädie, Berlin 1773-1858, 82 (1801), S. 154-181.

Lafontaine, August, Leben eines armen Landpredigers, Berlin 1801, I.

LaLande, Joseph Jérôme Le François de, Die Kunst, Papier zu machen, Berlin 1762.

Lange, Samuel Gotthold, Horatzische Oden nebst G.F. Meiers Vorrede vom Werthe der Reime, Halle 1747.

Lappenberg, Johann Martin, Zur Geschichte der Buchdruckerkunst in Hamburg, Hamburg 1840.

Lempertz, Heinrich, Beiträge zur ältern Geschichte der Buchdruck-und Holzschneidekunst, Köln 1839.

Lessing, Gotthold Ephraim, »An Friedrich Nicolai« (27. August 1768), in: ders., Werke und Briefe, hg. v. Wilfried Barner u.a., Frankfurt a.M. 1984-2003, 11/1 (1987), S. 533f. [431]. 
Lessing, Gotthold Ephraim, »Brief an Christian Friedrich Voß« (6. Dezember 1771), in: ders., Werke und Briefe, hg. v. Wilfried Barner u.a., Frankfurt a.M. 1984-2003, 11/2 (1988), S. 278f. [744].

Lessing, Gotthold Ephraim, »An Christian Friedrich Voß«(24. Dezember 1771), in: ders., Werke und Briefe, hg. v. Wilfried Barner u.a., Frankfurt a.M. 19842003, 11/2 (1988), S. 304-306 [764].

Lessing, Gotthold Ephraim, Nathan der Weise, Werke und Briefe, hg. v. Wilfried Barner u.a., Frankfurt a.M. 1984-2003, Bd. 9 (1993), S. 483-628.

Lessing, Gotthold Ephraim, Kleinigkeiten. Faksimile des Marbacher Manuskripts, vorgestellt von Jochen Meyer, Göttingen 2000.

Lessing, Karl (Hg.), Gotthold Ephraim Lessings Leben, nebst seinem noch übrigen litterarischen Nachlasse, Berlin 1793, I.

Leuchs, Johann Carl, Allgemeines Waaren-Lexicon oder vollständige Waarenkunde. Zweiter Theil, Nürnberg 1826.

Lichtenberg, Georg Christoph, »Ueber Bücher-Formate«, in: Göttinger Taschen Calender (1796), S. 171-178.

Lichtenberg, Georg Christoph, »An Johann Andreas Schernhagen«, in: ders., Lichtenberg in England, hg. v. Hans Ludwig Gumbert, Wiesbaden 1977, I, S. 316-320 [XXII].

Lichtenberg, Georg Christoph, Lichtenberg in England, hg. v. Hans Ludwig Gumbert, Wiesbaden 1977, II.

Lichtenberg, Georg Christoph, Briefwechsel, im Auftrag der Akademie der Wissenschaften zu Göttingen hg. v. Ulrich Joost, Albrecht Schöne u.a., München 1983-2004.

Lichtenberg, Georg Christoph, »An Joel Paul Kaltenhofer«, in: ders., Briefwechsel, hg. v. Ulrich Joost, Albrecht Schöne u.a., München 1983-2004, I (1983), S. 194-197 [103].

Lichtenberg, Georg Christoph, "An Johann Christian Dieterich « (28. September 1773), in: ders., Briefwechsel, hg. v. Ulrich Joost, Albrecht Schöne u.a., München 1983-2004, I (1983), S. 390-391 [206].

Lichtenberg, Georg Christoph, »Brief an Johann Andreas Schernhagen« (28. September 1773), in: ders., Briefwechsel, hg. v. Ulrich Joost, Albrecht Schöne u.a., München 1983-2004, I (1983), S. 391-393 [207].

Lichtenberg, Georg Christoph, »An das Geheime Rats-Kollegium« (28. April 1774), in: ders., Briefwechsel, hg. v. Ulrich Joost, Albrecht Schöne u.a., München 1983-2004, I (1983), S. 456-457 [247]. 
Lichtenberg, Georg Christoph, »An Johann Christian Dieterich« (30. September 1774), in: ders., Briefwechsel, hg. v. Ulrich Joost, Albrecht Schöne u.a., München 1983-2004, I (1983), S. 472-473 [261].

Lichtenberg, Georg Christoph, "An Johann Christian Dieterich« (30. Oktober 1774), in: ders., Briefwechsel, hg. v. Ulrich Joost, Albrecht Schöne u.a., München 1983-2004, I (1983), S. 480-482 [265].

Lichtenberg, Georg Christoph, »An Johann Christian Dieterich« (28. Januar 1775/4., 5. Februar 1775), in: ders., Briefwechsel, hg. v. Ulrich Joost, Albrecht Schöne u.a., München 1983-2004, I (1983), S. 503-509 [272].

Lichtenberg, Georg Christoph, "An Johann Christian Dieterich, 13.10.1775«, in: ders., Briefwechsel, hg. v. Ulrich Joost, Albrecht Schöne u.a., München 1983-2004, I (1983), S. 556-559 [287].

Lichtenberg, Georg Christoph, „An Franz Ferdinand Wolff« (26.? Februar 1787), in: ders., Briefwechsel, hg. v. Ulrich Joost, Albrecht Schöne u.a., München 1983-2004, III (1990), S. 331f.

Lichtenberg, Georg Christoph, "An Georg August Ebell« (19. Januar 1789), in: ders., Briefwechsel, hg. v. Ulrich Joost, Albrecht Schöne u.a., München 1983-2004, III (1990), S. 644-646 [1654].

Lichtenberg, Georg Christoph, »An Wilhelm Gottlieb Becker« (19. April 1795), in: ders., Briefwechsel, hg. v. Ulrich Joost, Albrecht Schöne u.a., München 1983-2004, IV (1992), S. 435f. [2512].

Lichtenberg, Georg Christoph, Observationes. Die lateinischen Schriften, hg. v. Dag Nikolaus Hasse, Göttingen 1997.

Lichtenberg, Georg Christoph, Schriften und Briefe, hg. v. Wolfgang Promies, 6. Aufl., Frankfurt a.M. 1998, I, II, K I+II.

Lindheimer, Friedrich, Die Leihbibliothek. Ein Lustspiel in zwey Akten, Grätz 1799. Locke, John, Two treatises of government, hg. v. Peter Laslett, 2. Aufl., Cambridge 1967.

Lorenz, Gottlieb Friedrich (Hg.), Theatralisches Quodlibet für Schauspieler und Schauspielliebhaber, Warschau 1782, I.

Ludwig, Carl Friedrich Ernst, Phantasien und Reflexionen aufeiner Reise durch das südliche Deutschland in die Schweiz, 2 Bde., Leipzig 1810.

Makulaturen. Erstes Bändchen, Pilsen, Klattau 1790.

Markwordt, Jacob Friedrich, Darstellung der Lehrart und Einrichtung in der im Monat Oktober dieses Jahrs zu eröffnenden Schreib-und Elementar-Zeichnenschule, Berlin 1817.

Mencke, Johann Burchard, Compendioses Gelehrtenlexikon, Leipzig 1715. 
Mencke, Johann Burchard, Zwey Reden von der Charlatanerie oder Marcktschreyerey der Gelehrten, Leipzig 1716.

Mendelssohn, Moses, »Von Moses Mendelssohn« (25. Oktober 1757), in: Gotthold Ephraim Lessing, Werke und Briefe, hg. v. Wilfried Barner u.a., Frankfurt a.M. 1984-2003, 11/1 (1987), S. 256-258 [162].

Merck, Johann Heinrich, Gedanken über die Irrwege der deutschen Schriftsteller, Werke, hg. v. Arthur Henkel, Frankfurt a.M. 1968, S. 490ff.

Meusel, Johann Georg, Georg Christoph Hamberger, Das gelehrte Teutschland oder Lexikon der jetzt lebenden teutschen Schriftsteller, 1.-5. Ausgabe, Lemgo 1767-1834.

Meusel, Johann Georg, Leitfaden zur Geschichte der Gelehrsamkeit, Leipzig 17991800, I (1799).

Moeckel, Christian Heinrich, Vollständige Anweisung zur Deutschen Schreibekunst, Altenburg 1797.

Morhof, Daniel Georg, Polyhistor Literarius, Philosophicus et Practicus, 4. Aufl., Lübeck 1747.

Moser, Ferdinand Christian, »Der Unterricht im Schreiben«, in: Taschenbuch für teutsche Schulmeister 3 (1788), S. 311-378.

Moser, Ferdinand Christian, »Zugabe«, in: Taschenbuch für teutsche Schulmeister 3 (1788), S. 480-483.

Moser, Johann Jacob, Von der Teutschen Unterthanen Rechten und Pflichten, Frankfurt a.M., Leipzig 1774.

Müller, Johann Gottwerth, Emmerich, eine komische Geschichte vom Verfasser des Siegfried von Lindenberg, Fünfter Theil, Göttingen 1788.

Musäus, Johann Karl August, Physiognomischen Reisen, Altenburg 1788, H. 2.

Natorp, Bernhard Christoph Ludwig (Hg.), Briefwechsel einiger Schullehrer und Schulfreunde, 2. Aufl., Essen 1823.

[Nicolai, Friedrich], »Vorbericht«, in: Allgemeine Deutsche Bibliothek 1 (1765), 1. Stk., S. I-IV.

Nicolai, Friedrich, »Friedrich Nicolai an Johann von Müller« (16. März 1773), in: Johann von Müller, Sämmtliche Werke, Supplement: Briefe an Johann von Müller, Schaffhausen 1810-1840, IV (1840), S. 52-62 [6.].

Nicolai, Friedrich, »Von Friedrich Nicolai« (9. August 1768), in: Gotthold Ephraim Lessing, Werke und Briefe, hg. v. Wilfried Barner u.a., Frankfurt a.M. 1984-2003, S. 531f. [429].

Nicolai, Friedrich, Verlegerbriefe, hg.v. Bernhard Fabian und Marie-Luise Spieckermann, Berlin 1988. 
Nicolai, Friedrich, »An Johann Peter Uz, 5. Oktober 1762«, in: ders., Verlegerbriefe, hg. v. Bernhard Fabian und Marie-Luise Spieckermann, Berlin 1988, S. 19-24.

Nicolai, Friedrich, "An Gotthold Ephraim Lessing, 8. November 1769«, in: ders., Verlegerbriefe, hg. v. Bernhard Fabian und Marie-Luise Spieckermann, Berlin 1988, S. 65-70.

Nicolai, Friedrich, Sebaldus Nothanker, Sämtliche Werke - Briefe - Dokumente, hg. v. Rainer Falk, István Gombocz, Hans-Gert Roloff, Jutta Weber, Berlin, Stuttgart-Bad Cannstatt u.a. 1991ff., 1.1 (2015).

Niemeyer, August Hermann, Grundsätze der Erziehung und des Unterrichts für Eltern, Hauslehrer und Schulmänner, 5. Aufl., Halle 1802.

Oelrich, Johann Carl Conrad, Beyträge zur Geschichte und Litteratur, Berlin, Stettin, Leipzig 1760.

Pestalozzi, Johann Heinrich, Die Methode. Eine Denkschrift Pestalozzi's. 27. Juni 1800, Sämtliche Werke, Berlin, Leipzig 1932, XIII (Bearb. v. H. Schönebaum, K. Schreinert), S. 101-125.

Pezzl, Johann, Skizze von Wien, Viertes Heft, Wien 1787.

Pöhlmann, Johann Paul, Meine Schreiblectionen oder praktische Anweisung für Schullehrer, welche den ersten Unterricht im Schönschreiben zugleich als Verstandesübung benützen wollen, Fürth 1803.

Poppe, Johann Heinrich M., Geschichte der Technologie seit der Wiederherstellung der Wissenschaften bis ans Ende des achtzehnten Jahrhunderts, Göttingen 1810, II.

R.A.F.N. [d.i. Christian Siegmund Krause], »Ueber den Büchernachdruck«, in: Deutsches Museum 1 (1783), S. 400-430, 487-514.

[Reich, Philipp Erasmus], Zufällige Gedanken eines Buchhändlers über Herrn Klopstocks Anzeige einer gelehrten Republik, O.o. 1773.

Reich, Philipp Erasmus, Der Bücher-Verlag in allen Absichten genauer betrachtet, o.O. 1773.

[Reimarus, Johann Albert Heinrich], Der Bücherverlag in Betrachtung der Schriftsteller, der Buchhändler und des Publikums, Hamburg 1773.

Reimarus, Johann Albert Heinrich, »Der Bücherverlag in Betrachtung der Schriftsteller, der Buchhändler und des Publikums abermals erwogen«, in: Deutsches Magazin I (1791), S. 383-414.

Resewitz, F.G., »Die große Lehre vom Gewissen, in so fern sie die Gesetze der Religion und die Gesetze der Staaten verbindet«, in: Allgemeine Deutsche Bibliothek 13 (1770), 1, S. 214-31. 
[Riedel, Friedrich Justus], »Umständlicher Beweiß, daß im heiligen Römischen Reiche viele Narren sind«, in: ders., Sieben Satyren, nebst drei Anhängen, gesammlet von N. N., [Jena] 1765, S. 241-266.

[Riedel, Friedrich Justus], »Skribleriana«, in: ders., Sieben Satyren, nebst drei Anhängen, gesammlet von N.N., [Jena] 1765, S. 277-308.

[Riedel, Friedrich Justus], »Lies Ochse oder Anzeige der vornehmsten Druckfehler«, in: ders., Sieben Satyren, nebst drei Anhängen, gesammlet von N.N., [Jena] 1765, S. 337-351.

Schelling, Friedrich Wilhelm Joseph, Texte zur Philosophie der Kunst, ausgewählt u. eingeleitet v. Werner Beierwaltes, Stuttgart 2004.

Schiller, Friedrich, "An Körner, 17. 3. 1788«, in: ders., Schillers Werke. Nationalausgabe [NA], begründet v. Julius Petersen, fortgeführt v. Lieselotte Blumenthal und Benno von Wiese, hg. im Auftrag der Nationalen Forschungs- und Gedenkstätten der klassischen deutschen Literatur in Weimar (Goethe- und Schiller-Archiv) und des Schiller-Nationalmuseums in Marbach v. Norbert Oellers, Siegfried Seidel, Weimar 1943ff., 25 (1979), 7.1.3, S. 28-31 [20].

Schiller, Friedrich, »Brief an Cotta, 13. März 1796«, in: ders., Schillers Werke. Nationalausgabe [NA], begründet v. Julius Petersen, fortgeführt v. Lieselotte Blumenthal und Benno von Wiese, hg. im Auftrag der Nationalen Forschungs- und Gedenkstätten der klassischen deutschen Literatur in Weimar (Goethe- und Schiller-Archiv) und des Schiller-Nationalmuseums in Marbach v. Norbert Oellers, Siegfried Seidel, Weimar 1943ff., 28 (1969), 7.1.6, S. 200-201.

Schiller, Friedrich, »Brief an Crusius, 10. März 1803«, in: ders., Schillers Werke. Nationalausgabe [NA], begründet v. Julius Petersen, fortgeführt v. Lieselotte Blumenthal und Benno von Wiese, hg. im Auftrag der Nationalen Forschungs- und Gedenkstätten der klassischen deutschen Literatur in Weimar (Goethe- und Schiller-Archiv) und des Schiller-Nationalmuseums in Marbach v. Norbert Oellers, Siegfried Seidel, Weimar 1943ff., 32 (1984), 7.1.10, S. 21.

Schlegel, August Wilhelm, Vorlesungen über schöne Literatur und Kunst [Berlin 1801-1804]. Kritische Ausgabe der Vorlesungen, hg. v. Ernst Behler, Paderborn, München, Wien u.a. 1989, I, S. 179-781.

Schüddekopf, Carl (Hg.), Briefwechsel zwischen Gleim und Uz, Tübingen 1899. Schüddekopf, Carl (Hg.), Briefwechsel zwischen Gleim und Ramler, Tübingen 1906-1907, I (1906). 
Schütze, Johann Friedrich »Jean Paul Friedrich Richter«, in: Deutsches Magazin 15 (1798), S. 97-119.

[Schummel, Johann Gottlieb], Spitzbart, eine komi-tragische Geschichte für unser pädagogisches Jahrhundert, Leipzig 1779.

Shaftesbury, Anthony Ashley Cooper of, Selbstgespräch oder Ratschlag an einen Autor, Standard Edition, hg. v. Gerd Hemmerich, Wolfram Benda, Stuttgart 1981ff., I/I (1981), S. 35-301.

[Sp], Rez. »Tobiae Mayeri in Vniuersitate litt. Göttingensi quondam Professoris - Opera Inedita. Vol. I«, in: Allgemeine Deutsche Bibliothek 33 (1778), S. 362-370.

Stephani, Heinrich, Ausführliche Beschreibung meiner einfachen Lese-Methode, Erlangen 1814.

Stephani, Heinrich, Ausführliche Beschreibung der genetischen Schreibmethode für Volksschulen, Erlangen 1815.

Stephani, Heinrich, Handbuch der Unterrichtskunst nach der bildenden Methode für Volksschullehrer, Erlangen 1835.

Täubel, Christian Gottlob, Orthotypographisches Handbuch, Halle, Leipzig 1785.

Täubel, Christian Gottlob, Praktisches Handbuch der Buchdruckerkunst für Anfänger, Leipzig 1791.

Täubel, Christian Gottlob, Neues theoretisch-practisches Lehrbuch der Buchdruckerkunst für angehende Schriftsetzer und Drucker in den Buchdruckereyen, Leipzig 1810.

Thomasius, Christian, „Christian Thomasens/Erinnerung/Wegen einer gedruckten Schrifft/Deren Titul: Christiani Thomasii Confessio Doctrinae Suae«, in: ders. (Hg.), Allerhand bißher publicirte Kleine Teutsche Schrifften, Halle 1701, S. 435-451.

Unger, Johann Friedrich, »Noch etwas über Didotsche Lettern, als eine Antwort auf das anonyme Schreiben im 40sten Stück des Intelligenzblatts der allgemeinen Literatur-Zeitung «, in: Intelligenzblatt der ALZ (1791), Nr. 64 (14. Mai 1791), Sp. 528-530.

Villaume, Peter, Praktisches Handbuch für Lehrer in Bürger- und Land-Schulen, Wien 1788.

Wehrs, Georg Friedrich, Vom Papier und von den Schreibmassen, derer man sich vor der Erfindung desselben bediente, Hannover 1779.

Wieland, Christoph Martin, Sympathien, C.M. Wielands sämmtliche Werke, Leipzig 1824ff., 29 (1857), S. 1-61.

Wieland, Christoph Martin, »An M. Künzli in Winterthur« (12. April 1757), in: ders., Wielands Briefwechsel, Berlin 1963-2007, I (1963), S. 299-300 [253]. 
Wieland, Christoph Martin, "An Zimmermann in Brugg« (August 1758), in: ders., Wielands Briefwechsel, Berlin 1963-2007, I (1963), S. 355-356 [312].

Young, Edward, Gedanken über die Original-Werke, hg. v. Gerhard Sauder, Heidelberg 1977.

[Zachäus Fidibusifer], »Der Autor erzählt seine schlechten Umstände, die ihn bewogen haben, Fidibus zu machen, und wünscht der Stadt Leipzig, seinen Lesern, den Schönen und Häßlichen, den vier Facultäten, den Studirenden, den Kaufleuten und schlechten Schriftstellern in wäßrigen Versen ein glückseliges neues Jahr«, in: Fidibus 1 (1768), Nr. 1 (8. Januar 1768), S. 1-9.

[Zachäus], »Der Fabricant Zachäus entschuldigt sich bey dem Publico, daß er, statt der versprochnen gelehrten Werke, andre geringe papierne Waare verfertigen müsse, und erzählt hernach, was für ein Gemälde seine Kunden auf diesen Tapeten zu erwarten haben«, in: Tapeten 1 (1771), 1. Stk. (3. April 1771), S. 1-8.

[Zachäus], »Antwort auf das Schreiben des Herrn Alexander Gernegroß«, in: Tapeten 1 (1771), 12. Stk. (19. Juni 1771), S. 89-96.

[Zachäus], »Noch etwas an Herrn Alexander Gernegroß«, in: Tapeten I (1771), 13. Stk. (26. Juni 1771), S. 97-104.

Zedler, Johann Heinrich, Art. »Mackeltur«, in: ders. (Hg.), Grosses vollständiges Universal-Lexicon aller Wissenschaften und Künste, Leipzig, Halle 1731-54, 19 (1739), Sp. 95, hier: Sp. 95.

Zedler, Johann Heinrich, Art. »Pasquino«, in: ders. (Hg.), Grosses vollständiges Universal-Lexicon aller Wissenschaften und Künste, Leipzig, Halle 1731-54, 26 (1740), Sp. 1148, hier: Sp. 1148.

Zedler, Johann Heinrich, Art. »Schreiben, Lat. Scribere«, in: ders. (Hg.), Grosses vollständiges Universal-Lexicon aller Wissenschaften und Künste, Leipzig, Halle 1731-54, 35 (1743), Sp. 1142-43.

Zerrenner, Heinrich Gottlieb, Volksbuch. Ein faßlicher Unterricht in nüzlichen Erkenntnissen und Sachen mittelst einer zusammenhängenden Erzählung für Landleute. Erster Theil, Magdeburg 1787.

Zimmermann, Johann Georg, Briefe an einige seiner Freunde in der Schweiz, hg. v. Albrecht Rengger, Aarau 1830.

Zincke, Georg Heinrich, Art. »Buch«, in: ders., Allgemeines Oeconomisches Lexicon, 2. Aufl., Leipzig 1744, I, Sp. 442.

[Zschokke, Heinrich], Der Schriftstellerteufel. Ein klassisches Original-Lesebuch für unglückliche Autoren, Berlin 1791. 


\section{Sekundärliteratur}

Agamben, Giorgio, Profanierungen, aus dem Italienischen von Marianne Schneider, Frankfurt a.M. 2005.

Agamben, Giorgio, Was ist ein Dispositiv?, Zürich u.a. 2008.

Albrecht, Wolfgang, Lessing. Gespräche, Begegnungen, Lebenszeugnisse, Kamenz 2005.

Albrecht, Wolfgang, Lessing. Chronik zu Leben und Werk, Kamenz 2008. Alkemeyer, Thomas, »Subjektivierung in sozialen Praktiken. Umrisse einer praxeologischen Analytik «, in: ders., Gunilla Budde, Dagmar Freist (Hg.), Selbst-Bildungen. Soziale und kulturelle Praktiken der Subjektivierung, Bielefeld 2013, S. 33-68.

Aristoteles, Poetik. Griechisch/Deutsch, übers.u. hg. v. Manfred Fuhrmann, Stuttgart 2001.

Assmann, Aleida, »Texte, Spuren, Abfall. Die wechselnden Medien des kulturellen Gedächtnisses«, in: Hartmut Böhme, Klaus R. Scherpe (Hg.), Literatur und Kulturwissenschaften, Reinbek b. Hamburg 1996, S. 96-111.

Assmann, Aleida, Erinnerungsräume. Formen und Wandlungen des kulturellen Gedächtnisses, München 1999.

Baisch, Martin, »Textualität - Materialität - Materialität - Textualität. Zugänge zum mittelalterlichen Text«, in: Literaturwissenschaftliches Jahrbuch 54 (2013), S. 9-30.

Bappert, Walter, Wege zum Urheberrecht. Die geschichtliche Entwicklung des Urheberrechtsgedankens, Frankfurt a.M. 1962.

Barthes, Roland, »Der Tod des Autors«, in: Fotis Jannidis, Gerhard Lauer, Matias Martinez, Simone Winko (Hg.), Texte zur Theorie der Autorschaft, Stuttgart 2000, S. 185-193.

Barthes, Roland, Variations sur l'écriture - Variationen über die Schrift [1973], übers. v. H.-J. Ortheil, Mainz 2006.

Bauer, Elke, »>Der Buchdruckerjunge aber klopfte und verlangte Manuscript<. Lessings Arbeitsweise und ihre mögliche Konsequenz für eine historischkritische Ausgabe«, in: Jochen Golz, Manfred A. Koltes (Hg.), Autoren und Redaktoren als Editoren, Tübingen 2008, S. 130-143.

Bauer, Konrad F., »Zur Geschichte der Unger-Fraktur«, in: Gutenberg-Jahrbuch (1929), S. 287-296.

Begemann, Christian, »Der Körper des Autors. Autorschaft als Zeugung und Geburt im diskursiven Feld der Genieästhetik«, in: Heinrich Detering (Hg.), Autorschaft. Positionen und Revisionen, Stuttgart 2002, S. 44-61. 
Bellingradt, Daniel, »Trading Paper in Early Modern Europe. On distribution logistics, traders, and trade volumes between Amsterdam and Hamburg in the mid-late eighteenth century«, in: Jaarboek vorr Nederlandse boekgeschiedenis 21 (2014), S. 117-131.

Bellingradt, Daniel, »Book lotteries as sale events for slow-sellers: The case of Amsterdam in late eighteenth century«, in: Shanti Graheli (Hg.), Buying and Selling. The Business of Books in Early Modern Europe, Leiden, Boston 2019, S. 154-177.

Bender, Wolfgang, Johann Jakob Bodmer und Johann Jakob Breitlinger, Stuttgart 1973.

Benne, Christian, »Aporetik der Materialität und Philosophie der Philologie - läßt sich mit Handschriften philosophieren?«, in: Text. Kritische Beiträge 14 (2014), S. 3-21.

Benne, Christian, Die Erfindung des Manuskripts. Zur Theorie und Geschichte literarischer Gegenständlichkeit, Berlin 2015.

Berend, Eduard (Hg.), Jean Pauls Persönlichkeit in Berichten der Zeitgenossen, Weimar 1956.

Berg, Gunter, »Die Selbstverlagsidee bei deutschen Autoren im 18. Jahrhundert «, in: Börsenblatt für den deutschen Buchhandel 43 (1965), S. 448-460.

Berhorst, Ralf, Anamorphosen der Zeit. Jean Pauls Romanästhetik und Geschichtsphilosophie, Tübingen 2002.

Bernauer, Markus, Angela Steinsiek, Jutta Weber (Hg.), Jean Paul. Dintenuniversum. Schreiben ist Wirklichkeit, Berlin 2013

Bernauer, Markus, »Katalog: Lektüren«, in: ders., Angela Steinsiek, Jutta Weber (Hg.), Jean Paul. Dintenuniversum. Schreiben ist Wirklichkeit, Berlin 2013, S. 49-55.

Blum, Rudolf, Bibliographia. Eine wort- und begriffsgeschichtliche Untersuchung, Frankfurt a.M.1969, Sp. 1141-1190.

Blum, Rudolf, »Bibliographie. Eine wort- und begriffsgeschichtliche Untersuchung «, in: Archiv für Geschichte des Buchwesens 10 (1970), Sp. 1009-1246.

Bödeker, Hans Erich, »Die bürgerliche Literatur- und Mediengesellschaft «, in: Notker Hammerstein, Ulrich Herrmann (Hg.), Handbuch der deutschen Bildungsgeschichte, München 1996ff., II (2005), S. 499-520.

Boghardt, Martin, Archäologie des gedruckten Buches, hg. v. Paul Needham, Wiesbaden 2008.

Böning, Holger, »'Gewiss ist es/dass alle gedruckte Zeitungen erst geschrieben seyn müssen . Handgeschriebene und gedruckte Zeitungen im Span- 
nungsfeld von Abhängigkeit, Koexistenz und Konkurrenz«, in: Daphnis 37 (2008), S. 202-242.

Bosse, Heinrich, »Die gelehrte Republik«, in: Hans-Wolf Jäger (Hg.), »Öffentlichkeit« im 18. Jahrhundert, Göttingen 1997, S. 51-76.

Bosse, Heinrich, ")Die Schüler müßen selbst schreiben lernen oder: Die Einrichtung der Schiefertafel«, in: ders., Bildungsrevolution 1770-1830, hg. v. Nacim Ghanbari, Heidelberg 2012, S. 161-236.

Bosse, Heinrich, Autorschaft ist Werkherrschaft. Über die Entstehung des Urheberrechts aus dem Geist der Goethezeit (1981), Paderborn 2014.

Bosse, Heinrich, »Schreiben«, in: Heiko Christians, Matthias Bickenbach, Nikolaus Wegmann (Hg.), Historisches Wörterbuch des Mediengebrauchs, Köln 2015, I, S. 482-497.

Bremer, Thomas (Hg.), Materialitätsdiskurse der Aufklärung. Bücher-Dinge-Praxen, Halle 2016.

Brendecke, Arndt (Hg.), Praktiken der Frühen Neuzeit. Akteure - Handlungen Artefakte, Köln 2015.

Burnett, Cathy, Guy Merchant, Kate Phal, Jennifer Roswell, »The (im)materiality of literacy. The significance of subjectivity to new literacies research «, in: Discours. Studies in the cultural politics of education 35 (2014), 1, S. 90-103.

Büttner, Peter O., Schreiben lehren um 1800, Hannover 2015.

Cahn, Michael, Der Druck des Wissens. Geschichte und Medium der wissenschaftlichen Publikation, Berlin 1991.

Campe, Rüdiger, »Die Schreibszene, Schreiben« (1991), in: Sandro Zanetti (Hg.), Schreiben als Kulturtechnik. Grundlagentexte, Berlin 2012, S. 269-282.

Carius, Hendrikje, Recht durch Eigentum. Frauen vor dem Jenaer Hofgericht (16481806), München 2012.

Chartier, Roger, Lesewelten. Buch und Lektüre in der frühen Neuzeit, Frankfurt a.M. u.a. 1990.

Chartier, Roger, »Macht der Schrift, Macht über die Schrift«, in: Hans Ulrich Gumbrecht, Karl L. Pfeiffer (Hg.), Schrift, München 1993, S. 147-156.

Chartier, Roger, The Order of Books. Readers, Authors, and Libraries in Europe Between the Fourteenth and Eighteenth Centuries, Stanford 1994.

Chartier, Roger, Guglielmo Cavallo (Hg.), Die Welt des Lesens: Von der Schriftrolle zum Bildschirm, Frankfurt 1999.

Chartier, Roger, The Author's Hand and the Printer's Mind. Transformations of the Written Word in Early Modern Europe, Cambridge 2013. 
Conrad, Marcus, »Kostenfaktoren beim Publikationsprojekt der Allgemeinen Welthistorie im Verlag Gebauer in Halle (1744-1814)«, in: Archiv für Geschichte des Buchwesens 68 (2013), S. 105-118.

D’Aprile, Iwan, Conrad Wiedemann (Hg.), Daniel Jenisch. Kant-Exeget, Popularphilosoph und Literat in Berlin, Laatzen 2003.

Dane, Joseph A., The Myth of Print Culture. Essays on Evidence, Textuality, and Bibliographical Method, Toronto u.a. 2003.

Darnton, Robert, Literaten im Untergrund. Lesen, Schreiben und Publizieren im vorrevolutionären Frankreich, Frankfurt a.M. 1988.

Darnton, Robert, »What is the History of Books?«, in: Daedalus 111 (1982), 3, S. 65-83.

Darnton, Robert, Die Wissenschaft des Raubdrucks. Ein zentrales Element im Verlagswesen des 18. Jahrhunderts, München 2003.

Darnton, Robert, »What is the History of Books?« Revisited«, in: Modern Intellectual History 4 (2007), 3, S. 495-508.

Décultot, Elisabeth (Hg.), Lesen, Kopieren, Schreiben. Lese- und Exzerpierkunst in der europäischen Literatur des 18. Jahrhunderts, Berlin 2014.

Décultot, Elisabeth, »Einleitung. Die Kunst des Exzerpierens - Geschichte, Probleme, Perspektiven«, in: dies. (Hg.), Lesen, Kopieren, Schreiben. Lese- und Exzerpierkunst in der europäischen Literatur des 18. Jahrhunderts, Berlin 2014, S. 7-47.

Dembeck, Till, Texte rahmen. Grenzregionen literarischer Werke im 18. Jahrhundert (Gottsched, Wieland, Moritz, Jean Paul), Berlin 2007.

Deneke, Otto, Lichtenbergs Leben, München 1944, I.

Dilthey, Wilhelm, »Archive für Literatur«, in: ders., Zur Geistesgeschichte des 19. Jahrhunderts. Portraits und biographische Skizzen, Quellenstudien und Literaturberichte zur Theologie und Philosophie im 19. Jahrhundert, hg. v. Ulrich Herrmann, 3. Aufl., Göttingen 1991, S. 1-16.

Doede, Werner, Schön schreiben, eine Kunst. Johann Neudörffer und seine Schule im 16. und 17. Jahrhundert, München 1957.

Doede, Werner, Bibliographie deutscher Schreibmeisterbücher von Neudörffer bis 1800, Hamburg 1958.

Dommann, Monika, Autoren und Apparate. Die Geschichte des Copyrights im Medienwandel, Frankfurt a.M. 2014.

Dotzler, Bernhard J., Diskurs und Medium III: Philologische Untersuchungen. Medien und Wissen in literaturgeschichtlichen Beispielen, München 2011.

Douglas, Mary, Purity is Danger. An Analysis oft he Concepts of Pollution and Taboo (1966), London 2000. 
Eibl, Karl, Die Entstehung der Poesie, Frankfurt a.M. 1995.

Eisenstein, Elisabeth, The Printing Press as an Agent of Change. Communications and cultural Transformations in early-modern Europe, Cambridge 1980.

Erb, Andreas, Schreib-Arbeit. Jean Pauls Erzählen als Inszenierung "freier« Autorschaft, Wiesbaden 1996.

Erlin, Matt, Necessary Luxuries. Books, Literature, and the Culture of Consumption in Germany, 1770-1815, Ithaca, NY 2014.

Ezell, Margaret J. M., Social Authorship and the Advent of Print, Baltimore Md. u.a. 1999.

Fertig, Ludwig, »'Ein Kaufladen voll Manuskripte<. Jean Paul und seine Verleger«, in: Archiv für Geschichte des Buchwesens 32 (1989), S. 273-395.

Fick, Monika, Lessing-Handbuch. Leben - Werk - Wirkung, Stuttgart, Weimar 2000.

Fischer, Bernhard, Johann Friedrich Cotta. Verleger-Entrepreneur-Politiker, Göttingen 2014.

Fischer, Bernhard, "Johann Friedrich Cotta und der Deutsche Idealismus (Fichte und Schelling)«, in: Cornelia Ortlieb, Tobias Fuchs (Hg.), Schreibekunst und Buchmacherei. Zur Materialität des Schreibens und Publizierens um 1800, Hannover 2017, S. 117-138.

Fontius, Martin, »Zur literarhistorischen Bedeutung der Messkataloge im 18. Jahrhundert«, in: Weimarer Beiträge 7 (1961), S. 607-616.

Fontius, Martin, »libertas philosophandi< und ssiècle de la philosophie<. Zum geistesgeschichtlichen Standort Formeys«, in: ders., Jens Häseler (Hg.), Franzosen in Berlin: Über Religion und Aufklärung in Preußen. Studien zum Nachlass des Akademiesekretärs Samuel Formey, Berlin 2019, S. 125-252.

Foucault, Michel, Archäologie des Wissens, Frankfurt a.M. 1981.

Foucault, Michel, »Was ist ein Autor?«, in: ders., Schriften zur Literatur, aus dem Frz. v. Karin von Hofer, Anneliese Botond, Frankfurt a.M. 1991, S. 7-30.

Franck, Georg, Ökonomie der Aufmerksamkeit. Ein Entwurf, München 1998.

Friedrich, Hans-Edwin, Fotis Jannidis, Marianne Willems, »Bürgerlichkeit im 18. Jahrhundert«, in: dies. (Hg.), Bürgerlichkeit im 18. Jahrhundert, Tübingen 2006, S. IX-XL.

Fuchs, Tobias, Büchermachen. Autorschaft und Materialität des Buches in Jean Pauls "Leben Fibels«, Hannover 2012.

Fuchs, Tobias, Art. »Urheberrecht«, in: Joseph Vogl, Burkhardt Wolf (Hg.), Handbuch Literatur und Ökonomie, Berlin 2020, S. 305-308.

Füssel, Marian, »Die Rückkehr des `Subjekts` in der Kulturgeschichte. Beobachtungen aus praxeologischer Perspektive«, in: Stefan Deines, Stephan 
Jaeger, Ansgar Nünning (Hg.), Historisierte Subjekte - Subjektivierte Historie. Zur Verfügbarkeit und Unverfügbarkeit von Geschichte, Berlin 2003, S. 141-159. Füssel, Marian, »)Charlataneria Eruditorum‘. Zur sozialen Semantik des gelehrten Betrugs im 17. und 18. Jahrhundert«, in: Berichte zur Wissenschaftsgeschichte 27 (2004), S. 119-135.

Füssel, Marian, Thomas Weller (Hg.), Ordnung und Distinktion. Praktiken sozialer Repräsentation in der ständischen Gesellschaft, Münster 2005.

Füssel, Marian, Gelehrtenkultur als symbolische Praxis. Rang, Ritual und Konflikt an der Universität der Frühen Neuzeit, Darmstadt 2006.

Füssel, Marian, »Praktiken historisieren. Geschichtswissenschaft und Praxistheorie im Dialog«, in: Anna Daniel, Frank Hillebrandt, Franka Schäfer (Hg.), Methoden einer Soziologie der Praxis, Bielefeld 2015, S. 267-287.

Füssel, Stephan, Studien zur Verlagsgeschichte und zur Verlegertypologie der GoetheZeit, Berlin, New York 1999.

Gaskell, Philip, John Baskerville. A Bibliography, Cambridge 1959.

Genette, Gérard, Palimpsestes. La littérature au second degré, Paris 1982.

Genette, Gérard, Paratexte. Das Buch vom Beiwerk des Buchs, Frankfurt a.M. 1989.

Gibhardt, Boris, Vorgriffe aufdas schöne Leben. Weimarer Klassik und Pariser Mode um 1800, Göttingen 2019.

Gierl, Martin, »Bestandsaufnahme im gelehrten Bereich: Zur Entwicklung der >Historia literaria< im 18. Jahrhundert«, in: Klaus A. Vogel (Hg.), Denkhorizonte und Handlungsspielräume. Historische Studien für Rudolf Vierhaus zum 70. Geburtstag, Göttingen 1992, S. 53-80.

Gierl, Martin, »Kompilation und die Produktion von Wissen im 18. Jahrhundert«, in: Helmut Zedelmaier, Martin Mulsow (Hg.), Die Praktiken der Gelehrsamkeit in der Frühen Neuzeit, Tübingen 2001, S. 63-94.

Giesecke, Michael, Von den Mythen der Buchkultur zu den Visionen der Informationsgesellschaft, Frankfurt a.M. 2003.

Gieseke, Ludwig, Die geschichtliche Entwicklung des deutschen Urheberrechts, Göttingen 1957.

Gieseke, Ludwig, Vom Privileg zum Urheberrecht. Die Entwicklung des Urheberrechts in Deutschland bis 1845, Baden-Baden 1995.

Giuriato, Davide, Stephan Kammer, »Die graphische Dimension der Literatur? Zur Einleitung«, in: dies. (Hg.), Bilder der Handschrift. Die graphische Dimension der Literatur, Frankfurt a.M., Basel 2006, S. 7-24.

Gleixner, Ulrike, Constanze Baum, Jörn Münkner, Hole Rößler (Hg.), Biographien des Buches, Göttingen 2017. 
Göbelbecker, Ludwig Friedrich, Entwicklungsgeschichte des ersten Leseunterrichts von 1477 bis 1932. In quellenmäßiger Darstellung und theoretischer Beleuchtung, Kempten, Leipzig 1933.

Goebel, Ralf, Markus Bernauer, Der handschriftliche Nachlass Jean Pauls und die Jean-Paul-Bestände der Staatsbibliothek zu Berlin - Preußischer Kulturbesitz, 2 Bde., Wiesbaden 2002-2011.

Goldfriedrich, Johann (Hg.), Aus den Briefen der Göschensammlung des Börsenvereins der Deutschen Buchhändler in Leipzig, Leipzig 1918.

Goodman, Nelson, Sprachen der Kunst. Entwurf einer Symboltheorie, Frankfurt a.M. 1997.

Götze, Jannis, Martin Meiske (Hg.), Jean Henri Samuel Formey. Wissensmultiplikator der Berliner Aufklärung, Hannover 2016.

Grimm, Gunter E., »Nachwort«, in: ders. (Hg.), Satiren der Aufklärung, Stuttgart 1975, S. 325-398.

Grimm, Gunter E., »Vom Schulfuchs zum Menschheitslehrer. Zum Wandel des Gelehrtentums zwischen Barock und Aufklärung«, in: Hans Erich Bödeker, Ulrich Herrmann (Hg.), Über den Prozess der Aufklärung in Deutschland. Personen, Institutionen und Medien, Göttingen 1987, S. 14-38.

Grimm, Gunter E., Letternkultur. Wissenschaftskritik und antigelehrtes Dichten in Deutschland von der Renaissance bis zum Sturm und Drang, Tübingen 1998.

Grunert, Frank, Friedrich Vollhardt (Hg.), Historia literaria. Neuordnungen des Wissens im 17. und 18. Jahrhundert, Berlin 2007.

Gumbert, Hans Ludwig, Bibliotheca Lichtenbergiana. Katalog der Bibliothek Georg Christoph Lichtenbergs, Wiesbaden 1982.

Gumbrecht, Hans Ulrich, Diesseits der Hermeneutik. Die Produktion von Präsenz, Frankfurt a.M. 2004.

Haferkorn, Hans Jürgen, »Der freie Schriftsteller. Eine literatur-soziologische Studie über seine Entstehung und Lage in Deutschland zwischen 1750 und 1800«, in: Archiv für Geschichte des Buchwesens 5 (1963), Sp. 523-711.

Hahn, Hans Peter, Materielle Kultur. Eine Einführung, 2. Aufl., Berlin 2014.

Haubenreich, Jacob, »The materiality of the manuscript. Textual production in Rainer Maria Rilke's Berner Taschenbuch«, in: Hannes Bajohr u.a. (Hg.), The Future of Philology. Proceedings of the 11th Annual Columbia University German Graduate Student Conference, Cambridge 2014, S. 162-182.

Haug, Christine, »Das größte Ereignis in der Geschichte des deutschen Selbstverlags $<$. Die >Allgemeine Buchhandlung der Gelehrten und die >Verlagskasse für Gelehrte und Künstler im Fürstentum Dessau um 1800«, in: Hanno Schmitt, Holger Böning (Hg.), Dessau-Wörlitz und Reck- 
ahn. Treffpunkte für Aufklärung, Volksaufklärung und Philanthropismus, Bremen 2014, S. 85-110.

Hauke, Marie-Kristin, »In allen guten Buchhandlungen ist zu haben...«. Buchwerbung in Deutschland im 17. und 18. Jahrhundert, Dissertation, ErlangenNürnberg 1999.

Hauswedell, Ernst L., Christian Voigt, Buchkunst und Literatur in Deutschland 1750 bis 1850, Hamburg 1977.

Heesen, Anke te, »Die Schere in der Hand des Wissenschaftlers", in: Staffan Müller-Wille (Hg.), Sammeln - Ordnen - Wissen. Beiträge zu einem Festkolloquium aus Anlaß des 80. Geburtstages von Ilse Jahn, Berlin 2002, S. 31-41.

Herrmann, Britta, »Wir leben in einem colossalen [...] Roman<. Fiktivität und Faktizität um 1800«, in: dies., Barbara Thums (Hg.), Ästhetische Erfindung der Moderne? Perspektiven und Modell 1750-1850, Würzburg 2003, S. 115-137.

Hettling, Manfred, »Die Kleinstadt und das Geistesleben. Individuum und Gesellschaft um 1800«, in: Hans-Werner Hahn Dieter Hein (Hg.), Bürgerliche Werte um 1800. Entwurf-Vermittlung-Rezeption, Köln 2005, S. 273-290. Hettling, Manfred, »Bürger/Bürgerlichkeit«, in: Heinz Thoma (Hg.), Handbuch Europäische Aufklärung. Begriffe - Konzepte - Wirkung, Stuttgart 2015, S. 123-131.

Hey, Carl, »Die Methodik des Schreibunterrichts in ihrer geschichtlichen Entwicklung «, in: Karl Kehr (Hg.), Geschichte der Methodik des deutschen Volksschulunterrichts, Gotha 1877-1893, IV (1889, 2. Aufl.), S. 1-157.

Hilgert, Markus, »Praxeologisch perspektivierte Artefaktanalysen des Geschriebenen. Zum heuristischen Potential der materialen Textkulturforschung«, in: Friederike Elias, Albrecht Franz, Henning Murmann u.a. (Hg.), Praxeologie: Beiträge zur interdisziplinären Reichweite praxistheoretischer Ansätze in den Geistes- und Sozialwissenschaften, Berlin, Boston 2014, S. 149164.

Hinrichs, Ernst, »Zur Erforschung der Alphabetisierung in Nordwestdeutschland in der Frühen Neuzeit«, in: Anne Conrad, Arno Herzig, Franklin Kopitzsch (Hg.), Das Volk im Visier der Aufklärung. Studien zur Popularisierung der Aufklärung im späten 18. Jahrhundert, Hamburg 1998, S. 35-56.

Hirschi, Caspar, Carlos Spoerhase, »Kommerzielle Bücherzerstörung als ökonomische Praxis und literarisches Motiv. Ein vergleichender Blick auf das vorindustrielle und digitale Zeitalter", in: Kodex 3 (2013), S. 1-23.

Hoffmann, Julia, »Ich laufe und renne den gantzen Tag, mit allen Sinnen sperrweit offen«. Lichtenbergs Reisen nach England«, in: Ulrich Joost 
(Hg.), Georg Christoph Lichtenberg, 1742-1799. Wagnis der Aufklärung, München 1992, S. 211-228.

Höffner, Eckhard, Geschichte und Wesen des Urheberrechts, München 2010-2011, I (2010).

Holm, Christiane, Günter Oesterle (Hg.), Schläft ein Lied in allen Dingen? Romantische Dingpoetik, Würzburg 2011.

Holm, Christiane, »Erinnerungsdinge«, in: Stefanie Samida, Manfred K. H. Eggert, Hans Peter Hahn (Hg.), Handbuch Materielle Kultur. BedeutungenKonzepte - Disziplinen, Stuttgart 2014, S. 197-200.

Holm, Christiane, Art. »Andenken/Souveneir«, in: Susanne Scholz, Ulrike Vedder (Hg.), Handbuch Literatur \& materielle Kultur, Berlin, Boston 2018, S. 377-379.

Hunfeld, Barbara, »Die Autographen sind schuld. Jean Pauls (un)absichtliche Errata«, in: Jochen Golz, Manfred A. Koltes (Hg.), Autoren und Redaktoren als Editoren, Tübingen 2008, S. 204-214.

Hurrelmann, Bettina, Susanne Becker, Irmgard Nickel-Bacon, Lesekindheiten. Familie und Lesesozialisation im historischen Wandel, Weinheim, München 2006.

Innis, Harold A., »Tendenden der Kommunikation (The Bias of Communication, 1949)«, in: ders., Kreuzwege der Kommunikation. Ausgewählte Texte, hg. v. Karlheinz Barck, Wien, New York 1997, S. 95-119.

Jäger, Georg, Empfindsamkeit und Roman. Wortgeschichte, Theorie und Kritik im 18. und frühen 19. Jahrhundert, Stuttgart, Berlin u.a. 1969.

Jäger, Georg, »Keine Kulturtheorie ohne Geldtheorie. Grundlegung einer Theorie des Buchverlags«, in: Monika Estermann, Ernst Fischer, Ute Schneider (Hg.), Buchkulturen. Beiträge zur Geschichte der Literaturvermittlung. Festschrift für Reinhard Wittmann, Wiesbaden 2005, S. 59-78.

Jänich, Volker, Geistiges Eigentum - eine Komplementärerscheinung zum Sacheigentum?, Tübingen 2002.

Jannidis, Fotis, Gerhard Lauer, Matias Martinez, Simone Winko (Hg.), Rückkehr des Autors. Zur Erneuerung eines umstrittenen Begriffs, Tübingen 1999.

Jannidis, Fotis, Gerhard Lauer, Matias Martinez, Simone Winko, »Rede über den Autor an die Gebildeten unter seinen Verächtern. Historische Modelle und systematische Perspektiven«, in: dies (Hg.), Rückkehr des Autors. Zur Erneuerung eines umstrittenen Begriffs, Tübingen 1999, S. 3-35.

Jochum, Uwe, »Textgestalt und Buchgestalt. Überlegungen $\mathrm{zu}$ einer Literaturgeschichte des gedruckten Buches«, in: LiLi 26 (1996), H. 103, S. 20-34. 
Joost, Ulrich, »Über Nicolai, Boie und die Druckgeschichte des >Timorus« «, in: Lichtenberg-Jahrbuch 14 (1992), S. 132-137.

Joost, Ulrich, Georg Christoph Lichtenberg, 1742-1799. Wagnis der Aufklärung. Ausstellungskatalog, München 1992.

Joost, Ulrich, Lichtenberg - der Briefschreiber, Göttingen 1993.

Joost, Ulrich, »Zweckbündnisse. Georg Christoph Lichtenberg und Friedrich Nicolai«, in: Stefanie Stockhorst u.a. (Hg.), Friedrich Nicolai (1733-1811), Berlin 2011, S. 107-124.

Joost, Ulrich, »Lichtenbergs London«, in: Burkhard Moennighoff, Wiebke von Bernstorff, Toni Tholen (Hg.), Literatur und Reise, Hildesheim 2013, S. 97131.

Kammer, Stephan, »Visualität und Materialität der Literatur«, in: Claudia Benthien, Brigitte Weingart (Hg.), Literatur und visuelle Kultur, Berlin, New York 2014, S. 31-47.

Kammer, Stephan, »Buchmacherei, Bücher, Buchstäblichkeit bei Kant«, in: Cornelia Ortlieb, Tobias Fuchs (Hg.), Schreibekunst und Buchmacherei. Zur Materialität des Schreibens und Publizierens um 1800, Hannover 2017, S. 199215.

Kauffmann, Kai, »Es ist nur ein Wien!«. Stadtbeschreibungen von Wien 1700 bis 1873, Wien, Köln, Weimar 1994.

Kellenbenz, Hermann, Deutsche Wirtschaftsgeschichte, München 1977-1981, Bd. 2 (1981).

Keunecke, Hans-Otto, »Meusel, Johann Georg«, in: Neue Deutsche Biographie, Bd. 17, S. 274f.

Kilcher, Andreas B., ")Litteratur<. Formen und Funktionen der Wissenskonstitution in der Literatur der Frühen Neuzeit«, in: Frank Grunert, Anette Syndikus (Hg.), Wissensspeicher der Frühen Neuzeit. Formen und Funktionen, Berlin, Boston 2015, S. 357-375.

Killius, Christina, Die Antiqua-Fraktur-Debatte um 1800 und ihre historische Herleitung, Wiesbaden 1999.

Kimmich, Dorothee, Art. »Literaturwissenschaft«, in: Stefanie Samida, Manfred K. H. Eggert, Hans Peter Hahn (Hg.), Handbuch Materielle Kultur. Bedeutungen - Konzepte - Disziplinen, Stuttgart 2014, S. 305-308.

Kittler, Friedrich A., Aufschreibesysteme 1800-1900, 4. Aufl., München 2003.

Knebel, Kristin, Cornelia Ortlieb, »Sammlung und Beiwerk, Parerga und Paratexte. Zur Einführung«, in: dies., Gudrun Püschel (Hg.), Steine rahmen, Tiere taxieren, Dinge inszenieren. Sammlung und Beiwerk, Dresden 2018, S. 730. 
Köhler, Erich, Der literarische Zufall, das Mögliche und die Notwendigkeit, München 1973.

Körte, Mona, Essbare Lettern, brennendes Buch. Schriftvernichtung in der Literatur der Neuzeit, München 2012.

Koschorke, Albrecht, Körperströme und Schriftverkehr. Mediologie des 18. Jahrhunderts, 2. Aufl., München 2003.

Košenina, Alexander, »Ein deutscher Horaz? Karl Wilhelm Ramler in der zeitgenössischen Rezeption«, in: Laurenz Lütteken, Ute Pott, Carsten Zelle (Hg.), Urbanität als Aufklärung. Karl Wilhelm Ramler und die Kultur des 18. Jahrhunderts, Göttingen 2003, S. 129-152.

Košenina, Alexander, Der gelehrte Narr. Gelehrtensatire seit der Aufklärung, Göttingen 2003.

Krajewski, Markus, Zettelwirtschaft. Die Geburt der Kartei aus dem Geiste der Bibliothek, Berlin 2002.

Krämer, Sybille, »Zur Sichtbarkeit der Schrift oder: Die Visualisierung des Unsichtbaren in der operativen Schrift. Zehn Thesen«, in: Susanne Strätling, Georg Witte (Hg.), Die Sichtbarkeit der Schrift, München 2006, S. 75-83.

Kyora, Sabine, »Subjektform >Autor«? Einleitende Überlegungen«, in: dies. (Hg.), Subjektform Autor. Autorschaftsinszenierungen als Praktiken der Subjektivierung, Bielefeld 2014, S. 11-20.

Lauer, Gerhard, „Offene und geschlossene Autorschaft. Medien, Recht und Topos von der Genese des Autors im 18. Jahrhundert «, in: Heinrich Detering (Hg.), Autorschaft. Positionen und Revisionen, Stuttgart, Weimar 2004, S. $461-478$.

Lehmann-Brauns, Sicco, »Neukonturierung und methodologische Reflexion der Wissenschaftsgeschichte. Heumanns Conspectus reipublicae literariae als Lehrbuch der aufgeklärten Historia literaria«, in: Frank Grunert, Friedrich Vollhardt (Hg.), Historia literaria. Neuordnungen des Wissens im 17. und 18. Jahrhundert, Berlin 2007, S. 129-160.

Lepenies, Wolf, Das Ende der Naturgeschichte. Wandel kultureller Selbstverständlichkeiten in den Wissenschaften des 18. und 19. Jahrhunderts, München 1976.

Loescher, Jens, Schreiben. Literarische und wissenschaftiche Innovation bei Lichtenberg, Jean Paul, Goethe, Berlin u.a. 2014.

Lucius, Wulf D., "Anmut und Würde. Zur Typographie des Klassizismus in Deutschland «, in: Monika Estermann, Michael Knoche (Hg.), Von Göschen bis Rowohlt. Beiträge zur Geschichte des deutschen Verlagswesens, Wiesbaden 1990, S. 33-63. 
Lucius, Wulf D. von, Akka von Lucius, Anmut und Würde. Bücher und Leben um 1800, Stuttgart 2005.

Ludwig, Otto, »Alphabetisierung und Volksschulunterricht im 19. Jahrhundert. Der Beitrag der Schreib- und Stilübungen«, in: Dieter Cherubim, Siegfried Grosse, Klaus J. Mattheier (Hg.), Sprache und bürgerliche Nation. Beiträge zur deutschen und europäischen Sprachgeschichte des 19. Jahrhunderts, Berlin 1998, S. 148-166.

Lühmann, Frithjof, Buchgestaltung in Deutschland 1770 bis 1800, München 1981.

Lupton, Christina, »Gender and Materiality on the Eigteenth-Century Page«, in: SEL. Studies in English Lierature 1500-1900 54 (2014), 3, S. 770-771.

Martus, Steffen, Werkpolitik. Zur Literaturgeschichte kritischer Kommunikation vom 17. bis ins 20. Jahrhundert, Berlin 2007.

Maurer, Michael, Die Biographie des Bürgers. Lebensformen und Denkweisen in der formativen Phase des deutschen Bürgertums (1680-1815), Göttingen 1996.

Maurer, Michael, »Alltagsleben«, in: Notker Hammerstein (Hg.), Handbuch der deutschen Bildungsgeschichte, München 1996ff., II (2005), S. 33-68.

Maurer, Michael, »Kultur und bürgerliche Vergesellschaftung«, in: HansEdwin Friedrich, Fotis Jannidis, Marianne Willems (Hg.), Bürgerlichkeit im 18. Jahrhundert, Tübingen 2006, S. 31-44.

McGann, Jerome J., The Textual Condition, Princeton 1991.

McKenzie, Donald F., Bibliography and the Sociology of Texts, Cambridge 1999.

Meier, Thomas, Michael R. Ott, Rebecca Sauer (Hg.), Materiale Textkulturen. Konzepte-Materialien - Praktiken, Berlin u.a. 2015.

Menke, Bettine, »Alphabetisierung. Kombinatorik und Kontingenz Jean Pauls >Leben Fibels, des Verfassers der Bienrodischen Fibel«", in: Zeitschrift für Medien- und Kulturforschung I (2010), H. 2, S. 43-60.

Menke, Bettine, »Ein-Fälle aus Exzerpten. Die inventio des Jean Paul«, in: Renate Lachmann, Riccardo Nicolosi, Susanne Strätling (Hg.), Rhetorik als kulturelle Praxis, München 2008, S. 291-307.

Meyer, Hermann, »Reformbestrebungen im achtzehnten Jahrhundert «, in: Archiv für Geschichte des deutschen Buchhandels 12 (1889), S. 201-300.

Meyer, Hermann, »Reformbestrebungen im achtzehnten Jahrhundert «, in: Archiv für Geschichte des deutschen Buchhandels 13 (1890), S. 213-244.

Meyer, Jochen, »Nachwort: Einige Bogen Wein und Liebe«, in: Gotthold Ephraim Lessing, Kleinigkeiten. Faksimile des Marbacher Manuskripts, vorgestellt von Jochen Meyer, Göttingen 2000, S. 195-238.

Müller, Götz, Jean Pauls Exzerpte, Würzburg 1988. 
Müller, Lothar, »Das Ungedruckte autorisieren. Wie die Wahrheit zu Papier kommt«, in: Zeitschrift für Ideengeschichte 4 (2010), 4, S. 14-22.

Müller, Lothar, Weiße Magie. Die Epoche des Papiers, München 2012.

Müller-Tamm, Jutta, Caroline Schubert, Klaus Ulrich Werner (Hg.), Schreiben als Ereignis. Künste und Kulturen der Schrift, Paderborn 2018.

Mulsow, Martin, Prekäres Wissen: Eine andere Ideengeschichte der Frühen Neuzeit, Berlin 2012.

Münch, Paul, »Nachdruck und literarischer Markt im späten 18. Jahrhundert. J.G. Müller, J.A.H. Reimarus, A. von Knigge und die >Schmiederey«, in: Alexander Ritter (Hg.), J. G. Müller von Itzehoe und die deutsche Spätaufklärung. Studien zur Literatur und Gesellschaft im 18. Jahrhundert, Heide 1978, S. 228-247.

Nelles, Jürgen, Bücher über Bücher. Das Medium Buch in Romanen des 18. und 19. Jahrhunderts, Würzburg 2002.

Neumann, Florian, »Jeremias Drexels Aurifodina und die Ars excerpendi bei den Jesuiten«, in: Helmut Zedelmaier, Martin Mulsow (Hg.), Die Praktiken der Gelehrsamkeit in der Frühen Neuzeit, Tübingen 2001, S. 51-61.

Nutt-Kofoth, Rüdiger, »Schillers Medienpolitik«, in: Cornelia Ortlieb, Tobias Fuchs (Hg.), Schreibekunst und Buchmacherei. Zur Materialität des Schreibens und Publizierens um 1800, Hannover 2017, S. 93-115.

Nutt-Kofoth, Rüdiger, Wolfgang Lukas, Madleen Podewski (Hg.), Text-Material-Medium. Zur Relevanz editorischer Dokumentationen für die literaturwissenschaftliche Interpretation, Berlin u.a. 2014.

Ober, Patricia, Der Frauen neue Kleider. Das Reformkleid und die Konstruktion des modernen Frauenkörpers, Berlin 2005.

Ortlieb, Cornelia, "»Materielle Wahrheit «. Zur Kritik des Exzerpierens und seiner Wiederentdeckung im späten 18. Jahrhundert«, in: Christoph Hoffmann, Caroline Welsh (Hg.), Umwege des Lesens. Aus dem Labor philologischer Neugierde. Festschrift für Wolf Kittler, Berlin 2006, S. 49-60.

Ortlieb, Cornelia, »Anstreichen, Durchstreichen«, in: dies., Mona Körte (Hg.), Verbergen - Überschreiben-Zerreißen. Formen der Bücherzerstörung in Literatur, Kunst und Religion, Berlin 2007, S. 247-270.

Ortlieb, Cornelia, »Ochsenknochen, Scherben und Papier. Jean Pauls Schreibmaterialien«, in: Markus Bernauer, Angela Steinsiek, Jutta Weber (Hg.), Jean Paul. Dintenuniversum. Schreiben ist Wirklichkeit, Berlin 2013, S. 130-139.

Ortlieb, Cornelia, »Schachtel, Blume, Uhr. Mallarmés Buch-Basteleien«, in: dies., Tobias Fuchs (Hg.), Schreibekunst und Buchmacherei. Zur Materialität des Schreibens und Publizierens um 1800, Hannover 2017, S. 69-90. 
Pabst, Stephan, »Anonymität und Autorschaft. Ein Problemaufriss«, in: ders. (Hg.), Anonymität und Autorschaft. Zur Literatur- und Rechtsgeschichte der Namenlosigkeit, Berlin 2011, S. 1-34.

Pape, Helmut, Klopstocks Autorenhonorare und Selbstverlagsgewinne, Frankfurt a.M. 1969.

Paulus, Jörg, Philologie der Intimität. Liebeskorrespondenz im Jean-Paul-Kreis, Berlin 2013.

Peirce, Charles Sanders, Semiotische Schriften, hg. v. Christian J. W. Kloesel, Helmut Pape, Frankfurt a.M. 1986, I.

Plumpe, Gerhard, »Eigentum - Eigentümlichkeit. Über den Zusammenhang ästhetischer und juristischer Begriffe im 18. Jahrhundert«, in: Archiv für Begriffsgeschichte 23 (1979), S. 175-196.

Plumpe, Gerhard, »Der Autor im Netz. Urheberrechtsprobleme neuer Medien in historischer Sicht«, in: Klaus Städtke, Ralph Kray (Hg.), Spielräume des auktorialen Diskurses, Berlin 2003, S. 177-194.

Polaschegg, Andrea, »)diese geistig technischen Bemühungen..... Zum Verhältnis von Gestalt und Sinnversprechen der Schrift: Goethes arabische Schreibübungen und E.T.A. Hoffmanns Der goldene Topf«, in: Gernot Grube, Werner Kogge, Sybille Krämer (Hg.), Schrift. Kulturtechnik zwischen Auge, Hand und Maschine, München 2005, S. 279-304.

Preisendanz, Wolfgang, »Zur Korrelation zwischen Satirischem und Komischem«, in: ders., Rainer Warning (Hg.), Das Komische, München 1976, S. 411-413.

Raabe, Paul, »Der Buchhändler im achtzehnten Jahrhundert in Deutschland«, in: Giles Barber, Bernhard Fabian (Hg.), Buch und Buchhandel in Europa im 18. Jahrhundert, Hamburg 1981, S. 271-291.

Rahmede, Stephanie, Die Buchhandlung der Gelehrten zu Dessau. Ein Beitrag zur Schriftstelleremanzipation um 1800, Wiesbaden 2008.

Rautenberg, Ursula, Dirk Wetzel, Buch, Tübingen 2001.

Rautenberg, Ursula, "Die Entstehung und Entwicklung des Buchtitelblatts in der Inkunabelzeit in Deutschland, den Niederlanden und Venedig. Quantitative und qualitative Studien «, in: Archiv für Geschichte des Buchwesens 62 (2008), S. 1-105.

Rautenberg, Ursula, »Buchmedien«, in: Natalie Binczek u.a. (Hg.), Handbuch Medien der Literatur, Berlin 2013, S. 235-46.

Reckwitz, Andreas, »Grundelemente einer Theorie sozialer Praktiken. Eine sozialtheoretische Perspektive«, in: Zeitschrift für Soziologie 32 (2003), 4, S. 282-301. 
Reckwitz, Andreas, Die Erfindung der Kreativität. Zum Prozess gesellschaftlicher Ästhetisierung, Berlin 2012.

Reckwitz, Andreas, »Die Materialisierung der Kultur«, in: Friederike Elias, Albrecht Franz, Henning Murmann u.a. (Hg.), Praxeologie: Beiträge zur interdisziplinären Reichweite praxistheoretischer Ansätze in den Geistes- und Sozialwissenschaften, Berlin, Boston 2014, S. 13-28.

Reckwitz, Andreas, »Praktiken und Diskurse. Zur Logik von Praxis-/Diskursformationen«, in: ders., Kreativität und soziale Praxis. Studien zur Sozial- und Gesellschaftstheorie, Bielefeld 2016, S. 49-66.

Reckwitz, Andreas, »Doing subjects. Die praxeologische Analyse von Subjektivierungsformen«, in: ders., Kreativität und soziale Praxis. Studien zur Sozialund Gesellschaftstheorie, Bielefeld 2016, S. 67-82.

Reh, Sabine, Denise Wilde (Hg.), Schreiben- und Lesenlernen in der Schule der Moderne: Praktiken - Medien - Materialitäten, Bad Heilbrunn 2016.

Reinlein, Tanja, Der Briefals Medium der Empfindsamkeit. Erschriebene Identitäten und Inszenierungspotentiale, Würzburg 2003.

Reulecke, Anne-Kathrin, »Hinter dem Rücken der Bücher. Zerstörte Enzyklopädien in Jorge Luis Borges' Tlön, Uqbar, Orbis Tertius«, in: Mona Körte, Cornelia Ortlieb (Hg.), Verbergen - Überschreiben - Zerreißen. Formen der Bücherzerstörung in Literatur, Kunst und Religion, Berlin 2007, S. 227-243.

Ritter, Alexander, "Der freue und gelehrte Schriftsteller Johann Gottwerth Müller und seine enzyklopädische Privatbibliothek«, in: Ulrich Johannes Schneider (Hg.), Kulturen des Wissens im 18. Jahrhundert, Berlin, New York 2008, S. 221-228.

Roberts, Jane (Hg.), George III \& Queen Charlotte. Patronage, Collecting and Court Taste, London 2004.

Röcke, Per, »Schreibgründe. Die Materialität des Papiers zwischen skripturaler und editorischer Praxis«, in: Variations 17 (2009), S. 143-154.

Rosenstrauch, Hazel, »Buchhandelsmanufaktur und Aufklärung. Die Reformen des Buchhändlers und Verlegers Ph. E. Reich (1717-1787). Sozialgeschichtliche Studie zur Entwicklung des literarischen Marktes«, in: Archiv für Geschichte des Buchwesens 26 (1986), S. 1-128.

Samida, Stefanie, Manfred K. H. Eggert, Hans Peter Hahn (Hg.), Handbuch Materielle Kultur. Bedeutungen - Konzepte - Disziplinen, Stuttgart 2014.

Schäfer, Armin, »Jean Pauls monströses Schreiben«, in: Jahrbuch der Jean-PaulGesellschaft 37 (2002), S. 216-234. 
Schaffrick, Matthias, Marcus Willand, »Autorschaft im 21. Jahrhundert. Matthias Schaffrick und Marcus Willand«, in: dies. (Hg.), Theorien und Praktiken der Autorschaft, Berlin, Boston 2014, S. 3-150.

Schatzki, Theodore R., Social Practises. A Wittgensteinian Approach to Human Activity and the Social, Cambridge 1996.

Schenda, Rudolf, Volk ohne Buch. Studien zur Sozialgeschichte der populären Lesestoffe 1770-1910, Frankfurt a.M. 1970.

Schlaffer, Heinz, »Der Umgang mit Literatur. Diesseits und jenseits der Lektüre«, in: Poetica 31 (1999), Nr. 1/2, S. 1-25.

Schmidt-Bachem, Heinz, Aus Papier. Eine Kultur- und Wirtschaftsgeschichte der Papier verarbeitenden Industrie in Deutschland, Berlin, Boston 2011.

Schmidt, Georg, Wandel durch Vernunft. Deutschland 1715-1805, München 2009.

Schmidt, Jochen, Die Geschichte des Genie-Gedankens in der deutschen Literatur, Philosophie und Politik, 1750-1945, Band 1: Von der Aufklärung bis zum Idealismus, Darmstadt 1985.

Schmitz-Emans, Monika, »Vom Leben und Scheinleben der Bücher. Das Buch als Objekt bei Jean Paul«, in: Jahrbuch der Jean-Paul-Gesellschaft 28 (1993), S. 17-46.

Schmitz-Emans, Monika, "Kinderfiguren, Kindheitsorte, Kinderspiele und Kinderzeit bei Jean Paul«, in: Caroline Roeder (Hg.), Topographien der Kindheit. Literarische, mediale und interdisziplinäre Perspektiven aufOrts- und Raumkonstruktionen, Bielefeld 2014, S. 283-300.

Schmidt-Funke, Julia A., »Kommerz, Kultur und die >gebildeten Ständeく. Konsum um 1800« (15.01.2012), in: Goethezeitportal, URL: www.goethezeitportal.de/db/wiss/epoche/Schmidt-Funke_Konsum.pdf (2.9.2019).

Schmidt-Hannisa, Hans-Walter, "Lesarten. Autorschaft und Leserschaft bei Jean Paul«, in: Jahrbuch der Jean-Paul-Gesellschaft 37 (2002), S. 35-52.

Schneider, Ferdinand Josef, Jean Pauls Altersdichtung Fibel und Komet. Ein Beitrag zur litterarhistorischen Würdigung des Dichters, Berlin 1901.

Schneider, Ulrich Johannes, »Merkur und andere enzyklopädische Götter«, in: Zeitschrift für Ideengeschichte (2007), I,2, S. 89-100.

Schneider, Ulrich Johannes (Hg.), Jöchers 60.000. Ein Mann, eine Mission, ein Lexikon. Katalog zur Ausstellung in der Bibliotheca Albertina, 6. März-28. Juni 2008, Leipzig 2008.

Schneider, Ute, Friedrich Nicolais Allgemeine Deutsche Bibliothek als Integrationsmedium der Gelehrtenrepublik, Wiesbaden 1995.

Scholz, Susanne, Ulrike Vedder, Handbuch Literatur \& Materielle Kultur, Berlin, Boston 2018. 
Schönert, Jörg, »Professionalisierung der Schriftsteller? Zu Praxisformen und Reflexionstypen des Schriftstellerberufs zwischen 1850 und 1920«, in: ders., Perspektiven zur Sozialgeschichte der Literatur. Beiträge zu Theorie und Praxis, Berlin u.a. 2007, S. 161-182.

Schorch, Günther Manuela Böhm, Olaf Gätje, »Geschichte der Didaktik des Handschreibens«, in: OBST 85 (2014), S. 83-110.

Schubert, Martin (Hg.), Materialität in der Editionswissenschaft, Berlin, New York 2010.

Schuller, Marianne, ")Es sind wunderliche Dinger, meine Briefe ‘. Randbemerkungen zur Schreibweise Meta Klopstocks«, in: Inge Stephan, Hans-Gerd Winter (Hg.), Hamburg im Zeitalter der Aufklärung, Berlin, Hamburg 1989, S. 269-283.

Schulz, Manuel, »Zur Rezeption der Papierkrise 1788-1793 im Halleschen Verlag Gebauer«, in: Leipziger Jahrbuch zur Buchgeschichte 20 (2011/12), S. 143154.

Schwab, Dieter, »Eigentum«, in: Otto Brunner, Werner Conze, Reinhard Koselleck (Hg.), Geschichtliche Grundbegriffe. Historisches Lexikon der politischsozialen Sprache in Deutschland, Stuttgart 1972-1997, II (1975), S. 65-115.

Selwyn, Pamela E., Everyday Life in the German Book Trade. Friedrich Nicolai as Bookseller and Publisher in the Age of Enlightenment, 1750-1810, University Park, Pennsylvania 2000.

Sennett, Richard, Handwerk, aus dem Amerikanischen von Michael Bischoff, Berlin 2008.

Siegrist, Hannes, »Geschichte des geistigen Eigentums und der Urheberrechte. Kulturelle Handlungsrechte in der Moderne«, in: Jeanette Hofmann (Hg.), Wissen und Eigentum. Geschichte, Recht und Ökonomie stoffloser Güter, Bonn 2006, S. 64-80.

Simons, Olaf, „Von der Respublica Literaria zum Literaturstaat? Überlegungen zur Konstitution des Literarischen«, in: Aufklärung 26 (2014), S. 291330.

Sinemus, Volker, »Stilordnung, Kleiderordnung und Gesellschaftsordnung im 17. Jahrhundert«, in: Albrecht Schöne (Hg.), Stadt, Schule, Universität, Buchwesen und die deutsche Literatur im 17. Jahrhundert, München 1976, S. 22-43.

Soentgen, Jens, Art. »Materialität«, in: Stefanie Samida, Manfred K. H. Eggert, Hans Peter Hahn (Hg.), Handbuch Materielle Kultur. Bedeutungen - Konzepte - Disziplinen, Stuttgart 2014, S. 226-229.

Soffke, Günther, Jean Pauls Verhältnis zum Buch, Bonn 1969. 
Spoerhase, Carlos, »'Manuscript für Freunde rarischer Netzwerke, 1760-1830«, in: DVjs 88 (2014), S. 172-205.

Spoerhase, Carlos, »The Manuscript Book in the Age of >Empfindsamkeit< (sSentimentalism‘). Caroline Flachsland's und Johann Gottfried Herder's 'Silver Book«", in: Archiv für Geschichte des Buchwesens 69 (2014), S. 59-75.

Spoerhase, Carlos, Das Format der Literatur. Praktiken materieller Textualität zwischen 1740 und 1830, Göttingen 2018.

Steiner, Harald, Das Autorenhonorar - seine Entwicklungsgeschichte vom 17. bis 19. Jahrhundert, Wiesbaden 1998.

Stingelin, Martin (Hg.), »Mir ekelt vor diesem tintenklecksenden Säkulum«. Schreibszenen im Zeitalter der Manuskripte, München 2004.

Stingelin, Martin, » Dämmerpunkte< der Überlieferung. Autor, Text und Kontingenz«, in: MLN 117 (2002), Nr. 3, S. 650-660.

Süssmann, Johannes, Geschichtsschreibung oder Roman? Zur Konstruktionslogik von Geschichtserzählungen zwischen Schiller und Ranke (1780-1824), Stuttgart 2000.

Tietzel, Manfred, Literaturökonomik, Tübingen 1995.

Ungern-Sternberg, Wolfgang von, »Schriftstelleremanzipation und Buchkultur im 18. Jahrhundert«, in: Jahrbuch für Internationale Germanistik 8 (1976), 1, S. 72-98.

Unseld, Siegfried, Goethe und seine Verleger, Frankfurt a.M. 1991.

Vogl, Christine, »Zur Materialität des handschriftlichen Nachlasses von Gotthold Ephraim Lessing. Ein Plädoyer für analytische Handschriftenforschung«, in: Editio 32 (2018), S. 137-166.

Vollhardt, Friedrich, »Die Bildung des Bürgers. Wissensvermittlung im Medium der Moralischen Wochenschriften«, in: Hans-Edwin Friedrich, Fotis Jannidis, Marianne Willems (Hg.), Bürgerlichkeit im 18. Jahrhundert, Tübingen 2006, S. 135-147.

Wachtel, Joachim, Vom Ballenbinder zur Selbstbedienung. Verpackung - anno dazumal und heute, Gütersloh 1965.

Wadle, Elmar, »Der langsame Abschied vom Privileg: Das Beispiel des Urheberrechts «, in: ders., Geistiges Eigentum. Bausteine zur Rechtsgeschichte, München 1996ff., II (2003), S. 101-116.

Wadle, Elmar, »Entwicklungsschritte des Geistigen Eigentums in Frankreich und Deutschland«, in: Hannes Siegrist, David Sugarman (Hg.), Eigentum im internationalen Vergleich. 18.-20. Jahrhundert, Göttingen 1999, S. 245-263. Wagner, Monika, »Material«, in: Karlheinz Barck u.a. (Hg.), Ästhetische Grundbegriffe, Stuttgart, Weimar 2000-2005, III (2001), S. 866-882. 
Warning, Rainer, »Der inszenierte Diskurs. Bemerkungen zur pragmatischen Relation der Fiktion«, in: Dieter Heinrich, Wolfgang Iser (Hg.), Funktionen des Fiktiven, München 1983, S. 183-206.

Wehde, Susanne, Typographische Kultur. Eine zeichentheoretische und kulturgeschichtliche Studie zur Typographie und ihrer Entwicklung, Tübingen 2000.

Wehler, Hans-Ulrich, Deutsche Gesellschaftsgeschichte. Erster Band: Vom Feudalismus des Alten Reichs bis zur Defensiven Modernisierung der Reformära, 1700-1815, München 2008.

Weichselbaumer, Nikolaus, »Die Druckerfamilie Decker und die klassizistische Typographie in Berlin um 1800«, in: Imprimatur N.F. 25 (2017), S. 249268.

Weidmann, Heiner, »Rhetorik der Kleidung um 1800«, in: Andreas Härter (Hg.), Dazwischen. Zum transitorischen Denken in Literatur- und Kulturwissenschaft, Göttingen 2003, S. 215-234.

Weidner, Daniel, »Himmelskarten und Erdkarten. Gott und der Romanerzähler bei Fielding und Jean Paul«, in: Christel Meier, Martina WagnerEgelhaaf (Hg.), Autorschaft. Ikonen - Stile - Institutionen, Berlin 2011, S. 231251.

Weigl, Engelhard, Aufklärung und Skeptizismus. Untersuchungen zu Jean Pauls Frühwerk, Hildesheim 1980.

Weiss, Wisso, »Zum Papier einiger Lessing-Druckschriften«, in: GutenbergJahrbuch 55 (1980), S. 174-182.

Weissberg, Liliane, Geistersprache. Philosophischer und literarischer Diskurs im späten 18. Jahrhundert, Würzburg 1990.

Wellberry, David E., »Die Äußerlichkeit der Schrift«, in: Hans Ulrich Gumbrecht, Karl L. Pfeiffer (Hg.), Schrift, München 1993, S. 337-348.

Wellmanns, Günter Theodor, Studien zur deutschen Satire im Zeitalter der Aufklärung. Theorie, Stoffe, Form und Stil, München 1969.

Wieland, Magnus, »Jean Pauls Sudelbibliothek. Makulatur als poetologische Chiffre«, in: Jahrbuch der Jean-Paul-Gesellschaft 46 (2011), S. 97-119.

Wieland, Magnus, Vexierzüge. Jean Pauls Digressionspoetik, Hannover 2013.

Wieland, Magnus, »Exzerpte aus Eden. Sekundäre Schöpfung bei Jean Paul«, in: KulturPoetik 13 (2013), H. 1, S. 26-40.

Wieland, Magnus, »Litteratur. Die Lesbarkeit des Mülls«, in: Zeitschrift für deutsche Philologie 133 (2014), Sonderheft: Entsorgungsprobleme: Müll in der Literatur, S. 33-50.

Wieland, Magnus, "Der Satz der Sätze. Praxis und Poesis des Schriftsetzers«, in: Cornelia Ortlieb, Tobias Fuchs (Hg.), Schreibekunst und Buchma- 
cherei. Zur Materialität des Schreibens und Publizierens um 1800, Hannover 2017, S. 171-195.

Will, Michael, »Die (Un-)Ordnung der Dinge«, in: Jahrbuch der Jean-PaulGesellschaft 41 (2006), S. 71-95.

Will, Michael, »Lesen, um zu schreiben - Jean Pauls Exzerpte«, in: Markus Bernauer, Angela Steinsiek, Jutta Weber (Hg.), Jean Paul. Dintenuniversum. Schreiben ist Wirklichkeit, Berlin 2013, S. 39-48.

Wirth, Uwe, Die Geburt des Autors aus dem Geist der Herausgeberfiktion. Editoriale Rahmung im Roman um 1800: Wieland, Goethe, Brentano, Jean Paul und E.T.A. Hoffmann, München 2008.

Wirth, Uwe, »(Papier-)Müll und Literatur: Makulatur als Ressource«, in: Zeitschrift für deutsche Philologie 133 (2014), Sonderheft: Entsorgungsprobleme: Müll in der Literatur, S. 19-32.

Wittmann, Reinhard, Buchmarkt und Lektüre im 18. und 19. Jahrhundert: Beiträge zum literarischen Leben 1750-1880, Tübingen 1982.

Wittmann, Reinhard, Geschichte des deutschen Buchhandels. Ein Überblick, München 1991.

Wittmann, Reinhard, „Gibt es eine Leserevolution am Ende des 18. Jahrhunderts?«, in: Roger Chartier, Guglielmo Cavallo (Hg.), Die Welt des Lesens. Von der Schriftrolle zum Bildschirm, Frankfurt a.M. 1999, S. 419-454.

Zanetti, Sandro, »Einleitung«, in: ders. (Hg.), Schreiben als Kulturtechnik. Grundlagentexte, Berlin 2012, S. 7-34.

Zaremba, Michael, Christoph Martin Wieland. Aufklärer und Poet. Eine Biografie, Köln, Weimar, Wien 2007.

Zedelmaier, Helmut, »'Historia literaria<. Über den epistemologischen Ort des gelehrten Wissens in der ersten Hälfte des 18. Jahrhunderts«, in: Das achtzehnte Jahrhundert 22 (1998), 1, S. 11-21.

Zentner, Wilhelm, Johann Peter Hebel. Eine Biographie, Karlsruhe1965.

Ziessow, Karl-Heinz, "Den Gedanken zu Papier bringen: Feder und Tinte als Schreibmaterial«, in: ders., Utz Maas u.a., Hand-Schrift - Schreib.Werke. Schrift und Schreibkultur im Wandel in regionalen Beispielen des 18. bis 20. Jahrhunderts, Cloppenburg 1991, S. 37-74. 



\section{Abbildungen}

Abbildung 1: »Verschiedenes aus den neuesten Schriften«: Handgeschriebenes Titelblatt von Jean Pauls erstem Band mit Exzerpten. .53 Abbildung 2: »Ende des ersten Bandes«: Auch der Abschluss des ersten ExzerptBandes folgt der typographischen Gestaltung zeitgenössischer Publikationen. 54 Abbildung 3: Titelblatt von Tobias Mayer, »0pera Inedita«, Göttingen 1775, Bd. 1, Titelblatt. 123

Abbildung 4: Titelblatt von Friedrich von Hagedorn, »Die Freundschaft«, Hamburg 1748. 162

Abbildung 5: Druckfehler-Verzeichnis aus Jean Paul, »Hesperus, oder 45 Hundsposttage. Erstes Heftlein«, Berlin 1795. 178

Abbildung 6: Titelkupfer der Zeitschrift »Tapeten« 1 (1771). 248 



\section{Danksagung}

Bei diesem Buch handelt es sich um die geringfügig überarbeitete Fassung meiner Dissertation, die ich im Februar 2020 an der Freien Universität Berlin verteidigt habe. Der erste Dank gebührt Cornelia Ortlieb, meiner Doktormutter, die auch eine großartige akademische Lehrerin und Chefin für mich war. Ohne sie gäbe es dieses Buch nicht.

Ich danke Roman Lach, dem Zweitgutachter meiner Doktorarbeit, der mich mit intellektueller Neugier begleitet hat, sowie Jutta Müller-Tamm, Sandra Fluhrer und Elisabeth Paefgen, die sofort bereit waren, der Promotionskommission anzugehören. Für den fruchtbaren Austausch und die immer hilfreichen Rückmeldungen in den Kolloquien von Cornelia Ortlieb in München, Erlangen und Berlin bedanke ich mich insbesondere bei Sandra Fluhrer, Matthias Kandziora, Jasmin Pfeiffer, Gudrun Püschel, Timm Reimers und Timo Sestu.

Der Fritz Thyssen Stiftung für Wissenschaftsförderung bin ich dankbar für die großzügige Förderung des Forschungsprojekts »Manuskript, Buch, Makulatur«, das ich unter der Leitung von Cornelia Ortlieb als wissenschaftlicher Mitarbeiter der Ludwig-Maximilians-Universität München und der Friedrich-Alexander-Universität Erlangen-Nürnberg von 2013 bis 2016 bearbeitet habe. Im Rahmen dieses Projektes fand 2015 die Tagung »Büchermachen - Zur Materialität des Publizierens in der europäischen Literatur um 1800« statt, der ich wichtige Anregungen verdanke. $\mathrm{Zu}$ Dank verpflichtet bin ich auch Elisabeth Dobringer, Isabelle Urban und den studentischen Mitarbeiterinnen und Mitarbeitern unseres Projekts.

In diesen Jahren befand sich mein Arbeitsplatz hauptsächlich in den Lesesälen der Staatsbibliothek zu Berlin, deren Mitarbeiterinnen und Mitarbeitern ich ebenso danken will wie dem Personal der Universitätsbibliotheken von TU und FU Berlin, der Bibliothek für Bildungsgeschichtliche Forschung (BBF) sowie der übrigen Bibliotheken und Archive, die ich nutzen durfte. In 
der Abschlussphase habe ich die Saarländische Universitäts- und Landesbibliothek (SULB) in Saarbrücken schätzen gelernt.

Dem fachlichen Austausch im Berliner Arbeitskreis "Materialität der Literatur «, den Carlos Spoerhase lange Jahre leitete, habe ich wichtige Impulse zu verdanken, nicht zuletzt durch die Vortragsreihe »Die Materialität von Schriftlichkeit«, die der Arbeitskreis gemeinsam mit Christian Mathieu von der Berliner Staatsbibliothek initiierte. In dieser Reihe konnte ich meinen Forschungsansatz gemeinsam mit Cornelia Ortlieb vorstellen und diskutieren. Auch bei anderen Vorträgen in Berlin, Erlangen, München, Wittenberg und Wolfenbüttel habe ich wertvolles Feedback erhalten.

Dem transcript Verlag danke ich für die Aufnahme meines Buches in sein Programm, der Freien Universität Berlin für die großzügige Ko-Finanzierung der Open-Access-Ausgabe, Birgit Schlegel und Astrid Herzog für die Hilfe bei deren Abwicklung. Den Verlagen Wehrhahn und Klinkhardt, bei denen Teile meiner Doktorarbeit vorab erschienen sind, danke ich für die gewährten Abdruckgenehmigungen. Gleiches gilt für die Handschriftenabteilung der Staatsbibliothek zu Berlin und die übrigen Rechteinhaber der in diesem Buch gezeigten Abbildungen.

Ann-Kristin Müller, Rüdiger Wack und Simone Dorscheid danke ich für die aufwendige Lektüre des Manuskripts. Deniz Alavanda hat mich vor der Abgabe der Doktorarbeit in Berlin entscheidend unterstützt. Ich danke meinen Eltern und Großeltern, die mir diesen Lebensweg ermöglicht haben, Herrn Breme, ohne den ich nie eine Universität besucht hätte, sowie meinen Freundinnen und Freunden, die in den Jahren der Promotion immer ein offenes Ohr für mich hatten. Mein größter Dank gilt Anna, Marlene und Leo für ihre Hilfe und Geduld, den steten Zuspruch und ihre Nachsicht. 


\section{Vorveröffentlichungen}

- »Aus der blauen Reihe. Über Jean Pauls handgeschriebene Bücher«, in: Cornelia Ortlieb, Tobias Fuchs (Hg.), Schreibekunst und Buchmacherei. Zur Materialität des Schreibens und Publizierens um 1800, Hannover 2017, S. 47-68, englischsprachige Version: »Jean Paul's Handwritten Books«, in: Eve Rosenhaft, Helga Müllneritsch, Annie Mattsson (Hg.), The Materiality of Writing. Manuscript Practices in the Age of Print, Uppsala 2019, S. 19-52. (Kapitel 2)

- »Buchstaben bilden. Zur Materialität des Schreibenlernens um 1800«, in: Sabine Reh, Denise Wilde (Hg.), Schreiben- und Lesenlernen in der Schule der Moderne: Praktiken-Medien-Materialitäten, Bad Heilbrunn 2016, S. 139-157. (Kapitel 2) 


\section{Literaturwissenschaft}

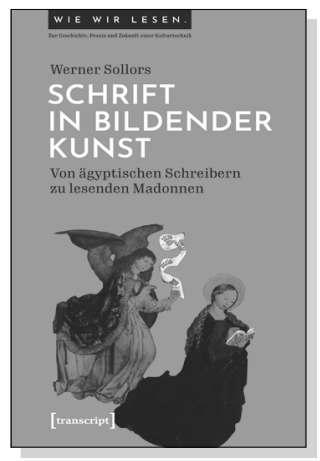

Werner Sollors

\section{Schrift in bildender Kunst}

Von ägyptischen Schreibern zu lesenden Madonnen

September 2020, 150 S., kart.,

14 Farbabbildungen, 5 SW-Abbildungen

16,50€ (DE), 978-3-8376-5298-7

E-Book:

PDF: $14,99 €$ (DE), ISBN 978-3-8394-5298-1

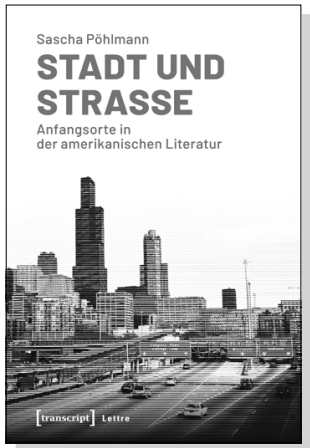

Sascha Pöhlmann

\section{Stadt und Straße}

Anfangsorte in der amerikanischen Literatur

2018, 266 S., kart.

29,99€ (DE), 978-3-8376-4402-9

E-Book:

PDF: $26,99 €$ (DE), ISBN 978-3-8394-4402-3

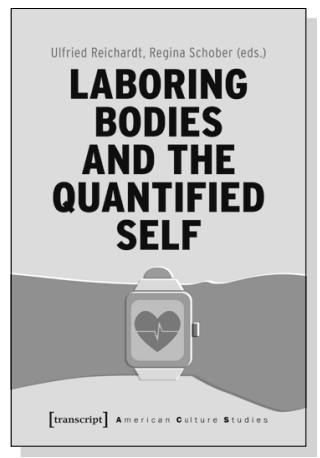

Ulfried Reichardt, Regina Schober (eds.)

Laboring Bodies and the Quantified Self

October 2020, 246 p., pb.

40,00€ (DE), 978-3-8376-4921-5

E-Book:

PDF: 39,99 € (DE), ISBN 978-3-8394-4921-9 


\section{Literaturwissenschaft}
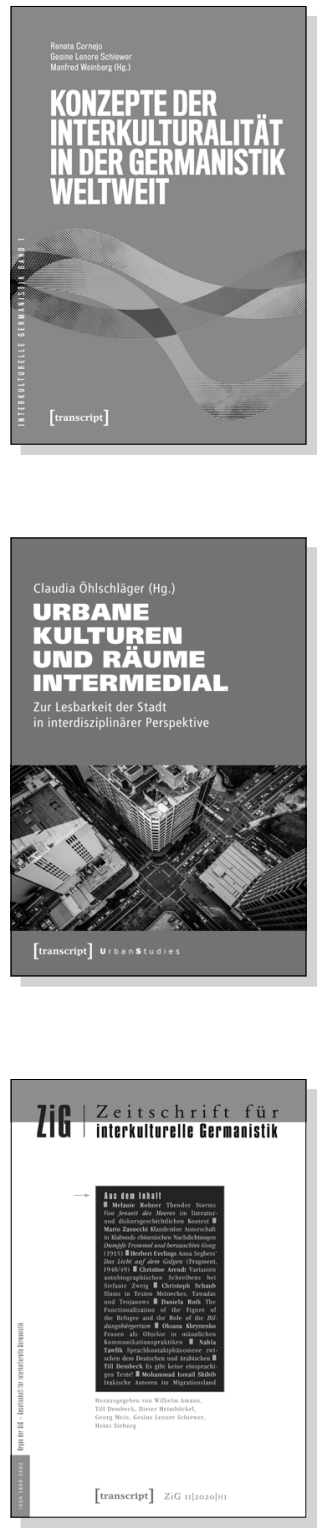

Renata Cornejo, Gesine Lenore Schiewer, Manfred Weinberg (Hg.)

Konzepte der Interkulturalität in der Germanistik weltweit

August 2020, 432 S., kart., 6 SW-Abbildungen 50,00€ (DE), 978-3-8376-5041-9

E-Book: kostenlos erhältlich als Open-Access-Publikation PDF: ISBN 978-3-8394-5041-3

Claudia Öhlschläger (Hg.)

\section{Urbane Kulturen und Räume intermedial}

Zur Lesbarkeit der Stadt in interdisziplinärer Perspektive

Juli 2020, 258 S., kart., 10 SW-Abbildungen

40,00€ (DE), 978-3-8376-4884-3

E-Book:

PDF: 39,99€ (DE), ISBN 978-3-8394-4884-7

Wilhelm Amann, Till Dembeck, Dieter Heimböckel, Georg Mein, Gesine Lenore Schiewer, Heinz Sieburg (Hg.) Zeitschrift für interkulturelle Germanistik 11. Jahrgang, 2020, Heft 1

August 2020, 226 S., kart.

$12,80 €(D E), 978-3-8376-4944-4$

E-Book:

PDF: $12,80 €(D E)$, ISBN 978-3-8394-4944-8 
